\title{
MICROSEISMICITY IN THE CENTRAL SOUTHERN ALPS, WESTLAND, NEW ZEALAND
}

by

\author{
Carolin Boese
}

\author{
A thesis \\ submitted to Victoria University of Wellington \\ in fulfilment of the requirements for the degree of \\ Doctor of Philosophy \\ in Geophysics
}

Victoria University of Wellington

August 1, 2012 

"Der moderne Mensch kann ins All fliegen, tödliche Krankheiten besiegen und in sekundenschnelle gigantische Datenmengen um den Globus schicken. Doch wenn die Erde bebt, ist er so machtlos, wie seine Vorfahren ..."

Gewaltige Natur, Der Spiegel, 2011 



\section{Abstract}

Present-day seismicity associated with the central Alpine Fault and the zone of active deformation and rock uplift in the central Southern Alps is reported in this thesis. Robust hypocentre locations and magnitude estimates for $\sim 2300$ earthquakes have been obtained analysing 18 months of data from the Southern Alps Microearthquake Borehole Array (SAMBA), designed for this study. The earthquakes are distributed between the Alpine Fault and the Main Divide Fault zone and confined to shallow depths (90\% of events $\leq 12.2 \mathrm{~km}$ ). The thickness of the seismogenic zone follows lateral variations in crustal resistivity: earthquake hypocentres are restricted to depths where resistivities exceed $390 \Omega \mathrm{m}$. Rocks at greater depth are interpreted to be too hot, too fluid-saturated, or too weak to produce detectable earthquakes. A low-seismicity zone extends between the Whataroa and Wanganui rivers at distances $15-30 \mathrm{~km}$ southeast of the fault, which is concluded to be a relatively strong, unfractured block that diverts deformation around it. A new magnitude scale is developed incorporating the effects of frequency-dependent attenuation, which enables magnitudes to be calculated consistently for earthquakes of different sizes and frequency contents. Focal mechanism solutions for 379 earthquakes exhibit predominantly strike-slip mechanisms. Inversion of these focal mechanisms to determine the prevailing tectonic stress field reveals a maximum horizontal compressive stress direction of $115 \pm 10^{\circ}$, consistent with findings from elsewhere in South Island. The $60^{\circ}$ angle between the strike of the Alpine Fault and the direction of maximum horizontal compressive stress suggests that the Alpine Fault is poorly oriented in an Andersonian sense. Earthquake swarms of at least 10 events with similar waveforms frequently occur within the region, of which some were remotely triggered by two major South Island earthquakes. Focal mechanisms of the largest event in each swarm $\left(\mathrm{M}_{\mathrm{L}} \leq 2.8\right)$ reveal at least one steeply-dipping nodal plane $\left(\geq 50^{\circ}\right)$ and one well-oriented nodal plane in the tectonic stress field. The swarms exhibit a distinctly different inter-event time versus duration pattern from that of typical mainshock-aftershock sequences. The triggered seismicity commences with the passage of the surface waves, continues for $\sim 5$ and $\sim 2$ days, and is followed by a quiescence period of approximately equal length. Remotely triggered swarms occur delayed by several hours and their delay and locations are consistent with fluid diffusion from a shallow fluid reservoir. Estimated peak dynamic stresses 
$(\geq 0.09 \mathrm{MPa})$ imposed by the surface waves are comparable to observations of triggering thresholds $(>0.01 \mathrm{MPa})$ elsewhere. The triggered swarms have no apparent differences from the background swarms, and appear to have been clock-advanced. Tectonic tremor in the vicinity of the Alpine Fault coincides with a low-velocity, high-attenuation zone at depth. The tremor occurs at the downdip extension of the Alpine Fault and in the region where bending of the Australian and Pacific plates is largest at depths spanning 12-49 km. Similarities with tremor occurring on the San Andreas Fault near Cholame in terms of tremor duration, depth, spatial extent and amplitude distribution, imply property variations in the lower crust and upper mantle along the strike of the Alpine Fault. 


\section{Acknowledgements}

This $\mathrm{PhD}$ thesis would not have been the same without the assistance and support by numerous people and some organisations which should not go unnoticed.

I would like to sincerely thank Tim Stern for the possibility to work in such a diverse, well-planned and securely funded project, and for his confidence and patience over the last three and a half years. Thank you, Euan Smith, for having your office door wide open, your general helpfulness regarding any problems and concerns, and your encouragement throughout my PhD studies. John Townend's kind guidance and good advice, his help with phrasing and structuring my work are greatly appreciated.

Over 100 days spent for fieldwork would have been impossible without the support and experience of Mark Henderson. Thanks for all the tips and tricks, Mark, that I learned from you when installing sensors and servicing stations. A special thanks to Richard Arnold for spending many hours programming and developing parts of the focal mechanism program with me and for me. I am grateful to Mike Hasting for his help with the station deployment, his kindness in general and for getting me involved in the Paralana hydraulic fracture. Many thanks to Martha Savage for the opportunity to test my sea legs on the OBS retrieval cruise, for interesting but also scary experiences in Christchurch after the Darfield earthquake, for insight obtained in the student discussion group and for encouraging me to discuss my research with visiting scientists.

A big hug to Yannik Behr and Aaron Wech for helping me with many little things along the way, for a great time at the Kelburn pub and for sharing their tips and tricks regarding programming and presentations with me. I thoroughly enjoyed working with Katrina Jacobs during my last year. Thanks to Bronwyn O'Keefe and the SEISAN team for helping me getting started, to Sandra Bourguignon and Ellen Syracuse for help with the program tomoDD and Eliana Arias-Dotson from IRIS/PASSCAL for support in processing Reftek data. All other geophysics students at Victoria, especially Laura Brooks, Katharina Unglert, Denise Fernandez, Jessica Johnson, Sapi Karalliyadda, Richard Davy, Adrian 
Shelley, Nicolas Brikké, and Adrian Benson have been good company and great friends.

The people on the Westcoast as far as involved in this project have been incredibly friendly and supportive, especially Keith Green and Alex Miller. Thank you so much for hosting our "earthquake boxes".

I would like to acknowledge the good cooperation with DOC staff Tina Pizzato, Wayne Castello, Ray Bellringer and Cornelia Vervoorn, West Coast Regional Council staff Gary Hilton and Wayne Moen, as well as the GeoNet team represented by Lara Bland.

Thanks to Phil Wannamaker, Donna Eberhart-Phillips, Martin Scherwath and Harm van Avendock for providing their results for comparison with mine and to Anthony Lomax, Jean Virieux and Haijiang Zhang for providing software and programs used in this study. Simon Cox supported me by providing contacts on the Westcoast and data for maps. Steven Bannister and Simon Lamb are thanked for their advice regarding event location and strain release by earthquakes. The assistance of Andrew Mellanby with all computer-related problems was invaluable and is greatly appreciated. Administrative staff at Victoria University, especially Barry Lewis and Suzanne Weaver, were very helpful in getting me started and sorting things out.

I am grateful for funding of my living costs by the New Zealand International Doctoral Research Scholarship and for my research by the Marsden Fund. This allowed me to visit two international and three national conferences and to timely finish my studies without worrying about financial aspects.

My parents are profoundly thanked for all their advice and support, for sharing my enthusiasm about New Zealand and for their general and growing interest in seismology and tectonics. Without Matthias Bertram's love and support over the last years, I would not have accomplished the entire project! 


\section{Contents}

Abstract $\quad$ i

Acknowledgments $\quad$ v

List of Figures $\quad$ xi

List of Tables $\quad$ XV

1. Introduction 1

1.1. Motivation, thesis objectives and outline . . . . . . . . . . . 1

1.2. Tectonic and geological setting of the Alpine Fault . . . . . . . . 3

1.2.1. Characteristics of the central Southern Alps region . . . . . . 9

1.3. Seismicity in the central Southern Alps . . . . . . . . . . . . . . 17

1.4. The Southern Alps Microearthquake Borehole Array (SAMBA) . . . . . 24

1.4.1. Study area and station networks . . . . . . . . . . . . . . 24

1.4.2. Data acquisition, processing and quality control . . . . . . . 27

1.4.3. Performance of the SAMBA stations . . . . . . . . . . . . . . 29

2. Theoretical considerations 39

2.1. Earthquake location . . . . . . . . . . . . . . . . . . . . . . 39

2.1.1. Geiger's location method . . . . . . . . . . . . . . . . . 40

2.1.2. Probabilistic non-linear location methods . . . . . . . . . . . 41

2.2. Arrival-time residuals and uncertainty assessment . . . . . . . . . 42

2.2.1. Uncertainty in absolute earthquake locations . . . . . . . . . . 44

2.2.2. Uncertainty assessment with probabilistic non-linear location methods 44

2.2.3. Influence of station configuration on location uncertainty . . . . 4 46

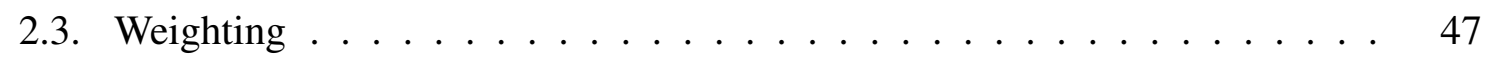

2.3.1. Jeffreys' weighting . . . . . . . . . . . . . . . . 47

2.4. Cross-correlation . . . . . . . . . . . . . . . . . . 48

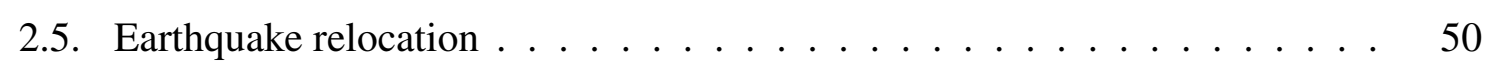

2.5.1. Uncertainty assessment of relative earthquake locations . . . . . 50 
2.6. Amplitude decay . . . . . . . . . . . . . . . . . . 51

2.6.1. Geometrical spreading and attenuation . . . . . . . . . . . . 52

2.7. Earthquake magnitudes . . . . . . . . . . . . . . 53

2.8. Gutenberg-Richter relationship and b-value . . . . . . . . . . . 55

2.9. Seismic tomography . . . . . . . . . . . . . . . . 56

2.10. Focal mechanisms . . . . . . . . . . . . . . . . . . . 59

2.11. Stress estimates . . . . . . . . . . . . . . . 63

2.12. Mohr-Coulomb stress analysis . . . . . . . . . . . . . . 64

3. Data analysis $\quad 67$

3.1. Travel-time residuals and weighting . . . . . . . . . . . 67

3.1.1. Travel-time residual analysis . . . . . . . . . . . . . . 67

3.1.2. Weighting of the travel-time residuals . . . . . . . . . . 71

3.1.3. Time corrections of residuals for station COSA . . . . . . . . . 77

3.1.4. Time corrections of residuals for station DRC . . . . . . . . . 77

3.1.5. Station terms from the residuals . . . . . . . . . . . . . . 79

3.2. A local magnitude scale for the Southern Alps . . . . . . . . . . . . . . 80

3.2.1. Geometrical spreading and attenuation parameter . . . . . . . . 80

3.2.2. Magnitude station correction terms _. . . . . . . . . . . 84

3.3. Hypocentre comparisons and stability . . . . . . . . . . . . . . . 89

3.3.1. Events from the GeoNet catalogue . . . . . . . . . . . . . . 89

3.3.2. Quarry blasts . . . . . . . . . . . . . . . . . . 89

3.4. Station configuration . . . . . . . . . . . . . . . . . 90

3.4.1. Earthquakes outside the station network . . . . . . . . . . . . 90

3.4.2. Number of recording stations . . . . . . . . . . . . . . . . 92

3.4.3. Hypocentre locations before and after weighting . . . . . . . . 92

3.4.4. Hypocentre relocations . . . . . . . . . . . . . . . . . . . 96

3.5. Focal mechanism comparisons . . . . . . . . . . . . . . . . . . 100

4. Microseismicity and stress in the vicinity of the Alpine Fault 109

4.1. Methods . . . . . . . . . . . . . . . . . . . . . . . . . . . 109

4.1.1. Earthquake hypocentre and uncertainty determination . . . . . . . . 109

4.1.2. Magnitudes . . . . . . . . . . . . . . . . . 111

4.1.3. Focal mechanisms . . . . . . . . . . . . . . . 113

4.1.4. Stress inversion . . . . . . . . . . . . . . . . . . . . 114

4.2. Results . . . . . . . . . . . . . . . . . . . . . . . 114

4.2.1. Earthquake locations and their uncertainties . . . . . . . . . . . 114

4.2.2. Magnitudes . . . . . . . . . . . . . . . . . 120 
4.2.3. Focal mechanisms . . . . . . . . . . . . . . . . 125

4.2.4. Stress inversion . . . . . . . . . . . . . . . . . 127

4.3. Discussion and conclusions . . . . . . . . . . . . . . . 131

4.4. Shear and normal stresses on the fault plane . . . . . . . . . . . . . . 134

4.5. Seismicity gap between the Whataroa and Wanganui rivers . . . . . . . 135

5. The characteristics of earthquake swarms in the central Southern Alps 143

5.1. General aspects of earthquake swarms and triggering . . . . . . . . . 143

5.1.1. Earthquake swarms . . . . . . . . . . . . . . . . 143

5.1.2. Earthquake triggering . . . . . . . . . . . . . . . . 146

5.1.3. Previous observations of earthquake triggering . . . . . . . . . 147

5.1.4. Suggested mechanisms of earthquake triggering . . . . . . . . . 153

5.2. Earthquake triggering in the Southern Alps and its implications . . . . . . 156

5.2.1. Seismicity rates in the study area . . . . . . . . . . . . . 157

5.3. Research methodology . . . . . . . . . . . . . . . . . 161

5.4. Observed earthquake sequences . . . . . . . . . . . . . . . 166

5.5. Remotely triggered seismicity . . . . . . . . . . . . . . . 169

5.6. Discussion . . . . . . . . . . . . . . . . . . 178

5.6.1. Observed earthquake sequences . . . . . . . . . . . . 178

5.6.2. Remotely triggered seismicity . . . . . . . . . . . . . . 183

5.6.3. Long-term record of swarms and triggering of swarms . . . . . . 186

5.7. Conclusions . . . . . . . . . . . . . . . . . . . 189

6. Deep earthquakes, tremor and other preliminary results 191

6.1. Deep earthquakes . . . . . . . . . . . . . . . . . . 191

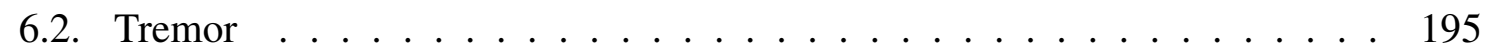

6.3. Tomography . . . . . . . . . . . . . . . . . 202

6.3.1. Expected errors from velocity variations . . . . . . . . . . . 213

6.4. Moment and strain release by microearthquakes . . . . . . . . . . . . 215

6.5. Fault-guided waves . . . . . . . . . . . . . . . 218

7. Summary and conclusions 223

7.1. Main contributions . . . . . . . . . . . . . . . 223

7.2. Main results . . . . . . . . . . . . . . . . . . . . . 224

7.2.1. Earthquake distribution . . . . . . . . . . . . . . . . . . 224

7.2.2. Magnitude distribution . . . . . . . . . . . . . . . 225

7.2.3. Focal mechanisms and stress field . . . . . . . . . . . . 225

7.2.4. Swarms and triggered seismicity . . . . . . . . . . . . 226 


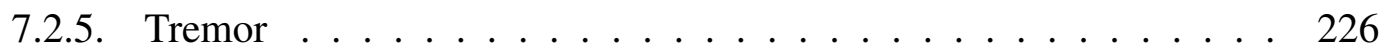

7.3. Implications . . . . . . . . . . . . . . . 226

7.4. Suggestions for future work . . . . . . . . . . . . . . 231

A. Response functions 233

A.1. Response functions of the SAMBA stations . . . . . . . . . . . . 235

B. Polarity tests 239

C. Station recording times 245

D. Noise signals $\quad 247$

D.1. Solar controller . . . . . . . . . . . . . . . . . . . . . . . . 247

D.2. Other noise sources . . . . . . . . . . . . . . . . . . . . . 249

E. Assessment of individual station performance 253

F. Noise characteristics of the SAMBA stations 257

G. Travel-time residuals of SAMBA and DFDP10 stations 261

H. Comparisons of focal mechanism solutions 267

I. Slip, frequency, rupture and recording range of various-sized earthquakes 273

J. Hypocentre locations 275

$\begin{array}{ll}\text { K. Focal mechanism solutions } & 287\end{array}$

L. Waveform examples of earthquake sequences 297

M. Overview of combined global studies of seismicity and resistivity 307

$\begin{array}{ll}\text { Bibliography } & 311\end{array}$ 


\section{List of Figures}

1.1. Regional tectonic and geological map of New Zealand . . . . . . . . . 4

1.2. Variation of the dip of the Alpine Fault in the South Island . . . . . . . . . 6

1.3. Map of South Island showing key locations . . . . . . . . . . . . . . 7

1.4. Segmentation of the Alpine Fault and Main Divide Fault Zone . . . . . . . 11

1.5. Deep tectonic structures beneath South Island . . . . . . . . . . . . . 15

1.6. Focal mechanisms of large earthquakes and faults in the central South Island 18

1.7. Seismicity in the central Southern Alps recorded during previous studies . . 22

1.8. GeoNet, SAMBA and DFDP10 station networks in the study area . . . . 25

1.9. Temperature decay with depth in response to periodic temperature fluctuations 30

1.10. Power spectral density of noise under low and high-noise conditions . . . . 34

1.11. Power spectral density of noise at GeoNet stations . . . . . . . . . . . 35

1.12. Power spectral density of noise at borehole and surface stations . . . . . . 37

2.1. Idealised focal mechanisms and principal stress directions for Andersonian faulting ........................ 60

2.2. P- and S-wave amplitude patterns for a double-couple source . . . . . . . . 62

2.3. Mohr-Coulomb stress analysis . . . . . . . . . . . . . 65

3.1. Root-mean-squared travel-time residuals . . . . . . . . . . . . . . 68

3.2. Histograms of the travel-time residuals of SAMBA and DFDP10 stations . 69

3.3. Weights assigned to the travel-time observations . . . . . . . . . . 75

3.4. Correction of the travel-time residuals at station COSA . . . . . . . . . 78

3.5. Map showing station correction terms . . . . . . . . . . . . . . . . . 79

3.6. Magnitude residuals resulting from routine GeoNet magnitude estimation . 81

3.7. Amplitude readings and calibration magnitudes . . . . . . . . . . . 81

3.8. Overview of different magnitude estimation procedures . . . . . . . . . . 82

3.9. Magnitude residuals resulting using frequency-dependent attenuation . . . . 85

3.10. Station correction terms resulting from magnitude estimation . . . . . . . 87

3.11. Comparison of SAMBA and GeoNet magnitudes . . . . . . . . . 88 
3.12. Epicentral and magnitude differences for events in the SAMBA and GeoNet catalogues . . . . . . . . . . . . . . . . . . 88

3.13. Example of a quarry blast . . . . . . . . . . . . . . . . 91

3.14. Hypocentre location test for events outside the SAMBA network . . . . . . 93

3.15. Uncertainty volumes for different numbers of recording stations . . . . . . 94

3.16. Dependence of the hypocentre coordinates on the number of recording stations 95

3.17. Hypocentre locations before and after weighting . . . . . . . . . . . . . . 97

3.18. Histogram of hypocentral changes due to weighting . . . . . . . . . 98

3.19. Double-difference hypocentre relocations . . . . . . . . . . . . . . 101

3.20. Reconstruction of the focal mechanisms solutions of Leitner et al. (2001) 102

3.21. Comparison of focal mechanism solutions . . . . . . . . . . . . . . . . . . 104

3.22. First motions and P/T-axes for earthquakes within region $2 \ldots \ldots$

4.1. Hypocentre locations and magnitudes of earthquakes recorded in this and previous studies . . . . . . . . . . . . . . . . 115

4.2. Hypocentral depths and uncertainties for different profiles . . . . . . . . . . 117

4.3. Hypocentre locations in comparison with the resistivity structure . . . . . . 120

4.4. Depth, root-mean-squared residual and azimuthal gap distributions . . . . . 121

4.5. Frequency-dependence of the attenuation function and magnitude residuals versus distance . . . . . . . . . . . . . . . . . . . 123

4.6. Calibration magnitudes and their residuals . . . . . . . . . . . . . . 124

4.7. Focal mechanism solutions obtained in this study . . . . . . . . . . . 126

4.8. Principal stress directions obtained from focal mechanism inversion . . . . 128

4.9. Normal and shear stresses on the Alpine Fault plane . . . . . . . . . . . . . 136

4.10. Principal stress directions for a fixed depth and variable stress ratio R . . . 137

4.11. Seismicity in the Whataroa-Wanganui gap . . . . . . . . . . . . . . . . 139

4.12. Variation of the seismogenic thickness . . . . . . . . . . . . . . . . . . 140

4.13. Seismicity in comparison with the attenuation structure . . . . . . . . . . . 140

5.1. Definition of earthquake sequences, swarms and mainshock-aftershock sequences . . . . . . . . . . . . . . . . . . . . . . . . 144

5.2. Map of California showing key locations . . . . . . . . . . . . . . . . 148

5.3. Possible triggering mechanisms as summarised by Prejean et al. (2004) . . 155

5.4. Swarms and mainshock-aftershocks recorded in the study area . . . . . . 159

5.5. Sequence identification and magnitude distributions . . . . . . . . . . . . . 162

5.6. Event identification during aftershock sequences of major earthquakes . . . 164

5.7. Examples of two earthquake swarms . . . . . . . . . . . . . . 167

5.8. Example of a triggered swarm . . . . . . . . . . . . . . . 168 
5.9. Seismicity following the Dusky Sound and Darfield earthquakes

5.10. Dip and orientation of the preferred fault plane for the largest event in each swarm . . . . . . . . . . . . . . . . . .

5.11. Close-up view of remotely triggered seismicity in comparison with swarms and background seismicity . . . . . . . . . . . . .

5.12. Inter-event time patterns for background swarms, triggered swarms and mainshock-aftershock sequences . . . . . . . . . . . . . . . . . . 180

5.13. Example of focal mechanism solutions for events in a swarm . . . . . . . . 181

5.14. Cumulative sum and Omori-law fit for events recorded after the Dusky Sound earthquake . . . . . . . . . . . . . . . .

5.15. Peak ground velocities of major New Zealand earthquakes in comparison with seismicity in the study area $\ldots \ldots \ldots \ldots$. . . . . . . . . .

6.1. Subcrustal earthquakes reported in previous studies . . . . . . . . . . . . . 192

6.2. Example of a deep earthquake . . . . . . . . . . . . . . . . . . . . . 193

6.3. P-wave polarities and focal mechanism solutions for three deep earthquakes

6.4. Examples of tremor . . . . . . . . . . . . . . . . . . . . . . . . . 197

6.5. Tremor locations in comparison with the Q-structure . . . . . . . . . . 200

6.6. Tremor depths in comparison with velocity along SIGHT transect T2 . . . . 201

6.7. Tradeoff curves of the data variance versus the model variance . . . . . . . 204

6.8. Histogram of $\mathrm{V}_{\mathrm{P}} / \mathrm{V}_{\mathrm{S}}$-ratios in the study area . . . . . . . . . . . . 206

6.9. Grid orientation and initial hypocentre locations used for the joint hypocentre relocation and velocity inversion . . . . . . . . . . . . . . . . 207

6.10. Velocity profiles parallel to the Alpine Fault ～. . . . . . . . . . . . . 208

6.11. Comparison of tomographic results for the different velocity models . . . . 209

6.12. $\mathrm{V}_{\mathrm{S}}$-velocity models for different $\mathrm{V}_{\mathrm{P}} / \mathrm{V}_{\mathrm{S}}$-ratios $\ldots \ldots \ldots . \ldots . \ldots 211$

6.13. Results of checkerboard tests . . . . . . . . . . . . . . . . . 214

6.14. Shear-strain rates from GPS measurements in comparison with maximum horizontal compressive stress directions . . . . . . . . . . . . 215

6.15. Velocity and strain rate versus distance from the Alpine Fault as shown by Beavan and Haines (2001) _ . . . . . . . . . . . . . . . . . . 216

6.16. Magnitude distributions in comparison with shear-strain rates along two profiles . . . . . . . . . . . . . . . . . 217

6.17. Cumulative moment release in the study area f . . . . . . . . . . . 218

6.18. Shallow earthquakes with long durations recorded at station WHYM . . . . 221

6.19. More shallow earthquakes with long durations recorded at station WHYM . 222 
7.1. Factors influencing the depth of the brittle-ductile transition zone after Sibson (1984) . . . . . . . . . . . . . . . . . . . . . 229

A.1. Schematic representation of a passive seismometer after Havskov and Ottemöller (2010) _ . . . . . . . . . . . . . . . . . 233

A.2. Amplitude and phase response for the GeoNet stations . . . . . . . . . 237

A.3. Amplitude and phase response for the SAMBA and DFDP10 stations . . . 238

B.1. Examples of two teleseismic earthquakes recorded by the SAMBA stations 240

B.2. Locations and focal mechanisms of teleseismic events used for polarity checks 241

B.3. Examples of two teleseismic earthquakes recorded by the SAMBA and DFDP10 arrays . . . . . . . . . . . . . . . . . . 242

B.4. Two examples of quarry blasts . . . . . . . . . . . . . . . 243

C.1. Station recording times of the SAMBA, GeoNet and DFDP10 stations . . . 245

D.1. Examples of recorded spikes . . . . . . . . . . . . . . . . . . 248

D.2. Identified nuisance signals . . . . . . . . . . . . . . . . . . 250

D.3. Noise generated by lightning/thunder and within the recording equipment . 251

D.4. Noise generated by helicopters and electric fences . . . . . . . . . . . . . . 252

F.1. Power spectral densities of SAMBA borehole stations WHAT and POCR . 258

F.2. Power spectral densities of GeoNet stations WVZ and RPZ . . . . . . . . . 259

G.1. Travel-time residuals of SAMBA and DFDP10 stations . . . . . . . . . 261

H.1. First motions and P/T-axes for earthquakes within region $4 \ldots \ldots$. . . . 268

H.2. First motions and P/T-axes for earthquakes within region $6 \ldots \ldots$. . . . . 270

H.3. First motions and $\mathrm{P} / \mathrm{T}$-axes for earthquakes within region $1 \ldots \ldots$. . . . 271

L.1. Examples of earthquake swarms and mainshock-aftershock sequences _ . . 298 


\section{List of Tables}

1.1. Large earthquakes in the central South Island since 1888 . . . . . . . . . 19

1.2. 1-D velocity models for the central Southern Alps region . . . . . . . . 23

1.3. GeoNet station locations in the central Southern Alps . . . . . . . . . . 26

1.4. SAMBA station locations in the central Southern Alps . . . . . . . . . 26

1.5. DFDP10 station locations in the central Southern Alps . . . . . . . . . 27

3.1. Travel-time residuals and outliers of the SAMBA stations . . . . . . . . . . 72

3.2. Mean and standard deviations of the travel-time residuals for impulsive and emergent P- and S-phases . . . . . . . . . . . . . . . . . . . . . . . . . . . . . . .

3.3. Code for assigning weights . . . . . . . . . . . . . . . . . 74

3.4. Standard 1-D velocity model used by GeoNet . . . . . . . . . . . . . . 89

3.5. Recorded quarry blasts . . . . . . . . . . . . . . . . . . . 90

3.6. HypoDD parameters . . . . . . . . . . . . . . . . . . . 99

3.7. Comparison of focal mechanism solutions . . . . . . . . . . . . . . 103

3.8. Uncertainties and rotation angles of groups of focal mechanism solutions . 108

4.1. Principal stress directions obtained from focal mechanism inversion . . . . 129

4.2. Principal stress directions obtained in other studies . . . . . . . . . . . . 129

5.1. Observations of delayed triggering . . . . . . . . . . . . . . 158

5.2. Earthquake sequence catalogue . . . . . . . . . . . . . . . . . 170

5.3. Major South Island and distant events recorded by SAMBA . . . . . . . . . 175

5.4. Peak ground accelerations and velocities for major South Island and distant earthquakes . . . . . . . . . . . . . . . 176

5.5. Peak ground accelerations after the Dusky Sound earthquake as reported by Fry et al. (2010) . . . . . . . . . . . . . . . . . . . 178

5.6. Focal mechanism parameters of the largest event in each sequence . . . . . 182

5.7. List of major earthquakes that caused strong shaking in the study area . . . 187

6.1. Subcrustal earthquakes recorded by the SAMBA and GeoNet network . . . 195

6.2. Mean and standard deviation of $\mathrm{V}_{\mathrm{P}} / \mathrm{V}_{\mathrm{S}}$-ratios $\ldots \ldots . . . . . . . .205$ 
6.3. Hypocentre stability resulting from different starting velocity models . . . . 206

A.1. Specifications of the GeoSpace Technologies HS-1-LT sensor . . . . . . . . 236

A.2. Specifications of the Mark Products sensors . . . . . . . . . . . . . . . 236

A.3. Specifications of the GeoNet sensors . . . . . . . . . . . . . . . 236

B.1. Origin time and hypocentre locations of teleseismic earthquakes with impulsive P-arrivals . . . . . . . . . . . . . . . . . . . . . . . . 244

D.1. Solar controllers and their spike characteristics _ . . . . . . . . . . . . 247

E.1. Overview of site conditions and assessment of station performance . . . . 254

I.1. Source dimensions, frequency of occurrence and recording range for different event magnitudes . . . . . . . . . . . . . . . . . . . 273

I.2. Amplitudes and periods of stress changes from different sources after Manga and Brodsky (2006) . . . . . . . . . . . . . . . . . 274

J.1. Hypocentre locations . . . . . . . . . . . . . . . . . . 286

K.1. Focal mechanism solutions . . . . . . . . . . . . . . . . . . 295

M.1. Comparison of seismicity and resistivity as reported by Gürer and Bayrak (2007) . . . . . . . . . . . . . . . . . . 310 


\section{Introduction}

\subsection{Motivation, thesis objectives and outline}

This PhD project is part of the Marsden-funded project "Putting a stethoscope on the Alpine Fault", which sought to address the following topics

- the accommodation of strain due to plate movement in the mid and upper crust of the central South Island;

- the generation of earthquakes and other strain signals such as slow-slip events and non-volcanic tremor in a fluid-rich, continental transform fault zone; and

- the distribution of strain in both time and space, especially at depths below the brittleductile transition zone.

To investigate these topics the Southern Alps Microearthquake Borehole Array (SAMBA) was deployed, a station network designed for the detection of microearthquakes in the central Southern Alps. We note that the terms "array" and "network" are used interchangeably throughout this thesis. Despite this, "array" is more commonly used for small station networks (with inter-station distances $<20 \mathrm{~km}$ ).

In addition to the station installation, service and maintenance of the SAMBA network, an analysis and interpretation of the recorded earthquake data has been performed in the cause of this project. Earthquake activity at the microseismicity level $\left(\mathrm{M}_{\mathrm{L}}<3\right)$ is investigated in order to distinguish between structural and fluid-driven processes that generate earthquakes. Temporal and spatial seismicity patterns and the deformation and rheology associated with them are studied.

This thesis begins with an introduction to the Alpine Fault within the central Southern Alps region, its broader tectonic setting and the seismotectonic activity revealed by recent seismicity studies. An overview of the SAMBA station network, the data processing and the network performance is also provided. Chapter 2 outlines the theoretical background 
to the methods applied to the data. Chapter 3 focuses on the analysis of the data and tests performed with the data. A summary and comprehensive discussion of the earthquake locations, magnitudes and focal mechanisms in the prevailing stress field from the first 1.5 years of data is given in Chapter 4 which has been recently published in the Journal of Geophysical Research (Boese et al. 2012). This chapter has been modified regarding references to other figures and chapters to better fit the context of this thesis. Repetition of some of the material presented elsewhere in this thesis may occur but this has been kept to a minimum. Chapter 5 characterises swarms and remotely triggered seismicity in the central Southern Alps. This chapter consists of two parts: a general introduction to swarms, observations and suggested mechanisms of triggering and a discussion of the observations of swarms in the study area and their implications. The second part has been written for submission as a publication. Some of the results incorporated were obtained by Katrina Jacobs as outlined in the introduction to the chapter. Chapter 6 summarises unpublished results of different topics that were investigated, specifically deep earthquakes, tremor, tomography, fault-guided waves and strain release by microearthquakes. The tremor analysis was performed together with Aaron Wech. His contributions are described at the beginning of this chapter. The concluding chapter, Chapter 7, summarizes the key findings of the research and discusses their implications. It also provides topics and suggestions for future work with longer records of seismic data from the SAMBA network. 


\subsection{Tectonic and geological setting of the Alpine Fault}

New Zealand is situated on the plate boundary between the Pacific and Australian plates. The Pacific Plate is subducted westwards beneath the Australian Plate along the TongaKermadec Trench and its southern continuation, the Hikurangi Trough, which extends from East Cape of the North Island to the northernmost part of the South Island. Eastward-dipping subduction of the Australian plate occurs at the southern part of South Island along the Puysegur Trench beneath Fiordland and offshore. The Alpine Fault, together with the Marlborough Fault system, links these subduction zones of opposite polarity (Berryman et al. 1992). The Alpine Fault forms the western boundary of the Southern Alps, which are the result of oblique continental collision between two largely submerged continental fragments, the Chatham Rise and Campbell Plateau to the east and the Challenger Plateau to the west (Fig. 1.1) (e.g. Cox and Sutherland 2007).

The New Zealand land mass encompasses different geological terranes of varying age (Mortimer 2004). The basement rocks of the Western Province, extending from Fiordland, along the West Coast to west Nelson (Fig. 1.1) formed from sediment deposits along the margin of the Gondwana Supercontinent during the Palaeozoic. These sediments were metamorphosed and intruded by igneous rocks (Devonian-Cretaceous granites and granitoids) when rifting occurred in the Gondwana break-up phase. The Western Province basement rocks span an age range from Precambrian to late Mesozoic (Cox and Barrell 2007).

Eastern Province rocks, known as the Torlesse Supergroup, which can be found over much of the country from Otago to East Cape, formed from the deposition of sediments (sandstone, mudstone and volcanic rocks) in turbidity currents along the eastern coastline of Gondwana. These sedimentary rocks are Permian to Jurassic in age (Mortimer 2004). In the South Island, they are now being rapidly uplifted along the Alpine Fault. Their metamorphic grade increases from east to west with the once most deeply buried rocks (oligoclase and garnet zone from 20-30 km, Kamp et al. 1989; Cooper 1980; Little et al. 2002; Norris and Cooper 2003) exposed at the surface adjacent to the Alpine Fault. A distinct suite is the Dun Mountain-Maitai Terrane, of originally volcanic rocks that were deposited in discrete pulses of magmatism in the subduction back-arc. These rocks are Carboniferous to Early Cretaceous in age and were highly deformed during the Cretaceous and Late Cenozoic (Mortimer et al. 1999). The schist in different regions on the South Island is referred to as Otago, Alpine and Marlborough Schist despite the lack of formally 


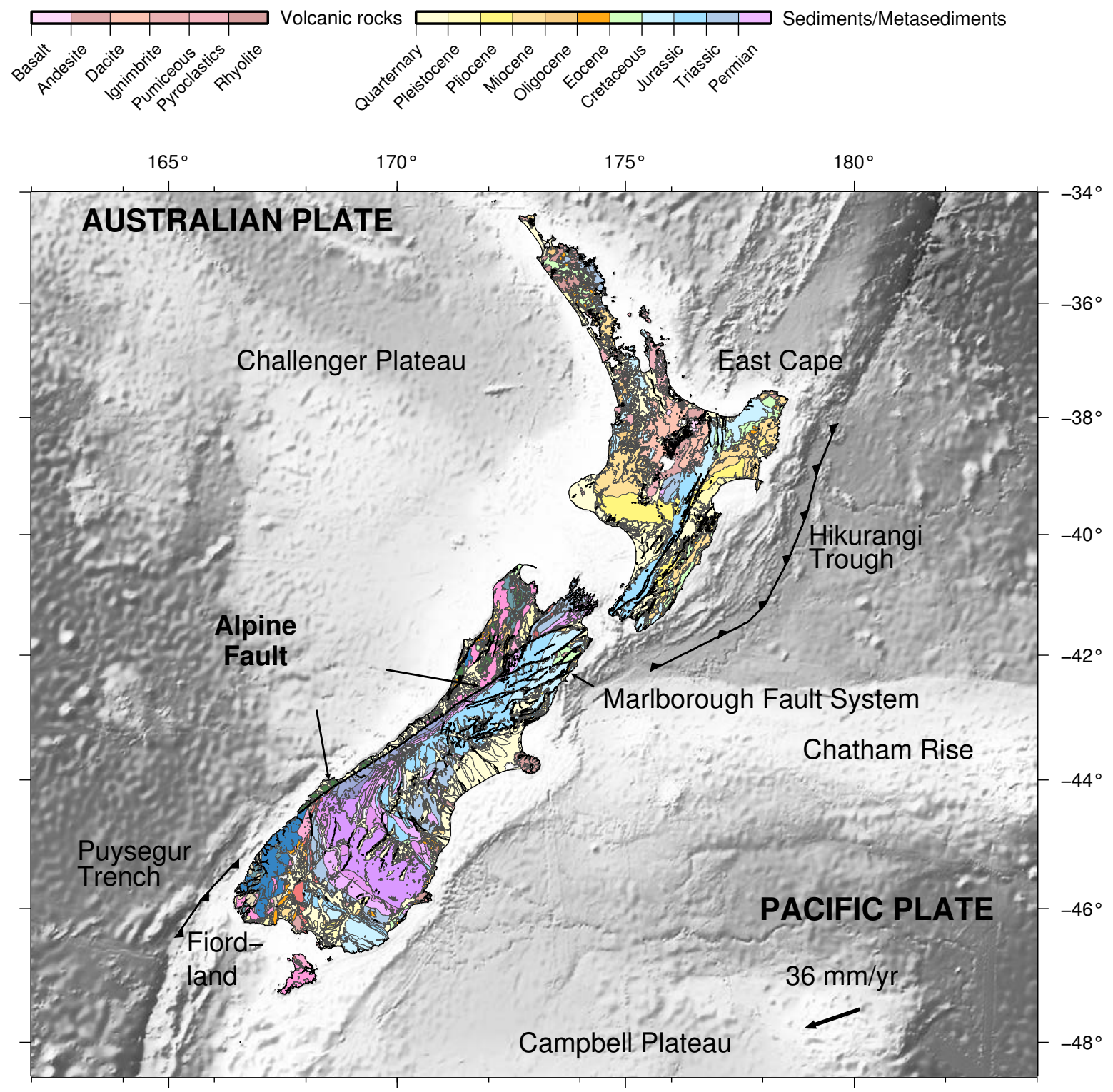

Figure 1.1. Regional geological map highlighting the plate boundary between the Australian and Pacific plates through New Zealand (from Officers of the New Zealand Geological Survey 1972 with limited updates by P.J. Forsyth and N. Mortimer (2004) and GNS Science Active Faults Database). Key locations referred to in the text are shown. 
defined boundaries between them (Cox and Sutherland 2007).

Eastern and Western Province rocks in South Island are separated by the Alpine Fault and its northern continuation, the Wairau fault. They displace the Dun Mountain Ophiolite Belt by a total of $460 \mathrm{~km}$ (e.g. Sutherland 1999). This feature can be accurately traced on the North and South Islands due to its characteristic magnetic properties and is therefore a distinct geologic marker of plate motion. However, the total amount of dextral displacement of the western North Island with respect to the eastern South Island of New Zealand from plate model reconstruction is estimated to be $850 \pm 100 \mathrm{~km}$ (Molnar et al. 1999). The extent of distributed dextral shear deformation of the Dun Mountain-Maitai Terrane before or during the inception of the Alpine Fault is still debated (Sutherland 1999, and references therein). Mesozoic to late Cenozoic ages for the initiation of deformation on the Alpine Fault have been proposed, but Eocene ages for the localisation of strain on the plate boundary are favoured by Sutherland (1999). Sutherland (1999) and Sutherland et al. (2000) suggested that this major fault evolved from reactivation of a zone of pre-existing fractures, inherited from extensional deformation related to sea-floor spreading south of New Zealand in the Eocene. According to these authors, the Alpine Fault formed during the Miocene when the displacement rates increased significantly in response to a change in the plate motion direction.

Uplift of the Southern Alps started in the late Miocene/early Pliocene when oblique compression of the relative plate motion between the Pacific and Australian Plates increased (e.g. Walcott 1978). Cande and Stock (2004) argued that the onset of convergence occurred in the northern section of the Alpine Fault about $11 \mathrm{Ma}$ in contrast to the southern section where no convergence occurred prior to $11 \mathrm{Ma}$. Increasing convergence rates between $11 \mathrm{Ma}$ and $6 \mathrm{Ma}$ led to shortening in the central South Island by a maximum amount of 90-110 km (Walcott 1998). The earliest appearance of overthrusts of Haast Schist over Pleistocene gravels is dated at 2.5-3.0 Ma (Rattenbury 1986). These gravels indicate an increase in plate boundary convergence rate rather than the onset of convergent movement on the Alpine Fault (Walcott 1978; Yeats and Berryman 1987). Estimates of the total uplift during the last $5 \mathrm{Myr}$ (the Kaikoura Orogeny) range between $21.5 \mathrm{~km}$ (Kamp et al. 1989) and 25-30 km (Cooper 1980; Little et al. 2002; Norris and Cooper 2003).

The Alpine Fault can be divided into three segments (e.g. Sutherland et al. 2000) which differ significantly in their dips and structural styles, and in the widths of deformation adjacent to the fault (Fig. 1.2). In the northernmost part of South Island, slip-partitioning occurs between the Hikurangi subduction zone and several major strike-slip faults (Little and Jones 


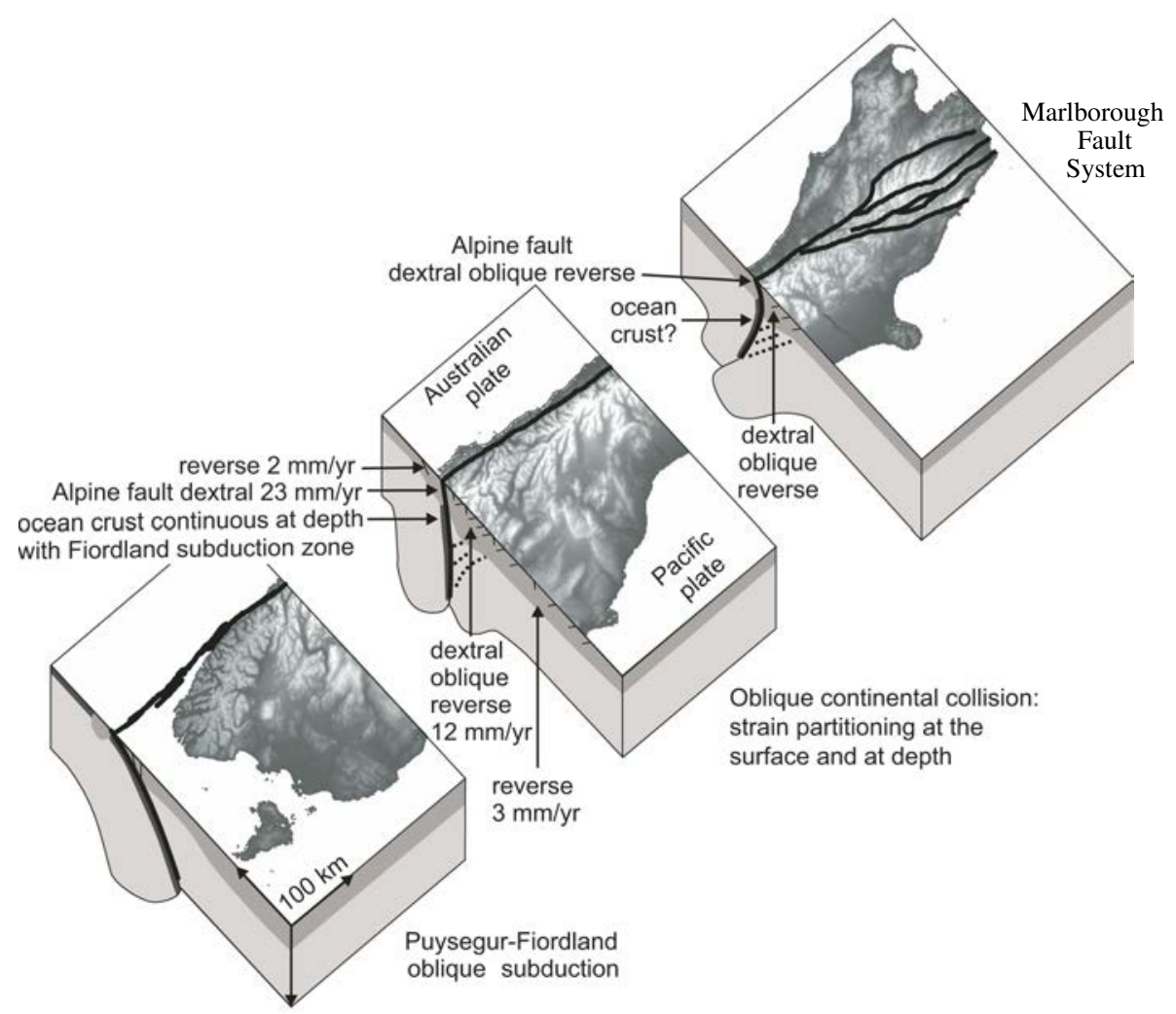

Figure 1.2. The three segments of the Alpine Fault and its variation in style and dip (modified from Sutherland et al. 2006).

1998), known collectively as the Marlborough Fault System. The faults traverse the northernmost South Island and merge with the Alpine Fault in the southwest. This broad zone of deformation has a width of about $200 \mathrm{~km}$. The four major faults, Wairau, Awatere, Clarence, and Hope Fault, are steeply-dipping, evenly-spaced approximately $30 \mathrm{~km}$ apart, and have parallel strike directions (Little and Jones 1998; Grapes et al. 1998). The average regional strike of the Marlborough Faults is $055^{\circ}$ in the northernmost South Island but changes to $070^{\circ}$ further south (Lamb and Bibby 1989). The Marlborough Faults become progressively younger from the north to the south (Little and Jones 1998, and references therein). The northernmost part of the Alpine Fault, named Wairau Fault, is the oldest (early Miocene age) of the Marlborough faults. It currently has the lowest displacement rates of the Marlborough Fault System, which are estimated to be $4 \pm 1 \mathrm{~mm} / \mathrm{yr}$ (Knuepfer 1992). The Hope Fault is the southernmost and youngest (Pleistocene age) active fault. It has the highest slip-rates of $23 \pm 4 \mathrm{~mm} / \mathrm{a}$ (Langridge et al. 2003). Approximately $60 \mathrm{~km}$ south of the Hope Fault, the Porters Pass-Amberley Fault Zone (PPAFZ) may form the incipient continuation of the fault system to the south (Cowan et al. 1996). The PPAFZ consist of several smaller fault segments, including the Porters Pass Fault, a young active, $40 \mathrm{~km}$-long segment, northeast of Lake Coleridge (Cowan 1992, Fig. 1.3 and 1.6). The faults that 


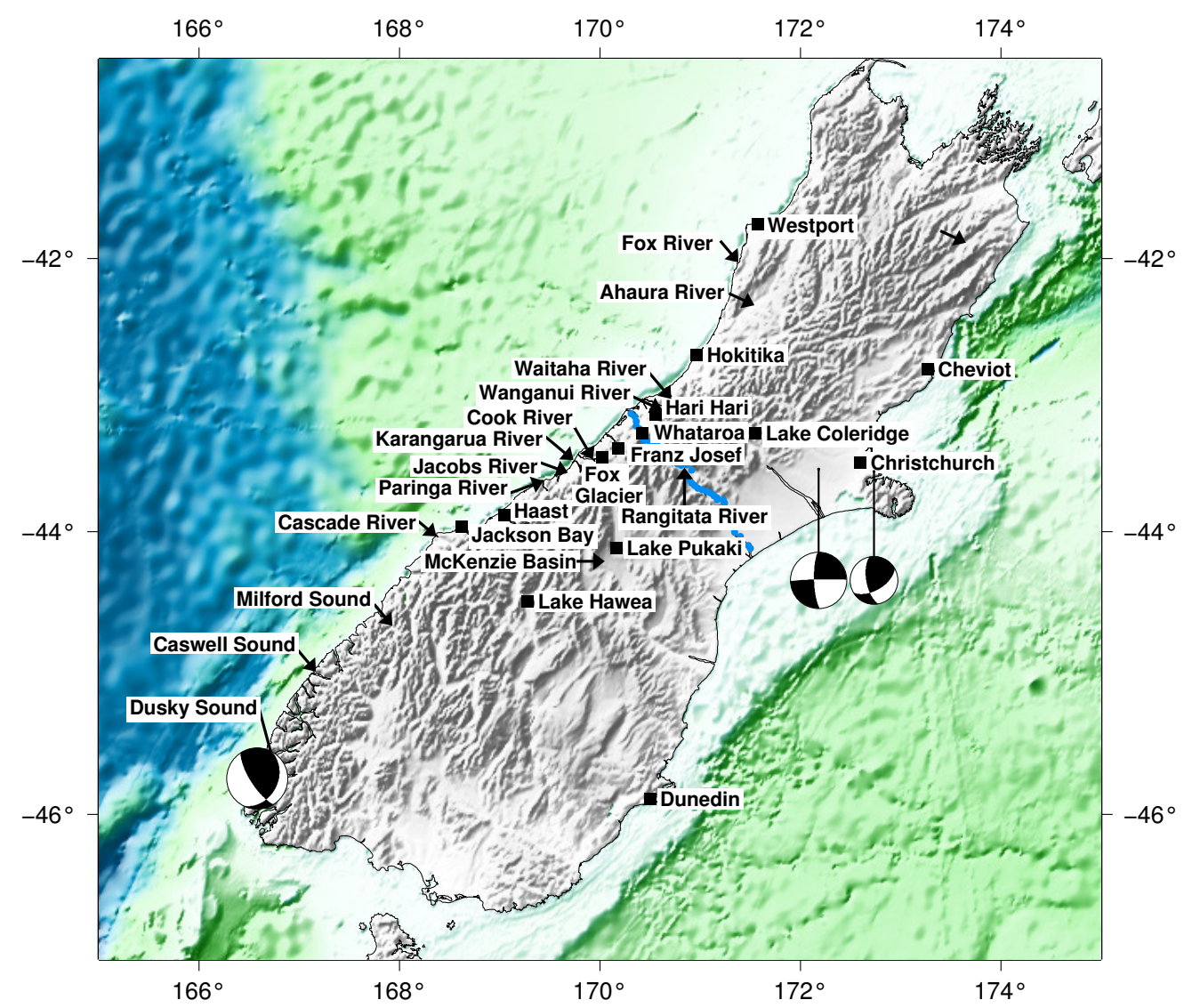

Figure 1.3. Map of South Island showing key locations referred to in this introduction. Focal mechanism solutions for the Dusky Sound (Fry et al. 2010), Darfield and Christchurch earthquakes (USGS) are shown. The blue transect shows the locations occupied during magnetotelluric sounding.

ruptured in the Christchurch earthquake sequence 2010/11 approximately $30 \mathrm{~km}$ south of the PPAFZ (e.g. Gledhill et al. 2011; Quigley et al. 2012) involved several fault segments, e.g. the east-west striking $\left(\sim 089^{\circ}\right)$ Greendale Fault and inferred faults striking $55-65^{\circ}$ and $68^{\circ}$ for the major Christchurch events](Quigley et al. 2012; Sibson et al. 2011; Beavan et al. 2011; Holden 2011).

Slip rates in the Marlborough Fault System show that about $95 \%$ of the plate motion is accommodated by the faults (Holt and Haines 1995). Primarily, dextral strike-slip faulting occurs. The amount of dip-slip is small but increases to the northeast, causing uplift of the coastal Kaikoura ranges (Davey et al. 2007).

With the transition from westward subduction to continental collision, a change from predominantly strike-slip to convergent motion takes place on the central section of the Alpine Fault. This transition zone coincides closely with the region in which the Wairau 
and Awatere faults splay off from the Alpine Fault (Davey et al. 2007) and is characterised by the abrupt termination of earthquakes at depths greater than $40 \mathrm{~km}$ (Anderson and Webb 1994). A line between Westport and Cheviot (Fig. 1.3) has been suggested to mark the present-day southern termination of the subducting Pacific Plate (Robinson 1991). Reyners and Robertson (2004) argued that subduction of the Pacific Plate extends south to $-43^{\circ}$ and Reyners et al. (2011) suggested that it extends even further southwards beyond $-45^{\circ}$. The crust of the Pacific Plate changes from thick oceanic to thin continental crust, which is inferred to be associated with a change in dehydration conditions within the slab (Reyners and Robertson 2004). The fault dip inferred from seismic reflection studies (Stern et al. 2007) and from the surface dip of the mylonite foliation (Sibson et al. 1981) is estimated to be $60^{\circ}$. Strong reflections at a depth of $33 \mathrm{~km}$ are consistent with a subhorizontal fault (Kleffman et al. 1998), indicating a listric geometry with depth.

In the central South Island, the zone of deformation is only $80 \mathrm{~km}$ wide (Cox and Barrell 2007). The width of the Alpine schist is narrowest $(8 \mathrm{~km}$ between Franz Josef and Fox Glacier versus a maximum of 26 km; Little et al. 2005; Cox and Sutherland 2007). According to Norris and Cooper (2001), the central Alpine Fault accommodates $75 \%$ of the total plate motion in horizontal movement and up to $100 \%$ of the convergence. Both thrust and strike-slip motion are accommodated on a single fault (Norris and Cooper 2001). The surface trace of the Alpine Fault is characterised by serial partitioning into 3-5 km-long segments of strike-slip and reverse segments (Norris and Cooper 1997; Norris and Cooper 2001). Sections of north-east striking $\left(020-050^{\circ}\right)$, oblique thrust segments alternate with more easterly $\left(065-090^{\circ}\right)$ striking dextral strike-slip segments (Norris and Cooper 1995). Shallow overthrusts of the thrust segments generally extend less than a few kilometres west of the main Alpine Fault trace (Norris et al. 1990). Sandbox-modelling of the fault by Norris and Cooper (2001) suggests that the strike-slip and thrust segments represent the surface structure of a single fault at depth. According to Norris and Cooper (2001), this serial partitioning at the surface results from the perturbation of the stress field by valleys crossing the fault in combination with an oblique-slip ductile fault zone at depth.

In the southern section, between Jackson Bay and Milford Sound (Fig. 1.3), the Alpine Fault is steeply-dipping $\left(70-90^{\circ}\right)$ and purely strike-slip in character (Sutherland et al. 2000). About 55-85\% of the total plate motion is accommodated on the Alpine Fault. Approximately $10 \mathrm{~mm} / \mathrm{yr}$ of right-lateral movement is accommodated by active faulting in a $300 \mathrm{~km}$-wide zone southeast of the Alpine Fault (Sutherland et al. 2000). Several faults, notably the Hollyford Fault System and the Moonlight-Siberia Fault System (White 2002), are located to the southeast of the Alpine Fault. The convergent component of plate motion 
is partially accommodated by thrust faulting west of the Alpine Fault. A change in the strike direction of the Alpine Fault by $7^{\circ}$ counterclockwise occurs south of the Cascade River (Sutherland et al. 2007). The strike-slip motion, inferred from surface displacements, is $23 \pm 2 \mathrm{~mm} / \mathrm{yr}$ (Sutherland 1994; Sutherland et al. 2007). South of Caswell Sound, the fault continues for $230 \mathrm{~km}$ offshore and ends near the Puysegur trench (Barnes et al. 2005). The fault trace is continuous but geometrically complex, with right-stepping segments and small pull-apart basins (Barnes et al. 2005). Slip rates determined from displaced submarine, glacial geomorphologic features span 24-33.5 mm/yr (Barnes 2009). This accounts for $90 \%$ of the total relative plate motion and indicates a high degree of strain partitioning between the Fiordland subduction zone and the southern Alpine Fault (Barnes 2009).

\subsubsection{Characteristics of the central Southern Alps region}

The present-day relative plate motion between the Australian and the Pacific plate from the NUVEL-1A model is $37 \pm 2 \mathrm{~mm} / \mathrm{yr}$ at an azimuth of $071 \pm 2^{\circ}$ (De Mets et al. 1994). The Alpine Fault strikes at an angle of approximately $18^{\circ}$ to the plate motion direction, so that the boundary-parallel component amounts to $35.5 \pm 1.5 \mathrm{~mm} / \mathrm{yr}$ and the fault-perpendicular component to $10 \pm 1.5 \mathrm{~mm} / \mathrm{yr}$ at $-43.5^{\circ} / 170.5^{\circ}$ (Little 2004). Paleoseismic studies suggest that the recent dextral strike-slip component of the fault is constant along the central section of the fault at $27 \pm 5 \mathrm{~mm} / \mathrm{yr}$, but that dip-slip rates are spatially variable and range between 0 and $10 \mathrm{~mm} / \mathrm{yr}$ (Norris and Cooper 2001). Little et al. (2005) suggest that enhanced uplift occurs between Franz Josef and Fox Glacier due to a localised steepening by $15-20^{\circ}$ of the Alpine Fault's dip. The change in the geometry of the (Australian) footwall at depth is inferred to be the cause of upramping of a backshear array in the hanging wall in an escalator-like fashion in this region (Wightman and Little 2007). The southern end of this transition lies in the vicinity of the Karangarua River (Fig. 1.3). This may cause a localised zone of enhanced deformation associated with elevated seismicity levels along a band of seismicity south of Mt. Cook (Little et al. 2005).

The shape of the Southern Alps orogen is highly asymmetric. It has been described as a two-sided deforming wedge, with the Australian plate behaving as a rigid indentor (Koons 1990). This causes two zones of localised shear deformation, one in the inboard side of the orogen and the other in the outboard side (Koons 1990; Beaumont et al. 1996). The highest elevation within the orogen is reached at the Main Divide. Its position and height result from differences in fluvial erosion between the inboard (eastern) and outboard (western) side of the orogen, driven by the asymmetry in orographic precipitation, and the tectonic advection associated with the convergence (Herman and Braun 2006). Uplift is 
highest in the zone between the Alpine Fault and the Main Divide Fault Zone, a >60 km-long backthrust system immediately below and to the east of the Main Divide (Cox et al. 1997; Cox and Findlay 1995) (Fig. 1.4) that separates semi-schists from unmetamorphosed greywacke. The Main Divide Fault Zone exhibits a similar small-scale segmentation to the Alpine Fault, and its overall strike is parallel to the Alpine Fault (Cox and Findlay 1995). The segmentation of the Main Divide Fault Zone consists of oblique-reverse faults of 5-15 km length which dip 40-60 $\mathrm{NW}$ and are linked by shorter, 3-5 km-long, more steeply-dipping strike-slip faults forming dextral steps (Cox and Findlay 1995). The Main Divide Fault Zone lies 15-30 km southeast of the Alpine Fault and assuming an Alpine Fault dip of $50^{\circ}$ SE likely merges with the Alpine Fault at approximately 10-12.5 km depth (Fig.1.4). All inboard structures are progressively advected into the orogen during uplift along the Alpine Fault ramp and exposed due to the erosion (Cox and Findlay 1995). The Main Divide, as the crest of the Southern Alps, controls the drainage patterns. The landscape features steep hillslopes on the western side of the Main Divide, covered by dense rain forest below $1000 \mathrm{~m}$ and a small stripe of coastal plain. East of the Main Divide, the topography is less steep, controlled by differential uplift along large southwest-northeast trending, west-dipping reverse faults. The orogen flattens out progressively towards the east coast (Cox and Sutherland 2007) and extends about $100 \mathrm{~km}$ eastwards.

A $20 \mathrm{~km}$-long segment of the central Southern Alps has reached an exhumational steady state according to thermochronology studies (Little et al. 2005). Rock is exhumed more rapidly than it can cool, so high temperatures prevail in originally lower-crustal rocks at shallow depths. According to Craw (1997), who analysed adularia veins at high altitudes ( $>1400 \mathrm{~m}$ above sea level), fluid boiling occurs at $500 \pm 150 \mathrm{~m}$ below the surface. These adularia-bearing veins formed at temperatures of ca. $320-350^{\circ} \mathrm{C}$ and ca. $1.5 \mathrm{kbar}$ pressure corresponding to ca. $6 \mathrm{~km}$ depth assuming lithostatic conditions. Koons (1987) derived one of the earliest models of the thermal structure of the Southern Alps by modelling the Alpine Fault as a vertical discontinuity, assuming uplift rates of $10 \mathrm{~mm} / \mathrm{a}$ east of the fault and $4 \mathrm{Myr}$ for exhumation of the Southern Alps. His results indicated a $5 \mathrm{~km}$-wide zone of maximum uplift immediately adjacent to the discontinuity with elevated geotherms. Neither heat generation due to radioactive decay nor shearing was considered, and heat transfer was assumed to occur by conduction only. Modelling results indicated temperatures of $350^{\circ} \mathrm{C}$ at $5 \mathrm{~km}$ depth after $2.5 \mathrm{Myr}$ in a narrow zone of high uplift. After this time, the vertical thermal structure remained constant but thermal diffusion caused the high-temperature region to widen horizontally. Later models by Shi et al. (1996), Batt and Braun (1997) and most recently by Toy et al. (2010) all indicate high temperatures at shallow depths in the vicinity of the Alpine Fault, especially in a narrow zone of $10 \mathrm{~km}$ 


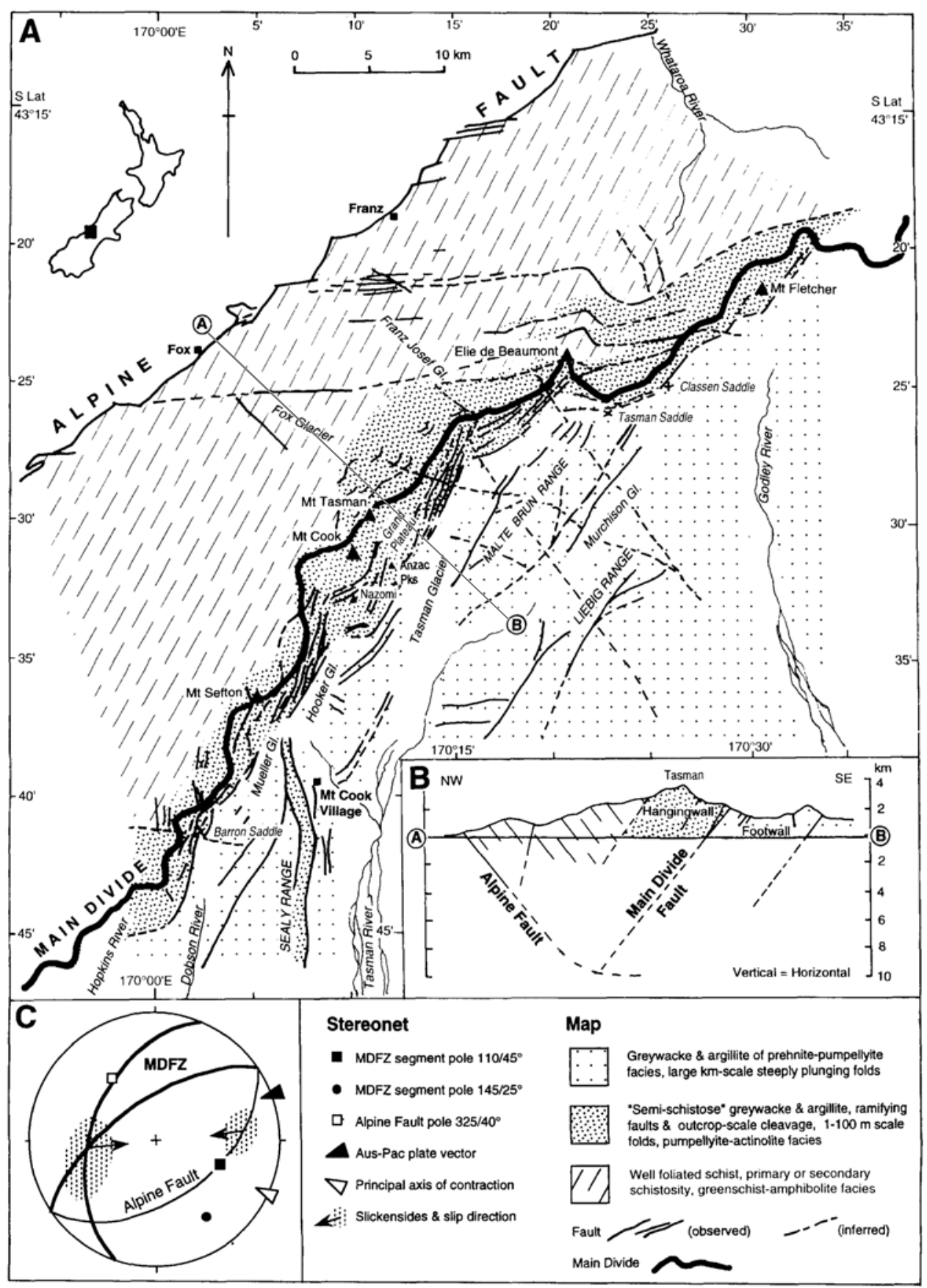

Figure 1.4. A) Map of the central section of the Alpine Fault and Main Divide Fault Zone (separating semi-schist from greywacke) by Cox and Findlay (1995; their Fig. 1), illustrating the segmentation of both faults and their average orientation. Thin lines indicate mapped faults, dashed lines their inferred traces. The thick black line shows the position of the Main Divide, the crest of the mountain range. B) Inferred intersection of the Alpine Fault and the Main Divide Fault at 10-12 km depth along the cross section between Fox Glacier and Mt. Cook as shown in A). C) Equal angle, lower hemisphere stereonet showing the overall orientation of the segments of the Main Divide Fault Zone (two thick lines) in relation to the Alpine Fault (thin line) and the orientation of slickensides after Norris et al. (1990). 
(Shi et al. 1996) to $25 \mathrm{~km}$ in width (Toy et al. 2010) immediately east of the fault. These studies emphasise the importance of high erosion rates as a constraint on the thermal models.

Fluid flow at shallow depths in the central Southern Alps is inferred to be driven by topography and dominated by surface waters of meteoric origin that penetrate to depths of 5-6 km (Upton et al. 1995). Evidence for this comes from fluid inclusion studies on calcite and quartz veins (Jenkin et al. 1994; Craw 1997). Jenkin et al. (1994) sampled fluid inclusions from steeply-dipping fissures in the vicinity of the Alpine Fault between the Waiho and Fox River that were deposited by circulating fluids of meteoric origin at depths of 1-6 km assuming hydrostatic fluid pressures. Fluid inclusions originate from fluids composed of water, 15-20\% carbon-dioxide and up to $5 \mathrm{wt} \% \mathrm{NaCl}$ equivalent. Templeton et al. (1998) studied fluid inclusions in the Mackenzie Basin in the eastern, outboard region of the Southern Alps which has lower uplift rates and a lower geothermal gradient. They found evidence for mixing of meteoric fluids with metamorphic hydrothermal fluids at temperatures of $300-350^{\circ} \mathrm{C}$ at depths greater than $5 \mathrm{~km}$. Near the surface, these fluids mix with basinal waters, characterised by a systematic shift from low $\delta 18_{\text {calcite }}^{\mathrm{O}}$ and high $\delta 13^{\mathrm{C}}$ to higher $\delta 18_{\text {calcite }}^{\mathrm{O}}$ and lower $\delta 13^{\mathrm{C}}$ values in post-metamorphic veins. Several hot springs within $10 \mathrm{~km}$ of the Alpine Fault north of Franz Josef have oxygen and hydrogen isotope compositions typical of meteoric water and rock-equilibration temperatures of $90-150^{\circ} \mathrm{C}$, suggesting circulation to depths shallower than $3 \mathrm{~km}$ (Barnes et al. 1978; Jenkin et al. 1994; Allis and Shi 1995; Templeton et al. 1998).

Fluids at mid-crustal depths have been inferred from magnetotelluric studies by Wannamaker et al. (2002) as the cause of high conductivity. Modelling by Vry et al. (2009) showed that rapid exhumation and near-isothermal decompression of typical Alpine schist causes dehydration of the rock, due to a phase transition from epidote to plagioclase. This phase transition occurs in a narrow temperature range $\left(400^{\circ} \mathrm{C}<\mathrm{T}<560^{\circ} \mathrm{C}\right)$ during decompression and generates up to 0.009 moles of fluid per mole of rock. This is possible if the rock has not experienced the same phase transition at higher temperatures and pressures before. Such temperatures are associated with the biotite zone/garnet zone transition that lies approximately midway between the Alpine Fault and the Main Divide Fault Zone (Vry et al. 2009). According to Vry et al. (2009), low volumes of fluid $(<1 \%)$ interconnected through permeable rock and salinities of 2.5-5 wt $\%$ are sufficient to cause the high conductivities observed for the middle to lower crust of the Southern Alps during magnetotelluric sounding by Wannamaker et al. (2002). Wannamaker et al. (2002) inferred that large volumes of fluids, released from metamorphic processes, ascend in a U-shaped conductivity anomaly towards the brittle-ductile transition zone. The centre point of this anomaly lies at $20 \mathrm{~km}$ 
depth and terminates at $10 \mathrm{~km}$ depth with subvertical legs 5-10 km and $60 \mathrm{~km}$ southeast of the Alpine Fault. The depth of the top of the conductor is well-resolved (Jiracek et al. 2007) and the conductivity significantly exceeds that of the overlying crust. Wannamaker et al. (2002) proposed that the fluids are trapped in the mylonitised, ductile shear zone, inferred from other studies to lie at these depths. When the uplifted, ductile rocks cross the brittle-ductile transition zone, these fluids are released and ascend, causing a change from lithostatic to hydrostatic fluid pressures in the fault zone.

The high-conductivity region coincides with a zone of low seismic P-wave velocities (reduced by 10\%; Smith et al. 1995; Stern et al. 2001). Velocity profiles derived from active source wide-angle reflection and refraction data collected during the SIGHT (South Island Geophysical Transect) project in 1996 and 1998 (Davey et al. 1998; Okaya et al. 2002) show the extent of the low-velocity zone in the Pacific Plate between depths of $6 \mathrm{~km}$ (transect 1) and $14 \mathrm{~km}$ (transect 2) to the base of the crust at maximum depths of 37-44 km (Scherwath et al. 2003; Van Avendonk et al. 2004). A second low-velocity zone in the Australian plate at 5 to $10 \mathrm{~km}$ depth is interpreted to be the result of flexural bending (Fig. 1.5).

A broad, negative, Bouguer gravity anomaly (represented by the -80 mgal contour) extends over a $50 \times 200 \mathrm{~km}^{2}$ area (Woodward 1979) about $70 \mathrm{~km}$ south of Mt. Cook. The Bouguer gravity anomaly indicates an extensive crustal root of lower density material. The crustal root is inferred to result from lithospheric thickening caused by the plate convergence, and is formed by thickened middle and lower crust (Scherwath et al. 2003). The crust is 15-20 km thick east and west offshore South Island (Scherwath et al. 2003; Van Avendonk et al. 2004) and $27 \mathrm{~km}$ at the west coast (Melhuish et al. 2005). Shortening of the crust has increased crustal thicknesses to $40-50 \mathrm{~km}$ beneath and slightly east of the Southern Alps (e.g. Davey et al. 2007). The thickness of the crustal root also increases southwards. Gerbault et al. (2002) suggested that southward extrusion of ductile lower crustal material has occurred since significantly more crustal thickening has been inferred in the northern part than in the southern part of the Southern Alps. The area of lowest isostatic gravity anomaly ( $-30 \mathrm{mgal}$ ) extends just southeast of the maximum topography of Southern Alps. Since the crustal root is much larger than needed to balance the Southern Alps isostatically, this suggests a mass excess in the upper mantle (Bourguignon 2009, and references therein). The lithospheric structure is asymmetric in the crust (concentrated in the Pacific plate) but symmetric within the mantle (Stern et al. 2000, Figure 1.5). This has been inferred from P-wave travel-time residuals of teleseismic earthquakes which decrease across the South Island and can be explained by a subvertical high-velocity mantle anomaly 
(Stern et al. 2000). Bourguignon (2009) modelled its minimum extent as $110 \pm 20 \mathrm{~km}$ in width and $70 \pm 20 \mathrm{~km}$ in thickness assuming a density contrast of $300 \mathrm{~kg} / \mathrm{m}^{3}$ between lower crust and mantle.

More than 15 regional global positioning system (GPS) surveys were conducted in the central and southern South Island between 1994 and 2004 (Wallace et al. 2007). These campaign surveys showed that velocities parallel to the strike of the Alpine Fault are fairly uniform. Two temporary GPS transects, one extending from Lake Hawea to Haast (Pearson et al. 2000) and the other from Christchurch to Hokitika (Pearson et al. 1995, Fig. 1.3), showed that the highest strain rates occur in the vicinity and to the east of the Alpine Fault. Vertical velocities across the Hawea-Haast transect are zero within the 95\% confidence limits (Pearson et al. 2000). Beavan et al. (1999) state that errors in vertical velocities obtained in the campaign surveys are too large ( $>10 \mathrm{~mm} / \mathrm{yr})$ to give reliable estimates. A permanent continuous GPS array crossing the Southern Alps between Jacobs River and Waitaha River, the Central South Island (CSI) network, has been recording since 2000 (Beavan et al. 2004; Beavan et al. 2010a). Vertical GPS rates are calculated with respect to a local reference frame. The station OUSD near Dunedin is assumed to be far enough away from the plate boundary that it can be treated as a stable point on the non-deforming Pacific plate with a fixed vertical velocity of $0.0 \pm 0.4 \mathrm{~mm} / \mathrm{yr}$ (e.g. Beavan et al. 2004). Results from analysis of the CSI data yield maximum rates of vertical movement of $6-9 \mathrm{~mm} / \mathrm{yr}$ relative to the east coast which occur about $20-30 \mathrm{~km}$ southeast of the Alpine Fault (Beavan et al. 2010a). Vertical rates have higher uncertainties than horizontal velocities (by a factor of three in the Southern Alps according to Beavan et al. 2007), due to smaller uplift rates, systematic errors (e.g. satellite geometry, atmospheric and ionospheric effects) and are more influenced by various processes such as seasonal cycles, localised erosion and isostatic compensation.

Linear elastic two-dimensional dislocation modelling is commonly used to model GPS data. Beavan et al. (1999) and Pearson et al. (2000) found that single-fault models of the Alpine Fault require much greater locking depths $(22 \pm 1 \mathrm{~km}$ for the central South Island data and $20 \pm 2 \mathrm{~km}$ for the Hawea-Haast transect) than suggested by the seismicity. In both cases, strike- and dip-slip rates (of $36 \pm 0.8 \mathrm{~mm} / \mathrm{yr}$ and $15.5 \pm 1.1 \mathrm{~mm} / \mathrm{yr}$ or $34 \pm 2 \mathrm{~mm} / \mathrm{yr}$ and $25 \pm 9 \mathrm{~mm} / \mathrm{yr}$, respectively) differ from geological rates. If a two-fault model is used with a second fault dipping in the opposite direction approximately $80 \mathrm{~km}$ southeast of the Alpine Fault, this results in shallower locking depths and/or lower coupling on the Alpine Fault. For the Hawea-Haast data, the best-fitting model has a locking depth of $10 \pm 2 \mathrm{~km}$ and strikeand dip-slip rates of $23 \pm 2 \mathrm{~mm} / \mathrm{yr}$ and $11 \pm 8 \mathrm{~mm} / \mathrm{yr}$, respectively (Pearson et al. 2000). 


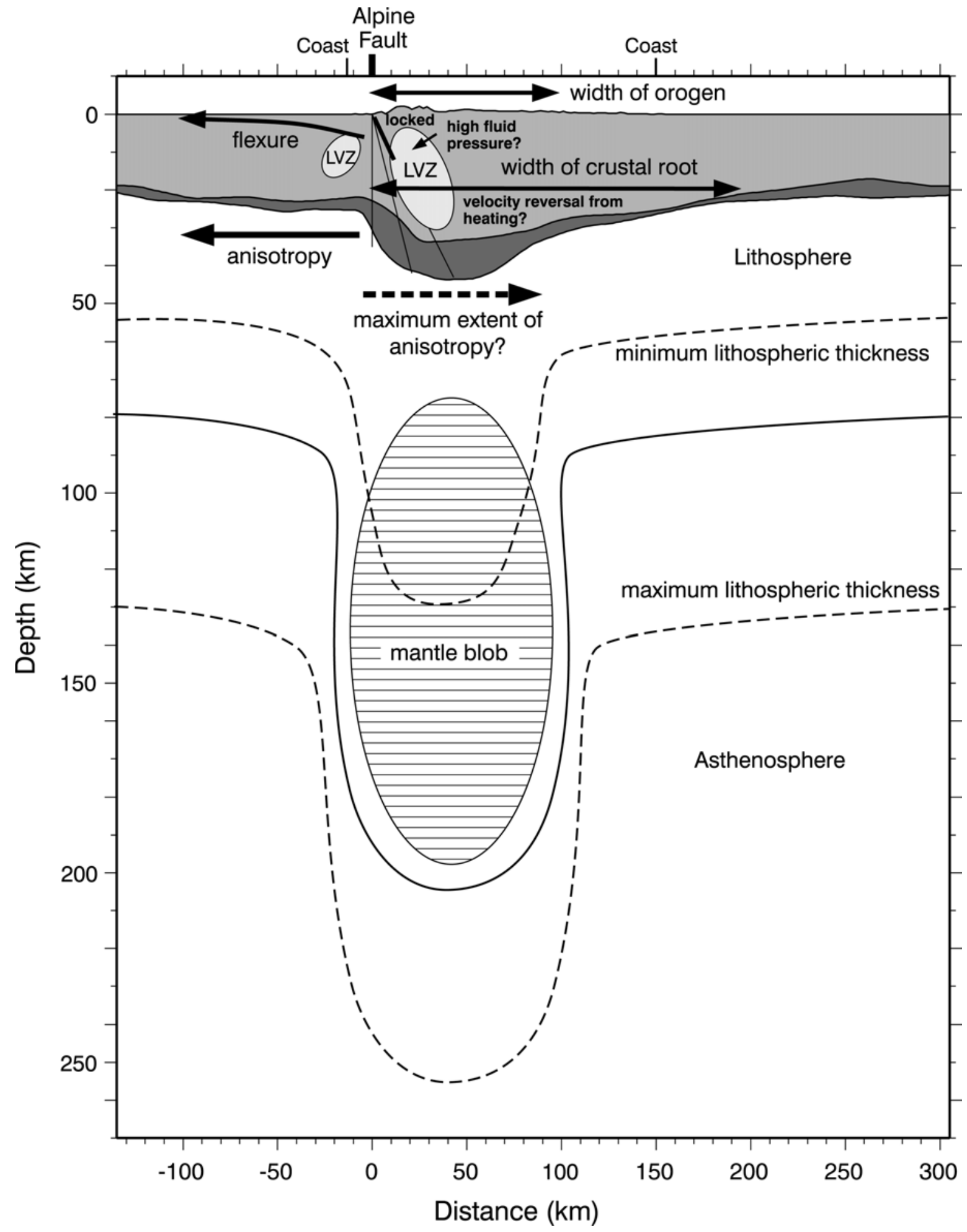

Figure 1.5. Deformation in crust and mantle beneath the central Southern Alps after Davey et al. (2007; their Fig. 14) 
Beavan et al. (1999; 2004) found two-fault dislocation models that matched horizontal surface deformation by modelling a second opposite-dipping fault below $30 \mathrm{~km}$ depth. This model fits high uplift rates within the mountains but cannot fit observations to the east of the Southern Alps (Beavan et al. 2004). Two-fault models assume a fixed dip for the second structure and are insensitive to whether a single second fault or numerous faults in a broad shear zone accommodate motion (Pearson et al. 2000). Moore et al. (2002) showed that the observed horizontal velocity field can be modelled equally well with a model in which deformation in the upper crust is localised on faults but distributed over a shear zone 30-40 km wide in the lower lithosphere.

Simultaneous inversions for angular velocities of rotating 3-D elastic blocks and the degree of fault coupling has been conducted by Wallace et al. (2007). For the central section of the Alpine Fault between latitudes $-43.0^{\circ}$ and $-43.5^{\circ}$, Wallace et al. (2007) obtained slightly weaker coupling at $1-18 \mathrm{~km}$ depths $(\Phi=0.7$ where the coupling coefficient is defined by Wallace et al. (2007) as $\Phi=1-V_{c} / V$ for creep-rates $V_{c}$ and long-term slip-rates $V$ ) than in surrounding strongly coupled segments $(\Phi=0.85)$, indicating a shallower coupling depth in this section.

Geological, geophysical and geodetic studies suggest that only a portion (2/3) of the relative plate motion is accommodated on the central Alpine Fault. The remaining third must be accommodated by structures within and to the east (or west) of the Alpine Fault (Norris and Cooper 2001). Walcott (1978) suggested that distributed deformation occurs on the numerous smaller faults on the eastern side of the Southern Alps. This is difficult to prove, since juvenile faults are abundant in the Southern Alps region and it is not known which of these faults are active. Within $60 \mathrm{~km}$ of the Alpine Fault 110 mapped faults of 4-73 km length have been mapped (Cox et al. 2012). The four largest bound the glacial valleys east of the Main Divide and strike north-northeast at angles 85-120 to the maximum compressive stress direction (Cox et al. 2012). The Black Bob Fault and the Haast Ridge Fault form parts of the Main Divide Fault Zone. The Murchison Fault and Liebig Fault bound adjacent high-elevation ranges. The direction of fault slip on these faults obtained from slickenside is predominantly dip-slip, however, minor components of both dextral and sinistral motions are present (Cox et al. 2012). Known active faults in the southeastern foothills of the central Southern Alps ( $\geq 60 \mathrm{~km}$ from the Alpine Fault) include the Ostler Fault and the Lake Heron/Forest Creek/Irishman's Creek fault system (e.g. Barrell and Strong 2010). The Ostler Fault Zone is a $\sim 50 \mathrm{~km}$-long, north-south striking, low-angle reverse fault. Its surface trace borders the western margin of the Mackenzie Basin (e.g. Blick et al. 1989). The fault dips $50-60^{\circ} \mathrm{W}$ at shallow depths and Ghisetti et al. (2007) inferred it to be a reactivated 
normal fault based on its dip (Sibson and Xie 1998). There is little evidence constraining slip-rates on the Ostler fault, but Ghisetti et al. (2007) estimated them to be low $(<1.5 \mathrm{~mm} / \mathrm{a})$.

Recent large earthquakes in the vicinity of Christchurch (e.g. Gledhill et al. 2011; Quigley et al. 2012) may indicate that the zone of deformation in the central South Island extends further east than previously assumed. Several eastwest-trending faults have been identified in the Canterbury plains by active seismic reflection/refraction studies (Dorn et al. 2010). The only large tectonic structure mapped northwest of the Alpine Fault is the South Westland Fault Zone or Coastal Monocline (Nathan 1986; Cox and Barrell 2007). It consists of a number of continuous southeast-dipping reverse faults and runs offshore between Franz Josef and Fox Glacier.

\subsection{Seismicity in the central Southern Alps}

Large earthquakes in the South Island have occurred in historic times in the Puysegur subduction zone to the south of the central Southern Alps region, in the Buller region (Doser et al. 1999; Anderson et al. 1993; Dowrick 1991) to the north, near Arthur's Pass (Doser et al. 1999; Berryman and Villamor 2004), in the Marlborough Fault System (Cowan 1991) in the northeast and most recently near Christchurch in the east (Gledhill et al. 2011; Quigley et al. 2012). Strike-slip displacements were observed for the September 1888 Glynn Wye earthquake ( $\mathrm{M} \geq 7$ ) on the Hope Fault with $3 \mathrm{~m}$ offset on fences crossing the fault (Cowan 1991), and for the March 1929 Arthur's Pass earthquake on the Kakapo/Poulter fault (Doser et al. 1999; Berryman and Villamor 2004). The Darfield earthquake on 4 September 2010 showed maximum dextral displacements of $4.6 \mathrm{~m}$ on the previously unknown Greendale fault (Gledhill et al. 2011; Quigley et al. 2012).

Since the beginning of European settlement in Westland in 1840 (Wells et al. 1999), no rupture on the Alpine Fault has been observed (Evison 1971; Anderson and Webb 1994). Only two earthquakes of $\mathrm{M}_{\mathrm{W}} \geq 6$ have been reported in the central Southern Alps region: the $1946 \mathrm{M}_{\mathrm{W}} 6.7$ Lake Coleridge (Doser et al. 1999) and the $1984 \mathrm{M}_{\mathrm{W}} 6.1$ Godley Valley earthquake (Anderson et al. 1993). Both strike-slip events occurred southeast of the Alpine Fault, at distances of 40 and $55 \mathrm{~km}$ from the surface trace (Fig. 1.6 and Table 1.1). These earthquakes have similar strike directions and steeply-dipping fault planes. Anderson et al. (1993) favoured the northeast-striking fault plane undergoing right-lateral strike-slip as the rupture plane of the Godley Valley earthquake, a fault geometry similar to that of the Porter's Pass-Amberley Fault Zone to the northeast (Fig. 1.6). The Godley Valley earthquake was 


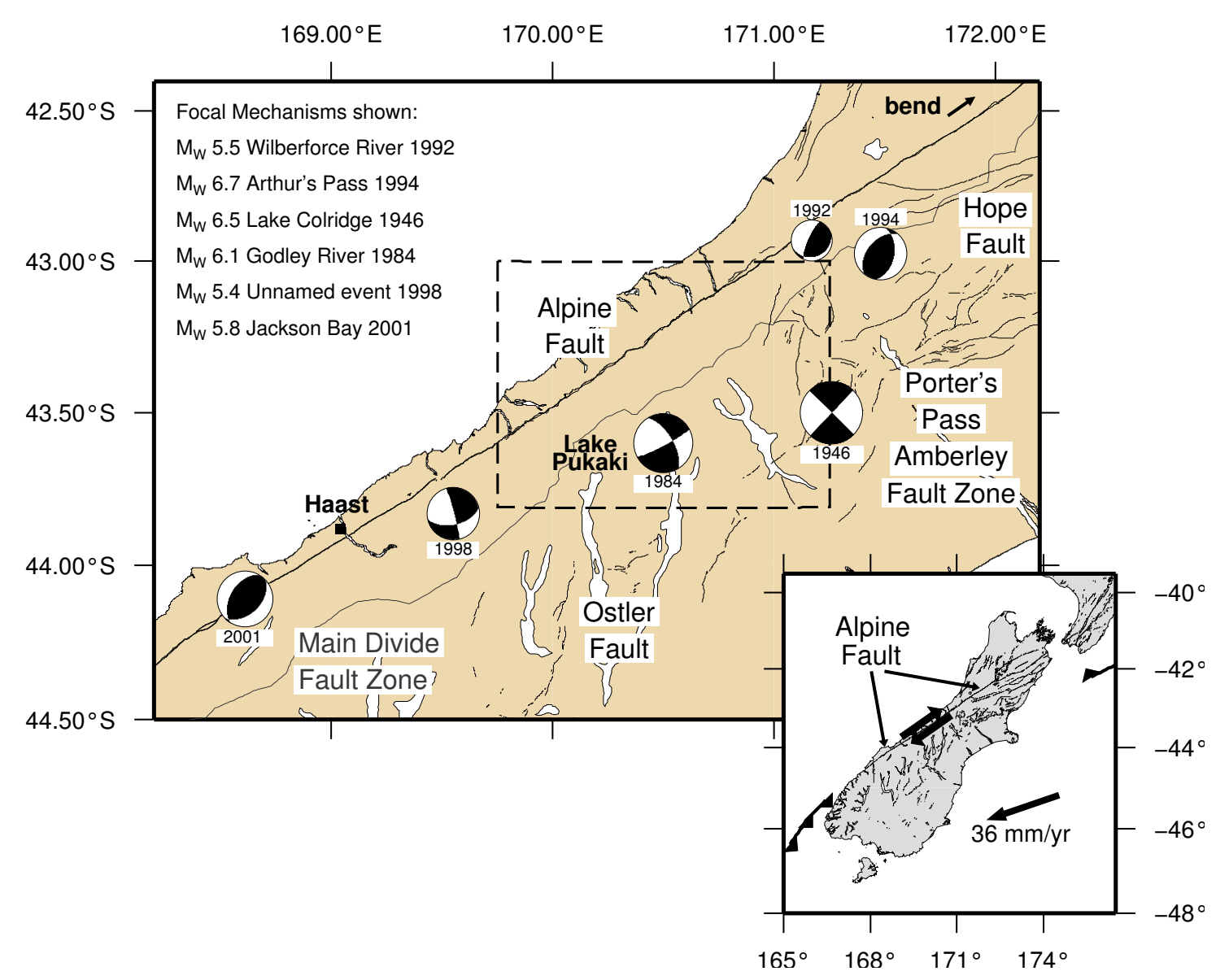

Figure 1.6. Major faults and focal mechanism solutions for the six largest, more recent events in and adjacent to the study area (dashed rectangle) since 1946 (Table 1.1) in the central South Island of New Zealand. All focal mechanism solutions are lower-hemisphere projections of the focal sphere. Displayed faults are from the Active Faults Database by GNS Science. The inset map shows the tectonic setting of the Alpine Fault.

followed by a $\mathrm{M} \sim 5$ aftershock in 1987, $10 \mathrm{~km}$ to the east of the epicentre (Little et al. 2005), and the region still exhibits elevated levels of microseismicity (Leitner et al. 2001).

The Marlborough faults have produced three large earthquakes $(\mathrm{M}>7)$ since 1840 (Grapes et al. 1998; Cowan 1991; Doser et al. 1999; Berryman and Villamor 2004). Notably seismically active is the region where the Hope Fault merges with the Alpine Fault. Seven earthquakes of $\mathrm{M}_{\mathrm{W}}>5.4$ have occurred in this zone of high deformation since 1888 (e.g. Rynn and Scholz 1978; Árnadóttir et al. 1995)(Table 1.1). These events exhibited a mixture of strike-slip and reverse focal mechanisms (Doser et al. 1999). The two most recent earthquakes in this region were shallow reverse-faulting events (Abercrombie et al. 2000), the $\mathrm{M}_{\mathrm{W}} 6.7$ Arthur's Pass earthquake in 1994 (Robinson and McGinty 2000) followed by the $1995 \mathrm{M}_{\mathrm{W}} 6.2$ Cass earthquake $30 \mathrm{~km}$ to the east (Gledhill et al. 2000). The largest after- 


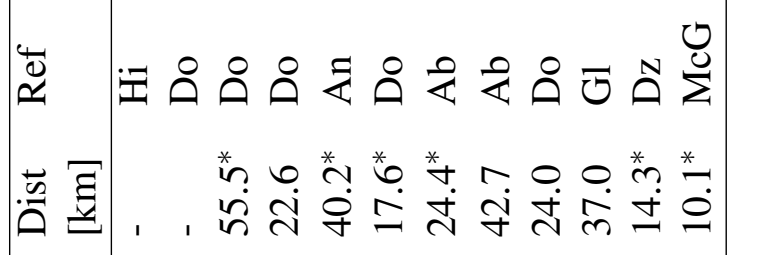

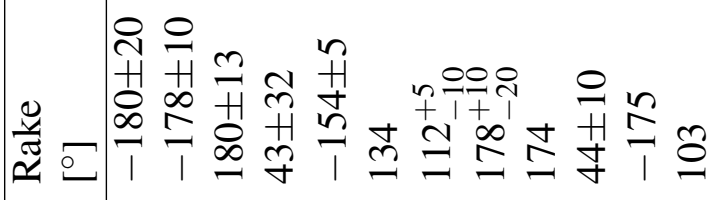

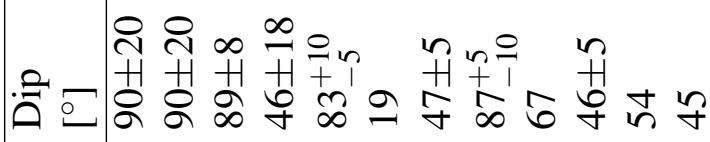

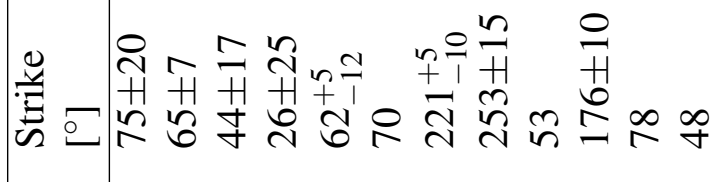

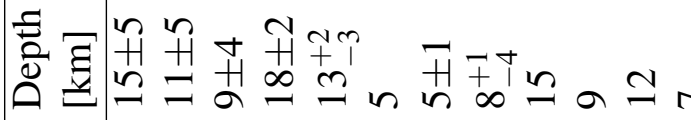

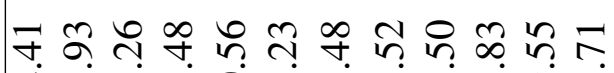

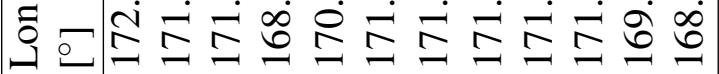

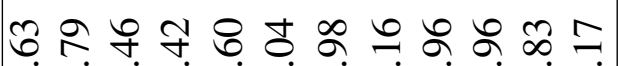

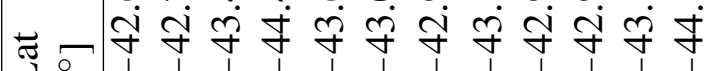

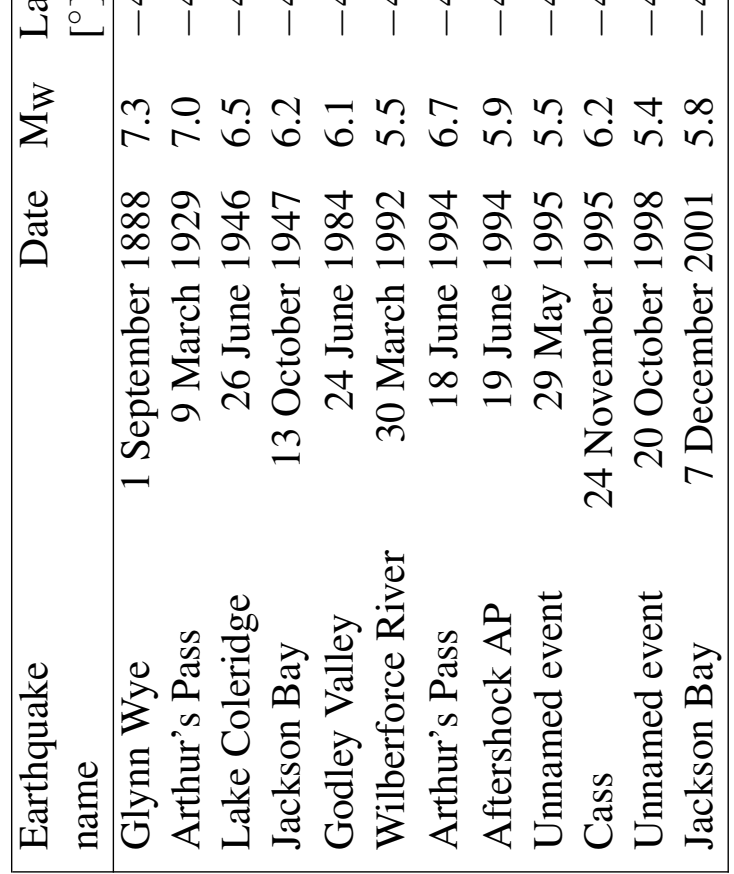

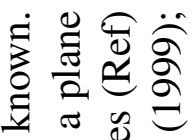

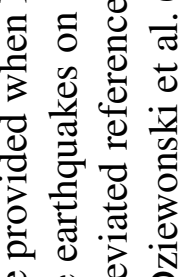

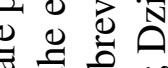

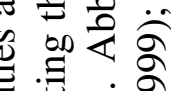

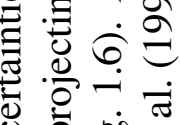

ڤं

5 .

焉

प्र

赔

年

可产

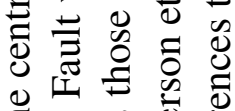

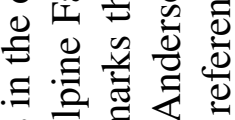

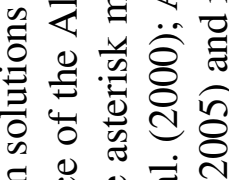

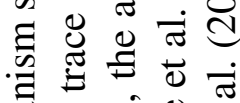

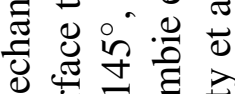

政

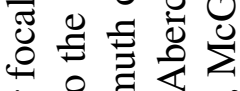

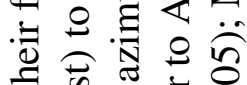

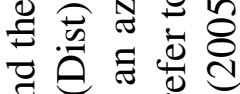

政

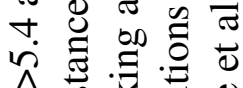

产产产言。

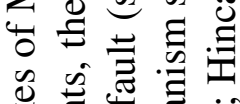

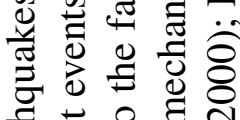

F

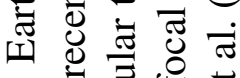

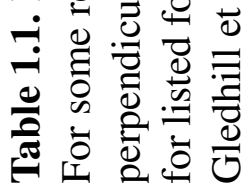


shocks of the Arthur's Pass earthquake exhibited strike-slip mechanisms (Abercrombie et al. 2000; Doser et al. 1999).

At the southern limit of the central Alpine Fault, two large events occurred at distances of 14 and 3-10 km, respectively, southeast of the surface trace of the Alpine Fault in 1998 and 2001 (Fig. 1.6 and Table 1.1). The $1998 \mathrm{M}_{\mathrm{W}} 5.4$ earthquake has not yet been studied in detail (but was referred to by Eberhart-Phillips and Bannister 2002). The CMT focal mechanism solution (Dziewonski et al. 1999) gives a strike-slip mechanism but the solution is poorly constrained. The $2001 \mathrm{M}_{\mathrm{W}} 5.8$ Jackson Bay earthquake (McGinty et al. 2005) was a shallow thrust earthquake with no surface rupture. The aftershock distribution exhibited clustered events $5 \mathrm{~km}$ to the southeast of the Alpine Fault. McGinty et al. (2005) obtained a variety of focal mechanism solutions for the aftershocks with predominantly strike-slip faulting. Further south of Jackson Bay, a $\mathrm{M}_{\mathrm{W}} 6.2$ event in 1947 exhibited an oblique-reverse mechanism (Doser et al. 1999) (Table 1.1).

Paleoseismic studies by Adams (1980), Wells et al. (1999) and Wells and Goff (2007) of aggradation terraces, coastal dunes, landslides, trenches across the active fault trace, forest (re-)establishments and tree-ring growth indicate that the two most recent, major events occurred in 1717 and 1630 C.E. with rupture lengths of several hundred kilometres and individual offsets of 8-12 m (Walcott 1998; Sutherland and Norris 1995; Sutherland et al. 2007; Berryman et al. 2012). These studies suggest that failure of the Alpine Fault resulted in large surface displacements along broad sections of the fault (Norris and Cooper 2001).

Seismicity of the South Island was first discussed by Eiby (1971) and Evison (1971). Eiby (1971) distinguished seismicity in the Central Seismic Region from the Main Seismic Region to the northeast and the Fiordland Seismic Region to the southwest, due to pronounced differences in the number and distribution of earthquakes. In 1972, Scholz et al. (1973) conducted a microseismicity study along several parts of the Alpine Fault including a section between Hari Hari and Haast with a network consisting of 10 seismometers. They recognised distinctly lower seismicity rates in this region than to the northeast and southwest. Events occurred at 2-20 km depth and appeared to be spatially continuous to the east of the fault. In a subsequent microseismicity study of the Haast Region in 1973, Caldwell and Frohlich (1975) located 60 of the 122 events recorded over 32 days in a depth range of 4-14 km. Those stations within $5 \mathrm{~km}$ of the fault recorded many unlocatable events with S-P travel times smaller than $2.5 \mathrm{~s}$. More than $90 \%$ of the locatable earthquakes occurred in a $20 \mathrm{~km}$-wide area about $10 \mathrm{~km}$ to the southeast of the fault. Events occurred in groups but did not show a pattern or a defined fault plane and did they have a common focal 
mechanism. Caldwell and Frohlich (1975) did not determine magnitudes but estimated them to range between -1 and 3 .

Between 1975 and 1983, when the level of Lake Pukaki was raised by $37 \mathrm{~m}$ for hydroelectric power generation, seismicity was monitored by an array of nine short-period seismometers around the lake. Reyners (1988) located 2825 earthquakes of $\mathrm{M}_{\mathrm{L}} \geq 0.8$. Of these events only 48 occurred at depths greater than $15 \mathrm{~km}$ and $65 \%$ of all earthquakes were located between 5 and $9 \mathrm{~km}$. Reyners (1988) reported a completeness magnitude of $\mathrm{M}_{\mathrm{L}}=1.8$. A background seismicity rate of approximately 6.2 events per 30 days was observed. Reyners (1988) obtained a b-value (Section 2.8) of approximately 1 for the background seismicity and observed temporal changes in the b-value in the lake vicinity during the survey period. An increase in seismicity associated with the impounding of the lake was observed and the largest triggered event of $\mathrm{M}_{\mathrm{L}} 4.6$ occurred on 17 December 1978 at shallow depth $(<5 \mathrm{~km})$.

Eberhart-Phillips (1995) investigated seismicity occurring between March 1991 and April 1994 recorded by the New Zealand National Seismograph Network (NZNSN) in the central South Island. The network was relatively sparse at that time, with an average distance between each earthquake and the nearest station of $40 \mathrm{~km}$ and only 2 stations (WVZ and EWZ) in the central Southern Alps. Eberhart-Phillips (1995) reported mainly diffuse seismicity southeast of the Alpine Fault (complete to a magnitude of 2.6) with aftershocks in the area of the Godley Valley earthquake and one swarm further southwest. Although uncertainties in depth were large, an increase in the average depth from $10 \mathrm{~km}$ adjacent to the fault to $20 \mathrm{~km}$ in $60-70 \mathrm{~km}$ distance from the Alpine Fault could be observed.

The Southern Alps Seismic Passive Experiment (SAPSE) comprised 26 broadband and 14 short-period stations deployed across the central South Island for six months (Anderson et al. 1997) in 1995/1996. Average station distances were 30 to $50 \mathrm{~km}$. Leitner et al. (2001) used the data from SAPSE, high-quality location data of the New Zealand National Station Network (NZNSN) and the Lake Pukaki network, and data recorded during a temporary Mount Cook aftershock deployment to conduct a comprehensive study of seismicity along the Alpine Fault. They report a triangular section between the Wanganui River and Franz Josef Glacier where the seismicity of $M_{L} \leq 2$ is almost absent (Fig. 1.7). According to Leitner et al. (2001), the eastern boundary of the low-seismicity zone coincides with the south-western extension of the Porter's Pass Fault Zone. That study reported 5491 earthquake locations with magnitudes of $2 \leq \mathrm{M}_{\mathrm{L}} \leq 4.2$. A simultaneous inversion to determine hypocentre locations and P-wave velocity structure was 


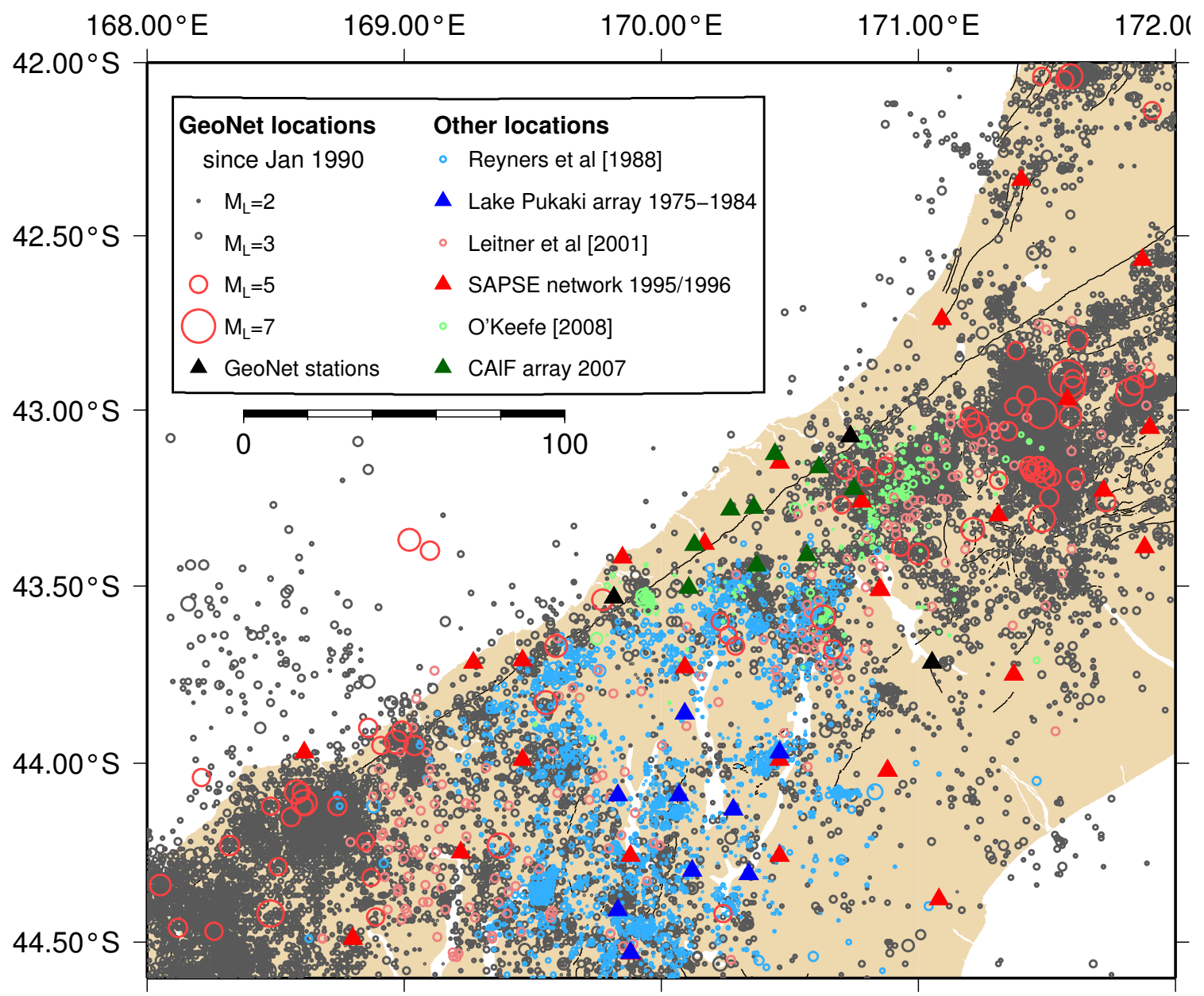

Figure 1.7. Seismicity recorded in the central Southern Alps since 1990 by GeoNet (grey, magenta large earthquakes since 1900), Reyners (1988) (light blue), Leitner et al. (2001) (light red) and (O' Keefe 2008) (light green). The stations of the networks which recorded these events are shown in equivalent colours 


\begin{tabular}{|r|c|c|c|}
\hline Depth [km] & \multicolumn{3}{|c|}{ Velocity [km/s] } \\
\hline & Leitner et al. (2001) & O' Keefe (2008) & this study \\
\hline-2 & & 3.50 & 5.67 \\
0 & 6.0 & 5.67 & \\
8 & & 5.79 & 5.79 \\
18 & 6.3 & 6.28 & 6.28 \\
35 & 7.2 & 7.35 & 7.35 \\
40 & 8.0 & 8.00 & 8.00 \\
\hline
\end{tabular}

Table 1.2. 1-D velocity models for the central Southern Alps in comparison. Note that not all models have the same depth boundaries, so the velocity column is blank if there is no such depth boundary in the model.

carried out using a subset of 195 earthquakes (Table 1.2). With this amalgamated dataset, 53 well-constrained focal mechanisms throughout a large part of the South Island were computed. Well-constrained focal mechanisms beneath the central Southern Alps exhibited oblique strike-slip and thrust mechanisms, as well as two normal-faulting mechanisms which were inferred by the authors to have been hydrologically triggered. The latter were derived from a swarm of events following severe rainfall and flooding (102 $\mathrm{mm}$ of rain in $32 \mathrm{hr}$ ) in mid-December 1995 (Leitner et al. 2001). The observed maximum seismogenic depth was rather uniform with $12 \pm 2 \mathrm{~km}$ except under the highest elevations of the Alps where it was 3-4 km shallower.

In a recent study by O' Keefe (2008) using eight surface seismographs between Fox Glacier and Hari Hari between September 2006 and March 2007, 411 earthquakes with magnitudes $\mathrm{M}_{\mathrm{L}} \geq 1.6$ were located. O' Keefe (2008) identified five earthquake swarms, one near Fox Glacier, one near station Whymper Hut, one in the upper Clyde River, one near Whataroa and one near Waitaha. During the survey, seismicity revealed a "horseshoe" pattern with the open side pointing to the fault. Only a few earthquakes occurred close to the fault trace, so no information could be gained about the Alpine Fault's structure. O' Keefe (2008) obtained a b-value of $0.75 \pm 0.06$, much lower than in previous studies, and a maximum seismogenic depth of $15 \mathrm{~km}$ for most of the survey region but only $10 \mathrm{~km}$ for the Fox region. Following the simultaneous inversion for velocity structure (Table 1.2) and hypocentre locations, an average depth error less than $3 \mathrm{~km}$ was obtained.

Sporadic subcrustal earthquakes were reported by Eiby (1971), Calhaem et al. (1977), Haines (1979), Reyners (1987) and in several recent studies. Reyners (2005) inferred a subcrustal depth of $\sim 50 \mathrm{~km}$ for the 8 May 1943, $\mathrm{M}_{\mathrm{W}} 5.9$ Lake Hawea earthquake. Kohler and Eberhart-Phillips (2003) analysed in detail intermediate-depth earthquakes in 
the central South Island with magnitudes $\mathrm{M}_{\mathrm{L}} \leq 4$.0. Events with well-constrained depths exceeding $30 \mathrm{~km}$ recorded by the NZNSN between 1990 and 2000 and by the Lake Pukaki network between 1975 and 1983 were investigated. These results show that deep crustal or mantle events are more frequent at the southern end of the Southern Alps than at the northern end. These events correspond to regions of high P-velocity anomalies or their boundaries. The shallowest of these intermediate-depth events lie at $>30 \mathrm{~km}$ depth near or below the crustal root. Reyners (1987) suggested, that subcrustal events occur on a $19^{\circ} \mathrm{NW}$-dipping plane associated with intra-continental subduction. Kohler and Eberhart-Phillips (2003) concluded that these events are controlled by high shear-strain gradients associated with depressed geotherms and viscous deformation of mantle lithosphere.

\subsection{The Southern Alps Microearthquake Borehole Array (SAMBA)}

\subsubsection{Study area and station networks}

In this study, we investigate the area bounded by the three permanent broadband stations WVZ, RPZ and FOZ, operated by GeoNet in the central Southern Alps (Table 1.3 and Fig. 1.8). These stations are spaced $80-100 \mathrm{~km}$ apart and have been recording continuously since 1990 following a nation-wide update to digital recording (e.g. Anderson and Webb 1994; Petersen et al. 2011). To supplement the New Zealand national station network in the central section of the Southern Alps, the Southern Alps Microearthquake Borehole Array (SAMBA) comprising eleven short-period seismometers was installed between November 2008 and June 2009. Seven of those instruments are deployed in shallow boreholes of 1-2 m depth, three in deeper boreholes of 46, 61 and $98 \mathrm{~m}$ depths, and one surface sensor was added in January 2010 to extend the array to the south (Table 1.4). Along the strike of the Alpine Fault, these stations are approximately evenly spaced $8 \mathrm{~km}$ apart on alternating sides of the fault. Perpendicular to the fault, the average distance between SAMBA stations is $16 \mathrm{~km}$. This geometry allows for accurate depth estimates for events located within the network (where the distance between the earthquake hypocentres and the closest station does not exceed 1.5 times the focal depth, see Section 3.4.1 and 4.2.1).

Before March 2009, when the three deep boreholes were drilled, temporary sites near the drilling locations were established (Table 1.4). A "2" appended to the station name is used to indicate a subsequently installed borehole station. A drill rig mounted on a truck was 


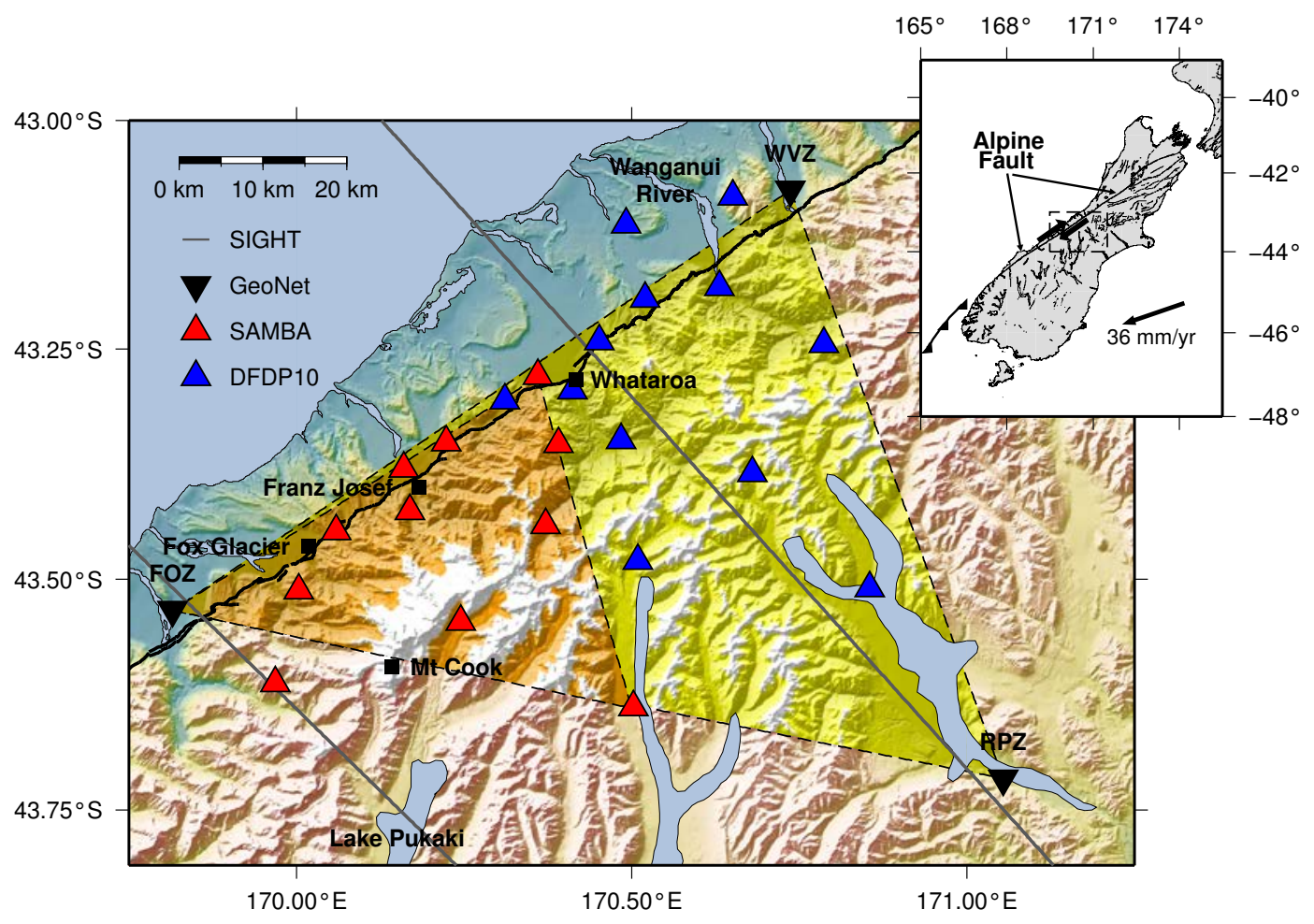

Figure 1.8. Distribution of the GeoNet broadband stations (black reversed triangles), shortperiod SAMBA (red triangles) and DFDP10 stations (blue triangles) in the study area. The inset shows the location of the study area in the central Southern Alps.

used to drill the three deep boreholes. A combination of rotary drilling and hammering was applied using compressed air for cooling and to remove the rock chips. For the shallow holes, a portable drill rig was mounted on the rock and drilling was carried out by water-cooled rotary drilling. This enabled the whole rock core to be extracted (albeit in pieces). All boreholes of the SAMBA project have a diameter of approximately $11 \mathrm{~cm}$ (4.5 inch), are uncased, and in solid rock except for one which is located in a sediment-filled valley (POCR). The latter has a diameter of approximately $15 \mathrm{~cm}(6 \mathrm{inch})$ and is completely steel-cased. In order to suppress air motion near the sensor, the boreholes were filled with sand. A study by Holcomb et al. (1997) showed that this particularly improves the noise level on the horizontal components of the seismogram.

The SAMBA stations are equipped with GeoSpace Technologies HS-1-LT short-period three-component seismometers. Most of the sensors are in small tubes of $26.5 \mathrm{~cm}$ length 


\begin{tabular}{|lccccccc|}
\hline Name & Location & $\begin{array}{c}\text { Lat. } \\
{\left[{ }^{\circ}\right]}\end{array}$ & $\begin{array}{c}\text { Lon. } \\
{\left[{ }^{\circ}\right]}\end{array}$ & $\begin{array}{c}\text { Alt. } \\
{[\mathrm{m}]}\end{array}$ & Ground & $\begin{array}{c}\text { Sen- } \\
\text { sor }\end{array}$ & $\begin{array}{c}\text { Date } \\
\text { installed }\end{array}$ \\
\hline WVZ & Waitaha Valley & -43.076 & 170.736 & 75 & Granite & 3ESP & 06.09 .2003 \\
FOZ & Fox Glacier & -43.566 & 169.689 & 10 & Greywacke & 3ESP & 13.10 .2004 \\
RPZ & Rata Peaks & -43.719 & 171.054 & 412 & Rhyolite & 3TB & 06.06 .2001 \\
\hline
\end{tabular}

Table 1.3. Station locations of the three permanent broadband stations operated by GeoNet in the study area. Table modified from Petersen et al. (2011)

and $7.3 \mathrm{~cm}$ diameter, have no gimbals and were orientated manually before being lowered into the borehole. The three seismometers in the deeper boreholes have a length of $1 \mathrm{~m}$ and a diameter of approximately $10 \mathrm{~cm}$, and contain gimbals. A Mark Products L-4C3D short-period seismometer was temporarily placed on top of each borehole sensor, so that the orientation of the borehole sensor could be determined by comparison of the waveforms on the horizontal components. The same L-4C3D sensor was later used for the additional surface site COVA deployed in the Copland Valley. Each station consists of a Reftek data logger RT130-01, a Reftek GPS clock, a three-component short-period seismometer and a power supply.

\begin{tabular}{|ccccrrl|}
\hline Name & Location & $\begin{array}{c}\text { Lat. } \\
{\left[{ }^{\circ}\right]}\end{array}$ & $\begin{array}{c}\text { Lon. } \\
{\left[{ }^{\circ}\right]}\end{array}$ & $\begin{array}{r}\text { Alt. } \\
{[\mathrm{m}]}\end{array}$ & $\begin{array}{r}\text { Depth } \\
{[\mathrm{m}]}\end{array}$ & Ground \\
\hline COSA & Cook Saddle & -43.448 & 170.060 & 377 & 1.40 & $(+5$ m of gravel) \\
EORO & End of Road & -43.426 & 170.169 & 233 & 1.35 & schist \\
MTFO & Mount Fox & -43.512 & 170.003 & 1216 & 2.00 & schist (bed) \\
WHAT2 & Whataroa Quarry & -43.279 & 170.360 & 95 & 61.00 & granite (bed) \\
WHYM & Whymper Hut & -43.441 & 170.371 & 906 & 1.30 & landslide \\
POCR2 & Potter's Creek & -43.352 & 170.223 & 185 & 46.00 & sediments \\
LABE & De la Beche & -43.546 & 170.245 & 1590 & 2.15 & greywacke (bed) \\
GOVA & Godley Valley & -43.639 & 170.503 & 814 & 1.95 & greywacke (bed) \\
FRAN & Carnavan's Knob & -43.380 & 170.160 & 124 & 98.00 & granite (bed) \\
REYN & Reynold's Creek & -43.353 & 170.391 & 1310 & 1.20 & semi-schist (bed) \\
COVA & Copland Valley & -43.613 & 169.968 & 1477 & $\sim 1$ & schist (bed) \\
\hline \hline Name & Time & Lat. & Lon. & Alt. & Depth & Ground \\
& & {$\left[{ }^{\circ}\right]$} & {$\left[{ }^{\circ}\right]$} & {$[\mathrm{m}]$} & {$[\mathrm{m}]$} & \\
\hline WHAT & $11 / 2008-03 / 2009$ & -43.279 & 170.361 & 106 & 2.40 & granite (bed) \\
POCR & $12 / 2008-03 / 2009$ & -43.348 & 170.177 & 95 & 0.40 & sediments \\
MARI & $12 / 2008-02 / 2009$ & -43.727 & 170.575 & 771 & 1.00 & soil \\
\hline
\end{tabular}

Table 1.4. Final station locations (top) and temporary station locations before March 2009 (bottom) of the SAMBA network. The depth gives the total borehole depth. Note that the sensor at COSA was covered by at least $5 \mathrm{~m}$ of additional gravel from a landslip nearby. Stations that are thought to be located in bedrock (bed) are marked. 
A second temporary seismometer array deployed as part of the Deep Fault Drilling Project (DFDP10) operated temporarily northeast of SAMBA (Fig. 1.8). This array comprised twelve short-period Mark Products L-22D3D seismometers recording from 20 January to 1 May 2010. Most of these instruments were either buried approximately $0.4 \mathrm{~m}$ deep in soil or sediments or directly placed on bedrock and covered with sand and stones (Table 1.5). The DFDP10 stations were initially operated on normal gain $(\times 1)$ but this was changed to high gain $(\times 32)$ at the first station service (Julian day 074/075 2010). All stations consisted of a Reftek data logger RT130-01, a Reftek GPS clock, a three-component short-period seismometer and a power supply.

\begin{tabular}{|lcccrl|}
\hline Name & Location & $\begin{array}{c}\text { Latitude } \\
{\left[{ }^{\circ}\right]}\end{array}$ & $\begin{array}{c}\text { Longitude } \\
{\left[{ }^{\circ}\right]}\end{array}$ & $\begin{array}{r}\text { Altitude } \\
{[\mathrm{m}]}\end{array}$ & Ground \\
\hline BLO & Blue Lookout & -43.244 & 170.787 & 1607 & bedrock \\
BON & Mt Bonar & -43.083 & 170.651 & 1031 & soil \\
DRC & Dry Creek & -43.241 & 170.452 & 128 & soil \\
ERE & Erewhon Station & -43.510 & 170.855 & 600 & soil \\
GCK & Gaunt Creek & -43.306 & 170.311 & 114 & soil \\
GHU & Godley Hut NZAC & -43.480 & 170.509 & 1108 & moraine \\
NOL & Nolans Hut & -43.349 & 170.484 & 181 & soil \\
ONE & One One Road & -43.114 & 170.492 & 62 & soil \\
POE & Poerua Valley & -43.195 & 170.520 & 103 & soil \\
VBV & Veil Bivouac & -43.385 & 170.680 & 1019 & moraine \\
WHB & Whataroa Bridge & -43.295 & 170.412 & 97 & sediments \\
WNQ & Wanganui Quarry & -43.182 & 170.631 & 180 & sediments \\
\hline
\end{tabular}

Table 1.5. Station locations of the DFDP10 array between January and May 2010

All stations operate with continuous GPS recording. The response functions of all the different sensors used in this study are given in Appendix A. The polarities of the SAMBA and DFDP10 stations have been checked as described in Appendix B. No polarity reversals were found for the SAMBA borehole stations. However, the polarity of the Mark Products sensors used for station COVA and all stations of the DFDP10 network were found to be reversed for the vertical component. Also, the instrument response of GeoNet station RPZ was identified as wrong in the sense that it reverses the correct polarity (Appendix A).

\subsubsection{Data acquisition, processing and quality control}

All the short-period sensors used in the SAMBA and DFDP10 arrays have a natural frequency of $2 \mathrm{~Hz}$, except for the sensor in the deepest borehole (FRAN) which has a natural 
frequency of $4.5 \mathrm{~Hz}$ and the surface sensor (COVA; $1 \mathrm{~Hz})$. The SAMBA stations record at a sample rate of 200 samples per second on high gain. The DFDP10 stations recorded at 100 samples per second except for one instrument (BLO) which erroneously recorded at 40 samples per second for the second half of the recording period. Data obtained from GeoNet are also recorded at 100 samples per second.

The continuous Reftek raw data were processed by converting to miniseed format using the Reftek tool $r$ t_mseed and to sac format using $m s 2 s a c$. Miniseed data from all short-period stations and the data from the three GeoNet broadband stations were combined into single 15 minute-long miniseed files for inspection using the earthquake analysis software SEISAN (Havskov and Ottemöller 2000). The continuous data are scanned for events using a triggering routine that compares short-term and long-term averages in $0.5 \mathrm{~s}$ and $10 \mathrm{~s}$ data windows, respectively. When the signal-to-noise ratio exceeds a specified threshold of 3.0 at four stations, event windows of $60 \mathrm{~s}$ length are extracted for manual inspection. The detection threshold of the triggering routine is chosen to be low in order to detect microearthquakes recorded by only a few stations. The arrival-times of the Pand S-waves of all recorded earthquakes have been identified manually using SEISAN (Havskov and Ottemöller 2000). For wave arrival-times recorded by three or more stations, hypocentre locations are determined with the SEISAN tool HYP, a modified version of HYPOCENTER (Lienert et al. 1986). These preliminary hypocentres are then relocated using the non-linear location program NonLinLoc 5.0 of Lomax et al. (2000) to better constrain the posterior uncertainties in the hypocentre parameters (Section 4.2.1).

Continuous recordings were checked for GPS absolute timing uncertainties by scanning State of Health files from the Reftek data loggers. For short time spans, the program logpeek was used to check how long the GPS timing uncertainty lasted. Events which occurred during uncertain timing were assigned a weight of 9, so that relative arrival times $t_{S}-t_{P}$ instead of absolute arrival times were used. For time spans longer than several days, the timing uncertainty was determined from analysis of the residuals (Section 3.1.1). These longer periods of GPS timing uncertainties are discussed in Section 3.1.3 and 3.1.4.

The location quality was checked by comparing hypocentre locations of those earthquakes located by GeoNet with locations obtained using SAMBA (Section 3.3.1). The hypocentre locations before and after weighting (Section 3.1.2) were also compared. If the new location shifted more than $5 \mathrm{~km}$ upwards (which in almost all cases corresponded to moving the earthquake to the surface), the arrival-times of those events were reviewed and repicked. 


\subsubsection{Performance of the SAMBA stations}

In regions of high background noise, the installation of seismometers in boreholes can significantly improve the quality of the recorded data (Bormann 2002). A borehole reduces environmental influences on the sensor such as temperature and pressure fluctuations. Turcotte and Schubert (2002) derived the following formula for the amplitude of timedependent temperature fluctuations in the subsurface, assuming that the surface temperature is periodic in time $\mathrm{T}_{\mathrm{S}}=\mathrm{T}_{0}+\Delta \mathrm{T} \cos \omega \mathrm{t}$ :

$$
\mathrm{T}=\mathrm{T}_{0}+\Delta \mathrm{T} \exp (-\mathrm{z} / \mathrm{d}) \cos (\omega \mathrm{t}-\mathrm{z} / \mathrm{d}),
$$

where $\mathrm{T}_{0}$ is the average surface temperature, $\Delta \mathrm{T}$ is the variance of the temperature, $\mathrm{z}$ describes the depth, $\mathrm{d}=\sqrt{2 \kappa / \omega}$ the skin depth, $\kappa$ is the thermal diffusivity, $\omega=2 \pi \mathrm{f}$ is the angular frequency and $f$ the frequency of the temperature variation. Equation 1.1 is plotted for periods of 12 hours, half a year and one year in Fig. 1.9. The thermal diffusivities of different rocks at room temperature have been documented in many studies (e.g. Hanley et al. 1978; Whittington et al. 2009) and range between 1.3 and $1.8 \mathrm{~mm}^{2} / \mathrm{s}$ for schist (Whittington et al. 2009). At approximately $1 \mathrm{~m}$ depth, daily temperature fluctuations no longer affect the sensor. The influence of seasonal temperature cycles on the instrument vanish at depths of 10 to $15 \mathrm{~m}$ (Fig. 1.9).

The high-frequency content of the seismic waves is better recorded in a borehole because the attenuation which is highest in the near-surface layers is reduced. Abercrombie (1998) showed that the uppermost hundred metres of the crust are most attenuative $(Q \sim 10$; Section 2.6.1), independent of the rock-type.

It is common to analyse acceleration spectra of ambient seismic noise to assess the site quality (e.g. Bormann 2002). The power spectral density

$$
\mathrm{P}(\omega)=\int_{-\infty}^{\infty} \mathrm{p}(\tau) \exp (i \omega \tau) \mathrm{d} \tau
$$

is the Fourier transform of the auto-correlation function of the noise $\mathrm{p}(\tau)$ (Bormann 1998), $\omega$ is the angular frequency and $\tau$ a time interval. The acceleration power spectral density $\mathrm{P}_{\mathrm{a}}(\omega)$ is obtained from the velocity power spectral density $\mathrm{P}_{\mathrm{v}}(\omega)$ by

$$
\begin{aligned}
\mathrm{P}_{\mathrm{a}}(\omega) & =\omega^{2} \mathrm{P}_{\mathrm{v}}(\omega) \\
\rightarrow \mathrm{P}_{\mathrm{a}}(\mathrm{f}) & =4 \pi^{2} \mathrm{f}^{2} \mathrm{P}_{\mathrm{v}}(\mathrm{f})
\end{aligned}
$$




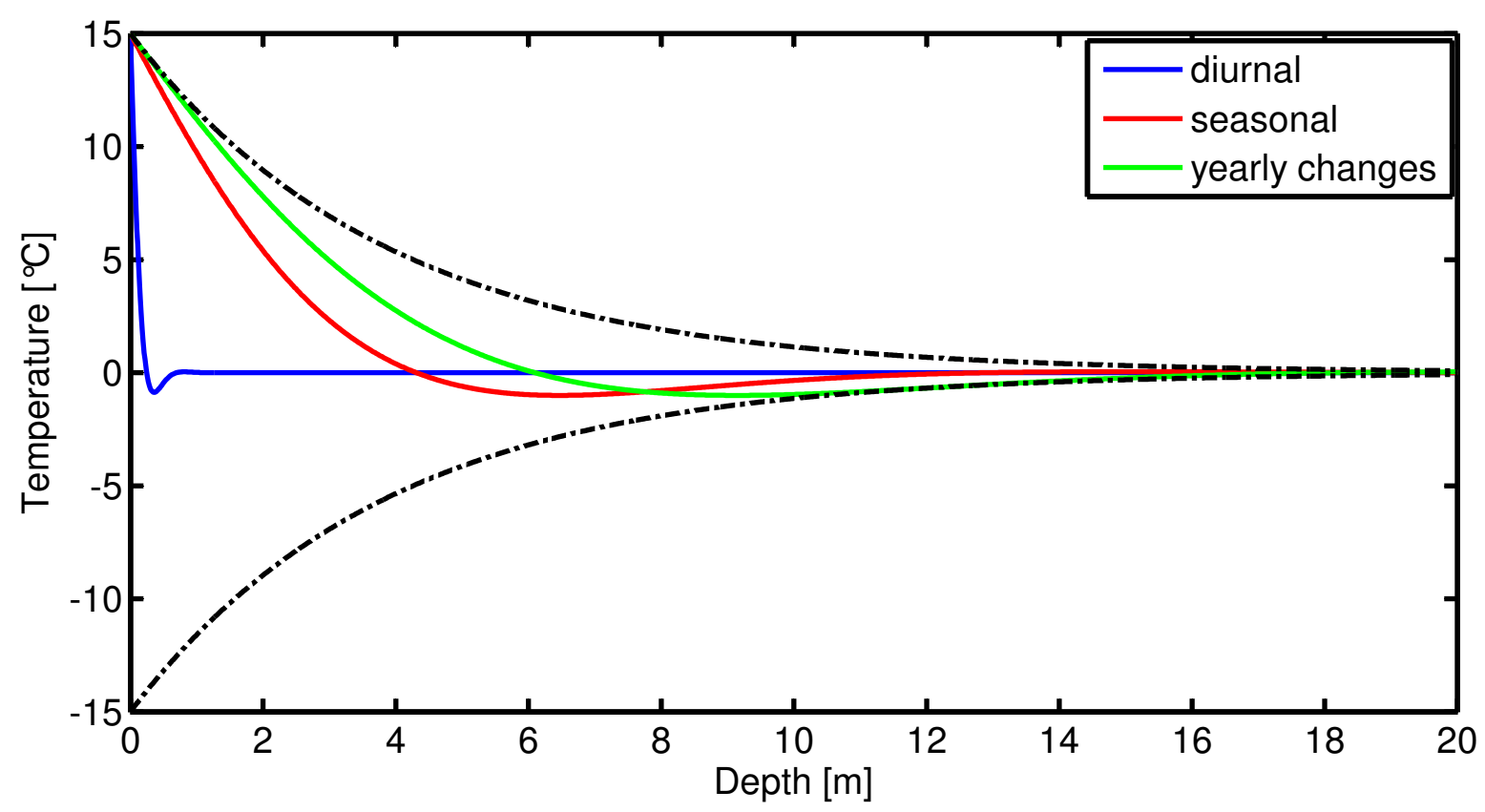

Figure 1.9. Temperature decay with depth for temperature variations with different periods. Equation 1.1 is plotted for $\mathrm{T}_{0}=0^{\circ} \mathrm{C}, \Delta \mathrm{T}=15^{\circ} \mathrm{C}$ and $\omega \mathrm{t}=$ const.

and expressed in units of decibel $[\mathrm{dB}]$ :

$$
\mathrm{P}_{\mathrm{a}}=10 \log \left(\mathrm{P}_{\mathrm{a}} / 1\left(\mathrm{~m} / \mathrm{s}^{2}\right)^{2} \mathrm{~s}\right)
$$

Typical seismic noise spectra are dominated by marine microseismic noise in the 0.05- $0.5 \mathrm{~Hz}$ band (Havskov and Alguacil 2004). This noise reflects the periods of the water waves (10-16 s) and mainly originates from storms and breaking surf along shorelines (Havskov and Alguacil 2004). At higher frequencies, wind and cultural noise dominate. Traffic and machinery usually generate noise at high frequencies (>2-4 Hz) (e.g. Bormann 1998). Seasonal and diurnal variations for microseismic and cultural noise at a given site can differ by one to two orders of magnitude in amplitude (Havskov and Alguacil 2004).

To assess the performance of the SAMBA stations and to quantify the improvement obtained by installing sensors in shallow boreholes, acceleration power spectral densities are calculated in the frequency range 0.01 to $80 \mathrm{~Hz}$. The traces have been corrected for instrument response and the spectra have been smoothed five times. The same time periods as identified by Petersen et al. (2011) for "low" and "high" noise conditions were analysed. The period between 8:00 and 18:00 UTC of 27 June 2009 (New Zealand night time) was characterised by "low wind noise" (wind velocities $<10 \mathrm{~km} / \mathrm{h}$; Petersen et al. 2011), no teleseismic events within the previous 24 hours and no regional earthquakes of $M \geq 3$. In contrast, "high" noise conditions prevailed on 29 June 2009 between 8:00 and 12:00 UTC 
(mean wind speed $22.3 \mathrm{~km} / \mathrm{h}$ ). Petersen et al. (2011) determined spectra for the whole tenand four-hour periods. Since noise spectra can be straightforwardly obtained with SEISAN for periods $\leq 35 \mathrm{~min}$ but not for longer time windows, $35 \mathrm{~min}$ of each hour in the given time periods were used to calculate spectra. These spectra were then stacked and the average and standard deviation determined. The results are shown in Fig. 1.10 (a), (b) and (c). A comparison of the results from Petersen et al. (2011) and those obtained in this study for station FOZ (Fig. 1.11) shows only minor differences. Therefore, the average spectra obtained in this study are inferred to be comparable with those obtained for longer time periods.

Reference models for the noise power spectra of a station are the Peterson New High and New Low Noise Models (NHNM and NLNM; Peterson 1993) which were obtained from globally recorded ambient seismic noise in different frequency bands on the vertical component. All SAMBA stations show a log-linear trend for frequencies below $0.1 \mathrm{~Hz}$. It is not clear whether this is an artefact due to the limited sensitivity of the short-period sensors in this frequency range or generally indicates high regional noise levels below $0.05 \mathrm{~Hz}$. All stations exhibit relatively high noise levels in the microseism band (frequencies of $0.1-0.5 \mathrm{~Hz}$ ), likely reflecting their proximity to the Tasman Sea. For frequencies above $1 \mathrm{~Hz}$, the SAMBA stations EORO, GOVA and FRAN are closest to the NLNM. The remaining stations show similar levels of $-140 \mathrm{~dB}$. Stations COSA, MTFO, WHYM, REYN and LABE feature a local maximum in the 3-15 Hz frequency range. Suggestions for sources for the noise in this frequency range are given in Table E.1. At POCR, the noise is elevated at around $0.4 \mathrm{~Hz}$. Since this station is the only station located in a deep, sediment-filled valley, this may be a resonance frequency (corresponding to sediment layer thicknesses of 340-450 m using the approach of Parolai et al. 2002).

GeoNet station FOZ was identified by Petersen et al. (2011) as a "good" station with low noise levels over the entire frequency band under both "low" and "high" noise conditions (Fig. 1.11). The spectra of WVZ and RPZ are comparable to that of FOZ under "low" noise conditions but are elevated under "high" noise conditions.

For the time period of "high" noise conditions, the acceleration power spectral density in the frequency range $0.1-1 \mathrm{~Hz}$ is elevated for all SAMBA stations. This is most distinct at station COSA and the GeoNet stations RPZ and WVZ. Station LABE was not recording on that day, so no comparison is possible for this station.

A comparison of the spectra from borehole and surface sensors was obtained for the 
2009627 cosa

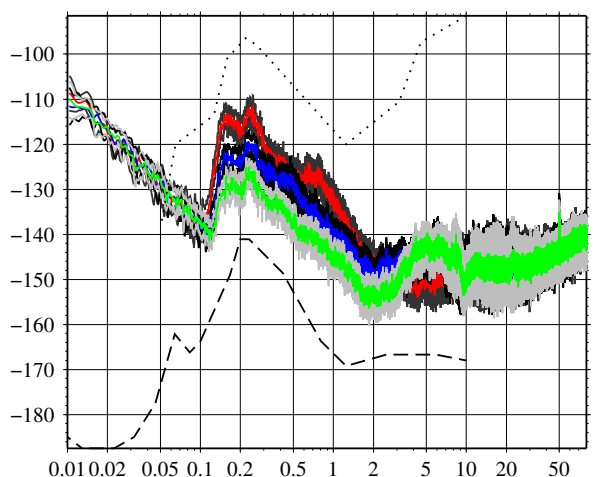

2009627 eoro

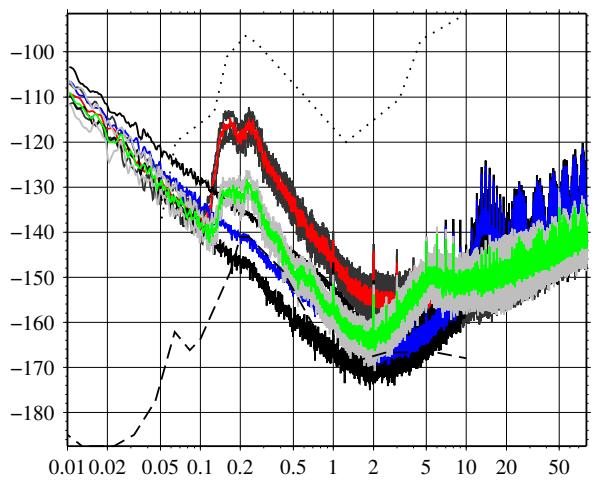

2009627 mtfo

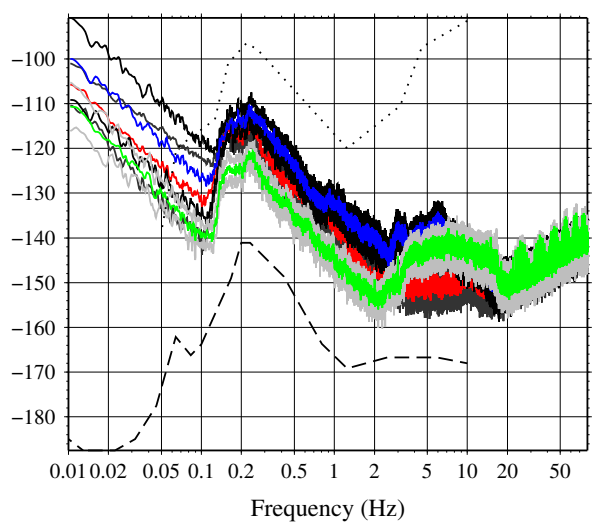

- SH Z av+sd - SH N av+sd

- SHZ av-sd - SH N av-sd

- SHZ av

- $\mathrm{SH} \mathrm{N}$ av
2009629 cosa

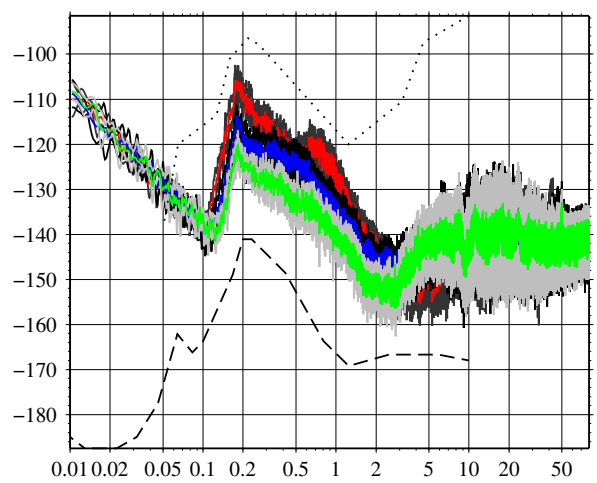

2009629 eoro

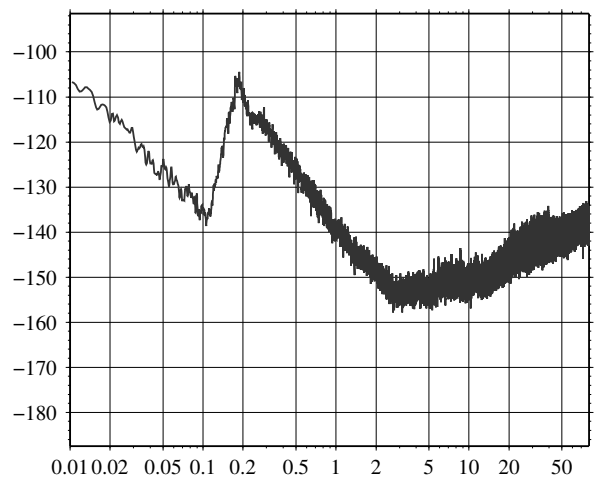

$2009629 \mathrm{mtfo}$

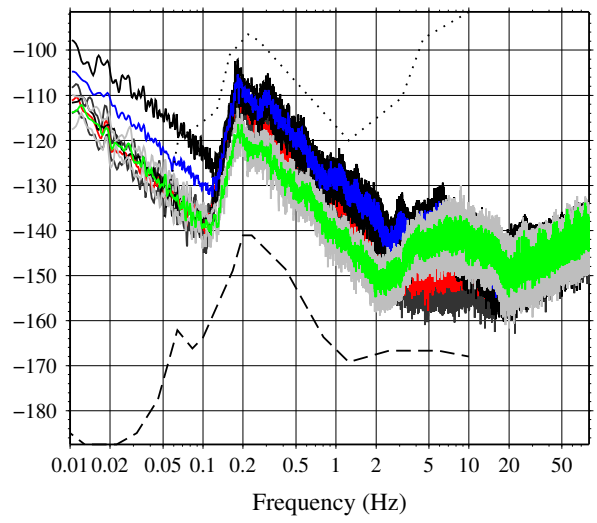

SH E av+sd - - NHNM

SH E av-sd $\quad \cdots \quad$ NLNM

- SHE av

Figure 1.10. (a) Power spectral density for "low" (left) and "high" (right) noise conditions for the shallow SAMBA stations. Each panel shows spectra for all three channels $(\mathrm{Z}, \mathrm{N}, \mathrm{E})$ with the title specifying date and station name. See (c) for more detail. 
2009627 whym

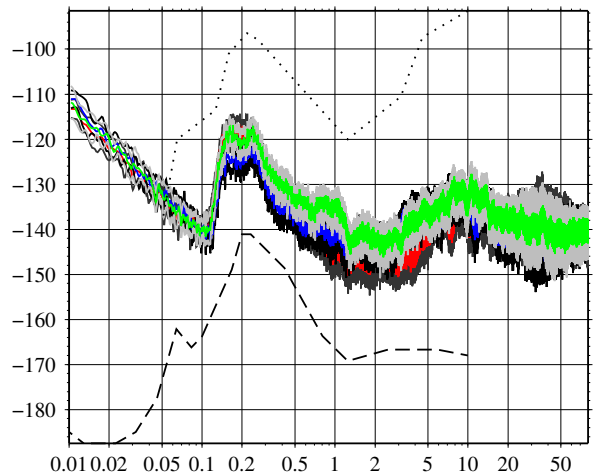

2009627 reyn

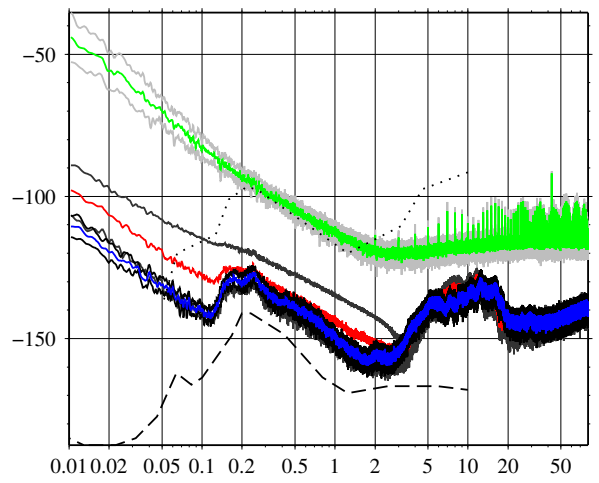

2009627 GOVA

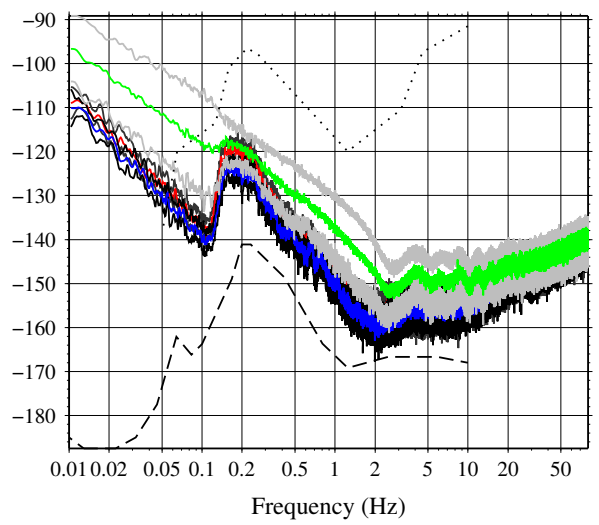

2009629 whym

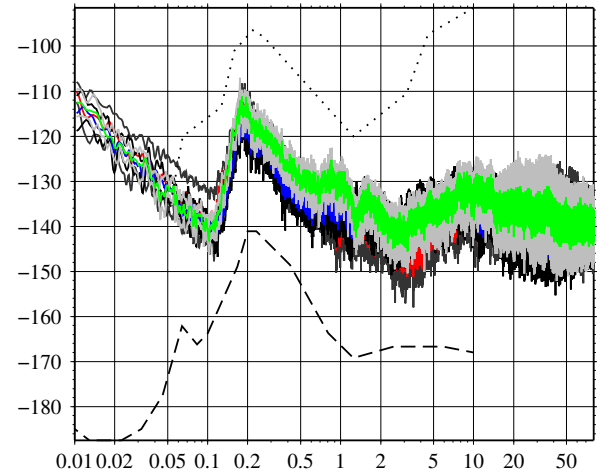

2009629 reyn

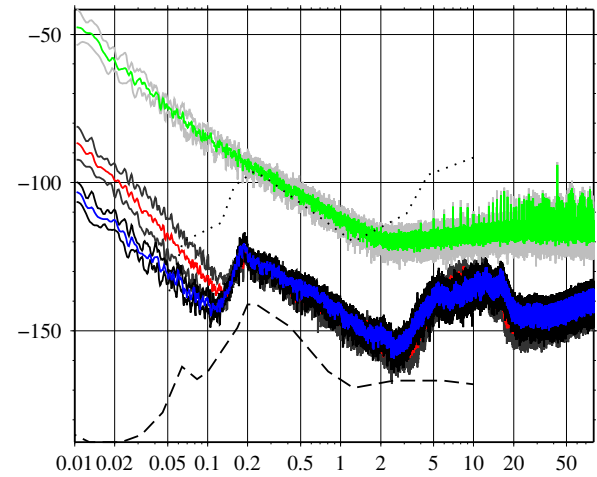

2009629 GOVA

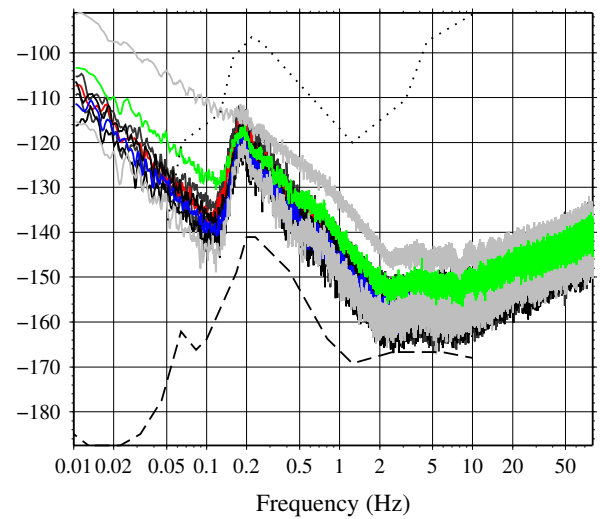

$$
\begin{aligned}
& - \text { SHZ av+sd - SH N av+sd - SHE av+sd - NHNM } \\
& \text { - SH Z av-sd - SH N av-sd - SH E av-sd } \cdots \text { NLNM } \\
& - \text { SHZav } \quad-\text { SHNav }- \text { SHEav }
\end{aligned}
$$

Figure 1.10. (b) Power spectral density for "low" (left) and "high" (right) noise conditions for the shallow SAMBA stations. Each panel shows spectra for all three channels (Z,N,E) with the title specifying date and station name. See (c) for more detail. 
2009627 fran

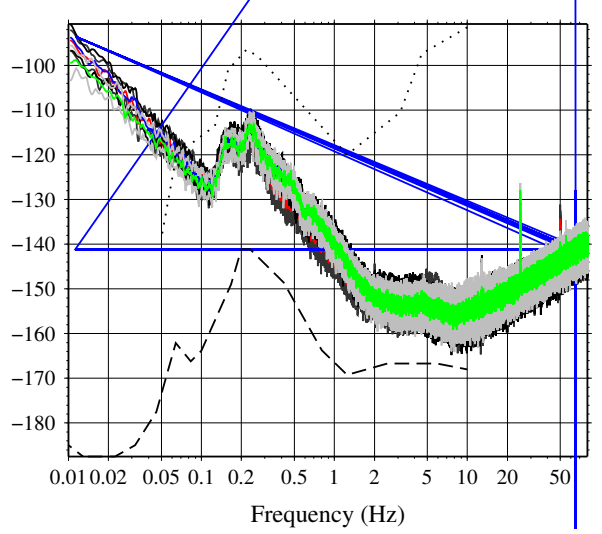

SHZ $\mathrm{Zur}+\mathrm{sd}$
2009629 fran

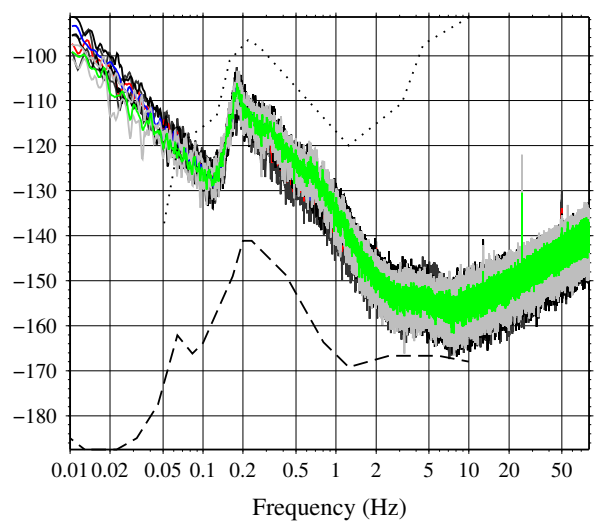

Frequency $(\mathrm{Hz})$

- SHZ av-sd - SH 1 av-sd

SH 2 av+sd - - NHNM

$-\mathrm{SHZ}$ av $-\mathrm{SH} 1 \mathrm{av}-\mathrm{SH} 2 \mathrm{av}$ 2009627 labe

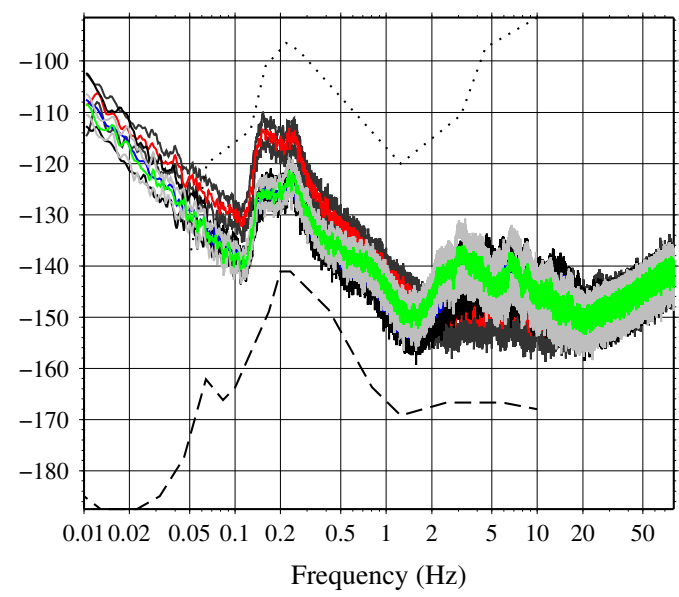

$\begin{array}{ll}- & \text { SH Z av+sd } \\ - & \text { SH Z av-sd } \\ - & \text { SH Z av } \\ - & \text { SH N av+sd } \\ - & \text { SH N av-sd } \\ - & \text { SH N av } \\ - & \text { SH E av+sd } \\ - & \text { SH E av-sd } \\ - & \text { SH E av } \\ --- & \text { NHNM } \\ \cdots & \text { NLNM }\end{array}$

Figure 1.10. (a-b) Power spectral density for "low" (left; 27 August 2009) and "high" (right; 29 August 2009) noise conditions for the shallow SAMBA stations. The average and the standard deviation of the stacked noise PSD resulting from stacking of several 35 min-long data windows are shown for the vertical (Z, red), the north (N, blue) and the east-component (E, green). SH specifies the short-period seismometer recording on high gain. Dashed and dotted lines show the New High and Low Noise Model of Peterson (1993). (c) The same for the deep borehole sensor FRAN (for which due to the unknown orientation channel 1 (blue) and 2 (green) are shown instead) and the shallow station LABE. The latter was not operating on the 29 August 2009 and cannot be assessed for high noise conditions on that date. Note that stations WHAT and POCR are shown in Fig. F.1 and 1.12. 
$2009627 \mathrm{FOZ}$

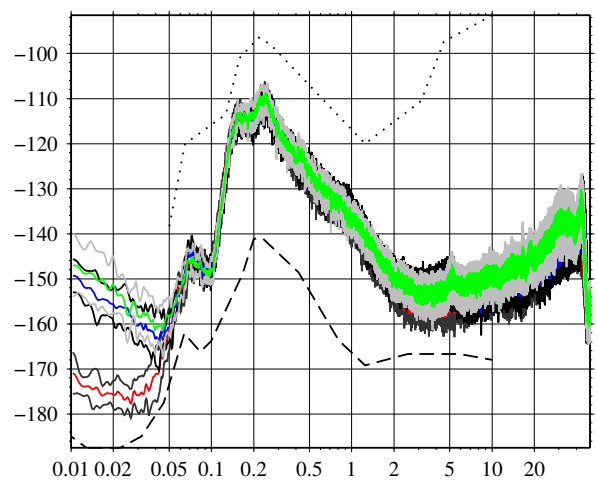

$2009629 \mathrm{FOZ}$

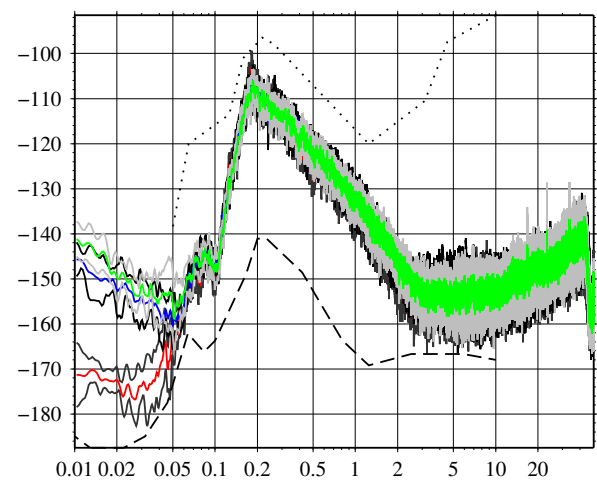

2009/06/27 foz

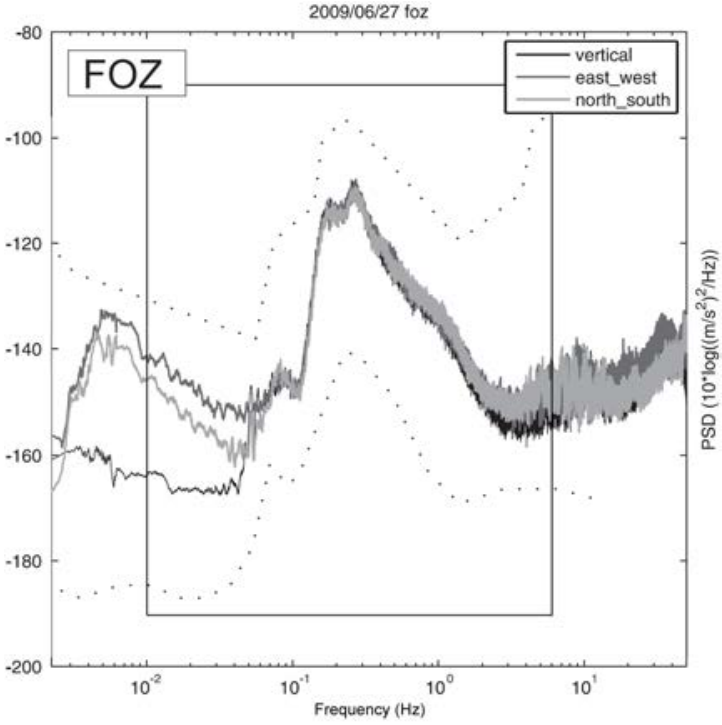

Figure 1.11. Power spectral density for "low" (left) and "high" (right) noise conditions at the GeoNet station FOZ (RPZ and WVZ shown in Fig. F.2). For this station a comparison with results by Petersen et al. (2011) is shown (lower panel) which indicates that the stacked 35 min-long data windows are comparable with $6 \mathrm{hr}$-long spectra obtained by Petersen et al. (2011). 
borehole sensors at station WHAT and POCR. This shows that the surface sensors have elevated noise levels over the entire frequency range. In particular, for frequencies of 0.5-1.5 Hz at POCR, the background noise is comparable to the NHNM. Also the variation for frequencies above $10 \mathrm{~Hz}$ is larger (Fig. 1.12).

Between November 2008 and June 2009, problems were encountered with the Reftek data logger firmware at the SAMBA stations. Data acquisition failures occurred after random periods of time. Consequently, not all stations were recording data at the same time (Fig. C.1 for more detail). Fortunately, throughout this period at least four stations were recording simultaneously.

Almost every SAMBA station, which is equipped with a solar panel, recorded regular spikes in the data generated by the solar controller when charging the batteries (pulsemodulation-width charging). Different solar controllers were tested, the sensor and power cables were separated and additional shielding added, and various filters applied. Despite these measures, the spikes in the data could not be eliminated. Solar controllers from five different suppliers were tested. The spikes could only be avoided with two types of solar controllers, which were both expensive, difficult to obtain and not designed for use in the field (see Table D.1 for more detail). Most of the SAMBA stations are now equipped with ProStar 15 and 30 solar controllers, which generate double-spikes every six minutes. These noise spikes are annoying but only influence the signal if they coincide with an earthquake.

Despite the difficulties encountered with the setup and the operation of the stations in their remote locations in the central Southern Alps, the overall performance of the SAMBA array is good. The primary objective of recording earthquakes down to magnitude $\mathrm{M}_{\mathrm{L}} \sim 0$ on and in the vicinity of the Alpine Fault has been obtained. This has enabled the detection of as many earthquakes within one year as were recorded by the permanent national station network within 13 years. Experience with drilling shallow boreholes and recording with borehole seismometers has been gained. Initial problems with the Reftek data loggers are now solved, and only one station (REYN) could not be maintained further after nine months of operation. The remaining stations are all still in operation. Stations MTFO, WHYM and GOVA have been performing particularly well and recording continuously since installation. The more problematic stations are EORO, LABE and COVA. These stations have difficult access, little sun and/or a lot of snow in winter, and were therefore non-operational for parts of the year. Individual station performance of the remaining stations is assessed in Table E.1. Table I.1 provides an overview over the source dimensions and the expected recording range of earthquakes regarding the distance to the source (and the station spacing). 
2009627 what 2

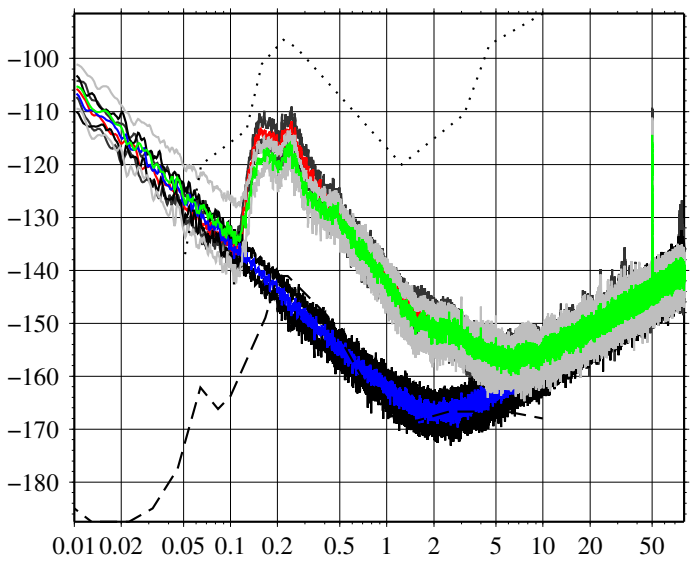

2009627 pocr2

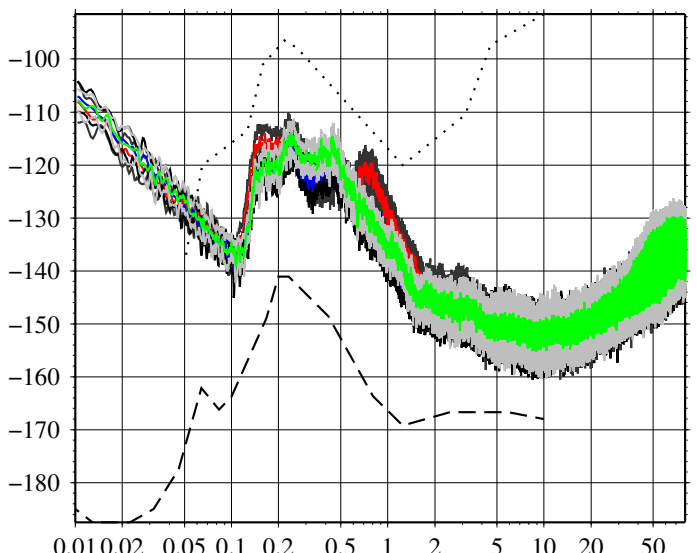

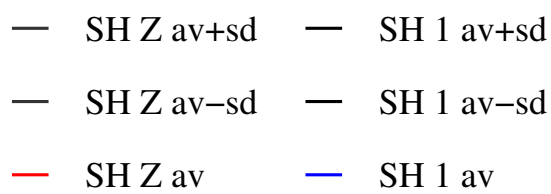

2009627 what 2

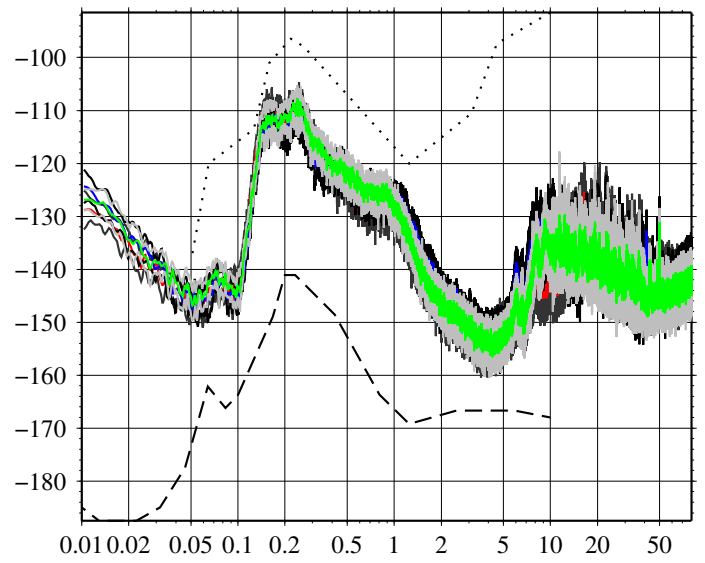

2009627 pocr2

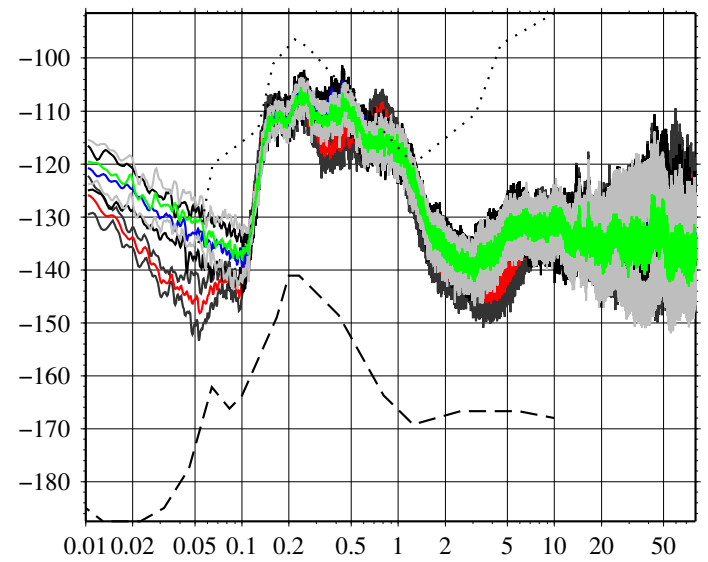

- SH 2 av+sd - - NHNM

- SH 2 av-sd $\cdots$ NLNM

- SH 2 av

Figure 1.12. Power spectral density for a pair of borehole (left) and surface sensors (right) at the same station at "low" noise conditions. Each panel shows spectra for all three channels $(\mathrm{Z}, 1,2$ due to the unknown orientation) with the title specifying date and station name. 
With a recording time of over 3.5 years and continuing, the SAMBA stations have enabled the longest microseismicity study in the region of high topography in central South Island to date. Several large earthquakes were recorded from around the globe in 2009-2012 (Table 5.3), including the two most recent large events in New Zealand, the $M_{W} 7.8$ Fiordland earthquake of 15 July 2009 and the $M_{W} 7.0$ Christchurch earthquake of 3 September 2010 and their aftershock-sequences. 


\section{Theoretical considerations}

The primary characteristics with which we commonly describe an earthquake are hypocentre coordinates (latitude, longitude and depth), origin time and energy release. Secondary parameters include the rupture mechanism and the driving stress field, which describe the nature of the earthquake and its tectonic setting. How these quantities are estimated from seismic observations is summarised in this chapter. Related topics such as weighting of the phase arrivals, uncertainty estimates of the hypocentre location and determination of the velocity model using seismic tomography are also explained.

\subsection{Earthquake location}

In the following, the term "earthquake location" refers to the process of determining the hypocentre parameters. Earthquake location involves two parts; the forward problem of computing theoretical travel-times from a given velocity model and the inverse problem of determining the unknown parameters representing the hypocentre. If we assume the simple case of a homogeneous medium with a constant wave speed $\mathrm{v}$, the arrival times $\mathrm{t}$ of the earthquake waves at $\mathrm{i}$ observation points $\mathrm{x}, \mathrm{y}, \mathrm{z}$ can be calculated from the equation

$$
\mathrm{t}_{\mathrm{cal}}^{\mathrm{i}}=\mathrm{T}+\frac{1}{\mathrm{v}} \sqrt{\left(\mathrm{X}-\mathrm{x}_{\mathrm{i}}\right)^{2}+\left(\mathrm{Y}-\mathrm{y}_{\mathrm{i}}\right)^{2}+\left(\mathrm{Z}-\mathrm{z}_{\mathrm{i}}\right)^{2}}
$$

with the earthquake origin time $\mathrm{T}$ and the hypocentre coordinates $\mathbf{P}=(\mathrm{X}, \mathrm{Y}, \mathrm{Z})$. This forward calculation can be performed for all possible hypocentres (e.g. nodes on a grid spanning a specific region), or an initial hypocentre $\mathbf{P}_{0}=\left(\mathrm{X}_{0}, \mathrm{Y}_{0}, \mathrm{Z}_{0}\right)$ is assumed (for example, the coordinates of the station with the earliest arrival times) to approximate the true hypocentre. The calculated arrival-time is than compared with the observed arrival-time at each station in order to determine the actual hypocentre coordinates. The best hypocentre is that which minimises the differences between observed and calculated arrival times (the so-called arrivaltime residuals):

$$
\mathrm{r}_{\mathrm{i}}=\Delta \mathrm{t}_{\mathrm{i}}=\mathrm{t}_{\text {obs }}^{\mathrm{i}}-\mathrm{t}_{\text {cal }}^{\mathrm{i}}
$$


Equation 2.1 clearly shows that non-linearity is an intrinsic characteristic of the earthquake location problem (Lomax et al. 2009).

\subsubsection{Geiger's location method}

If the initial hypocentre guess is close to the actual hypocentre, then the arrival-time residuals can be mathematically expressed by a first-order Taylor series about $\mathbf{P}_{0}$,

$$
\begin{aligned}
\mathrm{r}_{\mathrm{i}} & =\mathrm{t}_{\mathrm{obs}}^{\mathrm{i}}(\mathbf{P})-\left(\mathrm{t}_{\mathrm{cal}}^{\mathrm{i}}\left(\mathbf{P}_{0}\right)+\frac{\partial \mathrm{t}_{\mathrm{i}}\left(\mathbf{P}_{0}\right)}{\partial \mathbf{P}}\left(\mathbf{P}-\mathbf{P}_{0}\right)+\ldots\right)+\left(\mathrm{T}-\mathrm{T}_{0}\right) \\
& =\frac{\partial \mathrm{t}_{\mathrm{i}}}{\partial \mathrm{x}_{\mathrm{i}}} \Delta \mathrm{x}+\frac{\partial \mathrm{t}_{\mathrm{i}}}{\partial \mathrm{y}_{\mathrm{i}}} \Delta \mathrm{y}+\frac{\partial \mathrm{t}_{\mathrm{i}}}{\partial \mathrm{z}_{\mathrm{i}}} \Delta \mathrm{z}+\Delta \mathrm{t}_{0}
\end{aligned}
$$

in which only the linear terms are retained (since the corrections are small). The term $\Delta \mathrm{t}_{0}$ describes the correction needed to adjust the origin time estimate. For many stations, this yields a linear system of equations of the form

$$
\mathbf{r}=\mathbf{G} \Delta \mathbf{p}
$$

where $\mathbf{r}$ is the residual vector, $\mathbf{G}$ is a matrix of partial derivatives of the arrival-time to each station with respect to the hypocentre coordinates and an additional column of ones corresponding to the origin time correction term. The vector $\Delta \mathbf{p}$ contains the hypocentre and origin time corrections. The earthquake hypocentre solution can be iteratively found by adding the small changes $\Delta \mathbf{P}$ to successive hypocentre estimates. This inversion method originates from Geiger (1910). At least four observations of arrival-times for the recording stations are required to determine both the earthquake hypocentre and the origin time. Often many more stations record the earthquake, so the linear system is overdetermined. The most common technique applied for solving the system of equations is least squares with or without damping; however, several other methods exist (e.g. Buland 1976; Thurber 1985).

A linear approximation of the arrival-time residuals is only adequate for weakly nonlinear problems (e.g. Tarantola and Valette 1982b). This is the case if the stations are not too far away from the earthquake hypocentre and the seismic velocities are slowly varying with position. If so, the matrix containing the partial derivatives $\mathbf{G}$ in equation 2.4 can be inverted because it is of full rank. However, when all stations are far away from the earthquake, then the observations are insufficient to fully constrain the spatial location. In this ill-conditioned case, linear inversion becomes unstable (a small change in the input produces a large, physically implausible change in the output; Tarantola and Valette 1982a). To account 
for this, the depth is commonly fixed to a reasonable value during standard earthquake hypocentre determination with sparse station coverage. The mathematical explanation for instability of linear inversion is that the hypocentre location and the origin times are not independent variables but the least squares technique requires that all variables are strictly independent or can be made so (James et al. 1969).

\subsubsection{Probabilistic non-linear location methods}

Probabilistic non-linear locations of earthquakes most accurately describe the hypocentre uncertainty and can be used with complicated, 3-D velocity structures. Probabilistic methods make use of all available a priori information about the unknown parameters (as, for example, by specifying bounds), and about the distribution of the data (e.g. by assuming a Gaussian distribution). The following approach was described by Tarantola and Valette (1982b) to solve a non-linear inverse problem for a physical system $\Xi$ parameterisable with a finite set of parameters $\mathbf{X}=\left\{\mathrm{X}_{1}, \ldots, \mathrm{X}_{\mathrm{m}}\right\}$ in $\mathbb{R}^{\mathrm{m}}$. Any specific set of parameters is called a model $\mathbf{x}=\left\{\mathrm{x}_{1}, \ldots, \mathrm{x}_{\mathrm{m}}\right\}$ and any degree of knowledge about the parameters can be described by a density function $f(\mathbf{x})$. Two states of information, which have been obtained independently and can be represented by corresponding density functions $f_{\mathbf{i}}(\mathbf{x})$ and $f_{\mathbf{j}}(\mathbf{x})$, can be combined to produce a new state of information. The conjunction or the final state of information $f(\mathbf{x})$ can be expressed as

$$
f(\mathbf{x})=\frac{f_{\mathrm{i}}(\mathbf{x}) f_{\mathrm{j}}(\mathbf{x})}{\mu(\mathbf{x})},
$$

where $\mu(\mathbf{x})$ is the null information (or neutral element), representing the state of total ignorance that is often described with a uniform distribution.

Tarantola and Valette (1982b) transformed this relationship to incorporate probability density functions for the data and model parameters and derived a probabilistic formulation of the non-linear earthquake location problem. Three density functions are necessary to find the a posteriori density function of the hypocentre solution:

- $\rho(\mathbf{d}, \mathbf{p})$, which contains a combination of a priori information about the data $\mathbf{d}$ and the model parameters $\mathbf{p}$

- $\theta(\mathbf{d}, \mathbf{p})$, which contains the theory and errors caused by it, and;

- $\mu(\mathbf{d}, \mathbf{p})$, which represents the null information.

The data used to determine the spatial position and the origin time of an earthquake are the phase arrival-times at observing stations. A priori information about the distribution of 
arrival-time residuals and arrival time uncertainty can be specified by assuming Gaussian statistics. The velocity model is predefined and its influence on the hypocentre location is only accounted for by assuming uncertainties in the arrival times obtained by the theoretical forward computation of arrival-times. A priori information about the spatial location of the earthquake could be a depth or a lateral constraint (e.g. that the earthquake did not occur above the ground or outside a certain region). The null information on the spatial location is that the earthquake occurred in all regions of equal volume with the same probability. Generally, no a priori information about an earthquake's origin time, which is independent of the data, is available. So, a uniform a priori probability density function is assumed for the origin time. The theoretical relationship between calculated arrival times and the hypocentre position can be derived from wave propagation theory and the velocity model.

The resulting a posteriori probability density function corresponding to equation 2.5 is

$$
\sigma(\mathbf{d}, \mathbf{p})=\frac{\rho(\mathbf{d}, \mathbf{p}) \theta(\mathbf{d}, \mathbf{p})}{\mu(\mathbf{d}, \mathbf{p})} .
$$

Integration over the data space leads to the probability density function in the model space:

$$
\sigma_{\mathrm{p}}(\mathbf{p})=\int \sigma(\mathbf{d}, \mathbf{p}) d \mathbf{d}
$$

A detailed description about how the a priori information is expressed as probability density functions was presented by Moser et al. (1992). After analytical integration over the data (Tarantola and Valette 1982b), the a posteriori density function is

$$
\sigma_{\mathrm{p}}(\mathbf{P}, T)=K \rho_{\mathrm{p}}(\mathbf{P}, T) \exp \left[-\frac{1}{2}\left(\mathbf{t}^{\mathrm{obs}}-\mathbf{t}^{\mathrm{calc}}\right)^{\mathrm{T}}\left(\mathbf{C}_{\mathrm{t}}+\mathbf{C}_{\mathrm{T}}\right)^{-1}\left(\mathbf{t}^{\mathrm{obs}}-\mathbf{t}^{\mathrm{calc}}\right)\right]
$$

where $K$ is a normalisation factor, $\rho_{\mathrm{p}}(\mathbf{P}, T)$ is the a priori probability density function of the parameters, and $\mathbf{C}_{\mathrm{t}}$ and $\mathbf{C}_{\mathrm{T}}$ are the variance-covariance matrices of the observations and the velocity model, respectively (Section 2.2.2).

\subsection{Arrival-time residuals and uncertainty assessment}

The unknown spatial error of an earthquake's location is estimated by determining the uncertainty calculated using the travel-time residuals at all stations. Travel-time residuals typically result from measurement errors, misidentification of the phases, uncertainties in 
the absolute time as recorded at the station (Stein and Wysession 2003) and shortcomings in the velocity model employed.

The lower limit of uncertainty in arrival time readings, with typical values of 5 to $20 \mathrm{~ms}$, is governed by the sampling rate of the digitiser (Fremont and Malone 1987). The reading accuracy itself depends on the background noise level and the sharpness of the signal. S-phase arrivals are prone to phase misidentification because the phase onset is obscured by the P-coda. For the same reason, S-phase picks usually have larger uncertainties.

Systematic differences from the true phase arrival time can be expected when phases are identified using an automated process, whereas a random distribution around the true arrival time of an impulsive phase can be assumed when determined by eye. Also, any deviations of the true velocity along the whole ray path from the given model velocity are reflected in the travel-time residuals (e.g. Slunga et al. 1995). However, only the mean velocity effect can be seen, since velocity deviations can compensate for each other. Systematic errors due to unmodelled velocity structures, which are generally unknown, have been addressed in this study by a comprehensive analysis of the residuals (Section 3.1.1) and by a tomography study (Section 6.3).

It is standard to report the root-mean-squared residual $\sigma_{\mathrm{RMS}}$ as a estimate for the uncertainty of the observation. This parameter is obtained from the weighted sum of the travel-time residuals $\mathrm{n}$ at all stations:

$$
\sigma_{\mathrm{RMS}}=\sqrt{\frac{1}{\mathrm{n}} \sum_{\mathrm{i}=1}^{\mathrm{n}}\left(\mathrm{w}_{\mathrm{i}} \mathrm{r}_{\mathrm{i}}\right)^{2}} .
$$

Here $w$ is the weight of the phase (for which $\sqrt{\frac{1}{n} \sum_{i=1}^{n}\left(w_{i}\right)^{2}}=1$ ), and $r$ the travel-time residual for the respective phase. If the travel-time residuals at different stations are of similar size, the root-mean-squared residual $\sigma_{\mathrm{RMS}}$ represents the typical travel-time residual for each station. In this case, $\sigma^{2}{ }_{\text {RMS }}$ is approximately equal to the variance of the observations.

If not specified otherwise, $\mathrm{S}$-waves will have larger de facto weights than $\mathrm{P}$-picks in the travel-time inversion due to their lower velocity. As seen in equation 2.9, a single large residual not only influences the hypocentre location but also significantly alters $\sigma_{\text {RMS }}$. To prevent this, it is important to downweight large residuals of the travel-time arrivals (Section 3.1.2) which result from phase misidentification or timing errors. 


\subsubsection{Uncertainty in absolute earthquake locations}

Linear inversion often inaccurately describes the uncertainty of the absolute hypocentre location. In particular, a single-point hypocentre solution, with a confidence ellipsoid at the 95\% level, does not describe the uncertainty of the hypocentre location in all directions equally (e.g Lomax et al. 2009). Due to the station configuration relative to the earthquake hypocentre, the uncertainty ellipsoids can be elongated in some directions compared to others. Under unfavourable circumstances, these ellipsoids underestimate the uncertainty of the hypocentre (e.g. Deichmann 1992).

\subsubsection{Uncertainty assessment with probabilistic non-linear location methods}

It is apparent that non-linear location methods mitigate errors introduced by the non-linearity of the hypocentre estimation problem. Moreover, there is generally no need to calculate partial derivatives of the travel-times relative to the hypocentre as required for linearised inversion methods. Probabilistic earthquake hypocentre determination thus allows us to describe the location accuracy more thoroughly by giving the full specification of the uncertainty volume (e.g. Moser et al. 1992). The uncertainty of the hypocentre is then represented by the spatial probability density function, which often shows remarkable differences in form and volume compared to an idealised ellipsoid (particularly for ill-conditioned problems; Lomax et al. 2000). Husen and Smith (2004) found that for ill-conditioned problems the difference between the hypocentre obtained with linearised location methods and the maximum likelihood hypocentre solution is large (outside the uncertainty estimate), implying that linear methods are insufficient in this case. For this reason, they used this difference as a measure of the location accuracy.

Equation 2.8 contains the uncertainties of the observations and the velocity model in the form of the combined variance-covariance matrices $\mathbf{C}_{t}$ and $\mathbf{C}_{\mathrm{T}}$. This specific case only results if both uncertainty distributions are assumed to be Gaussian. The variance matrix of the observations $\mathbf{C}_{\mathrm{t}}$ is defined as

$$
\left(C_{\mathrm{t}}\right)_{\mathrm{ij}}=\left\{\begin{array}{lc}
\left(\sigma_{\mathrm{i}}^{2}\right)^{\text {reading }} & \text { if } \mathrm{i}=\mathrm{j} \\
0 & \text { otherwise }
\end{array}\right.
$$

where $\left(\sigma^{2}\right)^{\text {reading }}$ is the variance of the reading error (Moser et al. 1992). The theoretical model-error matrix contains the variances of the model on the diagonal and the covariances 
on the off-diagonal entries.

In the non-linear location method by Lomax et al. (2000) applied in this study, the model-error covariance terms are calculated as

$$
\left(C_{T}\right)_{\mathrm{ij}}=\left(\sigma^{2}\right)^{\text {model }} \exp \left(-\frac{\mathrm{D}_{\mathrm{ij}}^{2}}{2 L_{\mathrm{corr}}^{2}}\right)
$$

where $\sigma^{\text {model }}$ accounts for an estimate of the unknown model error in the travel-time residual, $\mathrm{L}_{\text {corr }}$ is an estimate of the characteristic length scale of the velocity anomaly between two stations, and D describes the distance between two stations $i$ and $j$. This matrix governs the extent to which a correlation in the uncertainties due to modelling exists between two stations. The value of $\sigma^{\text {model }}$ is varied in proportion to the travel-time, so that a distant station would have a greater uncertainty due to the assumed velocity model than a nearby station. These parameters directly influence the size of the uncertainty volume and have been thoroughly evaluated as described in Section 4.1.1.

To evaluate $\sigma^{\text {model }}$, the estimates of $\sigma_{\mathrm{RMS}}$ and $\sigma^{\text {reading }}$ are used. Assuming that the variance of an observation $\sigma^{\text {total }}$ results from the variance of the phase reading and the variance due to unmodelled velocity structure, then:

$$
\begin{aligned}
\sigma_{\text {total }}^{2} & =\left(\sigma^{2}\right)^{\text {reading }}+\left(\sigma^{2}\right)^{\text {model }} \\
\Leftrightarrow\left(\sigma^{2}\right)^{\text {model }} & =\sigma_{\text {total }}^{2}-\left(\sigma^{2}\right)^{\text {reading }}
\end{aligned}
$$

The estimate of the variance of an observation $\sigma_{\mathrm{RMS}}^{2}$ is here used as a proxy for $\sigma_{\text {total }}^{2} . \sigma_{\mathrm{RMS}}^{2}$ is a fair representation of $\sigma_{\text {total }}^{2}$ for large numbers of phase picks. A mean value of $\sigma_{\mathrm{RMS}}$ can be derived from the typical location error (Section 3.1.1). Two independent estimates for the variance of the reading error $\sigma^{\text {reading }}$ are obtained. First, we assume that the variance of the travel-time residuals from the mean is solely due to reading errors, whereas the mean value itself represents the error of the velocity model $\sigma^{\text {model }}$ (Chapter 3.1.1). The second estimate for $\sigma^{\text {reading }}$ comes from the variance of the time lag gained from cross-correlation of similar earthquakes in swarms (Section 4.2.1).

Nelson and Vidale (1990) found out that a small fraction of the absolute uncertainty arises from the finite-difference calculation of the travel times. They compared differences of the hypocentres for forward and backward calculations using the algorithm of Podvin and Lecomte (1991) and obtained average location uncertainties of $0.2 \mathrm{~km}$ in the horizontal plane and $0.3 \mathrm{~km}$ in depth due to differences in the computations. Husen et al. 
(2003) estimated absolute location uncertainties using the probabilistic non-linear location program NonLinLoc (Lomax et al. 2000) by locating 34 quarry blasts and shots distributed throughout Switzerland. They obtained maximum epicentral uncertainties of $\pm 2 \mathrm{~km}$ and \pm 5 $\mathrm{km}$ in focal depth with a typical station spacing of $30-50 \mathrm{~km}$.

Lomax et al. (2009) performed simulations to test absolute uncertainties of earthquakes located on a vertical fault plane. This fault caused a sharp velocity contrast of $20 \%$ between adjacent media. Assuming uncertainties of $\pm 0.1 \mathrm{~s}$ and $\pm 0.2 \mathrm{~s}$ for synthetic P- and S-wave arrivals, respectively, they observed shifts in hypocentre locations of up to $5 \mathrm{~km}$ in depth and $2 \mathrm{~km}$ horizontally. Within the network, the true hypocentre locations were generally within the probabilistically determined location volume. In contrast, location uncertainties became large and irregular outside of the station array.

Wittlinger et al. (1993) performed synthetic location tests for a structurally complex setting of a gas reservoir with strongly heterogeneous media. They showed that hypocentre locations for vertical lineaments of events outside the station network became strongly clustered and were shifted by up to $4 \mathrm{~km}$ horizontally and $6 \mathrm{~km}$ in depth when located with the linearised location program HYPO71. Using a non-linear location method, the general pattern of the synthetic vertical lineaments outside the network could be correctly retrieved.

\subsubsection{Influence of station configuration on location uncertainty}

The shape of the uncertainty volume directly reflects the station distribution of the network. In general, an elongated epicentral uncertainty ellipse indicates a sparse station distribution in one direction relative to the hypocentre (Havskov and Ottemöller 2010). For an event lying outside the station network, the estimated hypocentre is shifted relative to the true hypocentre towards or away from the centre of the network depending on the assumed velocity structure (as seen in tests reported by Lomax et al. 2009). To prevent mislocation of earthquake hypocentres, testing of uncertainties regarding absolute location is essential. The hypocentral uncertainties for events outside the SAMBA network were tested by locating earthquakes in the same area, once outside the SAMBA network and later within the DFDP10 network (Section 3.4.2). This enables us to estimate the amount of shifting due to the station distribution relative to the earthquake. 
Using different subsets of the station network to locate an earthquake can provide an estimate of how stable the event location is (James et al. 1969). Location and relocation of earthquakes also depend critically on the velocity model applied. This can be tested by locating the same set of earthquakes using different velocity models. The influence of anisotropy on the hypocentre location may also be non-negligible in some settings. The effect of velocity variations on the hypocentre location for the Southern Alps region is discussed in Section 6.3.1.

\subsection{Weighting}

A Gaussian uncertainty distribution is often assumed for arrival time phase picks (e.g. Pavlis 1986). This is valid for impulsive onsets of phase arrivals because picking uncertainties are randomly distributed around the true value (Buland 1976). Emergent arrivals, in contrast, are likely picked too late, depending on the signal to noise ratio, meaning that the uncertainty distribution tends to be asymmetric in time (Anderson 1982; Pavlis 1986). Travel-time uncertainties caused by an inadequate velocity model are often treated as Gaussian errors, simply because these model uncertainties are unknown (e.g. Pujol 2000). If the earthquake location is well-constrained (that is, when there are a suitable number of observations available from a range of distances and azimuths), the model uncertainty usually dominates the total location uncertainty. Otherwise, a bad phase pick can lead to a large location uncertainty. For well-located events, model uncertainties are systematic. A travel-time residual of $0.1 \mathrm{~s}$ resulting from an inappropriate velocity model corresponds to a typical hypocentre shift between 500 and $650 \mathrm{~m}$ for P-waves (e.g. Slunga et al. 1995) depending on the velocities.

Manual weights are often assigned depending on the sharpness of the phase onset and do not necessarily reflect its uncertainty. Assuming that the phase picks are randomly distributed around the true value, so that the distribution can be fitted by a Gaussian curve, a measure of the reading uncertainty can be calculated from the distance to the mean value (as applied in Section 3.1.2).

\subsubsection{Jeffreys' weighting}

Jeffreys (1973) proposed a weighting procedure for downweighting extreme travel-time residuals so that Gaussian statistics can be applied to the remaining residuals. This weight- 
ing scheme uses the ratio $\mu$ of the number of extreme values relative to all values and the standard deviation $\sigma_{0}$ of the population without extreme values to reduce the influence of outliers on the location:

$$
w(r)=\frac{1}{1+\mu \exp \left(\frac{r^{2}}{2 \sigma_{0}^{2}}\right)}
$$

where $w$ is the weight assigned to the travel-time residual $r$. To calculate $\sigma_{0}$, outliers were defined as those travel-time residuals greater than two standard deviations $\sigma$ of all travel-time residuals.

One problem with Jeffreys' weighting is that it introduces bias if the travel-time residuals do not have common variances (Section 3.1.1). Therefore, Jeffreys' function (equation 2.13) is effective for confining the influence of outliers but should not be used for weighting residuals unless they have common variances. The weighting scheme determined in this study is a combination of both Jeffreys' and systematic weighting (Section 3.1.2).

\subsection{Cross-correlation}

The cross-correlation function of two aperiodic functions $x(t)$ and $y(t)$ is defined as

$$
C_{x y}(t)=\int_{-\infty}^{\infty} x(\tau) y(\tau+t) d \tau
$$

(e.g. Havskov and Ottemöller 2010). Cross-correlation describes the process of shifting the function $y(\tau)$ relative to $x(\tau)$ by $t$ for $-\infty<t<\infty$, multiplying the two functions and integrating the product. This functional computes the area under the curve which both functions have in common while moving one function along the $t$-axis. In other words, the crosscorrelation function is a measure of the similarity of the two functions. If the two functions $y(\tau)$ and $x(\tau)$ are strictly identical the correlation is called the auto-correlation. Often the cross-correlation function is normalised by the auto-correlation functions

$$
C_{x y}^{N}(t)=\frac{\int_{-\infty}^{\infty} x(\tau) y(\tau+t) d \tau}{\sqrt{\left.C_{x x}(t) C_{y y}(t)\right)}}
$$

In this case, a cross-correlation coefficient for a particular time $t=t_{0}$ can be interpreted with regard to three key values: 
$C_{x y}^{N}\left(t_{0}\right)=\left\{\begin{array}{cl}0 & \text { the two functions are dissimilar, } \\ 1 & \text { the two functions are identical at that time, } \\ -1 & \text { the two curves are identical but one is flipped }(y(\tau)=-x(\tau))\end{array}\right.$

Cross-correlation is now used routinely to identify clusters of similar earthquakes (e.g. Nadeau et al. 1995), to determine the relative time for which the two events are most similar (lag-time), to detect low-frequency events within tremor (Shelly et al. 2007; Brown et al. 2008) or aftershocks immediately following the mainshock (Peng and Zhao 2009) and for high-precision earthquake relocation (e.g. Schaff et al. 2002; Du et al. 2004). Comparison of seismic waveforms over long periods of time can also be used to investigate temporal changes in the properties of a structure over time (e.g. Li et al. 2003).

The absolute value of the cross-correlation coefficient depends on filtering and the choice of time-window-length, which shifts the cross-correlation coefficients up and down by a constant amount. The lower the high-frequency content and the shorter the window length, the higher the cross-correlation coefficient (e.g. Nakahara 2004; Schaff et al. 2004).

Earthquakes with highly similar waveforms (cross-correlation coefficients larger than 0.9) are called repeating earthquakes or multiplets, and are associated with repeated rupture of the same asperity (e.g. Nadeau et al. 1995; Gans et al. 2003). Waveform similarity decreases with increasing inter-event distance (Nakahara 2004; Schaff et al. 2004). For inter-event distances on the order of several kilometres, the correlation coefficients diminish rapidly (e.g. Hutchings and Wu 1990). Several authors (e.g. Nadeau et al. 1995) showed that high cross-correlation coefficients $(>0.9)$ are associated with separation distances of only a few tens or hundreds of metres. This corresponds to source separations smaller or equal to one-quarter of the wavelength of the dominant wave frequency (Geller and Mueller 1980). However, the cross-correlation coefficient for events recorded at a common station depends strongly on the geological heterogeneities in the vicinity of the recording site (Hutchings and $\mathrm{Wu}$ 1990), the degree of velocity structure heterogeneity along the ray path (Schaff et al. 2004), and on the heterogeneous structure in the earthquake source region. Nakahara (2004) used the event separation distance above which cross-correlation coefficients fall below 0.6 to characterise the damage zones of two large earthquakes in Japan. He found that the structure around the source region of the Awaji earthquake is more heterogeneous (smaller correlation distances) than in the Kobe region. 


\subsection{Earthquake relocation}

Relative locations of earthquakes can be determined more accurately than absolute locations (e.g. Schaff et al. 2002). The reason for this is that differential travel-times of two closely spaced events, which are recorded by the same distant station, can be precisely calculated using cross-correlation of the waveforms. Location uncertainties due to unmodelled velocity structure are diminished because the ray paths of these events are similar along most of the path and differ only in the source region (Waldhauser and Ellsworth 2000). Differential travel-times resolvable by cross-correlation are on the order of milliseconds and therefore at least ten times better than the corresponding reading uncertainties (cf. Section 2.2.1). This is why relative locations of spatially clustered events can resolve the fine-scale structure of the cluster, while the uncertainty in the absolute locations of individual events is too large to resolve the separation between these events.

A first step in relative earthquake location is to locate similar events relative to one master event which has a well-determined absolute location (e.g. Pujol 2000). This is known as the master-event technique. A more sophisticated method is to locate all possible pairs of similar events relative to each other. The spatial location of an individual event is then constrained by its distance to all other surrounding events.

It has been argued by Menke and Schaff (2004) that relative relocation of earthquakes can, in principle, be used to determine absolute locations, provided that the station coverage and data quantity are excellent. Several authors have investigated how relative locations can constrain absolute locations. Slunga et al. (1995) reported that systematic arrival time differences between similar events at a $6 \mathrm{~km}$ distant station changed by $1 \mathrm{~ms}$ if a pair of events was moved by $200 \mathrm{~m}$ while retaining their relative locations, but this finding is clearly velocity dependent.

\subsubsection{Uncertainty assessment of relative earthquake locations}

The most commonly used program for relative earthquake locations is the double-difference algorithm hypoDD of Waldhauser and Ellsworth (2000). Dunn (2004) tested whether systematic and random errors can be identified using hypoDD assuming a synthetic data set of five earthquakes aligned north-south and separated by $1 \mathrm{~km}$. Systematic travel-time errors at a few stations become apparent using hypoDD. Random errors (ranging between 
0 and $0.7 \mathrm{~s}$ ) added to the theoretical travel-times affected both the epicentre and the depth. Epicentre locations were shifted approximately $1 \mathrm{~km}$, whereas the effect on the depth of the earthquakes was on the order of $2.5 \mathrm{~km}$. However, the overall linear feature could be resolved and event distances between the earthquakes remained approximately constant.

During the relocation process, the weighted sum of the squared double-difference residuals for pairs of earthquakes at each station is minimized. This can be accomplished using either the singular value decomposition (SVD) or the conjugate gradients method (LSQR). SVD reliably resolves relative location errors but can only be used for small datasets. Large datasets can be solved efficiently with by LSQR but a location error assessment is unreliable (Waldhauser and Ellsworth 2000).

\subsection{Amplitude decay}

The amplitude of a seismic wave diminishes as the wave propagates due to the redistribution of energy. With distance $\Delta$ from the wave's source the amplitude A of a seismic wave decays as

$$
\mathrm{A}(\Delta)=\mathrm{GA}_{0} \Delta^{-\alpha} \exp (-\gamma \Delta)
$$

where $\alpha$ is the geometric spreading coefficient, and $\gamma$ is the anelastic attenuation coefficient (describing the absorption of seismic energy) for a specific region (Stein and Wysession 2003). $\mathrm{G}$ is the instrument gain and $\mathrm{A}_{0}$ is the amplitude of the wave at the source $(\Delta=0)$. Note that equation 2.16 neglects the effect of scattering. The anelastic attenuation parameter $\gamma$ is known to be frequency dependent: $\gamma=\gamma(\mathrm{f})$. This frequency dependence originates from the relationship between $\gamma$ and the quality factor Q (e.g. Kim 1998),

$$
\gamma(\mathrm{f})=\frac{\pi \mathrm{f}}{\mathrm{Q}(\mathrm{f}) \mathrm{v}}
$$

where $\mathrm{v}$ is the velocity for $\mathrm{P}$ or $\mathrm{S}$-waves, $\mathrm{Q}(\mathrm{f})=\mathrm{Q}_{0} \mathrm{f}^{v}$ is a function of $\mathrm{f}$ containing the quality factor $\mathrm{Q}_{0}$ at a reference frequency $\mathrm{f}=1 \mathrm{~Hz}$ and $v$ is the frequency exponent.

The local magnitude $\mathrm{M}_{\mathrm{L}}=\log \mathrm{A}_{0}+$ const. is obtained by taking the logarithm of equation 2.16 and rearranging, which results in equation 2.23 (Section 2.7). 


\subsubsection{Geometrical spreading and attenuation}

Geometrical spreading of the wave describes the amplitude decay of the expanding wavefront in space, which causes increasing amplitude reduction with distance from the wave's source (Stein and Wysession 2003). The geometrical spreading coefficient $\alpha$ reflects the exponent of the amplitude decay with distance. This value is usually constrained based on theoretical considerations. The effects on the amplitude of wave-expansion in space can be shown by starting with the total mean energy density of a plane wave:

$$
\bar{E}=\frac{1}{2} \rho \omega^{2} \mathrm{~A}^{2}
$$

where $\rho$ is the density of the medium, $\omega=2 \pi \mathrm{f}$ the radial frequency t frequency $\mathrm{f}$, and A the wave amplitude. The energy flux through an areal element is given by:

$$
\begin{aligned}
\text { Energy flux per areal element } & =\text { energy density } \times \text { velocity } \times \text { areal element } \\
d \bar{E}^{\text {flux }} & =\frac{1}{2} \rho \omega^{2} \mathrm{~A}^{2} \times c \times d s
\end{aligned}
$$

Since the energy flux through two areas $d \bar{E}_{1}^{\text {flux }}=d \bar{E}_{2}^{\text {flux }}$ in a homogeneous medium must be the same for a spreading wave $(\rho, \omega, c$ all constant), the amplitude ratio corresponding to different areas is

$$
\frac{A_{2}}{A_{1}}=\sqrt{\frac{d s_{1}}{d s_{2}}} \approx \frac{r_{1}}{r_{2}}
$$

The area of the expanding spherical wavefront increases with $4 \pi r^{2}$, where $r$ is the radius of the sphere. Therefore, for body waves travelling directly from the source to the receiver, the amplitude decay is proportional to $1 / \mathrm{r}$, and $\alpha=1$. For distances greater than $100 \mathrm{~km}$, the first waves commonly recorded at the receiver are refracted waves, which show a different amplitude decay with $\alpha \sim 2$ (Stein and Wysession 2003). Surface wave decay is proportional to the circumference increase of a growing circle in two dimensions which results in $\alpha=0.5$ (Stein and Wysession 2003).

The second contribution to the amplitude decay results from attenuation, which can significantly decrease the amplitude. Crustal attenuation results from both intrinsic and scattering attenuation. Which mechanism dominates and what factors govern attenuation remain debated and seem to vary with tectonic settings (e.g. Frankel 1991; Adams and Abercrombie 1998). Aki and Richards (1980) suggested that attenuation is higher in regions of tectonic activity. Frankel (1991) showed that anelastic scattering is greater in southern California than in New York or South Africa, but noted that regional differences in attenuation could rather reflect the geologic complexity than tectonic activity. 
In general, local lithological variations, inhomogeneities, the state and amount of fractures, crustal fluids and temperature variations affect attenuation in the crust (Hauksson and Shearer 2006). The effect of temperature becomes prominent at temperatures above the solidus of the rock (e.g. Mavko 1980). Consequently, magma and partial melts are highly attenuative. In non-volcanic settings, however, where temperatures in the crust are below the solidus temperature, the effect on attenuation is much smaller than the effect of major tectonic structures on attenuation (e.g. Hauksson and Shearer 2006). Thus, attenuation in the crust is related to some degree to the permeability and the amount of fracturing of the rock, its fluid content and fluid pressure (Frankel 1991).

Geometrical spreading and scattering attenuation are elastic processes because the energy of the wave is redistributed but conserved. Scattering describes the redistribution of seismic energy at inhomogeneities, which shifts energy from the direct wave into the coda (Frankel 1991). Intrinsic attenuation, in contrast, is an anelastic process associated with mechanisms that convert seismic energy into heat. The wave's energy is transformed to heat by internal friction along grain boundaries (Stein and Wysession 2003). Therefore, attenuation increases with every oscillation of the wave. The longer the path through the crust, the more depleted the spectrum of high frequencies. For direct P- and S-waves, the quality factor $\mathrm{Q}_{\mathrm{P}}$ (inverse of the attenuation coefficient) for $\mathrm{P}$-waves is generally two to three times higher than $\mathrm{Q}_{\mathrm{S}}$. Knopoff (1971) derived $\mathrm{Q}_{\mathrm{P}} \sim 2.25 \mathrm{Q}_{\mathrm{S}}$ for a Poissonian solid under the assumption that little energy is lost in compression (bulk modulus is large). However, Hauksson and Shearer (2006) observed $\mathrm{Q}_{\mathrm{S}} / \mathrm{Q}_{\mathrm{P}} \approx 1.3$ and related this to fluid saturation of the rock. The near-surface structure of the crust strongly influences the attenuation of the seismic wave. A high percentage of crustal attenuation can be attributed to the uppermost few kilometres (<3 km; Abercrombie 1998). Q near the surface is low (in the range of 10 to 100), independent of rock type and frequency (Abercrombie 1998, and references therein).

\subsection{Earthquake magnitudes}

Earthquake magnitude is a logarithmic measure of earthquake size. Magnitudes can be calculated from the duration of the coda (length of decay of the scattered waves of a seismic phase), maximum amplitude or amplitude of a phase at a certain frequency.

Richter's 1935 original definition of the local magnitude $\mathrm{M}_{\mathrm{L}}$ included a station cor- 
rection term $\mathrm{S}$ (accounting for the instrument gain and the site amplification due to the local geology) and a distance correction term $-\log \left(\mathrm{D}_{0}\right)$. This term was defined in such a way that a magnitude 3 event would produce an amplitude of $1 \mathrm{~mm}$ on a Wood-Anderson torsion seismograph at $100 \mathrm{~km}$ distance from the source:

$$
M_{L}=\log (A(\Delta))-\log \left(D_{0}(\Delta)\right)+S
$$

The amplitude $A$ was measured as half the peak-to-peak displacement value determined from the maximum amplitude on the horizontal components of a Wood-Anderson seismograph. To separate the effects of geometrical spreading (proportional to $\log (\Delta)$ ) and scattering and anelastic attenuation (proportional to $\Delta$ ) along the path to the receiver, the distance correction term $-\log \left(D_{0}\right)$ can be replaced by

$$
-\log \left(D_{0}(\Delta)\right)=\alpha \log (\Delta)+\gamma \log (e) \Delta .
$$

Thus the local magnitude is

$$
M_{L}=\log (A(\Delta))+\alpha \log (\Delta)+\gamma \log (e) \Delta+S
$$

where $\alpha$ is the geometrical spreading coefficient and $\gamma$ the anelastic attenuation factor for a specific region. This formula is commonly used for shallow local events recorded by stations at distances of $\leq 1000 \mathrm{~km}$.

To calibrate the local magnitude $\mathrm{M}_{\mathrm{L}}$ in a certain region, the coefficients $\alpha$ and $\gamma$ have to be determined using regression analysis (e.g. Hutton and Boore 1987; Uski and Tuppurainen 1996). For the Wellington region, Robinson (1987) derived the relationship

$$
M=\log (A(\Delta))+1.0 \log (\Delta)+0.0029 \Delta+S
$$

which is currently used by GeoNet to estimate magnitudes all over New Zealand. O' Keefe (2008) determined a magnitude scale for the central Southern Alps region using 411 microearthquakes recorded in late 2006:

$$
M=\log (A)+1.0 \log (\Delta)+0.0073 \Delta+S
$$

This result indicates higher attenuation in the Southern Alps than accounted for in the magnitude determinations by GeoNet. A new magnitude scale for the Southern Alps region is derived in Section 3.2. 


\subsection{Gutenberg-Richter relationship and b-value}

The cumulative number of earthquakes $\mathrm{N}(\mathrm{M})$ for any magnitude $\mathrm{M}$ larger than the magnitude of catalogue completeness $\mathbf{M}_{\mathrm{c}}$ obeys an exponential distribution with increasing magnitude with an exponential decay parameter $\lambda$ :

$$
\begin{aligned}
\mathrm{N}(\mathrm{M}) & =\mathrm{N}_{0} e^{-\lambda\left(\mathrm{M}-\mathrm{M}_{\mathrm{c}}\right)} \\
\log \mathrm{N} & =\underbrace{\log \mathrm{N}_{0}}-\underbrace{\lambda \log e}_{\mathrm{b}}\left(\mathrm{M}-\mathrm{M}_{\mathrm{c}}\right) \\
\log \mathrm{N} & \left.=\mathrm{M}-\mathrm{M}_{\mathrm{c}}\right)
\end{aligned}
$$

The magnitude of completeness or cut-off magnitude is the lowest magnitude for which all events are detected in time and space (e.g. Woessner and Wiemer 2005). Equation 2.26c is known as the magnitude-frequency relationship and was first determined empirically by Gutenberg and Richter for earthquakes in California (Gutenberg and Richter 1944). The constant $\mathrm{a}=\log \mathrm{N}_{0}$ is specific to a certain region and corresponds to the logarithm of the number of earthquakes at the reference magnitude $\mathrm{M}_{\mathrm{c}}$. For this reason, a is also called the rate of occurrence or the productivity of a region. The value $b=\lambda \log$ e represents the slope of the relationship between the logarithm of the cumulative number of earthquakes $\mathrm{N}$ and their magnitudes $M \geq M_{c}$. In other words, the $b$-value describes the expected number of earthquakes of low relative to high magnitudes. A b-value close to unity represents a 10 -fold increase in the number of earthquakes with every decrease of one magnitude unit. A b-value lower than one indicates that a higher number of larger events can be expected compared to the reference model with $b=1$. For example, if 10000 events with $M \geq 4$ occurred and the $b$-value of the Gutenberg-Richter distribution is $b=1$, than 10 earthquakes of $M \geq 7$ can be expected, whereas for $b=0.9$ this results in 20 expected events with $M \geq 7$. Low b-values have been described as indicators for locked fault segments or high stress areas (e.g. Wiemer and Wyss 1997), or have been associated with the maturity of the fault system (Stirling et al. 1996).

To determine the b-value accurately, fitting of the slope of the Gutenberg-Richter relationship with linear least squares is insufficient because the b-value depends on the cut-off magnitude $\mathrm{M}_{\mathrm{c}}$ and the errors of the magnitudes $\mathrm{M}$. Therefore, the maximum likelihood estimate of $b$ has to be determined instead (Aki 1965). The maximum likelihood function $\mathrm{L}$ for a set of $n$ magnitudes $M_{j}$ above the cut-off magnitude $M_{c}$ which follow an exponential 
distribution as seen in equation $2.26 \mathrm{a}$ is

$$
\begin{aligned}
\mathrm{L} & =\prod_{\mathrm{j}=1}^{\mathrm{n}} \lambda e^{-\lambda\left(\mathrm{M}_{\mathrm{j}}-\mathrm{M}_{\mathrm{c}}\right)} \\
& =\lambda^{\mathrm{n}} e^{-\lambda\left[\left(\mathrm{M}_{1}-\mathrm{M}_{\mathrm{c}}\right)+\left(\mathrm{M}_{2}-\mathrm{M}_{\mathrm{c}}\right)+\ldots\right]} \\
\log \mathrm{L} & =\mathrm{n} \log \lambda-\lambda \log e \sum_{\mathrm{j}=1}^{\mathrm{n}}\left(\mathrm{M}_{\mathrm{j}}-\mathrm{M}_{\mathrm{c}}\right)
\end{aligned}
$$

At the maximum, $\partial \log \mathrm{L} / \partial \lambda=0$ and hence

$$
\begin{aligned}
0 & =\frac{\mathrm{n} \log e}{\lambda}-\log e \sum_{\mathrm{j}=1}^{\mathrm{n}}\left(\mathrm{M}_{\mathrm{j}}-\mathrm{M}_{\mathrm{c}}\right) \\
\frac{\mathrm{n}}{\lambda} & =\sum_{\mathrm{j}=1}^{\mathrm{n}}\left(\mathrm{M}_{\mathrm{j}}-\mathrm{M}_{\mathrm{c}}\right) \\
\lambda & =\left(\frac{1}{\mathrm{n}} \sum_{\mathrm{j}=1}^{\mathrm{n}}\left(\mathrm{M}_{\mathrm{j}}-\mathrm{M}_{\mathrm{c}}\right)\right)^{-1} .
\end{aligned}
$$

Since $\mathrm{b}=\lambda \log e$ it follows

$$
\mathrm{b}=\frac{\log e}{\overline{\mathrm{M}}-\mathrm{M}_{\mathrm{c}}}
$$

with the mean magnitude $\bar{M}$ for $M \geq M_{c}$. The uncertainty of the b-value reduces with the uncertainty of the mean magnitude. The larger the number of events $n$ with a magnitude, the smaller the standard deviation of the mean $\sigma_{n}=\sigma / \sqrt{n}$. Therefore

$$
\sigma_{\mathrm{b}}=\frac{b}{\sqrt{n}}
$$

To avoid errors in b-value calculation, a sufficiently large data set of well-located earthquakes are required (more than 2000 events are needed to calculate $b$ to within an accuracy 0.05 at the $98 \%$ confidence level, Felzer 2006).

\subsection{Seismic tomography}

Seismic tomography aims to resolve 3-D velocity structure based on the assumption that the model uncertainty dominates the location uncertainty of well-recorded events. This is often reflected by the station correction terms. Consequently, a systematic analysis of travel-time residuals can provide information about the velocity structure between the earthquake source and the recording stations. Negative residuals indicate higher velocities and positive 
residuals lower velocities in relation to the reference velocity model. Lateral variations that are not considered in the assumed velocity model can be studied using this approach. Those velocity anomalies can be located if many, preferably crossing ray paths between different sources and receivers are available.

In seismology, tomography studies are performed to image 2-D or 3-D structures of the ground using earthquake waves. Based on Fermat's principle that the ray path represents the path of minimum travel-time for direct waves, the travel-time $\tau$ of a seismic wave results from the integrated velocity $\mathrm{v}(\mathrm{s})$ of the wave along a ray path $\mathrm{s}$ through an isotropic medium

$$
\tau=\int \mathrm{ds} / \mathrm{v}(\mathrm{s})
$$

or alternatively expressed using the slowness $\mathrm{u}(\mathrm{s})=1 / \mathrm{v}(\mathrm{s})$ :

$$
\tau=\int \mathrm{u}(\mathrm{s}) \mathrm{ds}
$$

The arrival-time t of a body-wave generated at the source $\mathrm{k}$ and recorded by the receiver $\mathrm{i}$ is therefore

$$
\mathrm{t}_{\mathrm{i}}^{\mathrm{k}}=\mathrm{T}^{\mathrm{k}}+\int_{\mathrm{k}}^{\mathrm{i}} \mathrm{uds}
$$

with the origin time $\mathrm{T}$. The arrival-time residual $\mathrm{r}$ is calculated as the difference between observed and calculated arrival-times and is attributed to velocity perturbations along the ray-path:

$$
\mathrm{r}_{\mathrm{i}}=\mathrm{t}_{\mathrm{i}}^{\mathrm{obs}}-\mathrm{t}_{\mathrm{i}}^{\mathrm{cal}}
$$

Linearisation of equation 2.34 around an initial hypocentre and velocity model using a truncated Taylor series (as in equation 2.3a) yields

$$
\mathrm{r}_{\mathrm{i}}^{\mathrm{k}}=\sum_{\mathrm{l}=1}^{3} \frac{\partial \mathrm{t}_{\mathrm{i}}^{\mathrm{k}}}{\partial \mathrm{x}_{\mathrm{i}}^{\mathrm{l}}} \Delta \mathrm{x}_{\mathrm{i}}^{1}+\Delta \mathrm{T}^{\mathrm{k}}+\int_{\mathrm{k}}^{\mathrm{i}} \delta \mathrm{uds}
$$

For arrival-time tomography, the volume between the source and the receivers is divided into equal-sized blocks with a velocity perturbation $\Delta \mathrm{u}_{\mathrm{j}}$ for each block,

$$
\mathrm{u}_{\mathrm{j}}=\mathrm{l}_{\mathrm{j}} \Delta \mathrm{u}_{\mathrm{j}}
$$

with the path $l_{j}$ in block $j$. For a single source-receiver configuration the velocity perturbation $\Delta \mathrm{u}(\mathrm{s})$ can occur anywhere along the ray path. When there are enough ray paths and different source-receiver configurations, those blocks with different velocities can be 
identified. However, this is only possible if a certain number of rays propagate through each of the blocks. Also, the rays have to sample the same block on a number of ray paths in different directions, so that the structure can be resolved.

Using the discretisation of the ray path into ray segments within a block,

$$
\int_{\mathrm{k}}^{\mathrm{i}} \delta \mathrm{uds}=\sum_{\mathrm{j}=1} \mathrm{G}_{\mathrm{ij}} \Delta \mathrm{u}_{\mathrm{j}}
$$

equation 2.35 can be expressed in matrix form as

$$
\mathbf{r}=\mathbf{G} \Delta \mathbf{p}+\mathbf{H} \Delta \mathbf{m}
$$

where $\mathbf{G}$ and $\mathbf{H}$ contain the partial derivatives of the hypocentre and model part and $\Delta \mathbf{p}$ and $\Delta \mathbf{m}$ are the vectors of combined hypocentre/origin time and velocity model adjustments (Kradolfer 2003). The simultaneous inversion for hypocentre locations and velocity structure is a mixed-determined problem (Kradolfer 2003). This means some of the unknown model parameters are overdetermined while others are underdetermined and cannot be uniquely estimated. Therefore, no unique solution exists because too little information is available for some of the model parameters. Damping, smoothing and a priori constraints are needed to find a solution of the model parameters. If the solution is underdamped, the residual vector is minimised but not the solution vector. In the overdamped case the over- and underdetermined model parameters are minimised but the solution does not reflect the smallest residual vector. The solution of a mixed-determined problem using damped least squares solution is

$$
\Delta \mathbf{m}^{\text {est }}=\left(\mathbf{G}^{\mathrm{T}} \mathbf{G}+\theta \mathbf{I}\right)^{-1} \mathbf{G}^{\mathrm{T}} \Delta \mathbf{d}
$$

(e.g. Kradolfer 2003), which has to be solved iteratively.

In double-difference seismic tomography (Zhang 2003) as applied in this study, the observations of pairs of events are considered, and equation 2.35 becomes

$$
\mathrm{r}_{\mathrm{i}}^{\mathrm{k}}-\mathrm{r}_{\mathrm{i}}^{\mathrm{h}}=\sum_{\mathrm{l}=1}^{3} \frac{\partial \mathrm{t}_{\mathrm{i}}^{\mathrm{k}}}{\partial \mathrm{x}_{\mathrm{i}}^{1}} \Delta \mathrm{x}_{\mathrm{i}}^{1}+\Delta \mathrm{T}^{\mathrm{k}}+\int_{\mathrm{k}}^{\mathrm{i}} \delta \mathrm{uds}-\sum_{\mathrm{l}=1}^{3} \frac{\partial \mathrm{t}_{\mathrm{i}}^{\mathrm{h}}}{\partial \mathrm{x}_{\mathrm{i}}^{1}} \Delta \mathrm{x}_{\mathrm{i}}^{1}-\Delta \mathrm{T}^{\mathrm{h}}-\int_{\mathrm{h}}^{\mathrm{i}} \delta \mathrm{uds}
$$


This can be simplified if the events are sufficiently close in space so that the path from the sources $\mathrm{k}$ and $\mathrm{h}$ are similar except within the source region

$$
\begin{aligned}
\mathrm{dr}_{\mathrm{i}}^{\mathrm{kh}} & =\mathrm{r}_{\mathrm{i}}^{\mathrm{k}}-\mathrm{r}_{\mathrm{i}}^{\mathrm{h}} \\
& =\sum_{\mathrm{l}=1}^{3} \frac{\partial \mathrm{t}_{\mathrm{i}}^{\mathrm{k}}}{\partial \mathrm{x}_{\mathrm{i}}^{1}} \Delta \mathrm{x}_{\mathrm{i}}^{1}-\sum_{\mathrm{l}=1}^{3} \frac{\partial \mathrm{t}_{\mathrm{i}}^{\mathrm{h}}}{\partial \mathrm{x}_{\mathrm{i}}^{1}} \Delta \mathrm{x}_{\mathrm{i}}^{1}+\Delta \mathrm{T}^{\mathrm{k}}-\Delta \mathrm{T}^{\mathrm{h}} \\
& =\left(\mathrm{T}_{\mathrm{k}}^{\mathrm{i}}-\mathrm{T}_{\mathrm{h}}^{\mathrm{i}}\right)^{\mathrm{obs}}+\left(\mathrm{T}_{\mathrm{k}}^{\mathrm{i}}-\mathrm{T}_{\mathrm{h}}^{\mathrm{i}}\right)^{\mathrm{cal}}
\end{aligned}
$$

where $\mathrm{dr}_{\mathrm{i}}^{\mathrm{kh}}$ is the double difference between observed and calculated differential arrival times. The travel-time difference outside the source region is small compared to the difference inside the source region.

A joint inversion for absolute and relative locations as well as the velocity structure can be obtained using the double-difference seismic tomography program tomoDD of Zhang and Thurber (2003). It incorporates a special weighting scheme which includes distance weighting so that relative locations are only taken into account for closely spaced events and are suppressed for distant earthquakes. The program also explicitly accounts for path anomaly biases between event pairs (Zhang 2003).

\subsection{Focal mechanisms}

A focal mechanism characterises the geometry of the rupture on the fault plane of an earthquake. Three angles are used to characterise the mechanism and the orientation of the fault plane:

- the strike angle $\xi$ describes the orientation of a horizontal line in the fault plane measured clockwise from north $0^{\circ} \leq \xi \leq 360^{\circ}$

- the dip angle $\delta$ describes the inclination of the fault plane from the horizontal $0^{\circ} \leq \delta<90^{\circ}$ (where the dip direction is always measured to the right hand side looking along the strike)

- the rake angle $\lambda$ specifies the direction of the hanging-wall movement with respect to the footwall $-180^{\circ} \leq \lambda \leq 180^{\circ}$ (measured in the plane of the fault from the strike direction, where positive values indicate upwards movement of the hanging-wall as during reverse faulting and negative values represent downward movement during normal faulting) 
The polarities of the waves radiated by the earthquake and recorded at the stations are commonly used to determine focal mechanism solutions (Stein and Wysession 2003). If the first motion of the P-wave at a station is upwards the earthquake has caused compression of the source material in the direction to the receiver. If, in contrast, the polarity is downwards, the P-wave directed towards the receiver resulted from dilatation of the material around the source. S-waves show different polarisation characteristics and, in principle, can be used in the same way to determine the focal mechanism. However, the S-arrival is often emergent and the polarity obscured. Also, if shear-wave splitting occurred this has to be corrected for before the polarity of the S-wave can be studied (e.g. Zollo and Bernard 1989). The directions of the highest amplitude of compressional and tensional P-wave radiation can be derived from the compressional and dilatational quadrants and are described with the P-axis and T-axis.

Different mechanisms of faulting cause distinct radiation patterns of the waves emitted from the earthquake source (Fig. 2.1). The take-off angles of the ray paths from the source to the receivers are plotted on the focal sphere, a hypothetical unit sphere enclosing the source (Stein and Wysession 2003). Take-off angles on the upper hemisphere result from rays recorded near the source, and are projected onto the lower hemisphere. Most commonly, a focal mechanism solution is depicted on a lower-hemisphere projection of the focal sphere.

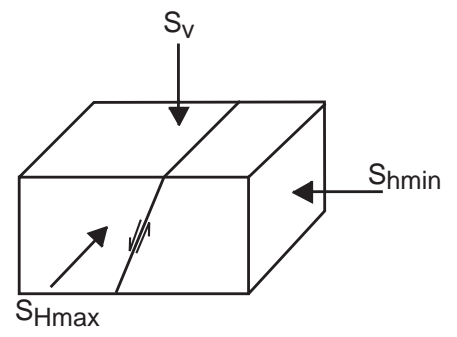

NORMAL

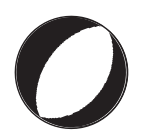

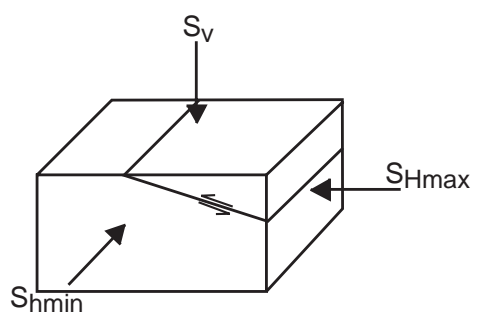

REVERSE

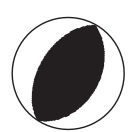

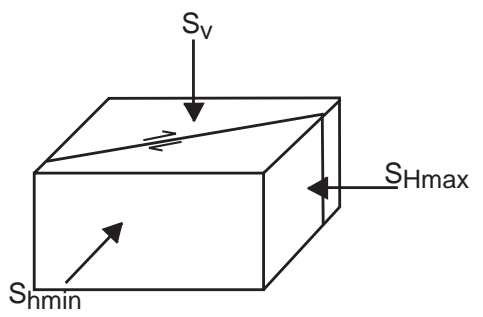

STRIKE-SLIP

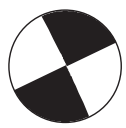

Figure 2.1. Principal stress directions, focal mechanism solutions and the orientation of faults after Anderson (1951). Compressional quadrants of the focal mechanism solutions are filled in black.

The focal mechanism solution determined from the far-field radiation alone contains an intrinsic ambiguity regarding the fault plane because the rupture plane is indistinguishable from the auxiliary plane. Other data, such as mapped faults, radiation patterns as a function 
of frequency of the seismic waves or aftershock distributions must be used to interpret the fault plane (McKenzie 1969).

Mathematically, the far-field radiation pattern of shear-failure on a fault can be modelled using a double couple of equivalent body forces (Stein and Wysession 2003). A double couple describes two force pairs a small distance apart which point in opposite directions, so that the total moment vanishes. The nine components of the seismic moment tensor $\mathbf{M}$ represent all double couples of different orientation. Thus, the seismic moment tensor describing shear failure on a fault in a coordinate system aligned with the fault plane and its normal is always symmetric and contains two components of opposite polarity.

Uncertainty in the focal mechanism solution is caused by several factors of which some can be tested and eliminated, but others cannot. The focal mechanism solution is constrained by

- the number of available polarity readings and the coverage of the focal sphere, as the number of recording stations is always limited and the stations can be distributed unevenly around the earthquake hypocentre;

- the influence of falsely wired seismometers on the solution (this can be checked by comparing first motions of a teleseismic event recorded by all stations, since the same first motion is expected for all stations on a small aperture array in a large distance, Fig. B.1);

- the signal to noise ratio of the recorded waveforms; and

- the uncertainty in the take-off angle which results from the uncertainty in the hypocentre location and the inaccuracy of the velocity model.

Since most earthquakes are recorded by only a few stations, the spatial coverage on the focal sphere is often insufficient to determine the mechanism. Several different methods exist which use additional information to increase the number of observations per earthquake. Regional moment tensor inversion uses the whole waveform recorded by broadband stations and fits it with theoretical waveforms. This method is typically applicable for earthquakes above a magnitude threshold of $\mathrm{M}_{\mathrm{L}} \sim 3.5$. For the New Zealand region, focal mechanisms for earthquakes of $\mathrm{M}_{\mathrm{L}} \geq 4$ are determined as part of the routine earthquake analysis by GeoNet (Ristau 2008). Amplitude ratios of P- and S-waves can be used to determine the focal mechanism because of the radiation pattern of P- and S-waves from the source (e.g. Hardebeck and Shearer 2003, and references therein). P-wave amplitudes have maximum wave amplitudes near the P- and T-axes and minimum amplitudes near the nodal planes. 
Maximum S-wave amplitudes are observed at the nodal planes (Fig. 2.2). Also, P- and $\mathrm{S}$-wave amplitude ratio methods have the advantage that no corrections for magnitude and geometrical spreading are necessary.
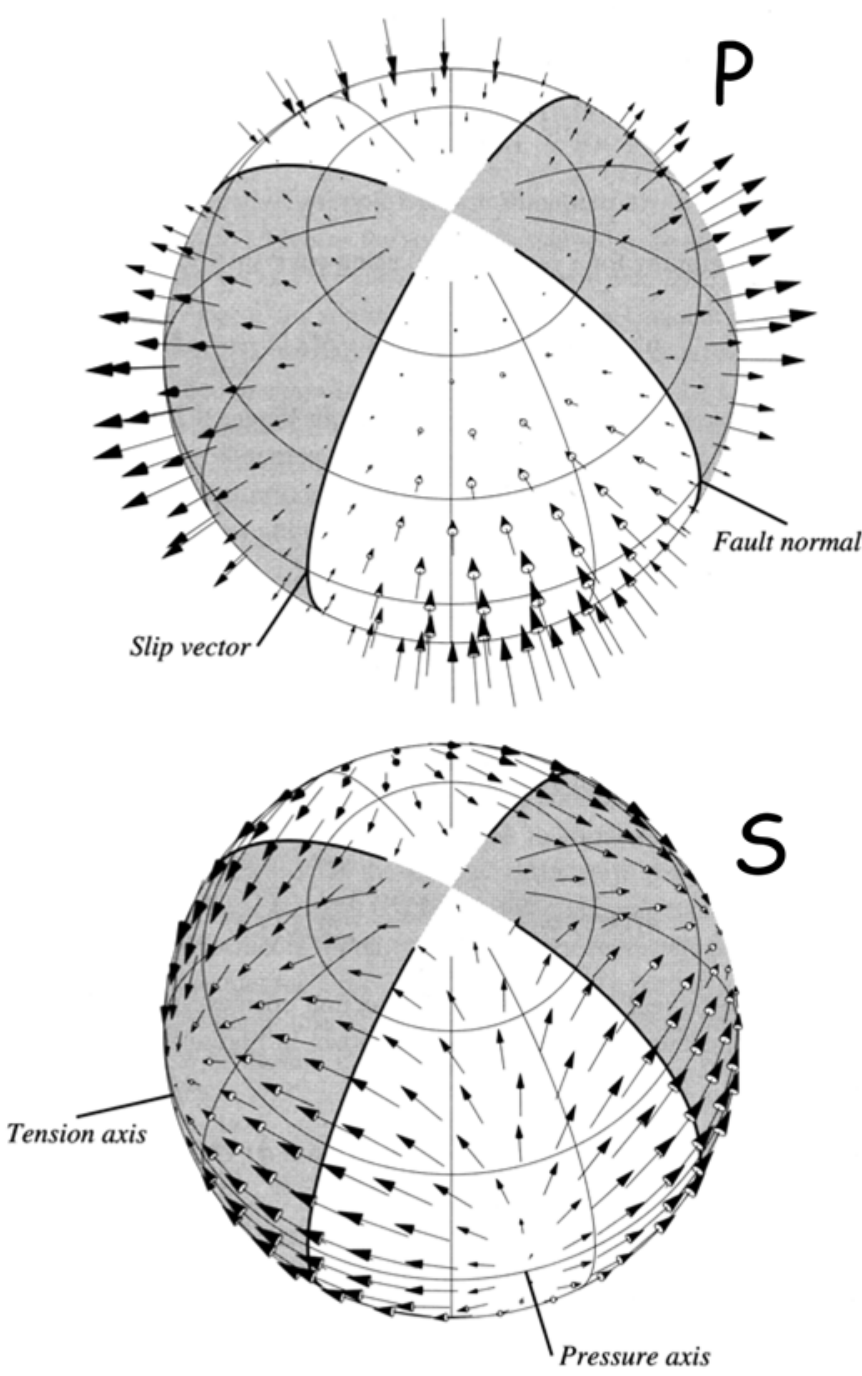

Figure 2.2. $\mathrm{P}$ - and S-wave amplitude patterns for a double-couple source. Note that the slip vector lies in the fault plane whereas the fault normal vector lies in the auxiliary plane.

Probabilistic approaches based on Bayes' theorem can also be used for focal mechanism parameter inversion (Walsh et al. 2009). To characterise the uncertainty thoroughly, the resulting Bayesian posterior probability density function (PDF) of the focal mechanism parameters is parameterised by a generalised Matrix-Fisher distribution (Arnold and Townend 2007; Walsh et al. 2009). The Matrix-Fisher distribution describes the distribution of vectors on a sphere. Three matrices, M, U and D characterise the distribution. M controls the 
orientation of the distribution, the spin matrix $U$ twists the shape of the distribution at the modes and the concentration matrix $\mathrm{D}$ describes the density of the distribution of vectors in one direction. A scalar Matrix-Fisher distribution allows for the simplest description of the distribution. Arnold and Townend (2007) used the scalar concentration parameter $\kappa$ from the scalar Matrix-Fisher distribution to determine the standard deviation $\sigma_{\Theta}$ of the focal mechanism parameters

$$
\sigma_{\Theta}=\exp (3.9155-0.5659 \log (\kappa))
$$

assuming equal errors in strike, dip and rake. However, the uncertainty of the focal mechanism solution is best represented graphically by the distribution of the P- and T-axes. The tighter the contours, the better the focal mechanism of the earthquake is constrained (Section 3.5).

\subsection{Stress estimates}

Assuming that individual focal mechanisms represent a uniform state of stress and are driven by the same stress field, regional stress estimates can be derived by inverting a set of independent focal mechanism observations as described by Gephart and Forsyth (1984), Michael (1984) and Arnold and Townend (2007). A focal mechanism solution enables the calculation of the orientation of the maximum, intermediate and minimum compressive stresses and a ratio of the magnitudes of the stresses for the tectonic stress field in a small crustal volume around the earthquake (Arnold and Townend 2007). Although six components are needed to fully describe the stress tensor, these four parameters suffice to calculate the direction but not the magnitude of maximum horizontal compressive stress (Lund and Townend 2007). Due to the free surface of the earth, which supports no shear stresses, one of the three principal stress axes is subvertical and this vertical stress increases linearly with depth $\left(\sigma_{\mathrm{v}}=\rho \mathrm{gh}\right)$. However, topographic stresses can regionally disturb the stress field (e.g. Liu and Zoback 1992). If one of the principal stresses is not strictly vertical, the direction of the maximum horizontal compressive stress can differ by up to tens of degrees from the direction of the prevailing larger subhorizontal compressive stress (Lund and Townend 2007). Depending on the stress ratio $\mathrm{R}=\left(\sigma_{1}-\sigma_{2}\right) /\left(\sigma_{1}-\sigma_{3}\right)$, small deviations of the direction of the principal stress axis from the vertical and horizontal, respectively, can be associated with substantial changes in the direction of the maximum horizontal compressive stress, especially for stress states in dominantly compressional or extensional tectonics (Lund and Townend 2007). 


\subsection{Mohr-Coulomb stress analysis}

According to Anderson's theory of faulting, failure on new or preexisting faults is governed by the normal $\sigma_{\mathrm{n}}$ and shear stress $\tau$ acting on the fault plane, the coefficient of internal friction $\mu$ as well as the cohesive strength $\tau_{0}$ of the rock. The cohesive strength is the inherent strength of the fault and corresponds to the minimum shear stress required for failure on new faults. It is zero for preexisting faults, but finite and positive if, for example, hydrothermal cementation has sealed the fault. This is expressed by the Coulomb frictional failure criterion:

$$
|\tau|=\tau_{0}-\mu \sigma_{\mathrm{n}}
$$

To account for fluid pressure this equation is modified to

$$
|\tau|=\tau_{0}-\mu\left(\sigma_{\mathrm{n}}-P_{\mathrm{f}}\right)
$$

where $P_{f}$ is the fluid pressure (Hubbert and Rubey 1959). The higher the fluid pressure for a given normal stress $\sigma_{\mathrm{n}}$, the lower the shear stress $\tau$ the failure surface can sustain before failing.

A 2-D Mohr circle (with the intermediate principal stress $\sigma_{2}$ lying in the fault plane) provides a means of determining the normal- and shear-stresses on a fault plane of given orientation in the prevailing stress field. All possible combinations of normal and shear stresses given by

$$
\begin{gathered}
\sigma_{\mathrm{n}}=\frac{\left(\sigma_{1}+\sigma_{3}\right)}{2}+\frac{\left(\sigma_{1}-\sigma_{3}\right)}{2} \cos (2 \theta) \\
\tau=\frac{\left(\sigma_{1}-\sigma_{3}\right)}{2} \sin (2 \theta)
\end{gathered}
$$

lie on a Mohr circle, where $\theta$ is the angle between $\sigma_{1}$ and the fault plane (Fig. 2.3). Failure occurs when the straight line that expresses the frictional failure criterion (equation 2.44) touches or intersects the circle. The formation of new conjugate faults occurs at angles of $\theta^{*}=1 / \tan (1 / \mu)=30^{\circ}$ (for $\mu=0.6$ ) to $\sigma_{1}$. Faults slipping with non-optimal orientation $\theta \neq \theta^{*}$ can be interpreted as having a low coefficient of friction $\mu^{\prime}<\mu$ or increased pore-fluid pressure P' ${ }_{\mathrm{f}}$ (Fig. 2.3 b) (e.g. Townend and Zoback 2004). If faults and fractures preexist, failure occurs on those favourably oriented structures first because $\tau_{0} \sim 0$ and fault reactivation is possible for $\theta<2 \theta^{*}$ (Sibson 1985). Sibson (1989) showed that severely misoriented faults $\left(\theta>2 \theta^{*}\right)$ can only be reactivated in fluid-overpressured regimes where $\mathrm{P}_{\mathrm{f}} \geq \sigma_{3}$. 

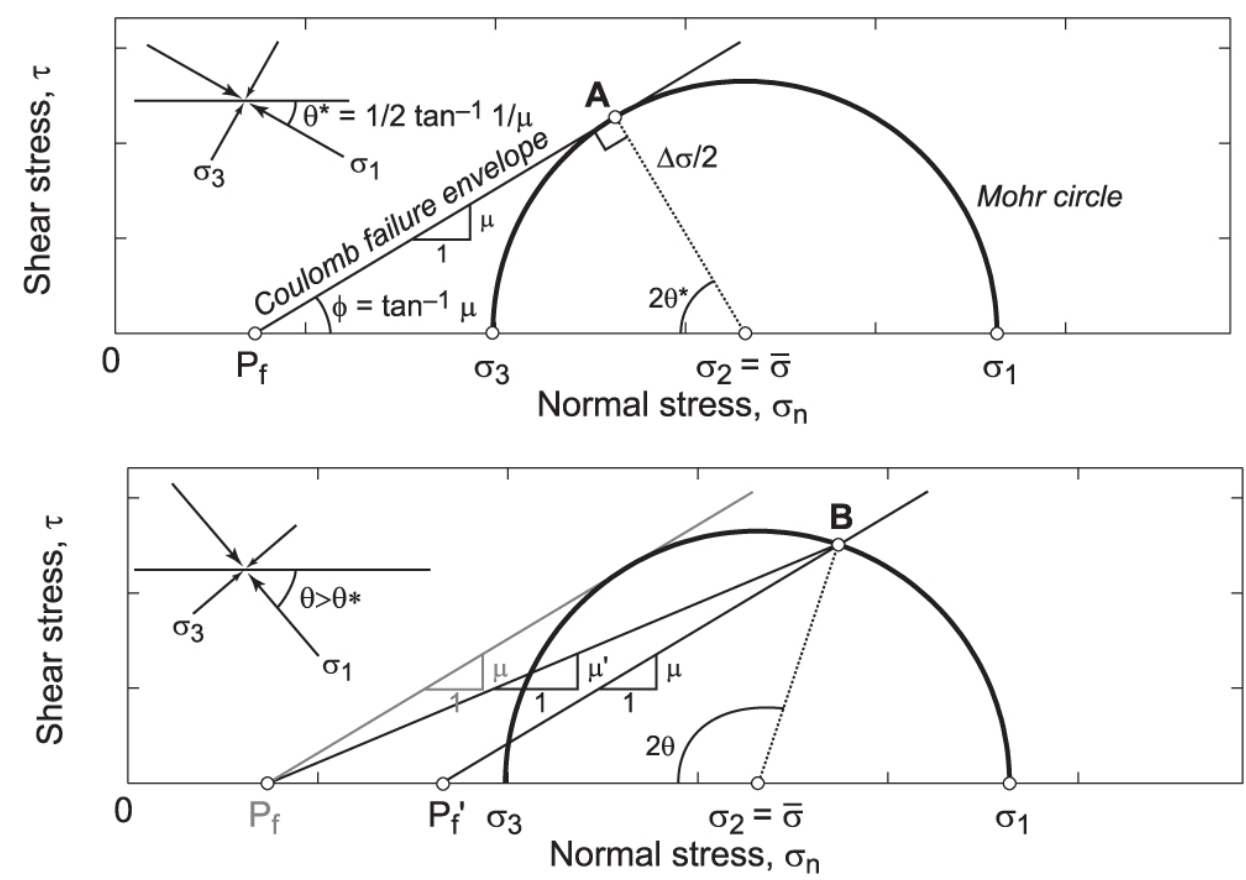

Figure 2.3. Figure 1 of Townend (2006) illustrating the Coulomb frictional failure criterion (equation 2.44) and the angle under which failure occurs using a Mohr circle. (a) New faults form at an angle $\theta^{\circ}$ to the maximum horizontal compressive stress $\sigma_{1}$ whereas (b) preexisting faults can be reactivated at a different angle $\theta>\theta^{\circ}$ in the case of reduced friction $\mu^{\prime}<\mu$ or increased pore-fluid pressure $\mathrm{P}_{\mathrm{f}}$.

In the tensile field $\sigma<0$ (extensional stress), the failure envelope is given by the Griffith failure criterion

$$
\tau^{2}=4 \mathrm{~T}_{0} \sigma_{\mathrm{n}}+\mathrm{T}_{0}
$$

The tensile strength of rock is in the order of 1-4 MPa, about ten to hundred times lower than compressional strength. Tensile failure is possible at shallow depths (small confining pressures which allows tensile cracks to open; e.g. Frohlich 1994) or high fluid pressures (usually near-lithostatic; e.g. Sibson 1994). 


\section{Data analysis}

\subsection{Travel-time residuals and weighting}

Outliers in the travel-time residuals can significantly affect an earthquake's estimated location if they are not downweighted, as demonstrated by Gomberg et al. (1990). This is because the location program attempts to fit all observed travel-times with the same weight equally well, so the effect of one outlier is distributed amongst the travel-time residuals of all other stations, shifting the hypocentre location away from its true position. Weighting of the travel-time residuals by the data analyst, as implemented in many location programs is important, but outliers are seldom recognised as such during the phase identification and weighting process. Anderson (1982) described the problem as follows: “... a good location cannot be determined until outliers have been identified, and outliers cannot be identified until a good location has been determined". Nevertheless, outliers can be identified and corrected for when all the travel-time residuals at one station are compared. Therefore, the analysis of the travel-time residuals at each station helps to identify mispicked phases, inaccuracies in the assumed velocity model and unstable hypocentre locations. Moreover, the residual analysis can be used to derive a reliable, objective weighting procedure.

\subsubsection{Travel-time residual analysis}

The travel-time residual analysis was first performed for events recorded by the SAMBA network between 24 March 2009 and 31 December 2009 (Fig. 3.1). This analysis was later repeated for earthquakes recorded by the DFDP10 array between 1 January 2010 and 31 April 2010.

Assuming that, on average, phases are correctly picked, the mean and the standard deviation of the travel-time residuals of all events at one station can be used to find outliers and trends in the dataset (Fig. G.1 (a) and (b) for the combined GeoNet and SAMBA stations and (c) and (d) for the DFDP10 network). Events with large residuals ( $\geq 2$ standard 
deviations) were double-checked.

Deviations of the mean of the travel-time residuals for one station from zero reflect inaccuracies in the applied 1-D velocity model. For example, the negative mean values for stations WHAT, COVA and WVZ (Fig. 3.2 a) show that calculated arrival times are on average greater than the observed arrival times, and thus that the velocity model is too slow. Since these three stations are located close to the Alpine Fault at either end of the combined SAMBA/GeoNet network, the seismic waves have the longest paths along the strike of the Alpine Fault. These negative residuals could, for example, indicate anisotropy with increased velocities parallel to the Alpine Fault. Mean positive residuals are observed for station POCR and ONE (Fig. 3.2 (a) and (b)), which are both situated in sediment-filled valleys. As the velocity model assumes bedrock at the surface, the velocity model is too fast in these cases. Assuming consolidated sediments at shallow depths with velocities of $\mathrm{V}_{\mathrm{P}}=2.2-2.7 \mathrm{~km} / \mathrm{s}$ (Davey 2010), the mean travel-time residual of $0.17 \mathrm{~s}$ for P-waves at POCR can be used to estimate the thickness of the sediment layer. For vertical incidence at the station, the estimated thickness of sediments $d=\Delta t\left(v_{\text {bedrock }}-v_{\text {sediments }}\right)$ is $500-600 \mathrm{~m}$ beneath POCR. This range is slightly larger than the 320-450 m obtained in Section 1.4.3 from the resonance frequency. However, the lower range may reflect the fraction of less consolidated sediments from the total sediment thickness. An equivalent calculation for station ONE suggests sediment thicknesses of 2.1-2.5 km. For comparison, Davey (2010) obtained a $2.5-3 \mathrm{~km}$-thick sediment cover in the coastal plain of the Whataroa valley from refraction/wide-angle reflection data. Onshore drillholes Harihari-1 (Sircombe and Kamp 1998) and Waiho-1 (Sutherland 1996) closer to the coast recorded $2.5 \mathrm{~km}$ and $3.6 \mathrm{~km}$, respectively, of sediments above basement. The average basement depth northeast of the South Westland Fault Zone is about 3 km (Sircombe and Kamp 1998).

Assuming that the majority of the earthquakes are well located and few outliers bias the travel-time residuals, the standard deviation of the travel-time residuals at one station reflects the typical reading uncertainty. A comparison of the travel-time residuals for impulsive and emergent P- and S-waves (Table 3.2) at all stations shows that for the majority of stations

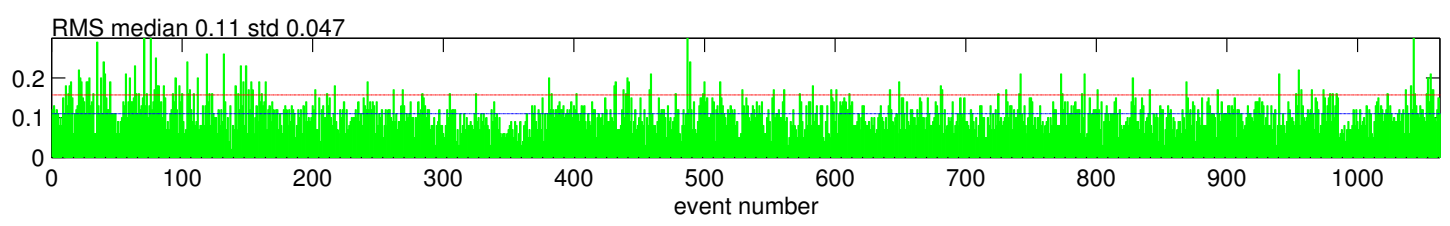

Figure 3.1. RMS residual of all events between 24 March 2009 and 31 December 2009 versus event number with its mean (blue) and standard deviation (red). 
FRAN P

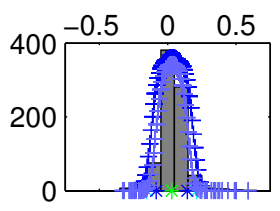

REYN P

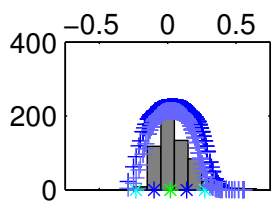

WHAT P

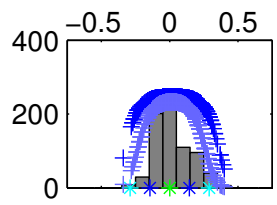

LABE $P$

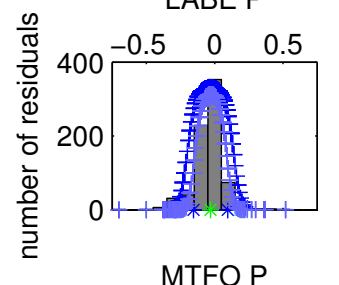

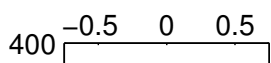

200

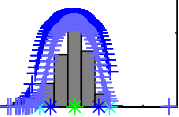

EORO P

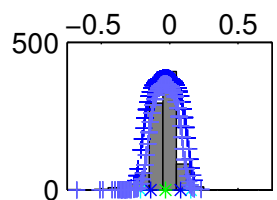

COSA P

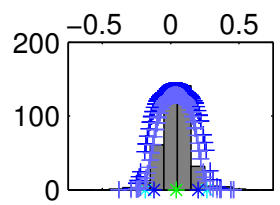

travel-time residual (s)

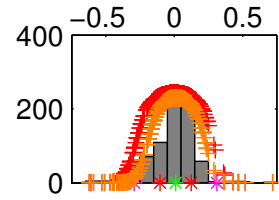

S

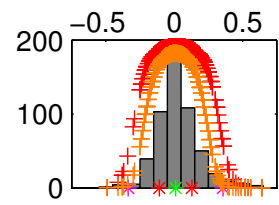

$\mathrm{S}$

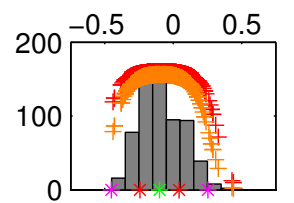

S

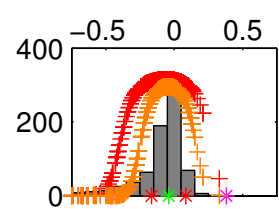

S

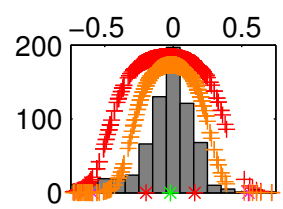

$\mathrm{S}$

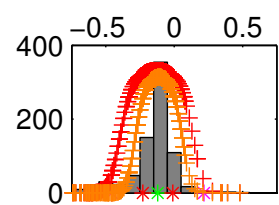

S

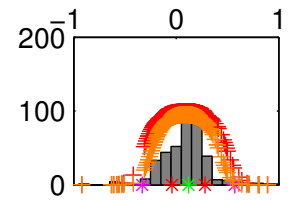

POCR P

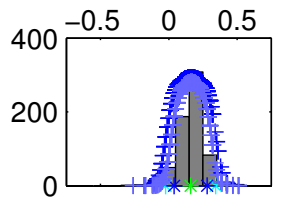

WHYM P

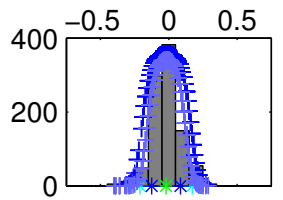

GOVA P

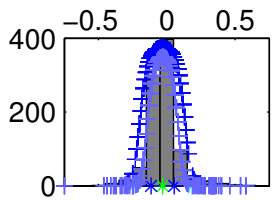

COVA P

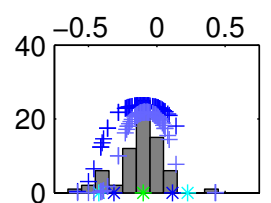

FOZ P

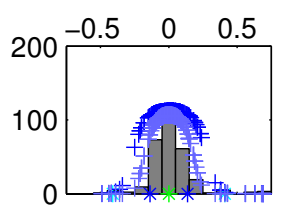

RPZ P

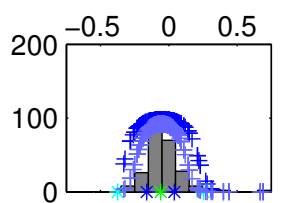

WVZ P

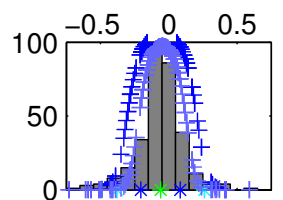

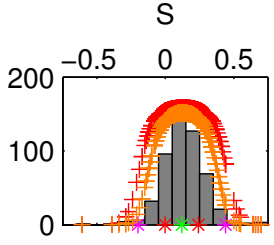

S

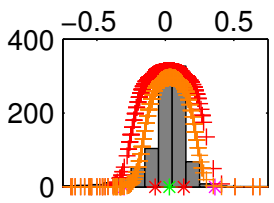

S

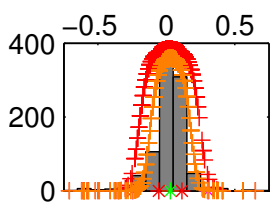

$S$

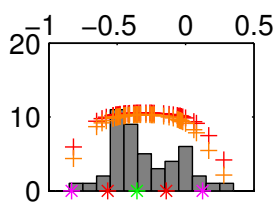

S

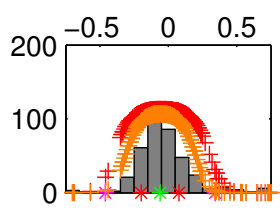

$\mathrm{S}$

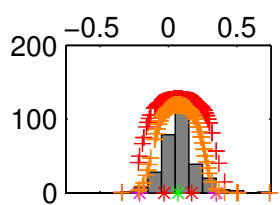

$\mathrm{S}$

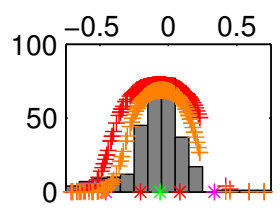

travel-time residual (s) travel-time residual (s) travel-time residual (s)

Figure 3.2. (a) Histograms of the residuals of SAMBA stations for the period November 2008 to December 2009. Note the different time-scales for the stations COSA and COVA. See Fig. 3.2 (b) for explanations of the symbols. 

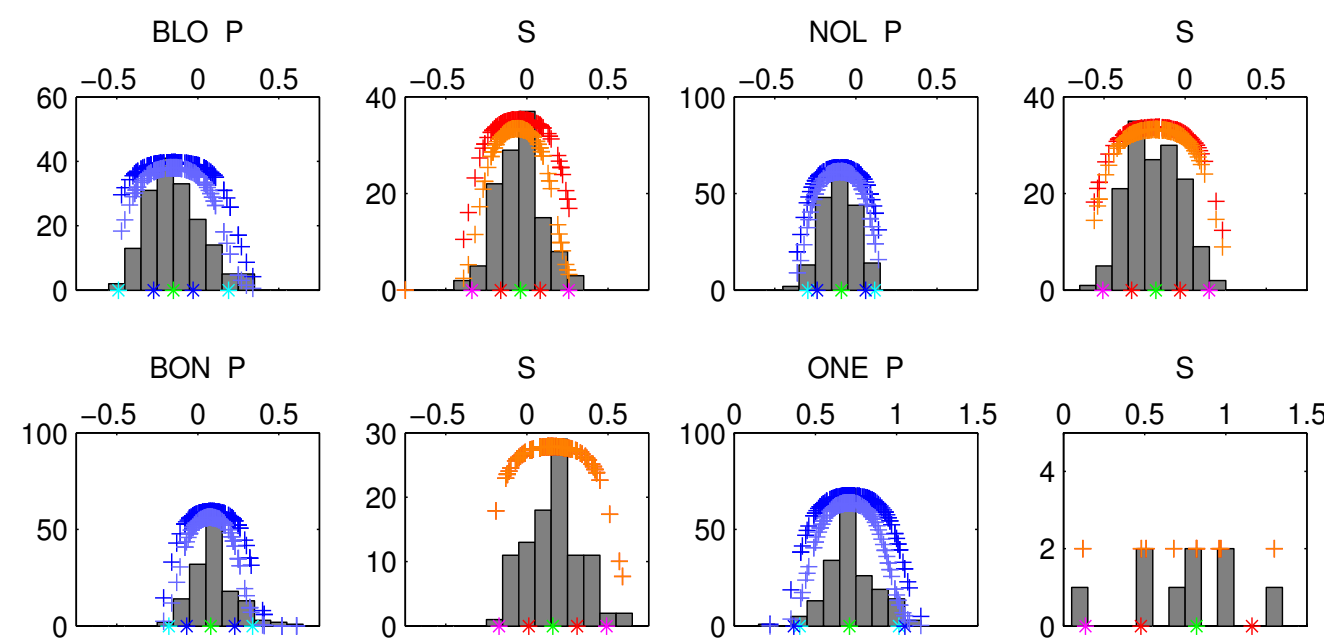

ONE P

S
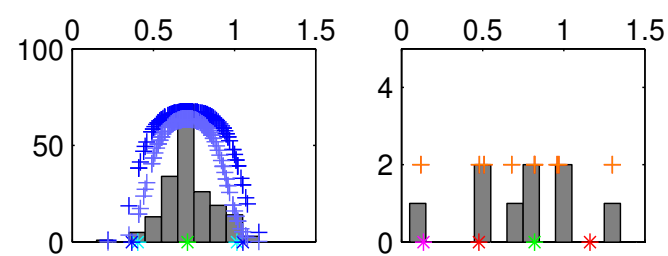

DRC P
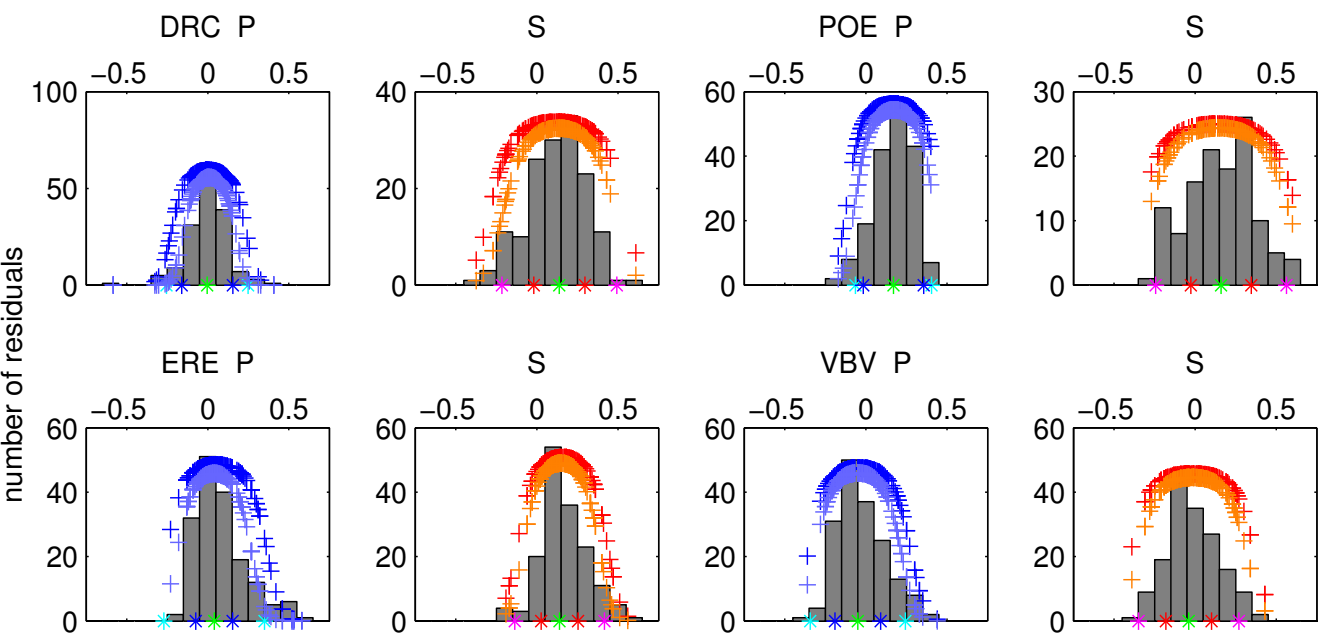

GCK P

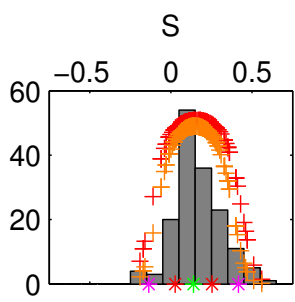

VBV P
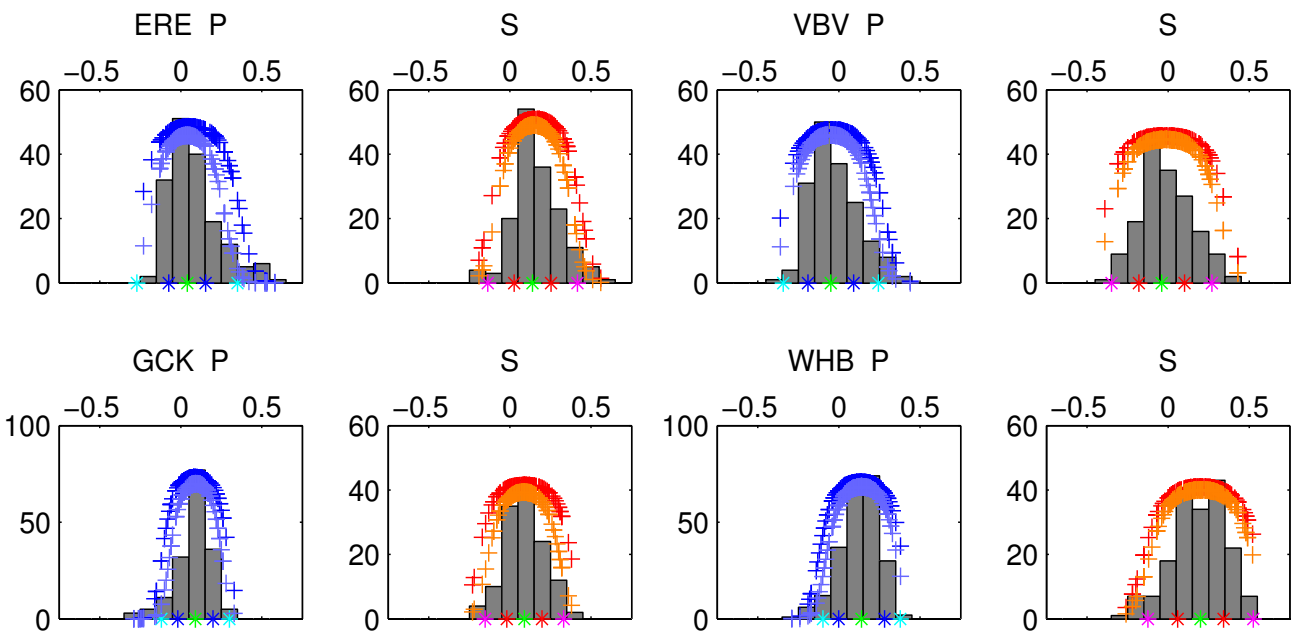

WHB P
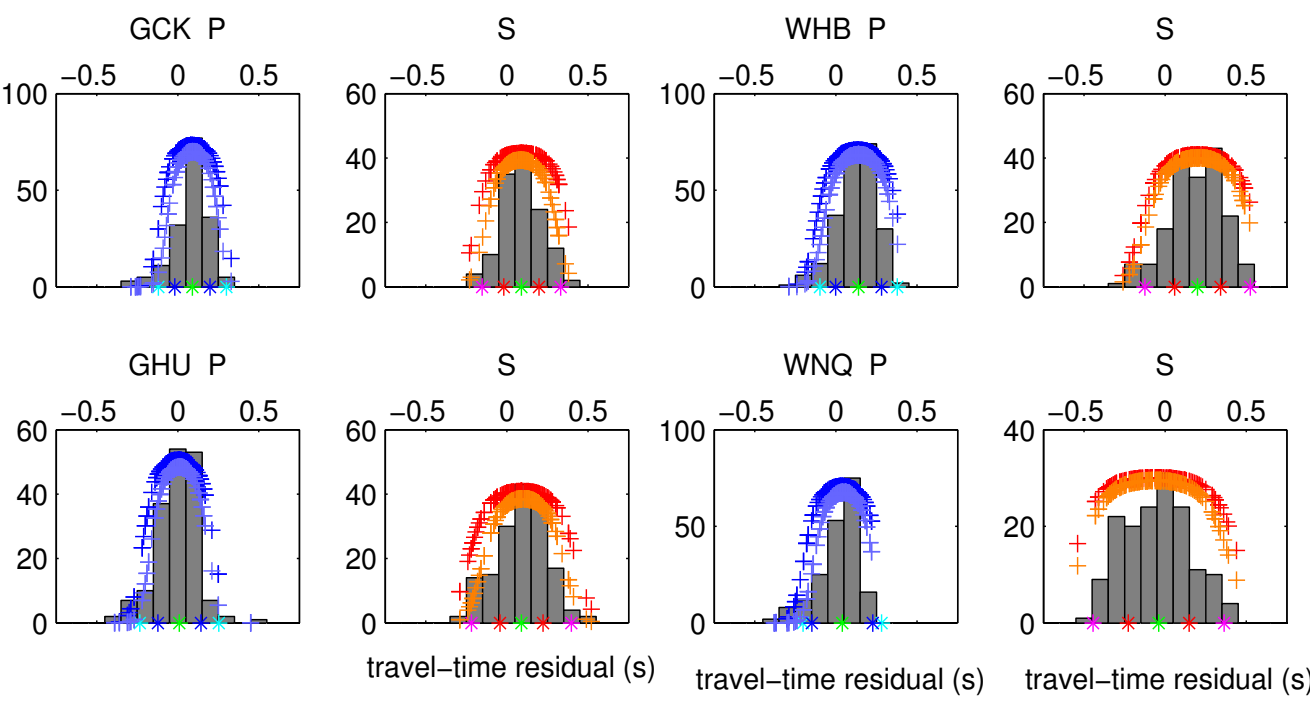

travel-time residual (s)

Figure 3.2. (b) Histograms of the residuals as in (a) for DFDP10 stations for the period January 2010 to April 2010. Note the different time-scale for station ONE which has a large delay. Blue and red crosses indicate the values of Jeffreys' weighting functions for P- and $\mathrm{S}$-waves as calculated according to equation 2.13 for the first iteration described in the text, light blue and orange crosses are used accordingly for the second iteration. 
the standard deviations for different phase onsets are similar. Consequently, impulsive and emergent phase arrivals can be treated as one population. However, the stations themselves do not have common variances. This means, Jeffreys' weighting function (Jeffreys 1973, equation 2.13) cannot be used on the collected residuals, since the weight for a particular residual is determined by the width of the initial residual distribution at each station. If two stations have the same percentage of outliers but not the same variances and Jeffreys' weighting is applied (equation 2.13), travel-time residuals at the station with the smaller variance contribute less to the location due to larger weights (although deviations from the mean value are smaller) than those at the other station exhibiting greater spread of the travel-time residuals. For the SAMBA stations, this was observed for the S-phase residuals at station WHYM $\left(\sigma_{S}=0.084 \mathrm{~s}\right)$, which is located close to the majority of the events. The assigned weights to the residuals were systematically higher than at station MTFO $\left(\sigma_{S}=0.132 \mathrm{~s}\right)$. This results in increased depth uncertainties, because the depth is particularly constrained by those stations near the hypocentre. For this reason, Jeffreys' weighting has to be modified to obtain a more consistent weighting scheme.

\subsubsection{Weighting of the travel-time residuals}

Jeffreys' intent in deriving the weighting scheme was to exclude those travel-time residuals in the tails of the weighting function (residuals that would contribute less than $5 \%$ in the location process), which is reasonable and can be consistently used for every station. To determine the number of outliers $\mu_{0}$ and the standard deviation without outliers $\sigma_{0}$ required for Jeffreys' weighting, the following procedure is applied. First the mean and standard deviation of the travel-time residuals (including extreme values) and the number of outliers, defined as those values greater than two standard deviations of all travel-time residuals, are determined. Then the mean and standard deviation are recalculated excluding the outliers (1st iteration). These values are used to recalculate the number of outliers. In the second iteration the new number of outliers are removed from the travel-time residuals and the final values $\mu_{0}$ and $\sigma_{0}$ are determined (mean and standard deviation of population without extreme values after two iterations; Table 3.1 (a) and (b)). These values are used to weight all residuals.

The new systematic weighting procedure implemented in the location process weights phases according to their deviation from the mean of all travel-time residuals and downweights outliers determined with Jeffreys' weighting. A weight of $75 \%$ was applied to residuals deviating from the mean travel-time residual by more than $0.1 \mathrm{~s}$ but less than $0.2 \mathrm{~s}$. Half the weight (50\%) was assigned to residuals differing from the mean by $\geq 0.2 \mathrm{~s} ; 25 \%$ to residuals $\geq 0.4 \mathrm{~s}$, 


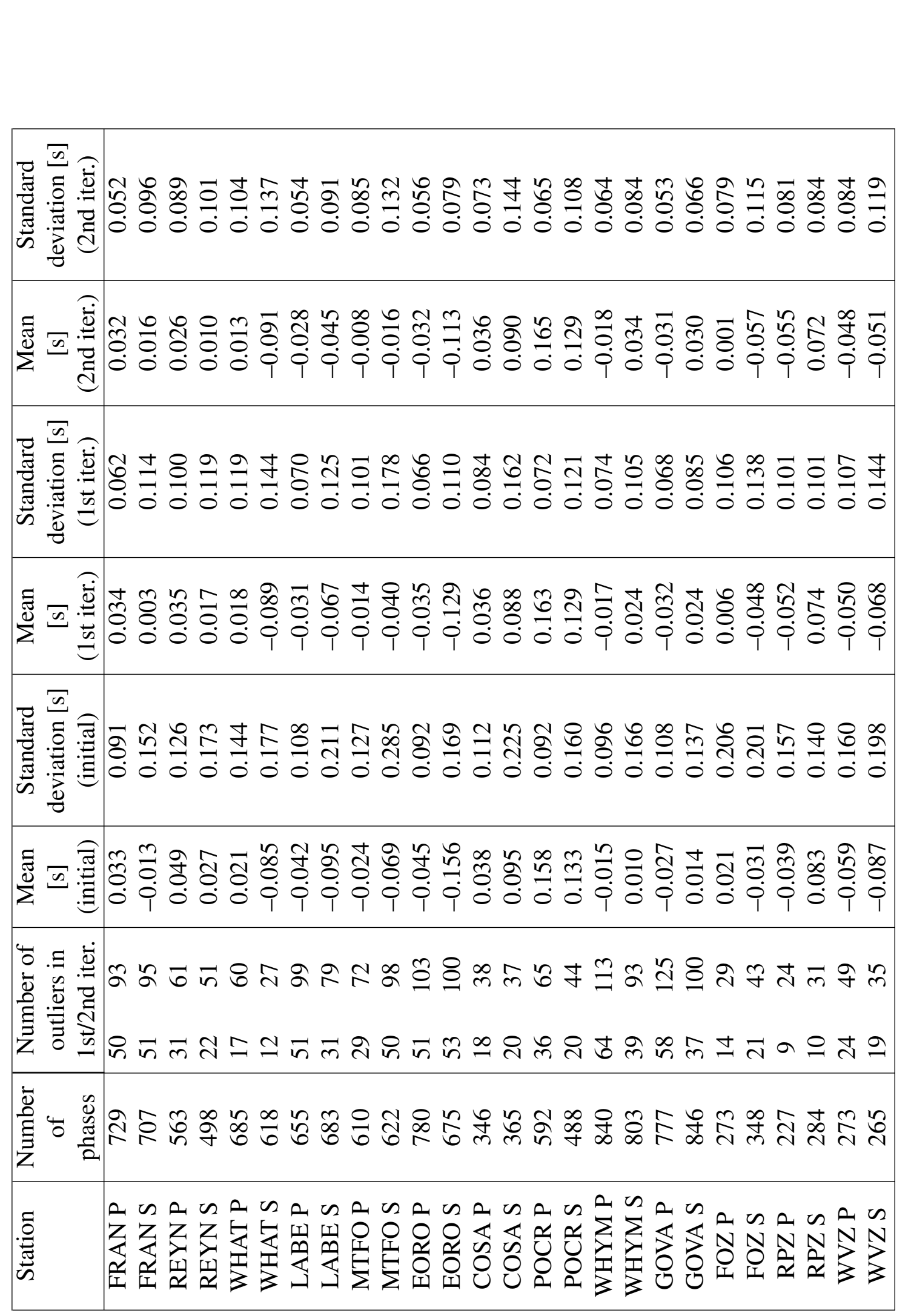




\begin{tabular}{|c|c|}
\hline 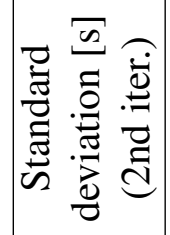 & 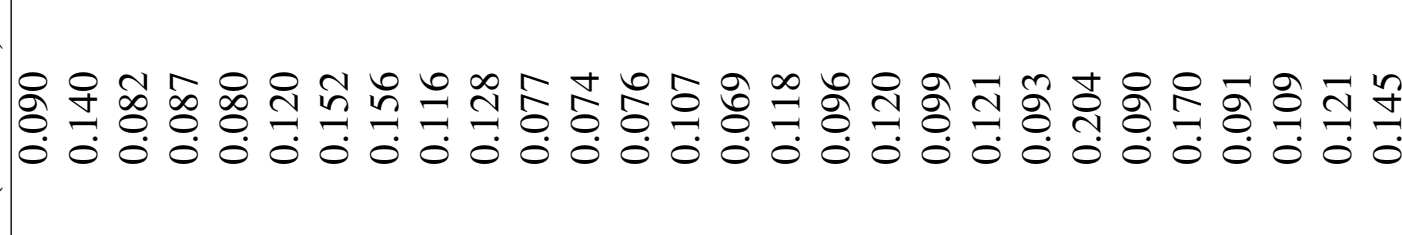 \\
\hline 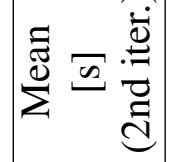 & 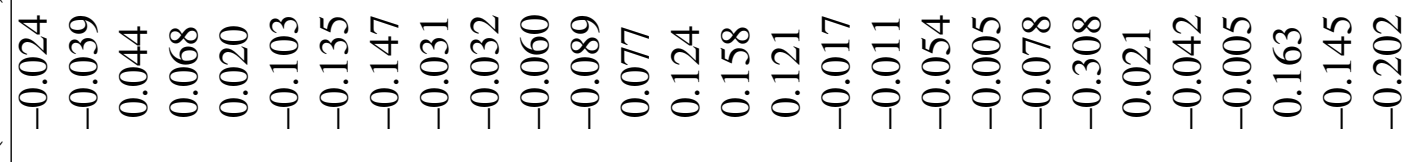 \\
\hline 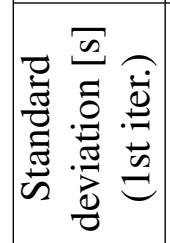 & 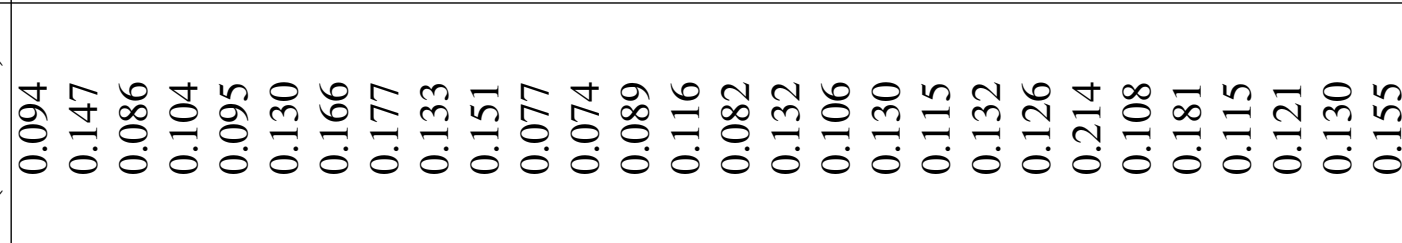 \\
\hline 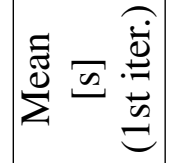 & 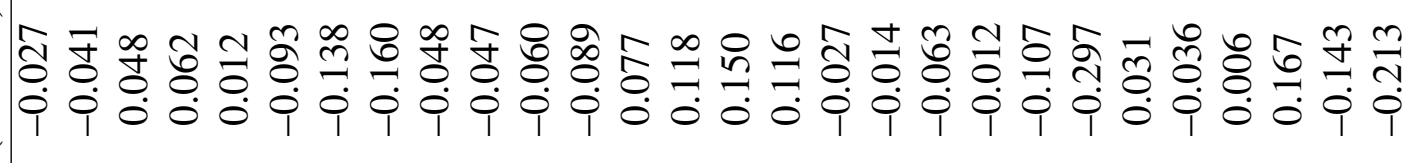 \\
\hline 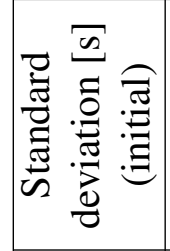 & 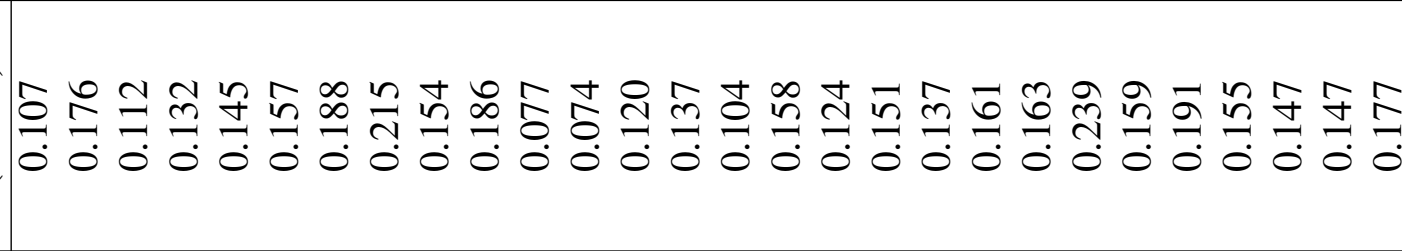 \\
\hline 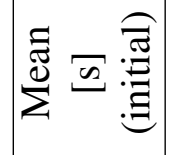 & 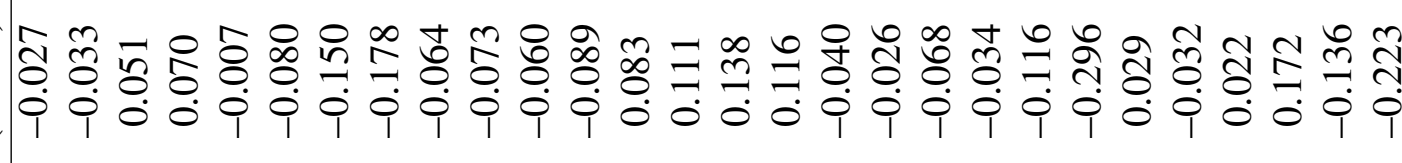 \\
\hline 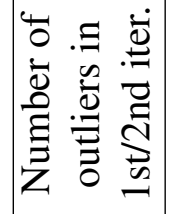 & 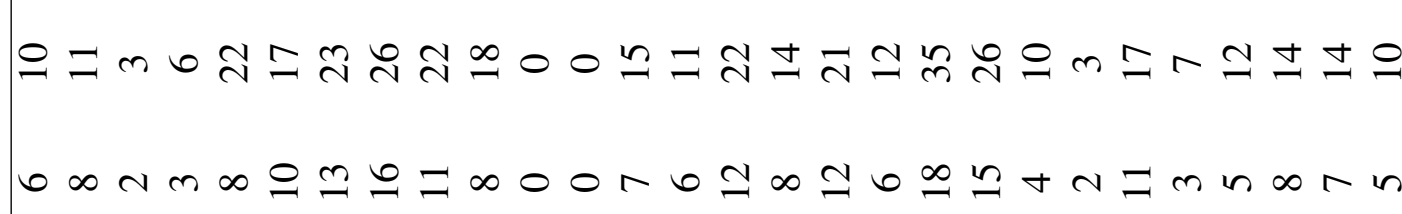 \\
\hline 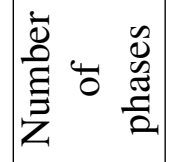 & 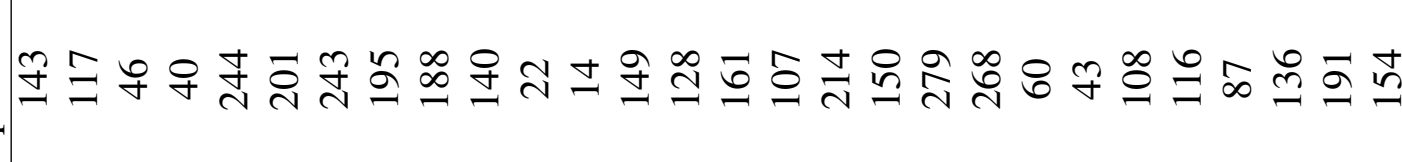 \\
\hline 菍 & 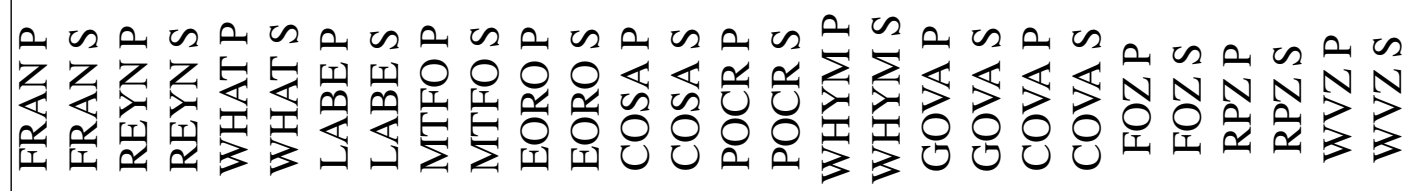 \\
\hline
\end{tabular}


and $0 \%$ for $\geq 0.8 \mathrm{~s}$ (summarised in Table 3.3 ).

\begin{tabular}{|lrrrrrrrr|}
\hline Station & $\mu_{\mathrm{IP}} \pm \sigma_{\mathrm{IP}}$ & $\mu_{\mathrm{EP}} \pm \sigma_{\mathrm{EP}}$ & $\mu_{\mathrm{IS}} \pm \sigma_{\mathrm{IS}}$ & $\mu_{\mathrm{ES}} \pm \sigma_{\mathrm{ES}}$ & IP & EP & IS & ES \\
& {$[\mathrm{s}]$} & {$[\mathrm{s}]$} & {$[\mathrm{s}]$} & {$[\mathrm{s}]$} & & & & \\
\hline FRAN & $0.03 \pm 0.06$ & $0.04 \pm 0.09$ & $0.02 \pm 0.11$ & $-0.01 \pm 0.15$ & 421 & 401 & 315 & 471 \\
REYN & $0.11 \pm 0.08$ & $0.04 \pm 0.11$ & $-0.00 \pm 0.09$ & $0.01 \pm 0.11$ & 8 & 610 & 88 & 446 \\
WHAT & $0.02 \pm 0.13$ & $0.02 \pm 0.15$ & $-0.10 \pm 0.18$ & $-0.07 \pm 0.18$ & 419 & 330 & 185 & 449 \\
LABE & $-0.03 \pm 0.07$ & $-0.04 \pm 0.14$ & $-0.06 \pm 0.16$ & $-0.06 \pm 0.13$ & 522 & 232 & 460 & 278 \\
MTFO & $-0.02 \pm 0.10$ & $-0.00 \pm 0.11$ & $-0.01 \pm 0.16$ & $-0.04 \pm 0.19$ & 322 & 357 & 177 & 507 \\
EORO & $-0.03 \pm 0.07$ & $-0.04 \pm 0.08$ & $-0.10 \pm 0.08$ & $-0.13 \pm 0.12$ & 406 & 478 & 245 & 479 \\
COSA & $0.03 \pm 0.12$ & $0.04 \pm 0.09$ & $0.16 \pm 0.15$ & $0.13 \pm 0.93$ & 75 & 304 & 67 & 331 \\
POCR & $0.16 \pm 0.09$ & $0.16 \pm 0.09$ & $0.14 \pm 0.25$ & $0.12 \pm 0.14$ & 345 & 313 & 71 & 444 \\
WHYM & $-0.01 \pm 0.08$ & $-0.00 \pm 0.11$ & $0.01 \pm 0.10$ & $0.02 \pm 0.12$ & 671 & 288 & 358 & 529 \\
GOVA & $-0.03 \pm 0.08$ & $-0.00 \pm 0.10$ & $0.03 \pm 0.08$ & $0.01 \pm 0.31$ & 699 & 195 & 614 & 333 \\
FOZ & $0.01 \pm 0.10$ & $0.01 \pm 0.10$ & $-0.02 \pm 0.18$ & $-0.04 \pm 0.16$ & 96 & 200 & 108 & 267 \\
RPZ & $-0.06 \pm 0.09$ & $-0.04 \pm 0.11$ & $0.04 \pm 0.09$ & $0.05 \pm 0.10$ & 130 & 117 & 156 & 152 \\
WVZ & $-0.08 \pm 0.14$ & $-0.08 \pm 0.14$ & $-0.05 \pm 0.12$ & $-0.13 \pm 0.22$ & 236 & 84 & 196 & 88 \\
\hline
\end{tabular}

Table 3.2. Post-weighting mean and standard deviations of the travel-time residuals for impulsive and emergent P- and S-phase arrival-times for all stations. The mean $\mu$ represents the model-error $\sigma^{\text {model }}$ of the 1-D velocity model for one station. The standard deviation $\sigma$ indicates the mean reading error $\sigma^{\text {reading }}$. The numbers give total numbers of $\mathrm{P}$ - and $\mathrm{S}$-phases recorded at the station.

\begin{tabular}{|ccc|}
\hline Weight & Contribution & Absolute deviation from the mean $[\mathrm{s}]$ \\
\hline 0 & $100 \%$ & $<0.1$ \\
1 & $75 \%$ & $\geq 0.1$ \\
2 & $50 \%$ & $\geq 0.2$ \\
3 & $25 \%$ & $\geq 0.4$ \\
4 & $0 \%$ & $\geq 0.8$ \\
\hline
\end{tabular}

Table 3.3. Weight assigned to the observed phase arrival-time according to its deviation from the mean phase arrival time at each station.

Figure 3.3 shows the final weights applied to P- and S-phases for all events between November 2008 and April 2010. Few phases are omitted entirely (weight=4) at each station, and the the majority of phases have a full weight (weight=0). P-picks seldom have a weight larger than 2, however some S-phases (especially at stations MTFO, REYN and POCR) were assigned with only half or less than the full weight. 

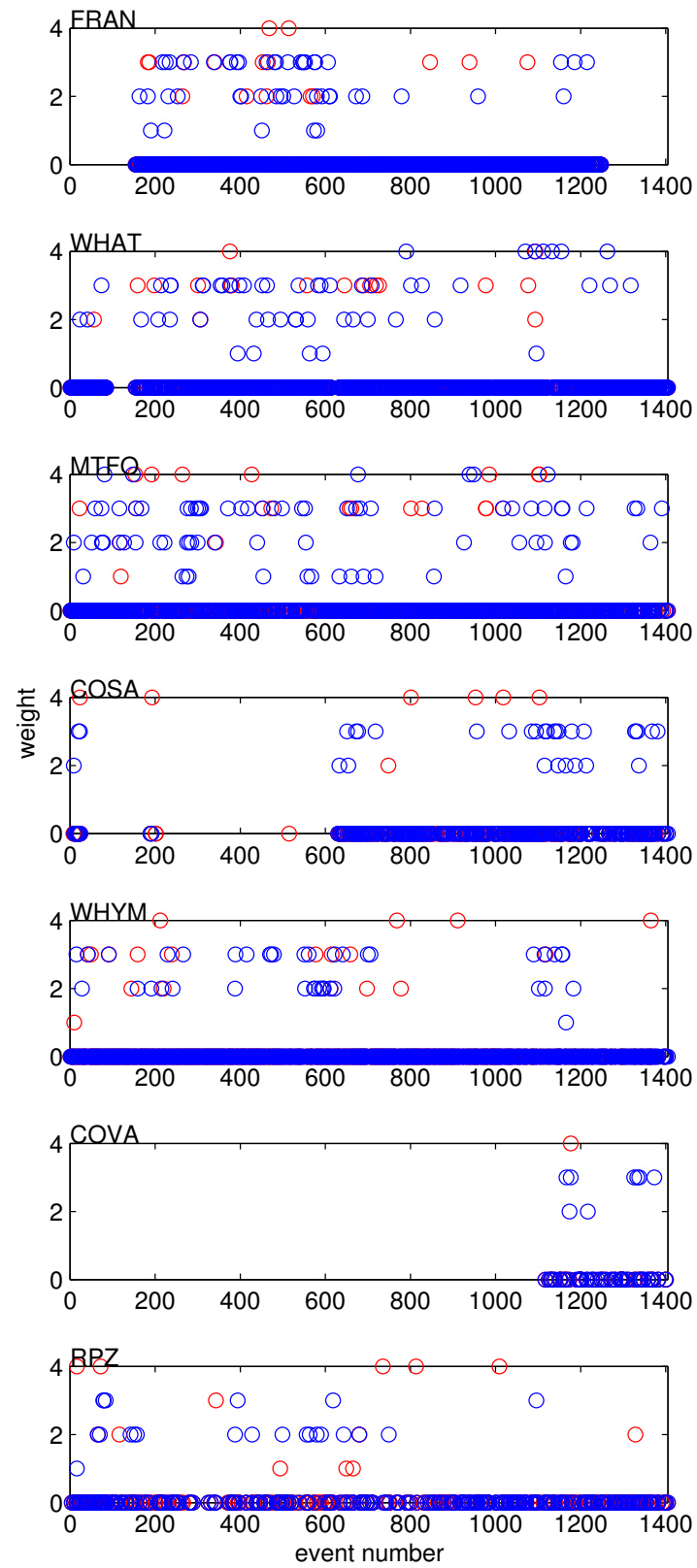
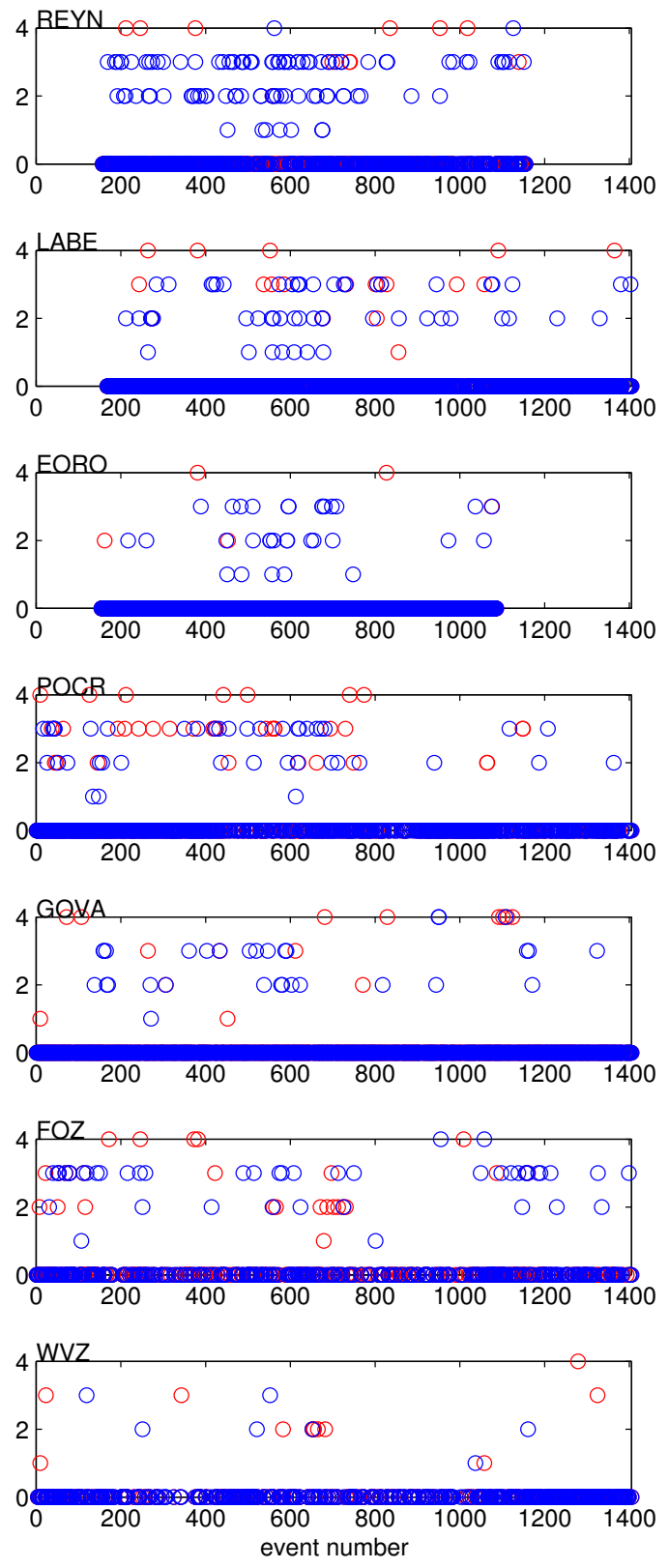

Figure 3.3. (a) Overview of weights assigned to $P$ (blue) and $S$ (red) phases for the SAMBA stations with the number of outliers listed in Table 3.1 (a) and (b) 

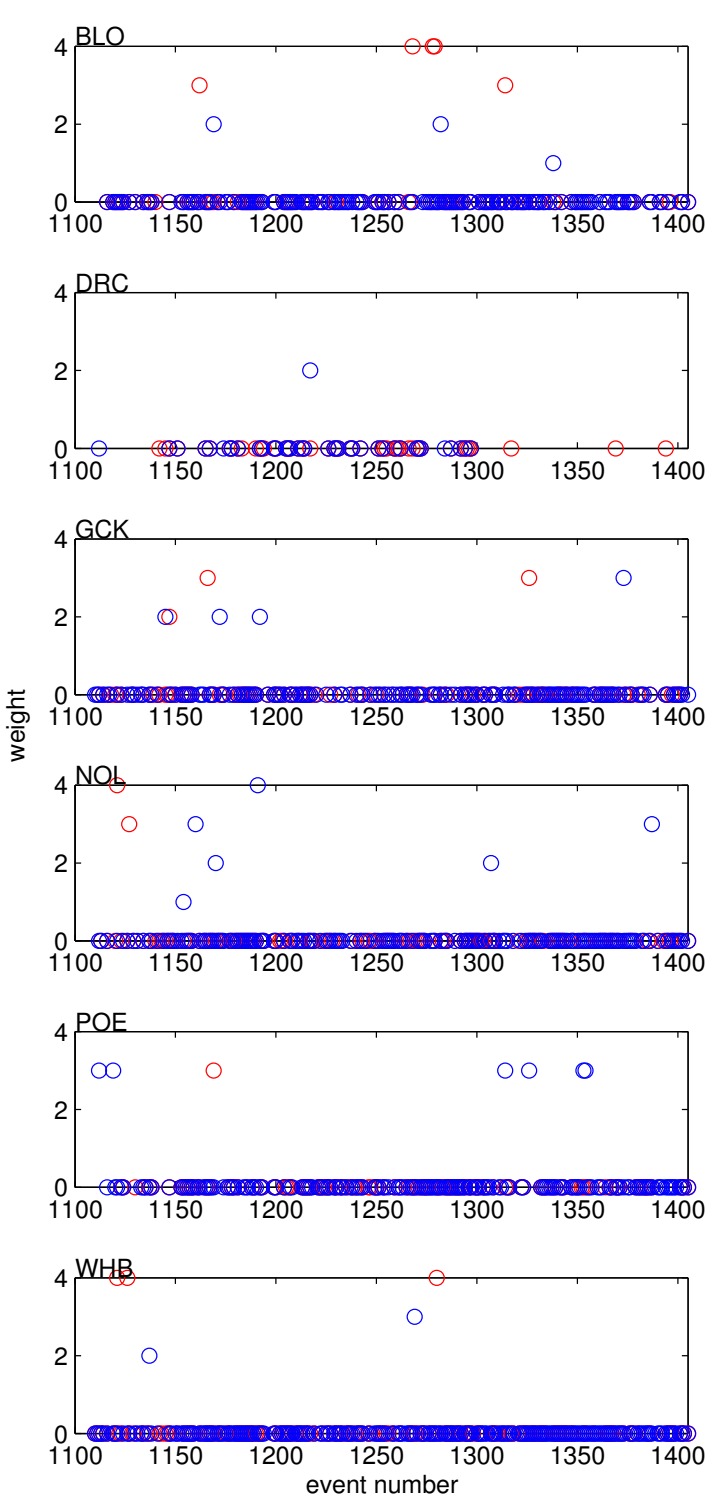
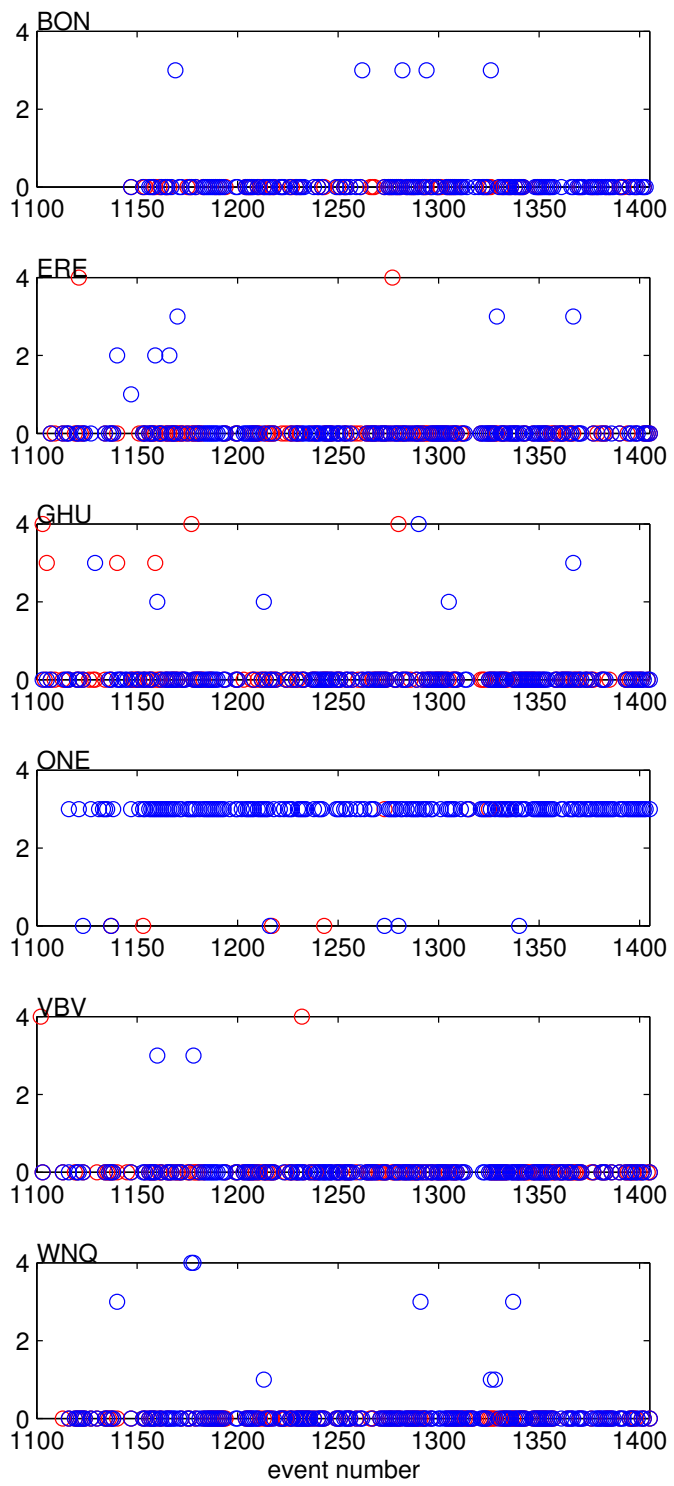

Figure 3.3. (b) Overview of weights assigned to $\mathrm{P}$ (blue) and $\mathrm{S}$ (red) phases for the DFDP10 stations applying the weighting scheme (Table 3.3). Note that the DFDP10 stations operated only for the last few months of the time analysed. 


\subsubsection{Time corrections of residuals for station COSA}

During a 77-day period between 25 June and 10 September 2009, station COSA near Cook's Saddle lost satellite contact, resulting in GPS clock uncertainties. Several metres of gravel (from a landslide nearby) had been dumped on top of the sensor and buried the GPS antenna approximately $20 \mathrm{~cm}$ deep. During this interval, no signal from the GPS satellites was received, resulting in missing time stamps from the external clock and the internal data logger clock began to drift. The uncorrected travel-time residuals are shown in Fig. 3.4 (a).

The uncorrected travel-time residuals show a systematic pattern. The total accumulated time difference between the internal Reftek clock and the external GPS clock for the 77-day period was $26 \mathrm{~s}$. A linear drift correction (blue crosses in Fig. 3.4 b) does not fully account for the differences as shown in (c): the linear correction introduces systematic bias to events within one group with the same clock differences (e.g. events 776 to 825 in (a) and (c). Applying the same correction value to selected groups of events results in a step function as shown by the black line in (d). The same correction was applied to the S-phase (green line in d) when no P-phase could be identified for the same event. If a P-phase exists, the location program HYPOCENTER (Lienert et al. 1986) used within SEISAN automatically corrects the S-phase. These corrections produce a normal distribution of the reduced travel-time residuals as shown in Fig. 3.4 (e) (cf. Fig. 3.2), which can be treated with the weighting scheme as described in Section 3.1.2. This observation implies that the clock drift of the Reftek data loggers (at least the 915x-series units used in this study) occurs in discrete pulses rather than continuously as assumed when using a linear drift correction. These pulses may be related to large temperature changes, but more observations would be needed to clarify the cause.

\subsubsection{Time corrections of residuals for station DRC}

DFDP10 station DRC lost satellite contact between Julian days 042 and 117 of 2010 (14 March-27 April). However, no apparent drift can be detected from the distribution of the residuals before the station service on day 074. During the servicing, the GPS problem was noted but could not be fixed. After Julian day 074, a constant time delay of $24.878 \mathrm{~s}$ was determined which persisted until day 117 on which satellite contact was reestablished and a time difference of $24 \mathrm{~s}$ between internal and external GPS clock was recorded by the Reftek. 


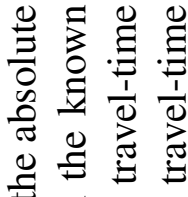

고용

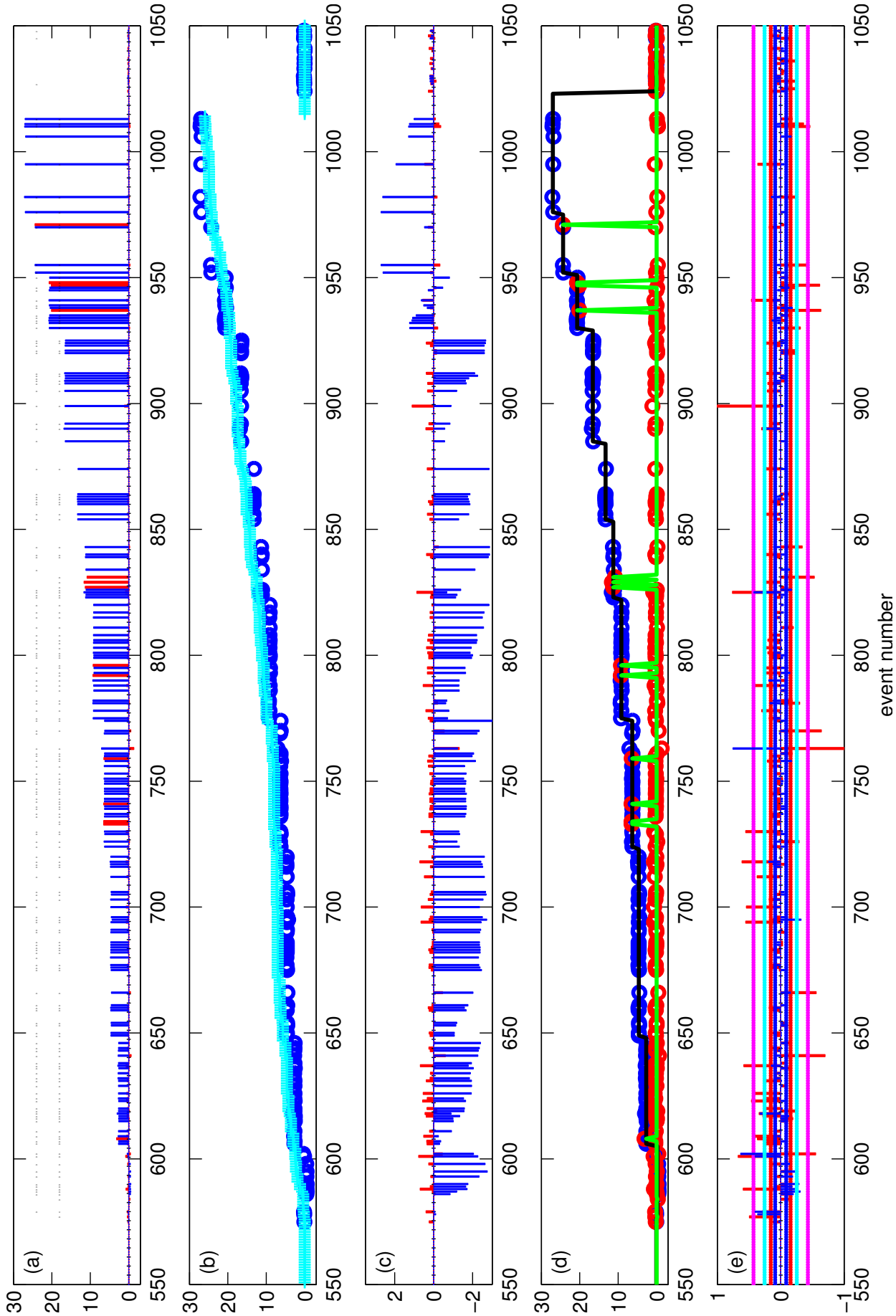

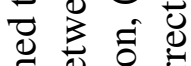
.50 00

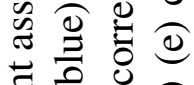
.0. 흐

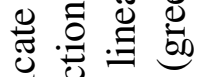
.尹

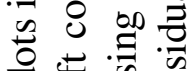
$\frac{0}{\exists} \stackrel{0}{=}$ y 0 is

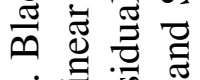
过卷 胥 $\Xi \Xi$

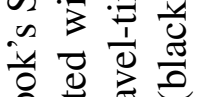
论 总 氜造 $\Xi$ \% 虫苞 ○ 仓 훙

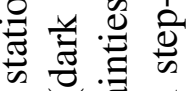

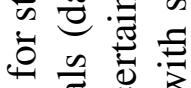
疍 胥导 矛 눈은

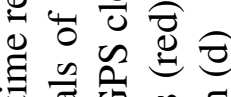

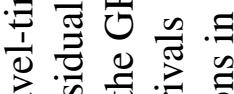

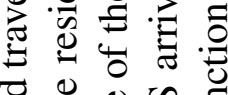
可屺导

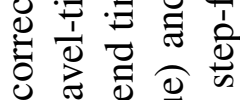

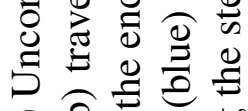
(s) ןenpısәג әщ!!-|әлеג

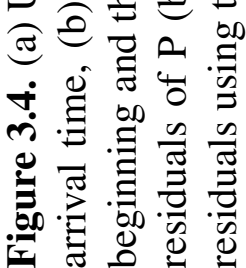




\subsubsection{Station terms from the residuals}

Figure 3.5 shows the average travel-time residuals (also called the station terms) of all stations that result from using the velocity model in Table 1.2. The majority of the station terms on the western side of the Alpine Fault and those on the eastern side close to the fault show positive average travel-time residuals. Those stations distributed within the "High" Alps have negative station terms on average. This systematic difference reflects lower velocities of the sediment-filled plains west of and within the damage zone of the Alpine Fault and higher velocities for the bedrock with little sediment cover in the Southern Alps. A tomographic inversion to resolve these differences in the velocity model is performed in Section 6.3.

\section{$\mathrm{X}(\mathrm{km})$}

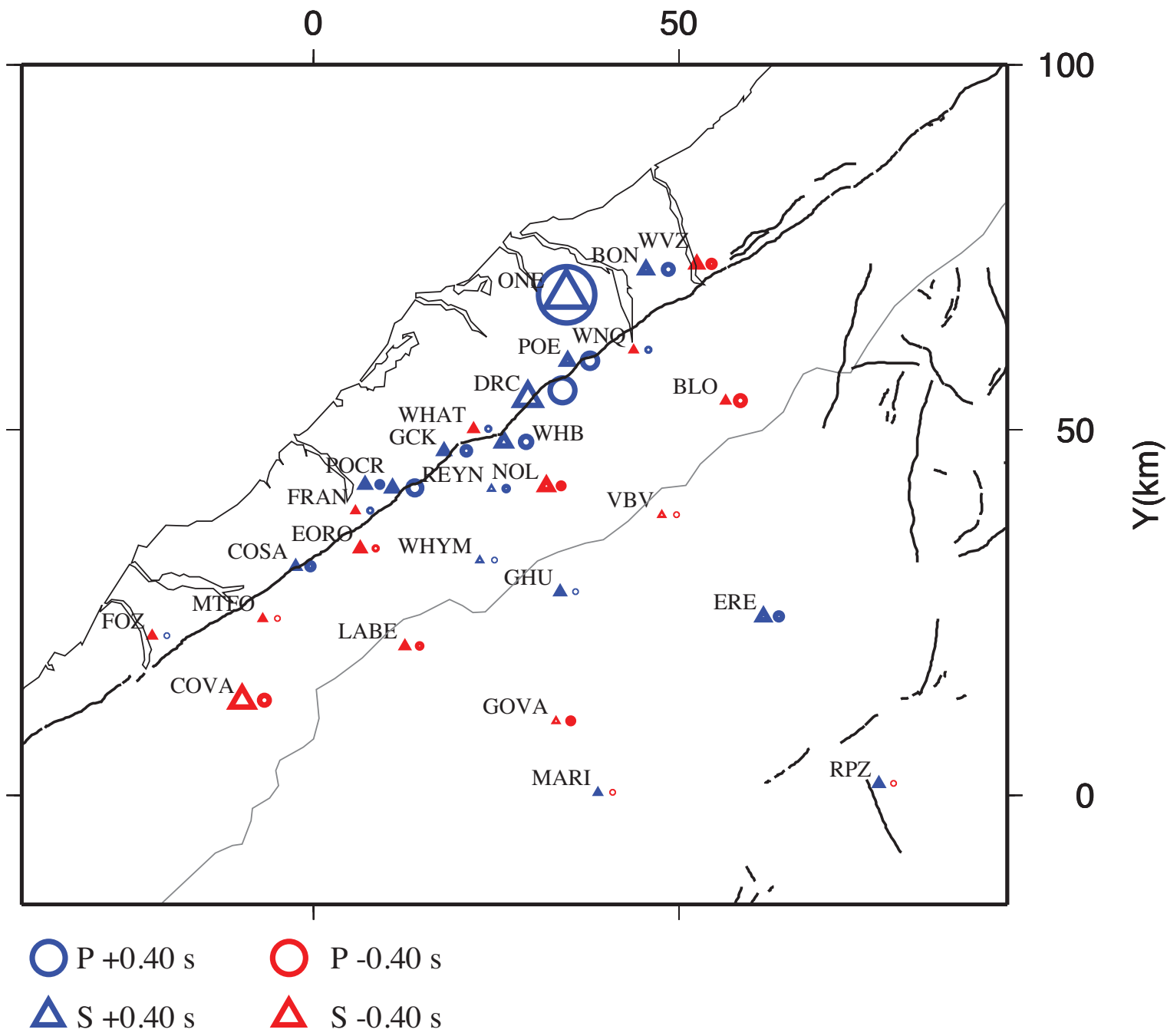

Figure 3.5. Station residuals for $\mathrm{P}$ - (circle) and $\mathrm{S}$-waves (triangles) as determined using NonLinLoc for all events recorded between November 2008 and April 2010. 


\subsection{A local magnitude scale for the Southern Alps}

\subsubsection{Geometrical spreading and attenuation parameter}

In routine, New Zealand-wide magnitude determination performed by GeoNet, an attenuation coefficient of $\gamma=6.7 \times 10^{-3} \mathrm{~km}^{-1}$ is used. This standard value was derived by Robinson (1987) from 1552 local events between 1978 and 1985 of magnitude 1.6-5.2, and depths of $0.5-90.0 \mathrm{~km}$ that occurred in the Wellington region. There, the subduction zone interface lies at 20-25 km depth (Ansell and Bannister 1996), so most local earthquakes occur in the crust and the subducting slab. Seismic waves of the deep earthquakes cross the crust vertically and are therefore less attenuated than waves which propagate laterally in the crust. Station WEL in Wellington, which has been equipped with a Wood-Anderson seismometer since January 1931 serves as a reference station (Haines 1981). Station correction terms for the GeoNet stations are adjusted in such a way that the reference seismograph in Wellington would have a zero station correction term ${ }^{1}$.

If the standard attenuation term is used for magnitude calculations from the SAMBA data (according to equation 2.23) the majority of the magnitude residuals are positive for hypocentral distances larger than $80 \mathrm{~km}$ as shown in Fig. 3.6. For this reason, a new local magnitude scale for the central Southern Alps region has had to be derived. The magnitudes determined in this study are calibrated using magnitudes obtained by GeoNet (e.g. Ristau 2009). Magnitude estimates are available from GeoNet for a total of 147 earthquakes $\left(1.6 \leq \mathrm{M}_{\mathrm{L}} \leq 4.2\right)$, enabling the new required magnitudes to be related and compared to the existing magnitude scale. Figure 3.7 shows all amplitude readings at the SAMBA stations for the period November 2008 to December 2009 and the GeoNet magnitudes for events recorded by both networks. Amplitude-readings are obtained from half the peak-to-peak displacement on one of the horizontal components of a pseudo-WoodAnderson seismograph, simulated in SEISAN (version 8.2.1, October 2008, and 8.3, May 2010) (Havskov and Ottemöller 2000). It is assumed that the gain of the Wood-Anderson instrument is $2080 \pm 60$, as reported by Uhrhammer and Collins (1990).

All amplitudes of the SAMBA stations are first inverted for the geometrical spreading coefficient $\alpha$ (equation 2.16), ignoring the effects of attenuation (Fig. 3.8, top). The obtained value of $\alpha=1.7$ indicates that normal body-wave expansion proportional to $\mathrm{r}^{-1}$ prevails, but that attenuation has a non-negligible effect on the amplitude decay. In the

\footnotetext{
${ }^{1}$ Information obtained from http://www.geonet.org.nz/resources/earthquake/hypocentre-derivation.html, last accessed February 2012
} 

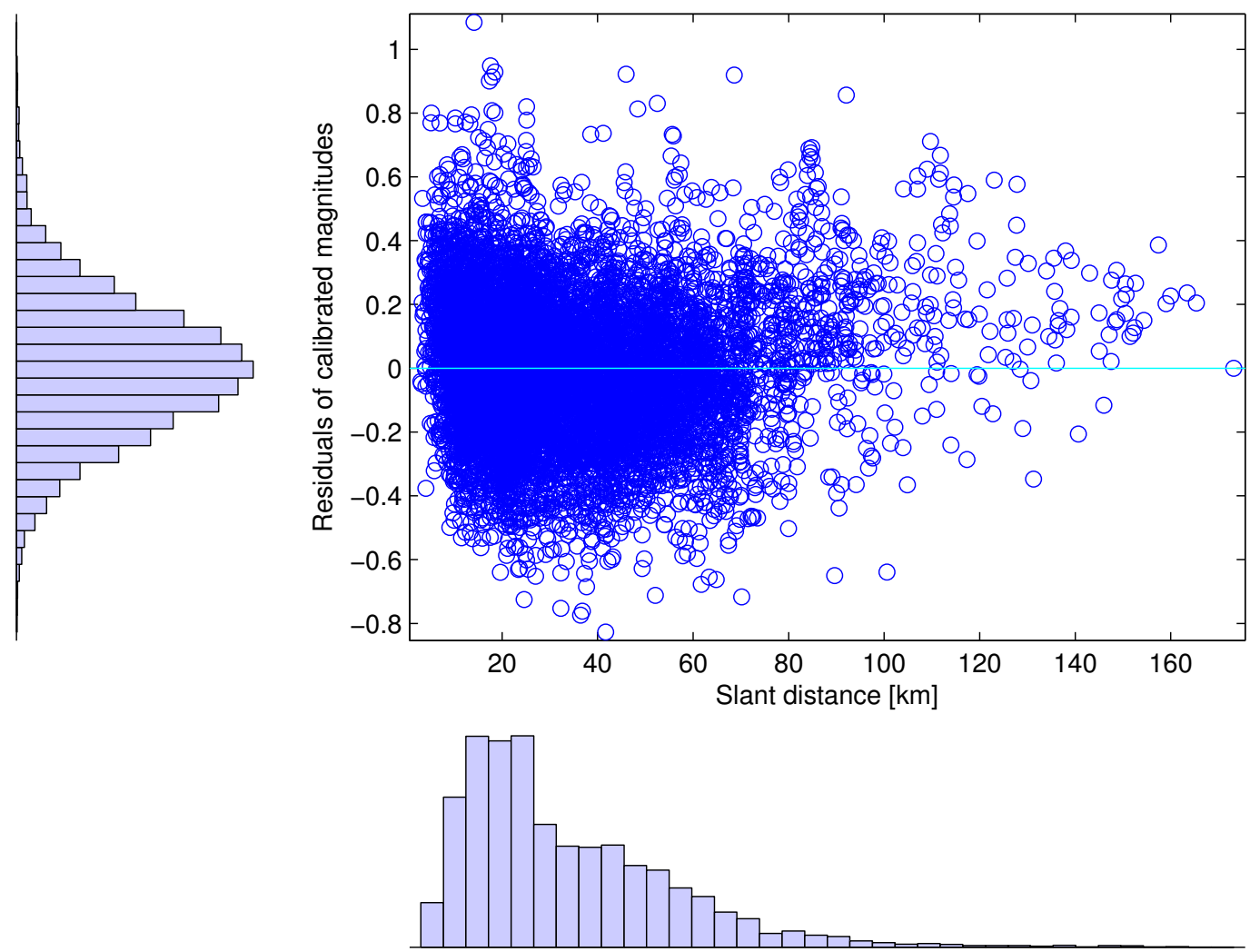

Figure 3.6. Magnitude residuals versus hypocentral distance for all earthquakes recorded by the SAMBA stations between November 2008 and December 2009. The same attenuation parameter $\gamma=6.7 \times 10^{-3} \mathrm{~km}^{-1}$ as used by GeoNet in routine magnitude determination has been applied.

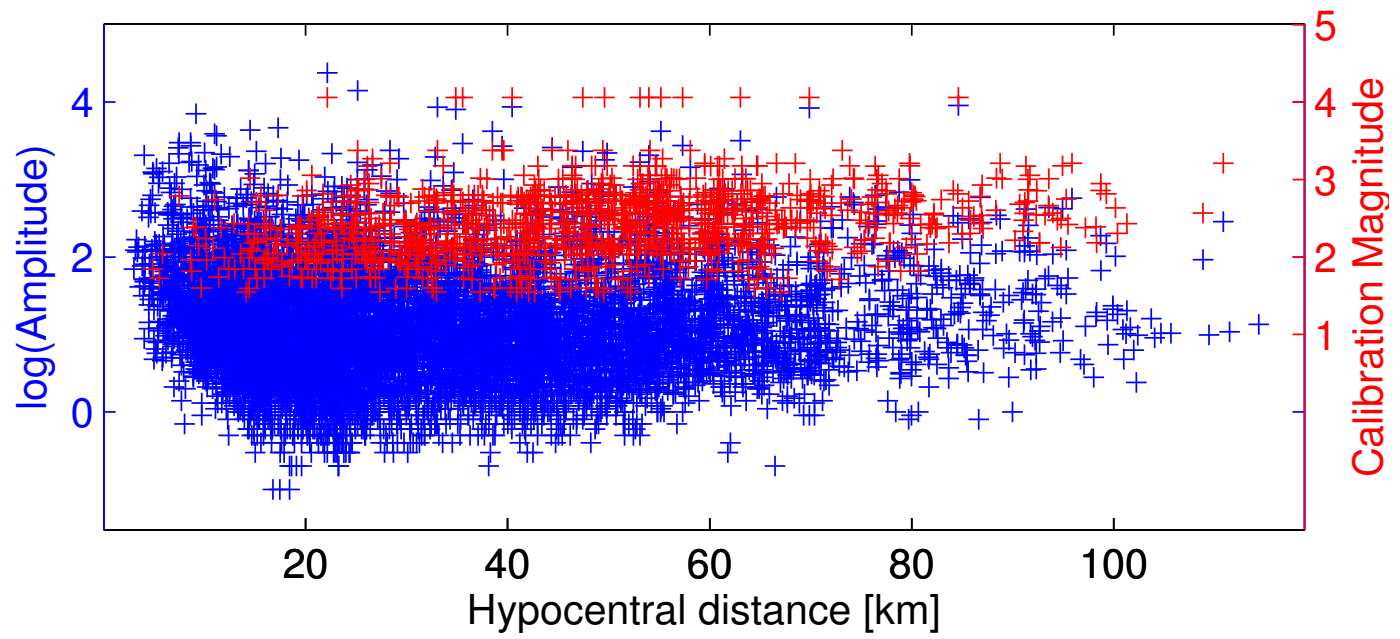

Figure 3.7. The logarithm of all available amplitude readings (blue) for earthquakes between November 2008 and December 2009 and calibration magnitudes (red) of events which were recorded by several GeoNet stations in relation to hypocentral distance. In order to derive the correct magnitude of the earthquakes, the amplitude decay with distance from the source due to geometrical spreading and attenuation has to be determined. 

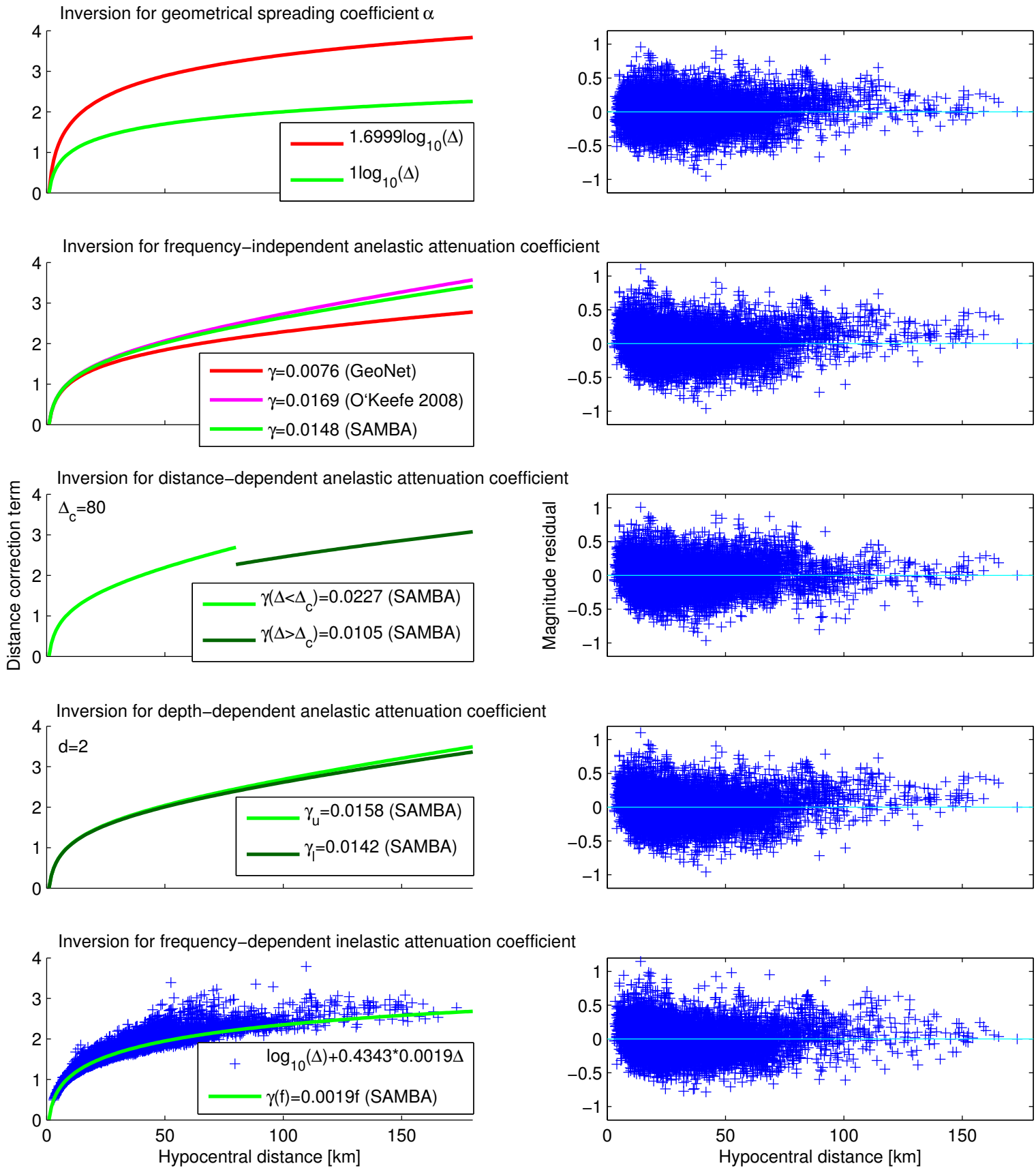

Figure 3.8. Distance correction term (left) and magnitude residuals (right) versus hypocentral distance for different inversion procedures as described in the text. 
following, $\alpha=1$ is assumed and all inversions are performed for the anelastic attenuation parameter.

Inversion of the amplitude data for a frequency-independent anelastic attenuation coefficient yields $\gamma=0.0148 \mathrm{~km}^{-1}$. This value is twice the standard attenuation coefficient used by GeoNet, but smaller than the value obtained by O' Keefe (2008). However, the result is unstable when amplitude data with different maximum hypocentral distances are inverted, in which case an increase of $\gamma$ with decreasing hypocentral distance is observed. Simultaneous inversion of the amplitude data for two distance ranges, separated by the crossover distance $\Delta_{c}$, indicates high $\gamma$-values for $\Delta<\Delta_{c}$ and low values for $\Delta \geq \Delta_{c}$ (Fig. 3.8, middle). Although this inversion fits the amplitude data best, the two attenuation coefficients cause an unphysical offset of approximately half a magnitude unit in the attenuation correction curve at $\Delta_{c}$. Similarly, a simultaneous inversion of the amplitude data separated for the SAMBA and GeoNet stations, indicates a low attenuation parameter for the GeoNet and a high attenuation parameter for the SAMBA stations (which are on average closer to the hypocentres in question).

In a different approach, the attenuation coefficients in an upper surface layer $\gamma_{\mathbf{u}}$ and a halfspace below $\gamma_{1}$ is inverted for simultaneously. This enables testing whether a highly attenuative surface layer exists, which has a proportionally larger effect on small station-event distances than on large hypocentral source-receiver distances. The inversion is performed for surface layer thicknesses of 1-8 km (and is shown for a thickness of $2 \mathrm{~km}$ in Fig. 3.8), revealing plausible values for all layer thicknesses and no particular improvement of the magnitude residual misfit at larger distances.

Those different inversion trials all produce predominantly positive magnitude residuals for hypocentral distances $\Delta \geq 60 \mathrm{~km}$, indicating that the applied attenuation curve overestimates the actual attenuation. Magnitude residuals which are normally distributed about zero can only be obtained if an additional correction term proportional to $\Delta^{2}$ is added in the inversion for frequency-independent $\gamma$.

However, when the same amplitude data are inverted for a frequency-dependent attenuation factor $\gamma=\gamma_{0}$ f the data can be fit for all hypocentral distances. This inversion is performed because the period of the wave corresponding to the maximum amplitude value shows a clear increase with hypocentral distance (Fig. 3.9, top). The resulting $\gamma_{0}=1.89 \times 10^{-3} \mathrm{~s} / \mathrm{km}$ explains the decrease of the attenuation function with distance. Earthquake waves from larger distances are depleted of their high-frequency content $(\mathrm{f}>10 \mathrm{~Hz}$ ) 
and are therefore less attenuated. High-frequency waves from nearby earthquakes, on the contrary, are highly attenuated. For the hypocentral distances considered in this study, which peak at $20 \mathrm{~km}$ and few amplitude readings for distances $\geq 70 \mathrm{~km}$, many more microearthquakes at short distances are inverted for attenuation.

Magnitude inversion for the period November 2008 to December 2009 for the SAMBA stations results in $\gamma_{0}=1.89 \pm 0.02 \times 10^{-3} \mathrm{~s} / \mathrm{km}$ (Section 4.2.2). When the same inversion method was applied to the data from the combined SAMBA and DFDP10 arrays for the period January to April 2010, the same frequency dependence of the attenuation coefficient was observed with a slightly larger value of $\gamma_{0}=2.37 \pm 0.01 \times 10^{-3} \mathrm{~s} / \mathrm{km}$.

Given the hypocentral ranges encountered in this study, the magnitude correction term corresponding to geometrical spreading $\alpha \log (\Delta)$ varies between 0 and 2 magnitude units. The attenuation term $0.4343 \gamma \Delta$, in contrast, ranges between 0 and 1 for frequencies of $10 \mathrm{~Hz}$, and 0 and 0.55 magnitude units for wave frequencies of $5 \mathrm{~Hz}$. In other words, the influence of attenuation can amount to half that of the geometrical spreading.

\subsubsection{Magnitude station correction terms}

Magnitude station correction terms reflect a systematic deviation of the magnitude at one station from the magnitude of an earthquake due to unmodelled subsurface structure. Stations above thick sediment layers exhibit larger magnitudes than stations on basement rocks due to amplification. The station correction terms obtained in this study overall reflect the depth at which the sensor is deployed and the site geology. The two deepest borehole stations in bedrock FRAN and WHAT have the lowest correction terms, followed by the third borehole station in sediments POCR and the GeoNet station RPZ, which is situated in a $50 \mathrm{~m}$ deep borehole in rhyolite (Petersen et al. 2011). The remaining GeoNet stations (FOZ, WVZ) and the SAMBA stations GOVA show lower than average values, indicating bedrock at these sites. Similarly, the lowest station correction terms from the DFDP10 network were found for station BLO, BON and GHU, where field observations suggest these sites are close to bedrock.

The station correction terms determined here for the GeoNet stations (FOZ, WVZ and RPZ) do not agree with values (0.34-0.52) used by GeoNet for these stations (K. Fenaughty, pers. comm., 2009). This may result from the distribution of earthquakes relative to the stations in this study versus the distribution of all earthquakes in New Zealand relative to these stations as used by GeoNet. However, since the magnitudes obtained 

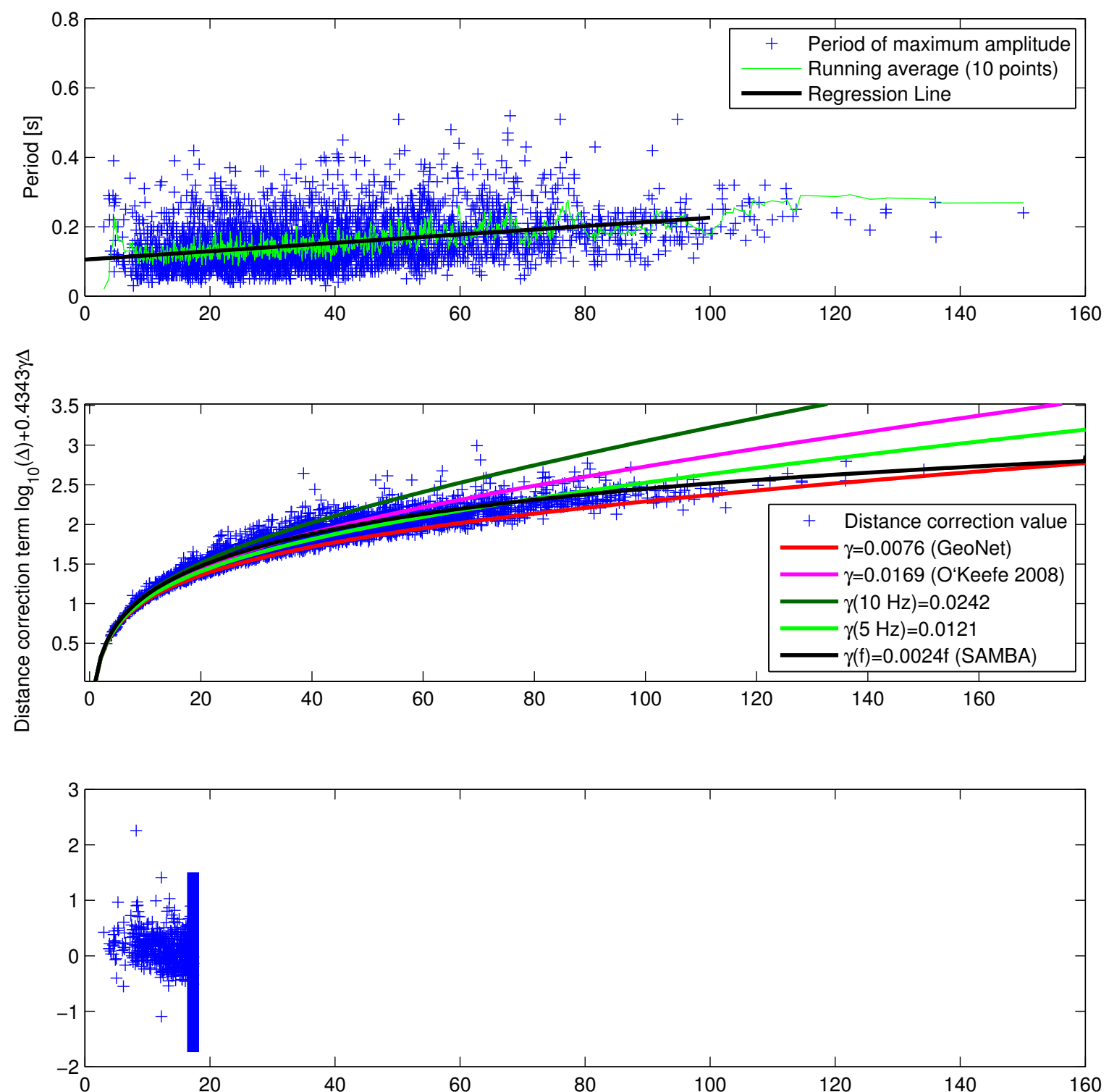

Figure 3.9. Period of the maximum Wood-Anderson displacement amplitude (top), attenuation functions (centre) and magnitude residuals (bottom) versus hypocentral distance for the period January to April 2010 for amplitude readings from the combined SAMBA and DFDP10 arrays. The same plot for the period November 2008 to December 2009, when only the SAMBA network was operational is shown in Fig. 4.5 
in this study are not significantly different from the magnitudes determined by GeoNet, whereas the attenuation coefficients are, this has to have an effect on the station correction terms (equation 2.23). Any systematic differences in the magnitudes will also be reflected in the station correction terms. The correction term attributed to attenuation in this study will be larger (on average) due to the frequency-dependent attenuation coefficient and the high-frequency content of nearby earthquakes than the same term used by GeoNet, and thus the station term by which the whole magnitude is reduced will also be larger in this study. This theoretically explains why the station terms derived here are one magnitude unit larger than those used by GeoNet.

A discussion about the errors of the magnitudes determined in this study due to the calibration described above is given in Section 4.2.2. One observation, however, that has not been mentioned is that low frequencies are amplified on simulated Wood-Anderson seismograms as a result of filtering. As a result, the displacement for a wave with lower frequency than that wave with the maximum displacement on the unfiltered trace appears larger than the actual maximum displacement on this trace. However, these large displacements of the low-frequency waves are not restricted to the earthquake signal. Therefore, peak amplitudes were only picked if the maximum amplitude corresponded to that on the unfiltered trace.

A comparison of the magnitudes of the events listed in the GeoNet and the SAMBA catalogue is shown in Figures 3.11 and 3.12. This shows that few earthquakes within the study area and the majority of earthquakes at the boundaries of the array are used for magnitude calibration. More discussion on the comparison between locations of the same events will be given in Section 3.3.1. The difference between the magnitude derived in this study and by GeoNet is small but significant. For events of $\mathrm{M}_{\mathrm{L}} \geq 3$, the resulting SAMBA magnitudes exhibit lower values than the GeoNet magnitudes (c.f discussion of magnitude uncertainties in Section 4.2.2). 


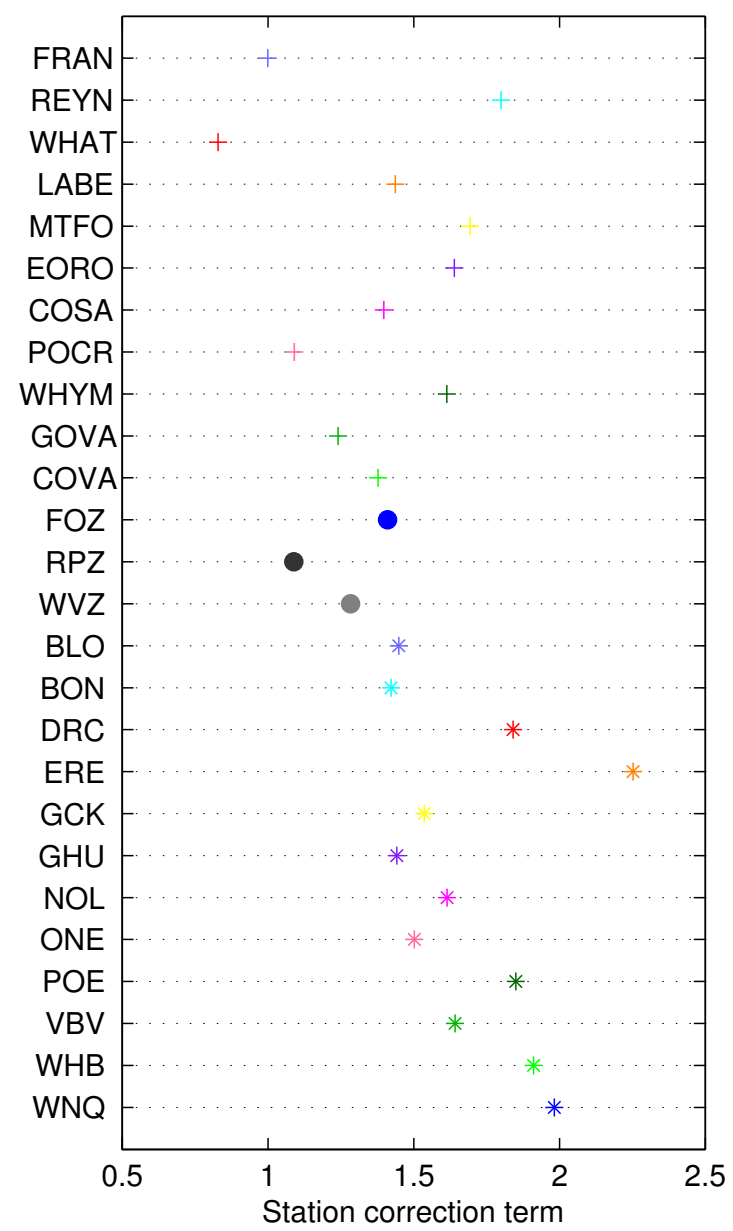

Figure 3.10. Station correction terms in magnitude units for the combined SAMBA and DFDP10 networks. Symbols are the same for stations belonging to one network. The bars that link the events indicate the depth differences between hypocentre locations obtained in this study and by GeoNet. Yellow bars show values greater than $10 \mathrm{~km}$, whereas green bars mark smaller hypocentral differences. 


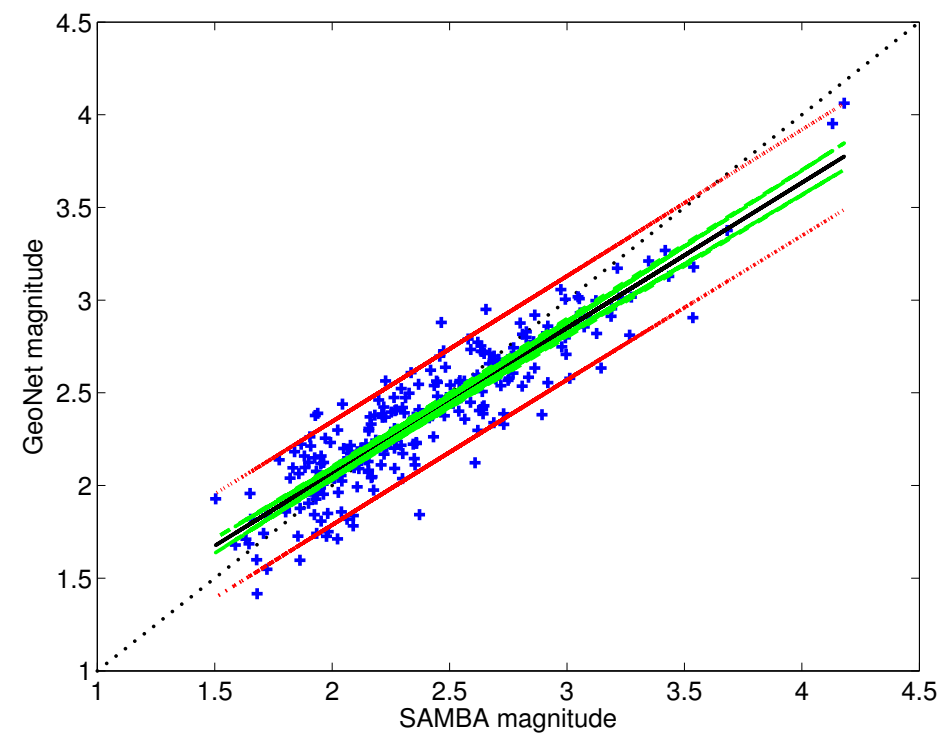

Figure 3.11. SAMBA magnitudes versus GeoNet magnitude for events listed in both catalogues. The black dotted line indicates equal values. The black solid line represents the best fitting regression line and its $95 \%$ confidence interval (green lines). The red lines reflect the spread in the magnitude values within the $95 \%$ interval.

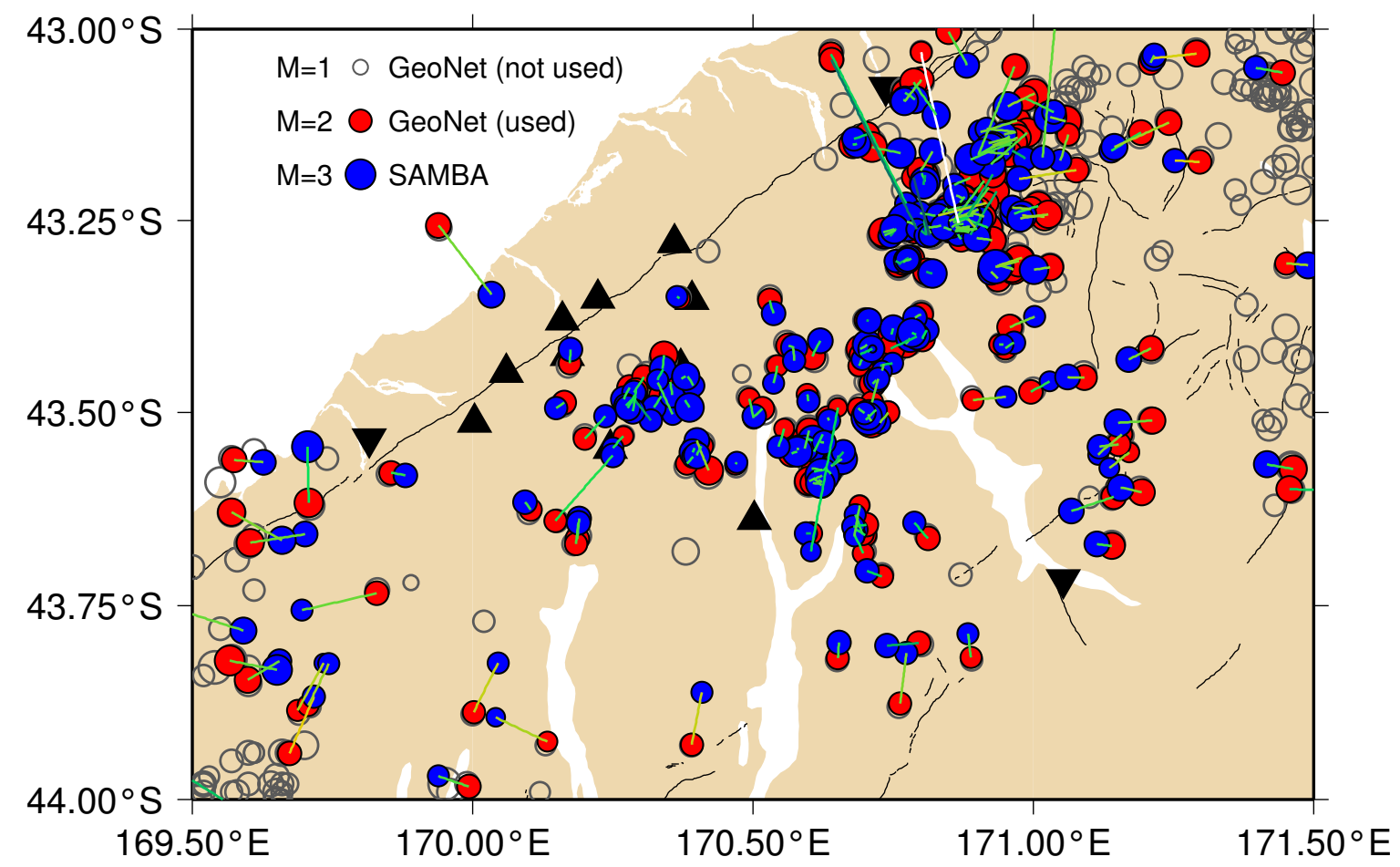

Figure 3.12. Epicentres of events listed in the GeoNet and the SAMBA catalogue and used for magnitude calibration in this study 


\subsection{Hypocentre comparisons and stability}

\subsubsection{Events from the GeoNet catalogue}

A comparison of the hypocentres of 245 events recorded by both the GeoNet network and the SAMBA array is shown in Fig. 3.12. The mean difference in latitude is $0.01 \pm 0.06^{\circ}$ ( \pm standard deviation of the data), $0.00 \pm 0.08^{\circ}$ in longitude, $2 \pm 6.4 \mathrm{~km}$ in depth and in RMS residual is $0.02 \pm 0.16 \mathrm{~s}$. The bars that link events in Fig. 3.12 indicate the depth differences between hypocentre locations obtained in this study and by GeoNet. Yellow bars show values greater than $10 \mathrm{~km}$, whereas green bars mark smaller hypocentral differences. Most events with large differences shifted towards the centre of the SAMBA array, reflecting the slightly faster $(+0.17 \mathrm{~km} / \mathrm{s}) \mathrm{P}$-wave velocity in the uppermost $8 \mathrm{~km}$ used in this study (Table 1.2) in comparison to the standard New Zealand velocity model used by GeoNet (Table 3.4).

\begin{tabular}{|r|c|c|}
\hline $\begin{array}{r}\text { Depth } \\
{[\mathrm{km}]}\end{array}$ & $\begin{array}{c}\mathrm{V}_{\mathrm{P}} \\
{[\mathrm{km} / \mathrm{s}]}\end{array}$ & $\begin{array}{c}\mathrm{V}_{\mathrm{S}} \text {-Velocity } \\
{[\mathrm{km} / \mathrm{s}]}\end{array}$ \\
\hline 0.0 & 5.5 & 3.3 \\
12.0 & 6.5 & 3.7 \\
33.0 & 8.1 & 4.6 \\
\hline
\end{tabular}

Table 3.4. Standard 1-D velocity model used by GeoNet for hypocentre location New Zealand-wide.

\subsubsection{Quarry blasts}

A total of seven quarry blasts from a quarry in Whataroa were recorded by the SAMBA stations and the combined SAMBA/DFDP10 arrays (Table 3.5). These quarry blasts are characterised by impulsive P- and weak S-waves (Fig. 3.13) (e.g. Allmann et al. 2008, and references therein). Similar amounts of energy were released as by $M_{L}$ 0.7-1.9 earthquakes. The quarry is located at $-43.283^{\circ} / 170.361^{\circ}$, approximately $0.4 \mathrm{~km}$ southeast of station WHAT. Unfortunately, the operating company would not provide origin times for these shots. Nevertheless, the events could be used to test the location and the polarity of the stations (Appendix B). When the depth was initially unconstrained, these events located at $5-8 \mathrm{~km}$ depth at epicentral coordinates matching the quarry location well. However, in this case the residuals for the closest station WHAT were high ( $>0.68 \mathrm{~s}$ too early). Fixing the depth to the surface resulted in a shift of the epicentre by $0.005-0.02^{\circ}(0.4-1.6 \mathrm{~km})$ north. The residuals for WHAT diminished to absolute values of $0.2-0.4 \mathrm{~s}$ but still indicate that the 
velocity model is too slow.

Husen et al. (1999) observed the same phenomenon for seven mine blasts recorded by a 35-station network in the vicinity of Antofagasta, Chile. They interpreted the consistently large offset in depth as the result of an inadequate approximation of the local near-surface velocities in the vicinity of the mine. An inversion for the velocities in the uppermost two layers shifted all events to 1-2 km depth, which reflects their absolute location error. Only few quarry blasts in Whataroa were recorded by the majority of stations (13 combined SAMBA/GeoNet network and additional 12 DFDP10 stations in 2010), so we do not invert for the velocities in the uppermost layers separately as Husen et al. (1999) did but instead these blasts are considered in the tomography described in Section 6.3.

\begin{tabular}{|l|l|c|c|c|c|c|c|c|c|}
\hline Date & Time & $\begin{array}{c}\text { Error } \\
{[\mathrm{s}]}\end{array}$ & $\begin{array}{c}\text { Lat. } \\
{\left[{ }^{\circ}\right]}\end{array}$ & $\begin{array}{c}\text { Error } \\
{[\mathrm{km}]}\end{array}$ & $\begin{array}{c}\text { Lon. } \\
{\left[{ }^{\circ}\right]}\end{array}$ & $\begin{array}{c}\text { Error } \\
{[\mathrm{km}]}\end{array}$ & $\begin{array}{c}\text { Stn } \\
\text { RMS } \\
{[\mathrm{s}]}\end{array}$ & $\begin{array}{c}\text { Gap } \\
{\left[{ }^{\circ}\right]}\end{array}$ \\
\hline 22.06 .2009 & $04: 06: 06$ & 0.51 & -43.279 & 1.3 & 170.361 & 1.6 & 11 & 0.2 & 177 \\
04.01 .2010 & $01: 08: 25$ & 0.35 & -43.245 & 1.5 & 170.373 & 1.5 & 10 & 0.1 & 298 \\
12.01 .2010 & $03: 37: 06$ & 0.40 & -43.251 & 2.5 & 170.361 & 2.1 & 6 & 0.2 & 297 \\
22.01 .2010 & $01: 29: 28$ & 0.42 & -43.280 & 1.9 & 170.364 & 1.4 & 10 & 0.2 & 123 \\
27.01 .2010 & $03: 16: 02$ & 0.55 & -43.276 & 1.3 & 170.357 & 1.3 & 13 & 0.2 & 155 \\
01.02 .2010 & $04: 24: 00$ & 0.48 & -43.273 & 1.5 & 170.355 & 1.4 & 13 & 0.2 & 184 \\
23.02 .2010 & $22: 25: 08$ & 0.40 & -43.282 & 1.0 & 170.355 & 1.4 & 14 & 0.2 & 154 \\
\hline
\end{tabular}

Table 3.5. Quarry blasts in Whataroa recorded by the SAMBA network or SAMBA and DFDP10 arrays (with the number of stations Stn that recorded events) that were located using a fixed depth of $0 \mathrm{~km}$.

\subsection{Station configuration}

\subsubsection{Earthquakes outside the station network}

To test the influence of the station network on the calculated hypocentres, we locate events that occurred outside the SAMBA array but inside the DFDP10 array using travel-time observations from the combined station networks and from the SAMBA stations only. Those earthquakes that were recorded by more than 20 stations between January and April 2010 are shown in Figure 3.14. The PDF hypocentre solutions shown in red were calculated from the travel-time observations at the SAMBA stations only. Black lines indicate the shift from the original hypocentres (using all stations for locating the event) to the relocated hypocentres (when only the SAMBA stations are considered). The epicentral coordinates are stable and 
2010/2/23 22:25

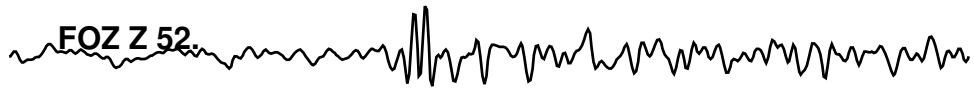

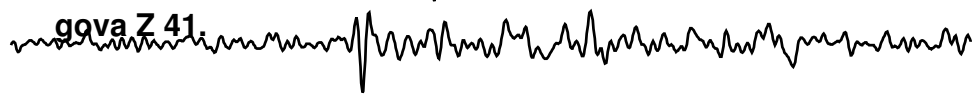

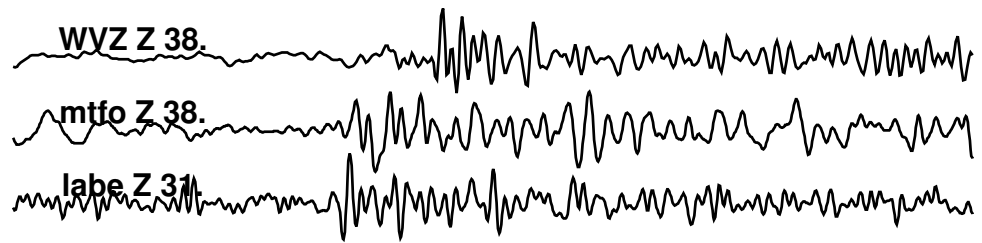

ONE Z 22.

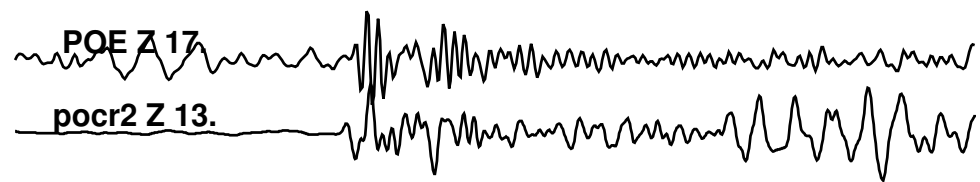

mol z 13.

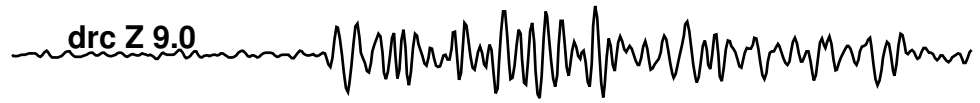

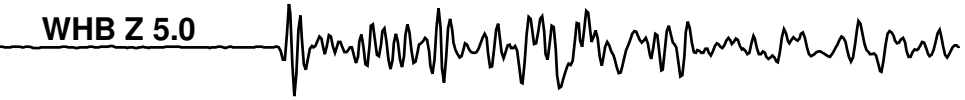

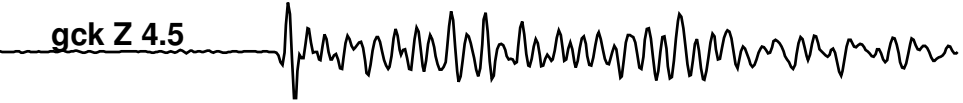

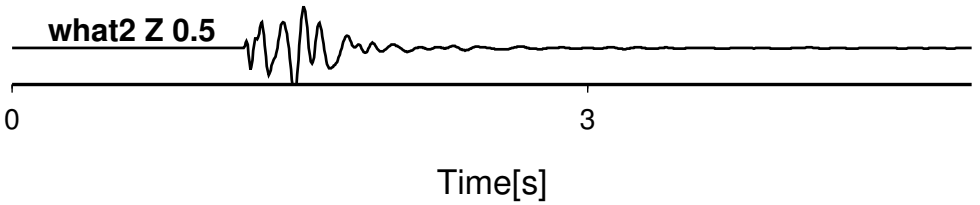

Figure 3.13. Distance versus reduced travel-time for the quarry shot (equivalent $M_{L}$ 1.5) of 23 February 2010 recorded by the SAMBA and DFDP10 stations. The travel-time was reduced by the time resulting from the velocity of the uppermost layer $(5.67 \mathrm{~km} / \mathrm{s})$ over the distance. The distance (in $\mathrm{km}$ ) is given by the number after the station name and component shown. Note that the delay at ONE is likely due to slow velocities associated with the sediments (cf. large station term in Fig. 3.5). WVZ and FOZ are the most distant stations for waves propagation parallel to the Alpine Fault and are both located on the Australian plate. 
horizontal changes are less than $1 \mathrm{~km}$ which is within the uncertainty of the hypocentres. However, this stability is due to the high number of stations that recorded the earthquake (Section 3.4.2). The depth, in contrast, changes markedly because there is no station within a distance of 1.5 times the focal depth. The hypocentres are moved to the surface (positive vertical shifts; Fig. 3.14 b). In most cases, however, the original location is contained in the uncertainty volume.

\subsubsection{Number of recording stations}

For a few events recorded by all SAMBA and the three surrounding GeoNet stations, the stability of the hypocentres was tested. The most distant stations to the centre of the SAMBA array were systematically taken out during the location process. This was repeated in six steps, starting with thirteen and ending with three stations (Fig. 3.15). The uncertainty in each hypocentre directly reflects the number of stations that recorded the earthquake and the station distribution. Its volume decreases markedly with increasing number of stations that recorded the event. Despite a poor azimuthal coverage of the recording stations relative to the event, the number of stations that record the event is significant (e.g. 10 versus 7 stations) in improving the hypocentre location.

Overall, the epicentral coordinates of the maximum likelihood hypocentre (latitude and longitude in Fig. 3.16) change little during the location steps with different numbers of recording stations. The root mean squared residual $\sigma_{\mathrm{RMS}}$ depends on the number of stations at which the earthquake is recorded. As expected, the $\sigma_{\mathrm{RMS}}$ value increases with the number of recording stations (Havskov and Ottemöller 2010). Fluctuations in depth are most pronounced and are on the order of several kilometres. Note that one particular phase arrival time can disturb the hypocentre solution (e.g. 5 versus 4 recording stations) as illustrated by Fig. 3.16. When the travel-time residuals become incompatible, the event is moved to the surface (depth=-2 km due to topography). This is usually accompanied by a change in the RMS value.

\subsubsection{Hypocentre locations before and after weighting}

A comparison of the hypocentres determined from the consistently weighted phases with those resulting from the original manually weighted phases reveals only minor differences for the majority of events but significant shifts for some individual events. All hypocentre locations that changed by more than $10 \mathrm{~km}$ either vertically or horizontally were re-checked 


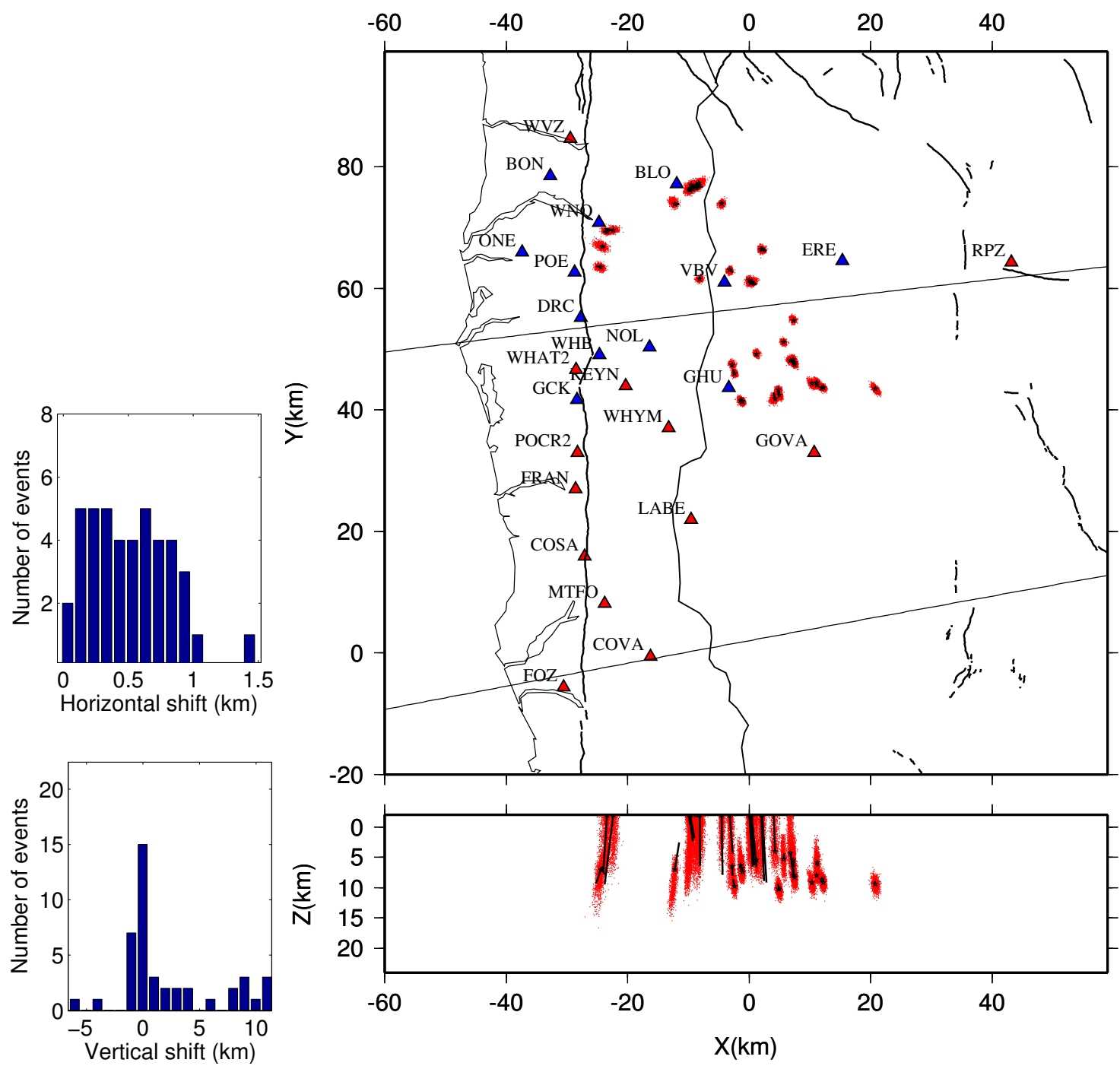

Figure 3.14. Hypocentre locations (maximum likelihood hypocentres, black dots) and their uncertainty represented by the probability density function (red) of each earthquake in map view (rotated by $55^{\circ}$ so that the Alpine Fault is shown by the solid black almost vertical line) and on a profile parallel to the $\mathrm{X}$-axis below. Short black lines represent shifting of the hypocentres from their original position (including DFDP10 station) to the new locations (excluding DFDP10) in order to test the stability of the hypocentres outside the SAMBA network. Horizontal and vertical fluctuation of the hypocentre coordinates are shown in the histograms. 

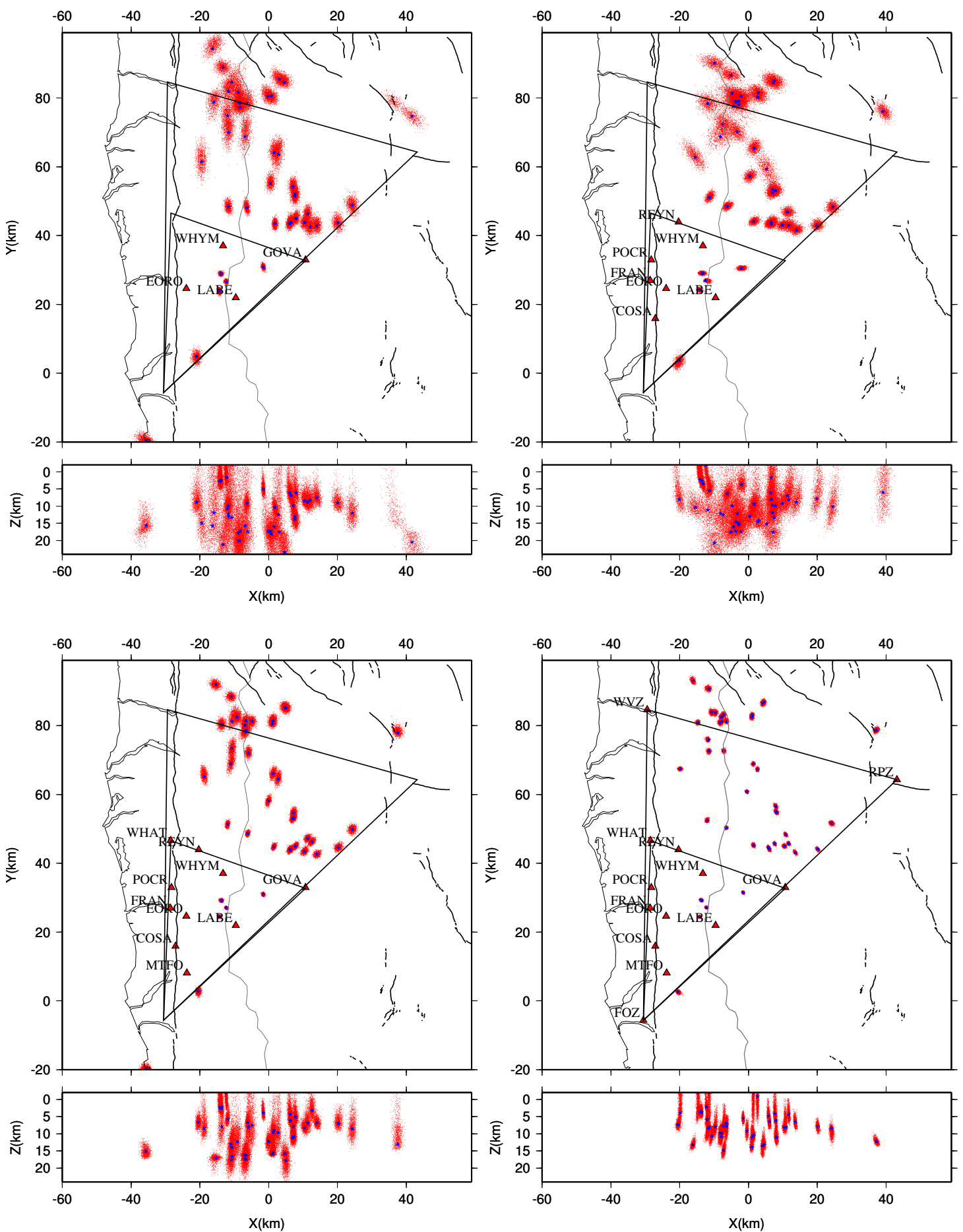

Figure 3.15. Probability density functions of the hypocentre solution for different numbers of stations that recorded the earthquake. In total 44 events were recorded by all SAMBA and GeoNet stations. For details about the plots see Fig. 3.14. 

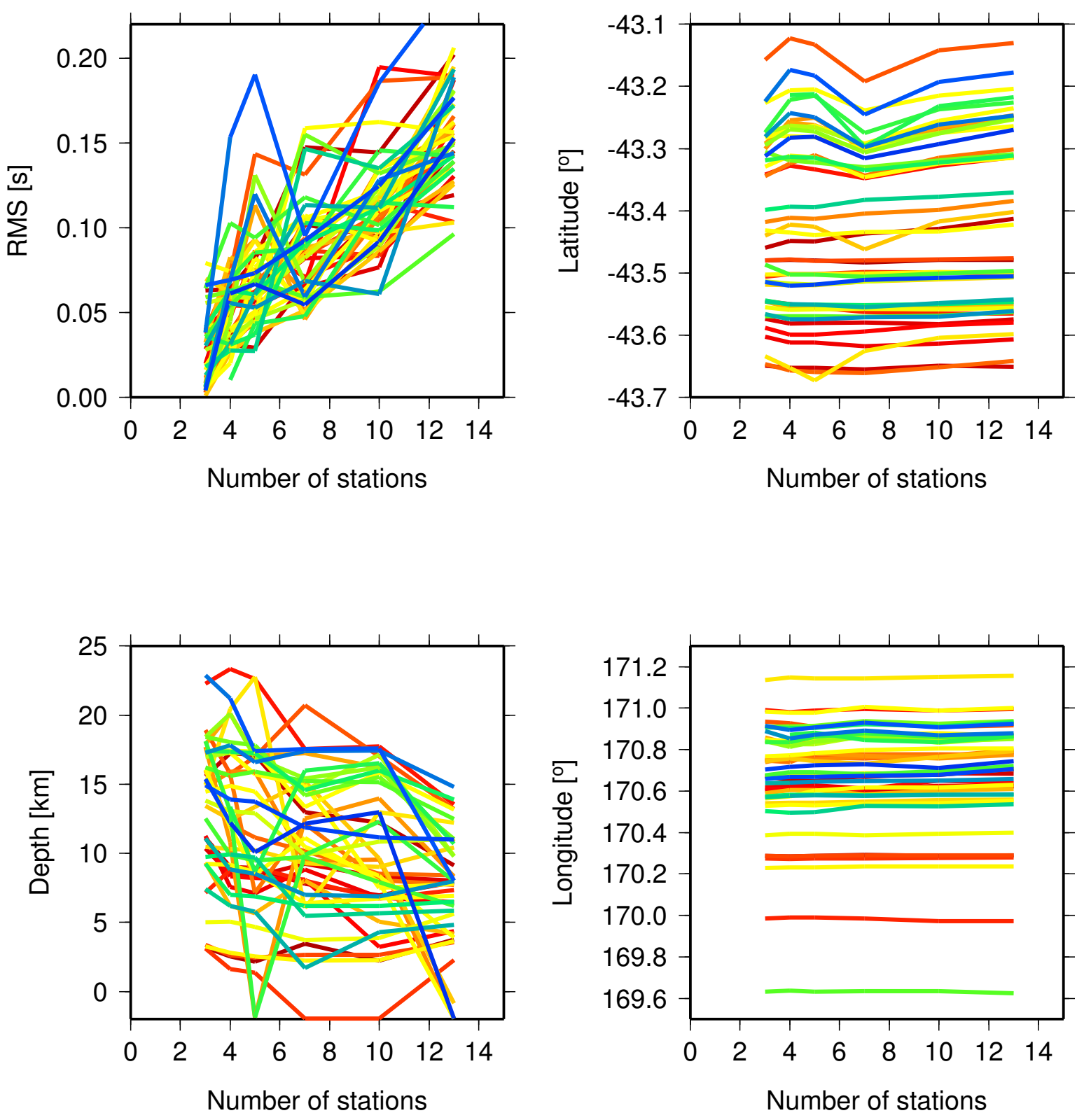

Figure 3.16. Fluctuation of hypocentre coordinates and RMS values due to the number of travel-time observations used for locating the earthquakes. Which stations were considered in the different steps is shown in Fig. 3.15. The different coloured lines in each panel correspond to individual earthquakes. 
manually for inconsistent travel-time residuals. Usually, in such cases, one mispicked phase could be identified that was downweighted when applying the weighting scheme. On average, the final epicentres shifted less than the mean horizontal uncertainty of $1 \pm 1.3 \mathrm{~km}$ (as shown in Fig. 3.17 and 3.18). In depth, the majority of the events shifted by less than $\pm 1.8 \mathrm{~km}$. The tails of the distribution of vertical shifts indicate extreme changes of as much as $10 \mathrm{~km}$ upwards (positive values, usually events with inconsistent picks that were moved to the surface) and downwards (negative depth shifts, where the weighting eliminated inconsistencies in the phase picks). These occurred predominantly at the boundaries of the array. All other vertical movements lie within the error volume of the hypocentre uncertainties $(3 \pm 2.9 \mathrm{~km})$. Changes in RMS-values show the improvement of the average travel-time residual due to weighting (as shown in Fig. 3.18, compare also Fig. 4.4). Our weighting procedure effectively removes the influence of the station term from the weight, so that stations with larger station terms, which were usually downweighted manually, get comparable weights to those stations with small station terms.

\subsubsection{Hypocentre relocations}

A total of 1993 events in the catalogue of absolute hypocentre locations were used for relocation with hypoDD Waldhauser and Ellsworth (2000). These events were filtered between $3-15 \mathrm{~Hz}$ and cross-correlated when the earthquake was recorded by the same station. A cross-correlation threshold of 0.5 for at least 5 station pairs had to be exceeded for the event to be listed in the cross-correlation catalogue. This resulted in a catalogue of 8137 pairs of earthquakes. Strong links (>8) between the events in the two catalogues are required for relocation, so that the events' spatial positions can be determined relative to those nearby events. Earthquake relocations are determined in an iterative process, starting with a full weight on the catalogue double-difference values. In five iterations, the catalogue differential-travel-times were systematically downweighted and the weights of the cross-correlation differential-travel-times were increased. The specifications for the iterations in the relocation process are shown in Table 3.6.

Initially, only catalogue P-wave differential travel-times are used in the relocation process so that the initial position of the events is determined by the absolute hypocentre location. Next, catalogue S-waves differential travel-times with half the weight of the P-wave differential travel-times are included. In the third iteration step, the cross-correlation differential travel-times are added and the maximum separation distances and the standard deviation of the catalogue differential travel-times are lowered. The maximum separation distance between absolute hypocentre locations is set here to $3 \mathrm{~km}$ (Maurer and Deichmann 


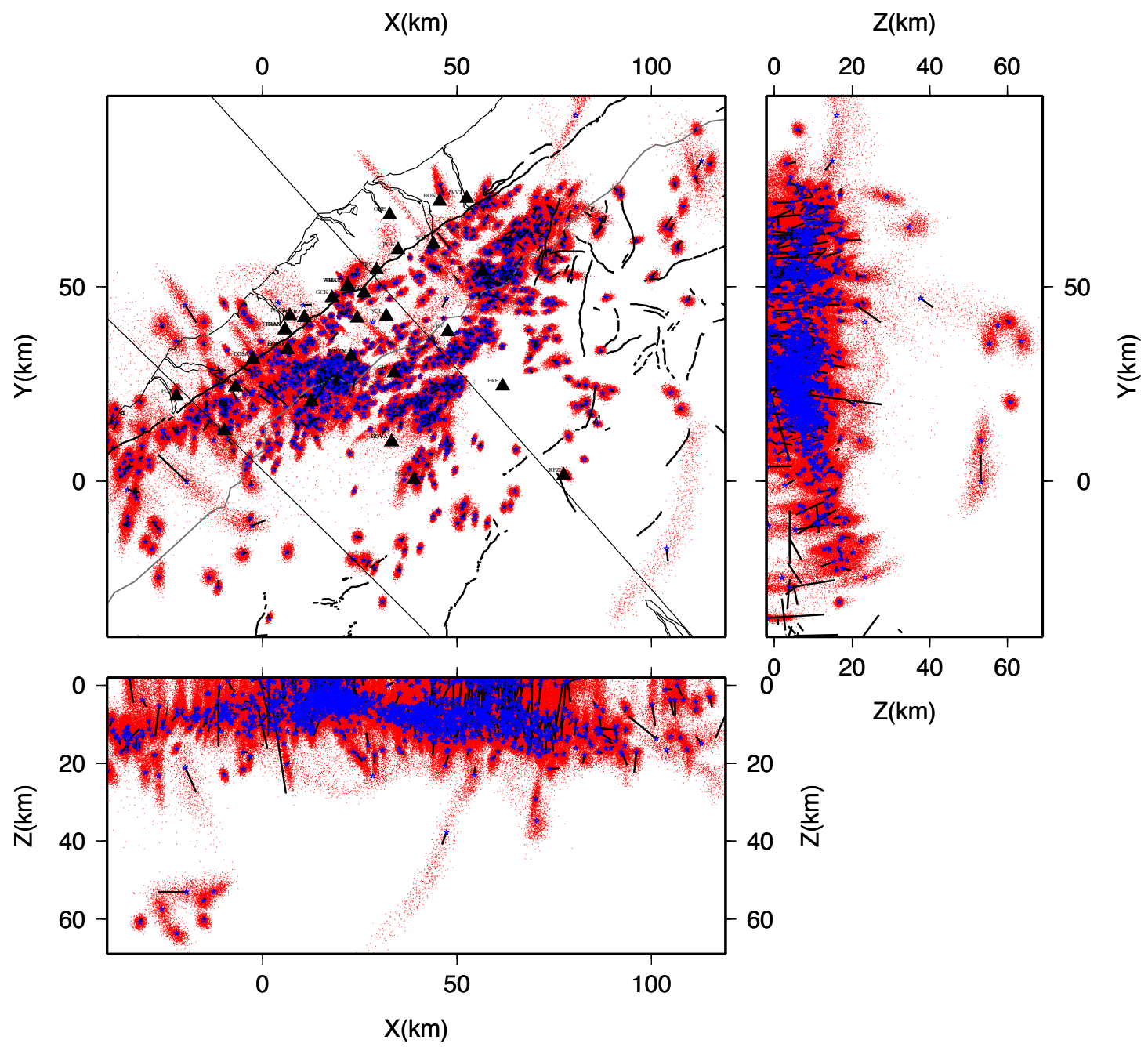

Figure 3.17. Hypocentre locations after the weighting scheme was applied (blue stars and uncertainty in red) and their changes (black lines) from the previous location without systematic weighting. Shown are all events between November 2008 and April 2010 on map view and projected on cross sections along the $\mathrm{X}$ - and $\mathrm{Y}$ axis through the origin of the coordinate system. 

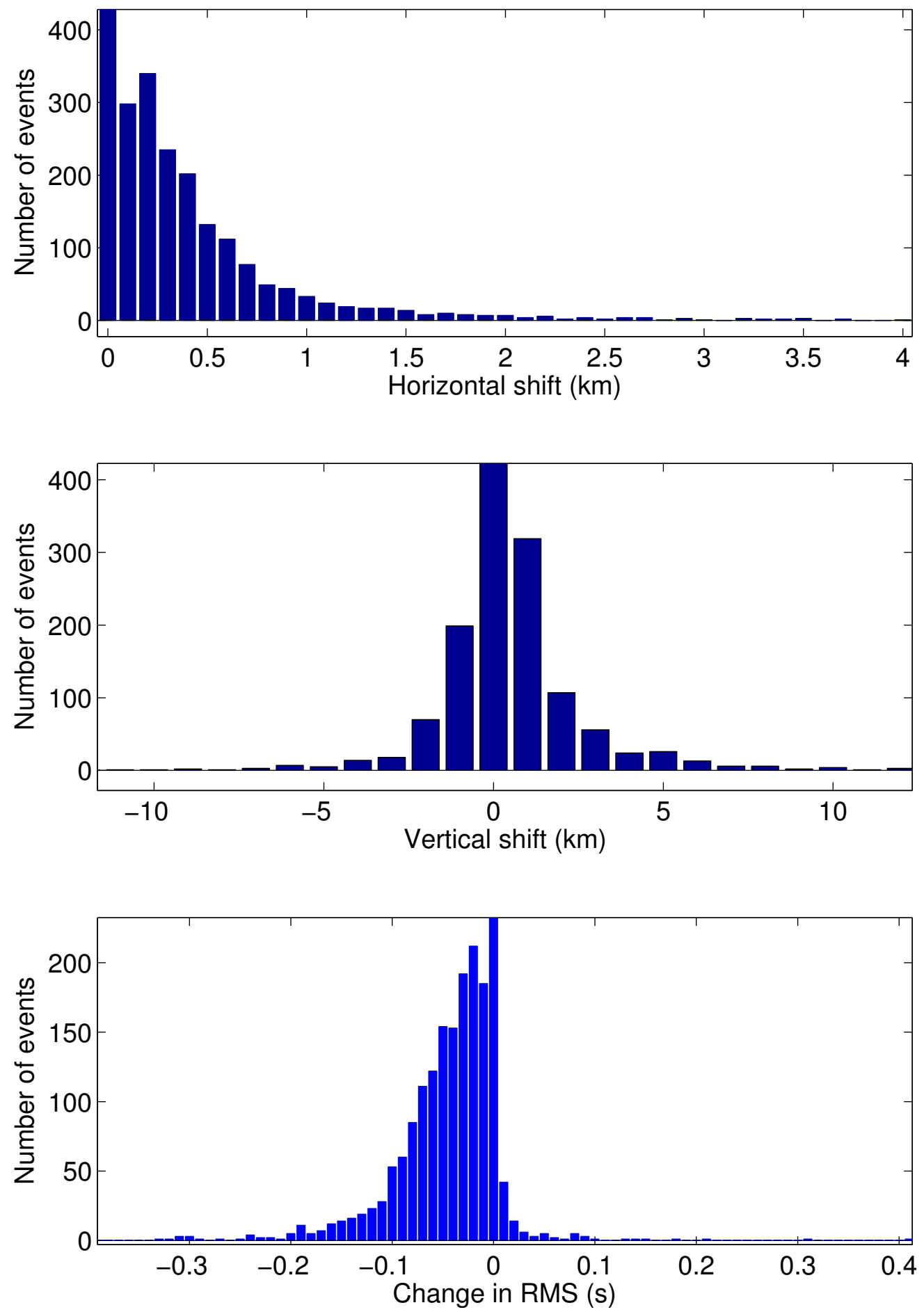

Figure 3.18. Horizontal and vertical location shifts between the hypocentres obtained without and with the weighting scheme. Note that the vertical scale extends to counts of 1500 for all three plots and has been truncated to make the tails of each histogram visible. 
1995) which corresponds to approximately twice the average location error of the events (average horizontal uncertainty of $1 \pm 1.3 \mathrm{~km}$ ), and two standard deviations as the residual threshold to be consistent with findings in Section 3.1.1.

\begin{tabular}{|c|c|c|c|c|c|c|c|c|c|}
\hline \multirow{2}{*}{$\begin{array}{l}\text { Iter- } \\
\text { ation }\end{array}$} & \multicolumn{2}{|c|}{$\begin{array}{l}\text { Cross-correla- } \\
\text { tion dt weights }\end{array}$} & \multirow{2}{*}{$\begin{array}{l}\text { Res. } \\
\text { thres. } \\
\text { in } \sigma\end{array}$} & \multirow{2}{*}{$\begin{array}{c}\text { Max. } \\
\text { event } \\
\text { sep. }\end{array}$} & \multicolumn{2}{|c|}{$\begin{array}{l}\text { Catalogue } \\
\text { dt weights }\end{array}$} & \multirow{2}{*}{$\begin{array}{c}\text { Res. } \\
\text { thres. } \\
\text { hold in } \sigma\end{array}$} & \multirow{2}{*}{$\begin{array}{c}\text { Max. } \\
\text { event } \\
\text { sep. }\end{array}$} & \multirow[t]{2}{*}{$\begin{array}{l}\text { Damp- } \\
\text { ing }\end{array}$} \\
\hline & $\mathrm{P}$ & $\mathrm{S}$ & & & $\mathrm{P}$ & $\mathrm{S}$ & & & \\
\hline 1 & 0.001 & - & - & - & 1 & 0.001 & - & - & 95 \\
\hline 2 & 0.01 & - & - & - & 1 & 0.5 & 7 & 6 & 95 \\
\hline 3 & 0.1 & 0.001 & 7 & 7 & 1 & 0.5 & 3 & 3 & 90 \\
\hline 4 & 1 & 0.001 & 5 & 5 & 0.5 & 0.01 & 2 & 3 & 90 \\
\hline 5 & 1 & 0.5 & 3 & 3 & 0.01 & -9 & 2 & 3 & 60 \\
\hline 6 & 1 & 0.5 & 2 & 0.5 & 0.001 & -9 & 2 & 3 & 60 \\
\hline
\end{tabular}

Table 3.6. Input parameters for hypoDD relocations. The residual threshold (column 3 for cross-correlation and 6 for catalogue data, respectively) is expressed in terms of number of standard deviations $\sigma$, so that a value of 3 means all residuals within $3 \sigma$ of the mean residual are included. Note that the maximum event separation (column 4 for cross-correlation and 7 for catalogue data, respectively) is in kilometres.

In the following iteration, weights for the cross-correlation differential travel-times are increased and the S-phase differential travel-times from the cross-correlation catalogue are added. In the fifth and six iteration steps, the maximum separation distance and the standard deviation of the cross-correlation differential travel-times are systematically reduced. The catalogue differential travel-times are downweighted to constrain the spatial position as a relative location between earthquakes. The final threshold for the maximum separation distance between relative hypocentre locations is $500 \mathrm{~m}$, significantly smaller than the overall absolute location error.

During the relocation process, the weighted square sum of these double-difference residuals for pairs of earthquakes at each station is minimized. This can be accomplished using either the singular value decomposition (SVD) or the conjugate gradients method (LSQR). SVD is applied to look at the fine-scale structure of several clusters of events otherwise LSQR is used.

In total 936 events were relocated and approximately 20 earthquakes were removed as "airquakes" (defined as events with depths above sealevel in hypoDD so topography is not taken into consideration). Conditioning numbers for the largest cluster of events start at high values of 140 but improve significantly once the airquakes are removed $(<100)$. The final two iterations have stable values between 60 and 70. For fewer than 11 links between 
events, the majority of earthquakes are combined to one large cluster. The larger the number of links, the more tightly clustered are the events and the smaller the overall number of relocated events per cluster. In principle, however, the clusters remain the same but get split into several smaller ones. The overall number of events that are relocated drops by one-third to 664 .

Figure 3.19 shows the relocated hypocentres for eight links. Also shown are the differences between the absolute catalogue locations and the relocated hypocentres (black bars). Individual clusters with more than eight events are shown in colour. Notably those events northeast of the SAMBA array which could be correlated with events that occurred in early 2010 within the DFDP10 array (when the depth was better constrained) shifted downwards by more than a few kilometres. Unfortunately, however, the hypocentre relocations do not reveal linear or planar fault structures in more detail. Nevertheless, they do show that earthquakes occur in a defined depth range and are not as scattered throughout the seismogenic zone as apparent in the absolute event locations (cf. Fig. 3.17). Several of the clusters identified in the relocation coincide with swarms identified in Chapter 5.

\subsection{Focal mechanism comparisons}

To test our focal mechanism program, we first tried to reproduce focal mechanism solutions obtained by Leitner et al. (2001) for the Southern Alps region. In order to get take-off angles for the events studied by Leitner et al. (2001), we use the station coordinates of the GeoNet and SAPSE networks, the 1-D velocity model applied by Leitner et al. (2001) and the travel-time observations to relocate the events with NonLinLoc. A total of 18 mechanisms for earthquakes that occurred between November 1995 and April 1996 could be compared (Fig. 3.20).

For the majority of events, we obtain a similar focal mechanism but our results differ in detail from those solutions by Leitner et al. (2001). The main reason for these differences is that the relocated hypocentres differ (especially in depth) from the original locations, resulting in different distributions of P-wave polarities on the focal sphere. Some of the original travel-time observations had to be disregarded because no information about the station location could be obtained. Additionally, some of the instruments showed a reverse polarisation compared to the majority of P-wave polarisations, but we had no information about which SAPSE stations had reversed Z-components. However, few reversals $(<20 \%)$ were accounted for in the focal mechanism determination. 


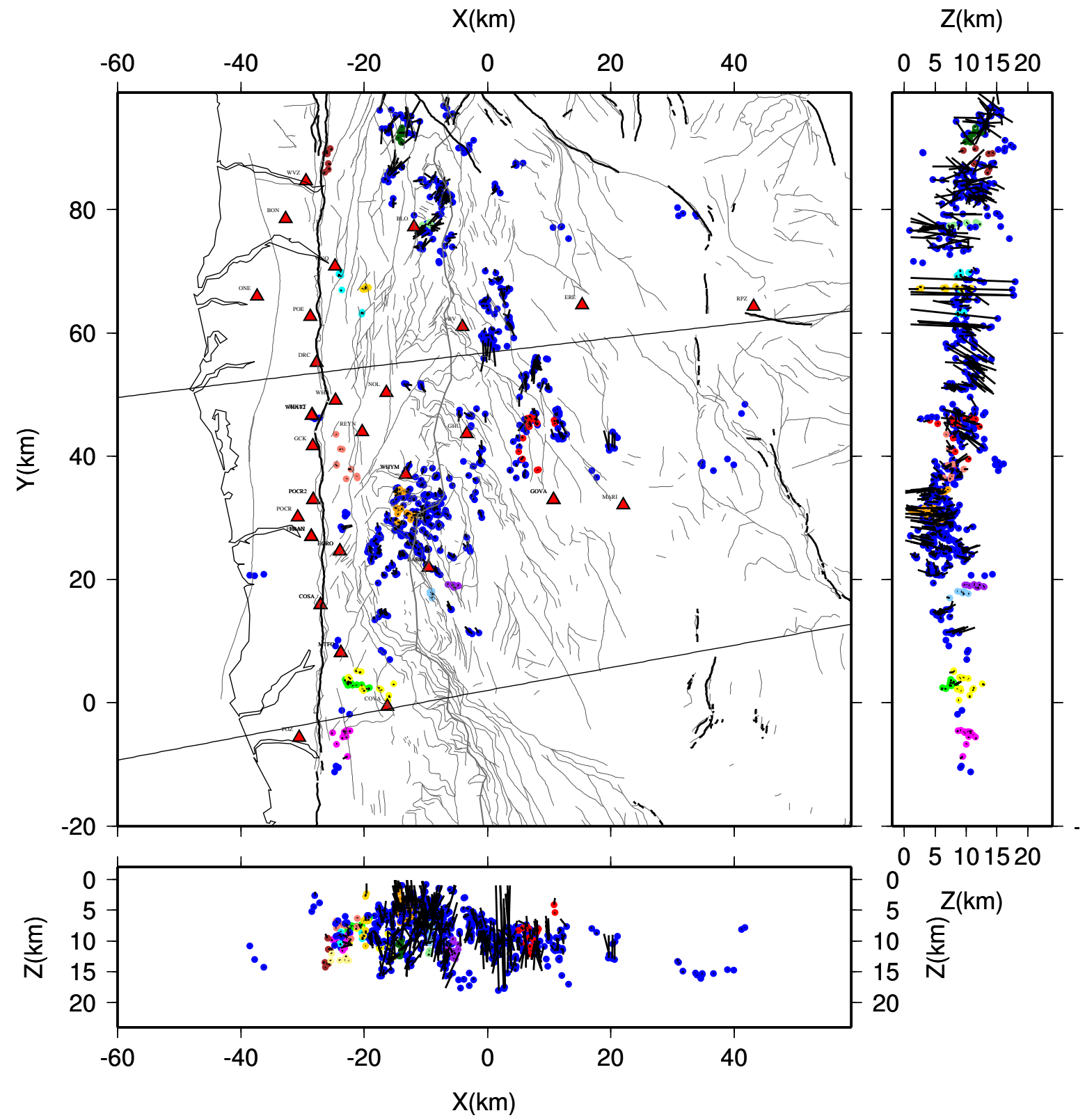

Figure 3.19. Double-difference hypocentre relocations of events between November 2008 and April 2010 on map view and as cross sections along the $\mathrm{X}$ - and $\mathrm{Y}$ axis through the origin of the coordinate system. Clusters with more than eight events that are not in the largest cluster (with $>700$ events) are shown in colour. Black bars indicate hypocentre changes resulting from the relocation of the events. 


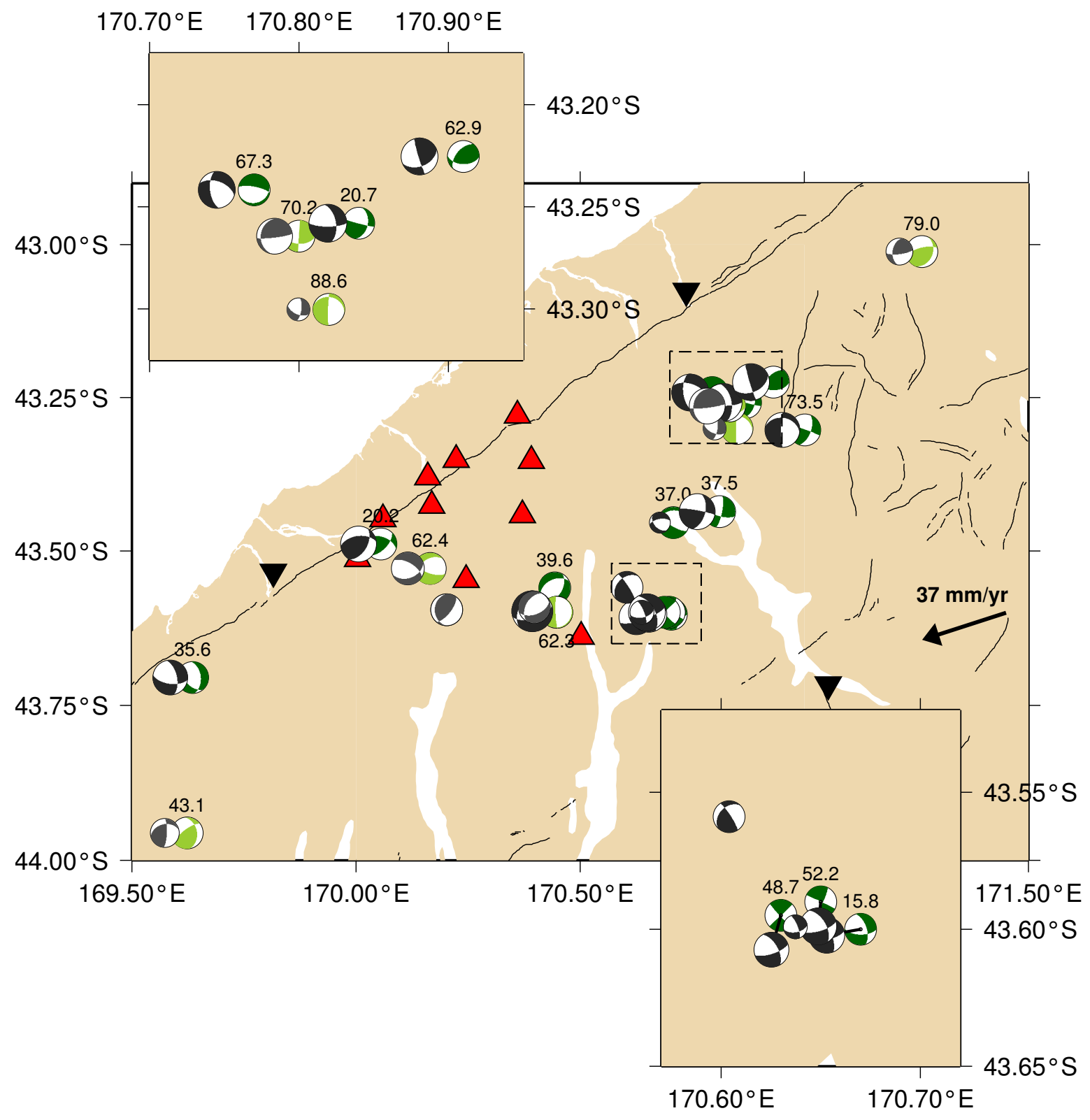

Figure 3.20. Focal mechanism solutions of quality A (light grey) and B (dark grey) by Leitner et al. (2001) in comparison to the solutions obtained in this study (dark and light green). The number on top of the mechanism gives the minimum rotation angle (Arnold and Townend 2007) required to map one mechanism onto the other. Note that the hypocentre locations of the original and reproduced focal mechanism are not the same due to different location methods. All focal mechanism solutions shown are lower hemisphere projections with the coloured quadrants representing compressional first arrivals. 
The minimum rotation angle or angular difference between the two focal mechanism solutions is determined using

$$
\alpha_{R}=\cos ^{-1}\left(\frac{\operatorname{tr}\left(\mathbf{R}_{1}^{T} \mathbf{R}_{2}\right)-1}{2}\right)
$$

by Arnold and Townend (2007). $\mathbf{R}_{1}$ and $\mathbf{R}_{2}$ are rotation matrices corresponding to the two focal mechanism solutions. The rotation angles between Leitner et al.'s (2001) and our solutions range between $15.8^{\circ}$ and $88.6^{\circ}$ (Fig. 3.20).

The focal mechanism solutions obtained in this study were also compared with those of Ristau (2008), who determined focal mechanisms for earthquakes of $\mathrm{M}_{\mathrm{W}} \geq 3.6$ after December 2004 using regional moment tensor inversion. Only three solutions are listed for the time period addressed in this study (Table 3.7). The first event (8 May 2009) and the most recent event (14 August 2009) are in the SAMBA catalogue, but the focal mechanism solutions differ markedly from those of Ristau (2008). A comparison of the focal mechanism solutions and the distribution of P-wave polarities for these two events are shown in Fig. 3.21. The difference between the mechanisms obtained here and those of Ristau (2008) is attributed to the compressional first motion at the NNW rim of the stereogram, which constrains the NNW strike of one of the fault planes. This compressional polarity was recorded by station RPZ which has a correct polarity but a wrong instrument response (cf. Appendix A). Since one of our focal mechanism solutions is well-constrained by the distribution of first motions on the focal sphere, we suggest that Ristau's solution is influenced by the erroneous instrument response of station RPZ.

\begin{tabular}{|c|c|c|c|c|c|c|c|c|c|c|}
\hline Date & Time & $\begin{array}{c}\text { Lat } \\
{\left[{ }^{\circ}\right]}\end{array}$ & $\begin{array}{c}\text { Lon } \\
{\left[{ }^{\circ}\right]}\end{array}$ & $\begin{array}{c}\text { Strike } \\
{\left[{ }^{\circ}\right]}\end{array}$ & $\begin{array}{c}\text { Dip } \\
{\left[{ }^{\circ}\right]}\end{array}$ & $\begin{array}{c}\text { Rake } \\
{\left[{ }^{\circ}\right]}\end{array}$ & $\begin{array}{c}\text { Strike } \\
{\left[{ }^{\circ}\right]}\end{array}$ & $\begin{array}{c}\text { Dip } \\
{\left[{ }^{\circ}\right]}\end{array}$ & $\begin{array}{c}\text { Rake } \\
{\left[{ }^{\circ}\right]}\end{array}$ & Mag \\
\hline 08.05 .2009 & $00: 34$ & -43.15 & 170.96 & 332 & 86 & 5 & 242 & 85 & 176 & $3.7^{*}$ \\
& $00: 34: 41$ & -43.15 & 170.93 & 151 & 48 & -44 & 280 & 78 & 336 & 4.1 \\
\hline 27.06 .2009 & $18: 32$ & -42.60 & 169.91 & 163 & 71 & 26 & 64 & 65 & 159 & $4.3^{*}$ \\
\hline 14.08 .2009 & $16: 24$ & -43.25 & 170.79 & 343 & 73 & 24 & 246 & 67 & 162 & $3.7^{*}$ \\
& $16: 24: 09$ & -43.25 & 170.78 & 152 & 38 & -29 & 186 & 73 & 48 & 4.1 \\
\hline
\end{tabular}

Table 3.7. Comparison of hypocentre locations and focal mechanism parameters for events analysed by Ristau (2008) and in this study. Note that the magnitudes determined by Ristau (2008) (marked by *) are moment magnitudes $\mathrm{M}_{\mathrm{W}}$ whereas in this study we have determined local magnitudes $\mathrm{M}_{\mathrm{L}}$

A total of 209 focal mechanism solutions for earthquakes of $M_{L}>0.44$ were obtained for the period November 2008 to December 2009 when the SAMBA network was operating and 165 solutions for January to April 2010 from the combined SAMBA/DFDP10 networks 

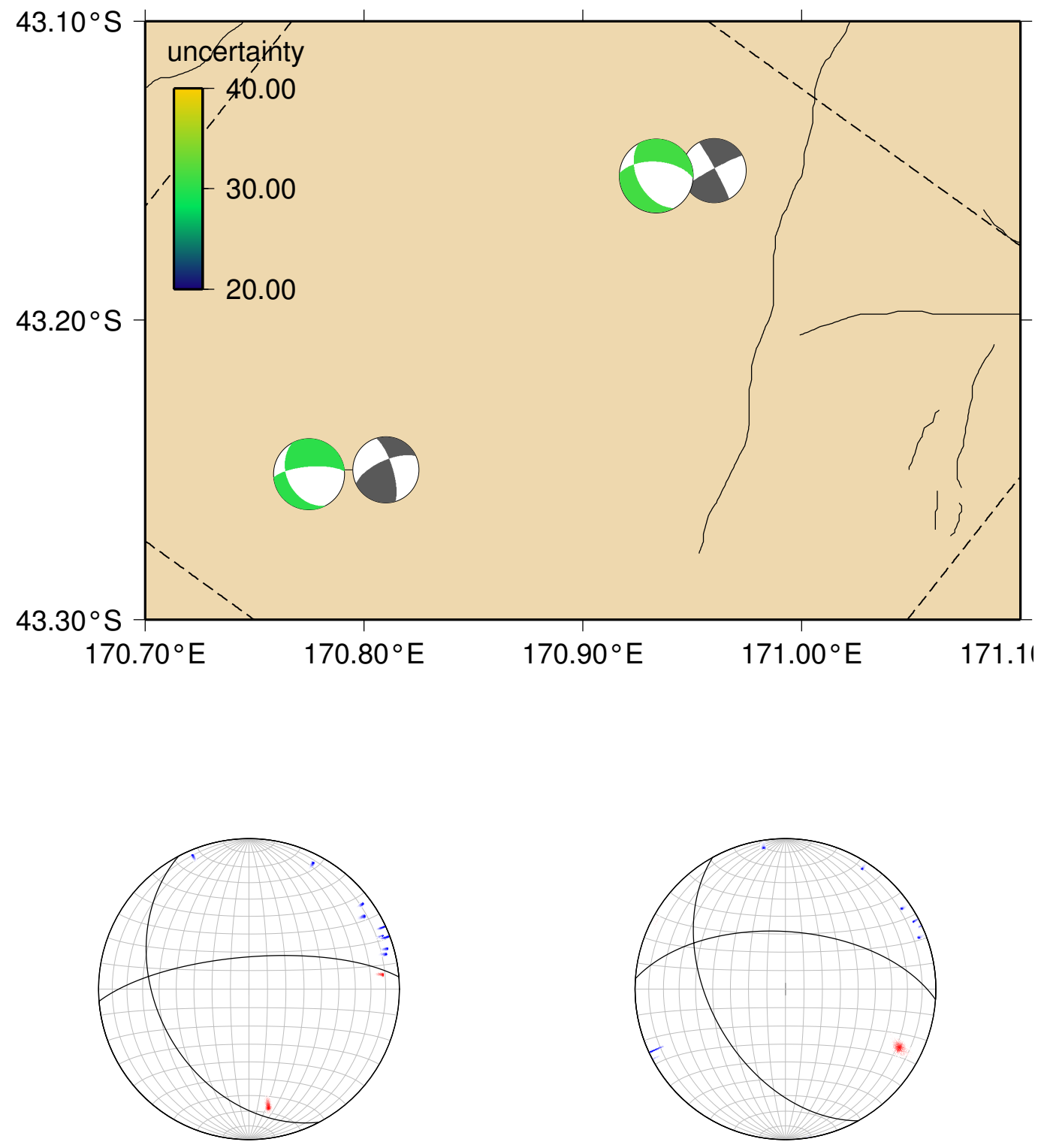

Figure 3.21. Focal mechanism solution of two events that were analysed by Ristau (2008) (grey) and in this study (green, with uncertainties of $30.3^{\circ}$ and $31.1^{\circ}$, respectively, as shown by the scale). The distribution of the first motions on the stereogram is plotted beneath for detail. 
(Table K.1). In the latter period a maximum of 24 stations (including the three GeoNet stations) were recording simultaneously compared to 13 stations in the earlier time period (Fig. C.1). Therefore, the solutions obtained with the larger number of recording stations were chosen as reference mechanisms and compared with those solutions obtained earlier. Focal mechanism solutions were grouped by region (as shown in Fig. 4.7) and compared by sorting their hypocentre locations (from upper left to lower right in each region) and are listed in Fig. 3.22, H.1- H.3. This comparison shows that the distribution of P-wave polarities on the focal sphere is similar for groups of events and that only the number of polarities varies as indicated by the number at the upper right of the focal mechanism. The strike, dip and rake of the focal mechanism solution of similar events differ insignificantly except when the number of polarity picks is low $(\leq 8)$. Then in some cases the solution exhibit large differences (minimum rotation angles $\geq 90^{\circ}$ ). This is especially the case when one polarity pick is wrong. For this reason, we computed the uncertainty of the focal mechanism and the minimum rotation angle for events with different numbers of P-polarities in Table 3.8.

The uncertainty of those mechanisms with the most P-wave polarity picks $(\geq 14)$ ranges between $21-24^{\circ}$. It increases to an average of $30^{\circ}$ for less picks, but does not exceed $35^{\circ}$ for events with only 7 polarity picks. The minimum rotation angles between the bestconstrained focal mechanisms ( $\geq 13$ polarity picks) range between 1.5 and $91.9^{\circ}$, indicating different faulting types. In other words, we can discriminate individual mechanisms when the rotation angles are much larger than the uncertainties of the focal mechanism solutions. The mean minimum rotation angle between all focal mechanism solutions is $60.1^{\circ}$ which is twice the mean uncertainty. This suggests that the mechanisms are different and that these can be distinguished from each other for earthquakes with polarity picks $\geq 13$.

The distribution of the P- and T-axis contours on the focal sphere (Fig. 3.22, H.1-H.3) reflect the similarity of the solutions better than the focal mechanism parameters due to many different mechanisms and the rather large uncertainties of the solutions. This comparison shows that composite focal mechanisms do not exhibit more information than the focal mechanism with the largest number of polarity picks. Sorting of the events in one region with depth, did not reveal any systematic changes in the focal mechanisms, as reported elsewhere (e.g. Imanishi et al. 2011). 


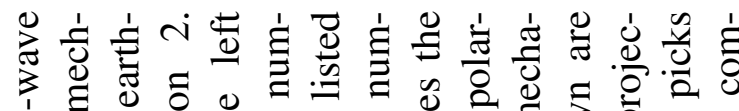

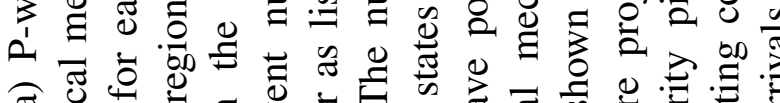

త

ํ.

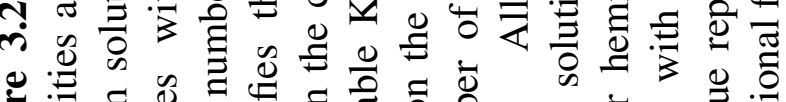

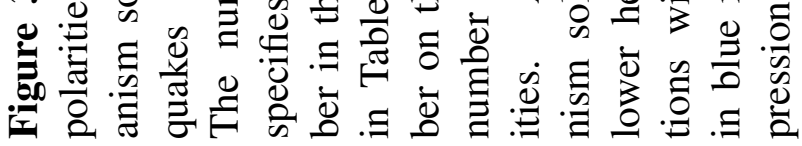

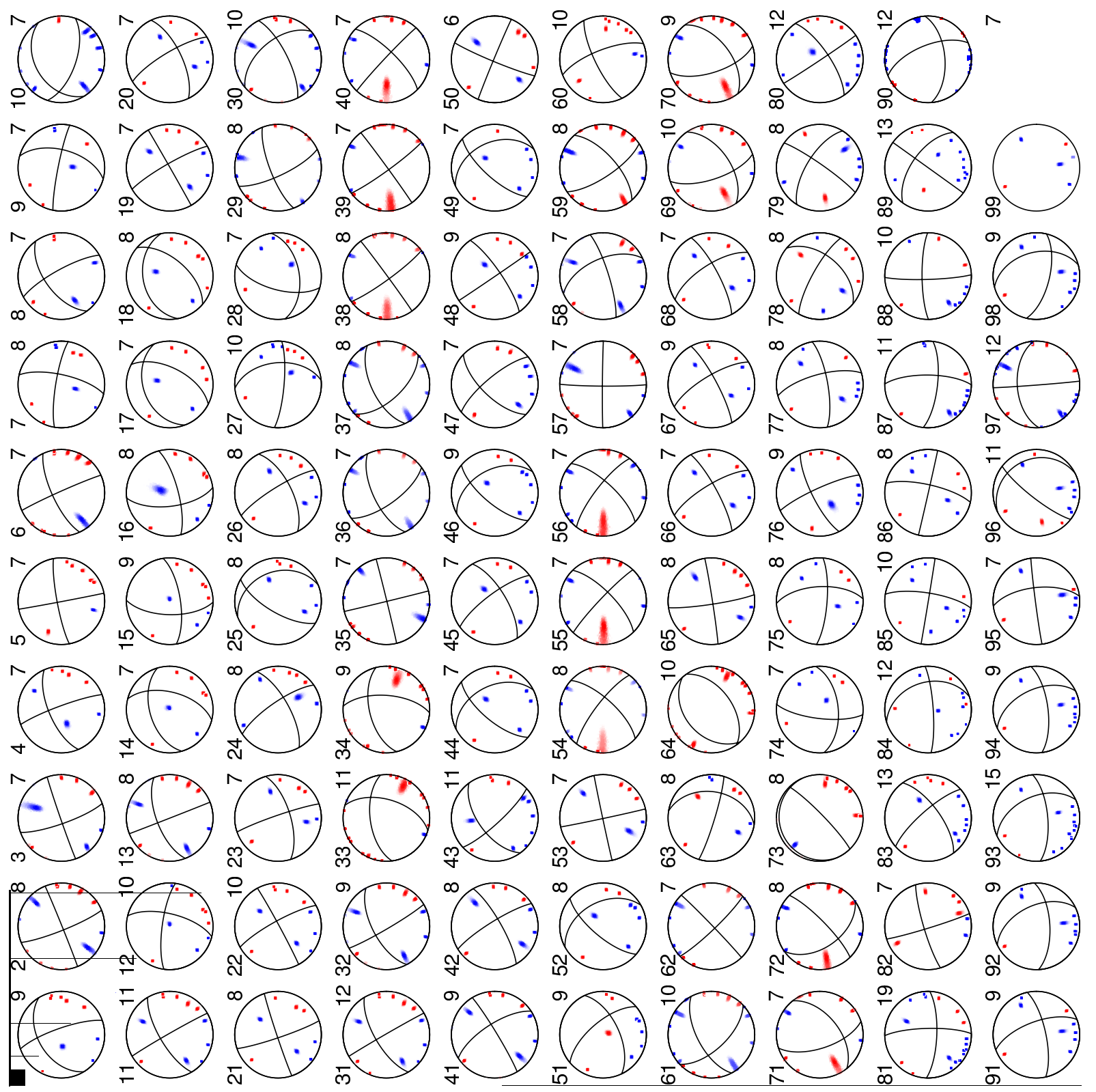




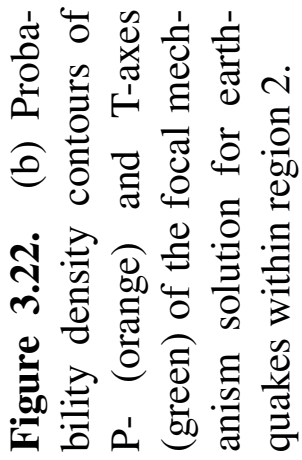
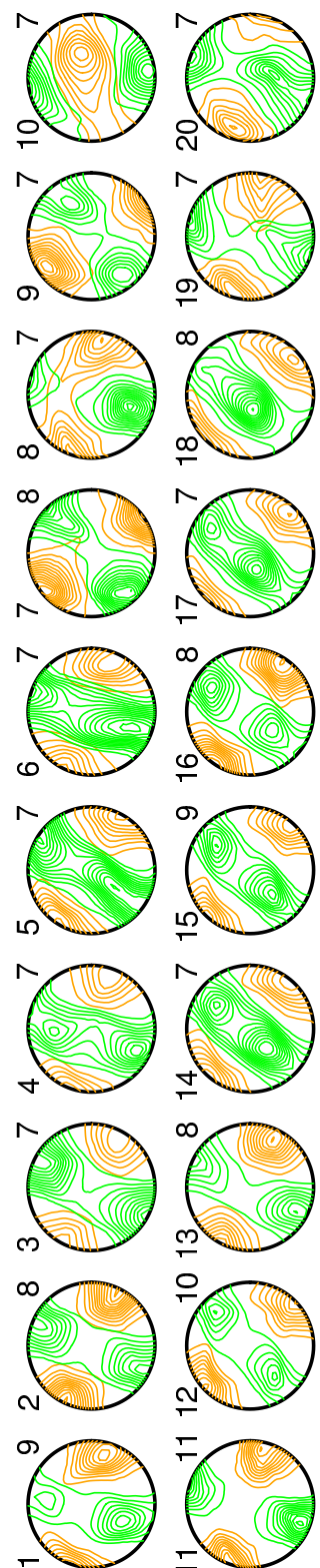
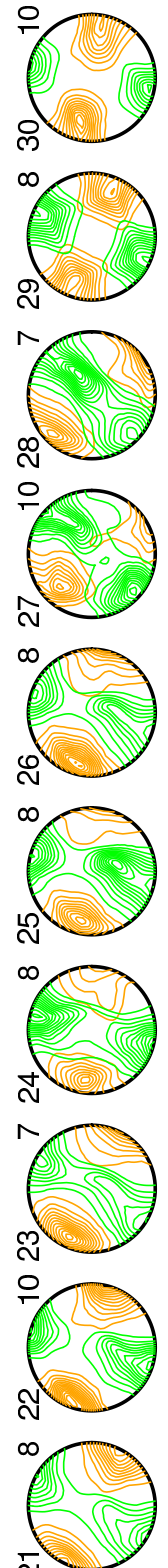
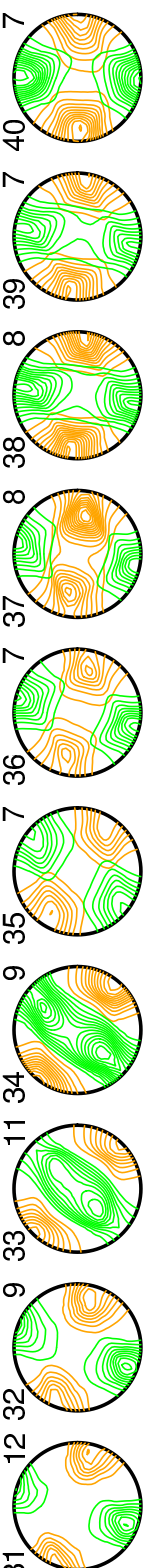
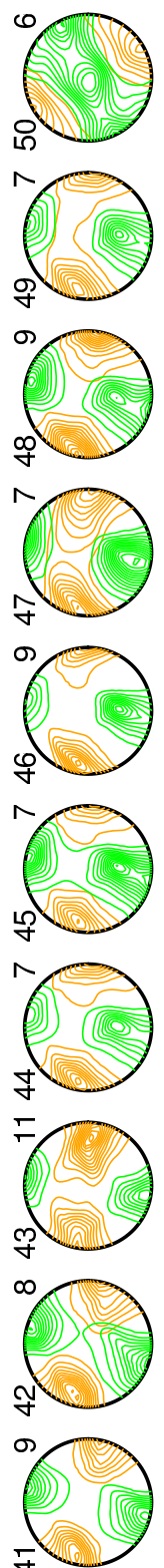
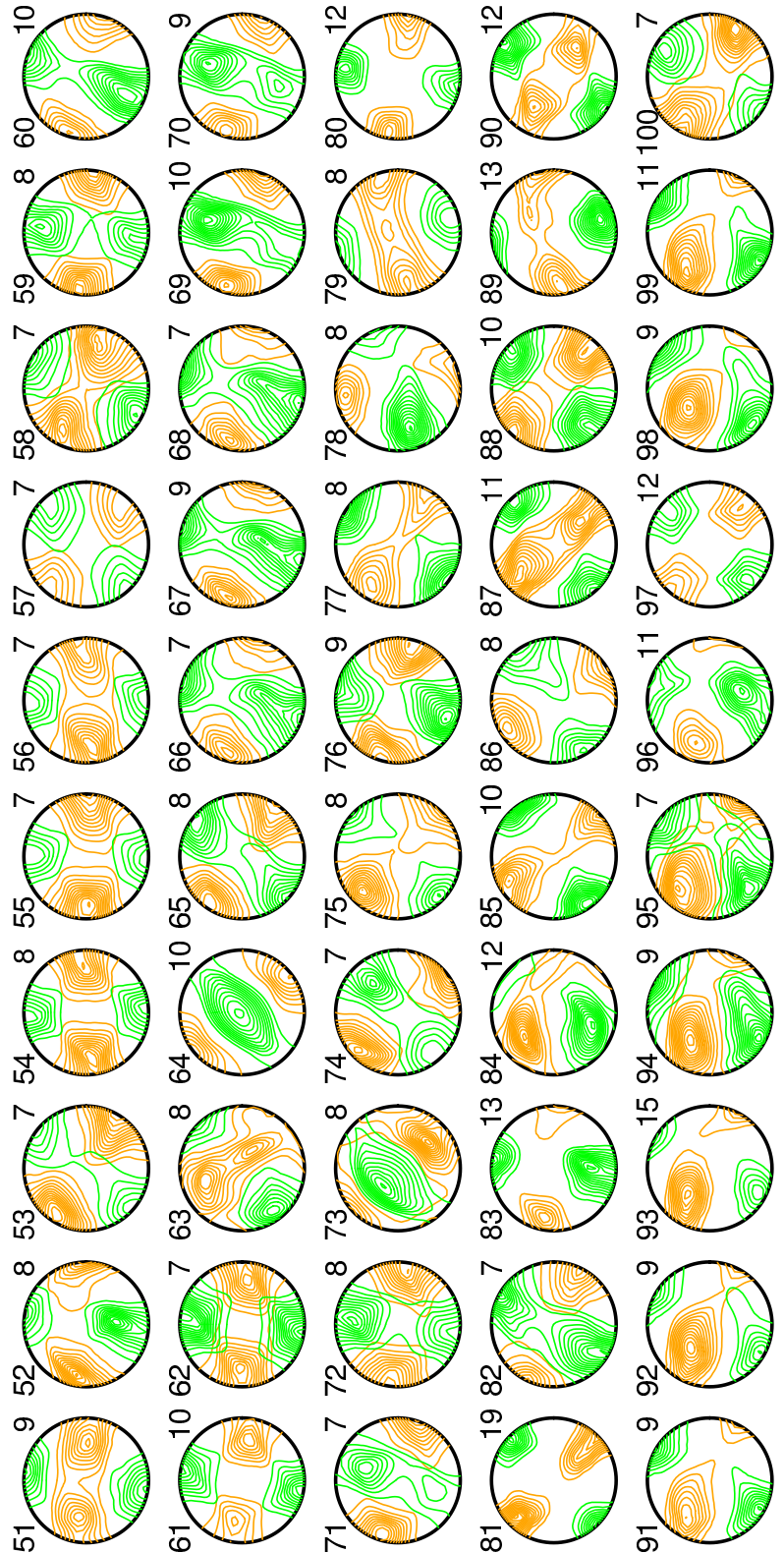


\begin{tabular}{|c|c|c|c|c|c|c|c|c|c|}
\hline \multirow{2}{*}{$\begin{array}{l}\text { Num. } \\
\text { P-pol. }\end{array}$} & \multirow{2}{*}{$\begin{array}{c}\text { Num. } \\
\text { eq. }\end{array}$} & \multicolumn{4}{|c|}{ Mechanism uncertainty } & \multicolumn{4}{|c|}{ Rotation angle } \\
\hline & & $\begin{array}{c}\min \\
{\left[{ }^{\circ}\right]}\end{array}$ & $\begin{array}{c}\max \\
{\left[{ }^{\circ}\right]}\end{array}$ & $\begin{array}{c}\text { mean } \\
{\left[{ }^{\circ}\right]}\end{array}$ & $\begin{array}{c}\text { td. dev. } \\
{\left[{ }^{\circ}\right]}\end{array}$ & $\begin{array}{c}\min . \\
{\left[^{\circ}\right]}\end{array}$ & $\begin{array}{c}\max . \\
{\left[{ }^{\circ}\right]}\end{array}$ & $\begin{array}{c}\text { mean } \\
{\left[{ }^{\circ}\right]}\end{array}$ & $\begin{array}{c}\text { std. dev. } \\
{\left[{ }^{\circ}\right]}\end{array}$ \\
\hline \multicolumn{10}{|c|}{ Region 4} \\
\hline$\geq 13$ & 10 & 20.3 & 27.3 & 24.5 & 2.1 & 10.8 & 74.6 & 35.1 & 11.3 \\
\hline $10-13$ & 23 & 25.8 & 29.3 & 27.6 & 1.1 & 1.6 & 108.2 & 48.9 & 16.6 \\
\hline $8-10$ & 33 & 26.2 & 31.6 & 29.4 & 1.2 & 3.5 & 107.3 & 52.2 & 15.9 \\
\hline 7 & 31 & 28.9 & 32.3 & 30.2 & 0.9 & 0.4 & 107.9 & 48.8 & 15.7 \\
\hline \multicolumn{10}{|c|}{ Region 6} \\
\hline$\geq 13$ & 6 & 24.3 & 30.6 & 27.2 & 2.3 & 1.5 & 91.9 & 47.3 & 23.8 \\
\hline $10-13$ & 24 & 25.8 & 30.0 & 27.9 & 1.5 & 5.2 & 102.4 & 48.9 & 13.8 \\
\hline $8-10$ & 22 & 27.9 & 32.3 & 29.8 & 1.3 & 2.1 & 100.7 & 53.2 & 16.9 \\
\hline 7 & 26 & 29.1 & 34.9 & 30.7 & 1.2 & 2.3 & 107.7 & 55.2 & 15.7 \\
\hline \multicolumn{10}{|l|}{ Region 2} \\
\hline$\geq 13$ & 4 & 22.6 & 26.9 & 25.1 & 1.9 & 34.0 & 63.6 & 32.4 & 16.2 \\
\hline $10-13$ & 21 & 25.2 & 30.7 & 27.5 & 1.5 & 2.9 & 101.4 & 49.9 & 13.4 \\
\hline $8-10$ & 40 & 27.0 & 35.4 & 29.0 & 1.7 & 2.2 & 109.2 & 50.8 & 13.1 \\
\hline 7 & 35 & 28.4 & 31.7 & 29.8 & 0.9 & 2.4 & 109.0 & 45.0 & 12.1 \\
\hline \multicolumn{10}{|l|}{ Region 1} \\
\hline 10 & 2 & 27.1 & 28.6 & 27.9 & 1.0 & 75.7 & 75.7 & 37.9 & 53.6 \\
\hline 9 & 5 & 27.6 & 31.7 & 29.1 & 1.6 & 16.9 & 105.2 & 50.0 & 21.1 \\
\hline 8 & 5 & 27.7 & 30.9 & 29.4 & 1.5 & 18.0 & 76.7 & 39.0 & 17.2 \\
\hline 7 & 8 & 28.5 & 33.8 & 30.2 & 1.9 & 19.6 & 109.4 & 54.5 & 19.6 \\
\hline
\end{tabular}

Table 3.8. Uncertainty of the focal mechanism parameters and rotation angles (for each minimum, maximum, mean and standard deviation of the mean) for focal mechanism solutions obtained for different numbers of P-polarity picks for regions shown in Fig. 4.7. 


\section{Microseismicity and stress in the vicinity of the Alpine Fault, central Southern Alps}

This chapter has been published in the Journal of Geophysical Research (Boese et al. 2012) and summarises the results of the data from November 2008 to December 2009. The published version has been altered to fit the context of this thesis and to avoid repetitions. The introduction has been omitted because it summarised information provided in Chapter 1.2. The two last sections have been added and are not included in the publication. These revisit two topics discussed only briefly in the paper-the normal and shear stresses on the Alpine Fault plane and the seismicity gap in the area between the Whataroa and Wanganui rivers.

\subsection{Methods}

\subsubsection{Earthquake hypocentre and uncertainty determination}

Hypocentres have been computed using a modified version of the minimum 1-D velocity model determined by O' Keefe (2008) (Table 1.2), in which we have removed the uppermost layer, that represented a mean surface velocity layer for stations on sediments and bedrock in O' Keefe's analysis. This layer is unnecessary in our case, since the majority of the SAMBA stations are situated on hard rock. Shear-wave velocities are determined using a $V_{P} / V_{S}$ ratio of 1.68 as obtained by O' Keefe (2008). This simple 1-D velocity model was favoured over existing 3-D models of Eberhart-Phillips and Bannister (2002) and Brikké (2010) due to its simplicity and similarity to $1-\mathrm{D}$ velocity structures determined previously in active seismic reflection/refraction studies (Smith et al. 1995; Kleffman et al. 1998; Scherwath et al. 2002) and from earthquake inversion (Eberhart-Phillips 1995; Leitner et al. 2001). The 3 -D velocity models lack sufficient resolution at shallow depths for our purposes, having been derived on regional scales with $8 \mathrm{~km}$ node spacing in the uppermost crust. Moreover, 
the complex near-surface-structure of these models make them difficult to apply in this study.

Earthquakes are initially located using SEISAN and are then relocated using the nonlinear location program NonLinLoc 5.0 (Lomax et al. 2000), to better constrain the posterior uncertainties in the hypocentre parameters (Section 2.2.2). We expand our 1-D velocity model (Table 1.2) across a grid with $1 \mathrm{~km}$ node spacing in all dimensions. The Alpine Fault is orientated at a $55^{\circ}$ angle with respect to the grid. Synthetic travel-times for P-and S-waves propagating from each grid node to each station are calculated within NonLinLoc. That algorithm can be applied to models with sharp first-order velocity contrasts, and accurately produces arrival-times of the first-arriving wave (such as diffracted and head waves) using Huygens' principle.

The posterior probability density function of the earthquake hypocentre is found using a grid-search method (Lomax et al. 2009). We adapted the hybrid "Oct-Tree" search method described by Lomax et al. (2000). This method maps the probability of the earthquake location on a coarse grid by multiplying the probability density function (PDF) in the centre of each cell by the cell volume. High-probability cells are subsequently subdivided into eight new cells, generating a cascade of sampled cells and calculated probabilities. The procedure is repeated until a predetermined number of processed nodes has been reached, or the smallest specified node size is reached (Lomax 2011). Oct-tree sampling is an importance-sampling method in the sense that it uses information gained from the previous sample to refine the search. This sampling method allows the identification of multiple modes of the probability density functions. The complete PDF can only be determined using a systematic grid-search, but a suitable representation of the PDF can be found by having samples in proportion to the probability. The resulting hypocentre PDF describes the earthquake hypocentre uncertainty as a volume of irregular form, which quantifies the agreement between predicted and observed arrival-times and may contain multiple solutions. It reflects uncertainties due to the network-event geometry, arrival-time reading errors and calculated travel-time errors. The final earthquake hypocentre location is selected as the point of maximum likelihood within the PDF solution.

Several parameters have to be predefined in NonLinLoc, which directly influence the uncertainty volume. These parameters are

- $\sigma^{\text {model }}$, the typical model error of the travel-time residual,

- $\mathrm{L}_{\text {corr }}$, which is an estimate of the characteristic length scale of the velocity anomaly between two stations, 
- $\Delta \sigma^{\text {model }} / \sigma^{\text {model }}$ which gives an estimate of the model error on the total uncertainty in proportion to the travel-time,

- $\sigma_{\text {min }}^{\text {model }}$ and $\sigma_{\max }^{\text {model }}$, which set lower and upper limits on the travel-time error due to unmodelled velocity structure.

The first two parameters, $\sigma^{\text {model }}$ and $\mathrm{L}_{\text {corr }}$, are needed for the calculation of the model-error covariance matrix (Tarantola and Valette 1982b), which describes whether a correlation in the model errors exists between two stations. We tested values of 1, 4, 8 and $80 \mathrm{~km}$ for $\mathrm{L}_{\text {corr }}$, with the latter two representing the average and the maximum station distance. The differences in the resulting uncertainty volumes were minimal and we set $\mathrm{L}_{\text {corr }}$ to $8 \mathrm{~km}$, an anomaly length which we expect to be able to resolve with the station spacing.

In order to estimate the Gaussian uncertainty of the arrival-time readings and the calculated travel-times for the earthquakes recorded in this study, we have performed a comprehensive analysis of the travel-time residuals for the SAMBA data (Section 3.1.1 and Table 3.2). This analysis showed that the typical model uncertainty $\sigma^{\text {model }}$ of the travel-time residual is small for the SAMBA station network in comparison to the reading uncertainty (Table 3.2). We obtain estimates of the reading uncertainty by two independent means. First, we determine the standard deviation of the travel-time residuals for all stations, and second, we analyse lag-times obtained from cross-correlation of similar events in a swarm. Error limits for the model uncertainty are here set to 0 and $0.2 \mathrm{~s}$. The maximum value was obtained for station POCR which exhibits (pre-weighting) mean model uncertainties of 0.17 and $0.16 \mathrm{~s}$ for P- and S-phases. This station is the only station located in a sediment-filled valley, so the assumed velocity model is not fully suitable for this setting. Our estimate for the model error as a fraction of the whole travel-time is obtained for a sample set of 46 earthquakes, distributed across the study area and recorded at all stations. We calculate values of $0-9 \%$ with mean values of $3.3 \%$ for the $\mathrm{P}$ - and $1.6 \%$ for the S-phase travel-times. We assume hereafter that $5 \%$ of the travel-time is a reasonable representation of the velocity model uncertainty.

\subsubsection{Magnitudes}

Earthquake magnitudes are determined from waveform amplitudes corrected for geometric spreading and attenuation (equation 2.23). Amplitude-readings are obtained from half the peak-to-peak displacement on one of the horizontal components of a pseudo-WoodAnderson seismograph, simulated in SEISAN (version 8.2.1, October 2008, and 8.3, May 2010) (Havskov and Ottemöller 2000). It is assumed that the gain of the Wood-Anderson 
instrument is $2080 \pm 60$, as reported by Uhrhammer and Collins (1990).

To determine magnitudes for the SAMBA data, we solve the general inverse problem

$$
\mathbf{Y}=\mathbf{X m}+\mathbf{e}
$$

by using LU-matrix factorisation. The parameters involved in the equation are as follows:

- $\mathbf{Y}$ is a two-part vector containing the amplitude readings and the geometrical spreading term $\mathrm{A}_{\mathrm{j}}+\alpha \log _{10} \Delta_{\mathrm{j}}$ of the $\mathrm{j}$-th event, and the magnitudes $\mathrm{M}_{\mathrm{j}}^{\mathrm{c}}$ from the New Zealand earthquake catalogue as reported by GeoNet, which are used for calibration of the SAMBA magnitudes $\mathbf{M}_{\mathbf{j}}$.

- $\mathbf{X}$ is a matrix representing which component of each station has an amplitude reading and which events have calibration magnitudes $\mathbf{M}_{\mathrm{j}}^{\mathrm{c}}$. $\mathbf{X}$ also contains the hypocentral distance $\Delta_{\mathrm{jk}}$, where $\mathrm{j}$ marks the event and $\mathrm{k}$ the station.

- $\mathbf{m}$ are the parameters of interest, namely the SAMBA magnitudes $\mathrm{M}_{\mathrm{j}}$, the attenuation term $0.4343 \gamma$ and the station correction terms $S_{k}$.

- $\mathbf{e}$ is a vector of residuals for the SAMBA magnitudes $\Delta \mathrm{M}_{\mathrm{j}}$ and the GeoNet magnitudes $\Delta \mathrm{M}_{\mathrm{j}}^{\mathrm{c}}$ used for calibration.

We have tested the dependency of the data on geometric spreading by separately inverting for the geometrical spreading coefficient $\alpha$ only (Section 3.2.1). We obtain $\alpha=1.6$ (Fig. 3.8). For geometric spreading due to expansion of the direct earthquake waves in space, we would expect $\alpha=1$. We therefore assume $\alpha=1$ and attribute the remaining amplitude decay to the effects of scattering and anelastic attenuation on the magnitude. Considering the hypocentral range and the dominant frequency of the wave, we find that the influence of attenuation can be up to half that of the geometrical spreading.

The anelastic attenuation parameter $\gamma$ is known to be frequency dependent $\gamma=\gamma(\mathrm{f})$, as seen from the relationship between $\gamma$ and the quality factor $\mathrm{Q}$ (equation 2.17). Eberhart-Phillips et al. (2008) studied 3-D attenuation in central South Island by analysing spectra of 5695 vertical-component velocity seismograms of earthquakes larger than $\mathrm{M}_{\mathrm{L}}$ 2.5. For the observed frequency range of the local earthquakes of 2-40 Hz, Eberhart-Phillips et al. (2008) were able to fit the spectra equally well with both frequency-independent and frequency-dependent Q. Abercrombie (1998, and references therein) found a clear change in frequency dependence of $Q(f)$ at $10 \mathrm{~Hz}$. Although Eberhart-Phillips et al. (2008) determined $Q_{P}$, we assume here that $Q_{S}$ can be treated 
similarly as frequency-independent, so we set $v=0$ and $Q=Q_{0}$. We invert for $\gamma=\gamma_{0} \mathrm{f}$ according to equation 2.17 .

\subsubsection{Focal mechanisms}

We determine focal mechanism solutions from P-wave first motion polarities for earthquakes recorded by the SAMBA array using the Bayesian approach of Walsh et al. (2009). This method treats observational uncertainties probabilistically in order to account for polarity errors arising from low signal-to-noise ratios and incorrectly wired seismometers, hypocentre location uncertainties, and imprecise knowledge of the seismic velocity structure. The prior probability of a falsely wired seismometer is here set to $20 \%$, as suggested by Hardebeck and Shearer (2002) who analysed inconsistencies amongst emergent polarity picks of similar event clusters in the Northridge area, California. We do not discriminate between impulsive and emergent polarity picks, although Hardebeck and Shearer (2002) found that only $10 \%$ of the impulsive polarities were inconsistent. Uncertainty in the hypocentre location results in a variety of possible ray paths from the hypocentre to the receivers and, therefore, in a range of possible take-off angles and azimuths. This causes a cloud of corresponding positions on the focal sphere. The density and the distribution of these points depend predominantly on the uncertainty in depth, since this is usually larger than the horizontal uncertainty. As an example, a change in depth of $1 \mathrm{~km}$ for earthquakes shallower than $7 \mathrm{~km}$ can cause a change in the take-off angle of up to $15^{\circ}$ for up-going rays Hardebeck and Shearer (2002), assuming a 1-D velocity model with a gradient of $\mathrm{dV} / \mathrm{dz}=0.25 \mathrm{~s}^{-1}$ and $\mathrm{V}_{0}=4.7 \mathrm{~km} / \mathrm{s}^{-1}$. Hardebeck and Shearer (2002) and Walsh et al. (2009) investigated the effect of the velocity model on the polarity distribution on the focal sphere. Hardebeck and Shearer (2002) found that the influence of the velocity model on the focal mechanism is larger than uncertainty in hypocentre location. Since take-off angles at shallow depth are most sensitive to the velocity model, the focal mechanisms of deeper earthquakes show smaller changes resulting from changes in the velocity model (McKenzie 1969; Hardebeck and Shearer 2002).

To characterise the uncertainty of the focal mechanism solution, we use the estimate of the standard deviation $\sigma_{\Theta}$ of the focal mechanism parameters by Arnold and Townend (2007) (equation 2.42). This approach assumes equal errors in strike, dip and rake. 


\subsubsection{Stress inversion}

Assuming that individual focal mechanisms represent a uniform state of stress and are driven by the same stress tensor, regional stress estimates can be derived by inverting a set of independent focal mechanism observations. Stress inversion aims to find the principal stress axes that are consistent with all the focal mechanism solutions in a geographically confined area. We apply the Bayesian approach developed by Arnold and Townend (2007) which accounts for observational errors and fault plane ambiguities in the focal mechanism solutions to estimate tectonic stress parameters.

\subsection{Results}

\subsubsection{Earthquake locations and their uncertainties}

A total of 1791 events were recorded between November 2008 and December 2009 in the study area. All events recorded by more than five SAMBA stations (87.3\%) are shown with their uncertainties in Fig. 4.1 (a), in comparison with the long-term seismicity in (b), and with magnitudes in (c). In order to show the depth variation of the hypocentre distribution along the strike of the Alpine Fault, the events are projected onto depth profiles in Fig. 4.2.

The error volume projected onto the horizontal plane is approximately circular for most of the earthquakes within the station network (Fig. 4.1), reflecting a uniform distribution of the recording stations around the events (azimuthal gaps for events in the inner triangle range between $57^{\circ}$ and $192^{\circ}$; see also Fig. 4.4).

The uncertainty in depths is controlled by the station distribution and varies throughout the network. Depth uncertainty increases markedly when there is no station within a distance of 1.5 focal depths of the earthquake. For this reason, vertical uncertainties increase towards the boundaries of the SAMBA network (as seen in depth transects 1, 2 and 7 of Fig. 4.2). Since the resolution of the hypocentre uncertainty varies throughout the study area, mean depth and mean uncertainties are displayed by grey bars in the background of the profiles in Fig. 4.2. Hypocentre depths are best constrained in the vicinity of the Alpine Fault where the station distribution is the densest (as can be seen by the increase in the error bars with distance from the Alpine Fault).

The distribution of the minimum hypocentral distances of all events to the nearest 
Figure 4.1. (a) Epicentral locations of events recorded by more than 5 stations between November 2008 and December 2009. Earthquake hypocentres were determined using the non-linear $43.6^{\circ} \mathrm{S}$ location program NonLinLoc. The probability density function (red) $43.8^{\circ} \mathrm{S}$

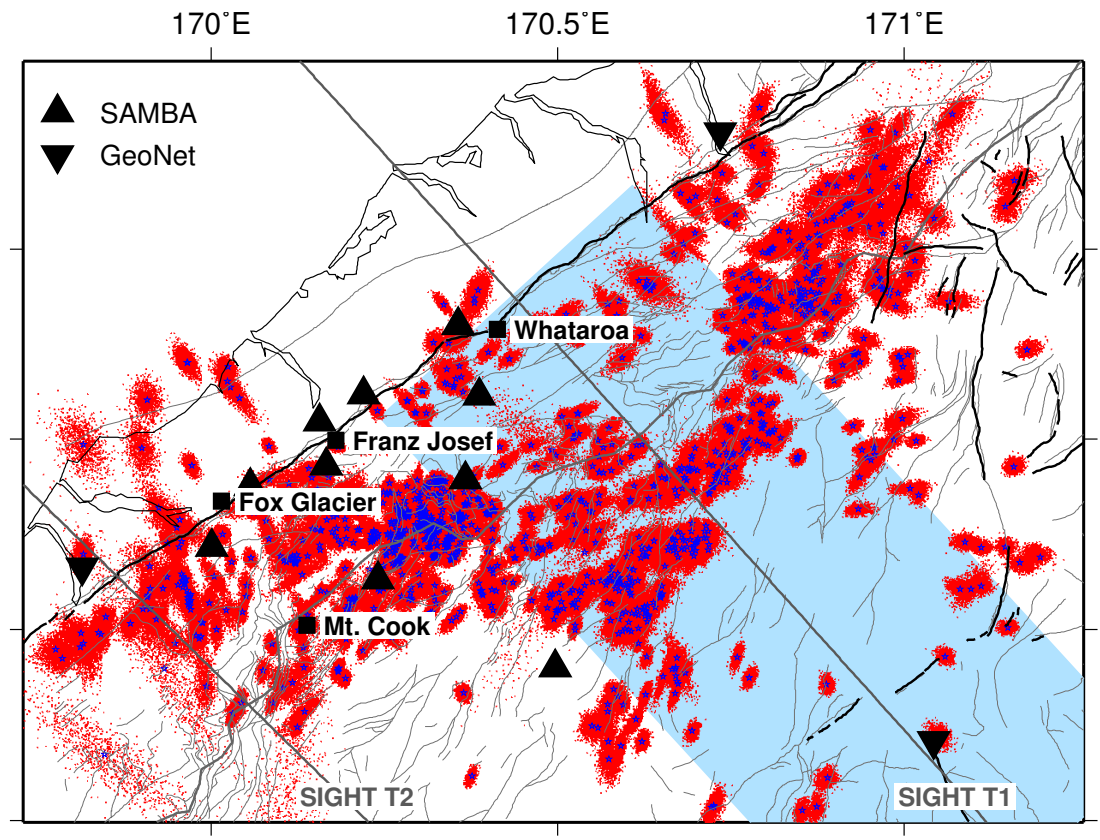
of each earthquake represents the uncertainty of the hypocentre location, the blue dot marks the maximum likelihood hypocentre location. The light blue area shows which earthquake hypocentres are projected onto SIGHT transect $\mathrm{T} 1$ as shown in Fig. 4.3. (b) Seismicity recorded in the central Southern Alps since 1984 by GeoNet (grey), Reyners (1988) (blue), Leitner et al.

(2001) (red), O' Keefe (2008) (green) and in this study (black).

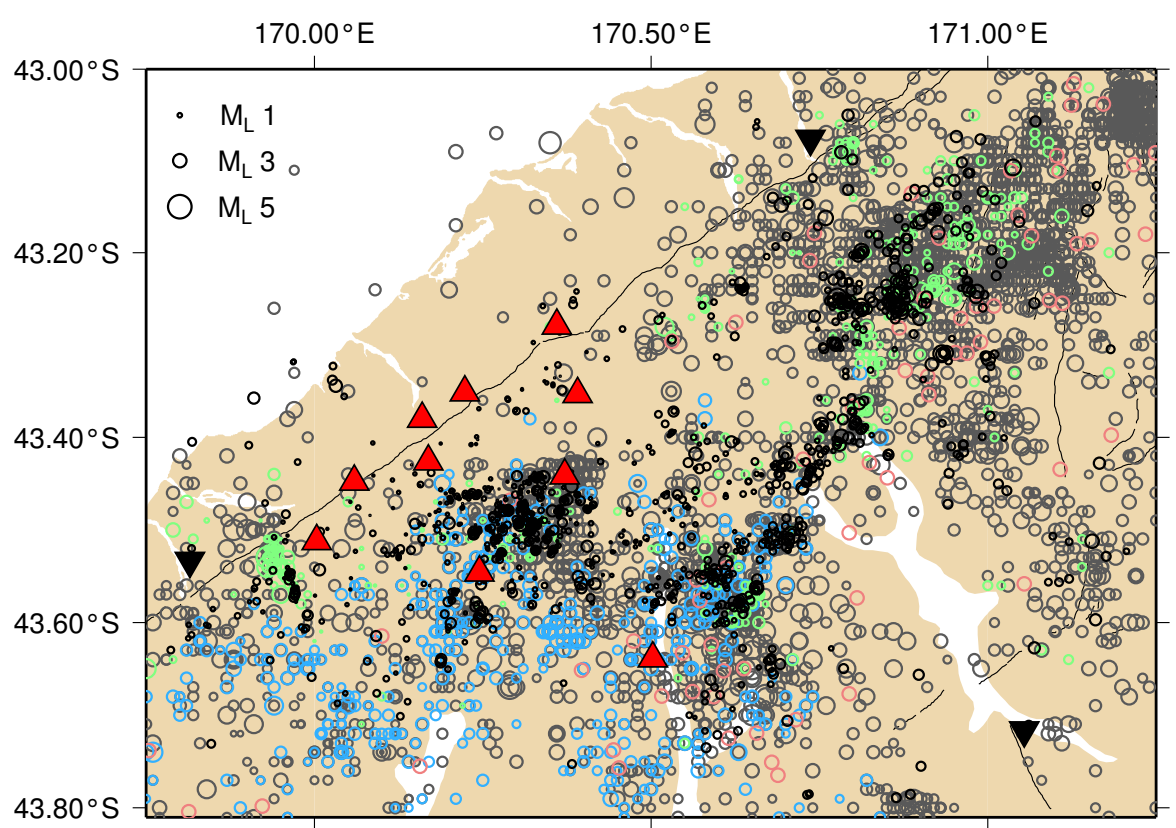




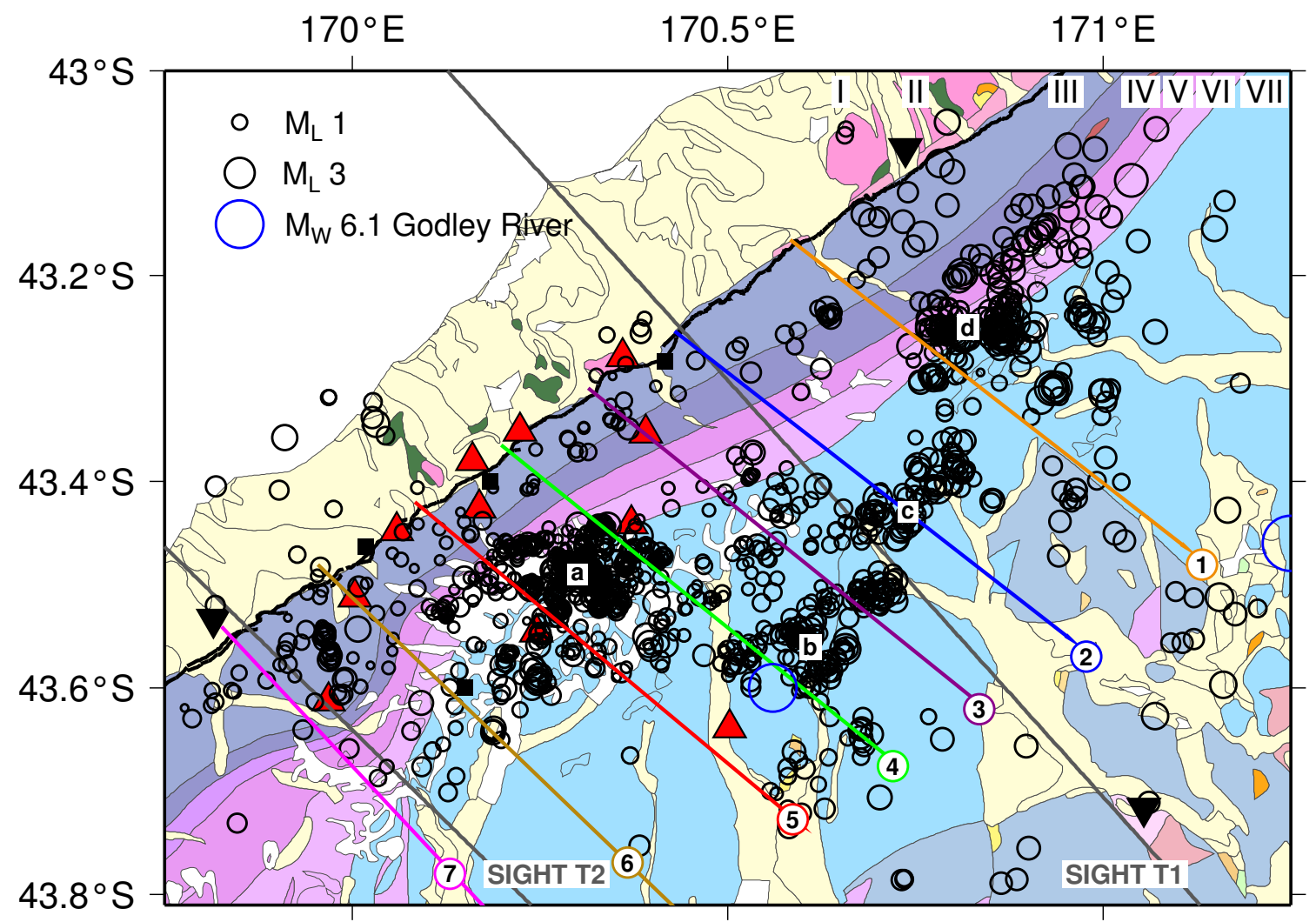

Figure 4.1. (c) Epicentres as shown in (a) with the symbol size representing the magnitude. Coloured lines and numbers indicate the depth profile onto which events within $\pm 5 \mathrm{~km}$ are projected (Fig. 4.2). Letters are used to mark seismicity clusters described in the text. In the background, a simplified geological map based on the geological data from the 1:1000000 Geological Map of New Zealand (Officers of the New Zealand Geological Survey 1972 with limited updates by P.J. Forsyth and N. Mortimer (2004)) is shown. Textural zones are I Quaternary deposits, II Palaeozoic and Mesozoic Western Province basement (gneiss, granite, granodiorite), III Rakaia Terrane mylonite, curly schist and schist, IV Rakaia Terrane schist, V+VI Rakaia Terrane semi-schist, VII Rakaia Terrane greywacke sandstone and mudstone according to Cox and Sutherland (2007) 

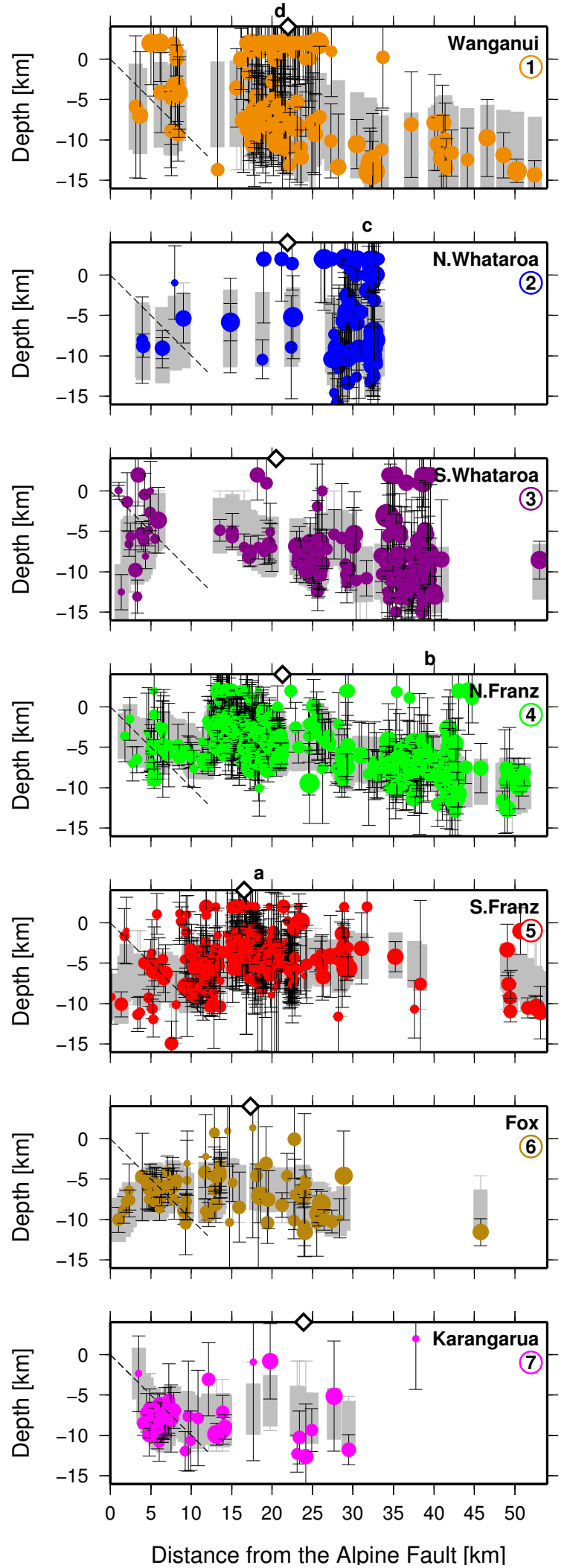

Figure 4.2 Hypocentral depth and depth uncertainty of earthquakes projected onto the corresponding profiles (number and colour) shown in Fig. $4.1 \mathrm{c}$ ), with the symbol size representing the magnitude of the event. Grey bars indicate mean depth and mean uncertainties (over seven points) for the events shown in the profile. Letters a-d indicate the position of clusters (Fig. $4.1 \mathrm{c}$ ) along the profile. Diamonds indicate the surface position of the Main Divide Fault Zone. The dashed line indicates the Alpine Fault for an assumed dip of $45^{\circ}$. 
stations, as an indicator of the range of well-constrained depths, is bimodal with modes at 7 and $20 \mathrm{~km}$. Its mean is $14 \mathrm{~km} \pm 9.5(1 \sigma) \mathrm{km}$. Consequently, deeper events are better constrained in the whole study area.

A comparison of the long-term background seismicity recorded by GeoNet during the last 20 years with the short-term seismicity recorded by SAMBA over 14 months (Fig. $4.1 \mathrm{~b}$ ) demonstrates distinct spatial patterns of quiescence and persistent activity in the epicentral distribution. Earthquakes are spatially clustered and occur in patches along and to the east of the Main Divide Fault Zone (MDFZ) (Fig. 1.6), a major backthrust off the Alpine Fault (Cox and Findlay 1995). The earthquakes are not confined to mapped surface fault traces (as shown in Fig. 4.1 a) but are distributed throughout an approximately $25 \mathrm{~km}$-wide region. However, there is some indication of reduced seismic activity in a $15 \mathrm{~km}$-wide zone adjacent to the Alpine Fault that coincides with the average width of the Alpine schist (Little et al. 2005; Cox and Sutherland 2007) (textural zones III and IV in Fig. 4.1 c). This may reflect different amounts and characteristics of fractures in the schist relative to the greywacke further southeast.

Four distinct clusters stand out in the seismicity distribution (letters in Fig. $4.1 \mathrm{c}$ ). Cluster a) occurs in the middle of the SAMBA array, has well-constrained depths $<7 \mathrm{~km}$, and comprises small events of $\mathrm{M}_{\mathrm{L}}<2.5$. Cluster b) may represent continuing aftershocks of the $\mathrm{M}_{\mathrm{W}} 6.1$ Godley Valley earthquake. Cluster c) is confined to a northeast-trending highseismicity zone which occurs within $30 \mathrm{~km}$ of the Alpine Fault. It borders a distinct aseismic gap that extends north-westwards to the surface trace of the Alpine Fault between the Wanganui and Whataroa rivers (Fig. 1.8). The fourth cluster, d), occurs at the northeastern boundary of the study area, has poorly-constrained depths and significantly larger magnitudes $\left(\mathrm{M}_{\mathrm{L}}<3.5\right)$. The depth distribution of clusters $\mathrm{b}, \mathrm{c}$ and $\mathrm{d}$ can at best be partially resolved.

Fig. 4.2 shows the earthquake hypocentres projected onto profiles perpendicular to the Alpine Fault. Three of these transects coincide with geological cross sections by Little et al. (2005). The north-easternmost profile 1 (orange hypocentres) shows distinct clusters of events approximately 8 and $16-25 \mathrm{~km}$ southeast of the fault. The latter cluster coincides with the MDFZ (as indicated by a black diamond in all profiles). In the Whataroa river valley (transect 2, blue hypocentres), few earthquakes occur close to the Alpine Fault. Events cluster at about $30 \mathrm{~km}$ distance from the Alpine Fault (cluster c) over a wide depth range. These depths are quite uncertain (mean depth uncertainty $5 \pm 1.6(1 \sigma) \mathrm{km}$ ) as there is no station in the vicinity, but the hypocentres align with a steeply-dipping fault mapped at the surface (Fig. 3a of Little et al. 2005). To the south, profile number 3 (purple hypocentres) 
reveals a distinct earthquake cluster within $5 \mathrm{~km}$ of the surface trace of the Alpine Fault and a number of events between 15 and $40 \mathrm{~km}$, increasing in depth with distance from the fault. Transect 4 (green hypocentres) shows several events $2-8 \mathrm{~km}$ southeast of the surface trace of the Alpine Fault at depths consistent with the estimated position of the fault. Abundant earthquakes with shallow hypocentral depths occur at $15 \mathrm{~km}$ distance to the fault trace (cluster a). At greater distances, the earthquake depths increase monotonically. Profiles 5 (red hypocentres, average uncertainty $\pm 2.6 \mathrm{~km}$ ) and 6 (brown hypocentres, average uncertainty $\pm 3 \mathrm{~km}$ ) indicate a bulge in the seismicity with a radius of curvature of $\sim 10 \mathrm{~km}$ despite the depth uncertainty. Events near the Alpine Fault and $20 \mathrm{~km}$ southeast of the surface trace occur at larger depths than those events centred around the MDFZ (depths of $6 \mathrm{~km})$. In this region, the distance between MDFZ and the Alpine Fault is narrowest $(15 \mathrm{~km}$ versus $30 \mathrm{~km}$ elsewhere; Cox and Findlay 1995). Transects 5 and 6 exhibit few events 45-50 km from the Alpine Fault trace, but in general earthquakes occur within a narrow zone close to the Alpine Fault. Transect number 7, which straddles the southern boundary of the SAMBA network, reveals a cluster of events $4-8 \mathrm{~km}$ southeast of the surface trace at depths possibly associated with the Alpine Fault. The remaining events exhibit increasing depths with distance from the fault but the uncertainty in depth is quite large $(4 \pm 2.9 \mathrm{~km})$.

Figure 4.3 shows the projection of earthquakes within $20 \mathrm{~km}$ on either side of SIGHT transect 1 (light blue area in Fig. 4.1 a) and six large earthquakes since 1946 from elsewhere (Fig. 1.6) onto the resistivity profile by Wannamaker et al. (2002). The depth-distribution of those earthquake hypocentres reveals that the seismogenic zone varies from northwest to southeast across the Southern Alps but nowhere it exceeds $17 \mathrm{~km}$. The seismicity correlates with the high-resistivity regions and is clustered where the resistivity gradient is high (see also 4.12). Wannamaker et al. (2002) interpreted the low-resistivity regions as zones of interconnected fluids, which are trapped within the mylonitised, ductile shear zone. The six largest events (white circles, events are shown in Fig. 1.6) occur at greater depths on average than the lower-magnitude seismicity, probably at the base of the seismogenic zone (Sibson 1984) in this region.

A histogram of the depths of all events is shown in Fig. 4.4. This distribution has a mode at $6 \mathrm{~km}$ depth due to the large number of shallow events in the centre of the SAMBA array (profiles 4 and 5 in Fig. 4.2). The second maximum at the surface results from inconsistent phase arrival times or hypocentre locations outside the station network with poor depths resolution. 


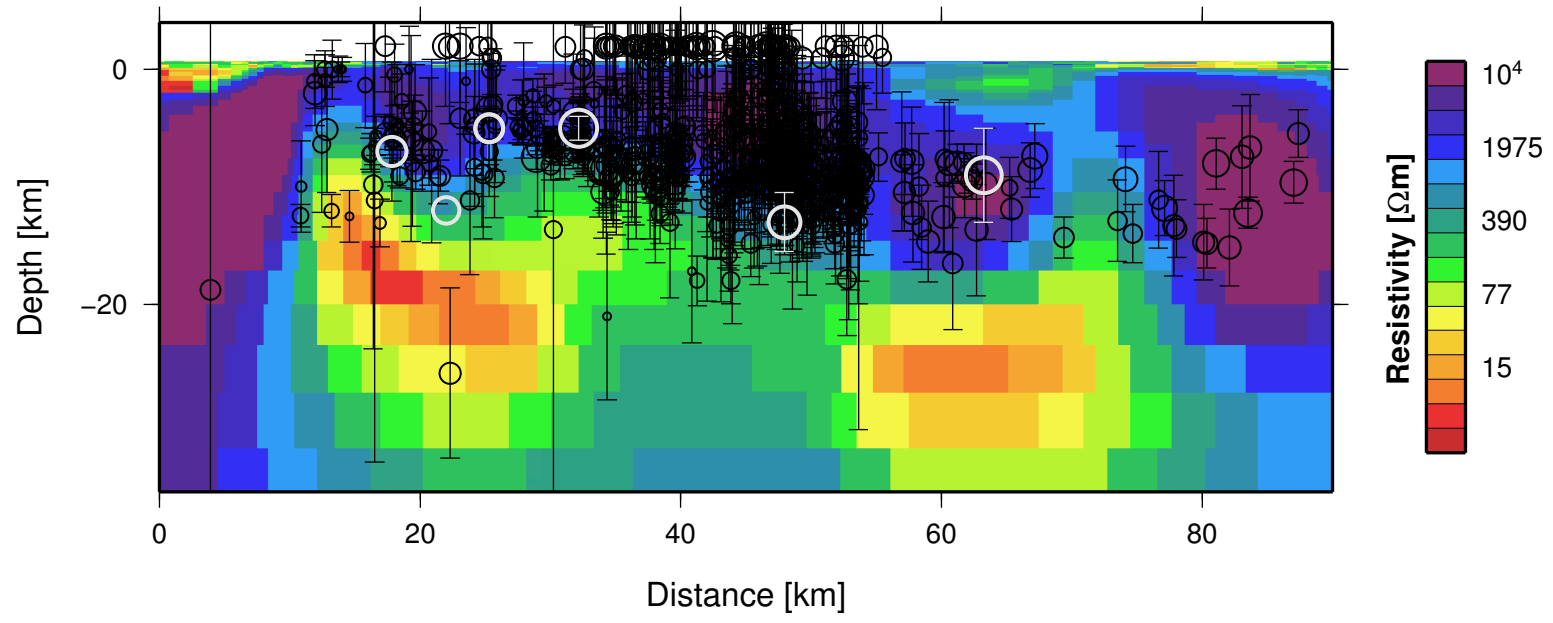

Figure 4.3. Hypocentre locations and depth uncertainty of local earthquakes (within $20 \mathrm{~km}$ of the transect, black) and large earthquakes (in the Southern Alps region, white, see Fig. 1.6 and Table 1.1 for details) projected onto SIGHT transect T1, for which a resistivity model has been derived by Wannamaker et al. (2002). Note that the average topography is $1.5 \mathrm{~km}$ in this area and that for distances $\geq 60 \mathrm{~km}$, earthquakes fall outside the recording range of the SAMBA network. Depth uncertainties are calculated from the maximum length of the uncertainty volume determined using NonLinLoc. Reprinted by permission from Macmillan Publishers Ltd: Nature (Wannamaker et al. (2009)), (c)2009

\subsubsection{Magnitudes}

We obtain a frequency-dependent attenuation factor $\gamma(\mathrm{f})=\gamma_{0} \mathrm{f}$ with $\gamma_{0}=1.89 \pm 0.02 \times 10^{-3} \mathrm{~s} / \mathrm{km}$, resulting in $\gamma=1.89 \times 10^{-2} \mathrm{~km}^{-1}$ at $10 \mathrm{~Hz}$ (representative of distances $<70 \mathrm{~km}$ ) and $\gamma=0.95 \times 10^{-2} \mathrm{~km}^{-1}$ at $5 \mathrm{~Hz}(\geq 70 \mathrm{~km})$ (Fig. 4.5). Our result is in agreement with estimates by Robinson (1987) $\left(\gamma=0.67 \times 10^{-2} \mathrm{~km}^{-1}\right)$ and O' Keefe (2008) $\left(\gamma=1.69 \times 10^{-2} \mathrm{~km}^{-1}\right)$, depending on the hypocentral distance of the earthquake to the station. The corresponding frequency-independent quality factor $\mathrm{Q}$ for direct $\mathrm{S}$-waves is $\mathrm{Q}_{S}=531 \pm 53$, a reasonable value in comparison with the $\mathrm{Q}_{P}$ of 250-800 determined by Eberhart-Phillips et al. (2008) for the central Southern Alps. Eberhart-Phillips et al. (2008) found that a sharp boundary exists between weakly attenuating schist and highly attenuating regions of altered schist for the shallow $Q_{P}$-structure in the central Southern Alps (depths $<10 \mathrm{~km}$ ). $\mathrm{Q}_{\mathrm{P}}$ values of $\sim 800$ were attributed to the Haast schist, which is inferred to be depleted of fluids and highly compacted due to dehydration during metamorphism and intense deformation, respectively. In contrast, Torlesse greywacke has moderate to low $Q_{P}$ of $\sim 450$. Low crustal $Q$ values typically result from fluid saturation and high temperature. Eberhart-Phillips et al. (2008) state that the $Q_{P}$ depth profile in the central Southern Alps closely matches the resistivity model of Wannamaker et al. (2002). A correlation of the seismicity distribution with low $Q_{P}$ was observed by Eberhart-Phillips et al. 

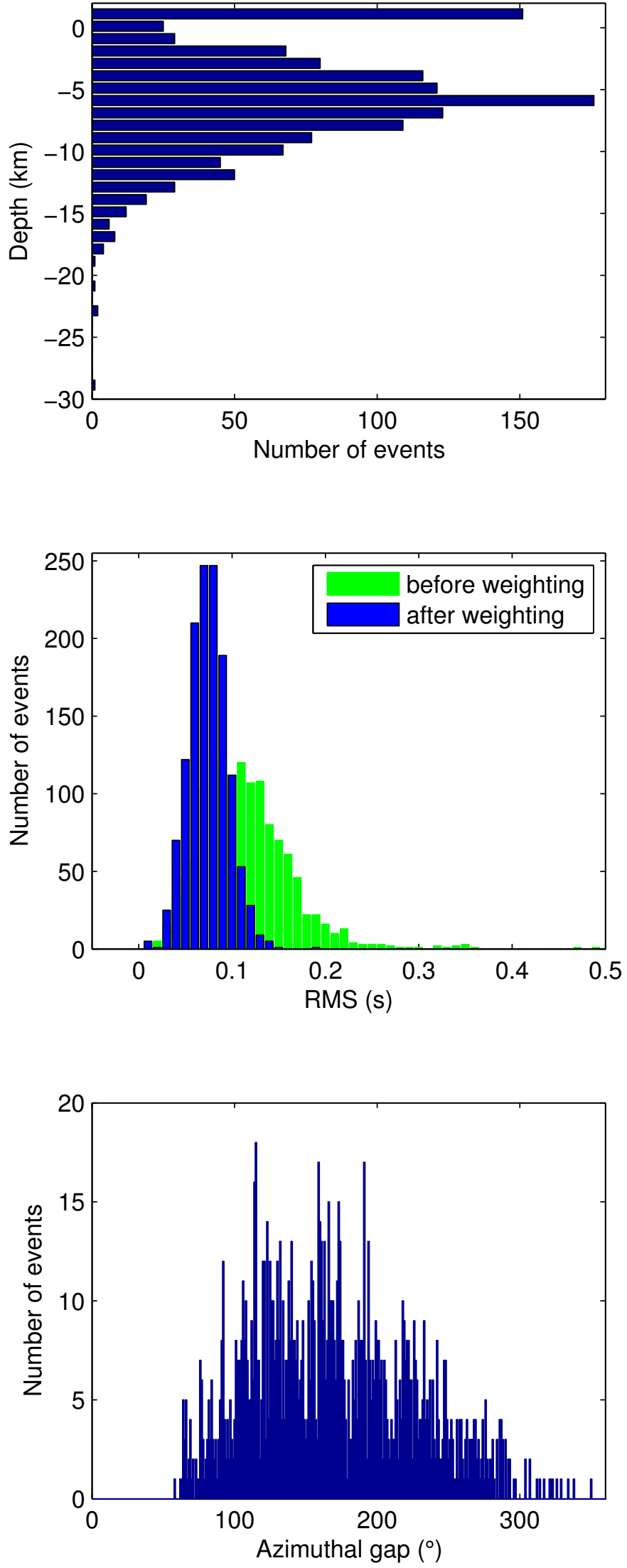

Figure 4.4 Depth, root-mean squared (RMS) residual and maximum azimuthal gap distribution for all events shown in Fig. $4.1 \mathrm{c}$ ) 
(2008) and interpreted to represent highly-fractured crust and increased fluid volumes in conjunction with fractures. The $Q_{P}$ values for the Haast Schist and the damage zone in the central Southern Alps, assuming that $\mathrm{Q}_{\mathrm{P}} \sim \mathrm{Q}_{\mathrm{S}}$, can be used to constrain the attenuation parameter $\gamma$ (according to equation 2.17), yielding $\gamma\left(\mathrm{Q}_{\mathrm{P}}=800\right)=0.5 \times 10^{-2} \mathrm{~km}^{-1}$ and $\gamma\left(\mathrm{Q}_{\mathrm{P}}=200\right)=3.45 \times 10^{-2} \mathrm{~km}^{-1}$ at a frequency of $5 \mathrm{~Hz}$ and an $\mathrm{S}$-wave velocity of $3.2 \mathrm{~km} / \mathrm{s}$. These values provide upper and lower limits for the attenuation parameter. The attenuation coefficients we obtain for frequencies between 3 and $17 \mathrm{~Hz}$ lie within these bounds.

We find that it is necessary to fit the amplitude readings with a frequency-dependent attenuation coefficient. Otherwise, we obtain a high constant attenuation coefficient of $\gamma \sim 2 \times 10^{-2} \mathrm{~km}^{-1}$ and uniformly positive magnitude residuals for hypocentral distances greater than $70 \mathrm{~km}$ (Fig. 4.5). The magnitudes determined using our frequency-dependent attenuation coefficient are not significantly different from those obtained by GeoNet $\left(1 / N \sqrt{\sum\left(M_{j}^{c}-M_{j}\right)^{2}} \leq 0.1\right)$. However, our preferred attenuation parameter produces consistent results for earthquakes of different sizes and frequency contents.

The magnitudes obtained for earthquakes recorded in the study area span $-0.3 \leq \mathrm{M}_{\mathrm{L}} \leq 4.2$ (Fig. 4.6). Earthquakes of low magnitude $\left(\mathrm{M}_{\mathrm{L}} \leq 2.5\right)$ occur in great numbers in the centre of the station network, conversely events with magnitudes $M_{L} \geq 3$ are distributed to the northeast of the SAMBA array (Fig. $4.1 \mathrm{c}$ ).

The magnitudes determined in this study were calibrated using the magnitudes obtained by GeoNet (e.g. Ristau 2009). For 147 of the larger earthquakes $\left(1.6 \leq \mathrm{M}_{\mathrm{L}} \leq 4.2\right)$ magnitude estimates are available (Fig. 4.6). However, magnitude calibration implies that if the reference values are consistently overestimated, so will be the SAMBA magnitudes. Comparisons of $\mathrm{M}_{\mathrm{W}}$ estimates obtained from waveform modelling (Ristau 2008; Leitner et al. 2001) with $M_{L}$ estimates for the central Southern Alps indicate that $M_{L}$ values overestimate the actual energy release by at least 0.2 but more likely 0.5 magnitude units. Deichmann (2006) estimated that local magnitude errors due to uncorrected attenuation effects for events of $\mathrm{M}_{\mathrm{W}}<1$ can amount to more than a whole magnitude unit. Due to the frequency-dependent attenuation factor, we consider the effect of uncorrected attenuation to be small. However, the size of the events relative to each other is more reliable than the absolute value, which might be uncertain by approximately half a magnitude unit. Once there are more $\mathrm{M}_{\mathrm{W}}$ estimates from moment tensor inversion available for earthquakes recorded by SAMBA (currently only two events), we will repeat our magnitude inversion using these $\mathrm{M}_{\mathrm{W}}$ for calibration. 

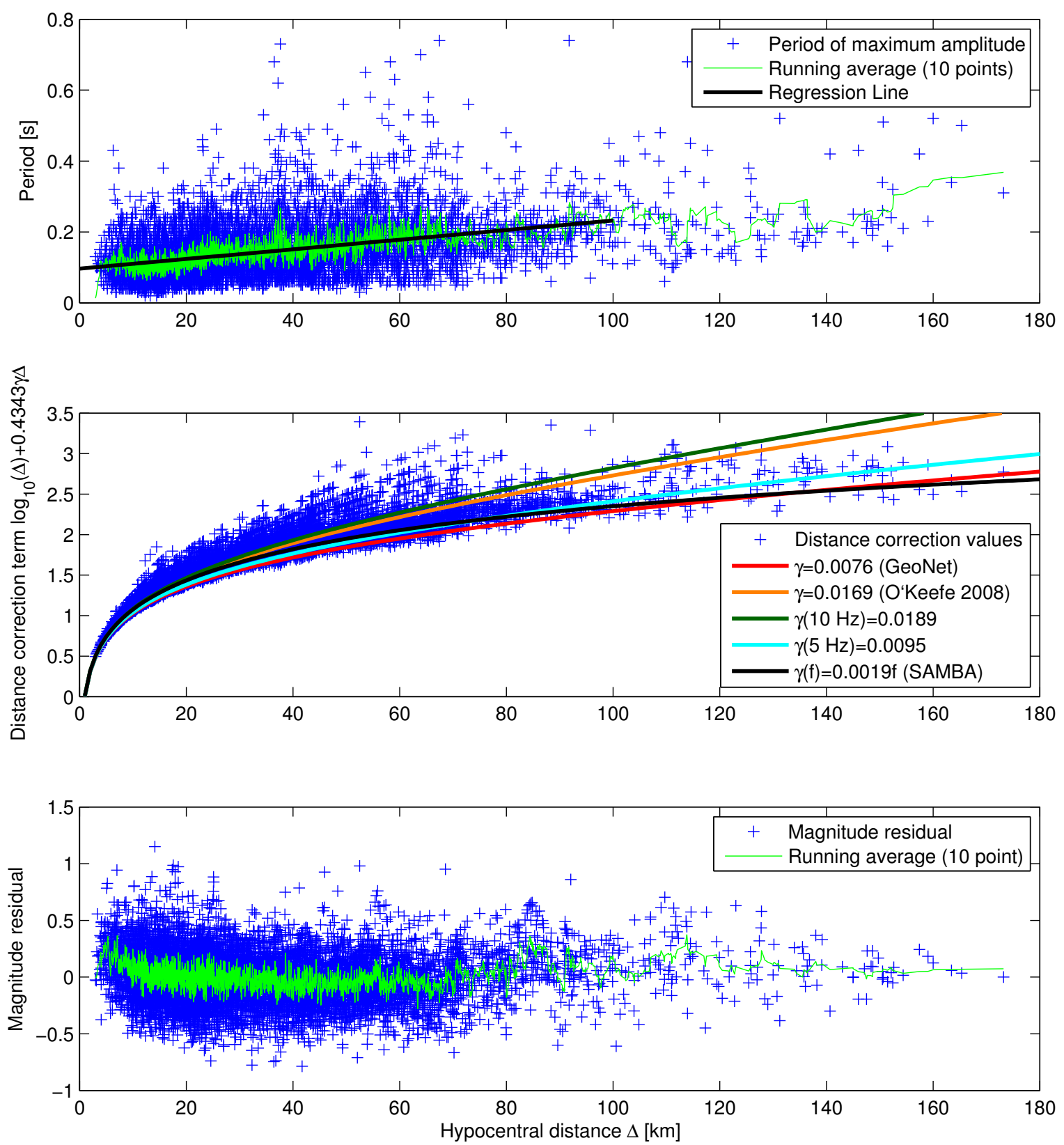

Figure 4.5. Period of the maximum Wood-Anderson displacement amplitude, attenuation functions and magnitude residuals versus hypocentral distance. The frequency dependence of the maximum amplitude needs to be fitted using a frequency dependent attenuation parameter $\gamma(\mathrm{f})$ to produce normally distributed magnitude residuals over all hypocentral distances. 

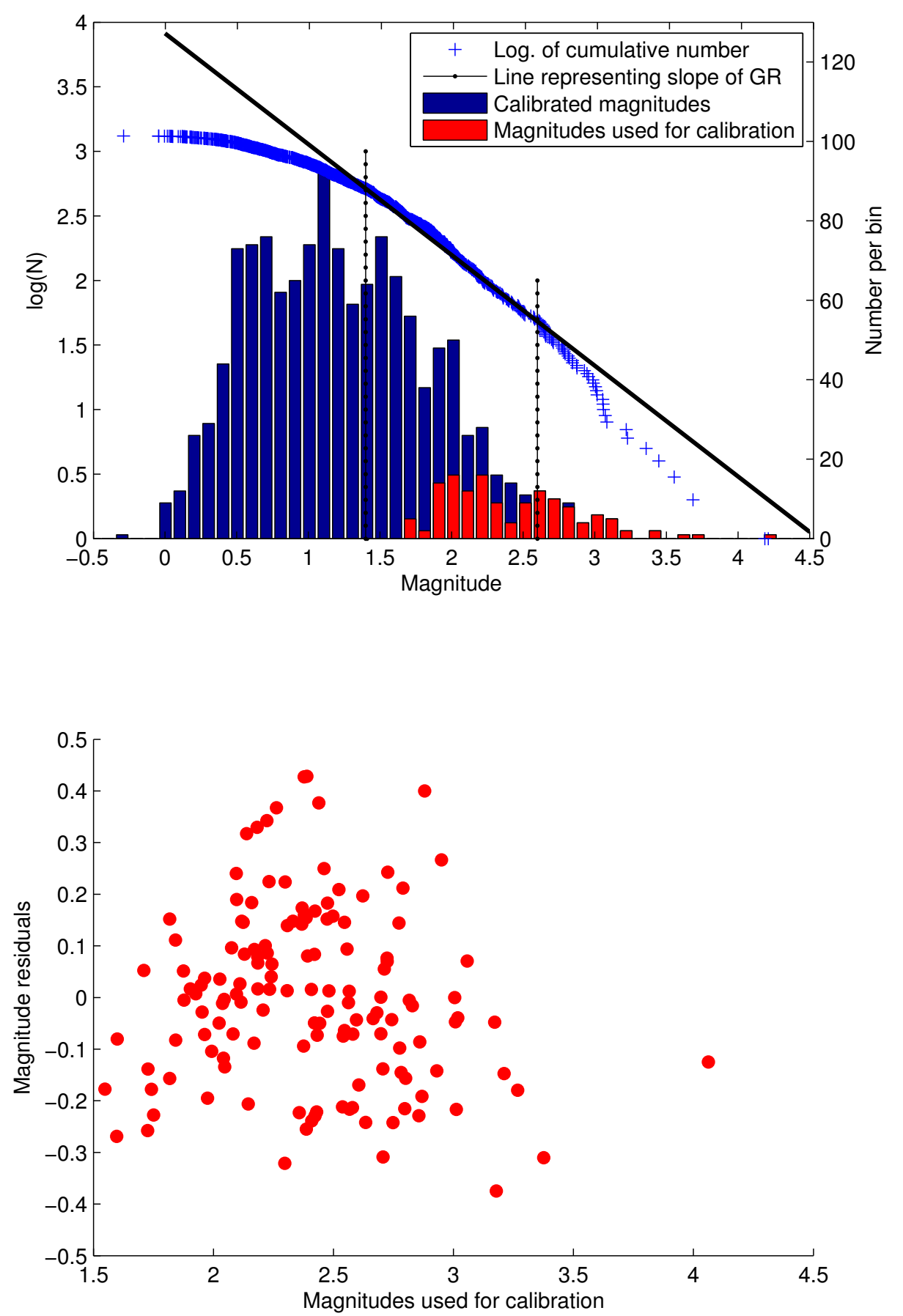

Figure 4.6. (a) Histograms of the magnitude distribution in the central Southern Alps region recorded by SAMBA (blue) and GeoNet (red) stations. The black line indicates the slope of the Gutenberg-Richter relation (b-value of 0.86 ) of the cumulative number of earthquakes versus magnitude. (b) Residuals of the magnitudes used for calibration in the inversion for all SAMBA magnitudes. 


\subsubsection{Focal mechanisms}

Focal mechanism solutions for earthquakes recorded by the SAMBA network were determined for events with seven or more P-wave polarity picks. Two deep teleseismic events (MW6.6 of 4 October 2009, 10:58:03.6 UTC at $626 \mathrm{~km}$ depth and $\mathrm{M}_{\mathrm{W}} 6.9$ of 28 August 2009, 01:51:25.9 UTC at $634 \mathrm{~km}$ ) with impulsive P-wave arrivals have been used to check the instrument polarities (Fig. B.1). This analysis revealed reversed polarities of the Z-component of the Mark Products L-4C3D sensors in comparison with the short-period borehole and the GeoNet broadband sensors. At one site, Reynold's Creek (REYN), all polarity picks have been removed from the dataset, since they are inconsistent with those of the other sensors.

Polarities of closely-spaced events have been checked in groups for their consistency. Reversed polarity picks were identified for the stations equipped with a borehole and a surface sensor, when the polarity was picked on the Z-component of the Mark Products L-4C3D surface sensor instead of the borehole sensor. These wrong polarity picks are easy to identify by visual inspection. Based on this checking procedure, the assumed probability of inconsistent polarity picks of 0.2 (Hardebeck and Shearer 2002) is likely to overestimate the number of inconsistent polarities in our dataset, since the polarities of the instruments are generally known and wrong polarity picks should be caused by misidentification only.

Due to the network size, the maximum number of available $P$-wave polarities is restricted to 13. Consequently, good coverage of polarity readings on the focal sphere is uncommon. However, this is an inherent problem of focal mechanism solutions. Those mechanisms obtained for the central Southern Alps region have standard deviations of the focal mechanism parameters of $\sigma_{\Theta}=29 \pm 1.6^{\circ}(1 \sigma)$. Events of this type were considered to be poorly constrained by Walsh et al. (2009) who compared their focal mechanism solutions with those of Reyners and McGinty (1999) for events with polarity picks from up to 36 stations. Their quality estimate was based on the angular difference between the focal mechanism solutions (equation 3.1). In Walsh et al.'s study the poorly-constrained focal mechanism solutions had minimum rotation angles of $21-84^{\circ}$, whereas for the wellconstrained solutions the minimum rotation angle was typically $5-26^{\circ}$. Minimum rotation angles of $24-32^{\circ}$ were found by Hardebeck (2006) for three high-quality focal mechanism datasets with events a few hundreds of metres apart. Hardebeck (2006) concluded that these focal mechanism solutions were indistinguishable within error.

We obtained minimum rotation angles of $1-88^{\circ}$ (with a mean of $32 \pm 22^{\circ}$ ), for the 
focal mechanism solutions of groups of events with similar polarity picks. We conclude that these values fairly describe the uncertainty of the focal mechanism solutions in our dataset. One well-defined nodal plane for the focal mechanisms was often observed, indicating that the strike and dip are well constrained but not the rake.

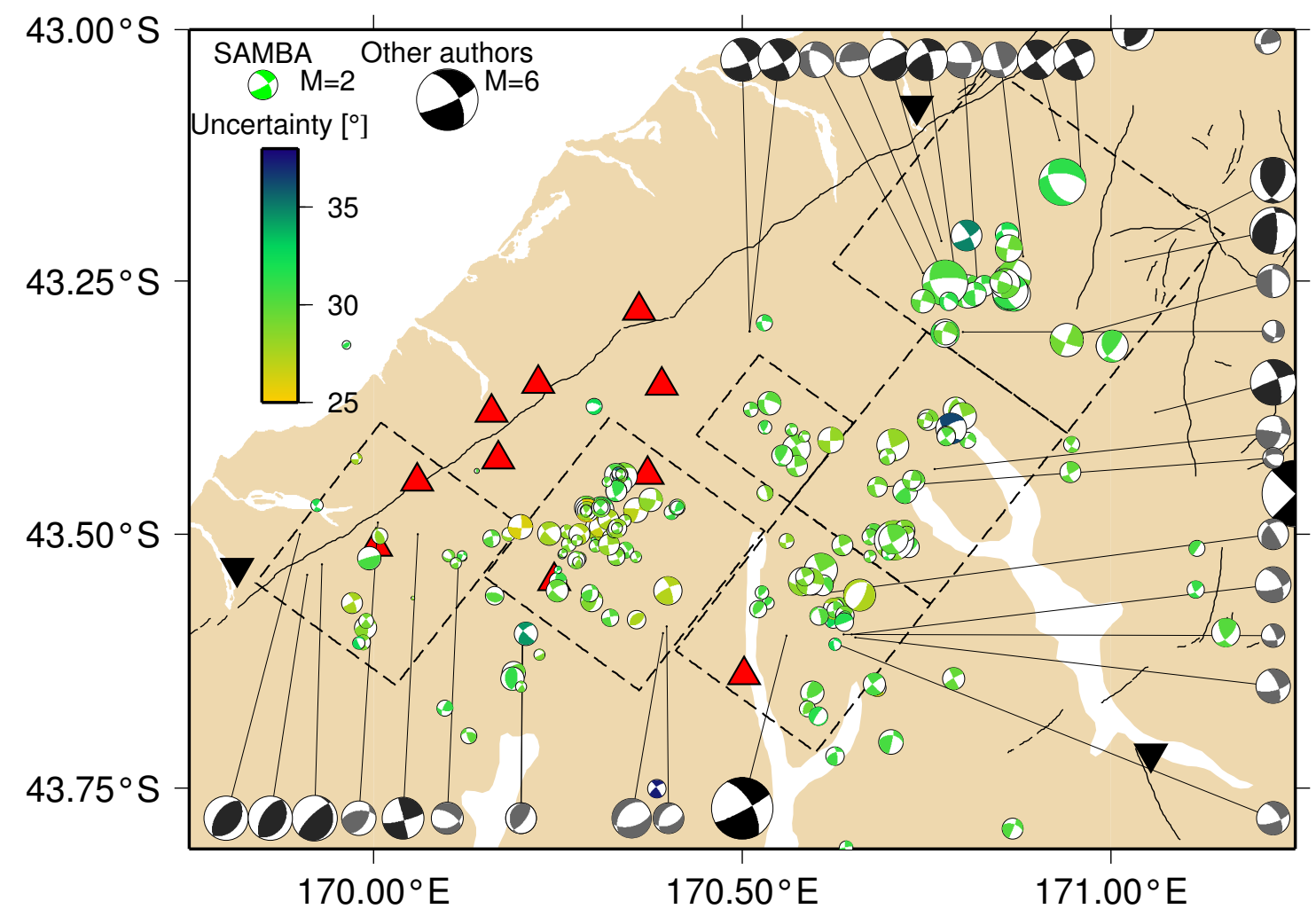

Figure 4.7. Focal mechanism solutions of 211 events derived in this study (coloured according to the uncertainty) and by Ristau (2008), Leitner et al. (2001) and Anderson et al. (1993) (dark grey, light grey and black, respectively). The symbol size represents the magnitude of the event, which is scaled up for the SAMBA data. Detailed information about each focal mechanism solution is listed in Table K.1.

Hardebeck and Shearer (2002) showed that focal mechanisms of earthquakes at shallow depths $(<10 \mathrm{~km})$ are most sensitive to changes in depth, especially for dip-slip events. This is because the take-off angles for up-going rays are sensitive to changes with the depth of the location. Ray take-off angles to the station are determined from the maximum likelihood hypocentre, which is in the best case centred in the middle of the uncertainty volume. Since we consider the depth uncertainty by calculating a range in take-off angles, we expect that these mechanisms are not sensitive to small changes in depth. The comparison of our focal mechanism solutions for the central Southern Alps with those of Leitner et al. (2001), Ristau (2008) and Anderson et al. (1993) (Fig. 4.7) shows overall similarity in the mechanisms but differences in the details of the focal mechanism parameters. These differences usually 
result from the increased uncertainty of one focal mechanism parameter.

Considering the uncertainty in the focal mechanism solutions, it is notable that the majority of our solutions exhibit consistently strike-slip mechanisms. We find approximately equal numbers of reverse and normal faulting mechanisms which form half of all solutions obtained for the studied microearthquakes. The ratio of reverse to strike-slip mechanisms becomes equal for intermediate (black and grey solutions in Fig. 4.7) and large earthquakes (Table 1.1) in the central South Island. The expected ratio of reverse to strike slip mechanisms would be 1:2 because the fault-normal displacement amounts to approximately one third of the fault-parallel component in the Southern Alps region.

Focal mechanism solutions have been determined for events as small as $\mathrm{M}_{\mathrm{L}}=0.44$. Although the station coverage is best in the vicinity of the Alpine Fault, we have obtained only a few focal mechanism solutions for earthquakes on or close to the fault.

\subsubsection{Stress inversion}

The prevailing directions of the principal stresses and the maximum horizontal compression obtained from analysing clusters of focal mechanisms are shown in Fig. 4.8 (a). The number of events used for the inversion is indicated by the number next to the stress contour plots. Different clusters exhibit only minor differences in the direction of the maximum horizontal compressive stress $S_{\mathrm{Hmax}}$ (Table 4.1) from the average value of $S_{\mathrm{Hmax}}=115 \pm 10^{\circ}$ at the $80 \%$ confidence level. Except for the north-easternmost cluster, where the directions of $S_{2}$ and $S_{3}$ overlap, the principal stress directions are well-defined and consistent over the study area. $S_{2}$ is near-vertical except for the south-westernmost region. Here, a rotation of the $S_{2}-S_{3}$ plane around the $S_{1}$ direction occurs, which increases the reverse component in this area. The stress ratio $\mathrm{R}$, in contrast, varies throughout the study area. Although this parameter is the least constrained in the inversion (Table 4.1), it reflects the topography throughout the region with low $R$ values where the topography is highest $\left(S_{2}>>S_{3}\right)$ and $R$ ranges between 0.5 $\left(S_{2}=0.5\left(S_{1}+S_{3}\right)\right)$ and $1\left(S_{2}=S_{3}\right)$ where the topography decreases. Lund and Townend (2007) showed that the maximum horizontal compressive stress $\mathrm{S}_{\mathrm{Hmax}}$ is less sensitive to variations in $\mathrm{R}$ for strike-slip stress states than for normal or thrust faulting stress states.

Our results are in agreement with previous stress measurements from the South Island. These results are summarised in Table 4.2 and the most recent results are displayed along with our results in Fig. 4.8 (b). These consistent angles in the range $107^{\circ}$ to $121^{\circ}$ are as expected for the principal axis of contraction $\left(111^{\circ}\right)$ inside a uniformly deforming zone parallel to the 


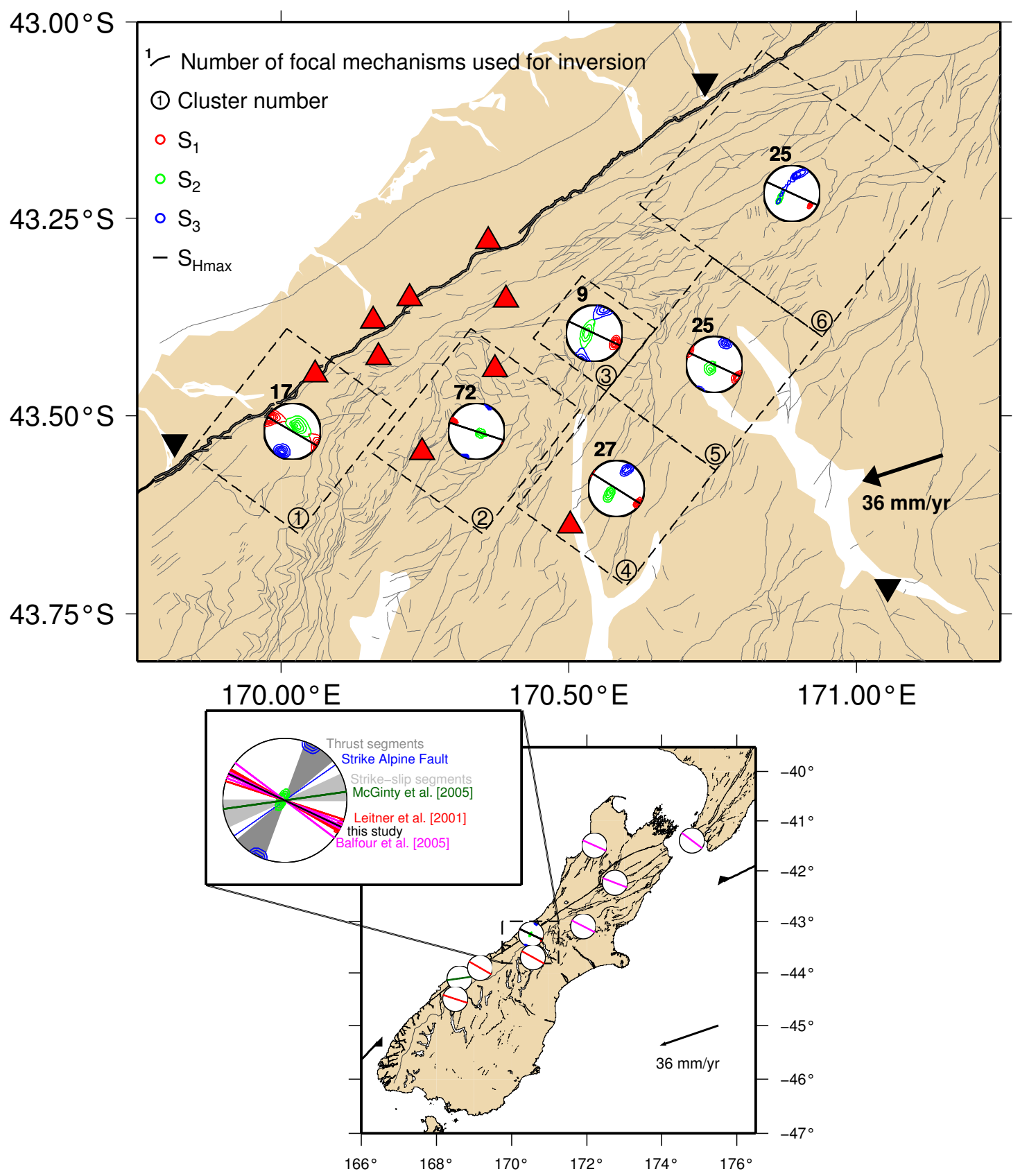

Figure 4.8. (a) Principal stress directions $\left(\mathrm{S}_{1}<\mathrm{S}_{2}<\mathrm{S}_{3}\right)$ and maximum horizontal compressive stress $\left(\mathrm{S}_{\mathrm{Hmax}}\right)$ derived from focal mechanism inversion of groups of events as shown in Fig. 4.7. The number on top of the stereogram indicates the number of focal mechanism solutions inverted for the principal stresses. The encircled number in the dashed rectangles gives the cluster number for which results are listed in Table 4.1.

(b) Stress inversion results of the 211 focal mechanism solutions in comparison with the maximum horizontal stress directions derived in other studies for different regions of northern and central South Island. The inset shows a summary of the stress directions in comparison to the strike of the Alpine Fault (blue) and its respective thrust and strike-slip segments (light and dark grey). 


\begin{tabular}{|llllll|}
\hline Cluster & $\mathrm{S}_{1}$ & $\mathrm{~S}_{2}$ & $\mathrm{~S}_{3}$ & $\mathrm{R}$ & $\mathrm{S}_{\operatorname{Hmax}}$ \\
\hline 1 & $121.1^{\circ} / 8.8^{\circ}$ & $65.0^{\circ} / 65.9^{\circ}$ & $27.4^{\circ} / 22.2^{\circ}$ & $0.25_{-0.250}^{+0.303}$ & $118 \pm 16.8^{\circ}$ \\
2 & $115.0^{\circ} / 13.7^{\circ}$ & $115.7^{\circ} / 76.3^{\circ}$ & $25.0^{\circ} / 0.0^{\circ}$ & $0.15 \pm 0.09$ & $115 \pm 10.2^{\circ}$ \\
3 & $115.0^{\circ} / 20.4^{\circ}$ & $56.6^{\circ} / 67.8^{\circ}$ & $23.2^{\circ} / 8.3^{\circ}$ & $0.77_{-0.321}^{+0.211}$ & $114 \pm 16.6^{\circ}$ \\
4 & $123.7^{\circ} / 9.4^{\circ}$ & $53.8^{\circ} / 63.3^{\circ}$ & $29.1^{\circ} / 24.8^{\circ}$ & $0.69 \pm 0.239$ & $122 \pm 13.1^{\circ}$ \\
5 & $119.2^{\circ} / 5.4^{\circ}$ & $49.1^{\circ} / 74.6^{\circ}$ & $27.7^{\circ} / 14.4^{\circ}$ & $0.47 \pm 0.306$ & $118 \pm 14.5^{\circ}$ \\
6 & $123.7^{\circ} / 24.4^{\circ}$ & $67.2^{\circ} / 52.0^{\circ}$ & $22.1^{\circ} / 27.4^{\circ}$ & $0.89_{-0.197}^{+0.097}$ & $122 \pm 12.0^{\circ}$ \\
\hline
\end{tabular}

Table 4.1. Principal stress directions (trend/plunge) and maximum horizontal compressive stress of all events in one region as shown in Fig. 4.8 (a). $R=\left(S_{1}-S_{2}\right) /\left(S_{1}-S_{3}\right)$ specifies the stress ratio. The uncertainty in $\mathrm{R}$ is estimated from the upper and lower bounds given by the $10 \%$ and $90 \%$ percentiles of the posterior probability density function. The posterior distribution is skewed near values of 0 and 1 because the R-value is confined to lie within these limits.

\begin{tabular}{|lccl|}
\hline $\mathrm{S}_{\mathrm{Hmax}}$ or $\mathrm{S}_{1}$ & Region & Method & Reference \\
\hline $300^{\circ} / 30^{\circ}$ & northern Marlborough & IPP & McGinty et al. (2000) \\
$118^{\circ} / 6^{\circ}$ & southern Marlborough & IPP & McGinty et al. (2000) \\
$299 \pm 17^{\circ}$ & Marlborough & FMI & Balfour et al. (2005) \\
$291^{\circ}$ & Lake Tennyson & FMI & Balfour et al. (2005) \\
$107 \pm 6^{\circ}$ & west of Arthur's Pass & TT+GPS & Pearson et al. (1995) \\
$116 \pm 9^{\circ}$ & east of Arthur's Pass & TT+GPS & Pearson et al. (1995) \\
$119 \pm 17^{\circ}$ & north of Mt. Cook & FMI & Leitner et al. (2001) \\
$121 \pm 36^{\circ}$ & south of Mt. Cook & TT & Blick et al. (1989) \\
$84^{\circ} / 16^{\circ}$ & Jackson Bay & IPP & McGinty et al. (2005) \\
\hline
\end{tabular}

Table 4.2. Maximum compressive stress $\mathrm{S}_{1}$ (trend/plunge) or maximum horizontal compressive stress $S_{\mathrm{Hmax}}$ (with uncertainties if reported) for South Island measurements obtained in previous studies. Abbreviations used to describe methods are: IPP inversion of P-wave polarities, FMI focal mechanism inversion, TT triangulation/trilateration

Alpine Fault subjected to loading at an azimuth of $077^{\circ}$ by the relative plate motion (Reilly 1990).

All stress measurements indicate a strike-slip faulting regime prevailing over wide areas of the South Island. A homogeneous, regional stress field has been noted before by Leitner et al. (2001), whose principal stress directions for three broad regions in central South Island were indistinguishable from each other at the $80 \%$ confidence level. Nevertheless, we see some indication for a locally increased reverse component at the southern boundary of our study area. The high topography in the central Southern Alps has little effect on the overall stress field in general, but causes local segmentation of the Alpine Fault's surface trace in thrust and strike-slip segments (Norris and Cooper 1995). Based on the stress estimates, we ob- 
serve that these segments have orientations close to optimal in terms of Andersonian faulting models (insert Fig. 4.8 b). Under the assumption that the horizontal stress is homogeneous, variations in the intermediate stress $S_{2}$ cause a rotation of the strike of a non-vertical strikeslip fault towards $S_{1}$ when there is a deficiency of load, and away from $S_{1}$ as a result of excess topography, according to the equation

$$
\frac{S_{2}-S_{3}}{S_{1}-S_{3}}=1-R=\sin ^{2} \phi
$$

given by Fialko et al. (2005) (where $\phi$ is the angle between the fault trace and the $\mathrm{S}_{1}$-axis). The topography therefore explains the segmentation into strike-slip faults coinciding with major river valleys crossing the Alpine Fault and thrust segments at higher angles to the Alpine Fault in regions of high elevation near the fault (see also Fig. 9 and 11 of Norris and Cooper 1995).

Our stress inversion results show that the Alpine Fault as a whole is orientated at a high angle $\left(59^{\circ}\right)$ to the direction of maximum horizontal compressive stress (Fig. $4.8 \mathrm{~b}$ ). This implies that the normal stress acting on the fault plane is high. Regarding Andersonian faulting, this angle suggests that the Alpine Fault sustains a low ratio of shear stress to effective normal stress. Balfour et al. (2005) obtained a $60^{\circ}$ angle between the average strike of faults in the Marlborough Fault System and the direction of the maximum horizontal compressive stress. In Southern Marlborough, where the strike of the faults changes to about $070^{\circ}$, this angle lessens to $44^{\circ}$. The San Andreas Fault is orientated at angles ranging between $60^{\circ}$ and $85^{\circ}$ to the maximum horizontal compressive stress (Townend and Zoback 2004). In Southern California, this angle between the San Andreas Fault and the maximum horizontal compressive stress direction is almost constant, despite pronounced changes in the strike of the San Andreas fault (Townend and Zoback 2001, 2004).

Low coefficients of friction have been suggested as the cause for the weakness of the San Andreas Fault (Townend and Zoback 2004). This has been confirmed by the low values ( $\mu=0.13-0.21)$ measured for the creeping section near Parkfield (Lockner et al. 2011). Balfour et al. (2005) concluded that the Marlborough faults are also frictionally weak due to either low coefficients of friction (coefficient of friction $\mu=0.35$, pore fluid factor $\lambda=0.4$ ), or increased pore fluid pressure $(\mu=0.58, \lambda=0.7)$ or due to some combination of the two. This interpretation seems applicable to the Alpine Fault, too. No indication of steady creep on the Alpine and Wairau Fault has been observed since 1964 on man-made structures crossing the fault (Evison 1971; Sutherland et al. 2007, and references therein) or by GPS surveying in the Whataroa river (Beavan et al. 1999), but cannot be ruled out in the mountainous region 
east of the Alpine Fault. Since high pore fluid pressures have been suggested as the cause for the low-velocity zone (Stern et al. 2001) in the vicinity of the Alpine Fault, we favour increased fluid pressures as the cause for the fault's reduced strength.

\subsection{Discussion and conclusions}

Hypocentre locations of more than 1700 earthquakes recorded by the SAMBA network have been determined between November 2008 and December 2009 in the central Southern Alps. The seismicity is diffuse and no particular fault or a small number of faults can be identified from the dense distribution of mapped faults in this region. However, the overall earthquake hypocentre distribution correlates with the boundaries between high- and low-attenuation zones as shown in the crustal attenuation model of Eberhart-Phillips et al. (2008), despite the rather large node spacing in the central Southern Alps. The Alpine Fault does not appear as a localised zone of deformation from the earthquake distribution. Instead, the inferred deformation is distributed between the Alpine Fault, the Main Divide Fault Zone and other major backthrusts to the east. Many active large faults in New Zealand appear aseismic on intermediate time-scales and are not delineated by the background seismicity (e.g. Anderson and Webb 1994; Robinson 2004). The Alpine Fault, however, is not totally aseismic because it exhibits several clusters of earthquakes $5-8 \mathrm{~km}$ southeast of its surface trace at depths consistent with a $45^{\circ}$-dipping fault. Earthquakes also occur at greater depths closer to the surface trace of the Alpine Fault. Therefore, the existence of a subvertical strand of the Alpine Fault, as expected from $\sim 15$ Myr of solely strike-slip motion on the fault (e.g. Cande and Stock 2005), cannot be ruled out. A high concentration of earthquakes on backthrusts at a range of distances from the Alpine Fault is observed, most obviously in the northernmost depth profiles (profiles 2 and 3 and marked by cluster $b$ and c). Otherwise, the hypocentre locations are distributed throughout the whole seismogenic zone $(<17 \mathrm{~km})$, but mean depths generally increase to the southeast across the Southern Alps perpendicular to the Alpine Fault. Earthquakes are anomalously shallow $(<6 \mathrm{~km})$, of small magnitude $\left(\mathrm{M}_{\mathrm{L}}<2.5\right)$ and highly clustered within the SAMBA array beneath the area of highest topography. In the vicinity of Mt. Cook, a bulge in the seismicity occurs with its maximum centred beneath the Main Divide Fault Zone at depths of $6 \mathrm{~km}$ (transect 6 of Fig. 4.2). The same depth has been identified by Stern et al. (2007) as the upper boundary of a low P-wave velocity zone that extends downwards to depths of $30 \mathrm{~km}$. A similar structure can be seen just south of Mt. Cook in the crustal seismic reflection profile of Long et al. (2003). Long et al. (2003) describe an "antifold" of $15 \mathrm{~km}$ half wavelength with its' crest at $3 \mathrm{~km}$ depth and imaged to $10 \pm 2 \mathrm{~km}$ depth. They interpreted that this structure 
accommodated $1.8 \mathrm{~km}(=12 \%)$ horizontal crustal shortening in less than $1 \mathrm{Myr}$ at current GPS strain rates. At the southwestern boundary of the SAMBA network, the seismically active zone is narrow and earthquake depths increase rapidly in the direction perpendicular to the strike of the Alpine Fault.

A depth of the seismogenic zone of $12 \pm 2 \mathrm{~km}$ has been suggested from seismicity studies in the central Southern Alps (Leitner et al. 2001; Reyners 1988) and 5-12 km has been suggested as the locking depth based on GPS measurements (Beavan et al. 1999; Beavan et al. 2004; Wallace et al. 2007). We find that the seismogenic depth varies across the Southern Alps with depths of $10 \pm 2 \mathrm{~km}$ beneath the surface trace of the Alpine Fault and $8 \pm 2 \mathrm{~km}$ within $20 \mathrm{~km}$ distance of the fault. At distances larger than $20 \mathrm{~km}$, it increases in depth to a thickness of $15 \pm 2 \mathrm{~km}$, similar to the shape of the high-resistivity zone. New earthquake hypocentre locations recorded by an additional short-term deployment of 12 stations in the area between the Wanganui and the Whataroa rivers during January and May 2010 indicate that our results for hypocentre depths along SIGHT transect T1 (Fig. 4.3) and the depth profiles $1-3$ (Fig. 4.2) are robust and slightly overestimate the earthquake depths. This will be discussed in more detail and in comparison with double-difference relocations in future studies.

The lateral variation in the near-surface resistivity structure correlates well with the distribution of microseismicity. Our results show that no earthquakes are generated in the conductive zone $<100 \Omega \mathrm{m}$ at depths greater than $20 \mathrm{~km}$. The material is either too hot, too fluid-saturated or too weak (or a combination of all three) to produce earthquakes of recordable size. Earthquakes are generated in the high-resistivity zones adjacent to or above the low-resistivity regions. We find that clustering of the events is strongest where the resistivity contrast is highest. A similar distribution of microearthquakes has been observed for the San Andreas Fault where resistivity measurements revealed a fault zone conductor with resistivities $<10 \Omega \mathrm{m}$ (Unsworth and Bedrosian 2004). The microseismicity occurs below or adjacent to these zones in high-resistivity zones. Similar distributions of earthquakes on the boundary between high- and low-resistivity regions have been observed for microearthquakes (Ichiki et al. 1999), swarms (Tank et al. 2003) and large earthquakes and their aftershocks (Eberhart-Phillips et al. 1990; Kasaya et al. 2002). Takeda et al. (1999) observed the occurrence of earthquakes at shallow depths in areas of low water saturation and high crack density surrounded by areas of high saturation. They attributed the generation of earthquakes to fluid flow into cracks in rocks with a low degree of saturation. Kato et al. (2010) observed intense seismic activity at shallow depths above a high-velocity body of intruded diorite, causing high heat flow and the release of fluids that invaded and fractured the overlying rock. 
We suggest that extensive fracturing occurs in the central Southern Alps due to ascending fluids and that the Main Divide Fault Zone (Cox et al. 1997) and other backthrust faults act as active fluid conduits. A resistivity model by Wannamaker et al. (2009) for a transect crossing the Marlborough Fault System shows similar low resistivity regions $<100 \Omega \mathrm{m}$ at depths greater than $10 \mathrm{~km}$ beneath the Awatere and Clarence faults. As observed for the central Southern Alps, the crustal seismicity in this region is also confined to high-resistivity bodies. Wannamaker et al. (2009) attribute this seismicity to fault fracture meshes created by the upwards migration of fluids from the subducting slab of the Pacific plate.

Notably, all of the largest, more recent earthquakes (marked by a star in Table 1.1) in the central South Island occurred southeast of the Alpine Fault. These events occurred at the lower end of the earthquake depth-distribution, presumably near the base of the seismogenic zone. If we assume that the hypocentre locations determined in this study reflect the vertical extent of the seismogenic zone, then the seismogenic depth reaches a maximum at distances $>25 \mathrm{~km}$ perpendicular to the surface trace of the Alpine Fault. At these distances, the seismogenic zone has almost twice the thickness of the seismogenic depth near the Alpine Fault. In other words, earthquakes generated in this area can potentially be larger than further west due to the vertical extent of the seismogenic zone.

The microearthquake locations in the region bounded by the Wanganui and the Whataroa river reveal in more detail the aseismic zone noted previously (e.g. Leitner et al. 2001). Within the vicinity of the Alpine Fault $(<10 \mathrm{~km})$, the seismicity does not change significantly along strike. The area with reduced seismicity extends from 15 to $30 \mathrm{~km}$ of the fault and is bounded by the cluster c) (Fig. $4.1 \mathrm{c}$ ). The distribution of earthquakes is symmetric around this gap, but the number of events is not (Fig. $4.1 \mathrm{a}$ and c). Earthquakes at the northeastern boundary of the low-seismicity region are larger in magnitude and more frequent than at the southwestern limit. The density of mapped faults in the aseismic region is reduced, too. The detection threshold of events at the southwestern limit of this area is better than to the northeast due to the station distribution. If similar sized events occurred at the southern boundary, they would have been recorded by the SAMBA stations. The low-seismicity area is characterised by a low-attenuation block in the attenuation model of Eberhart-Phillips et al. (2008). Changes in the geology with flat-lying sequences of schist and semi-schist occur in this region, as noted by Leitner et al. (2001). However, there is no obvious correlation between bedding dip and the distribution of earthquakes. The remnants of a major ice plateau are located in this area, but the plateau's exact location does not 
coincide with the observed distribution of events. However, the seismicity gap could be associated with seismic quiescence following pronounced activity associated with localised bending and uplift resulting from rapid ice loss since the end of last glacial period $14000 \mathrm{yr}$ ago (Suggate 1990). On the other hand, if that area forms a seismic gap, it could be a seismic gap of the second kind (Mogi 1979), which is characterised by quiescence in smaller magnitude activity before a large earthquake. If this is the case, the rupture area amounts to at least $\sim 300 \mathrm{~km}^{2}$ corresponding to a magnitude 6.5 earthquake. Since similarly large earthquakes have occurred at some distance from the Alpine Fault, further detailed studies in this region are necessary.

The magnitudes of the recorded earthquakes in the study area span $-0.3 \leq \mathrm{M}_{\mathrm{L}} \leq 4.2$ but are smaller in the region of highest uplift, where the upper magnitude threshold is $M_{L}$ 2.5. Based on our magnitude scale, we deduce that high-frequency waves $(f>10 \mathrm{~Hz})$ are attenuated more than twice as much as low-frequency waves $(\mathrm{f}<5 \mathrm{~Hz})$. The frequency-independent attenuation coefficient used in routine magnitude determination New Zealand-wide thus underestimates the local magnitude if the distance between the earthquake source and the recording station is small $(<70 \mathrm{~km})$.

Focal mechanism solutions for microearthquakes recorded in this study indicate predominantly strike-slip faulting. For intermediate-size and large earthquakes as recorded over longer timespans, the ratio of reverse to strike-slip mechanisms is equal. This suggests that with time larger amounts of compressional strain are accumulated and released in larger magnitude events. Stress inversion of our focal mechanisms reveals a homogeneous strikeslip stress field in the central Southern Alps except for localised topographic modifications. The direction of maximum horizontal compressive stress is $S_{H \max }=115 \pm 10^{\circ}$. The resulting angle between the average strike of the Alpine Fault and $\mathrm{S}_{\mathrm{Hmax}}$ is $59^{\circ}$ as characteristic of a weak fault. However, small-scale thrust segments are oriented at angles of $65^{\circ}-95^{\circ}$ and strike-slip segments are oriented at angles ranging between $25^{\circ}$ and $50^{\circ}$ to $\mathrm{S}_{\mathrm{Hmax}}$, implying that shallow segmentation of the Alpine Fault takes place on favourably-oriented structures.

\subsection{Shear and normal stresses on the fault plane}

We have determined the prevailing directions of the principal stresses and the maximum horizontal compression by analysing clusters of focal mechanisms using Arnold and Townend's (2007) algorithm and the stress transformations described by Lund and Townend (2007) 
(Fig. 4.8). This method allows us to determine the directions of the three principal stresses and the stress ratio but not the absolute magnitude of each principal stress. To get a sense of the absolute stress values acting on the inclined plane of the Alpine Fault, we assume that $S_{2}$ is vertical and that its magnitude can be calculated from the overburden pressure $S_{\mathrm{v}}=\rho \mathrm{gz}$, where $\rho$ is the assumed density of the rock ( $2700 \mathrm{~kg} / \mathrm{m}^{3}$ according to Godfrey et al. 2000), $\mathrm{g}$ the gravitational acceleration and $\mathrm{z}$ the depth. The differential stress for strike-slip stress regimes is

$$
\Delta \mathrm{S}=2 \rho \mathrm{gz}(\lambda-1)(1-\mathrm{F}) /(1+\mathrm{F})
$$

with the pore fluid factor $\lambda$ and $\mathrm{F}=\left(\sqrt{\mu^{2}+1}+\mu\right)^{2}$ according to Zoback and Townend (2001). Figure 4.9 shows the absolute values with depth calculated for each principal stress assuming a stress ratio $\mathrm{R}$ of 0.5 . Also displayed are the normal and shear stresses on the Alpine Fault determined using the method of De Paor (1990). For hydrostatic fluid pressure at depth $(\lambda=0.37)$, the differential stress increases similarly to $S_{3}$. The normal stress on the fault plane increases similarly to $S_{2}$, whereas the shear stress is only one fifth that of the normal stress. For lithostatic fluid pressure, the differential stress is small (less than half of $\mathrm{S}_{3}$ and approximately one-fifth of $\left.\mathrm{S}_{\mathrm{n}}\right)$. For a steeper dip $\left(60^{\circ}\right)$ of the Alpine Fault plane, the normal stress reduces slightly and the shear stress increases with depth. This is consistent with the apparent weakness of the Alpine Fault, implying that faulting occurs in response to low levels of shear stress (compared to normal stress and stress drop during the earthquake).

Since the stress ratio is the least constrained value in the stress inversion (uncertainties \pm 0.2 ; Table 4.1), the influence of the stress ratio for a fixed depth of $6 \mathrm{~km}$ was examined (Fig. 4.10). The larger the stress ratio, the lower the shear component and the larger the normal component of stress on the Alpine Fault. This trend is independent of the fault's dip and the assumed pore fluid factor. In conclusion, the ratio of shear to effective normal stress is low on the Alpine Fault and decreases with increasing $\lambda$ and $\mathrm{R}$, implying near-lithostatic fluid pressures within the Alpine Fault zone, and similar absolute values of the intermediate stress $\mathrm{S}_{2}$ (near-vertical) and the least compressive stress $\mathrm{S}_{3}$ (near-horizontal) represent the weakest scenario.

\subsection{Seismicity gap between the Whataroa and Wanganui rivers}

A zone of sparse seismicity between the Whataroa and Wanganui rivers (Fig. 1.8) has been described by Eiby (1971), Evison (1971), Scholz et al. (1973), Caldwell and Frohlich 

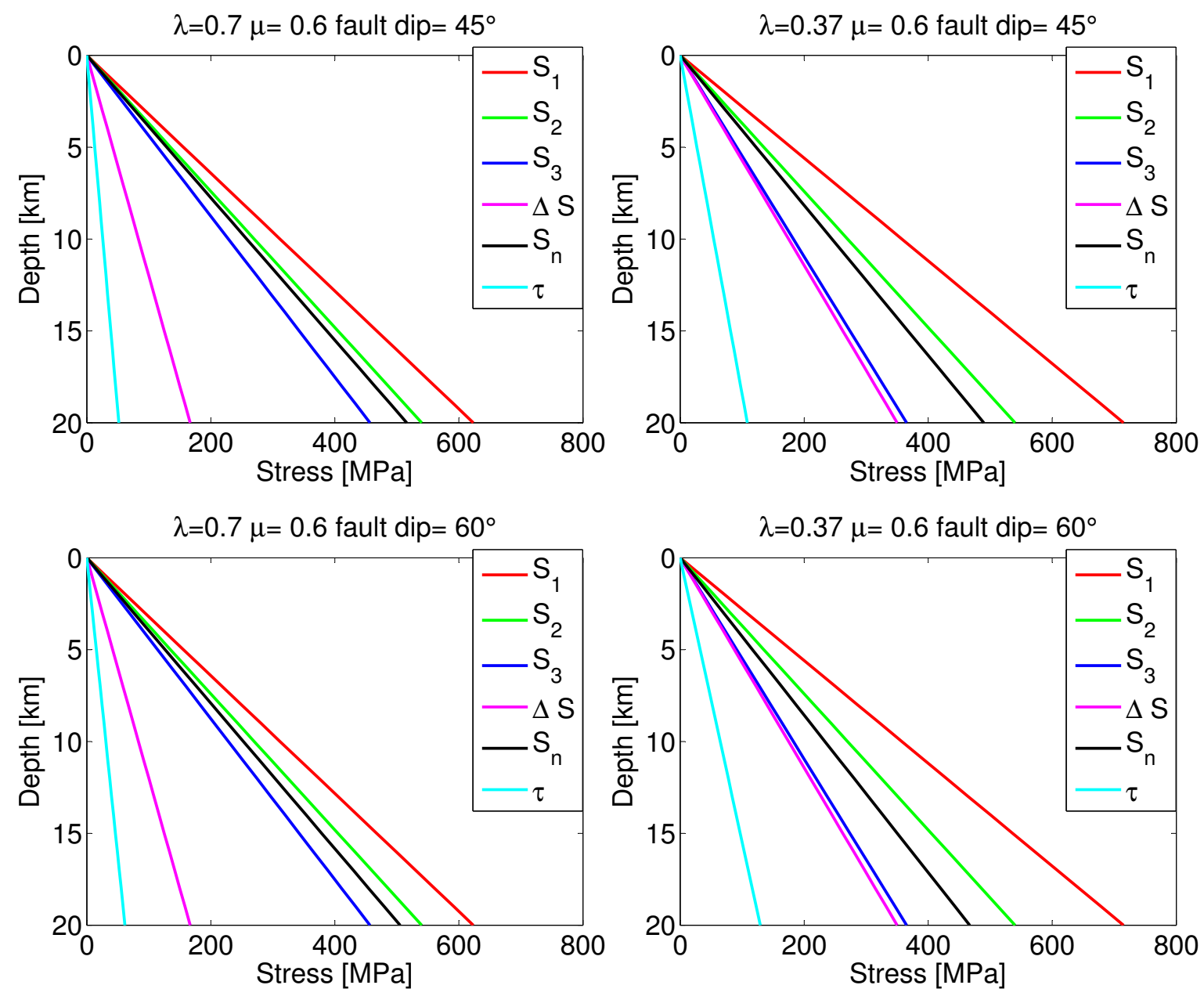

Figure 4.9. Principal stress directions and normal and shear stress on the fault plane with depth assuming a stress ratio $R$ of 0.5 , a vertical $S_{2}$ and horizontal $S_{1}$ and $S_{3}$ with orientations of $116^{\circ}$ and $206^{\circ}$. The figures on the left are for lithostatic, those on the right for hydrostatic fluid pressure. Stresses in the top row were calculated for a $45^{\circ}$ dipping Alpine Fault, whereas those for the bottom row result for a steeper fault dip of $60^{\circ}$. 

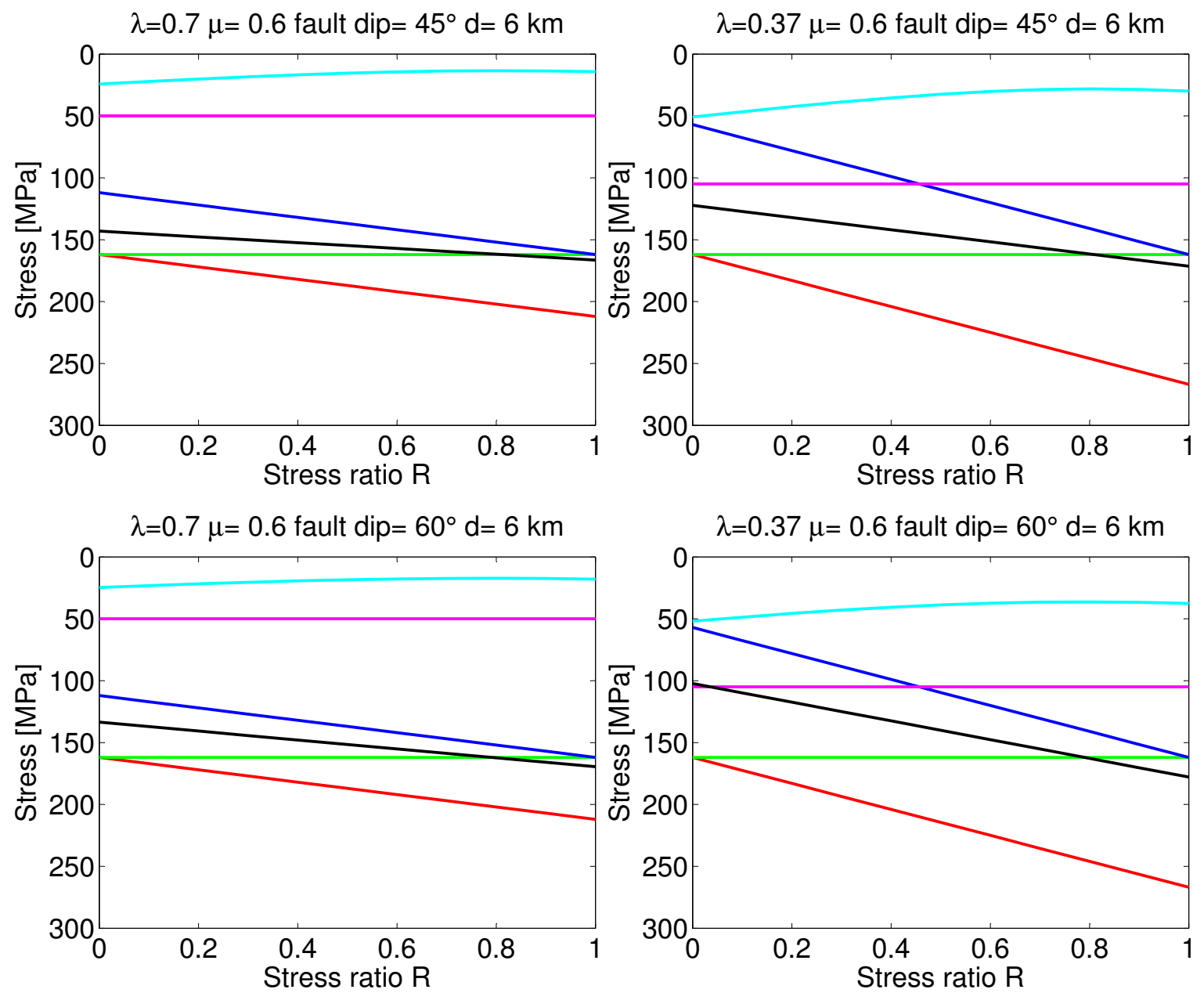

Figure 4.10. Principal stress directions for a fixed depth of $6 \mathrm{~km}$ and varying stress ratio $\mathrm{R}$. See Fig. 4.9 for details. 
(1975), Eberhart-Phillips (1995) and Leitner et al. (2001). Our results show that the seismicity in the direct vicinity (within $10 \mathrm{~km}$ ) of the fault is not significantly different from that southwest and northeast of this area and the gap extends from $\sim 15$ to $30 \mathrm{~km}$ southeast of the Alpine Fault (Fig. 4.11). The gap is bounded by a zone of high-seismicity rates and magnitudes to the northeast. At the southwestern boundary of the gap, earthquakes are on average one magnitude unit smaller, however there have been three events of $M_{L} \geq 4$ as reported by GeoNet since 1975 in this area (Fig. 4.11). In general larger events $\left(M_{L} \geq 4\right)$ occur at the edges of seismicity clusters indicating stress concentrations in these areas. Figure 4.12 shows a more detailed comparison (than Fig. 4.3) of the depth distribution of events within $10 \mathrm{~km}$ of SIGHT transect T1 with the resistivity profile by Wannamaker et al. (2002). It shows that earthquakes follow the $390 \Omega \mathrm{m}$ resistivity contour, which appears to determine the depth of the seismogenic zone in this area.

Well-recorded earthquakes ( $\geq 7$ stations) are shown in Fig. 4.13 in comparison with the attenuation structure obtained by Eberhart-Phillips et al. (2008). The gap correlates with high $\mathrm{Q} /$ low attenuation at shallow depths $(\leq 5 \mathrm{~km})$ whereas the earthquakes correspond to low $\mathrm{Q} /$ high-attenuation zones adjacent to the gap. This supports our interpretation that the gap represents a strong, unfractured block, surrounded by a highly-fractured damage zone. The deformation that occurs between the Alpine Fault and the Main Divide Fault Zone further northeast and southwest is diverted to larger distances southeast of the Alpine Fault.

The area between the Whataroa and Wanganui rivers is not the only low-seismicity region that stands out in short- and long-term seismicity rate studies. The Mackenzie Basin southeast and the Rangitata river valley east of the study area show equally low levels of seismicity (cf. Fig. 1.7). Since all three areas correspond to major valleys that have been glaciated (Suggate 1990), an alternative interpretation of the low seismicity to date is isostatic readjustment resulting from unloading due to deglaciation $14000 \mathrm{yr}$ ago. As several studies have shown (see below), deglaciation can increase the slip rates of faults significantly for a few thousand years after which the fault returns to its previous slip rate. Therefore, the hypothesis is that the current quiescence is the result of pronounced seismic activity previously associated with isostatic readjustment.

According to Suggate (1990), the Southern Alps region has experienced rapid ice-loss since the last glacial maximum. The Whataroa river valley is currently in a transitional state between glacial and non-glacial form (Herman and Braun 2006, and references therein). The Perth glacier (that drains via the Perth river into the Whataroa river) currently has the second largest retreat rate of $44 \mathrm{~m} / \mathrm{a}$ exceeded only by the Godley glacier (with $66 \mathrm{~m} / \mathrm{a}$; 


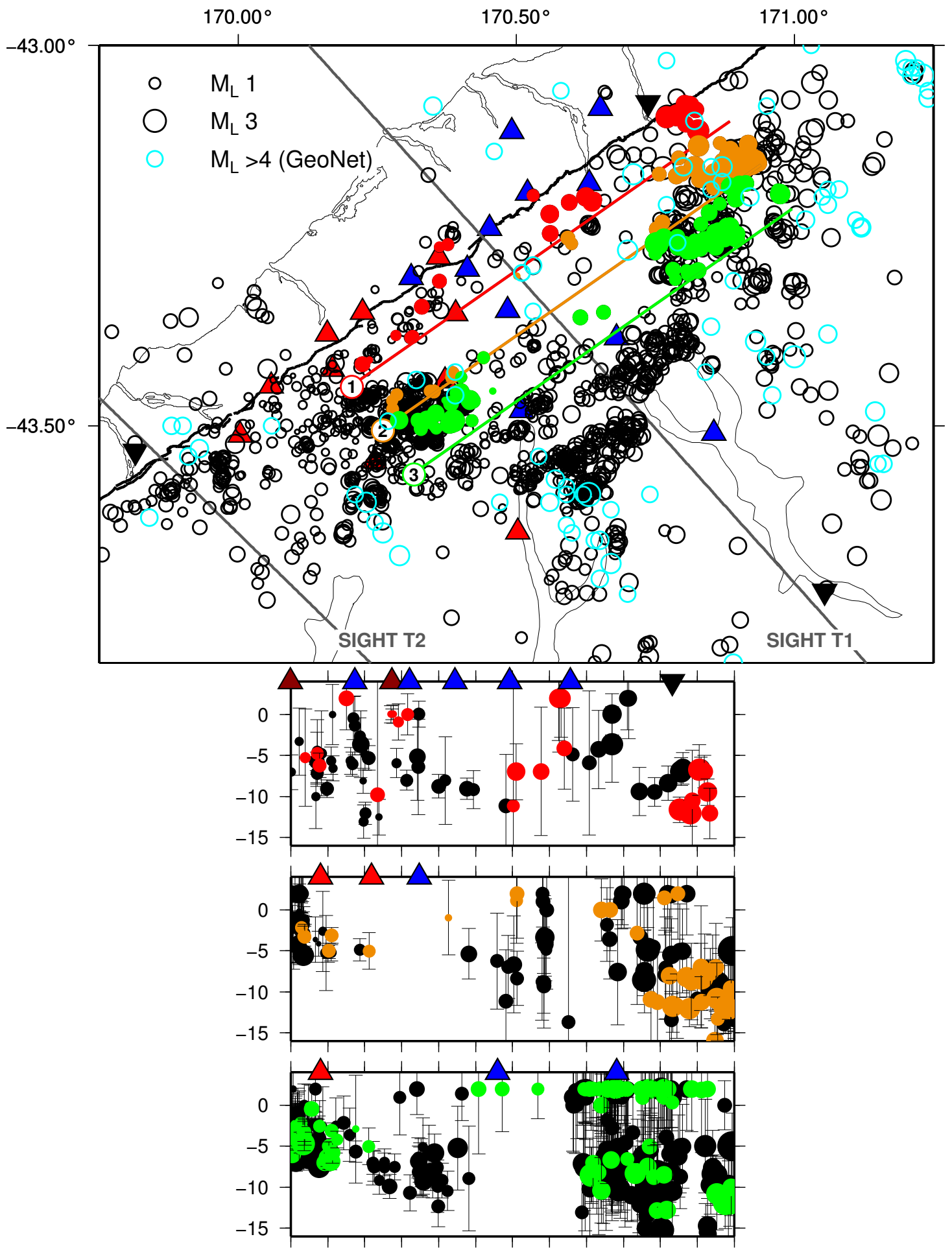

Figure 4.11. Seismicity in the Whataroa-Wanganui gap along profiles parallel to the Alpine Fault. Events with better depth resolution recorded by DFDP10 stations between January and April 2010 are in colour. Events in cyan are earthquakes of $\mathrm{M}_{\mathrm{L}} \geq 4.0$ recorded by GeoNet since 1975. See Fig. 1.8 for locations. 


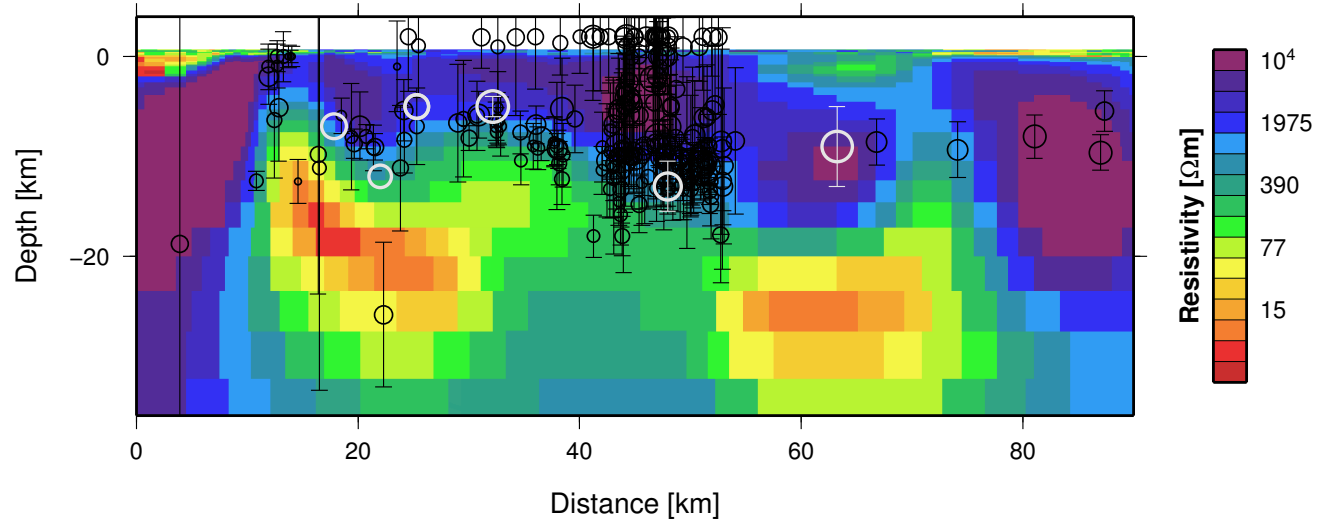

Figure 4.12. Seismicity within $10 \mathrm{~km}$ of the SIGHT transect T1 (black) projected onto the resistivity profile of Wannamaker et al. (2009). White circles are large earthquakes in the central South Island. See Fig. 4.3 for details.
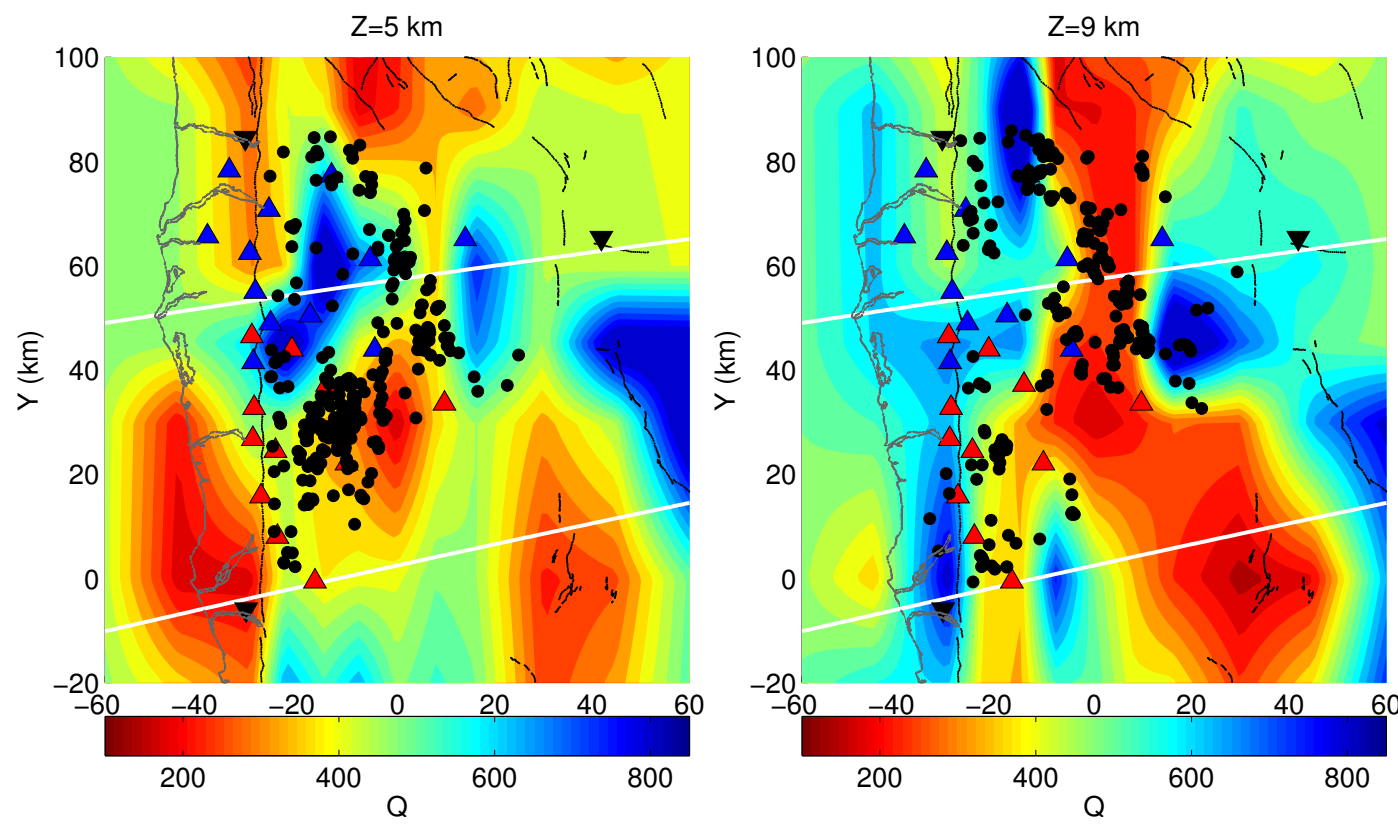

Figure 4.13. Seismicity in comparison with the attenuation structure at 5 (left) and $9 \mathrm{~km}$ depth (right) obtained by Eberhart-Phillips et al. (2008). Hypocentres within $2 \mathrm{~km}$ of the depth slice are shown in black. 
Chinn 1996). The Whataroa-Perth valley systems also experienced substantial denudation (Herman et al. 2010, and references therein). Consequently, extensive erosion could be an contributing factor to the unloading. The glaciers in the Mackenzie Basin experienced a major retreat since the last glacial maximum (Suggate 1990). The geomorphology of the Rangitata Valley shows that no significant glacier re-advance could have occurred between $16.4 \mathrm{ka}$ and $13.7 \mathrm{ka}$ (Shulmeister et al. 2011). The ice volumes affected in the three areas are approximately 338, 121 and $248 \mathrm{~km}^{3}$ (corresponding areas 2375,1750 and $1400 \mathrm{~km}^{2}$ ). Since isostatic adjustment is of importance for large and wide volumes affecting areas of regional scales, we only consider here the effect of this load removal on the principal stresses. In general, changes in the vertical stress due to the loss of overburden would be up to $10 \mathrm{MPa}$. This is only a small fraction of the stresses at depth as determined in Section 4.4. The effect would be largest near the surface, where the differential stress is low. In principle, if the rapid unloading causes the vertical stress $\left(S_{2}\right.$ in the study area) to become comparable or less than the minimum horizontal stress $\left(S_{3}\right)$ this would increase thrust faulting in the Southern Alps region. This may explain why the number of reverse faults mapped in outcrops east of the Main Divide (Cox et al. 2012) is much larger than the numbers of reverse focal mechanisms obtained for microearthquakes in this study (as shown in Fig. 4.7). On a regional scale, however, the effect of deglaciation appears to be significant. The volume of ice lost in the Southern Alps $\left(\sim 5550 \mathrm{~km}^{3}\right.$ over an area of 54000 $\mathrm{km}^{2}$ as modelled by N. Golledge, pers. comm., 2012) is overall comparable to the volume of water lost from Lake Bonneville between the Bonneville highstand (17.5 ka cal BP) and the Provo highstand (16.7 ka cal BP; see Karow and Hampel 2010) and the area affected (that experienced $69 \mathrm{~m}$ of uplift due to isostatic readjustment in the case of Lake Bonneville). Therefore, deglaciation may have played an important role on slip-rate variations of the Alpine Fault and should be considered in this area (Turpeinen et al. 2008)

Increases of slip-rates of major normal faults in the Wasatch Fault Zone have been documented and associated with the regression of Lake Bonneville and deglaciation in the Wasatch and Uinta Mountains in the Late Pleistocene/Early Holocene (e.g. Karow and Hampel 2010, and references therein). Hetzel and Hampel (2005) use finite difference models to show that glacial unloading decelerates slip because $S_{1}$ decreases, but isostatic rebound decreases $S_{3}$ and promotes normal faulting which can explain the observed slip-acceleration. These slip-rate accelerations can explain clustering of seven large earthquakes on the Wasatch front during the Holocene. Karow (2010) showed by finite element modelling that thrust faults show an increase of seismicity in response to unloading (that starts $0.5 \mathrm{ka}$ after unloading and lasts ca. $3.5 \mathrm{ka}$ after a loading period of $17 \mathrm{ka}$ in his model), as seen after the deglaciation of Scandinavia (e.g. Stewart et al. 2000). Strike-slip 
faults are affected similarly. Large earthquakes within the vicinity of the Dead Sea appear to coincide with intervals of lake regression (Karow 2010, and references therein). 


\section{The characteristics of earthquake swarms in the central Southern Alps}

This chapter combines a summary of our current understanding of earthquake swarms and triggered seismicity with observations made in this study about these topics. The latter is written in the form of a publication. Katrina Jacobs has contributed to the obtained results on earthquake swarms in the Southern Alps. Amongst others, she has analysed the earthquake rates in different regions, from different networks, and for different time periods as described in Section 5.2.1, developed the CURATE algorithm to identify sequences as described in Section 5.3, determined the probabilities of triggered swarms (Section 5.5) and found the observed inter-event patterns that are shown in Section 5.6.

A statement by Hill et al. (1993) provides the context for this chapter: "Whatever the triggering process, the results [are] a cascading failure sequence (earthquake swarm) in crustal volumes already loaded to a critical stress state".

\subsection{General aspects of earthquake swarms and triggering}

\subsubsection{Earthquake swarms}

The term "earthquake sequence" describes earthquakes related in space and time. "Earthquake swarms" are sequences of earthquakes which do not exhibit an event of greatest magnitude at, or near, the beginning of the sequence as characterises a "mainshockaftershock sequence" (e.g. Mogi 1963) (Fig. 5.1). Swarms stand out as discernible disturbances in the background seismicity. In non-volcanic settings, swarms are often 


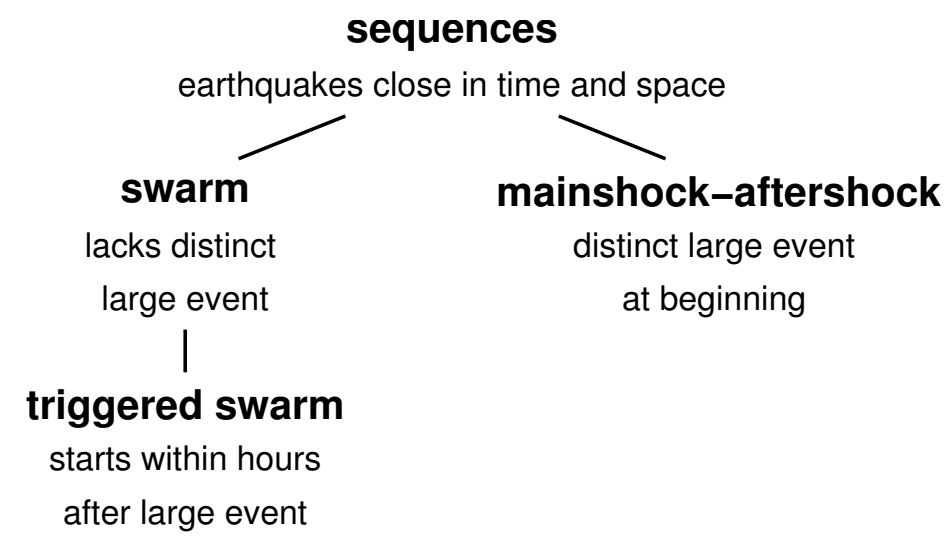

Figure 5.1. Classification of the terms earthquake sequences, swarms and mainshockaftershock sequences as used in this study based on original definitions by Mogi (1963). Note that a "distinct mainshock" is generally considered to be separated from its aftershocks by a magnitude separation value exceeding half a magnitude unit.

associated with rapid fluid redistribution in the vicinity of fault zones (Vidale and Shearer 2006) or with aseismic creep (e.g. Roland and McGuire 2009). This association has been established on the basis of their short temporal distribution (termed "bursts" by Vidale and Shearer 2006) and observations of hypocentre migration away from the point of initialisation.

One well-known example of a swarm is the Matsushiro earthquake swarm that occurred in Japan between 1964 and 1967 (Hagiwara and Iwata 1968; Nakamura 1969). The extensive and widely distributed seismicity (700,000 earthquakes in an elliptic area of about $34 \mathrm{~km}$ in length and $18 \mathrm{~km}$ in width, Hagiwara and Iwata 1968; Cappa 2010) was accompanied by surface cracking, $70 \mathrm{~cm}$ of ground uplift and the outflow of large volumes of groundwater (Mogi 1989; Yamashita 1999). The swarm was associated with pore-pressure changes induced by the M 7.5 Niigata earthquake that occurred nearby in 1964 (Mogi 1989).

In general, fluid migration follows zones of weaknesses (Grünthal et al. 1990; Miller et al. 2004) or aligns with permeability anomalies associated with lithological boundaries (Audin et al. 2002). Mogi (1963) postulated that tectonic swarms occur in regions that are highly fractured. At mid-ocean ridges, swarming is a characteristic style of seismic energy release (e.g. McGuire 2008; Roland and McGuire 2009). Sometimes, earthquake swarms precede large earthquakes, as in the case of the L'Aquila earthquake of 6 April 2009 (e.g. Papadopoulos et al. 2010) or the Izu-Hanto-Toho-Oki earthquake sequence of 1980 (Utsu et al. 1995, and references therein). Swarms in volcanic settings are attributed to the intrusion of magma, especially dikes. Benoit et al. (1996) and Vidale et al. (2006) observed 
that volcanic swarms have longer durations than tectonic swarms and that the hypocentral depths are shallower in volcanic swarms. Vidale and Shearer (2006) further reported the predominant occurrence of swarms on vertical planes or linear streaks. This led them to suggest that swarms are predominantly produced on strike-slip faults.

Earthquake swarms differ from mainshock-aftershock sequences in many respects, and each is most likely caused by a different physical mechanism. Aftershocks are observed in regions of stress concentrations within and adjacent to the rupture zone of the mainshock. Coseismic static stress-changes, that diminish approximately in proportion to $\mathrm{r}^{-3}$, cause loading of some faults in the vicinity of the mainshock rupture zone which respond with increased aftershock activity (King et al. 1994). Other factors, however, such as afterslip, pore-fluid pressure readjustments, viscoelastic readjustments, high dynamic stresses induced by directivity effects, and geological structures have been demonstrated to play a significant role in the aftershock distribution (e.g. Fialko 2004; Kilb et al. 2000). Dilatational fault jogs, for example, exhibit pronounced aftershock activity, most likely due to reduced mean stresses and pore-fluid pressures (Sibson 1987) causing fluid flow into these areas. Similarly, the comparisons of aftershock locations with pore-pressure changes in wells shows that aftershocks cluster in areas that have experienced a decrease in pore-pressure during the mainshock and fluid inflow afterwards (Jónsson et al. 2003). Kilb et al. (2000) showed a correlation between the seismicity rate change and the peak Coulomb stress change associated with dynamic waves in the aftershock zone of the Landers earthquake. Due to the rupture being unilateral, the high dynamic stresses that normally cannot be distinguished easily from the coseismic static stress changes could be identified in this case and used to explain the observed aftershock distribution.

Vidale and Shearer (2006) observed that earthquake swarms contain more earthquakes than mainshock-aftershock sequences for comparable magnitudes of the largest events (their Fig. 7). This fact is reflected in the high b-values commonly reported for swarms (e.g. Sykes 1970). The total duration of an individual mainshock-aftershock sequence as determined using a magnitude threshold is at least a factor of three smaller than that of an earthquake swarm (Vidale et al. 2006). However, the spatial distribution is more extensive for mainshock-aftershock sequences than for earthquake swarms. Vidale and Shearer (2006) observed that the proportion of mainshock-aftershock sequences with respect to the total number of sequences in Southern California is approximately 20\%. Swarms made up 25\% of the total whereas the remaining sequences were classified as "other". 


\subsubsection{Earthquake triggering}

Remotely triggered seismicity is commonly observed following earthquakes of $\mathrm{M}_{\mathrm{W}} \geq 7$ at locations that may be hundreds of kilometres away from the hypocentre of the mainshock (e.g. Hill et al. 1993; Steacy et al. 2005). At these distances, the dynamic stresses caused by the passage of the surface waves $\left(>10^{4} \mathrm{~Pa}\right)$ are larger than static stress changes from the mainshock $(<100 \mathrm{~Pa})$ as pointed out by Brodsky and Prejean (2005) for the Long Valley caldera in California. In some cases, static stresses may even be smaller than tidal stress levels (e.g. Hill et al. 1993). Remote dynamic triggering has been observed in different tectonic settings worldwide (Velasco et al. 2008). However, seismically active regions in extensional tectonic regimes (e.g. Hill et al. 1993) appear more susceptible to dynamic triggering than others. In particular, young volcanic centres, geothermal areas and regions of active faulting frequently exhibit triggered earthquakes (Hill et al. 1993; Husker and Brodsky 2004). If the minimum compressive principal stress direction lies in the horizontal plane, as in strike-slip and normal faulting stress regimes, the differential stress required for fault rupture of dynamically triggered events is less than when the minimum principal stress is vertical (e.g. Hill et al. 1993; Harrington and Brodsky 2006). Consequently, rock under extension and high fluid pressures may undergo failure in response to small stress changes. Husker and Brodsky (2004) identified regions of high heat flow with large volumes of total dissolved solids as favourable for dynamic triggering.

Seismically active regions (with high background seismicity rates, corresponding to high tectonic loading rates) are also more susceptible to remotely triggered seismicity (e.g Gomberg et al. 2004). This may be due to the larger number of faults close to failure in these areas. Although triggered events seem to generally occur in regions of high background seismicity, recent observations have shown that the largest number of triggered events in Greece occurred in a region of relatively low levels of seismicity (e.g. the Arta cluster of Brodsky et al. 2000). Remotely triggered swarms have also been observed in previously aseismic areas of Long Valley caldera (Prejean et al. 2004). In other words, the contrary view has been suggested as well: if the stressing rate is low, the perturbing stress changes are large relative to ambient stressing rates (Steacy et al. 2005). Gomberg et al. (2004) suggested that triggered seismicity in the western USA occurs in the transitional zone between old, cold, strong crust and younger, warmer and weaker crust.

In summary, the tectonic settings that repeatedly exhibit remotely triggered seismicity are commonly volcanic and geothermal settings, probably because the conditions are most favourable to dynamic triggering, but remote triggering is not restricted to these settings. 
Moreover,

- both Rayleigh and Love waves from earthquakes cause dynamic stress changes that can remotely trigger seismicity (Velasco et al. 2008, see next section);

- induced seismicity involves brittle slip on critically stressed faults favourably oriented in the prevailing stress field (e.g. Hill et al. 1993; Gomberg et al. 2004);

- triggering represents clock-advance of failure on the fault (e.g Anderson et al. 1994; Steacy et al. 2005); and

- areas undergoing swarm activity frequently respond more often to dynamic stress changes (e.g. Hill et al. 1993).

\subsubsection{Previous observations of earthquake triggering}

Dynamic triggering has been observed in many places, notably in the western USA, Alaska, Syria, Greece, Iceland and China. Observations of remotely triggered seismicity in California are particularly well described in the literature and summarised below. Locations named in the text are shown in Fig. 5.2.

Long Valley caldera in eastern California appears particularly susceptible to earthquake triggering. Elevated levels of seismicity occurred after the $1992 \mathrm{M}_{\mathrm{W}} 7.3$ Landers (Hill et al. 1993; Brodsky 2006), the $1999 \mathrm{M}_{\mathrm{W}} 7.1$ Hector Mine (Gomberg et al. 2001) and the 2002 $\mathrm{M}_{\mathrm{W}}$ 7.9 Denali earthquakes (Prejean et al. 2004; Brodsky and Prejean 2005). This region is monitored with a dense seismometer network and the catalogue completeness is low (cut-off magnitude of 1.2 according to Brodsky and Prejean 2005). Hill et al. (1993) reported 340 earthquakes within seven days of the Landers earthquake. These events coincided with a transient contractional strain pulse of about 45 days' duration that was recorded by one strainmeter and inferred to result from increased fluid pressure (Hill et al. 1993). Approximately 200 events of $M \leq 3$ occurred in Long Valley Caldera after the Denali earthquake (Prejean et al. 2004).

At the Geysers geothermal field in northern California, triggered seismicity has been observed for several earthquakes of $M \geq 6.6$ (Stark and Davis 1996), including the 1989 $\mathrm{M}_{\mathrm{W}}$ 6.9 Loma Prieta and $1992 \mathrm{M}_{\mathrm{W}} 7.1$ Petrolia earthquakes (Hill et al. 1993). The largest amount of triggered seismicity occurred in response to the $1992 \mathrm{M}_{\mathrm{W}} 7.3$ Landers earthquake (Stark and Davis 1996). The triggered seismicity consisted of a swarm of 60 events of $M<1$ (Hill et al. 1993), with locations that mimicked the background seismicity (Stark and Davis 


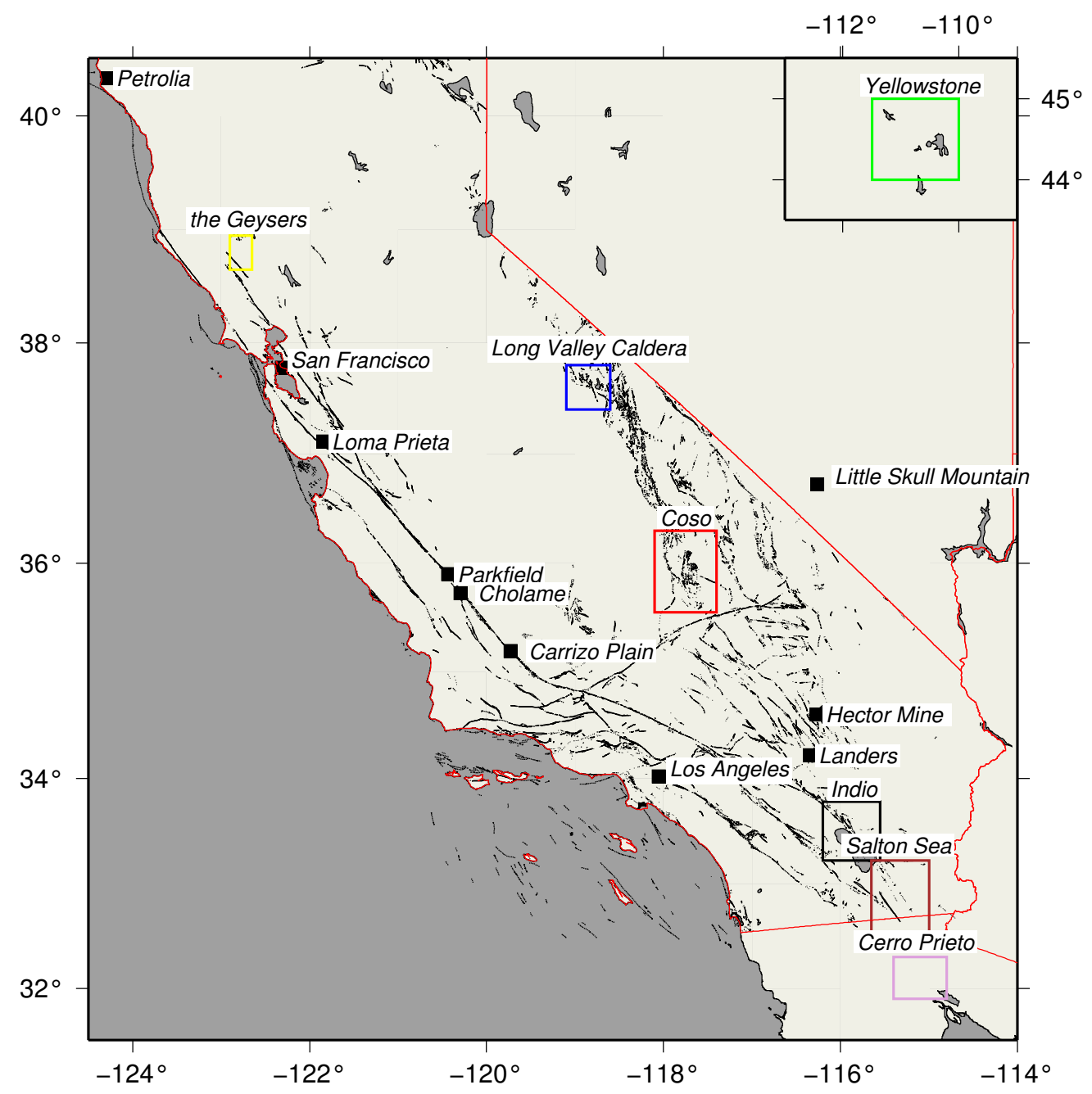

Figure 5.2. Map of California showing key locations named in the text and areas in which remotely triggered seismicity was observed (rectangles). Faults in California are adapted from Jennings (1975). 
1996).

The Coso geothermal field exhibited triggered seismicity after the Hector Mine, Landers and Denali earthquakes (Prejean et al. 2004). Following the Hector Mine earthquake, 26 small, unlocatable events were recorded (Prejean et al. 2004). After the Landers earthquake, 44 events of $M \leq 4.4$ were located (Prejean et al. 2004). A total of 80 earthquakes of $\mathrm{M} \leq 2.3$ were triggered in response to the Denali earthquake (Prejean et al. 2004).

A small cluster of earthquakes (16 events) occurred $15 \mathrm{~km}$ northwest of Yellowstone caldera after the Landers earthquake. Abundant seismicity ( 600$)$ of $\mathrm{M}<3.2$ was observed inside and outside the Yellowstone caldera following the Denali earthquake (Husen et al. 2004). Redistribution of hydrothermal fluids inside the caldera and alteration of the fault properties in the northwestern part of Yellowstone outside the caldera have been suggested as causes for the triggered seismicity (Husen et al. 2004).

Increases in seismicity were observed in southwestern Utah in the Hurricane fault zone after the Landers earthquake (60 earthquakes; Hill et al. 1993), and along the $500 \mathrm{~km}$ long section of the Intermountain Seismic Belt (including the $380 \mathrm{~km}$-long Wasatch Fault Zone) in central Utah (Pankow et al. 2004) after the Denali earthquake. In the latter case, the majority of earthquakes ( 65 events of $M \leq 2.6$ from a total of $\sim 110$ of $M \leq 3.2$ ) occurred within the first day.

Two swarms of $M<0.9$ occurred at Mt. Rainier in the cental Washington Cascades following the Denali earthquake (Prejean et al. 2004). Several sites of triggered seismicity were identified by Husker and Brodsky (2004) in Idaho and western Montana after the Denali earthquake. After the Landers earthquake, 51 triggered earthquakes of $\mathrm{M}_{\mathrm{L}} \leq 1.7$ occurred near Cascade, Idaho (Hill et al. 1993). Gomberg et al. (2001) reported triggered seismicity at Indio, the Salton Trough and Cerro Prieto, Mexico, after the Hector Mine earthquake. Anderson et al. (1994) reported 227 events in Nevada within 83 days following the Landers earthquake. Other places in the western United States, where triggered seismicity occurred have been documented by Hill et al. (1993).

At Katmai volcano, Alaska, seven locatable and four unlocatable events occurred after the Denali earthquake. Triggered earthquakes have been observed following three previous large earthquakes in the greater region (Moran et al. 2004, and references therein). After the $\mathrm{M}_{\mathrm{W}}$ 9.2 Sumatra-Andaman islands earthquake in 2004, a swarm of $14 \mathrm{mi}$ croearthquakes $(M \leq 1.9)$ was observed at Mount Wrangell, Alaska (West et al. 2005). An 
earthquake swarm $(\mathrm{M}<3.7)$ of 21 events in southwestern Syria, along the Dead Sea Fault system, was reported by Mohamad et al. (2000) after the $\mathrm{M}_{\mathrm{S}} 7.3$ Gulf of Aqaba earthquake of 22 November 1995. This swarm occurred in a region where the background seismicity rate is $0.5-1$ events per day. Brodsky et al. (2000) observed triggered seismicity in several places in Greece following the $\mathrm{M}_{\mathrm{W}} 7.4$ Izmit earthquake in 1999. Lei et al. (2011) detected significant rate changes after the $2004 \mathrm{M}_{\mathrm{W}} 9.3$ Sumatra earthquake in southwestern China. The triggered events were spatially clustered at step-overs, fault junctions, fault ends and bends. Several locations in northern China responded with remotely triggered seismicity to the $2008 \mathrm{M}_{\mathrm{W}} 7.9$ Wenchuan earthquake (Peng et al. 2010). These events occurred predominantly in aftershock zones of recent large events. Lei et al. (2011) and Peng et al. (2010) concluded that remote triggering occurs where the ground is damaged and where large numbers of faults and fractures are present.

Not all regions susceptible to dynamic triggering exhibit triggered seismicity. In Japan, only one example of triggering occurred after the great (M 8) Nankaido earthquake in 1946 (Hill et al. 1993). Harrington and Brodsky (2006) searched for triggered earthquakes after several large events in Japan and found very little evidence. They came to the conclusion that stresses cannot accumulate over time because Japan is so frequently shaken by large-amplitude, low-frequency events. After the $\mathrm{M}_{\mathrm{W}} 9.0$ Tohoku earthquake, a significant increase in the seismicity was observed throughout Japan (Toda et al. 2011). This increase was inferred to be caused partly due to large static stress changes $(\geq 0.1 \mathrm{MPa}$ or 1 bar $)$ over large parts of Japan. In some regions in northern Japan, the stress field changed due to a rotation of the principal stress directions (Yoshida et al. 2012). Large events (M 5-6) occurred within 3 rupture lengths of the mainshock (Miyazawa 2011). At distances $\geq 200$ $\mathrm{km}$ the static stresses were smaller than dynamic stresses caused by the surface waves and at $\geq 500 \mathrm{~km}$ the dynamic stresses were one order larger than the static stresses. Miyazawa (2011) showed that the seismicity triggered by dynamic stresses followed a triggering front consistent with surface wave propagation. According to Miyazawa (2011), all delayed triggered earthquakes were inferred to be triggered due to static stress changes.

In many places, triggered seismicity begins with or shortly after (within minutes to hours) the arrival of the Love or Rayleigh waves (West et al. 2005; Prejean et al. 2004). This has been shown by Velasco et al. (2008) for triggered seismicity around the globe with an increase of $37 \%$ above the background rate observed after the Love surface waves and an overall $60 \%$ increase after the Rayleigh waves. The observations of triggered seismicity by West et al. (2005) at Mt. Wrangell showed that the triggered earthquakes align in phase with the maximum vertical $30 \mathrm{~s}$ Rayleigh wave that exceeded an amplitude threshold of $0.25 \mathrm{~cm}$ 
ground displacement. This phase corresponded to maximum horizontal extensional stresses of $<25 \mathrm{kPa}$ at those shallow depths where the triggered events occurred. West et al. (2005) reported this triggering to be consistent with simple shear failure on normal faults.

In many cases, the small triggered events occur during or immediately after the passage of the surface waves. These events can be obscured by the waveforms of aftershocks. However, some evidence for delayed triggering also exists. Gomberg et al. (2001) observed a delay of 1.35 days at Cerro Prieto after the Hector Mine earthquake. Mohamad et al. (2000) reported a swarm $167 \mathrm{~min}$ after the Aqaba earthquake at $\sim 500 \mathrm{~km}$ distance, followed by a two-month period of quiescence. Similarly, at Yellowstone caldera, where seismicity begins with the passage of the surface waves, one isolated swarm of more than 20 events occurred after a delay of 8 days following the Denali earthquake in the West Thumb geyser basin (Husen et al. 2004). One burst of seismicity delayed by 13.4 days after the Denali earthquake occurred amongst clusters in the Intermountain Seismic Belt in central Utah (Pankow et al. 2004). One swarm of 112 events of $\mathrm{M} \leq 3$ delayed by $23.5 \mathrm{hr}$ relative to the onset of the Denali earthquake surface waves occurred at the Long Valley caldera (Prejean et al. 2004). The Little Skull Mountain earthquake, the largest event possibly triggered by the Landers earthquake, took place $22 \mathrm{hr}$ after the mainshock (Gomberg and Bodin 1994; Bodin and Gomberg 1994). Gomberg and Bodin (1994) proposed aseismic slip on faults in the vicinity of Little Skull Mountain triggered by the Landers earthquake as the cause for this delay. Syracuse et al. (2010) reported a swarm of seismicity two days after the $2007 \mathrm{M}_{\mathrm{W}} 8.1$ Solomon Islands earthquake at Kilauea volcano. They inferred fluid migration to be the cause for this swarm. Lei et al. (2011) observed event clusters resembling mainshock-aftershock sequences immediately (20 min) and several hours (7.5 hr) after the Sumatra earthquake. Other remotely triggered events (clusters 3-6) occurred with greater delays $(\geq 14 \mathrm{hr}$ ) and exhibited swarm-like characteristics (as a progressive increase in magnitude). Table 5.1 summarises these observations of delayed triggering.

In general, dynamically triggered seismicity lasts for a few hours to several days (e.g Husker and Brodsky 2004; Brodsky 2006), but in several cases seismicity has persisted for weeks (Hill et al. 1993; Husen et al. 2004; Pankow et al. 2004). Brodsky (2006) showed for the Long Valley caldera that the triggered events following the Landers earthquake resemble aftershock sequences from $\mathrm{M}_{\mathrm{L}} 4.1$ earthquakes. The late, triggered events can be explained as aftershocks of those events triggered by the surface waves. Accordingly, more than $80 \%$ of the triggered earthquakes could be explained via a process of local aftershock generation (Brodsky 2006). However, this mechanism does not explain isolated sequences delayed by several days at Cerro Prieto, Yellowstone or Utah. 
Interval times between sequences of triggered events range from a few months at the Geysers geothermal field (Stark and Davis 1996) to three years at Long Valley caldera (Brodsky and Prejean 2005). However, this time may depend on the background seismicity rate and the seismic energy released in the previous swarm. Remotely triggered events occur in the uppermost crust (e.g. $20 \%$ of all events at Long Valley occur at depths $<3 \mathrm{~km}$; Brodsky and Prejean 2005), <5 km at Yellowstone (Husen et al. 2004), around $2 \mathrm{~km}$ or less at Mt. Wrangell (West et al. 2005) and at depths shallower than $4 \mathrm{~km}$ for the majority of events at the Geysers (Stark and Davis 1996).

Mainshocks that excited most of the reported remotely triggered seismicity (the Landers, the Hector Mine and the Denali earthquakes) ruptured unilaterally (Hill et al. 1993; Kilb et al. 2000; Gomberg et al. 2001, 2004) and regions that exhibited remotely triggered seismicity were in line with the maximum radiated seismic energy. Rupture directivity causes a strong focusing effect of seismic waves and increases the dynamic stress in the direction of rupture propagation (Gomberg et al. 2003). The decrease in maximum magnitude and the total seismic moment of the remotely triggered events with distance from the Landers and Tohoku earthquakes support this (Hill et al. 1993; Miyazawa 2011).

The cumulative number of remotely triggered events exhibits similar decay characteristics as an aftershock sequence (Husen et al. 2004; Pankow et al. 2004; Brodsky 2006). Therefore, a modified (Utsu) Omori-law can be used to fit the data

$$
\mathrm{dN} / \mathrm{dt}=\mathrm{n}(\mathrm{t})=\mathrm{k}(\mathrm{t}+\mathrm{c})^{-\mathrm{p}}
$$

where $\mathrm{n}(\mathrm{t})$ is the number of earthquakes per unit time at time $\mathrm{t}$; $\mathrm{k}$ represents a measure of the productivity of the mainshock and depends on the lower magnitude threshold of the given earthquake catalogue; $c$ describes a temporal offset that compensates for incomplete data in the earliest part of the aftershock sequence, and $\mathrm{p}$ describes the exponential decay of the aftershock rate. For all events of $M>1.5$ at Yellowstone, Husen et al. (2004) obtained $\mathrm{p}=1.02 \pm 0.07$. This result was later on confirmed by Brodsky (2006) who calculated $\mathrm{p}=0.98 \pm 0.07$. Pankow et al. (2004) estimated a value of $\mathrm{p}=0.65 \pm 0.04$ for the sequence of events in Utah. Brodsky (2006) obtained $\mathrm{p}=1.03 \pm 0.03$ for the triggered seismicity at the Geysers and $p=1.16 \pm 0.17$ for the Long Valley caldera for events of $M>2$. Stark and Davis (1996) suggested that this decay reflects the redistribution of stress in a similar manner to that which occurs in a mainshock-aftershock sequence.

Brodsky and Prejean (2005) investigated whether dynamic triggering at the Long Val- 
ley caldera depends on the amplitude of the surface waves, the cumulative dynamic stress, or the amplitude of the seismic wave at a certain frequency. They found that, above a shaking threshold of $0.2 \mathrm{~cm} / \mathrm{s}$, dynamic triggering is independent of the amount of shaking (amplitude), its duration, and the energy-density of the waves. However, the frequency of the wave appears to be crucial for triggering (Brodsky and Prejean 2005). Long-period waves (>30 s) are most effective at triggering local earthquakes at Long Valley caldera. Different periods ranging between 10 and $40 \mathrm{~s}$ have been suggested by Anderson et al. (1994) and Prejean et al. (2004) to be responsible for triggering. Since the amplitude decay with depth depends on the period of the seismic wave, the frequency-dependence observed for triggering may vary in different locations depending on the depth at which earthquakes are triggered (e.g. Brodsky and Prejean 2005) .

\subsubsection{Suggested mechanisms of earthquake triggering}

It is currently assumed that remotely triggered seismicity reflects slip on favourably oriented faults, which fail in response to either temporal fluctuations of the driving shear stress $\tau$, the effective normal stress $\left(S_{n}-p\right)$ or short-term variations of the local frictional resistance $\mu$ or combinations of these. The temporal reduction of normal stress on the fault plane as the result of particle acceleration in the direction normal to the shear plane by $\mathrm{S}$ - or Love-waves polarised in the plane of maximum tectonic shear stress has been suggested by Hill et al. (1993): this amounts to unclamping of the fault caused by oscillations normal to the fault surface. Another mechanism involves crack growth in response to accelerated stress corrosion on the crack tip imposed by the dynamic stresses of the triggering surface waves (Brodsky et al. 2000). Stress corrosion describes the response of a crack to a sudden change in ambient conditions, such as an increase in loading associated with the presence of fluids or high temperatures. The crack tip weakens due to chemical corrosion caused by fluid-rock interactions (Das and Scholz 1981). All other proposed mechanisms (described in more detail below) involve pore fluid pressure changes that lower the effective normal stress on the fault. Hill et al. (1993) suggested that local pore pressure fluctuations occur at periods of 5-20 s in response to compression associated with the Rayleigh wave. Brodsky et al. (2003) proposed a mechanism involving the unclogging of blocked fractures, which describes the rupturing of seals in temporarily blocked fractures and consequent fluid redistribution. This mechanism may explain delays in the occurrence of remotely triggered earthquakes relative to the passing of the surface waves, because fluid flow depends on the velocity with which these fluids can propagate and hence on the permeability. Fluid diffusion typically occurs at velocities of $0.1-1 \mathrm{~km} /$ day, depending on the hydraulic diffusivity of the fractured rock (typical range 0.01-100 m²/s) (Steacy et al. 2005, and references therein). Much faster 
swarm migration rates of $0.1-1 \mathrm{~km} / \mathrm{hr}$ observed in the Salton Trough have been explained as triggering by aseismic slip. This has also been suggested by Bodin and Gomberg (1994) for faults of the Eastern Californian Shear Zone after the Landers earthquake to explain the delayed occurrence of the Little Skull Mountain earthquake. A similar mechanism has been suggested for the Mexicali Valley, where aseismic slip commenced after the Hector Mine earthquake and microseismicity occurred after a delay of more than 30 hours (Glowacka et al. 2002).

Several mechanisms have been suggested to explain fluid pressure increases in magmatic systems. These processes are associated with bubbles in magma bodies, which increase the compressibility of the magma chamber significantly. Linde et al. (1994) proposed a mechanism termed advective overpressure to explain triggered seismicity at the Long Valley caldera. According to this model, gas bubbles shaken loose due to dynamic stresses imposed by the waves from distant earthquakes rise slowly in the magma and lead to pressurisation. This mechanism would explain a delay in the triggered seismicity due to the rise-time of the bubbles. Rectified diffusion describes the pumping of volatiles into preexisting bubbles that experience a change in shape and volume in response to an oscillating stress field imposed by waves from the triggering event (Sturtevant et al. 1996). Because the surface of the bubble is larger during expansion, more of the dissolved, slightly supersaturated vapour in the fluid/rock/vapour system diffuses into the bubble than out of the bubble, so the bubbles grow and cause a pore pressure increase. Relaxation of any sustained stress differences in a partially crystallised magma chamber, or sinking of crystals shaken loose during the passage of the seismic waves within the magma chamber have also been suggested by Hill et al. (2002) as possible responses to dynamic stresses. Manga and Brodsky (2006) proposed bubble nucleation in a crystallising magma close to critical supersaturation in which the dissolved gas nucleates bubbles in response to small pressure changes associated with the triggering waves.

It has been suggested that several mechanisms may operate at the same time, since most of the proposed mechanisms cause an instantaneous response to the dynamic stresses imposed by the surface waves and only those that involve fluid flow account for a delay between the triggering waves and the remotely triggered events. The table compiled by Prejean et al. (2004) and reproduced in Figure 5.3 summarises the environments in which these mechanisms are most likely to occur and their ability to account for delays. A different mechanism not involving fluid processes but instead involving damage of the contact surfaces of faults caused by the dynamic stresses of the triggering surface waves was described by Parsons (2005). His approach is based on rate and state friction laws. 
Possible Mechanisms for Triggering

\begin{tabular}{|c|c|c|c|c|c|c|}
\hline & \multicolumn{3}{|c|}{$\begin{array}{l}\text { Events During } \\
\text { Wave Train }\end{array}$} & \multicolumn{3}{|c|}{$\begin{array}{c}\text { Swarms Delayed } \\
\text { by Hours to Days }\end{array}$} \\
\hline & A & G & $\mathrm{M}$ & A & $\mathrm{G}$ & $\mathrm{M}$ \\
\hline $\begin{array}{l}\text { Nonlinear friction } \\
\quad \text { (e.g., Gomberg et al., 1998) }\end{array}$ & $X$ & $X$ & $X$ & & & \\
\hline $\begin{array}{l}\text { Stress corrosion } \\
\quad \text { (e.g., Gomberg, 2001) }\end{array}$ & $X$ & $X$ & $X$ & & & \\
\hline $\begin{array}{l}\text { Unclogging fractures } \\
\text { (Brodsky et al., 2003) }\end{array}$ & $?$ & $X$ & $X$ & ? & $X$ & $X$ \\
\hline $\begin{array}{l}\text { Advective overpressure } \\
\text { (Linde } \text { et al., 1994) }\end{array}$ & & & & & & $X$ \\
\hline $\begin{array}{l}\text { Rectified diffusion* } \\
\text { (Brodsky et al., 1998) }\end{array}$ & & $X$ & $X$ & & $X$ & $X$ \\
\hline $\begin{array}{l}\text { Sinking crystal plumes } \\
\text { (Hill et al., 2002) }\end{array}$ & & & & & & $X$ \\
\hline $\begin{array}{l}\text { Relaxing magma body } \\
\text { (Hill et al., 2002) }\end{array}$ & & & & & & $X$ \\
\hline
\end{tabular}

Table assumes that triggered earthquakes are not aftershocks of local events. If triggered earthquakes are aftershocks, nonlinear friction and stress corrosion can lead to delayed swarms. A, anywhere; G, geothermal systems; $\mathrm{M}$, magmatically active area. $\mathrm{X}$ indicates that triggering can happen in this situation. ? indicates this mechanisms could happen anywhere, but is more effective in geothermal and magmatic systems.

*Note that Ichihara et al. (2003) have pointed out theoretical problems with rectified diffusion.

Figure 5.3. Table summarising possible triggering mechanisms as published by Prejean et al. (2004) 
Rate and state friction laws describe the dependency of fault friction on the rate at which the fault slips and the frictional state of the fault (Dieterich 1994). The state variable is influenced by the slip history (e.g. fault surface roughness, contact area, time-dependent strengthening of frictional contacts, gouge zone thickness, total slip, pore pressure, and normal stress history; see Dieterich 1994). Models based on rate- and state-dependent friction have been successful in describing various fault slip phenomena. Gomberg et al. (1998) ("frictional instability model") and Gomberg (2001) ("accelerating failure model") showed that a transient stress perturbation imposed late in the earthquake cycle causes greater clock-advance than an equal perturbation early in the cycle.

In contrast to the simple Coulomb failure model (in which clock-advanced failure due to dynamic stresses only occurs if the failure threshold is exceeded and in which the system returns to its former state when the transient perturbation is removed), the rateand state-dependent model is influenced by the transient stress perturbation even after this perturbation has gone. The quantity that characterises failure eventually accelerates towards failure. Parsons (2005) formalised this idea by proposing that damage to fault contacts induced by dynamic stress changes alters the critical slip distance $\mathrm{D}_{\mathrm{c}}$. A reduction in the mean $D_{c}$ decreases the time to failure (Parsons 2005). Accordingly, dynamic stress changes affect the state of the fault, which causes clock-advance or enhances a delayed response to triggering (Parsons 2005). Parsons' hypothesis is supported by observations by Li et al. (2003), who showed that damage on the Landers fault increased due to the dynamic waves from the Hector Mine earthquake $25 \mathrm{~km}$ away. This shaking-induced damage was noticed as a temporary reversal of the healing process that the fault had undergone within the first seven years following the Landers earthquake. The healing was manifested by the wave velocity increase of fault zone guided waves that were repeatedly generated by explosions.

\subsection{Earthquake triggering in the Southern Alps and its implications}

As noted in the previous section, remote dynamic triggering of small and intermediate events by large earthquakes has been observed worldwide (Velasco et al. 2008), but particularly in extensional or transtensional tectonic settings (Gomberg et al. 2001; Brodsky and Prejean 2005; West et al. 2005). The triggered seismicity starts with, or shortly after, the passage of the surface waves and typically continues for a few hours to several days (e.g. Husker and Brodsky 2004). This process has been termed "waveform triggering" (Brodsky 2006). In several places, however, such as Yellowstone and central Utah, seismicity 
persists for weeks after the passage of the surface waves of the triggering earthquake (Hill et al. 1993; Husen et al. 2004; Pankow et al. 2004). This may be related to the stressing rate and the background seismicity as predicted from rate and state friction theory (Dieterich 1994). Sequences that begin several hours (Hill et al. 1993; Gomberg and Bodin 1994; Bodin and Gomberg 1994; Gomberg et al. 2001) to several days (Husen et al. 2004; Pankow et al. 2004) after the surface waves of the triggering event have been referred to as "delayed triggering" (see Table 5.1 for a summary of these observations). These have been observed both in combination with and without initial "waveform-triggered" events. Two mechanisms have been proposed to explain the delay in non-magmatic systems (Table 5.3): unclogging of blocked fractures (Brodsky et al. 2003) and aseismic slip (Bodin and Gomberg 1994, e.g.). Brodsky (2006) showed for the Long Valley caldera that the triggered events following the Landers earthquake resembled aftershock sequences of $\mathrm{M}_{\mathrm{L}} 4.1$ earthquakes. The majority of the triggered events could be explained as aftershocks of those events triggered by the surface waves. However, this explanation is insufficient for isolated, "delayed-triggering" sequences of events.

Many authors have proposed that dynamically triggered events occur in areas where swarms occur regularly on critically stressed faults that experience clock-advance in response to the dynamic stresses imposed by the surface waves of the triggering earthquake (e.g. Gomberg 2001). If this were the case, we would expect similarities in the spatial and temporal characteristics between the triggered and background swarms. In the central Southern Alps region, we regularly observe swarms in an area of abundant seismicity. As described in Section 5.4 below, each swarm consists of a cascade of events of small magnitudes $\left(\mathrm{M}_{\mathrm{L}} \leq 2.8\right)$ with similar waveforms and focal mechanisms. Remotely triggered seismicity occurred in the same area after the 15 July 2009, $\mathrm{M}_{\mathrm{W}} 7.8$ Dusky Sound and the 3 September 2010, $\mathrm{M}_{\mathrm{W}} 7.1$ Darfield earthquake. We observe both "waveform triggering" of earthquakes and several instances of "delayed triggering" swarms. We compare those remotely triggered swarms to the background swarms in terms of waveform similarities, depths and magnitude distribution, duration, inter-event times and focal mechanisms to address previously described hypotheses about triggered seismicity and to contribute to ongoing discussions about the mechanisms of delayed triggered events and the causes of triggering in general.

\subsubsection{Seismicity rates in the study area}

The method applied to identify sequences is based on changes in the average earthquake rate (Section 5.3). To demonstrate that the seismicity rates throughout the study area are high, we compare the seismicity rates determined using our station array with those 


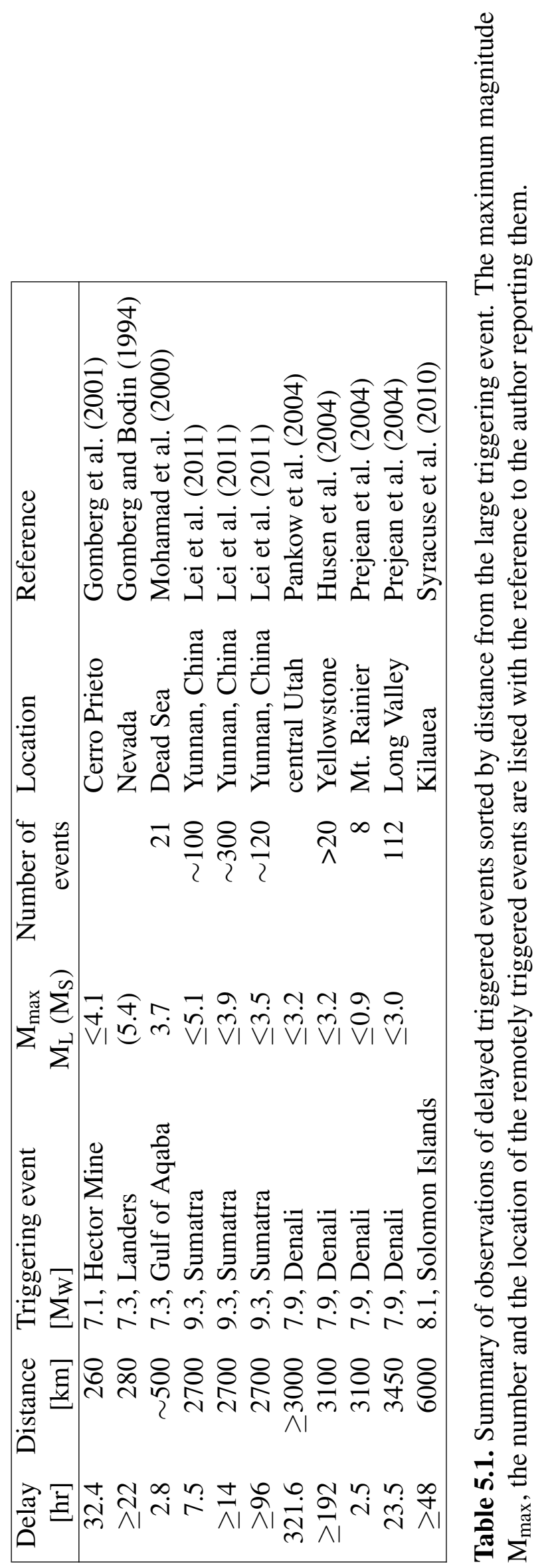




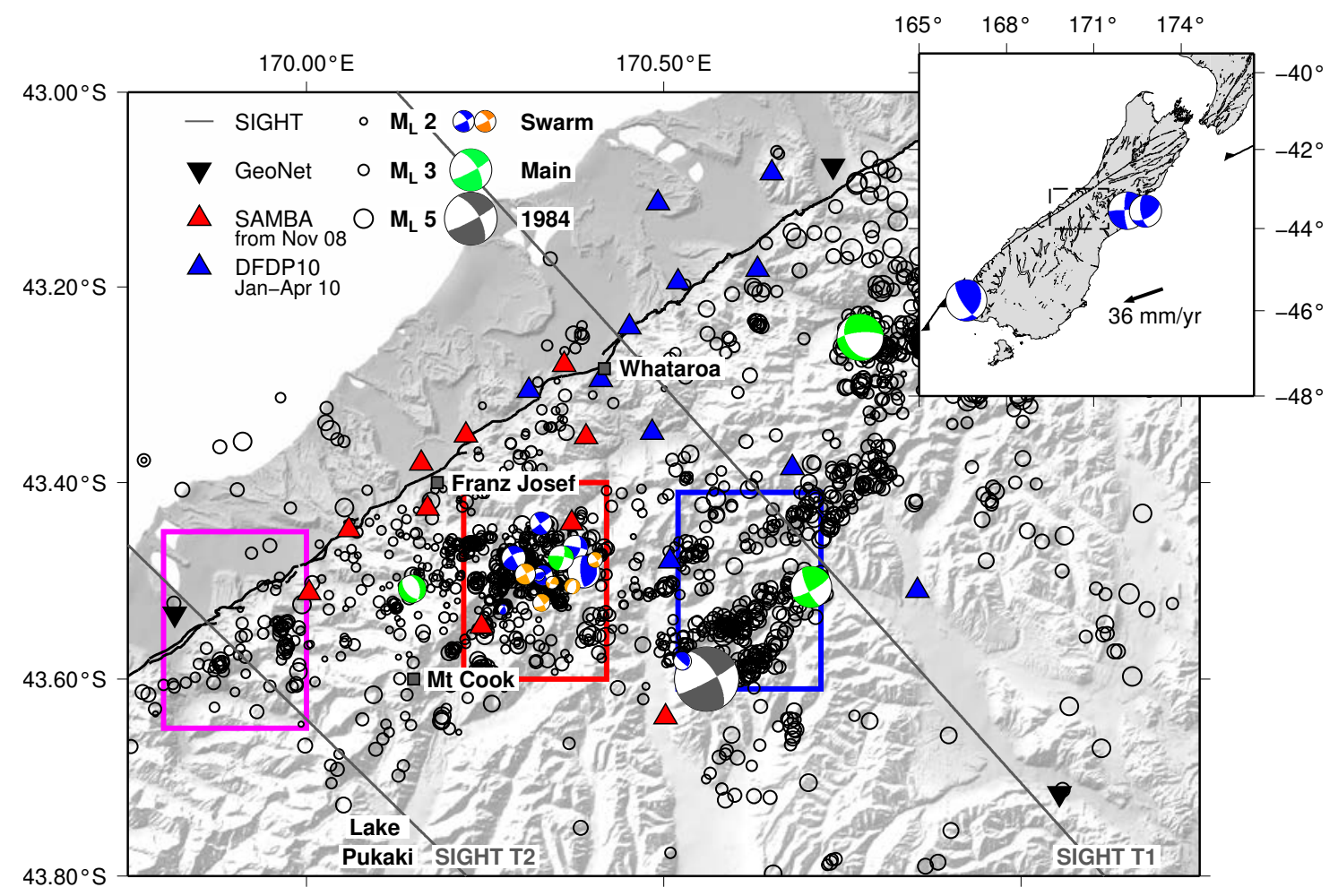

Figure 5.4. Study area in the central Southern Alps, showing the station network and the seismicity recorded between November 2009 and April 2010. The rectangles mark subregions of high and low seismicity. Focal mechanisms are shown for background swarms (blue), triggered swarms (orange) and mainshocks (green) of mainshock-aftershock sequences as well as the 1984, $\mathrm{M}_{\mathrm{w}} 6.1$ Godley Valley earthquake (grey). All focal mechanism solutions shown are lower hemisphere projections with the coloured areas representing compressional first arrivals (for details see Table K.1). The inset shows the setting of the study area in the central South Island and focal mechanisms of major earthquakes: the 2009 $\mathrm{M}_{\mathrm{W}} 7.8$ Dusky Sound earthquake approximately $350 \mathrm{~km}$ southwest and the $2010 \mathrm{M}_{\mathrm{W}} 7.1$ Darfield and $2011 \mathrm{M}_{\mathrm{W}} 6.3$ Christchurch earthquakes $\sim 180 \mathrm{~km}$ east of the study area. 
obtained by Reyners (1988) for the period 1975 to 1983 using the similarly dense Lake Pukaki station network (Haines et al. 1979; Reyners 1988). That network was designed to observe any reservoir-induced seismicity associated with the infilling of Lake Pukaki for hydroelectric purposes. During impounding of the lake, the seismicity rate at shallow depth within $15 \mathrm{~km}$ of the lake shore increased while the background seismicity decreased. The induced seismicity was concentrated near the lake and occurred along the Ostler Fault Zone, a $\sim 50 \mathrm{~km}$-long, north-south-striking, west-dipping, reverse fault (Ghisetti et al. 2007). $A M_{L} 4.6$ earthquake that occurred near the lake during the infilling was inferred by Reyners (1988) to have been triggered by pore pressure changes associated with the rise in groundwater level. After the final water level had been reached, the seismicity spread outwards away from the lake, possibly reflecting the diffusion of a pore pressure front.

In order to compare the seismicity rates, we only consider events above the magnitude of catalogue completeness of the Pukaki array $\left(\mathrm{M}_{\mathrm{L}}\right.$ 1.8, as reported by Reyners 1988). The rates are calculated for areas within each station network only. Since a seismicity rate decrease was observed in the background seismicity during the infilling of Lake Pukaki and a slight increase was observed thereafter, we use the rate of 6.09 events per 30 days prior to 1978, when the system was completely undisturbed (Reyners 1988). This results in a seismicity rate of 1.52 events per 30 days per $1000 \mathrm{~km}^{2}$. In comparison, we recorded $\mathrm{N}(\mathrm{M} \geq 1.8)=180$ events within an area of $3300 \mathrm{~km}^{2}$ (covered by the SAMBA array) between November 2008 and April 2010, equalling to 3.05 events per 30 days per $1000 \mathrm{~km}^{2}$, a rate twice that observed by Reyners (1988).

The rate of seismicity and the magnitude of catalogue completeness both vary markedly throughout the study area. A cut-off magnitude of $\mathrm{M}_{\mathrm{c}}=1.0$ best describes the completeness of detection in the whole study area. The westernmost area (magenta rectangle in Fig. 5.4) exhibits seismicity rates of 7.3 events per 30 days per $1000 \mathrm{~km}^{2}$ above the cut-off magnitude. In the central region (red rectangle), the seismicity rate is highest with 35.0 events per 30 days per $1000 \mathrm{~km}^{2}$. The seismicity is best recorded in this area and the earthquake catalogue is complete to $\mathrm{M}_{\mathrm{c}}=0.55$ (with a seismicity rate of 70.8 events per 30 days per $1000 \mathrm{~km}^{2}$ above this cut-off magnitude). This is the area where the majority of swarms are recorded. The easternmost area (blue rectangle) exhibits a uniform earthquake distribution in space and time with rates of 33.4 events per 30 days per $1000 \mathrm{~km}^{2}$. The magnitude of completeness in this region is $\mathrm{M}_{\mathrm{c}}=0.85$. $\mathrm{b}$-value approximately 1 . 


\subsection{Research methodology}

We apply the CURATE-algorithm developed by Jacobs et al. (submitted) to identify sequences in the SAMBA catalogue. We use the same definition for an earthquake sequence as Jacobs et al. (submitted); any group of earthquakes with a rate above the background rate that are close in space. The method uses a CUSUM technique (Page 1954) to identify deviations from the background rate. The CUSUM is the "reduced" cumulative sum of the rate change above the cut-off magnitude from the mean rate. Fig. 5.5 (a) shows periods of increased rate as periods of positive slope on the CURATE plot. The earthquakes occurring during periods of increased rates are then limited spatially from the mean location of events during that time. Separate sequences that occur within a designated number of days inside the defined spatial limit are amalgamated to allow for a temporary lull in the occurrence of earthquakes. Jacobs et al. (submitted) provide full details of the method. For our catalogue a number of spatial and temporal values were tested of which a radius of $2.5 \mathrm{~km}$ and a 3 day period best separated individual sequences.

We distinguish between swarms and mainshock-aftershock sequences by considering the magnitude difference between the largest and the second-largest events and the time of occurrence of the largest event. The value of this magnitude separation is often taken to be 1.2 from Båth's law (Båth 1965), but that value is an average and is typically determined for larger-magnitude sequences than we consider here. We use a lower value of 0.7 to distinguish between the two types of sequences. This threshold lies at the lower end of the broad range (0-3) of observed values for the magnitude differences between the largest and second-largest events in mainshock-aftershock sequences worldwide (Felzer et al. 2002). Since Sherburn (1992) have observed low values of 0.3 for swarms and 0.5-1 for other types between swarm and mainshock-aftershock sequences in the Central Volcanic Region of New Zealand, we consider this value appropriate for the non-volcanic Southern Alps region. If the largest event occurs at the beginning of the sequence ( $\leq 20 \%$ of the duration), we consider it a mainshock-aftershock sequence. If the magnitude separation is less than $0.7 \mathrm{and} /$ or the largest event occurs later in the sequence we call it a swarm.

During the search for sequences, we apply two different magnitude of completeness thresholds: $M_{c}=1$, which is applicable to the whole study area (Fig. $5.5 \mathrm{~b}$ ), and $\mathrm{M}_{\mathrm{c}}=0.5$, which is the cut-off magnitude within the centre of the SAMBA array (red triangle in Fig. 5.4) where the majority of the sequences occur.

During the aftershock sequences of the earthquakes which caused triggering, noise 

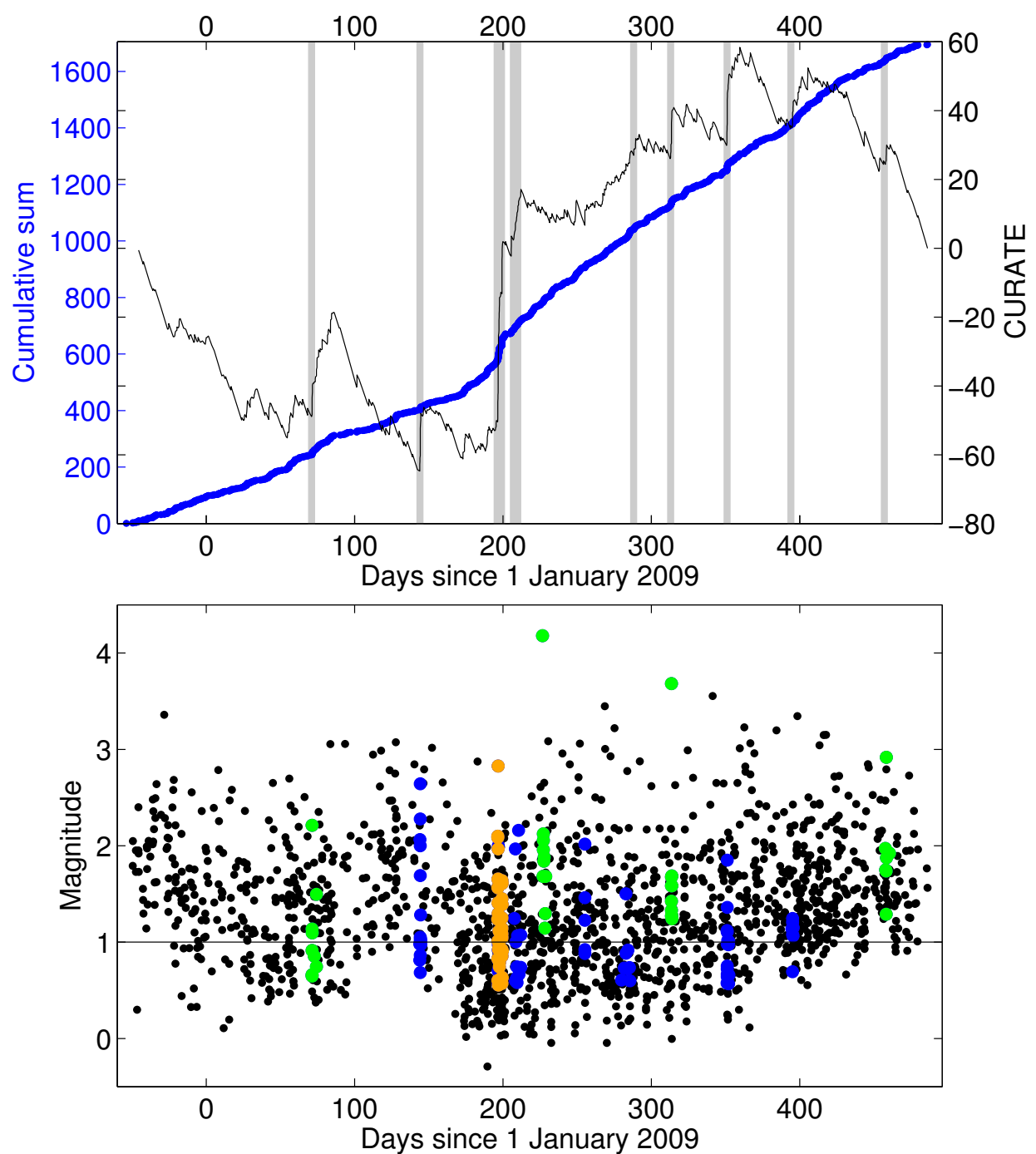

Figure 5.5. (a) Cumulative sum (blue) and CURATE (black) of earthquakes recorded in the centre of the SAMBA network between November 2008 and April 2010. Vertical grey lines mark times of the sequences listed in Table 5.2. (b) Magnitudes of earthquakes recorded in the whole study area versus time. Sequences of events that were identified in (a) are coloured with background swarms in blue, triggered swarms in orange and mainshocks in green. Note that some of the mainshock-aftershock sequences are not in the centre of the SAMBA array and are therefore not shown in (a). The horizontal line marks the cut-off magnitude of $M_{c}=1$. 
levels are particularly high, so that our standard event identification routine based on short-term/long-term averages (Boese et al. 2012) performs poorly. To obtain the same catalogue completeness during such times and to check for remotely triggered events during the arrival of the surface waves from the mainshock, we identify triggered earthquakes as high-frequency events in the spectrogram of station WHYM (Fig. 5.6) in addition to the standard identification method (which shows a significant increase in seismicity during this time). WHYM is one of the two stations closest to the swarm locations and has been recording continuously throughout the whole period SAMBA has been in place. All events that could be clearly identified as earthquakes were picked, even if they had been recorded by only one station. This procedure proved effective and in fact lowered the cut-off magnitude by approximately 0.5 during these periods.

In addition to the primary identification with the CURATE algorithm, earthquakes in the sequences were tested for their waveform similarity using cross-correlation. For this, we cross-correlate the waveforms of all 1993 earthquakes that occurred between November 2008 and April 2010. Cross-correlation windows of $0.25 \mathrm{~s}$ and $0.35 \mathrm{~s}$ for the P- and S-phase, respectively, were used starting $0.1 \mathrm{~s}$ before the actual phase pick. For such short time-windows, we set an upper limit of $0.2 \mathrm{~s}$ to the lag time which is large enough to identify mispicked phases, but sufficiently small to prevent correlation with converted phases. We bandpass-filtered the waveforms at $2-10 \mathrm{~Hz}, 3-15 \mathrm{~Hz}$ and $7-30 \mathrm{~Hz}$ in order to find the best frequency-band for the microearthquakes whose magnitudes were predominantly in the range $-1<\mathrm{M}_{\mathrm{L}}<2.5$.

Nakahara (2004) analysed the dependency of P-wave cross-correlation coefficients on frequency for aftershocks of the 1995 Hyogo-Ken Nanbu (Kobe) earthquake ( $\mathrm{M}_{\mathrm{W}}$ 6.9) and observed high cross-correlation coefficients for frequencies lower than $8 \mathrm{~Hz}$ and small coefficients for frequencies above $8 \mathrm{~Hz}$. By filtering the theoretical source-time-functions of two events with different magnitudes, he showed that the dependency of the crosscorrelation coefficients on frequency results mainly from the similarity of the two signals in the frequency band $2-4 \mathrm{~Hz}$ and the differences seen for 16-32 Hz. Therefore, Nakahara (2004) determined $8 \mathrm{~Hz}$ as the predominant frequency for an event with $\mathrm{M}=3$ which is the characteristic frequency limit for high versus low cross-correlation coefficients. Since the majority of earthquakes observed in this study are significantly smaller, we choose the 3-15 Hz filter band for further analysis, deliberately retaining the high-frequency content. At the same time, we lowered the minimum correlation coefficient to a threshold of 0.5 at at least five stations (cf. Schaff and Waldhauser 2005). With these settings, we obtained a cross-correlation catalogue consisting of 8136 event pairs with mean cross-correlation 

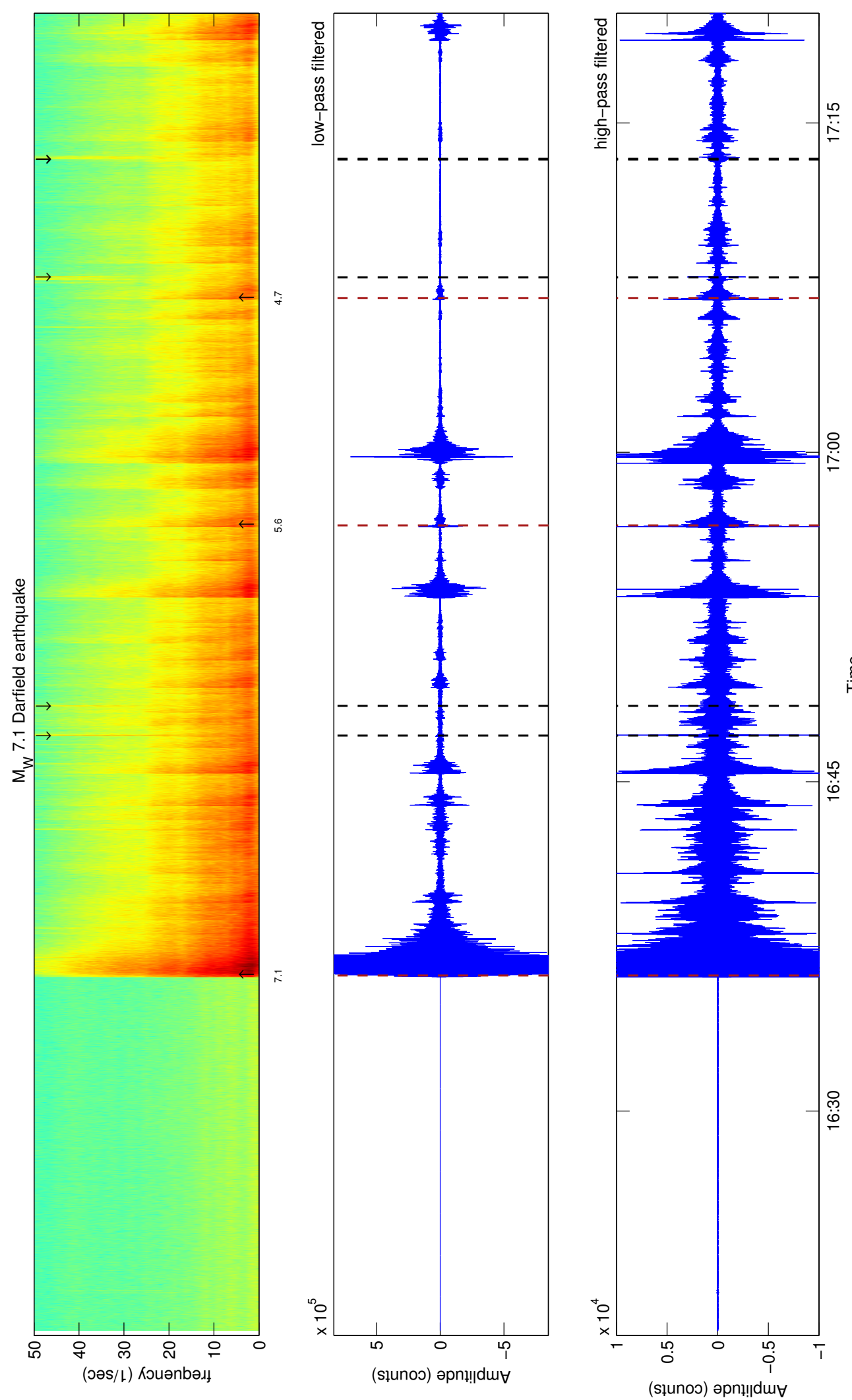

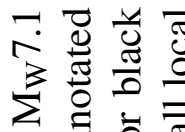

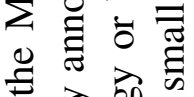

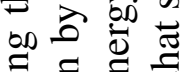

. ज्ञ

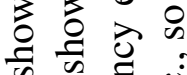

$\sum \stackrel{\Xi}{\Xi} \frac{0}{0}$

$\sum \stackrel{0}{2}$

$3 \sigma_{0} \frac{1}{5}$

엘

휴

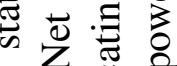

4 .

包.

Q

응

寻寻

원용

ฮี

चै

$>$ 능 兵

ङ $\frac{0}{\square}$

๕

ป छ 즌

$\Xi \stackrel{\Xi}{\Xi} \Xi$

क्ज E

むॄ屯

응

응

可 क्षे द्व

氖离

क 0.0

赵

交零 $\frac{2}{0}$

$\exists \circ 0$ 잉

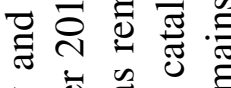

芯芯芯芯

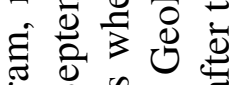

कू क थ 0

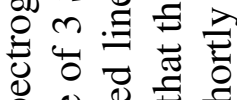

过

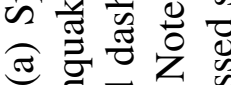

(ิ)

ம்

n 응 0

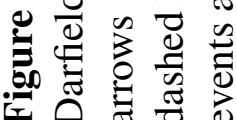



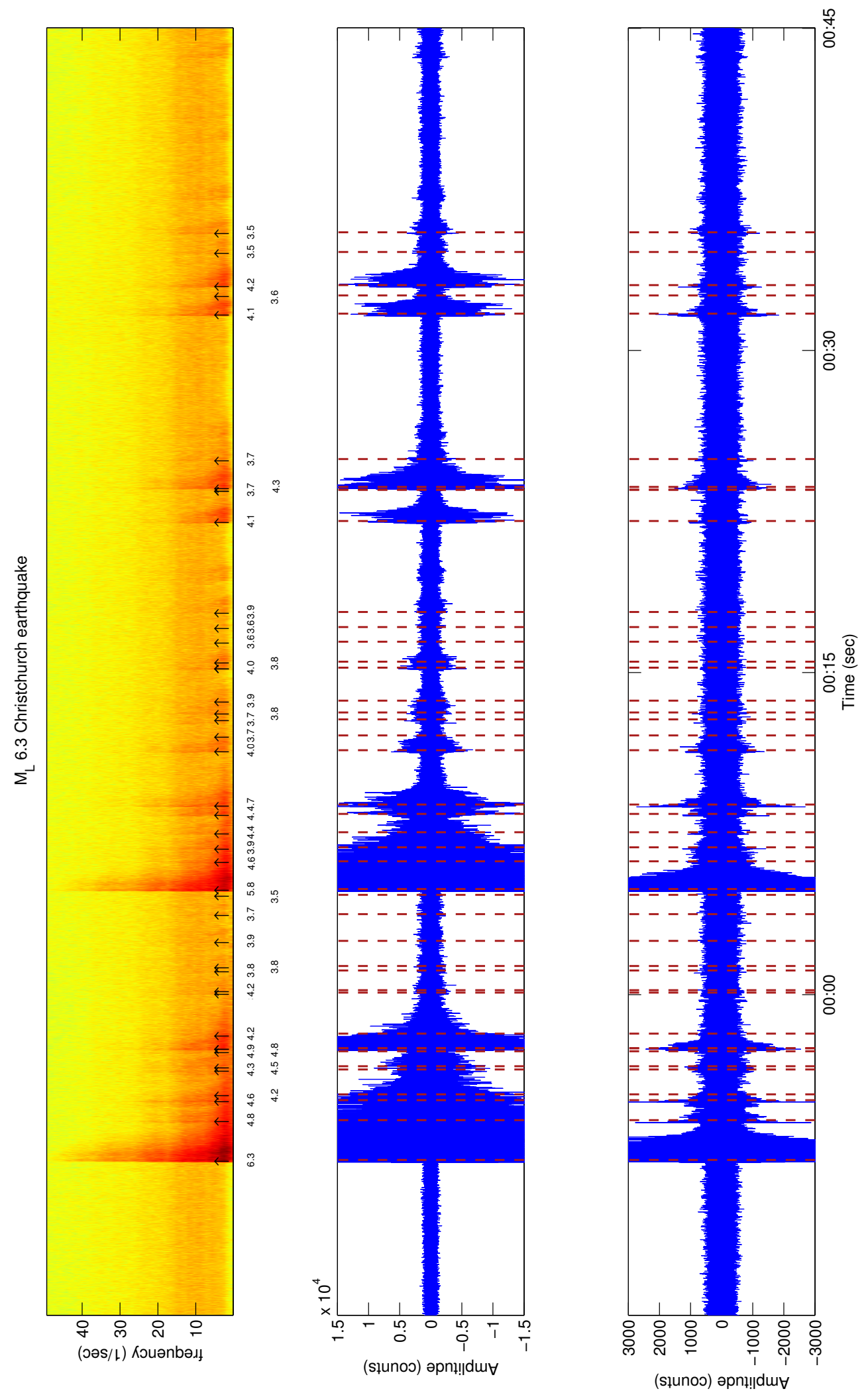

$\frac{\bar{d}}{\frac{y}{\bar{t}}}$

$\stackrel{0}{0}$

츨

$\frac{0}{0}$

ป

फ

产

胥

ตุ

$\sum$

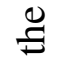

4

हี

망

需

ర.

ฮั ส

늠

कै

胥

立教

크

모

莡

可

हี ปี

잉

ठ․

क

อิ

宛

in

党 
coefficients of 0.662 and mean absolute lag times of $0.053 \mathrm{~s}$.

The identification of swarms based on high cross-correlation coefficients alone is not suitable for our dataset, since the swarms do not stand out in terms of high cross-correlation coefficients despite their waveform similarity (Fig. 5.7 and 5.8). In general, few events have cross-correlation coefficients above 0.8 and for the majority of all events the values range between 0.5 and 0.75 . This may simply reflect the multitude of small active faults in the region producing earthquakes or it could be the result of correlated Gaussian noise (Du et al. 2004) which lowers the cross-correlation coefficient. We inspected all events that are linked by cross-correlation coefficients $>0.5$ at 5 stations to those events in the sequences identified with the CURATE algorithm and chose the events which clearly belong to one family by visual inspection. In other words, a sequence is identified based on seismicity rate-changes but the individual events in a sequence are selected due to their waveform similarity. The final sequence catalogue is listed in Table 5.2.

We analyse inter-event time patterns of sequences for those earthquakes larger than the completeness magnitude. The average inter-event time (instantaneous rate) is calculated at the time of each earthquake in the sequence. We then plot this running mean inter-event time versus the normalized duration which allows the comparison of temporal patterns between sequences of different durations. This may help us to distinguish between mainshock-aftershock and swarm type sequences.

\subsection{Observed earthquake sequences}

Larger earthquake sequences were observed in the study area in September 1997 (the "Mt Cook swarm" described by Leitner et al. 2001) and in October 2006 (the "Fox swarm" of O' Keefe 2008). The "Mt Cook swarm" included two $M_{L} 5$ earthquakes followed by at least eight aftershocks. The "Fox swarm" consisted of at least 38 earthquakes of which three exceeded $\mathrm{M}_{\mathrm{L}}$ 4. Two-thirds of the "Fox swarm" events occurred within one day. Earthquake relocations indicated a point cluster at $8.6 \pm 2.6 \mathrm{~km}$ depth (O' Keefe 2008). Four smaller earthquake swarms in late 2006 were identified near Whymper Hut, in the upper Clyde River, near Whataroa and near Waitaha (O’ Keefe 2008).

Here, we report on 14 sequences comprising $\geq 10$ events of similar waveforms (Fig. 5.7 and 5.8). This excludes five sequences from our analysis with fewer similar events because there may be more of these smaller sequences that have not been identified due to detection 


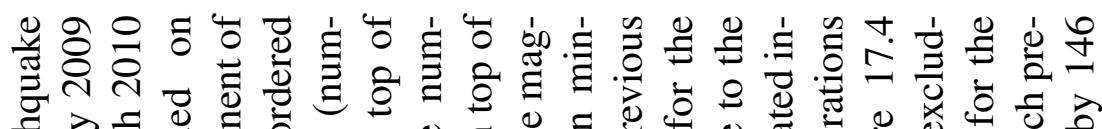

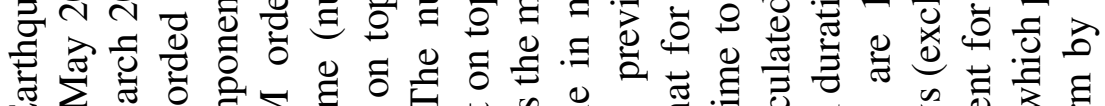

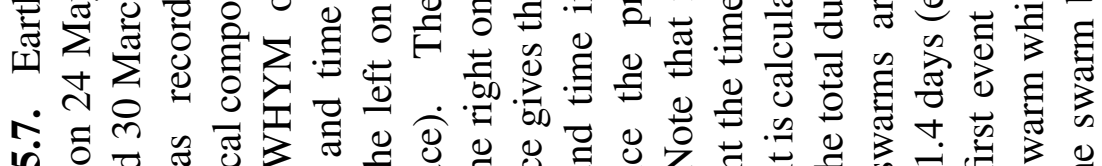

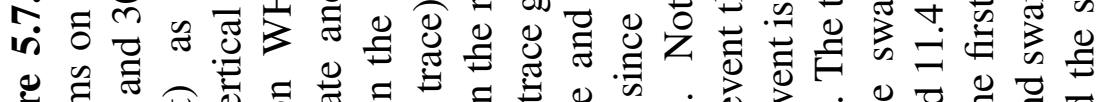

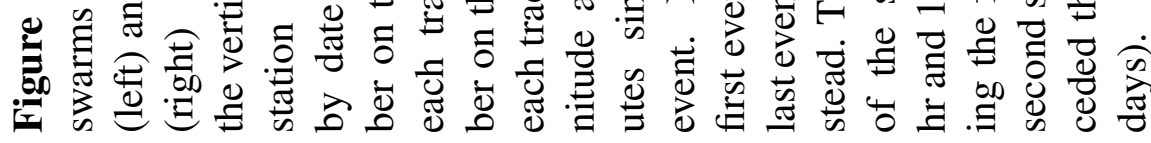
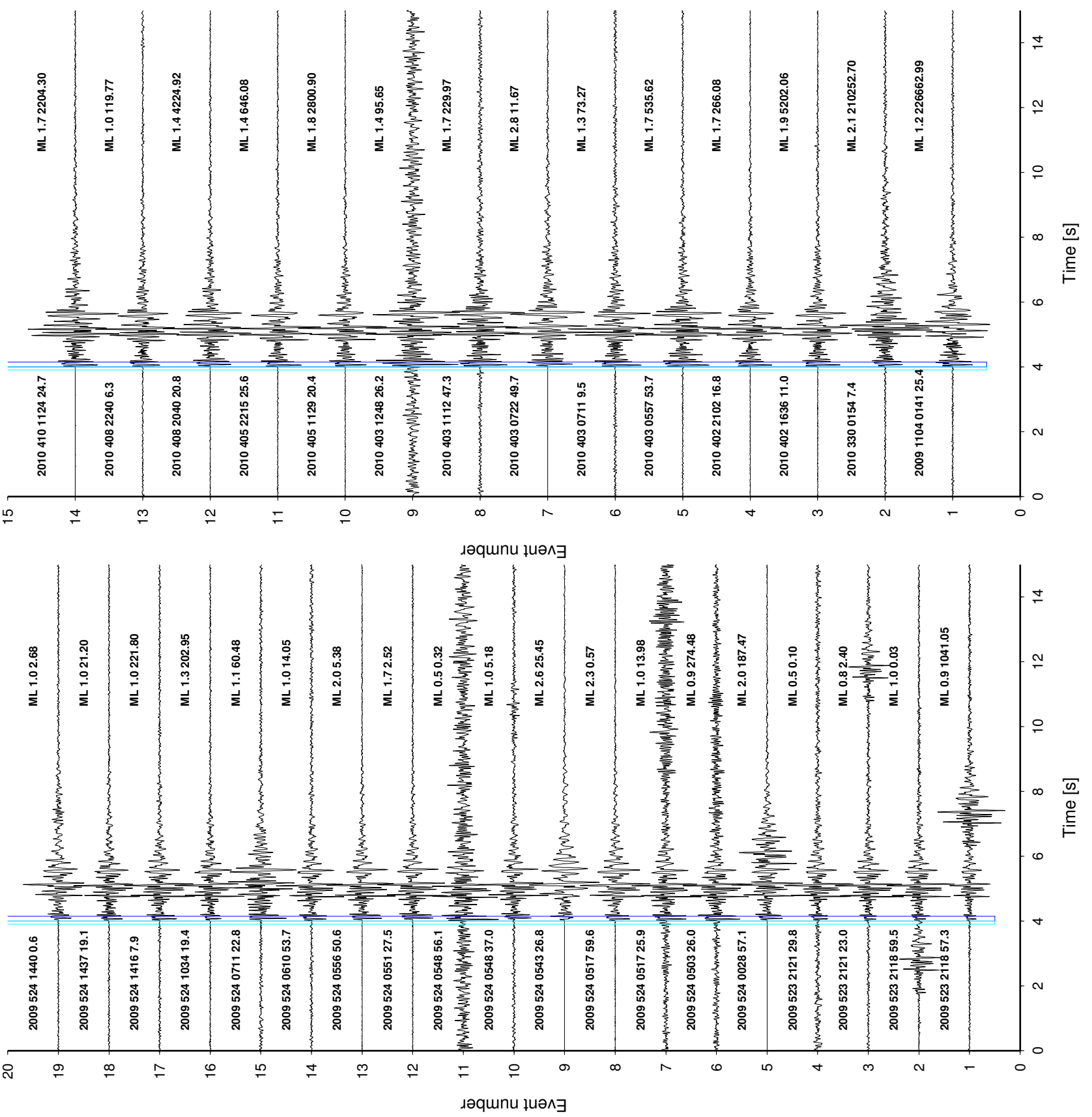
Figure 5.8. The triggered earthquake swarm on 18 June 2009 with the same specifications as shown in Fig. 5.7. Note that multiplets occur so close in time that events are overlapping (events 7-8, 10, 24-26). Note that the duration without the last event is is 7.9 days. The last event occurred 94.9 days after the swarm and was identified in the same location due to its waveform similarity with the remaining events.

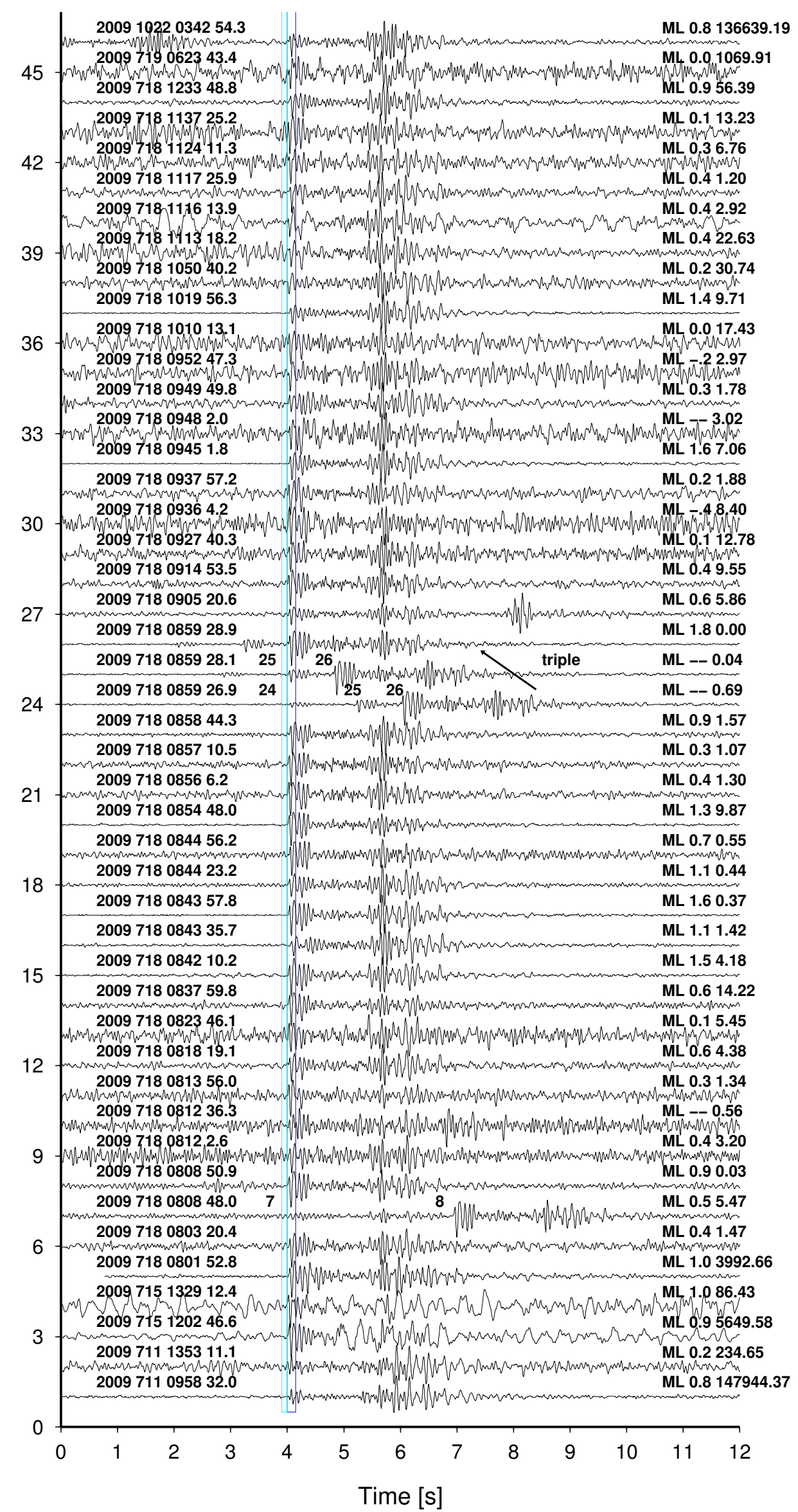


issues. These smaller sequences occur throughout the study area. Of the 14 sequences, all except four (three mainshock-aftershock sequences and one long swarm) occur in the centre of the SAMBA array (Table 5.2 and Fig. 5.9), an area of $10 \mathrm{~km} \times 12 \mathrm{~km}$ between stations WHYM and LABE. Together, the sequences account for $15.3 \%$ of the total number of recorded earthquakes above the cut-off magnitude $\left(M_{c} 1.0\right)$. The magnitudes of the sequence events range between $0 \leq \mathrm{M}_{\mathrm{L}} \leq 3.7$ and cross-correlation coefficients range between 0.32 and 0.8 with a mean of 0.58 .

The durations of the recorded "short" swarms range between less than one day to up to 12 days, with inter-event times spanning a few seconds to several hours. We also recorded several "long" swarms that continue for $\geq 30$ days. The majority of these swarms occur in the area of highest seismicity rates, where the best azimuthal coverage is obtained with SAMBA and the depths of the earthquakes are well-constrained (error $2.8 \pm 1.8(1 \sigma) \mathrm{km}$ ). Earthquake swarm events occur at mean depths of $5 \mathrm{~km}$ (Section 5.5). Focal mechanism solutions of the largest event in each swarm (Fig. 5.4) exhibit predominantly strike-slip mechanisms with a few oblique-reverse and reverse faulting mechanisms. The focal mechanisms solutions indicate steeply dipping faults. If we identify the fault plane as the nodal plane whose slip vector forms the smaller angle to the maximum compressive stress direction $S_{1}, 13$ of 17 measurements lie within $\pm 20^{\circ}$ of the angles, consistent with Andersonian faulting in the prevailing stress-field (Boese et al. 2012). A comparison of these planes with mapped faults is shown in Fig. 5.10. For four solutions, we prefer the other nodal plane as the fault plane due to similarities with the strike of local faults and consistency with spatially close swarms. For these focal mechanisms, however, both nodal planes are near-optimally oriented in an Andersonian sense (as shown by the numbers below the stereonets in Fig. 5.10).

Three of the recorded mainshock-aftershock sequences occur east and northeast of the area of persistent swarm activity (Fig. 5.4). The waveforms of events in these sequences have smaller cross-correlation coefficients, so the focal mechanism of the largest event may not be representative of all events in these sequences. The largest earthquake observed for the mainshock-aftershock sequences $\left(\mathrm{M}_{\mathrm{L}}\right.$ 2.4-4.2) are on average larger than those of the swarms $\left(\mathrm{M}_{\mathrm{L}} 1.1-2.8\right)$.

\subsection{Remotely triggered seismicity}

Remotely triggered seismicity has been observed after two major earthquakes in New Zealand at distances $>180 \mathrm{~km}$ from the SAMBA array. The Dusky Sound earthquake 

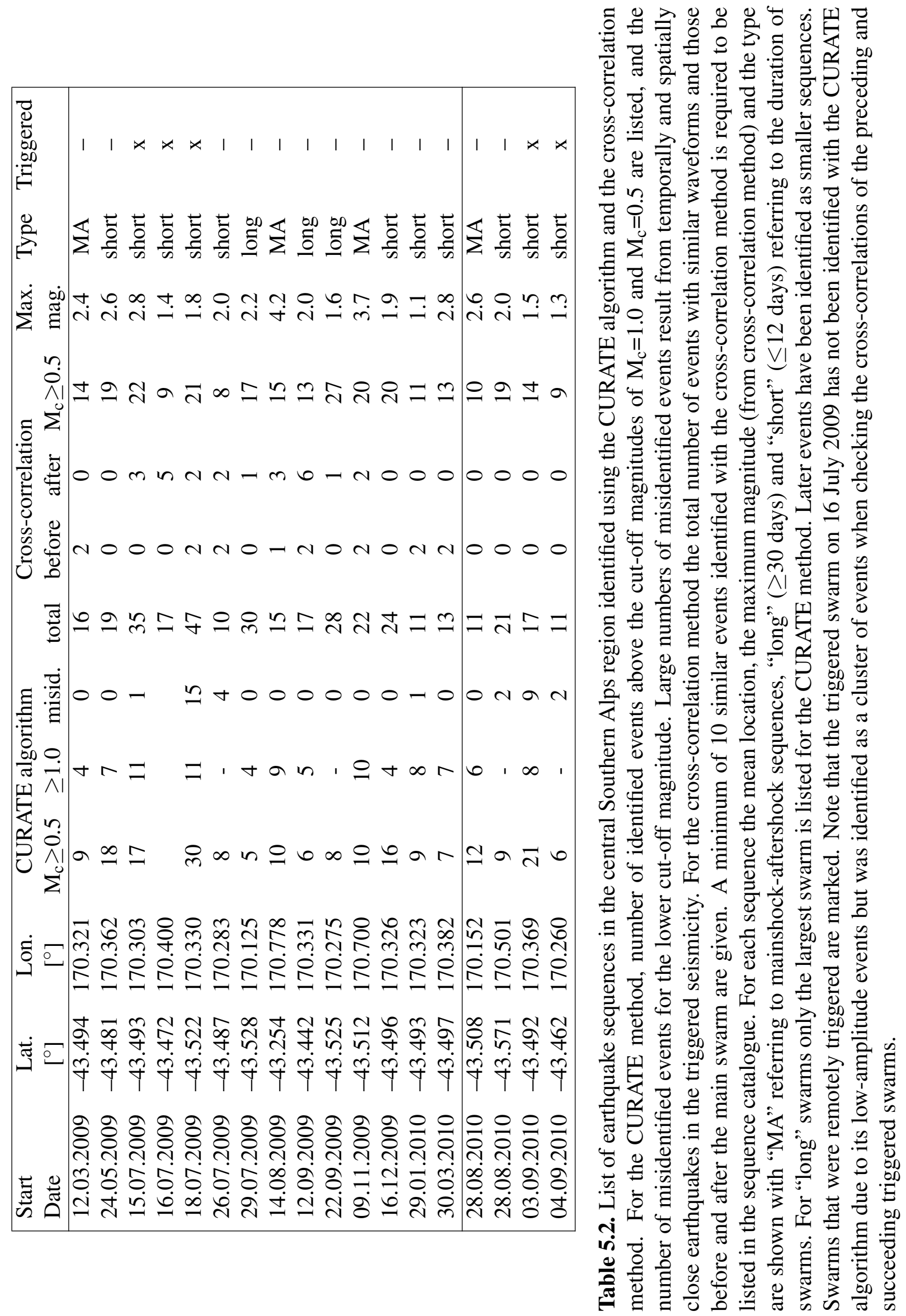

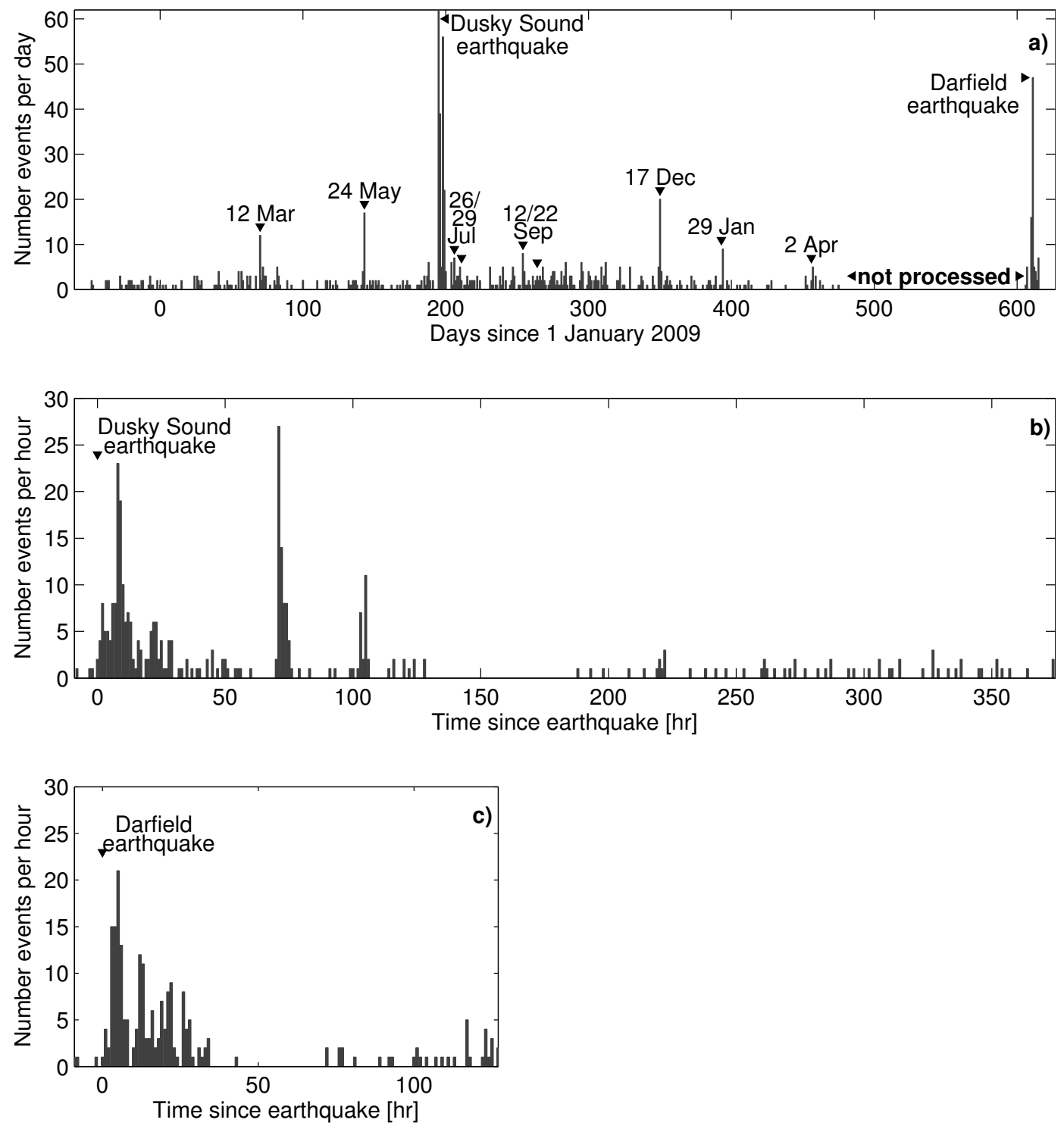

Figure 5.9. (a) Seismicity versus time in the centre of the SAMBA array (red rectangle in Fig. 5.4) where the majority of the swarms occur. (b-c) Hourly distributions of events after the $\mathrm{M}_{\mathrm{W}}$ 7.8 Dusky Sound earthquake and the $\mathrm{M}_{\mathrm{W}}$ 7.1 Darfield earthquake that caused triggered microseismicity in the central Southern Alps 

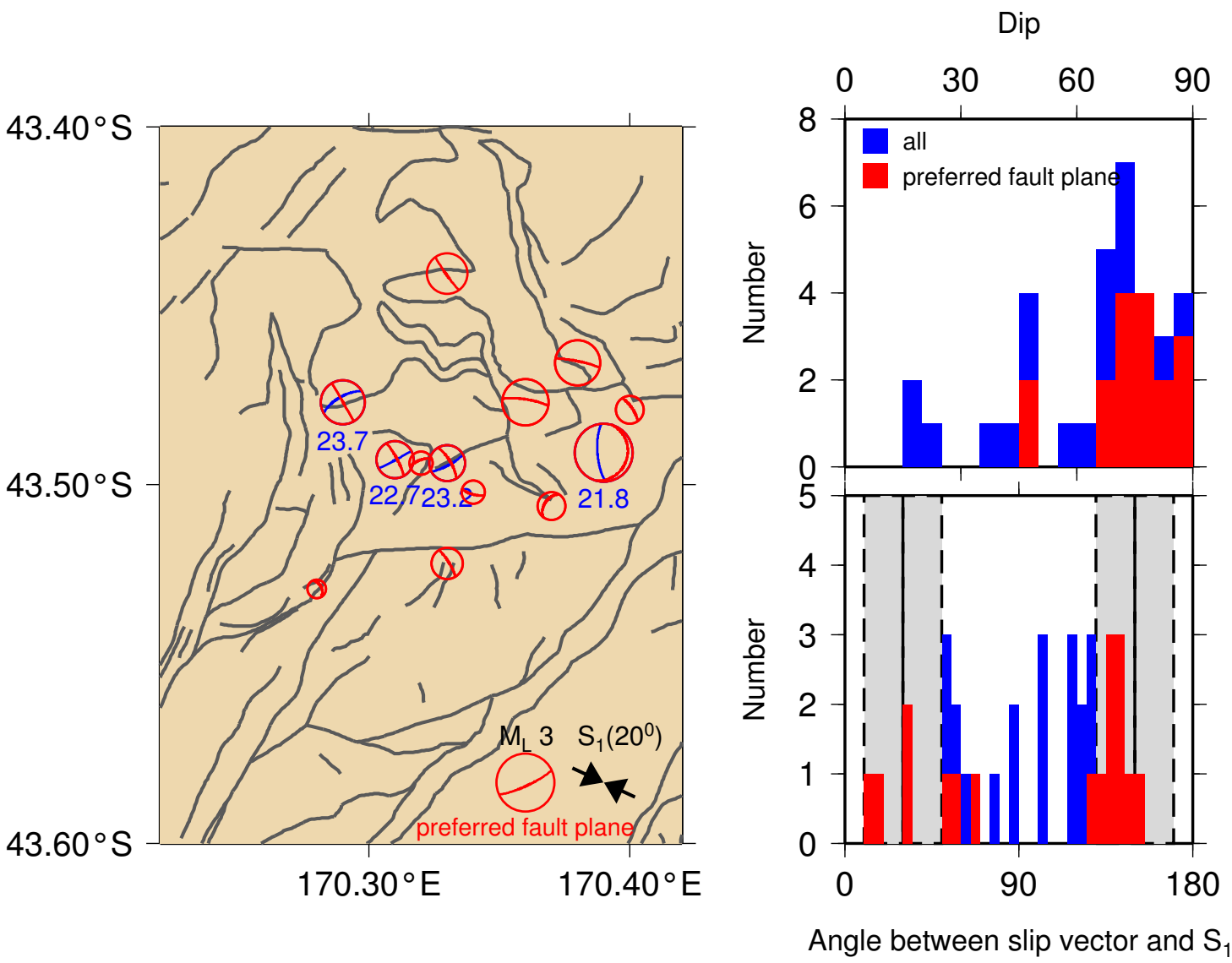

Figure 5.10. Preferred fault planes for swarm events in the central Southern Alps in mapview (left). By determining the angle between the slip vector and the direction of the maximum compressive stress $S_{1}$ (direction and plunge shown) for both nodal planes, we identify the fault plane (red) as the plane which is more consistent with Andersonian faulting. For those events not consistent with neighbouring events or fault orientations in the region, we adopt the other nodal plane (blue). The number indicates the angle between the slip vector and $S_{1}$ which shows that for these events both nodal planes are near optimally oriented in an Andersonian sense. Faults are adapted from Cox and Barrell (2007). Panels on the right show the dip (top) and the angle to $S_{1}$ of all nodal planes (blue) and the preferred fault plane (red). The grey boxes illustrate angles between the slip vector and $S_{1}$ that range within $20^{\circ}$ of the direction of $S_{1}$. 
(Table 5.3) occurred approximately $350 \mathrm{~km}$ south of the study area and ruptured the subduction zone interface between the subducting Australian plate and the overlying Pacific plate (Beavan et al. 2010b). It caused about $2.6 \mathrm{~cm}$ of permanent westward coseismic displacement at Haast (Mahesh et al. 2011) approximately $85 \mathrm{~km}$ southeast of the centre of the SAMBA array. This large earthquake stands out because of its waves' large low-frequency $(0.01-0.1 \mathrm{~Hz})$ and relatively small high-frequency contents ( $>5 \mathrm{~Hz}$; Fry et al. 2010). The Dusky Sound earthquake caused a maximum acceleration of $0.003 \mathrm{~g}$ on the vertical and horizontal components of station FRAN (a borehole sensor at a depth of $100 \mathrm{~m}$ in the vicinity of Franz Josef). The peak ground acceleration (PGA) was measured for $1 \mathrm{~s}$ period waves (Table 5.4). Similar values were observed on strong motion accelerometers in the area (Table 5.5). Since absolute PGA values are influenced by the local geology at the site and other factors (signal period, source dimensions of the earthquake, radiation characteristics, etc.), we also report the peak ground velocity (PGV; Table 5.4), which depends more on low-frequency components of ground motion than PGA (Boatwright et al. 2001, and references therein) and is therefore a better measure than PGA of the intensity of ground shaking (Tso et al. 1992). The peak dynamic stress $\sigma_{d}$ can be calculated from the peak ground velocity $\mathrm{u}_{\mathrm{d}}$ using the relationship

$$
\sigma_{d} \sim \mu_{S} \mathrm{u}_{\mathrm{d}} / \mathrm{v}_{\mathrm{S}}
$$

where $\mu_{S}=3 \times 10^{10} \mathrm{~Pa}$ is the shear modulus and $\mathrm{v}_{\mathrm{S}}$ the phase velocity (Jaeger and Cook 1979).

Within the first 24 hours after the Dusky Sound earthquake, 146 microearthquakes occurred in the central Southern Alps region, of which 93.2\% could be located (recorded by $\geq 3$ stations; Fig. 5.9). This is the highest number of events per day recorded since the installation of the SAMBA array. The triggered seismicity commenced shortly after the passage of the surface-wave trains and continued for approximately 120 hours. The earthquakes were of small amplitude and could be identified best as high-frequency energy on spectrograms of station WHYM. The triggered seismicity comprised three "delayed-triggered" swarms (orange mechanisms in Fig. 5.4) in the centre of the SAMBA array. The first swarm with events of slightly larger magnitude $\left(\mathrm{M}_{\mathrm{L}} \leq 2.8\right)$ occurred eight hours after the passage of the surface waves of the Dusky Sound earthquake. This swarm continued for several days, with a second burst occurring 4 days later in the same location (Fig. 5.9). The second swarm started $20 \mathrm{hr}$ after the Dusky Sound earthquake, $8 \mathrm{~km}$ northeast of the first swarm. A third swarm with the largest number of events started $71.6 \mathrm{hr}$ after the passage of the surface waves and lasted slightly over $4.5 \mathrm{hr}$ (Fig. 5.11). The centre of the third earthquake swarm lies $3.7 \mathrm{~km} \mathrm{SE}$ and $7.7 \mathrm{~km} \mathrm{SW}$ of the first and second swarms, respectively. On the whole, the microseismic activity lasted five days, and was followed by three days of quiescence 
(Fig. 5.9 b).

Elevated seismicity rates in the study area were also observed after the $\mathrm{M}_{\mathrm{W}}$ 7.1 Darfield earthquake, which occurred on a previously unknown fault in the Canterbury Plains, $175 \mathrm{~km}$ due east of the centre of the SAMBA array (Gledhill et al. 2011). This earthquake caused similar strong shaking at station FRAN as the Dusky Sound earthquake had with PGA and PGV values of $0.006 \mathrm{~g}$ and $2 \mathrm{~cm} / \mathrm{s}$ on the horizontal components for waves with periods of $0.6 \mathrm{~s}$ and $3 \mathrm{~s}$, respectively. The triggered events were not as well recorded as after the Dusky Sound earthquake, because three out of ten SAMBA stations were not operating at the time following a particularly harsh and snowy southern hemisphere winter. For this reason, most of the triggered seismicity was recorded on only one or two stations and only $53.4 \%$ of the events could be located. Figure 5.6 (a) shows triggered events (marked by arrows) as high-frequency energy hidden in the (lower-frequency) signal of the aftershocks. Two remotely triggered swarms of more than 10 similar events could be identified in the area where swarms occurred previously.

A long sequence of events in the vicinity of the 1984 Godley Valley earthquake that began before the Darfield earthquake and continued for six days after, was also studied. This sequence had only three events in the first three days after the Darfield event. This may be due to the detection being affected by the elevated noise levels during the aftershock sequence. In general, triggered and background seismicity during this time appear more distributed and are not as well-recorded as after the Dusky Sound earthquake.

The large, energetic $\mathrm{M}_{\mathrm{L}} 6.3\left(\mathrm{M}_{\mathrm{e}}\right.$ 6.7) Christchurch earthquake on 21 February 2011 (Holden 2011; Beavan et al. 2011, and references therein) did not trigger significant seismicity in the central Southern Alps. There is no hint of high-frequency events after the Christchurch event or within two subsequent days, as shown in Fig. 5.6 (b). This event caused comparable PGA but lower PGV values than the previous two South Island earthquakes. No remotely triggered seismicity was observed after other large distant earthquakes in 2009 and 2010 as listed in Table 5.3. All of these events caused significantly less shaking in the central Southern Alps (Table 5.4) than the large South Island earthquakes.

We test if the geometry and delay of the triggered swarms after the Dusky Sound earthquake can be explained by the expansion of a triggering front of high pore-fluid pressure. The expansion radius $r$ can be determined from $r=\sqrt{4 \pi \mathrm{Dt}}$ where $\mathrm{D}$ is the hydraulic diffusivity and $t$ is time (Shapiro et al. 1997). Reyners (1988) inferred a hydraulic diffusivity of 


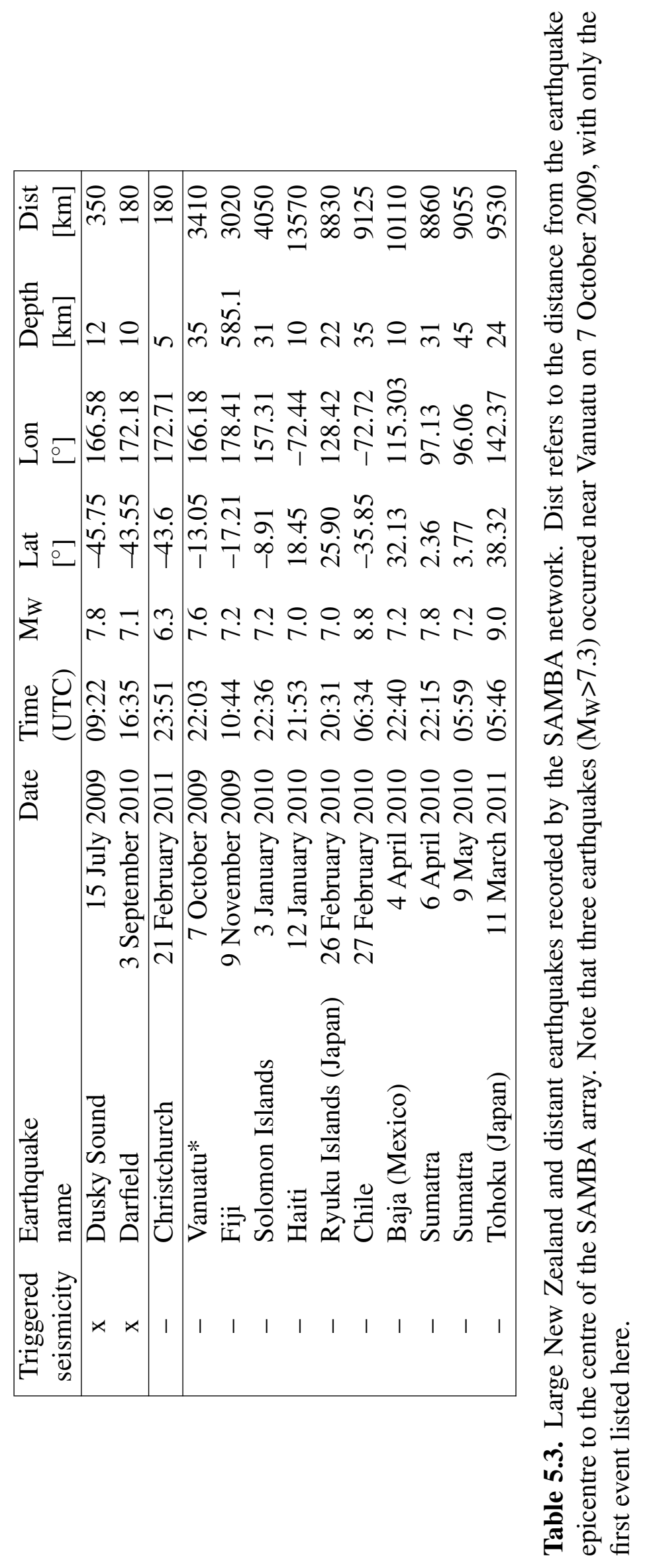




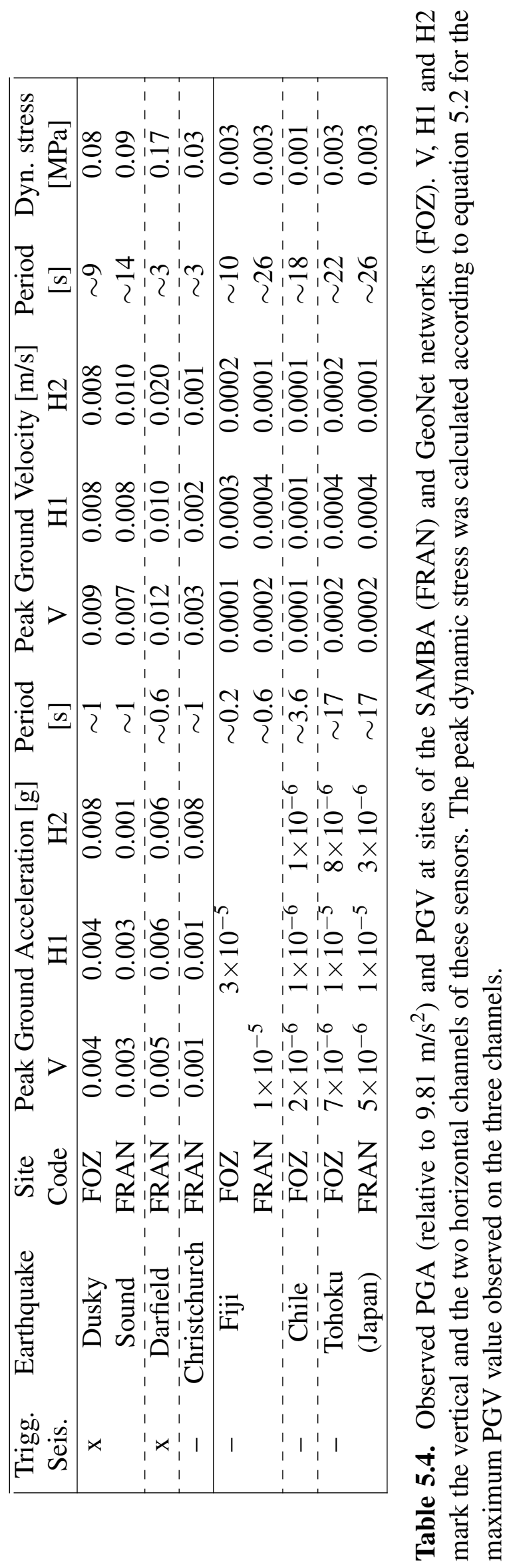



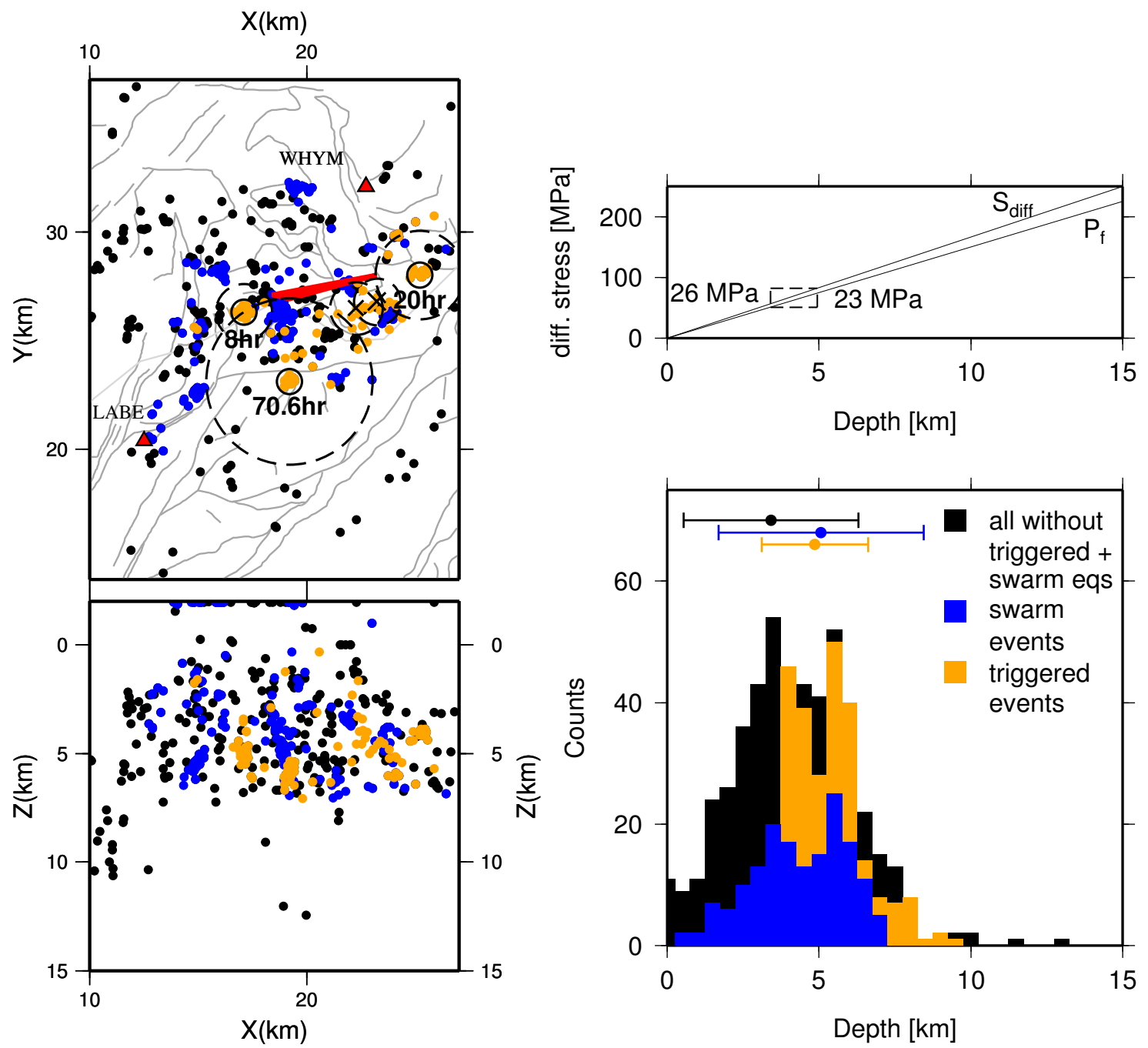

Figure 5.11. Background seismicity (black), swarm events (blue) and triggered swarm events (orange) in the centre of the SAMBA array in map view and on a cross-section along the horizontal (X-) axis (left). Circles and crosses indicate the mean locations of observed triggered swarms after the Dusky Sound and Darfield earthquake, respectively. Dashed circles reflect distances that fluids could propagate by diffusion. The red line marks the border of a common fluid source from which fluid diffusion would be consistent with the triggered swarms. Faults shown are from the QMAP Aoraki 1:250000 by Cox and Barrell (2007). The figures on the right show the increase of the differential stress and the pore-fluid pressure with depth (top) and the depth distributions (bottom) of all events without either triggered or nontriggered swarms (black), the swarms (blue) and the triggered seismicity only (orange). The average and the standard deviation of each are shown, too. 


\begin{tabular}{|c|c|c|c|c|c|c|}
\hline Distance to & \multicolumn{3}{|c|}{ Peak Ground Acceleration (g) } & Site & Name of & Subsoil \\
\hline Source $[\mathrm{km}]$ & V & H1 & $\mathrm{H} 2$ & Code & Recording Site & Category \\
\hline 302 & 0.005 & 0.005 & 0.005 & FOZ & Fox Glacier & B \\
\hline 305 & 0.004 & 0.008 & 0.010 & MCNS & Mount Cook Annex* & $\mathrm{C}-\mathrm{D}$ \\
\hline 312 & 0.002 & 0.005 & 0.004 & TKAS & Tekapo* & $\mathrm{A}-\mathrm{B}$ \\
\hline 319 & 0.006 & 0.010 & 0.011 & FGPS & Fox Glacier DOC & $\mathrm{D}$ \\
\hline 335 & 0.007 & 0.011 & 0.009 & FJDS & Franz Josef DOC & $\mathrm{D}$ \\
\hline 375 & 0.006 & 0.011 & 0.011 & HAFS & Hari Hari Fire Station & $\mathrm{D}$ \\
\hline 391 & 0.003 & 0.007 & 0.006 & WVAS & Waitaha Valley & $\mathrm{D}$ \\
\hline
\end{tabular}

Table 5.5. Observed PGA at sites on the eastern $(*)$ and western side of the central Southern Alps after the Dusky Sound earthquake from Fry et al. (2010)

$1.5 \mathrm{~m}^{2} / \mathrm{s}$ from the lag time of groundwater rise associated with the impounding of Lake Pukaki. Using this diffusivity estimate, which may not be strictly appropriate because it was derived for shallow depths on the eastern, dry (leeward) side of the Southern Alps, we determine that a pore-fluid pressure front could migrate $0.7,1.2$ and $2.2 \mathrm{~km}$ due to diffusion (for the given delay-times of 8,20 and $71.6 \mathrm{hr}$ ). These values are too small to explain the spatial separation of the swarms. Since we have three equations (3 diffusion radii of the pressure front), we can invert for a common fluid source assuming a hydraulic conductivity and a starting position between the three swarms. We find a circle that touches the three diffusion circles around each triggered swarm after the Dusky Sound earthquake (dashed in Fig. 5.11) which marks the boundary of a fluid source from which a pore pressure front radiates outwards. This boundary is indicated in red in Fig. 5.11 and it is also consistent with the two swarms after the Darfield earthquake for diffusivities of $4.5 \mathrm{~m}^{2} / \mathrm{s}$.

\subsection{Discussion}

\subsubsection{Observed earthquake sequences}

Our observations show that earthquake swarms are a common feature of the seismicity in the central Southern Alps region where background seismicity rates are high compared to elsewhere in the central South Island. They are best recorded in a small area of dense seismicity in the centre of the SAMBA array. However, small sequences of 6-8 events have been identified further east and northeast of that particular area. The swarm events are of low magnitude $\left(\mathrm{M}_{\mathrm{L}} \leq 2.8\right)$, exhibit similar waveforms and have short durations, usually ranging between a few hours and a few days. However, at least three sequences comprising two phases of activity linked by a few events have been recorded. This may either indicate 
short recurrence times (a few weeks) between individual repeating swarms or that the process causing the swarms can involve several phases of activity. The depth distribution of the background swarms overall reflects the distribution of all events in this area (Fig. 5.11). The absolute location uncertainty is too large to resolve any systematic changes that might indicate a shallowing of the hypocentre depths with time. We have analysed the relative travel-times at station WHYM for the swarms comprising the largest number of events, but we cannot see any systematic changes. This may still be a resolution problem due to the 2 $\mathrm{km}$ difference between the deep and shallow event depths.

Our analysis of the inter-event times of events in the swarms and mainshock-aftershock sequences shows that these processes are distinctly different at the beginning of the sequence. The average inter-event time between earthquakes in a swarm decreases steadily until a turning point is reached from which point on the inter-event time increases steadily (Fig. $5.12(\mathrm{a}-\mathrm{c}))$. This pattern differs from the temporal distribution of events in a mainshock-aftershock sequence in which case a systematic increase in inter-event times is observed (Fig. $5.12(\mathrm{f}-\mathrm{h})$ ). The latter is consistent with the Omori law of aftershock decay. Several swarms show that the largest events occur in the transition from decreasing to increasing inter-event times. This may indicate that the maximum stresses are released before the start of a decay process, marked by the increase in inter-event times.

These patterns suggest that the underlying processes of the swarms and mainshockaftershock sequences are distinct and different, although the decay portions (increasing inter-event times) may be similar. These patterns do not depend on the cut-off magnitude because theoretically the same number of small magnitude events are taken out at the beginning, middle and end of the sequence if the cut-off magnitude is increased and the overall pattern remains unaffected. We also note that not all swarms strictly follow this pattern or exhibit it as clearly as the examples shown. This may be due to the small numbers of events above the cut-off magnitude or the fact that multiple mechanisms exist that can cause an earthquake swarm. A continuum of types between swarms and mainshock-aftershock sequences (Sherburn 1992; Vidale and Shearer 2006) rather than discrete types (Sykes 1970) has been observed.

We obtain at least one focal mechanism solution for each swarm, most often from the largest event. If multiple focal mechanism solutions exist as shown in Fig. 5.13, these are identical within their uncertainty limits (cf. Boese et al. 2012) and are similar to those of other events in the vicinity. All solutions except one shown in Table 5.6 have one steeplydipping nodal plane $\left(\geq 50^{\circ}\right)$. This is consistent with the findings of Vidale and Shearer 

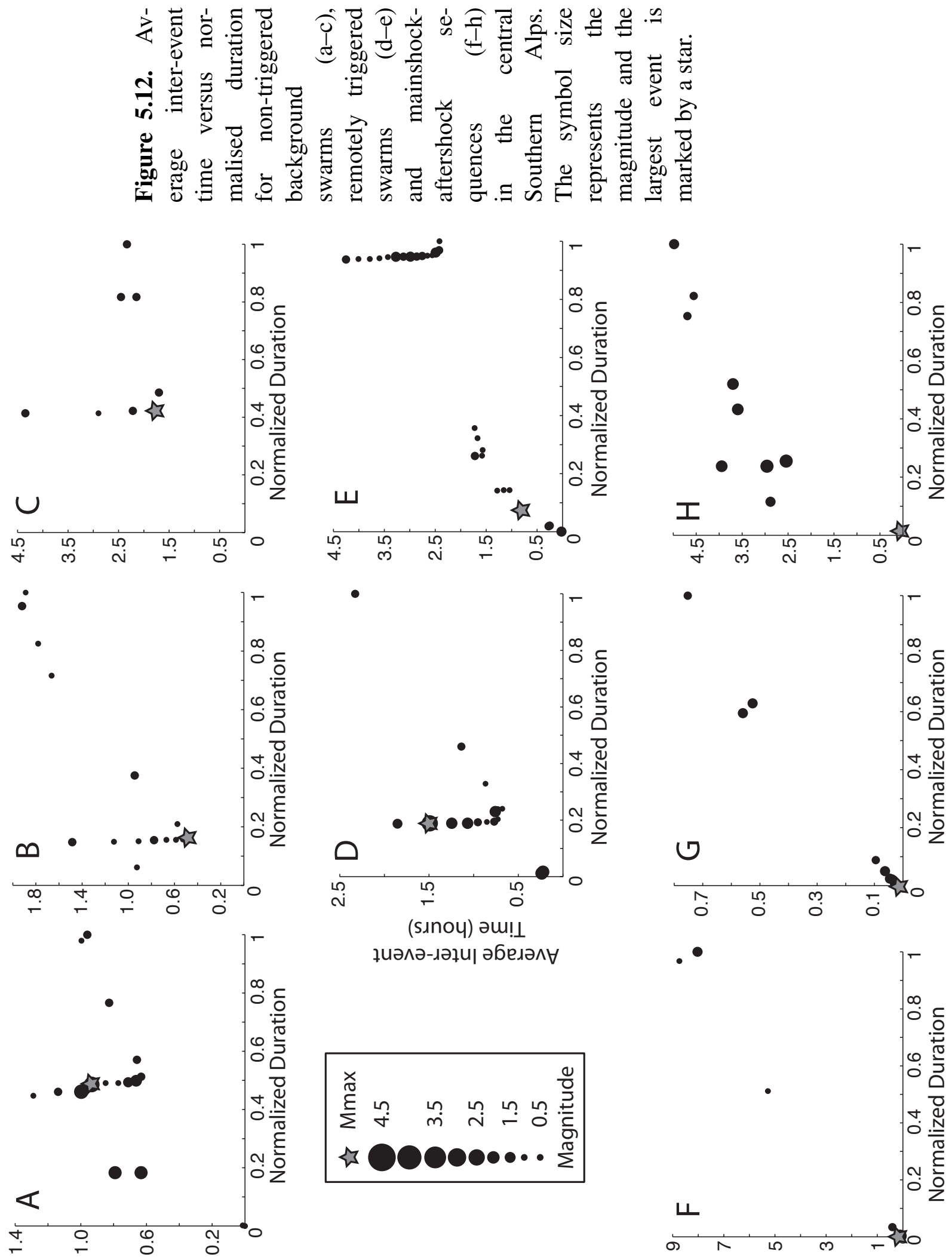

(sinoy) əu!
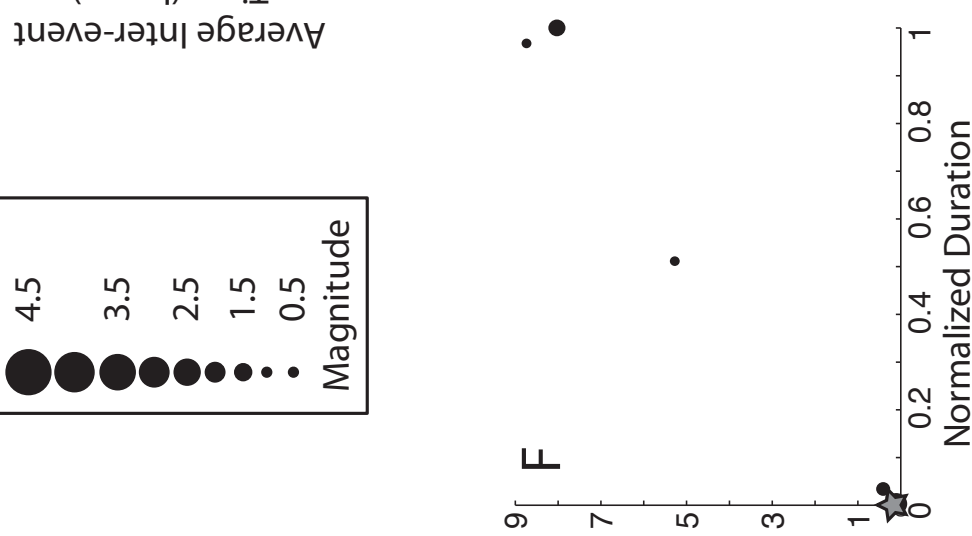

(s.noy) әس!

ұนәлә-ләџи әбеләл

(s.noy) әس! ұนәлә-ләји әбеләл 
(2006), who reported that swarms predominantly occur on vertical planes and form linear streaks. They suggested that swarms are preferentially produced on strike-slip faults, and that observed vertical hypocentre alignments could reflect density-driven fluid flow.
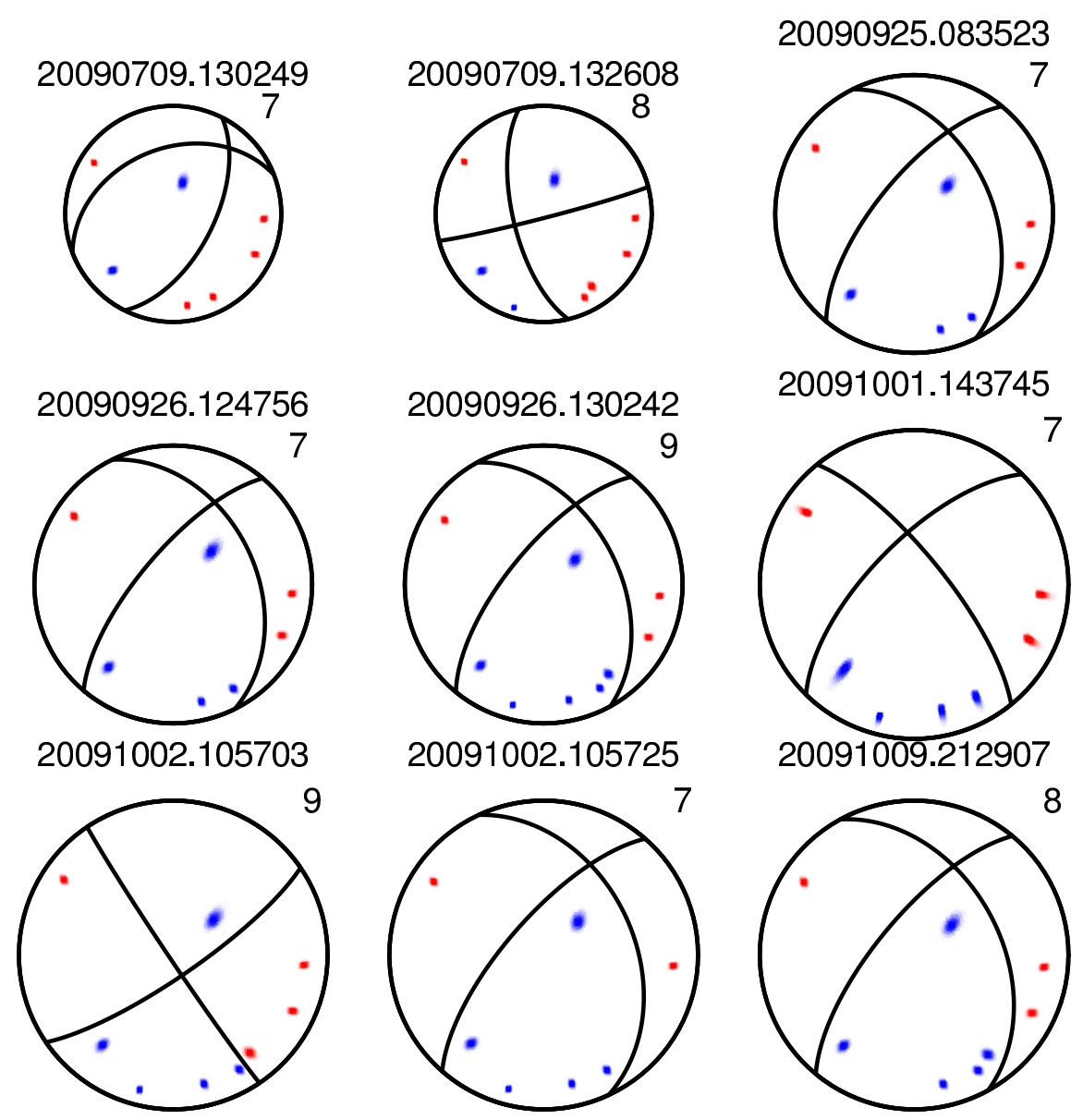

Figure 5.13. Focal mechanisms of all events within $0.05^{\circ}$ of the location of the swarm starting on the 22 September 2009. Note the slight difference for events in July which do not belong to the swarm and those during the September/October sequence. The number below the date indicates the number of $\mathrm{P}$-wave first motions. The size reflects the magnitude of the earthquake.

It is commonly assumed that swarms occur on fault planes that are favourably oriented in the prevailing stress field according to Andersonian faulting theory. We have tested this idea by determining the angle between the slip vectors of both nodal planes and the direction of maximum compressive stress $S_{1}$ determined previously (Boese et al. 2012). Of the two resulting angles, at least one complies with angles of $\pm 30^{\circ}$ or $\pm 150^{\circ}$ from $S_{1}$ as expected from Andersonian faulting theory, confirming that the low-magnitude earthquakes occur in response to the regional stress field on near-optimally oriented faults. 


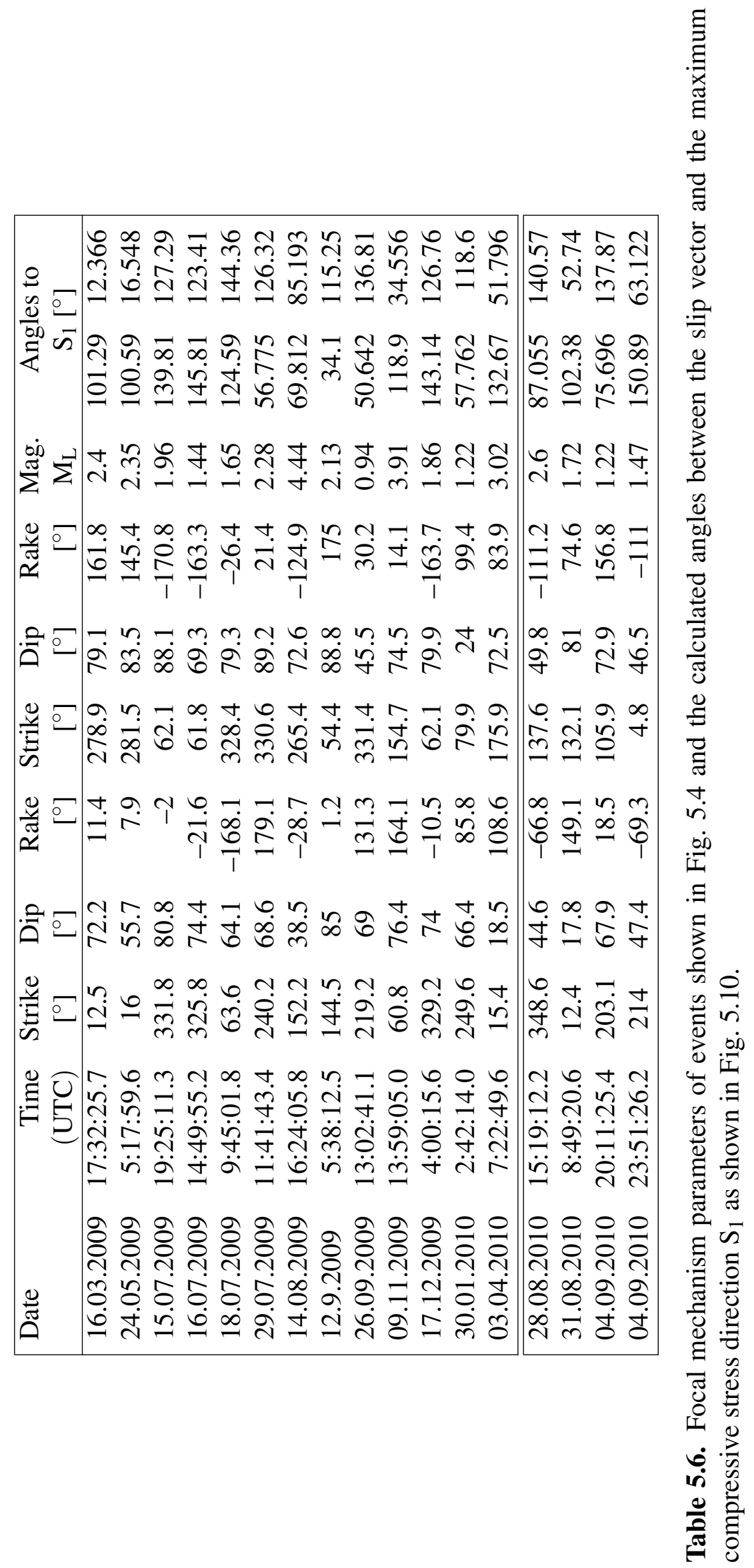




\subsubsection{Remotely triggered seismicity}

The remotely triggered swarms do not differ significantly from the background swarms in terms of their magnitude and depth distributions, focal mechanisms or inter-event time patterns except that there are more swarms within a shorter timespan. A systematic depth difference exists between triggered and non-triggered background swarms in comparison to the overall background seismicity. The triggered and non-triggered swarms have larger depths (a mean with a standard deviation of the mean of $4.9 \pm 0.10 \mathrm{~km}$ and $5.0 \pm 0.70 \mathrm{~km}$, respectively; Fig. 5.11) compared to the average depth of $3.4 \pm 0.13 \mathrm{~km}$ of all events. This difference in depth is statistically significant and may be related to the minimum differential stress required for failure. Finite element modelling results for the central Alpine Fault obtained by Ellis et al. (2006) show that the differential stress is highest at 6-7.5 km depth depending on the initial temperature model used. Assuming a hydrostatic pore-fluid factor, a Byerlee coefficient of internal friction of 0.6 , a stress ratio $\mathrm{R}=0.5$ and an intermediate principal stress due to overburden, $S_{2}=\rho \mathrm{gz}$, the differential stress $\left(\mathrm{S}_{1}-\mathrm{S}_{3}\right) / 2$ increases by 16.7 MPa per kilometre depth (Section 4.4 and Fig. 4.9). Consequently, a difference in depth of a few kilometres can reflect significant stress changes in terms of triggering thresholds (the stress difference for $3.4 \mathrm{~km}$ versus $4.9 \mathrm{~km}$ is shown in Fig. 5.11). According to Upton et al. (1995), meteoric waters penetrate to depths of 5-6 km in the central Southern Alps. If a fracture system extends to these depths as the background seismicity suggests, a pore-pressure gradient of $15 \mathrm{MPa}$ per kilometre depth exists (assuming hydrostatic fluid pressure). Unclogging of blocked fractures (Brodsky et al. 2003) or an increase of damage on the fault's contact surfaces (Parsons 2005) in response to the dynamic stresses imposed by the surface waves of the triggering event have been suggested as plausible triggering mechanisms. If a fracture connection is established, rapid fluid redistribution would occur while the pore-pressure difference is large and decay away as the pressure difference decreases. This would fit our inter-event time observations for the background and triggered swarms. According to this interpretation, the time interval between swarms represents the time required for the pressure to build up once the seal is reestablished.

The first triggered swarm after the Dusky Sound earthquake was the most energetic in terms of moment release $\left(\mathrm{M}_{\mathrm{L}}<2.8\right)$ whereas the second and third triggered swarms did not exceed $\mathrm{M}_{\mathrm{L}}$ 2. We did not calculate Coulomb stress changes to investigate if one swarm triggered the next swarm because static stress changes are insignificant at the distances between the remotely triggered swarms. Static stress changes are expected to affect only the area within several source dimensions, which is on the order of a few hundred metres for small earthquakes (e.g. Sibson 1989). The first and second triggered swarms are spatially 
separated by $\sim 8 \mathrm{~km}$, the third swarm occurs at approximately the same distance from the second and $3.7 \mathrm{~km}$ from the first. The geometry and delay between the swarms and the Dusky Sound earthquake are consistent with the expansion of a pore-fluid pressure front for diffusivities of $4.5 \mathrm{~m}^{2} / \mathrm{s}$ following the arrival of the surface waves. The same fluid source is also consistent with swarms after the Darfield earthquake as shown in Fig. 5.11.

Parotidis et al. (2003) showed that the spatio-temporal patterns of swarms in Vogtland/NWBohemia in 2000 were consistent with fluid diffusion from a fluid source of magmatic origin. They concluded that the swarm pattern depends on the hydraulic diffusivity and on the criticality (the critical pore-pressure value leading to failure) in the area. High fluid-pressure has been identified in the Southern Alps region as the cause of reduced seismic wave-speeds seen in wide-angle reflection and teleseismic P-wave arrival data at 6-8 km depth (Stern et al. 2001, 2002; Stern et al. 2007) on SIGHT transect 2 approximately $30 \mathrm{~km}$ to the south of the swarm area. A zone of low resistivities indicating interconnected fluids at depth coincides with the low-velocity zone (Wannamaker et al. 2002).

The triggered swarms and the majority of all other swarms occur in one area within the SAMBA network which seems most prone to a seismic response to small stress changes. As no remotely triggered seismicity was observed following large distant earthquakes and after the $\mathrm{M}_{\mathrm{W}}=6.3$ Christchurch earthquake (21 February 2011), this suggests that there may be a stress threshold, amongst other factors, that has to be exceeded to produce a fluid response. The distant events listed in Table 5.4 caused PGV of $0.01 \mathrm{~cm} / \mathrm{s}$ corresponding to peak dynamic stresses of $\sim 9 \times 10^{-4} \mathrm{MPa}$. The Christchurch earthquake caused comparable ground accelerations to the Dusky Sound earthquake but slightly lower PGV values $(0.3$ $\mathrm{cm} / \mathrm{s}$ corresponding to peak dynamic stresses of $0.03 \mathrm{MPa}$ ). However, the maximum PGV of the Christchurch earthquake was recorded on the vertical component whereas the other large earthquakes caused extreme values on one of the horizontal components. The ground motion of both triggering earthquakes, the Dusky Sound and the Darfield earthquake, locally exceeded PGV and PGA values of $0.7 \mathrm{~cm} / \mathrm{s}$ and $0.001 \mathrm{~g}$, respectively. These values correspond to peak dynamic stresses of $\geq 0.09 \mathrm{MPa}$. Observed peak dynamic stresses at Mammoth Mountain (Long Valley caldera) after the Denali, Hector Mine and Landers earthquakes were 0.06, 0.25 and 0.3 MPa, respectively (Prejean et al. 2004). Similar values of 0.01, 0.1 and 0.5 MPa were observed at the Coso geothermal field (Prejean et al. 2004). In Yellowstone those stresses reached 0.2 MPa (Husen et al. 2004), 0.12-0.35 MPa in Utah (Pankow et al. 2004), 0.09 MPa at Mt. Rainier in cental Washington (Prejean et al. 2004), $0.07 \mathrm{MPa}$ at the Geysers (all after the Denali earthquake; Prejean et al. 2004), and 0.18 MPa in Greece (after the Izmit earthquake; Brodsky et al. 2000). Peng et al. (2010) estimated 
peak dynamic stress of $0.085-0.17 \mathrm{MPa}$ at locations in north China after the Wenchuan earthquake.

The upper limit of static stress changes in the central Southern Alps at a distance of $350 \mathrm{~km}$ from the Dusky Sound earthquake (for a seismic moment of $2.72 \times 10^{20} \mathrm{~N} \mathrm{~m}$ according to Fry et al. 2010) is $\Delta \sigma=504.8 \mathrm{~Pa}=0.5 \mathrm{kPa}$. The same value results for the Darfield earthquake at a distance of $180 \mathrm{~km}$ (moment release of $3.5 \times 10^{19} \mathrm{~N} \mathrm{~m}$ from USGS, $\Delta \sigma=477.6 \mathrm{~Pa}$ ). Since these values are smaller than the dynamic stresses imposed by all other large distant earthquakes, we consider the static stresses to be insignificant. Regarding the frequency content of the triggering waves, the seismicity response to the Dusky Sound earthquake in the central Southern Alps was more intense (more earthquakes) than for the Darfield event, despite the larger PGA and PGV caused by the Darfield earthquake. The Dusky Sound earthquake generated more low-frequency energy than the Darfield event, which is clearly reflected in the periods of maximum ground velocities (Table 5.4). The maximum PGV values for both the Darfield and the Christchurch earthquakes were measured for waves with similar frequencies. Brodsky and Prejean (2005) showed that above a shaking threshold of $0.2 \mathrm{~cm} / \mathrm{s}$ dynamic triggering is independent of the amount of shaking (amplitude), its duration and the energy-density of the waves but it is dependent on the frequency of the wave. Waves that caused remote dynamic triggering exhibited periods ranging between 10 and 40 s (Anderson et al. 1994; Prejean et al. 2004; Brodsky and Prejean 2005). In this respect, the high stress-drop Darfield earthquake (Quigley et al. 2012) is unusual because of the dominant periods of $3 \mathrm{~s}$. The GeoNet stations in the vicinity of the SAMBA array are all clipped for longer periods and our sensor at FRAN is a $4.5 \mathrm{~Hz}$ short-period seismometer so the long-period waves may not be well-recorded.

Our results suggest a stress threshold for triggering of $0.03 \mathrm{MPa}<\sigma_{\text {thres }}<0.07 \mathrm{MPa}$ at the 100 m-deep borehole station FRAN. Gomberg et al. (2001) showed that the peak dynamic stress value depends on the local amplification at the site (since it is derived from the maximum amplitude of the velocity seismogram). Sites which recorded the Landers and Hector Mine earthquakes and exhibited remotely triggered seismicity after one of these events always showed larger PGV values for the triggering mainshock compared to the non-triggering one. However, the comparison of these PGV values between different stations showed a wide range of absolute values indicating site-dependence of the absolute value that has to be exceeded at any locality.

Based on the number of recorded sequences above the cut-off magnitude and the average time between these sequences, the probability of recording one sequence (or more) in 
any given five day time period is $12.7 \%$. The probability of observing two swarms or more with at least six events above the cut-off magnitude $M_{c}=1$ (Table 5.2) within five days after the Dusky Sound earthquake, but unrelated to it, is $0.8 \%$.

We can fit the change in rate after the Dusky Sound earthquake by a modified Omorilaw as shown in Fig. 5.14. Assuming $p=1$ in equation 5.1 (Utsu et al. 1995) and $c=10$, we obtain $\mathrm{k}=\mathrm{K} / \ln 10=10.8$ for a cut-off magnitude of 0.55 in the swarm area.

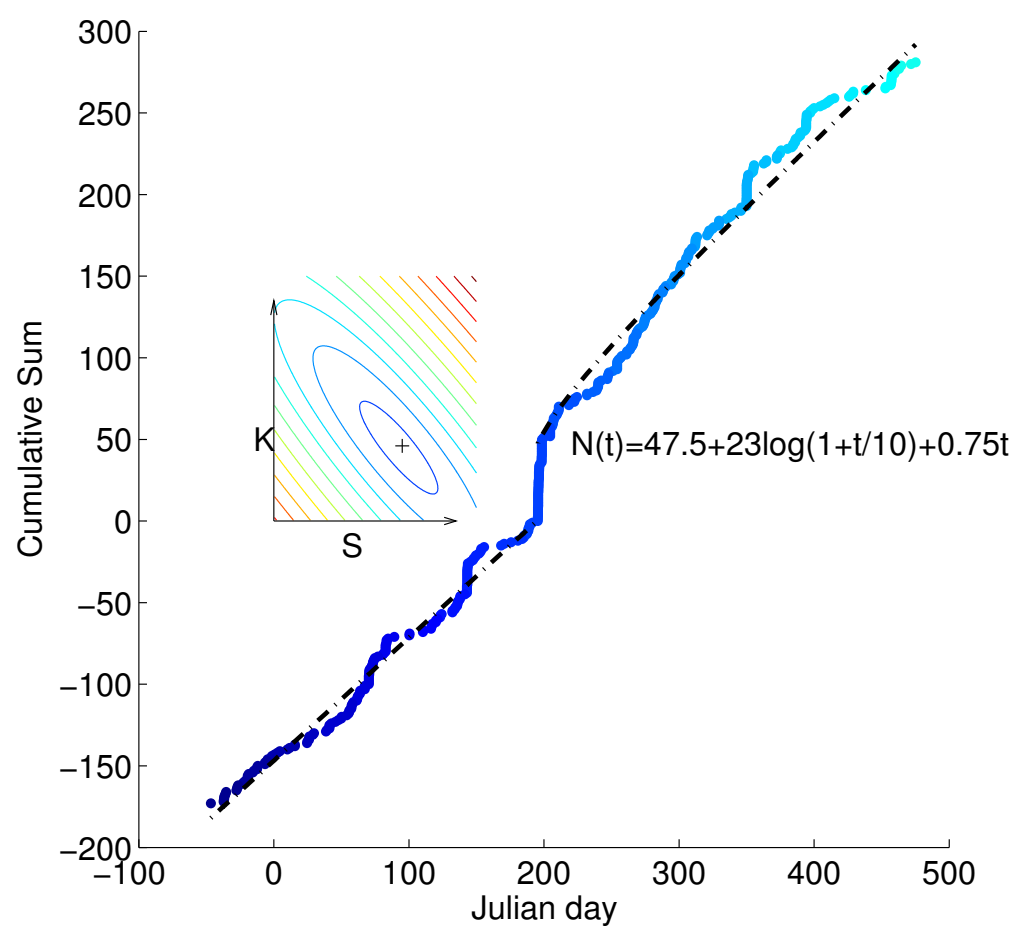

Figure 5.14. Cumulative sum of events versus Julian day since 1 January 2009 in the centre of the SAMBA network (red rectangle in Fig. 5.4). Dashed lines before and after the Dusky Sound event (on day 195) show the average rate and the average rate plus the Omori-law decay right after the earthquake. The inset shows how values for $\mathrm{K}$ and $\mathrm{S}$ in $\mathrm{N}(\mathrm{t})=\mathrm{S}+\mathrm{K} \log (1+\mathrm{t} / 10)+\mathrm{Rt}$ have been obtained from a grid search. $\mathrm{R}$ has been obtained from the seismicity rate before the Dusky Sound earthquake.

\subsubsection{Long-term record of swarms and triggering of swarms}

While many swarms have been observed in the centre of the SAMBA network, only a few small swarms were recorded in the rest of the study area. We analysed the seismicity in the GeoNet catalogue between 1993 and 2008 for different subregions throughout the study area (e.g. the areas of the Mt. Cook and Fox swarm). This reveals several clusters in the area where we have identified many swarms and another sequence in the Fox area in late 2001 
(in addition to the Fox swarm; O' Keefe 2008). Closer examination of our swarm catalogue with current search parameters reveals five clustered events in the Fox area (magenta) in January 2010.

In a different approach, we analyse the PGA recorded at Haast (approximately $85 \mathrm{~km}$ southwest of the array) for large earthquakes that caused similar amounts of shaking as those that caused the observed triggered seismicity. Candidate earthquakes for possible triggering are listed in Table 5.7. Note that a station upgrade of the GeoNet stations was undertaken in 2003 so apparent changes in the catalogue around this time are an artefact of the network upgrade. There may be a causal relationship between both the 1993 Secretary Island earthquake and 2003 Fiordland earthquake and sequences comprising large events three months later (Fig. 5.15). That is, these sequences may have experienced clock-advance due to the large earthquakes. There is no indication of remotely triggered seismicity commencing immediately after the large earthquake, but the triggered swarms recorded in 2009 and 2010 are not listed in the GeoNet catalogue because of their small magnitudes. A catalogue with a lower magnitude of completeness is required to resolve this issue.

\begin{tabular}{|r|l|l|}
\hline Date & $\mathrm{M}_{\mathrm{W}}$ & Earthquake \\
\hline 10 August 1993 & 6.8 & Secretary Island \\
18 June 1994 & 6.7 & Arthur's Pass \\
21 August 2003 & 7.2 & Fiordland \\
21 August 2003 & 6.2 & Fiordland aftershock \\
02 November 2003 & 6.4 & Fiordland aftershock \\
13 December 2004 & 8.1 & Macquarie Island \\
22 November 2004 & 7.1 & Puysegur Trench \\
15 October 2007 & 6.7 & George Sound \\
15 October 2007 & 6.2 & George Sound aftershock \\
19 December 2007 & 6.8 & Gisborne \\
15 July 2009 & 7.8 & Dusky Sound \\
04 September 2010 & 7.1 & Darfield \\
21 February 2011 & 6.3 & Christchurch earthquake \\
13 June 2011 & 6.0 & Christchurch aftershock \\
23 December 2011 & 6.0 & Christchurch aftershock \\
\hline
\end{tabular}

Table 5.7. Major earthquakes that caused comparable amounts of shaking at Haast as the 2009 Dusky Sound and 2010 Darfield earthquakes ( $\geq 1 \mathrm{~mm} / \mathrm{s})$, as shown in Fig. 5.15. 


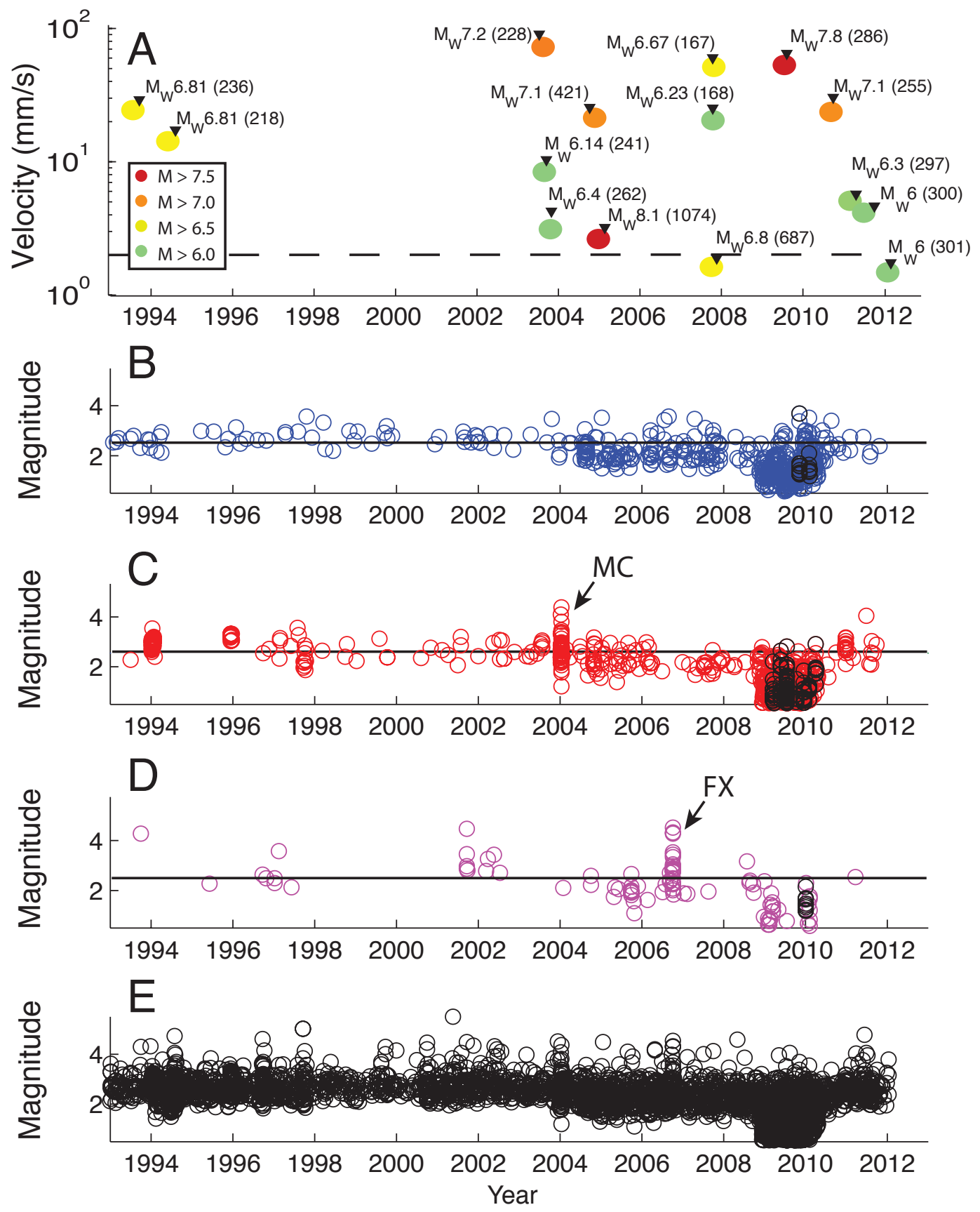

Figure 5.15. Search for triggered sequences in the central Southern Alps region after large earthquakes. (a) Peak ground velocities (PGV) from major earthquakes recorded at Haast ca. $85 \mathrm{~km}$ southeast of the centre of the SAMBA array (Table 5.7). The dashed line indicates the threshold proposed by Brodsky and Prejean (2005) above which triggering is independent of the waves' amplitude, duration and energy-density but depends on the frequency of the waves. (b-d) Seismicity versus time for the subregions as shown in Fig. 5.4. Black circles indicate sequences detected in this study, annotated arrows show the Mt. Cook (MC) and Fox swarms (FX). The daily seismicity rate is 0.86 (b), 1.66 (c) and 0.45 (d) events per 30 days per $1000 \mathrm{~km}^{2}$ for the GeoNet catalogue $\left(M_{c} 2.6\right)$ between 1993-2007. (e) Seismicity versus time for the whole study area. 


\subsection{Conclusions}

The detection of small earthquake swarms strongly depends on the local station network and its detection threshold (e.g. Frankel et al. 1980). With our dense station network in the central Southern Alps, we recorded 16 swarms of low magnitude $\left(-0.5<\mathrm{M}_{\mathrm{L}} \leq 2.9\right)$ between November 2008 and September 2010. Three swarms have been remotely triggered by the $\mathrm{M}_{\mathrm{W}} 7.8$ Dusky Sound and at least two by the $\mathrm{M}_{\mathrm{W}}$ 7.1 Darfield earthquakes. The triggered swarms are similar to the background swarms in terms of waveform similarity, maximum magnitudes, depth distribution, duration and inter-event time patterns, but they comprise more events (which may be a result of the different detection methods of events in the aftershock sequence). The triggered and non-triggered background swarms have larger depths than the background seismicity, which may correspond to the depth of ambient peak differential stresses, according to modelling results. The majority of the swarms occur in the centre of the network and have well-constrained hypocentres. The focal mechanism solutions of the largest event in each swarm indicate either strike-slip, reverse faulting or a combination of both. All mechanisms have one steeply-dipping nodal plane $\left(\geq 50^{\circ}\right)$ in common. The focal mechanisms of both the triggered and the non-triggered background swarms are in agreement with near-Andersonian faulting on favourably oriented faults in the stress field. The crust is highly fractured in this region with a wide variety of fault orientations, so potentially there is an abundance of faults near failure.

The observed remotely triggered seismicity started with the passage of the surface waves of the Dusky Sound and Darfield earthquakes and continued for several days. The triggered swarms occurred delayed by 8, 20 and 71.6 hours after the Dusky Sound and 6.4 and 7.3 hours after the Darfield earthquake. Since we observed dynamic triggering twice within two years in the same area, we conclude that earthquake triggering is a common phenomenon in the Southern Alps. However, in the long-term record there is no indication for triggered swarms (probably because the GeoNet catalogue cut-off magnitude of $\mathrm{M}_{\mathrm{c}} 2.6$ according to Eberhart-Phillips 1995; Petersen et al. 2011, is too high).

Based on results presented in this chapter, a triggering threshold of $0.09 \mathrm{MPa}$ has to be exceeded for remotely triggered seismicity to occur in the centre of the SAMBA array. This threshold is comparable to triggering thresholds observed worldwide and does not indicate that larger values are required in compressional settings than in transtensional and extensional regimes.

Inter-event times versus durations of these swarm earthquakes above a cut-off magni- 
tude of $\mathrm{M}_{\mathrm{L}} 1.0$ show a characteristic pattern that is markedly different from that of a typical mainshock-aftershock sequence. Both types of sequences are distinct in their initial phase: a swarm exhibits decreasing inter-event times followed by an increase. The events in a mainshock-aftershock sequence only show this increase or decay process. This suggests that different mechanisms exist and that a distinct repeatable process causes the swarms. The initially accelerating failure is consistent with fluid-flow within or into weak localities with an abundance of cracks and faults. Due to the delay of the triggered swarms and existing evidence of high fluid-pressure (Stern et al. 2007) and interconnected fluids at depth (Wannamaker et al. 2002), we favour a fluid-driven mechanism over the aseismic slip model and the order and occurrence of the triggered swarms is consistent with a common fluid source from which a pore pressure front diffuses away.

In general, our observations are consistent with the hypotheses that have been made to explain remotely triggered seismicity, namely:

- areas with frequent occurrence of swarms more often respond to dynamic stress changes than other areas (e.g. Hill et al. 1993);

- triggering involves brittle slip on critically stressed faults favourably oriented in the prevailing stress field, and;

- triggering represents clock-advance of failure on a fault or a number of faults (e.g Anderson and Webb 1994; Steacy et al. 2005).

The latter is based on the highest seismicity level in the area and the fact that the triggered seismicity is followed by a quiescence period of approximately the same length as the elevated seismicity period. This suggests that many faults near failure were clock-advanced in their seismic cycle. However, in order to establish if the periodicity between swarms was significantly disturbed, we need a longer history of swarm activity in this region which allows for a thorough analysis of the intervals between sequences. 


\section{Deep earthquakes, tremor and other preliminary results}

This chapter summarises unpublished results related to subsidiary topics explored during this research. Aaron Wech has been involved in the search, identification and analysis of tremor as described in Section 6.2. He has determined the tremor locations, uncertainties and magnitudes and written the publication in Geophysical Research Letters that summarises this section (Wech et al. 2012).

\subsection{Deep earthquakes}

Several earthquakes with depths exceeding $30 \mathrm{~km}$ have been recorded by the SAMBA and GeoNet networks (Table 6.1 and Fig. 6.1). These events have magnitudes $\mathrm{M}_{\mathrm{L}}<3.5$ and occur mostly west and southwest of the SAMBA station network. The deep earthquakes occur outside the SAMBA network but the majority of the events are still sufficiently close to the network that at least two stations are within distances smaller than the focal depth of the events. All events have at least three S-Picks. The uncertainties of the hypocentres in horizontal and vertical direction as shown in Table 6.1 are small, reflecting that the depths are accurate despite the locations outside the station network. The azimuthal coverage of the stations relative to the earthquakes, however, is not ideal with gaps $\geq 130^{\circ}$.

For three of these events, more than seven polarity picks from the SAMBA stations are available, enabling focal mechanism solutions to be calculated. Coverage on the focal sphere is sparse, so we have augmented the data of the largest events $\left(M_{L} \sim 3\right)$ that were recorded by GeoNet with polarities available from these stations. Three focal mechanisms have been obtained, one using only the available polarity data from the SAMBA and the other two from the combined SAMBA/GeoNet stations. The P-onsets of the deep events are usually impulsive as shown in the examples of Fig. 6.2. The two events listed in the GeoNet catalogue were recorded by stations across the whole South Island with some clear $P_{n}$ arrivals. The ray take-off angle of $P_{n}$ phases is uncertain (due to the complicating 


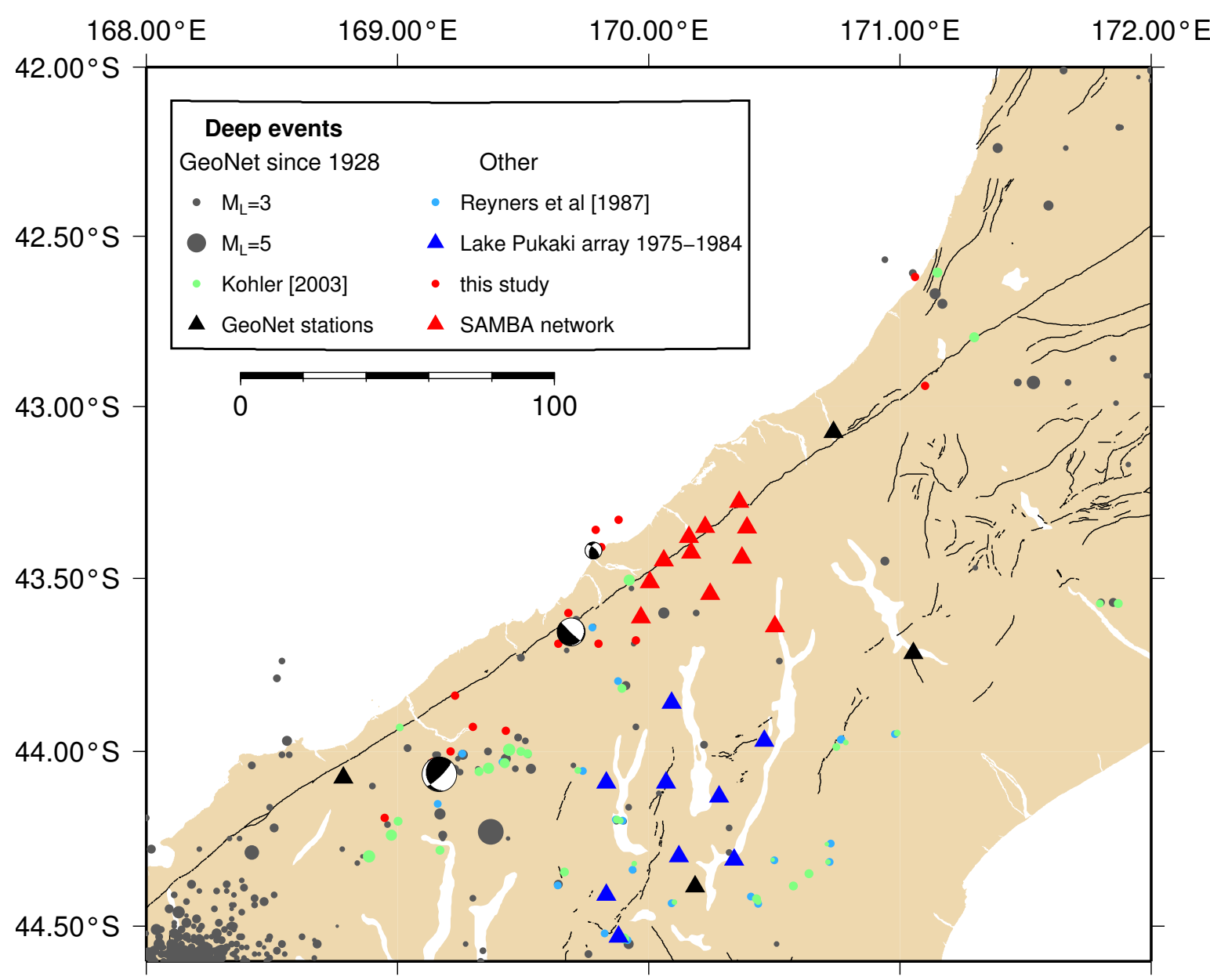

Figure 6.1. Subcrustal earthquakes (depth $>35 \mathrm{~km}$ ) reported by Reyners (1987), Kohler and Eberhart-Phillips (2003) and in this study (Table 6.1) recorded by various networks in comparison.

effects of the crustal structure), so ideally they should be assigned larger uncertainties in the focal mechanism analysis. This is currently not possible with the algorithm used here (Walsh et al. 2009) and would require substantial modifications of the code. Therefore, we compare the focal mechanism solutions obtained using these $P_{n}$ polarities with those excluding $\mathrm{P}_{\mathrm{n}}$ (Fig. 6.3). The additional $\mathrm{P}_{\mathrm{n}}$ polarity picks are in agreement with the reverse mechanisms obtained excluding $P_{n}$. However, due to the large epicentral distances of these stations, they correspond to the rim of the focal sphere and significantly influence the focal mechanism parameters. In conclusion, the focal mechanisms of the three deep events consistently exhibit reverse mechanisms, but the strike, dip and rake have large uncertainties and are poorly constrained. A more extensive station network in the Southern Alps region is needed to better resolve the focal mechanism parameters of such deep, small to moderate earthquakes. Nevertheless, our results are in agreement with a composite focal mechanism obtained by Reyners (1987) for events at depths of $\geq 25 \mathrm{~km}$ in this region. 


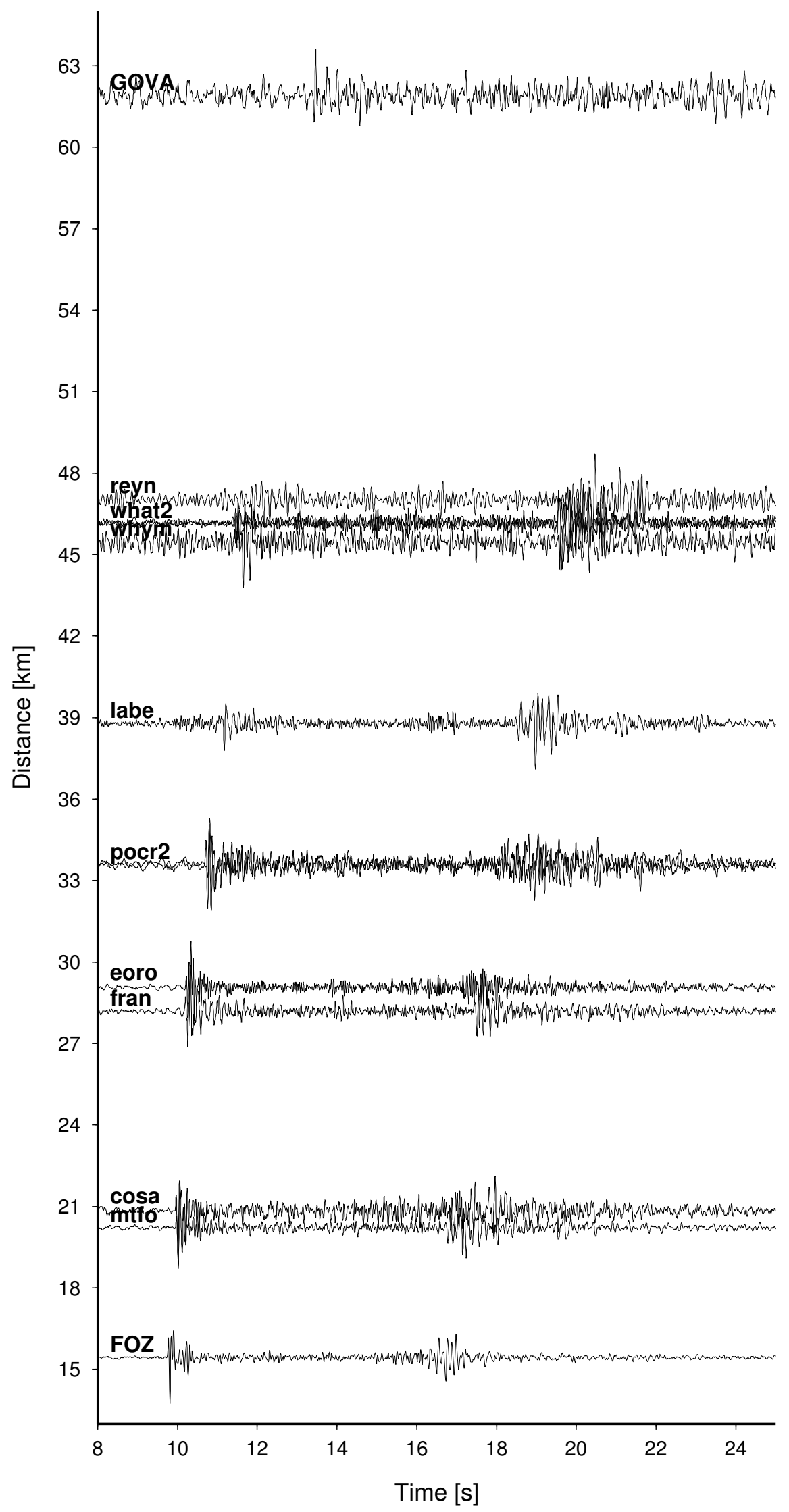

Figure 6.2. Travel-time versus distance plot for a deep earthquake recorded on the vertical component of the stations on 17.10.2009 as listed in Table 6.1. 

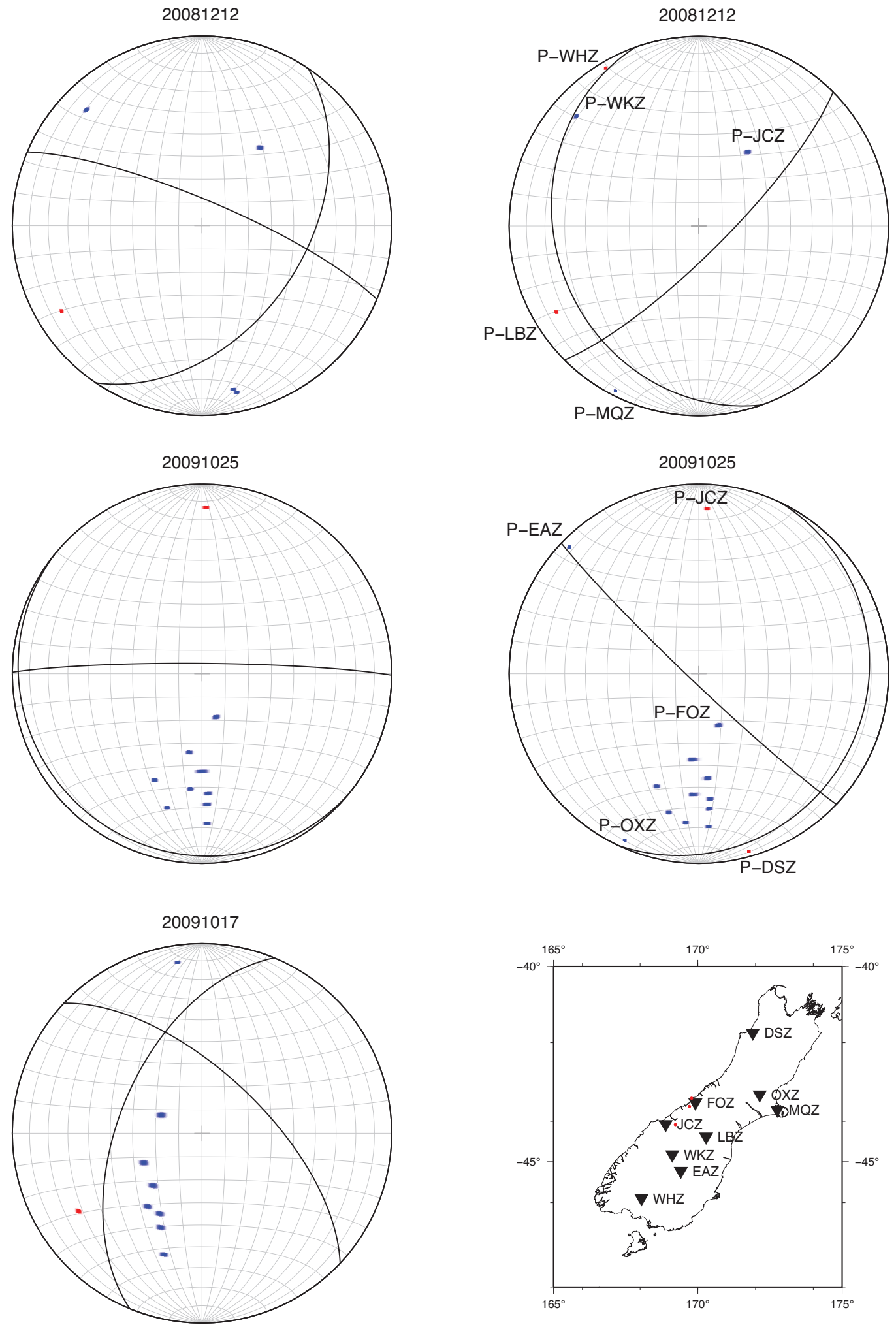

Figure 6.3. P-wave polarities and focal mechanism solution of the deep events (top 12.12.2008, centre 25.10.2009, bottom 17.10.2009) including (left) and excluding $P_{n}$ onsets (right, all polarity picks of the GeoNet stations marked). Note that the last event was only recorded by the SAMBA network. Compressional onsets are shown in blue, dilatational ones in red. 


\begin{tabular}{|rrrrrrrrrrr|}
\hline Date & Time & $\begin{array}{r}\text { Lat. } \\
\left.{ }^{\circ}\right]\end{array}$ & $\begin{array}{r}\text { Lon. } \\
{\left[{ }^{\circ}\right]}\end{array}$ & $\begin{array}{r}\text { Dep. } \\
{[\mathrm{km}]}\end{array}$ & $\begin{array}{r}\text { RMS } \\
{[\mathrm{s}]}\end{array}$ & $\begin{array}{r}\text { Stn. } \\
\text { Phs. }\end{array}$ & $\begin{array}{r}\text { Gap } \\
{\left[{ }^{\circ}\right]}\end{array}$ & $\begin{array}{r}\text { Uncertainty } \\
{[\mathrm{km}]}\end{array}$ & {$[\mathrm{km}]$} \\
\hline 8.12 .08 & $5: 46: 20.4$ & -44.64 & 168.04 & 98 & 0.39 & 18 & 25 & 155 & 1.1 & 1.2 \\
$12.12 .08^{*}$ & $14: 11: 45.7$ & -44.05 & 169.16 & 64 & 0.40 & 21 & 28 & 133 & 0.8 & 1.5 \\
8.01 .09 & $10: 04: 25.3$ & -44.03 & 169.14 & 58 & 0.29 & 16 & 21 & 139 & 0.8 & 1.5 \\
26.01 .09 & $0: 29: 26.1$ & -42.94 & 171.10 & 39 & 0.28 & 7 & 9 & 142 & 1.2 & 2.0 \\
27.01 .09 & $12: 29: 32.1$ & -43.69 & 169.80 & 55 & 0.16 & 6 & 10 & 177 & 2.8 & 5.6 \\
10.03 .09 & $13: 26: 50.6$ & -43.84 & 169.23 & 73 & 0.25 & 9 & 17 & 181 & 1.3 & 2.3 \\
23.03 .09 & $17: 22: 26.3$ & -44.00 & 169.02 & 70 & 0.26 & 12 & 15 & 165 & 1.2 & 3.6 \\
4.04 .09 & $8: 41: 56.1$ & -43.94 & 169.43 & 74 & 0.37 & 19 & 25 & 141 & 1.2 & 1.6 \\
11.07 .09 & $9: 30: 26.7$ & -43.53 & 169.94 & 61 & 0.33 & 11 & 18 & 160 & 1.8 & 3.8 \\
22.08 .09 & $10: 57: 51.3$ & -43.33 & 169.88 & 59 & 0.23 & 15 & 23 & 201 & 1.2 & 1.6 \\
$17.10 .09 *$ & $7: 53: 20.3$ & -43.41 & 169.81 & 65 & 0.22 & 14 & 26 & 195 & 1.3 & 1.4 \\
$25.10 .09 *$ & $15: 02: 40.8$ & -43.60 & 169.68 & 61 & 0.31 & 28 & 43 & 167 & 0.8 & 1.0 \\
25.12 .09 & $9: 57: 34.0$ & -43.68 & 169.95 & 54 & 0.04 & 8 & 12 & 290 & 2.1 & 8.1 \\
17.01 .10 & $22: 39: 2.0$ & -43.36 & 169.79 & 61 & 0.17 & 6 & 11 & 224 & 1.8 & 2.8 \\
\hline
\end{tabular}

Table 6.1. Subcrustal earthquakes recorded by the SAMBA and GeoNet network. Stars mark those events for which a focal mechanism could be obtained as shown in Fig.6.1 and 6.3. The number of stations and phases are listed, as are the location uncertainties in horizontal and vertical directions.

Two of the three deep events occur at depths in the lithospheric mantle where the Australian and Pacific plates intersect (Stern et al. 2002; Reyners 1987). This may represent a region where compression due to plate bending is largest (cf. Forsyth 1982).

\subsection{Tremor}

The emergent, low-frequency $(2-8 \mathrm{~Hz}$ ), low-amplitude and long-duration signal (several minutes to hours) observed on the seismograms of stations along the subduction zones of Cascadia, Nankai, Alaska, Mexico and Costa Rica and the strike-slip San Andreas fault has been termed tremor (Beroza and Ide 2011, and references therein). Tremor is inferred to represent slow shear-slip failure (rupture speeds slower than those of ordinary earthquakes) in the transition zone between stick slip and stable sliding of a fault (Shelly et al. 2009) or on the plate interface (Shelly et al. 2006; Wech and Creager 2007). This has been shown by the locations and first motions of low-frequency earthquakes occurring on or near the plate interface (Shelly et al. 2006) and indicate plate-boundary slip (Ide et al. 2007). Low-frequency earthquakes have been identified in parts of the tremor signal (Shelly et al. 2006, 2007) and it has been suggested that tremor results from a superposition of these events (Shelly et al. 
2006; Beroza and Ide 2011, and references therein). Tremor has also been attributed to fluidrelated processes at depth (Obara 2002) and high fluid pressure has been inferred near tremor sources in Japan, Cascadia and Mexico (Shelly et al. 2006; Audet et al. 2009; Song et al. 2009). It is not clear, however, if fluid movement is responsible for tremor and aseismic slip or if aseismic slip causes fluid redistribution which generates tremor (Shelly et al. 2006).

A clear correlation of tremor in subduction zones of Cascadia and Japan with slowslip events has been demonstrated by Rogers and Dragert (2003) and Obara et al. (2004) where both tremor and slow-slip exhibit remarkable periodicity. In strike-slip settings, however, no deformation signal has yet been observed in association with tremor (Johnston et al. 2006). Tremor observed on the San Andreas fault extends along a $150 \mathrm{~km}-$ long segment from the end of the locked segment near Cholame, through the transitional zone southeast of Parkfield, as far as Bitterwater near the creeping section northwest of Parkfield (Shelly et al. 2009; Peng et al. 2009) The tremor signal is shorter (4-20 min), less frequent ( $\leq 5$ events detected in any 24-hour period) and has smaller peak amplitudes $\left(\mathrm{M}_{\mathrm{W}}<0.5\right.$ for equivalent earthquakes) than in subduction zones (Nadeau and Dolenc 2005). The upper and lower depth-ranges of families of low-frequency events are 18 and $28 \mathrm{~km}$ (Shelly and Hardebeck 2010) with depth errors of individual events on the order of 3-5 km (Shelly et al. 2009). Tremor migrates along the fault at velocities of 15-40 km/hr (Shelly et al. 2009), and the largest amplitudes of the tremor signal (30-55 nm/s on the velocity seismogram) occur at the end of the locked zone near Cholame (Shelly and Hardebeck 2010).

Several episodes of triggered tremor have been observed along the San Andreas Fault following distant (Peng et al. 2009) and some regional events (Guilhem et al. 2010). Tremor responds to much lower stress changes than triggered earthquakes, especially if the incidence direction of the surface waves of the triggering earthquake is in a direction similar to the strike of the fault (Peng et al. 2009; Hill 2008). Tidal stress changes seem to be sufficient to trigger tremor since a correlation of tremor with the 12.4 and $25 \mathrm{hr}$ tidal periods has been observed in several places (e.g. Rubinstein et al. 2008).

The data recorded by the SAMBA stations have been systematically scrutinized for tremor in the period March 2009 to October 2011 (when the SAMBA station network was in its complete configuration and recording continuously). Envelopes of the filtered waveforms were calculated, which were then decimated, smoothed and reduced by a mean amplitude. Tremor could be identified due to its long-duration signal appearing on the majority of stations as shown in Figure 6.4. The tremor is located using cross-correlations of the tremor signal and a grid-search method over the delay between the maxima of the cross-correlation 


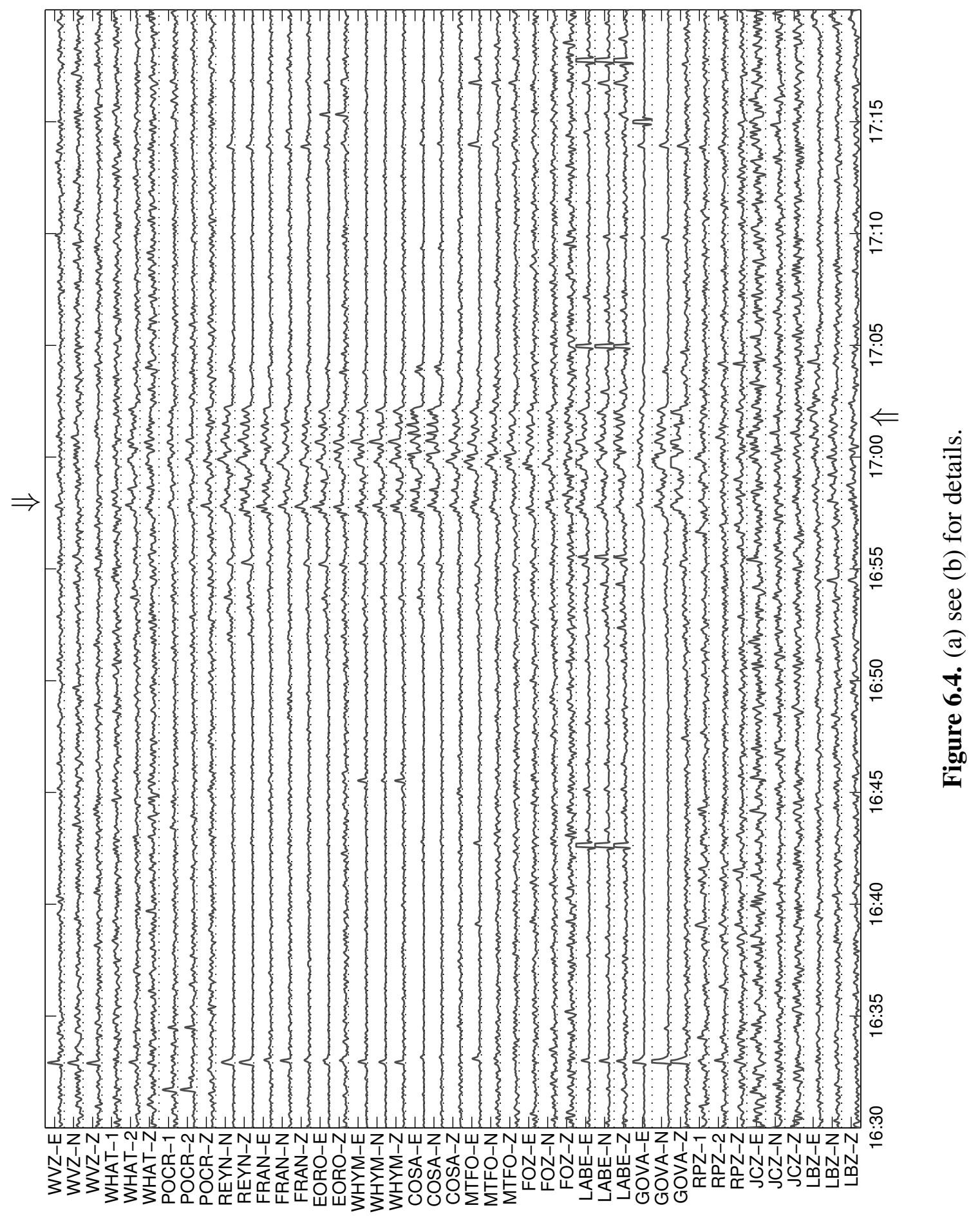




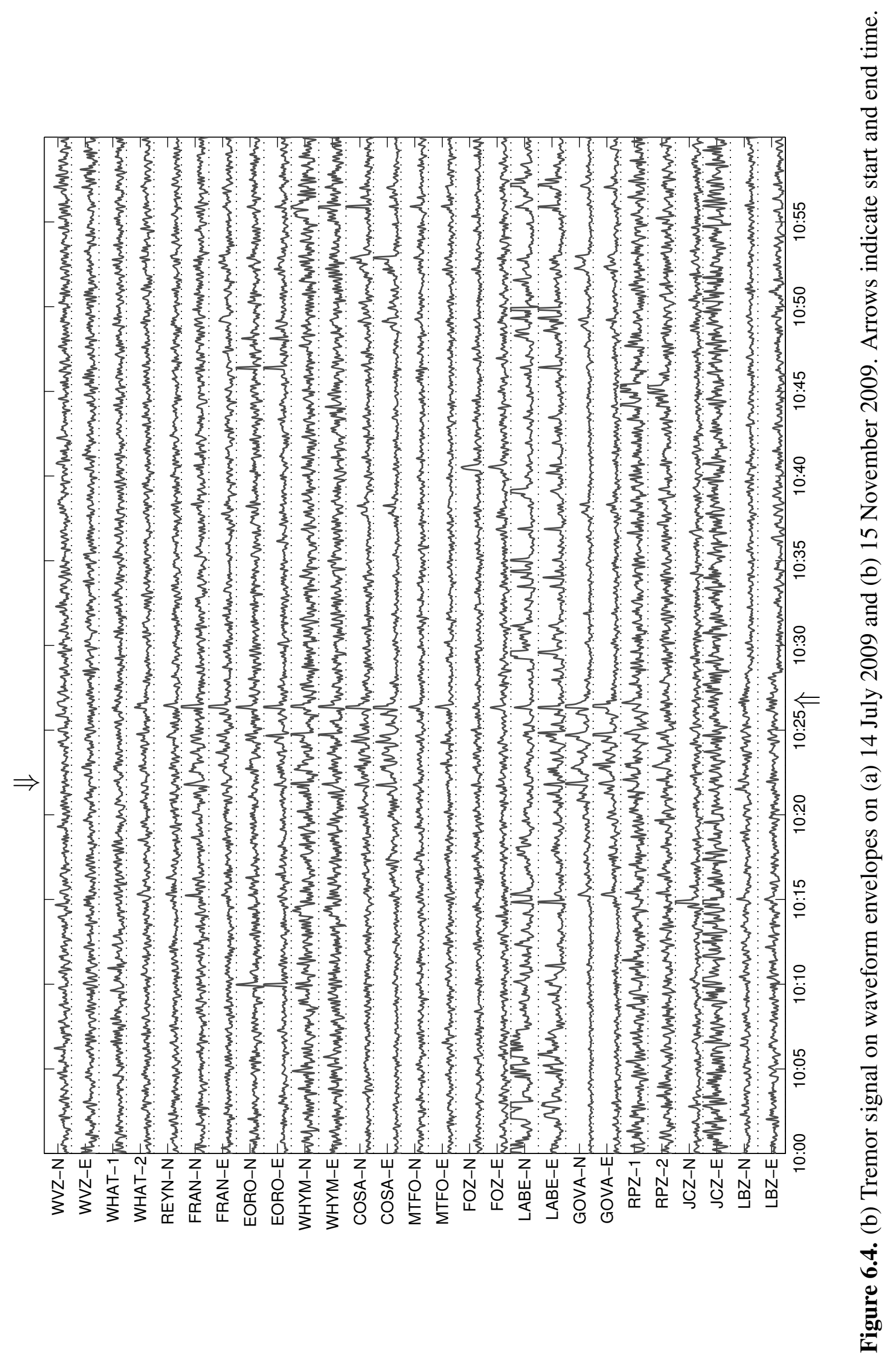


functions assuming S-wave propagation velocities to the stations (Wech and Creager 2008). In previous studies, this method has been shown to reliably identifying a common source of the signal but is insufficient for determining accurate depth estimates (depth uncertainties in the order of $15 \mathrm{~km}$; Wech and Creager 2008; Shelly and Hardebeck 2010).

Most of the tremor originates southeast of the SAMBA station network close to or beneath station COVA, which started recording in January 2010 (southernmost red station in Fig. 6.5). The tremor occurs irregularly with a few days to several months between individual tremor sequences and signal durations of 5-30 min. Magnitudes have been determined by calibrating the maximum amplitude of the signal with those determined for earthquakes. Magnitudes of the tremor signal are equivalent to $\mathrm{M}_{\mathrm{L}} \sim 1$ earthquakes. Despite the large depth uncertainties, the tremor can be concluded to occur at and below the lower end of the seismogenic zone (Fig. 6.6). This depth range overlaps with a high-attenuation zone (the lowest $Q$ values in the whole of South Island) extending downwards from $22 \mathrm{~km}$ depth (Eberhart-Phillips et al. 2008). Eberhart-Phillips et al. (2008) associated the $10 \mathrm{~km}$-thick, low-Q region with the downdip extension of the Alpine Fault. They interpret the high attenuation as an indication of metamorphic fluids within a high-strain zone. This region has slightly lower $\mathrm{V}_{\mathrm{P}}$ velocities than surrounding regions (Eberhart-Phillips and Bannister 2002) but in general the structure resolved in the attenuation model is not resolved in the 3-D velocity model (Fig. 6.5). However, the 2-D velocity profile along SIGHT transect T2 (Fig. 6.6) reveals a low-velocity zone extending downwards to 25-30 km depth (Scherwath et al. 2003). The tremor locations occur in the vicinity of Mt. Cook, the highest elevation in the Southern Alps, at depths in the mid to lower-crust and upper mantle. There appears to be a lineation with depth that dips in the opposite direction to the Alpine Fault (Fig. 6.6). This suggests that tremor extends downwards beyond the Alpine Fault and may represent deep slip where the bending of the Pacific and Australian plates is largest. Kohler and Eberhart-Phillips (2003) propose that deep earthquakes in the Southern Alps region are associated with high strain gradients. The deep earthquakes recorded in this study locate at 50-60 km depths, below the tremor (Fig. 6.6). Therefore, increasing strain-rate values with depth may explain the semi-brittle and brittle behaviour observed. If the tremor locations outline the plate interface, then its dip is much steeper than previously assumed. In general, this is in agreement with two-fault models of GPS measurements (e.g Beavan et al. 1999) that require an antithetic, slipping fault at depth.

The tremor durations of $<30 \mathrm{~min}$ obtained in this study are similar to those recorded at the San Andreas Fault (Nadeau and Dolenc 2005). Tremor durations show a large variability but tremor in the Cascadia and Japan subduction zones can last weeks to months (e.g. 

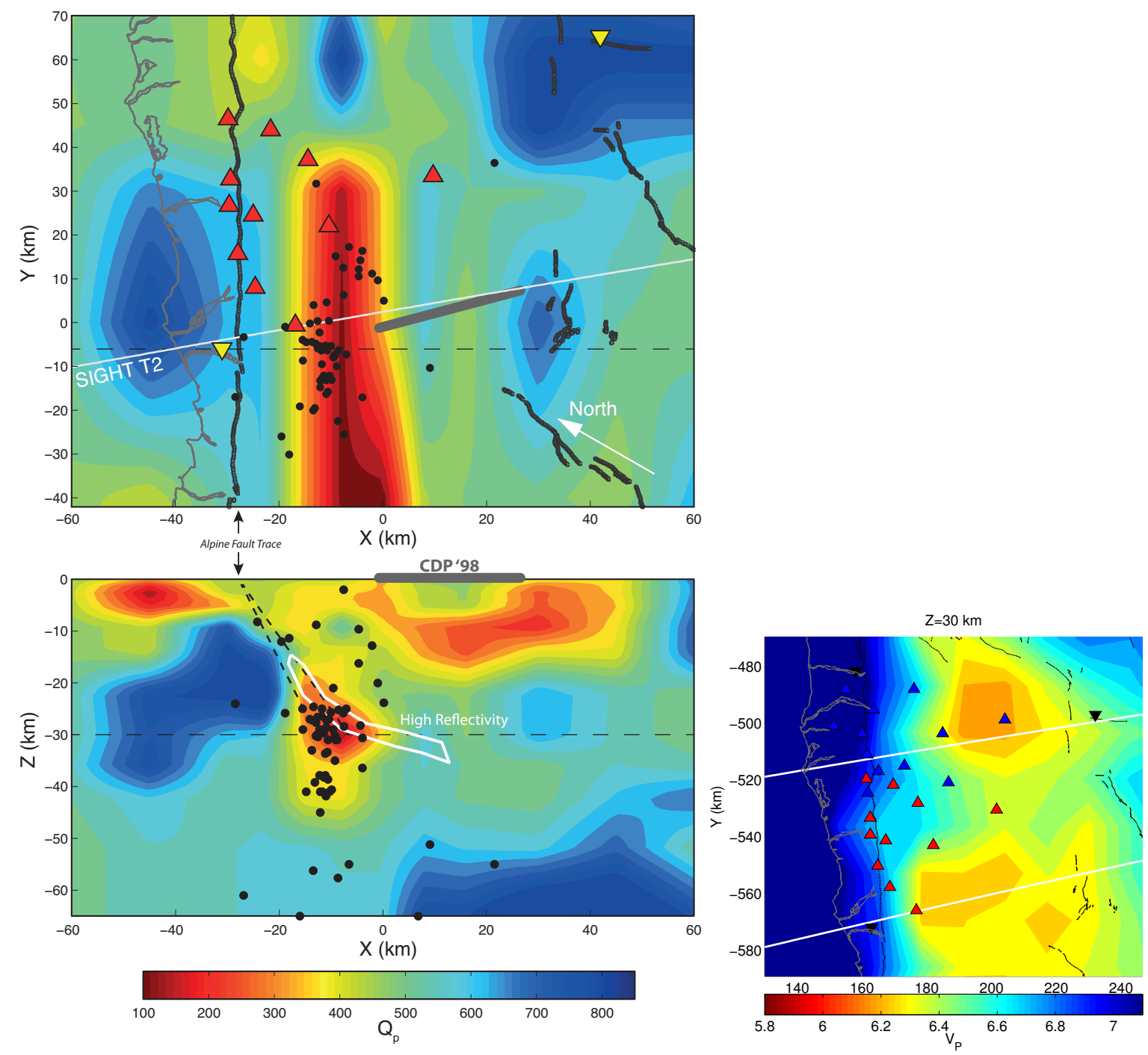

Figure 6.5. Tremor locations (black) for tremor events between March 2009 and October 2011 in comparison with the Q-structure (Eberhart-Phillips et al. 2008) and velocity structure (Eberhart-Phillips et al. 2010, small) at $30 \mathrm{~km}$ depth. The dashed line marks the position of the cross-section illustrated below. The white area outlines a region of high reflectivity observed in the migrated CDPâ98 reflection profile (grey line in both panels; Stern et al. 2007). 


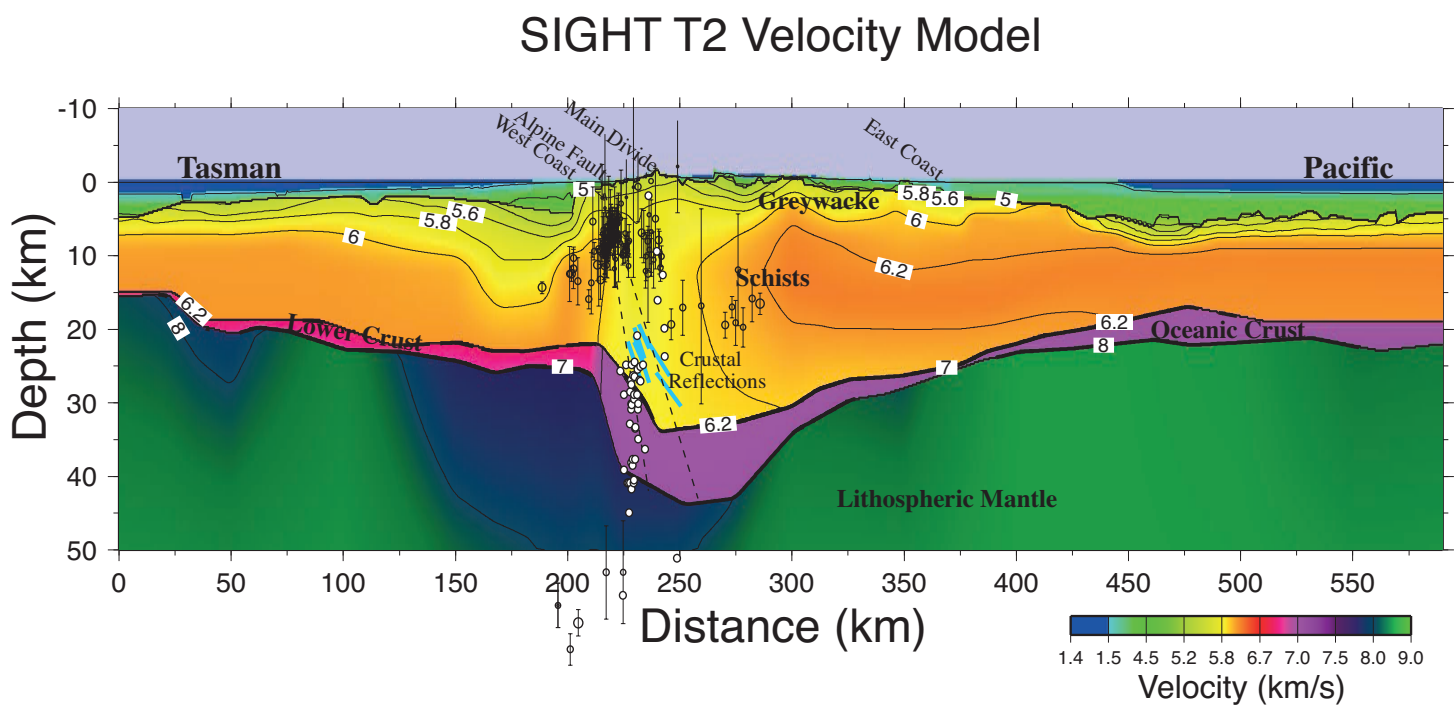

Figure 6.6. Tremor locations (white) and seismicity (black) projected within $\pm 15 \mathrm{~km}$ onto the velocity profile along SIGHT transect T2 of Scherwath et al. (2003). The blue lines show reflectors as explained in Fig. 6.5. Note that the resolution of the velocity model is variable in the upper mantle and confined to the central part of the profile.

Beroza and Ide 2011). In addition to the comparable durations, several similarities between the tremor recorded in the Southern Alps with the tremor near Cholame exist. Firstly, the tremor locations form a cluster that does not extend northwards along the fault (Fig. 6.5 and Fig. 3a of Becken et al. 2011). Secondly, the depths of tremor locations are comparable (Nadeau and Guilhem 2009; Shelly and Hardebeck 2010; Becken et al. 2011). And thirdly, bright seismic reflections and a low-velocity zone occur near or within the tremor region (at depth of 15-22 km near the San Andreas Fault according to Trehu and Wheeler 1987; at depths of 5-35 km along SIGHT transect T2; T. Stern pers. comm. 2012). The tremor near Cholame occurs in a high-resistivity zone adjacent to a low-resistivity zone extending along strike which is inferred to be the fluid source for the tremor (Becken et al. 2011). Along the strike of the San Andreas fault, a change from high (1000 $\Omega \mathrm{m}$ ) to low resistivity $(10-100 \Omega \mathrm{m})$ takes place at a depth of $\geq 10 \mathrm{~km}$ and the tremor activity diminishes in the low-resistivity region. In general, low resistivities extending to the surface within fault zones have been associated with creeping faults (Unsworth and Bedrosian 2004; Bedrosian et al. 2004). However, a distinctive, narrow, low-resistivity fault zone along the locked segment of the San Andreas Fault in the Carrizo Plain has also been identified (Unsworth et al. 1999).

On the San Andreas Fault, tremor occurs in a region of transition between locked and creeping sections at the surface. This region has been associated with resistivity changes (Becken et al. 2011). Due to similarities of the Alpine Fault tremor with that of the San Andreas Fault, and the Alpine Fault's attenuation and velocity structure, this may suggest 
strength variations along the strike of the Alpine Fault. The dip of the Alpine Fault changes from steeply-dipping to vertical between Fox Glacier and Haast. Whether this change is abrupt or gradual is not known. Little et al. (2005) suggest a localised steepening of the dip of the Alpine Fault by $15-20^{\circ}$ between Franz Josef and Fox Glacier just north of the tremor locations. Spatial variations in fault zone properties at shallow depths have been documented recently along the Alpine Fault in this region (Boulton et al. 2012).

\subsection{Tomography}

A simultaneous inversion for hypocentres and velocity structure can resolve systematic uncertainties in the velocity model as shown in Fig. 3.2 a) and b). The tomography method of Zhang (2003) is applied, which is based on the double difference approach of Waldhauser and Ellsworth (2000) and makes use of three types of data in the inversion: absolute arrival times, differential catalogue travel-time residuals, and differential cross-correlation travel-time residuals. Due to the incorporation of cross-correlation data, double-difference tomography has better fine-scale resolution in areas of high earthquake density than conventional tomography (Zhang and Thurber 2006). The forward problem, the calculation of travel-times between earthquakes and stations, is computed using the pseudo-bending 3-D ray-tracing algorithm of Um and Thurber (1987) (which is accurate for ray lengths up to at least $60 \mathrm{~km}$; Haslinger and Kissling 2001). This algorithm adjusts an initially straight ray-path between source and receiver in a piecewise manner by perturbing the position of the midpoint to determine the final ray path. Distance weighting controls the maximum separation between pairs of events. Weighting is applied according to the $a$ priori data uncertainty, the different weights assigned to P- and S-phases of catalogue and cross-correlation data in the particular iteration, and the relative weighting factor between catalogue and cross-correlation data, which determines the overall contribution of the individual data types in the iteration.

The velocities obtained are smoothed over neighbouring grid nodes in order to retain only as much structure as can be resolved from the data. The same smoothing weights in the horizontal and vertical directions are used. Damping is required to ensure convergence of the system since not all model parameters can be determined. The optimal damping and smoothing parameters are determined by calculating trade-off curves of the data variance versus the model variance (Eberhart-Phillips 1986) as shown in Fig. 6.7. For this, we run one iteration of joint hypocentre relocation and velocity inversion with equal weights for cross-correlation and catalogue data with a series of damping $(10,25,50,75,85,95,105$, 
$115,150,250,500$, and 1,000) and smoothing values $(3,5,10,15,20,30,50$, and 100). The optimal smoothing value which minimises the model variance is 10 . Damping values vary between 45 and 160 depending on the iteration.

The model resolution is given by the ray density in each block and the number of rays traversing the block in different directions. In tomoDD, instead of calculating the full resolution matrix, the derivative-weighted sum (DWS) is calculated as an indicator of well- and poorly-sampled regions. The DWS represents a measure of the number of rays that traverse near a grid point. It is affected by the weight of the pick in the input data as well as the relative weighting of the data types (cross-correlation versus catalogue data) in the particular iteration. The ray direction is not taken into account. We consider a DWS threshold of 15 as the lower resolution limit according to the value used by Zhang and Thurber (2006).

The earthquake data selected for the joint inversion consist of 1012 events in the study area that were recorded by more than six stations and have azimuthal gaps of $\leq 200^{\circ}$. A total of $9266 \mathrm{P}$ and $8591 \mathrm{~S}$ catalogue picks are available and 78505 and 69417 cross-correlation differential travel-times for P- and S-waves, respectively.

We examine the effects of several different starting velocity models; the 1-D velocity model of O' Keefe (2008), our modified version of that model (without the low-velocity surface layer; Table 1.2), a gradient model based on the same velocities and the 3-D model of Eberhart-Phillips et al. (2010), which was smoothed and interpolated onto the same grid used for the 1-D models. We test $\mathrm{V}_{\mathrm{P}} / \mathrm{V}_{\mathrm{S}}$-ratios of $1.64,1.68$ and 1.73 for the starting velocity models. $A V_{\mathrm{P}} / \mathrm{V}_{\mathrm{S}}$-ratio of 1.73 corresponds to the velocities in a Poisson solid. O' Keefe (2008) obtained a $\mathrm{V}_{\mathrm{P}} / \mathrm{V}_{\mathrm{S}}$-ratio of 1.68 in the inversion of a minimum 1-D velocity model (Kissling 1988). We obtain stable values of $1.64 \pm 0.03$ determined from Wadati diagrams of the input hypocentre data as shown in Table 6.2 and Fig. 6.8. This suggests that the $\mathrm{V}_{\mathrm{P}} / \mathrm{V}_{\mathrm{S}}$-ratio is even lower than obtained by O' Keefe (2008) and is consistent with laboratory results for Southern Alps schist samples studied by Godfrey et al. (2000) (for steeply-dipping bedding, compare their Fig. 13b), average velocities of $\mathrm{SmS}$ and PmP-phases in the Australian Plate (Fig. 4.9 of Pulford 2002) and $V_{P} / V_{S}$-ratios obtained tomographically by Eberhart-Phillips and Bannister (2002) $\left(\mathrm{V}_{\mathrm{P}} / \mathrm{V}_{\mathrm{S}}<1.65\right.$ within $20 \mathrm{~km}$ of the fault). The grid used in our inversion is rotated by $55^{\circ}$ so that the $\mathrm{X}$-axis is oriented parallel to the Alpine Fault and the Y-axis perpendicular to it as shown in Fig. 6.9. The finest grid node spacing of $5 \mathrm{~km}$ extends from just offshore to $60 \mathrm{~km}$ southeast of the Alpine Fault and from GeoNet station FOZ (south-westernmost station) to $10 \mathrm{~km}$ northeast of the north-easternmost station WVZ. This area of densest grid spacing is enclosed by a 

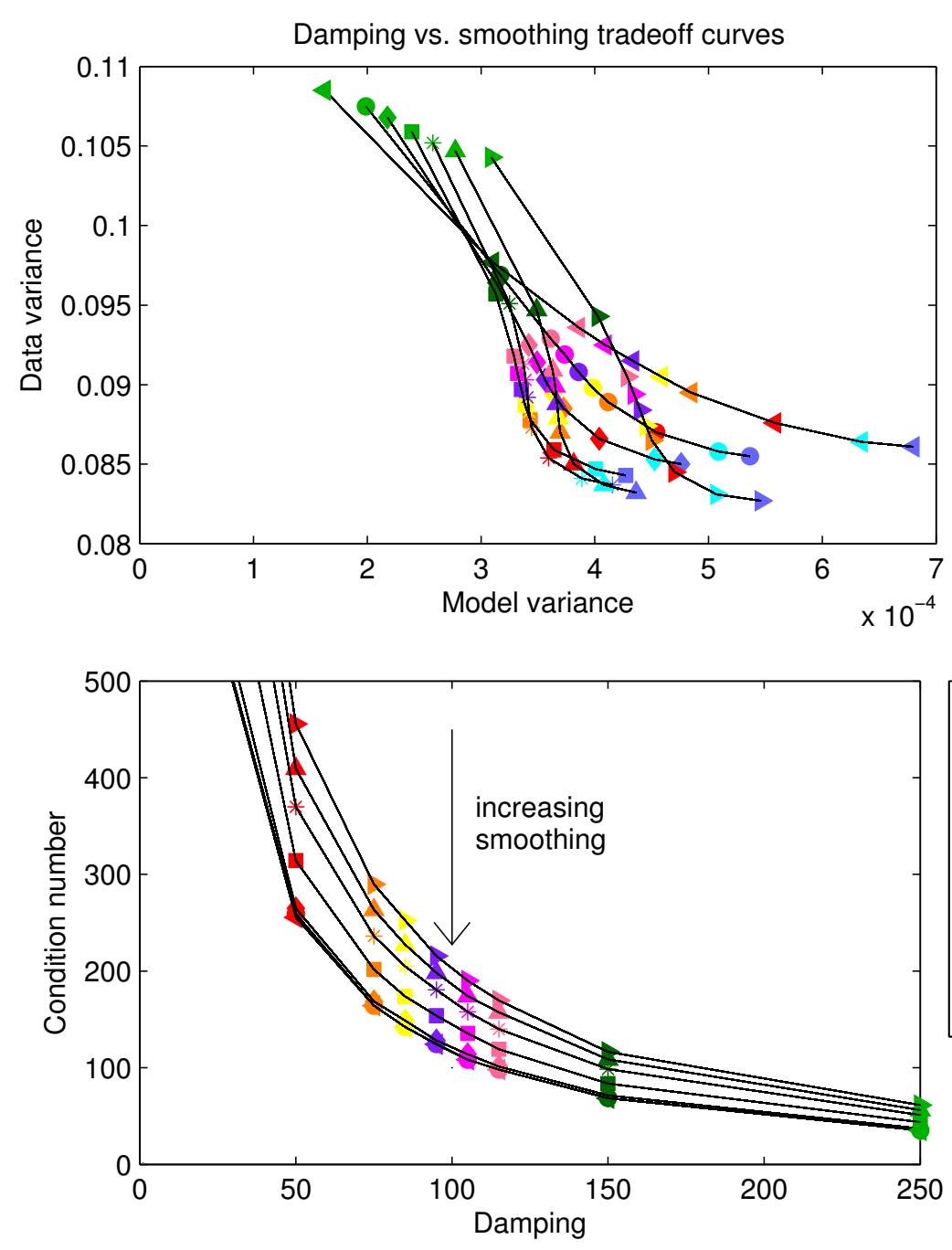

Damping
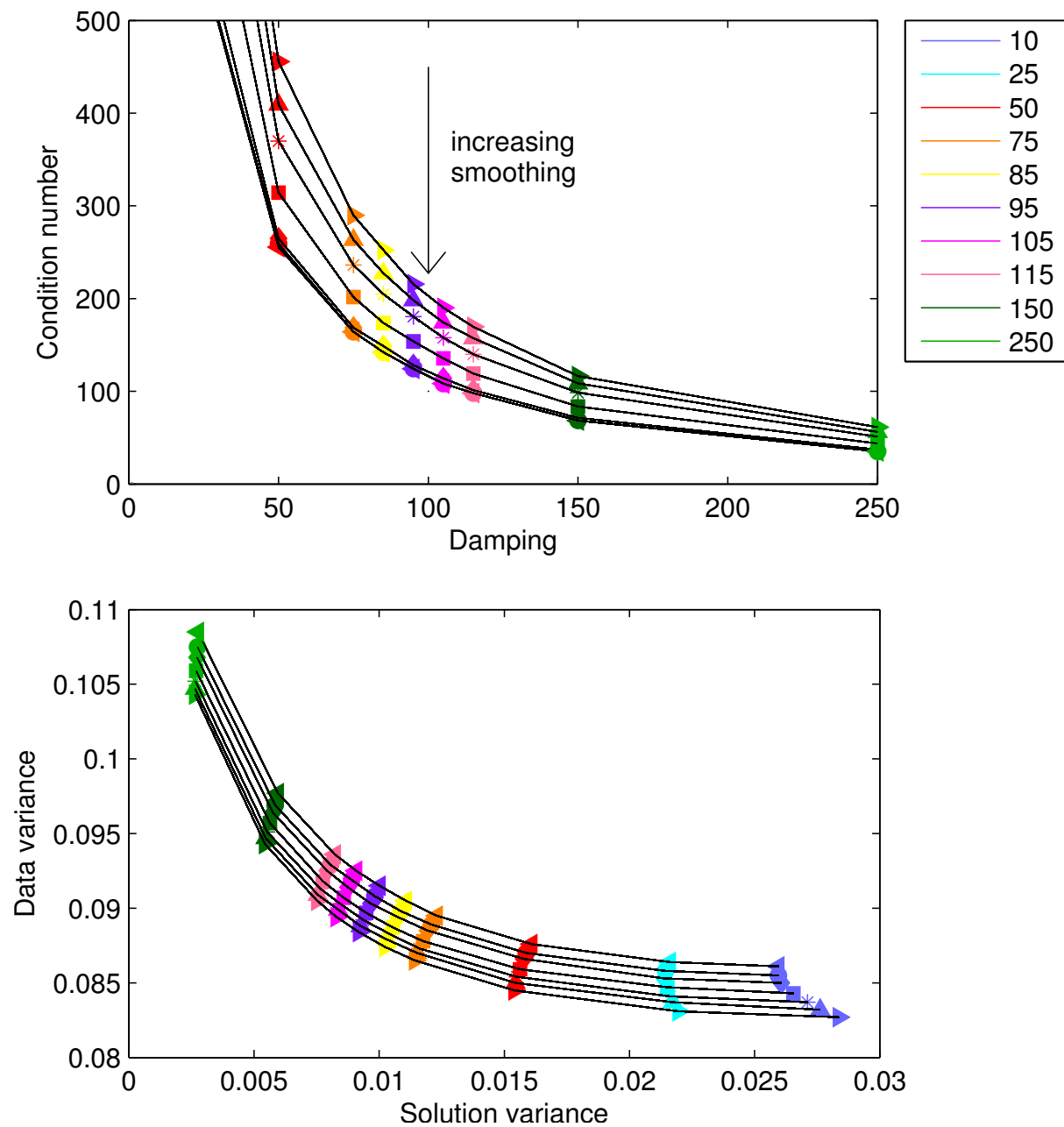

Figure 6.7. Tradeoff curves of (a) the data variance (weighted catalogue RMS) versus the model variance (variance of the model parameters), (b) the conditioning number (which expresses the stability of the solution and indicates ill-conditioned system of equations) versus the damping and (c) the data variance versus the solution variance (variance of the hypocentre changes and model parameters) for different damping and smoothing values. The symbol and the colour used for damping and smoothing apply to all three panels. 


\begin{tabular}{|c|c|c|c|c|}
\hline $\begin{array}{c}\text { Number } \\
\text { stations }\end{array}$ & $\begin{array}{c}\text { RMS } \\
{[\mathrm{s}]}\end{array}$ & $\begin{array}{c}\text { Mean } \\
\mathrm{V}_{\mathrm{P}} / \mathrm{V}_{\mathrm{S}}\end{array}$ & $\begin{array}{c}\text { Std } \\
\mathrm{V}_{\mathrm{P}} / \mathrm{V}_{\mathrm{S}}\end{array}$ & $\begin{array}{c}\text { Number } \\
\text { events }\end{array}$ \\
\hline 3 & 0.5 & 1.65 & 0.05 & 1067 \\
6 & 0.1 & 1.64 & 0.04 & 280 \\
6 & 0.2 & 1.65 & 0.04 & 655 \\
6 & 0.3 & 1.65 & 0.04 & 709 \\
7 & 0.1 & 1.64 & 0.03 & 196 \\
8 & 0.1 & 1.64 & 0.04 & 116 \\
9 & 0.1 & 1.65 & 0.03 & 65 \\
10 & 0.1 & 1.64 & 0.03 & 28 \\
\hline
\end{tabular}

Table 6.2. Mean and standard deviation of $\mathrm{V}_{\mathrm{P}} / \mathrm{V}_{\mathrm{S}}$-ratios determined for differing number of events, stations and RMS values from the input hypocentre locations

$10 \mathrm{~km}$-wide band with $10 \mathrm{~km}$ node spacing. All nodes outside this region have $\geq 15 \mathrm{~km}$ spacing. The origin of the grid is centred at Mt. Cook village for consistency with the 3-D velocity model of Eberhart-Phillips and Bannister (2002). The spacing in depth is $2 \mathrm{~km}$ between -3 and $18 \mathrm{~km}$ depth, $5 \mathrm{~km}$ below $18 \mathrm{~km}$ depth and $10 \mathrm{~km}$ below $40 \mathrm{~km}$ depth. This spacing is slightly smaller than the expected sizes of the velocity anomalies that can be resolved.

We start with the relocation of all earthquakes to test if we can reproduce our hypoDD results from Section 3.4.4. This is the case, except that the overall number of relocated events is larger (1012 versus 936 events) because tomoDD can account for topography. In the second step, we fix all hypocentre locations and invert for velocity structure only. We then continue with the joint inversion of hypocentre locations and velocity structure for the different starting velocity models. Comparison of the results (Fig. 6.12) shows that the same features are resolved despite the different "background" velocities, which mainly affect the amplitude of the resolved velocity structure. All inversions have in common that the hypocentres shift downwards by on average $1.75 \mathrm{~km}$ and slightly eastwards (approximately $320 \mathrm{~m}$; Table 6.3).

To test the resolution capabilities, we perform a checkerboard test in which the input velocity model is perturbed by $5 \%$ within blocks of three, four and six nodes separated by one node, which retains its previous velocity value. This corresponds to $15 \times 15,20 \times 20$ and $30 \times 30 \mathrm{~km}^{2}$ blocks of alternating high and low velocity in the area of finest grid spacing. The same $5 \%$ perturbation is applied to the $\mathrm{V}_{\mathrm{P}} / \mathrm{V}_{\mathrm{S}}$-ratios. For this "checkerboard" velocity model, synthetic absolute, cross-correlation and differential travel-times are calculated. We use the standard deviation of the P- and S-phase arrival-times of the input data of $0.11 \mathrm{~s}$ 


\begin{tabular}{|cc|cc|cc|c|}
\hline \multicolumn{2}{|c|}{ Latitude $\left[{ }^{\circ}\right]$} & \multicolumn{2}{c|}{ Longitude $\left[^{\circ}\right]$} & \multicolumn{2}{c|}{ Depth $[\mathrm{km}]$} & Velocity model \\
mean & std & mean & std & mean & std & \\
\hline 0.0055 & 0.0081 & -0.0007 & 0.0108 & 1.66 & 2.16 & Eberhart-Phillips et al. (2010) \\
0.0003 & 0.0066 & 0.0048 & 0.0101 & 1.79 & 2.09 & O' Keefe (2008) \\
0.0003 & 0.0066 & 0.0050 & 0.0101 & 1.83 & 2.15 & gradient \\
0.0005 & 0.0064 & 0.0045 & 0.0100 & 1.75 & 2.01 & $\mathrm{~V}_{\mathrm{P}} / \mathrm{V}_{\mathrm{S}}=1.73$ \\
0.0005 & 0.0064 & 0.0045 & 0.0100 & 1.75 & 2.01 & $\mathrm{~V}_{\mathrm{P}} / \mathrm{V}_{\mathrm{S}}=1.68$ \\
0.0005 & 0.0063 & 0.0047 & 0.0100 & 1.72 & 1.95 & $\mathrm{~V}_{\mathrm{P}} / \mathrm{V}_{\mathrm{S}}=1.64$ \\
\hline
\end{tabular}

Table 6.3. Shifts of hypocentres during the joint inversion using different starting velocity models

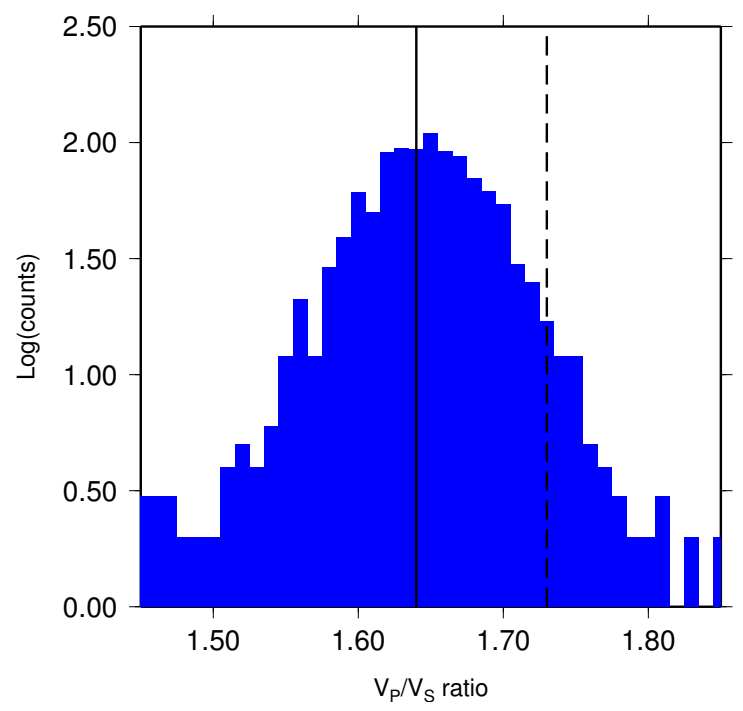

Figure 6.8. Histogram of $V_{\mathrm{P}} / \mathrm{V}_{\mathrm{S}}$-ratios of the input data from all events

and $0.16 \mathrm{~s}$, respectively, to determine the distribution of Gaussian noise which is added randomly to the synthetic absolute travel-time data. These synthetic travel-times are then used as input for the inversion of the velocity model with the same settings as in the velocity inversion of the real data. The similarity between the recovered and the input checkerboard model reveals how well-resolved the velocity structure actually is (e.g. Lévěque et al. 1993). Figure 6.13 shows the comparison of the input and recovered velocity models.

Lévěque et al. (1993) showed that the resolution capabilities resolved using a checkerboard model can be misleading under unfavourable but not unrealistic circumstances (if the solution matrix has eigenvalues equal to zero). They showed that if small-size structures can be retrieved this has no implications for the resolvability of larger structures and that the larger the structure the harder it is to resolve. To test the resolution, spheres and blocks of different size, orientation and amplitude should be used instead. Ideally several 


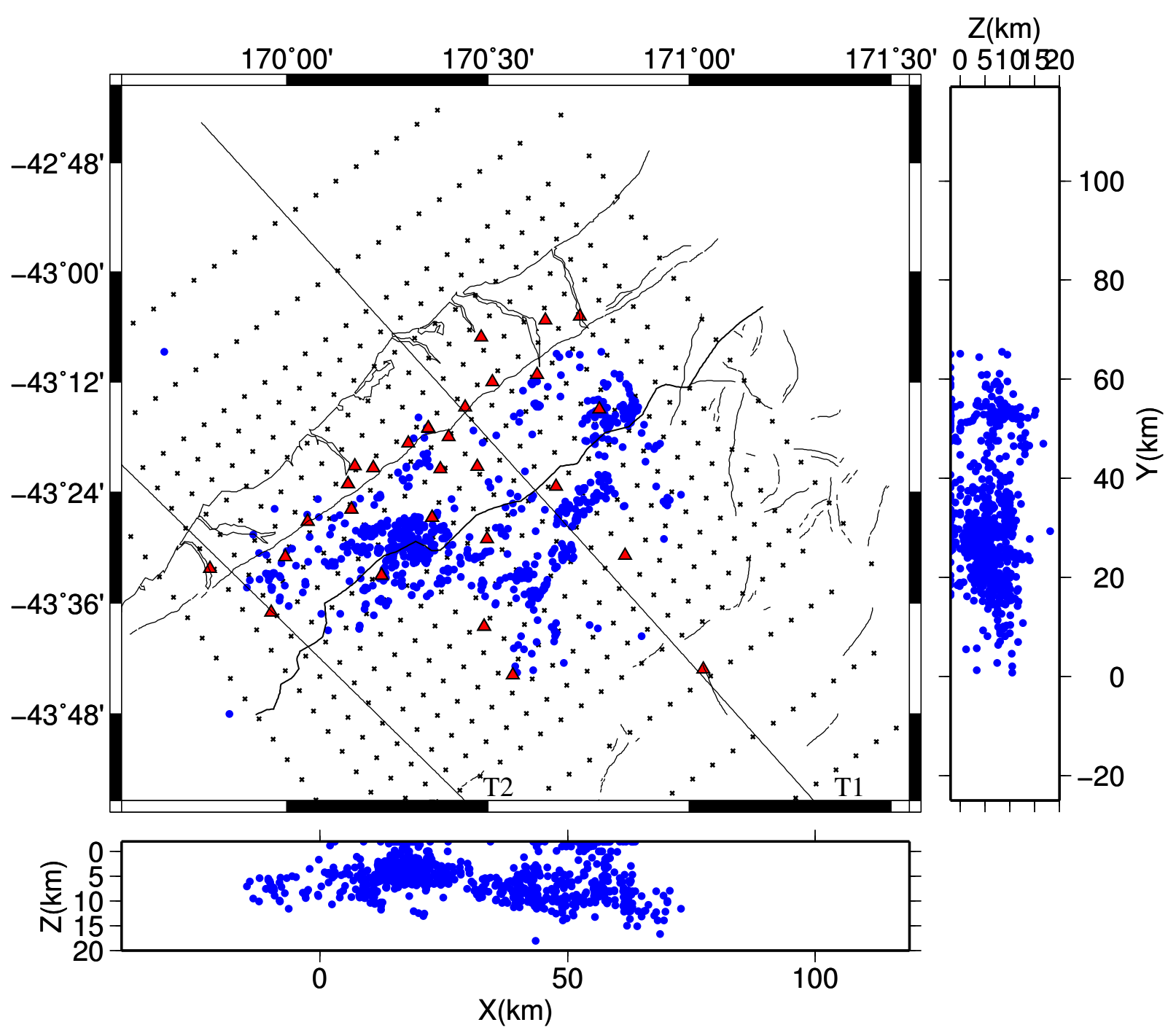

Figure 6.9. Grid orientation and initial hypocentre locations used for the inversion. 


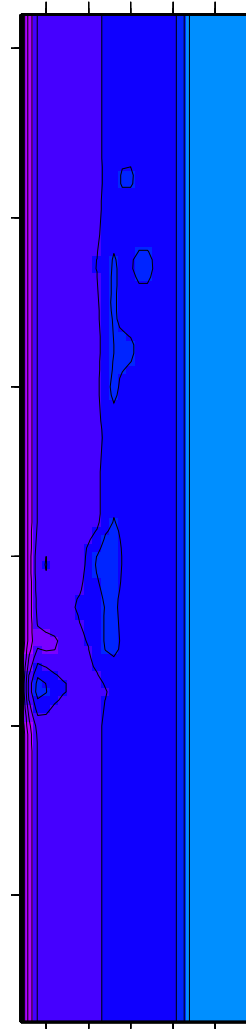

느은 늘요

$(\mathrm{my}) \mathrm{Z}$

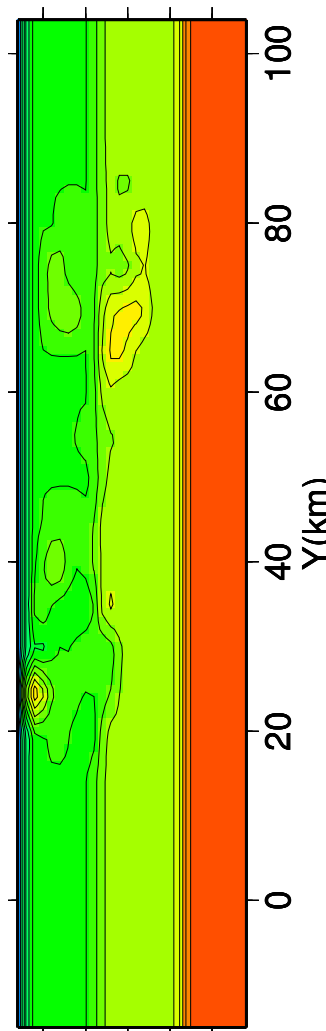

으으는요 은 $(\mathrm{ur}) \mathrm{Z}$

$\infty$

오

8

ㅇ

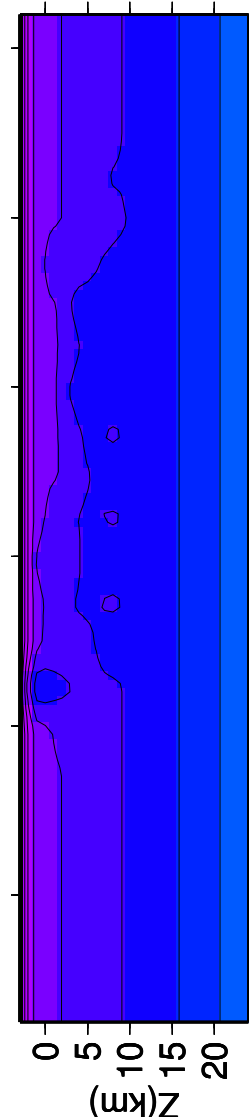

웅

$\infty$

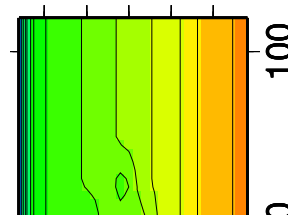

앟

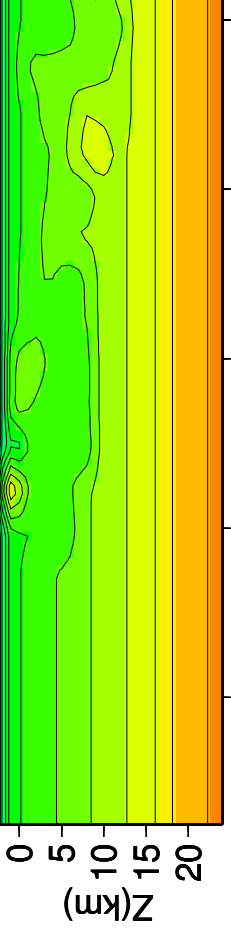

8

๙

8

ㅇ

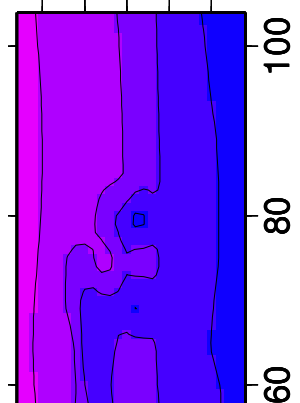

8

○

8

$\frac{\overrightarrow{0}}{0}$

$\frac{\ddot{\theta}}{0}$

:

아핳

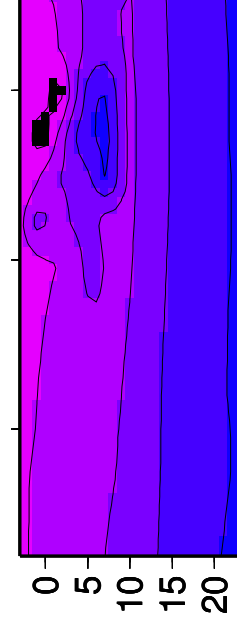

웅

$-\stackrel{\text { N }}{2}$

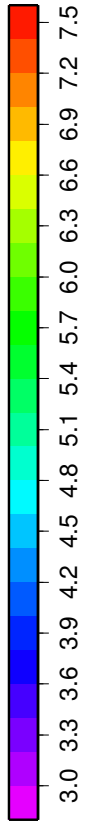

o

$(u y) Z$

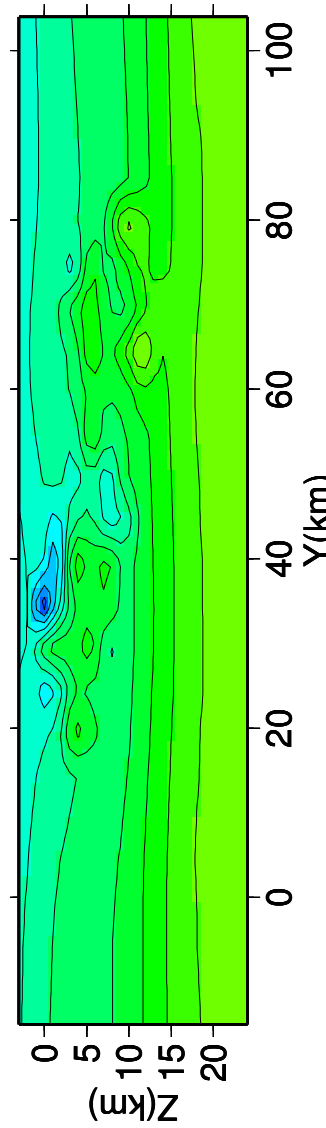



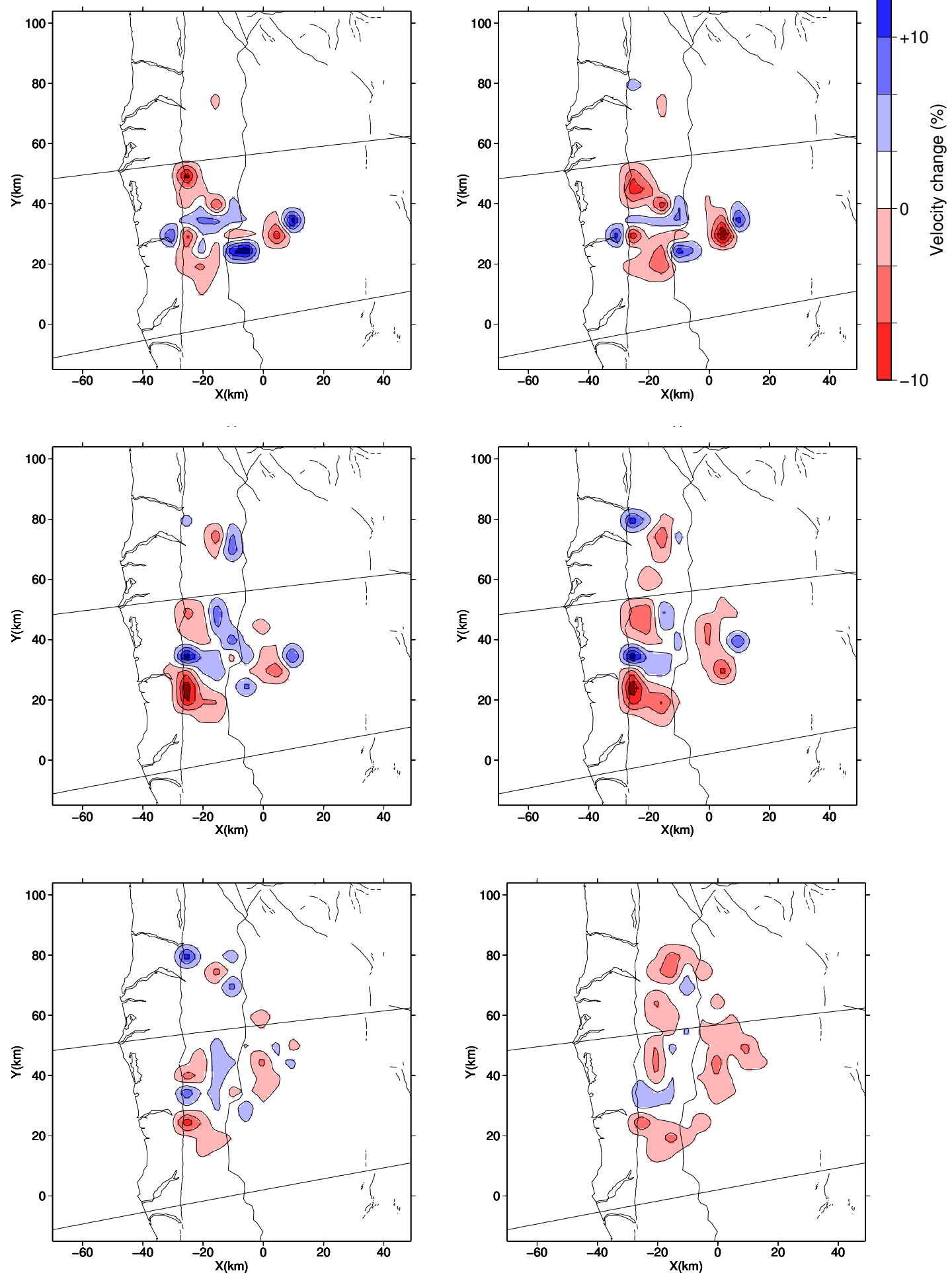

Figure 6.11. (a) Comparison of tomographic results for the preferred velocity model (left) and gradient model (right) as starting models for depths of 3 (top), 5 (centre) and $7 \mathrm{~km}$ (bottom) depth. The corresponding resolution maps are shown in (b) 

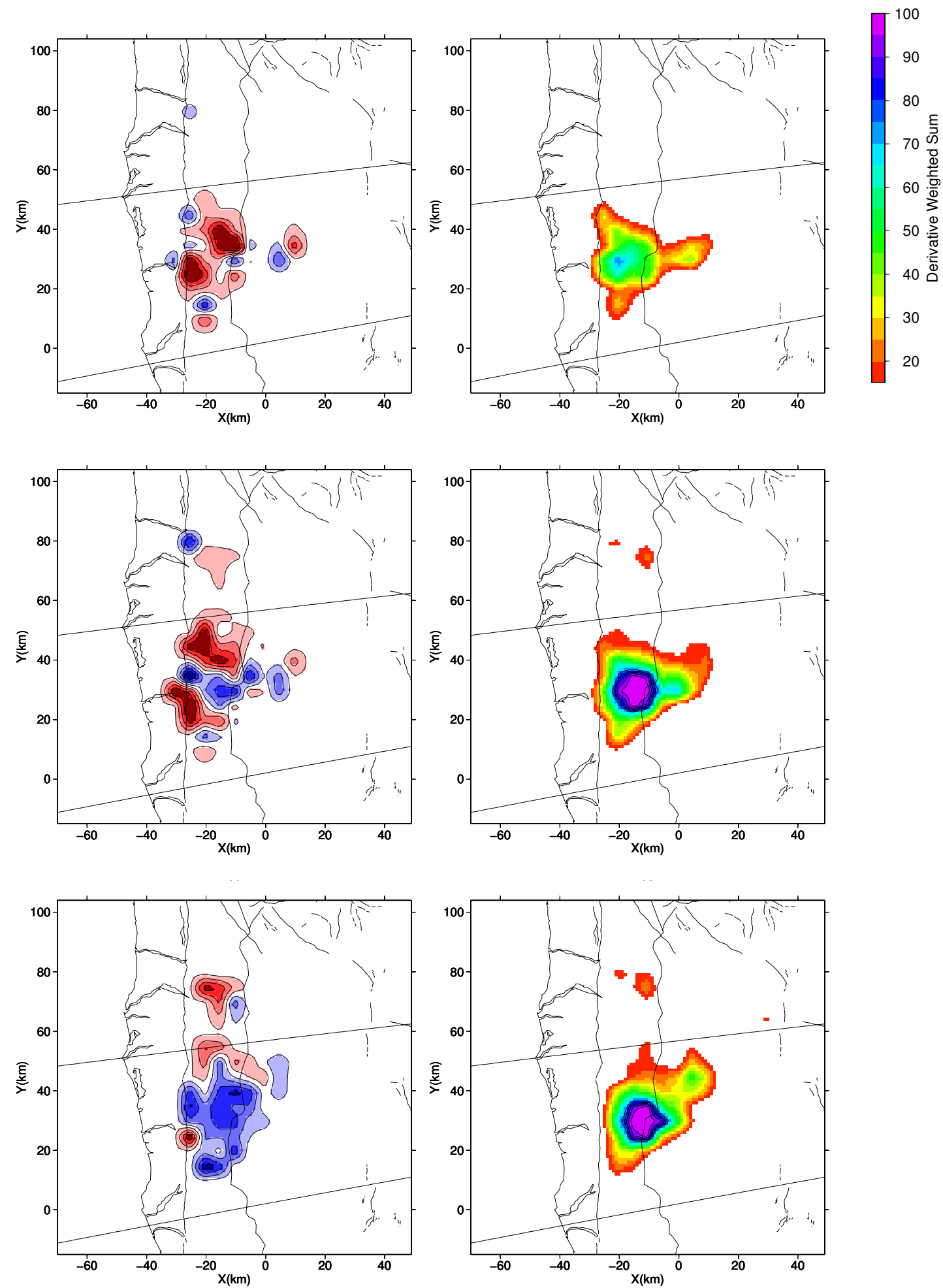

Figure 6.11. (b) $\mathrm{V}_{\mathrm{P}}$-velocity changes using the model of Eberhart-Phillips et al. (2010) as a starting model (left) and resolution (right) for depth sections at 3 (top), 5 (centre) and $7 \mathrm{~km}$ (bottom) depth. 
(\%) әбиечว К!оㅇㅅ
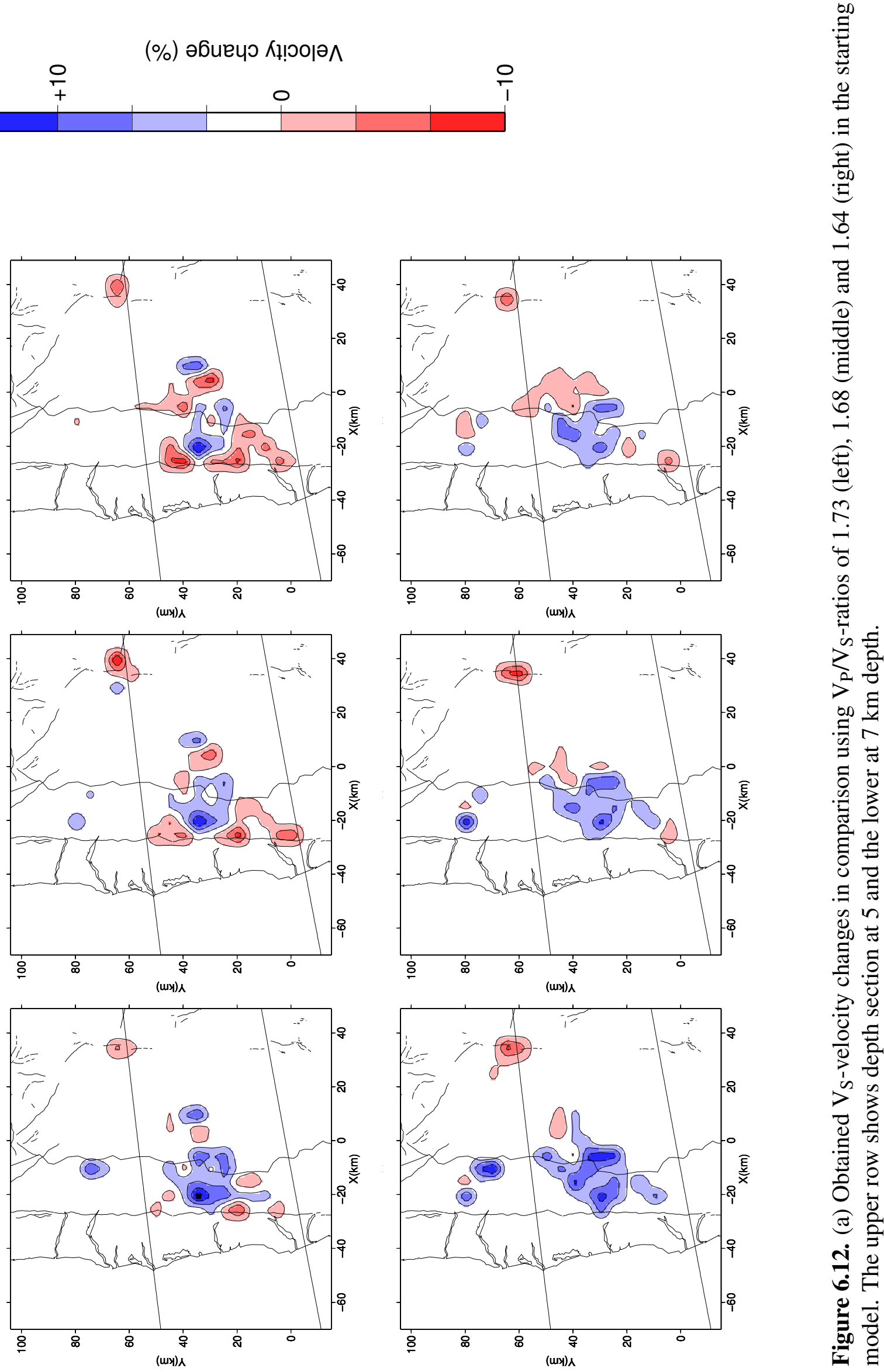

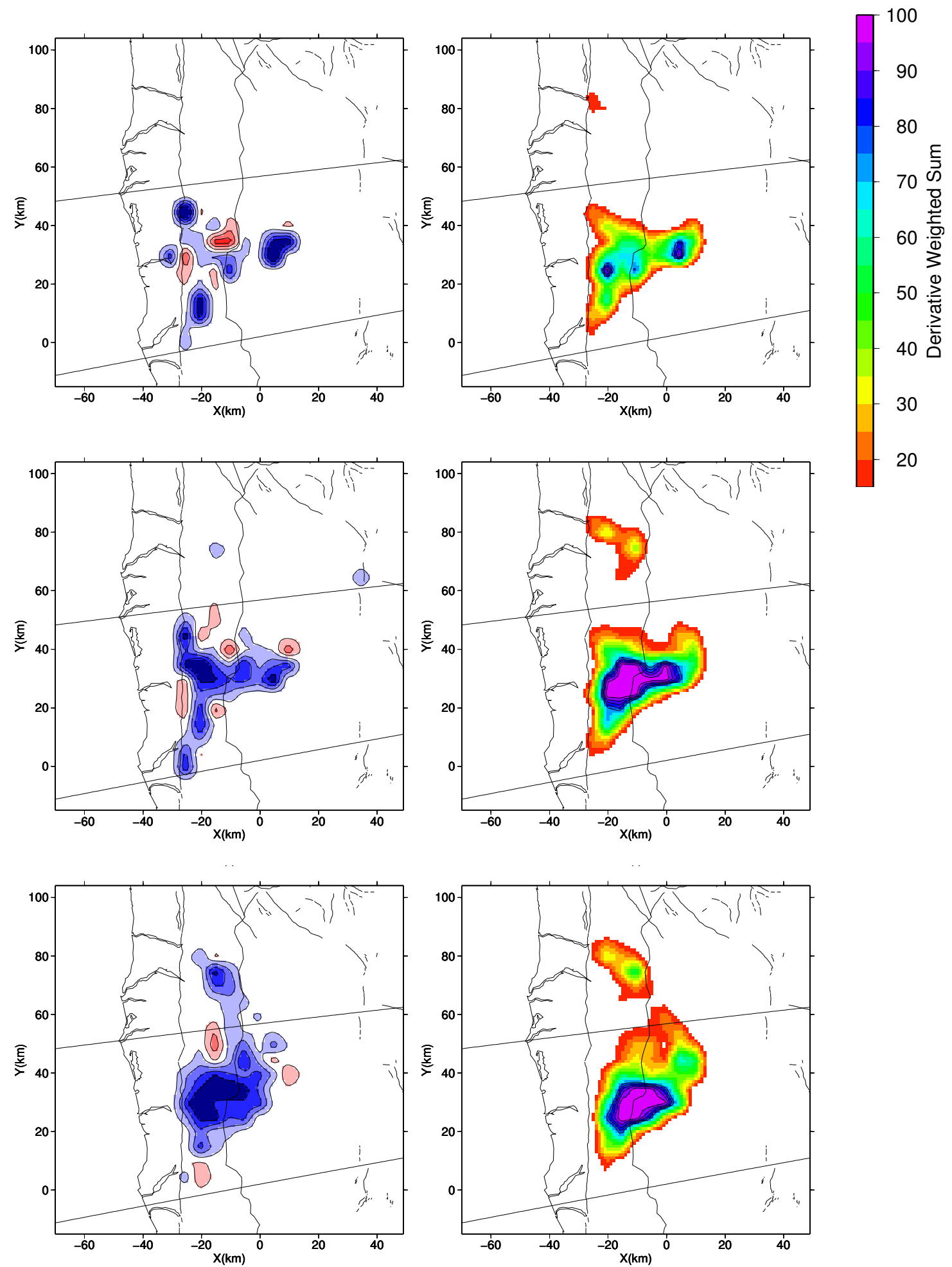

Figure 6.12. (b) $V_{S}$-velocity changes using the model of Eberhart-Phillips et al. (2010) as a starting model (left) and resolution (right) for depths sections at 3 (top), 5 (centre) and $7 \mathrm{~km}$ (bottom) depth. 
velocity inversions with different grid sizes and orientations should be performed (e.g. Koulakov et al. 2009) to test the resolvability and the stability of the obtained velocity structures and the extent of horizontal smearing. Also stepwise refining of the grid spacing in regions of high resolution is commonly applied (e.g. Eberhart-Phillips 1986). The same inversion with finer grid spacing of $2 \mathrm{~km}$ horizontally and $1 \mathrm{~km}$ vertically was tested. This resulted in a small region in the centre of the SAMBA array which could be resolved. Since the shape and amplitude of the blocks in the checkerboard model are poorly resolved, we omit further resolution tests. Our velocity model serves rather as an indicator of the inaccuracies of the 1-D velocity model used for the hypocentre location. The retrieved velocity structure suggests higher $\mathrm{V}_{\mathrm{S}}$-velocities at $7 \mathrm{~km}$ depth than used in the starting velocity model. However, the shape of the velocity anomaly is unreliable as shown in the checkerboard test. Too few rays propagate parallel to the Alpine Fault to resolve the shape of the anomalies in that direction. The DWS and the resolved structure is confined to a triangular area controlled by the distribution of the SAMBA stations. A repetition of the velocity inversion when more data and a denser station distribution are available would be preferable.

\subsubsection{Expected errors from velocity variations}

Although we can only resolve a small area in the centre of the SAMBA array with the current dataset, we can use the obtained velocity to give better estimates of the uncertainty caused by the velocity structure. If the velocities are elevated by $10 \%$ at $5-7 \mathrm{~km}$ depth (as indicated from the velocity structure inversion), this will shift the hypocentres downwards by $\sim 100 \mathrm{~m}$ per kilometre propagated through the higher-velocity medium. This effect is not as large as the effect expected due to anisotropy. Petrologic studies of the Haast schist have shown that the difference between fast and slow P-wave velocities due to anisotropy can amount to $0.77 \mathrm{~km} / \mathrm{s}$ (Godfrey et al. 2000), corresponding to $13 \%$ P-wave anisotropy. A similar result (17\%) was obtained by Okaya et al. (1995). The P-wave velocity of $5.67 \mathrm{~km} / \mathrm{s}$ applied to the uppermost layer in our study matches the velocities of the slow P-wave (propagating perpendicular to the foliation) obtained by Godfrey et al. (2000). Consequently, in the most unfavourable case of $\mathrm{P}$-waves propagating subvertically (parallel to the foliation) over a $8 \mathrm{~km}$ path through the anisotropic schist, we would expect a hypocentre location error of $1 \mathrm{~km}$, solely due to the anisotropic rock. However, this error lies within the error volume determined from probabilistic non-linear location which usually comprises errors in the order of $2 \mathrm{~km}$ in each direction (cf. Section 4.2.1). 

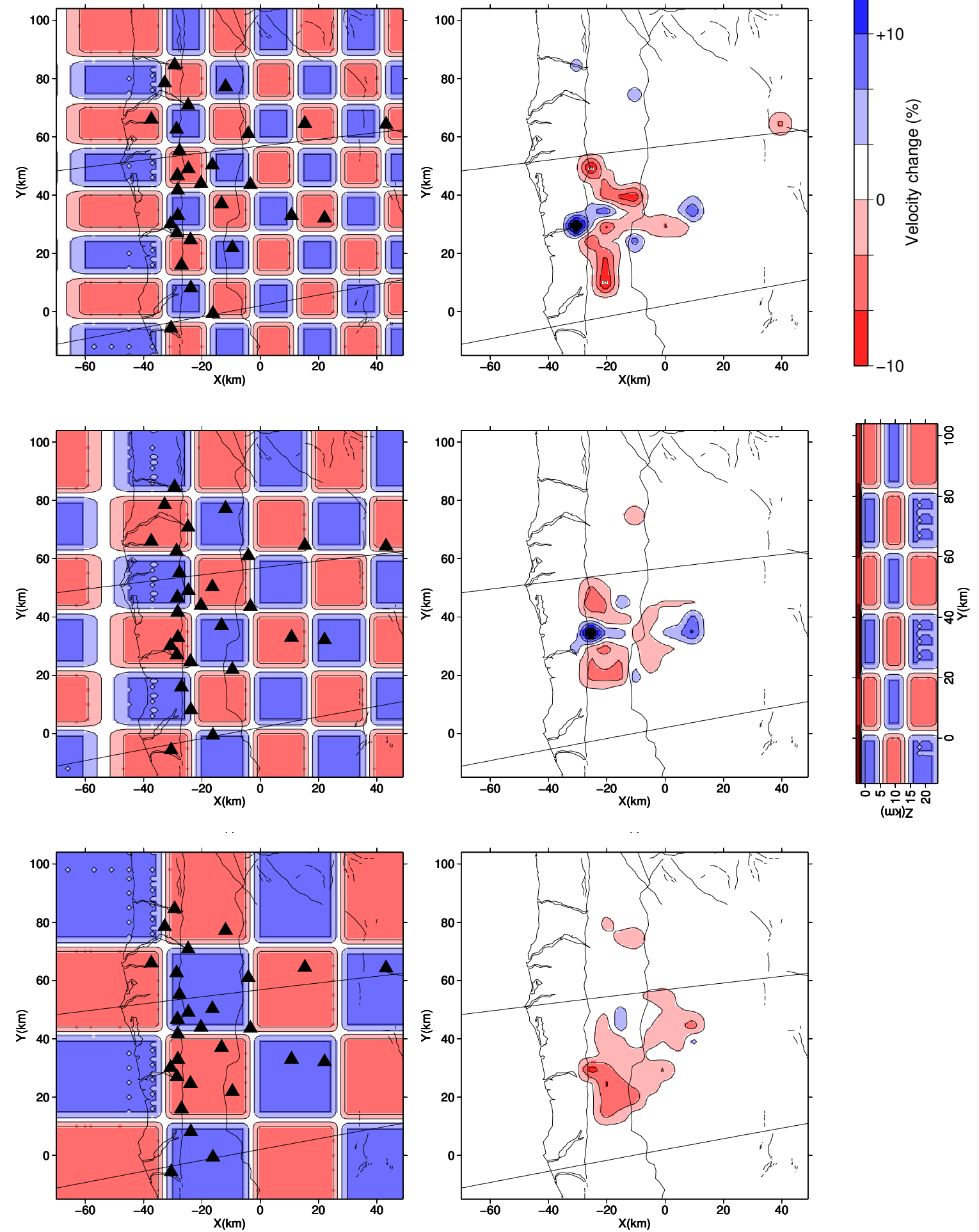

Figure 6.13. Input and retrieved synthetic velocity models obtained for different block sizes and depths 


\subsection{Moment and strain release by microearthquakes}

Estimates of the strain-rate represented by microearthquakes in comparison with the strainrates determined geodetically can be used to determine what fraction of the plate motion has been relieved and what has been accumulating (Hyndman and Weichert 1983; Jackson and McKenzie 1988). Geodetic observations over the last 15 years have shown that shear-strain rates are highest within $30 \mathrm{~km}$ of the Alpine Fault (Beavan and Haines 2001; Beavan et al. 2007, Fig. 6.14 and 6.15). The maximum horizontal contraction direction shows a systematic clockwise rotation with distance from the Alpine Fault. This direction differs by $10^{\circ}$ from the maximum horizontal stress direction determined from microearthquakes in this study. The magnitude distribution of earthquakes versus the strain-

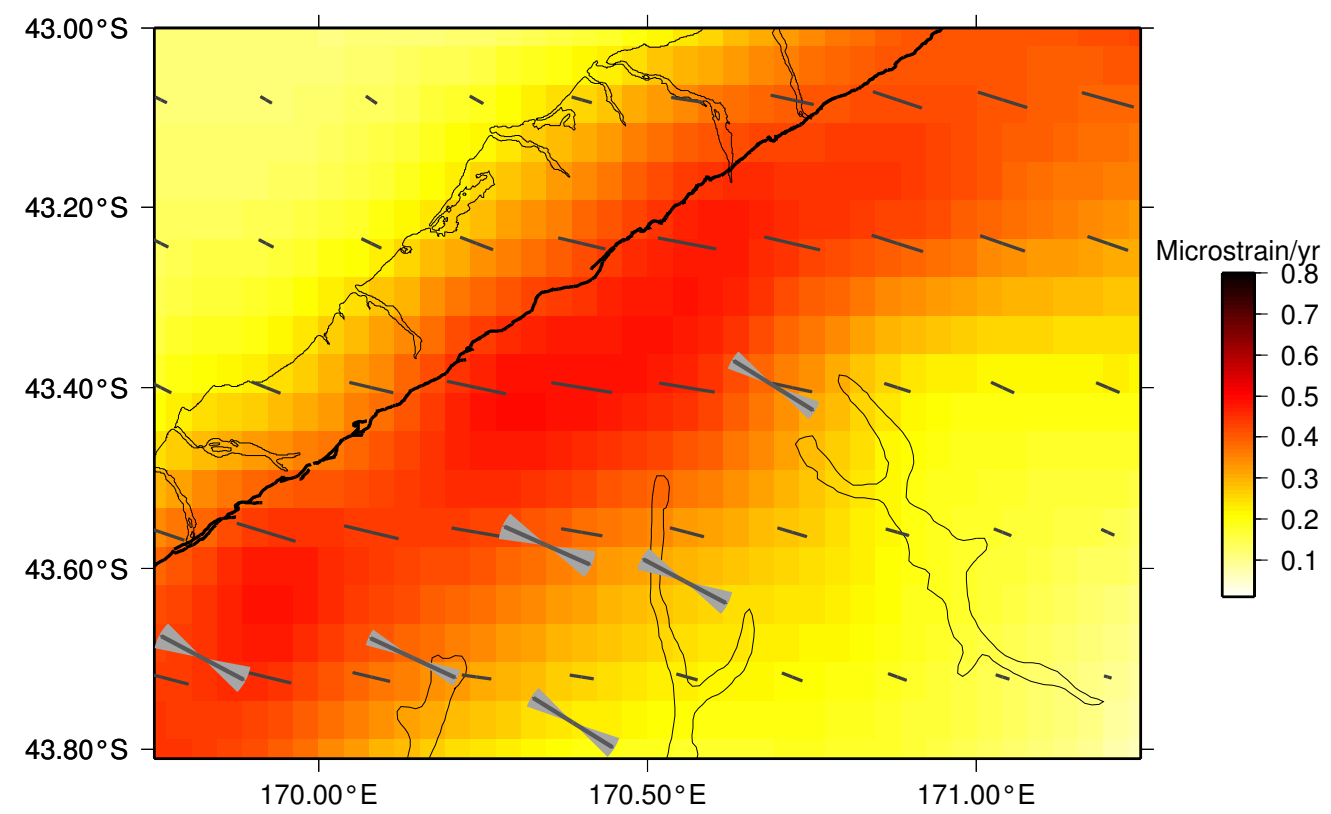

Figure 6.14. Shear-strain rates obtained from 1996-2010 GPS data with the grey bars giving the orientation of maximum contraction while the bar length and the background colour indicate the absolute value. The five bars with error estimates are maximum horizontal compressive stress directions obtained from focal mechanism inversion as shown in Fig. 4.8. The length of the latter bar has no meaning as the magnitude of the stress cannot determined from focal mechanism inversion. All other data shown are updated results of Beavan and Haines (2001) and Beavan et al. (2007)

rate obtained geodetically are shown in Fig. 6.16 for two transects (Fig. 6.17). Estimates of the long-term average slip rates of earthquakes are calculated from the cumulative moment of the earthquakes. Since the distribution of microearthquakes recorded in this study resembles 

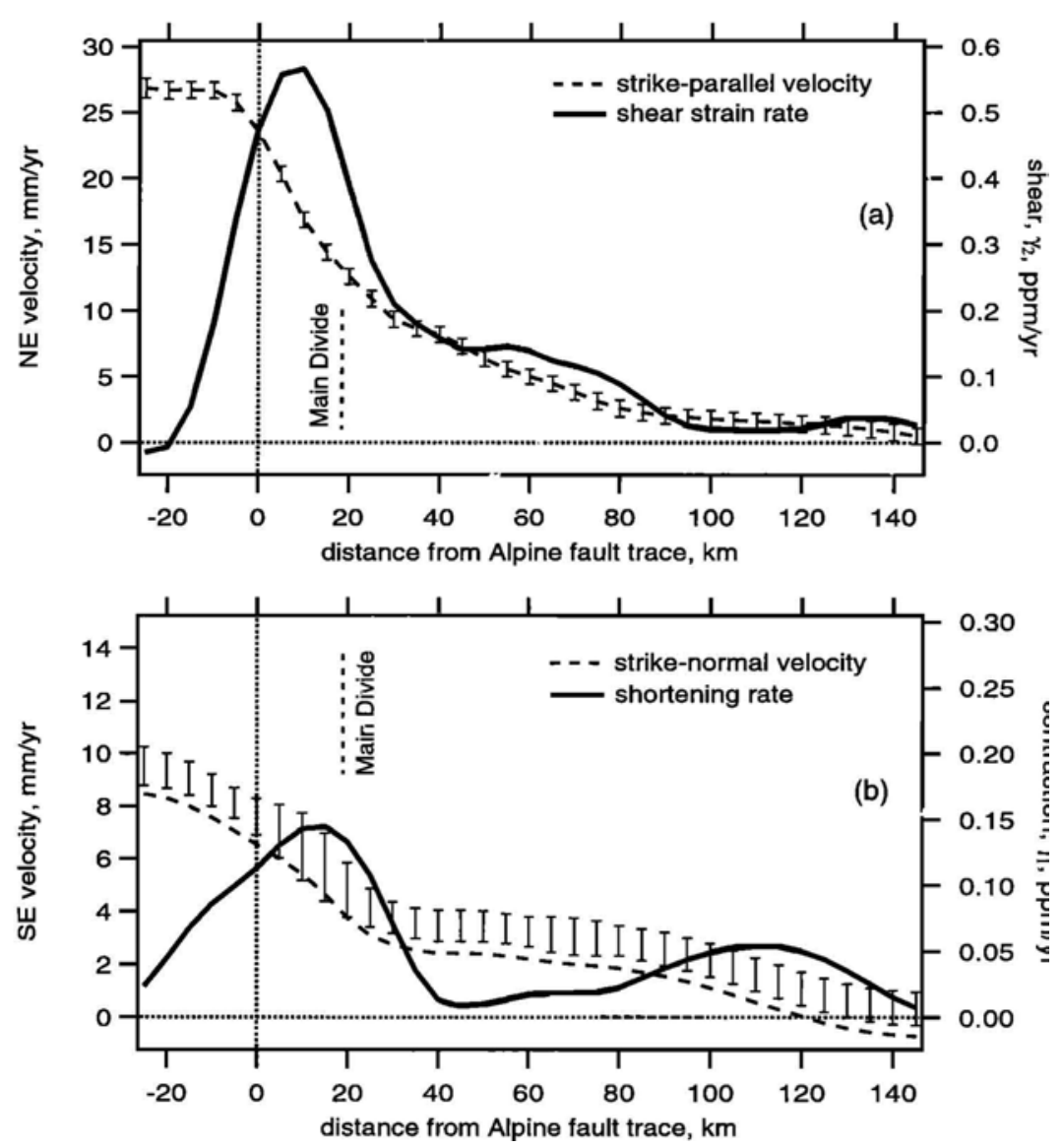

Figure 6.15. Velocity and strain rate versus distance from the Alpine Fault as published by Beavan and Haines (2001) (their Fig. 7). The profiles are averages of measurements in the central Southern Alps region where along-strike variations are minimal. The top panel (a) shows shear-strain rates and velocities parallel to the Alpine Fault whereas (b) shows contractional strain-rate and velocities normal to the Alpine Fault.

that of the at least 30 years recorded by GeoNet (Fig. 4.1 b), we assume that the 1.5 years of data available are representative of the decadal seismicity. Secondly, we assume that the local magnitude $\mathrm{M}_{\mathrm{L}}$ is equal to the moment magnitude $\mathrm{M}_{\mathrm{W}}$, although Abercrombie et al. (2001) and Leitner et al. (2001) obtained $\mathrm{M}_{\mathrm{W}}=\mathrm{M}_{\mathrm{L}}-0.25$ and $\mathrm{M}_{\mathrm{W}}=\mathrm{M}_{\mathrm{L}}-0.7$, respectively, which indicates that our assumption is likely to overestimate the moment magnitude by up to $2.57 \times 10^{15} \mathrm{~N} \mathrm{~m}$. This conversion is required for the calculation of the seismic moment $\mathrm{M}_{0}$, which Hanks and Kanamori (1979) determined to be related to $\mathrm{M}_{\mathrm{W}}$ by

$$
\log M_{0}=1.5 M_{\mathrm{W}}+9.0
$$

with $\mathrm{M}_{0}$ in [N m]. This relation was obtained for intermediate to large earthquakes but is consistent with microearthquakes scales in California (Bakun 1984). An alternative scale derived from microearthquakes in southern Germany (Hainzl et al. 2002) results in larger 
$\mathrm{M}_{0}$ for $\mathrm{M}_{\mathrm{L}}>1.5$.
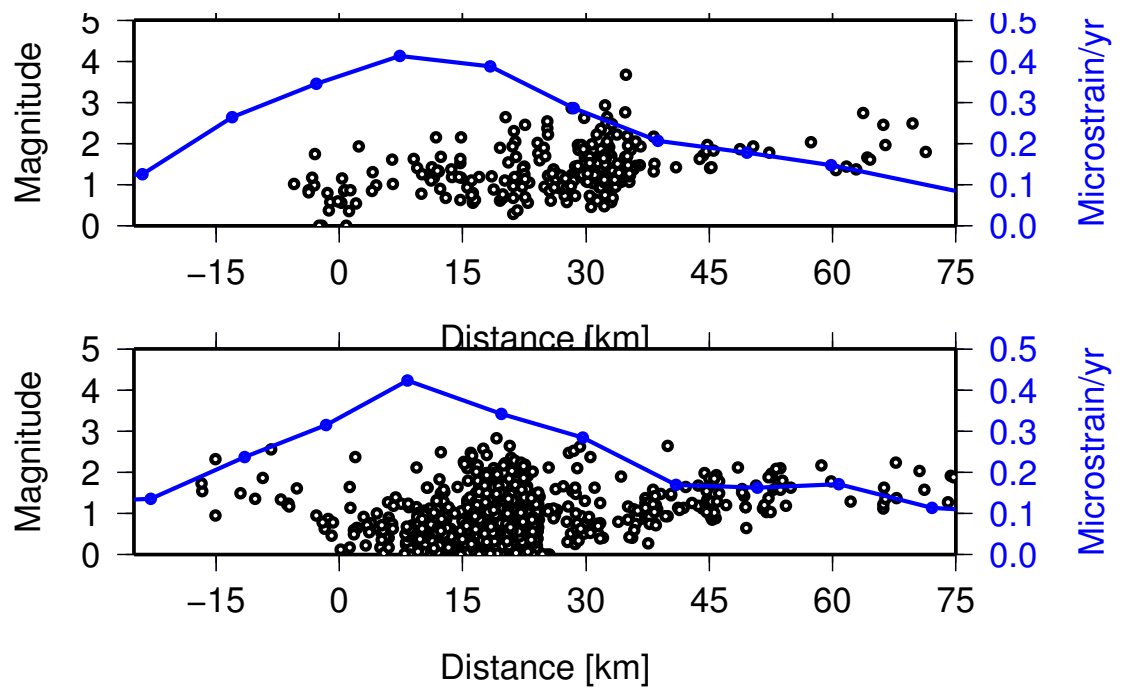

Figure 6.16. Earthquake magnitude (black) and computed, present-day shear-strain rate (blue) for transects shown in Fig. 6.17 along the Whataroa river in (upper panel, profile 2) and just south of Franz Josef in (lower panel, profile 5). The shear-strain rates at the grid nodes shown in Fig. 6.15 were projected onto the direction of the profiles shown in Fig. 6.17 within distances of $\pm 10 \mathrm{~km}$.

The average strain rate $\dot{\varepsilon}_{\mathrm{ij}}$ in a volume $\mathrm{V}$ can be calculated by summing the moment tensor components $\mathrm{M}_{\mathrm{ij}}$ of all earthquakes:

$$
\dot{\varepsilon}_{\mathrm{ij}}=\frac{1}{2 \mu \tau V} \sum_{\mathrm{n}=1}^{\mathrm{N}} M_{\mathrm{ij}}^{\mathrm{n}}
$$

(cf. Jackson and McKenzie 1988, and references therein), where $\mu$ is the shear modulus and $\tau$ the time. The volume is determined as the area marked in Fig. $6.17(102 \mathrm{~km} \times 38 \mathrm{~km})$ multiplied by the average seismogenic depth $(12.2 \mathrm{~km})$ in this area. The time that our data spans is $1.48 \mathrm{yr}$. The components of the moment tensor are given by the scalar seismic moment and the components of the unit normal vector to the fault plane and the unit slip vector in the fault plane (Stein and Wysession 2003). Since focal mechanism solutions could not be obtained for all events but magnitudes could, we first calculate the cumulative moment for the area $\mathrm{M}_{0}=5.359 \times 10^{15} \mathrm{~N} \mathrm{~m}$, assuming that the slip vector of all events lies in the direction of the maximum resolved shear-stress in the prevailing stress field. This is equivalent to a single $\mathrm{M}_{\mathrm{L}} 4.48$ earthquake with typical slip values of $4 \mathrm{~cm}$ on a rupture plane of $1 \mathrm{~km}^{2}$ (Sibson 1989). The total value depends only slightly on the largest annual events $\left(\mathrm{M}_{\mathrm{L}} 4.19\right.$ without the two largest events). In relation to the total area, this accounts for only a small fraction of the plate motion. Using equation 6.2, the total strain release is found to 


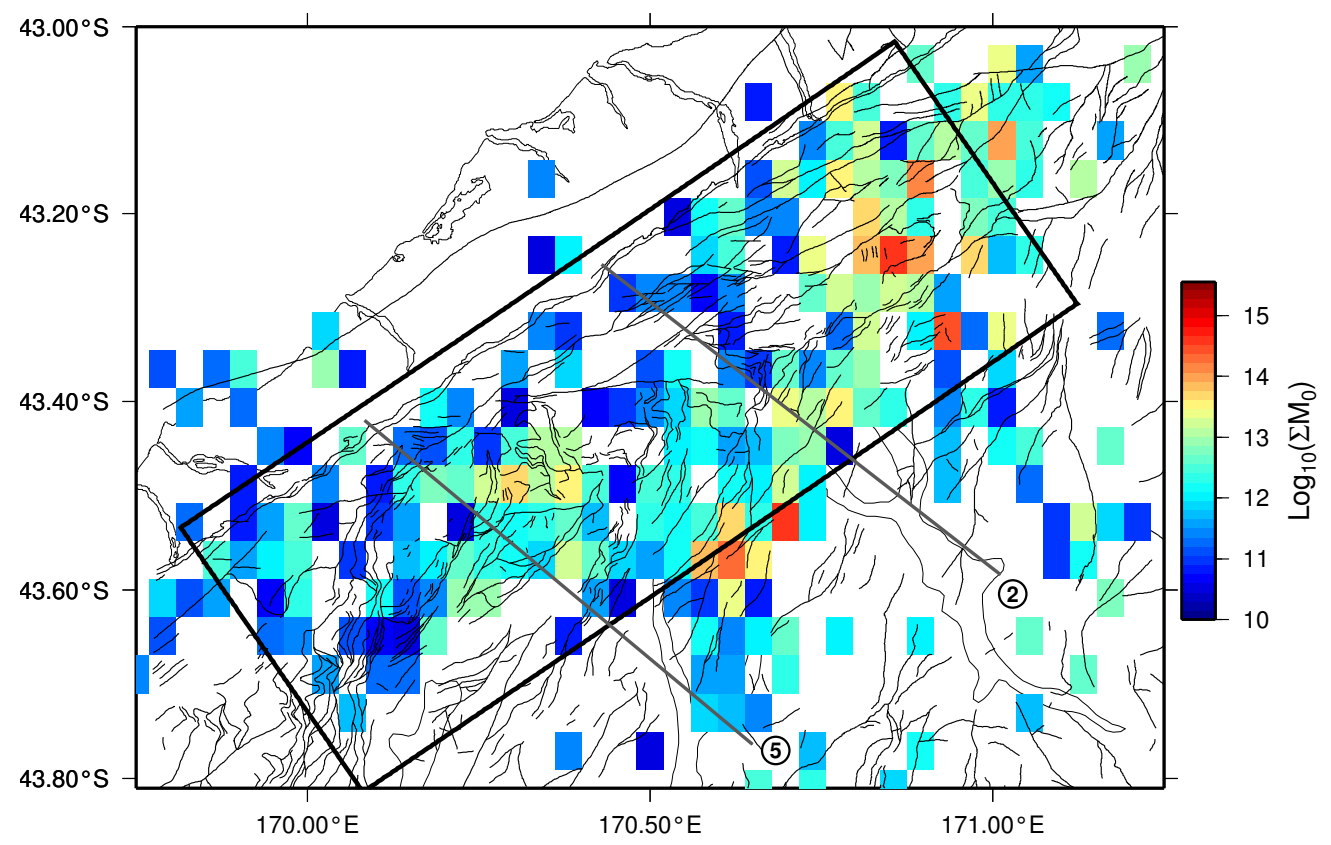

Figure 6.17. Cumulative moment release for square cells of $0.04^{\circ}$ length in the study area. The two profiles shown by grey lines correspond to profiles 2 and 5 in Fig. 4.2.

be $\varepsilon=1.9 \times 10^{-9}$ and the strain release rate $\dot{\varepsilon}=1.3 \times 10^{-9}=0.001$ microstrain/yr. In comparison to the strain rate derived geodetically of $\sim 0.4$ microstrain/yr (Beavan and Haines 2001; Beavan et al. 2007, Fig. 6.14), an insignificant amount of strain is released microseismically. Similar results have been obtained for the energy released by microearthquakes on creeping faults (Gans et al. 2003). The total strain released by microearthquakes is estimated to be $<0.01 \%$ of the total interseismic slip on the Hayward Fault, which repeatedly fails in $\mathrm{M}_{\mathrm{L}} \geq 6$ events (e.g. Malservisi et al. 2005). This suggests that the strain resulting from the relative plate movement between the Australian and Pacific plate in the upper crust is almost entirely accumulated in the interseismic cycle and results in large earthquakes on the Alpine Fault and secondary structures as shown by Cox et al. (2012) in the central Southern Alps region. Cox et al. (2012) estimated the magnitudes from the length of the fault traces adjacent to the Alpine Fault to be $\mathrm{M} \leq 7.5$.

\subsection{Fault-guided waves}

Fault-guided waves are trapped waves that propagate in the damage zone of a fault, which is characterised by reduced velocities relative to the wall rocks and consequently forms a natural waveguide ( $\mathrm{Li}$ et al. 1997). A guided wave develops due to constructive interference between multiple P-and $\mathrm{S}_{\mathrm{V}}$ (Rayleigh-type) or $\mathrm{S}_{\mathrm{H}}$-reflections (Love-type) at the boundaries 
of the fault zone ( $\mathrm{Li}$ et al. 1990). The higher the velocity contrast the better the trapping efficiency of the waveguide (e.g. Li et al. 1998). Fault-guided waves can be observed on stations that are located in the fault damage zone or in close proximity (less than 5 times the width of the damage zone, based on modelling; Li and Vidale 1996). They are best observed on dense linear arrays crossing the fault or perpendicular to the fault. In this case, those earthquakes that occur within or in close proximity to the fault zone and exhibit fault-guided waves can be discriminated from off-fault events. As the fault-guided waves travel slower than the S-wave, the moveout with distance or depth characterises the velocity reduction in the damage zone: the broader and slower the waveguide, the longer the duration and the lower the frequencies ( $\mathrm{Li}$ and Vidale 1996). Characteristic of fault-guided waves are the low-frequency content $(3-6 \mathrm{~Hz})$, the large amplitude (that exceeds the S-wave) and their dispersive nature (e.g. Li et al. 1997).

Fault-guided waves provide a means of mapping the fault at depth (Li et al. 1998, e.g. for the Nojima fault by), determining the fault plane of blind faults, and testing if fault planes are continuous ( $\mathrm{Li}$ and Vidale 1996). The width of the fault damage zone, with typical values ranging between a few tens to hundreds of metres (e.g. Li et al. 1994), and the velocity reduction (generally 20-30\%) can be obtained by comparison of observations with synthetic data.

Due to the dispersive nature and attenuation of fault-guided waves, not all earthquakes within the fault can be used for analysis. Fault-guided waves are best recorded at distances of $10-25 \mathrm{~km}$ if they are generated by earthquakes of small magnitude $\left(\mathrm{M}_{\mathrm{L}}<3.5\right.$; Y.-G. Li pers. comm., 2011). At this range, the incidence angles are steep, the phase arrivals are not too emergent and the earthquake sources still resemble a point source.

We have examined waveforms recorded by the SAMBA and DFDP10 arrays. Only three stations (POCR, DCR, GCK) qualify as able for recording fault-guided waves due to their proximity to the fault. However, these stations have intermediate to poor recording qualities and often exhibit cultural noise. The latter two DFDP10 stations were only recording during January-April 2010, which restricted the search for fault-guided waves markedly. Station COSA appears to be located in the vicinity of the Alpine Fault due to cataclasite outcrops next to the road a few hundred metres north of the station. However, this cataclasite is part of the abandoned, out-of-sequence Waikukupa thrust east of the active Hare Mare thrust (Norris and Cooper 1997).

Since the position of the Alpine Fault at depth is not known and the seismicity is dis- 
tributed, we have examined many events. A few candidate events were found but no obvious fault-guided waves were identified. In a second approach, we examined events with long, dispersive coda waves recorded by station WHYM to test whether a smaller fault in the vicinity of that station could have produced fault-guided waves. Since there is only this one station, we examined whether a moveout for events from different depths/distances can be observed. However, it is not clear which fault (within $1 \mathrm{~km}$ distance) could have generated these waves. We perform a search for events with long wave trains following the $S$-waves that exhibit either long periods, large amplitudes or both. A total of 328 earthquakes within a $0.1^{\circ} \times 0.1^{\circ}$ square in the vicinity of station WHYM were checked for fault-guided waves. The distribution of the earthquakes is scattered throughout the area and does not align with any mapped faults (Fig. 6.18). As all of the events lie at distances greater than $1.5 \mathrm{~km}$ from the station, only a dipping fault could be responsible for the generation of fault guided waves. Li et al. (1998) showed for earthquakes generated on and around the Nojima fault that long wavetrains are not always associated with fault trapped waves (Fig. $4 \mathrm{~b}$ of Li et al. 1998); this association could only be showed using a multitude of recording stations across the fault with similar low-frequency waves in the S-coda. Particularly shallow earthquakes often exhibit elongated wavetrains due to reverberations in the near-surface layers (e.g. Thouvenot et al. 2009). We suggest that the majority of the events with long, dispersive codas at WHYM originate due to the shallow depths of the events (Fig. 6.18). The frequencies of the S-coda decrease with time for most of the events, suggesting that the phases are attenuated. Fault-guided waves are difficult to identify without better knowledge of which events occur within and outside the fault plane and which stations are located within the fault's surface trace. This can be investigated if more stations are available within or across the fault zone, but not with the current configuration of the SAMBA stations. Fault-zone guided waves have been identified on records of a short-period borehole sensor located in the fault zone at the DFDP-1 drillhole. This station was installed in February 2011 by J.D. Eccles, University of Auckland. Those data will be combined with SAMBA recordings for further research on fault-guided waves that exceeds the scope of this thesis. 


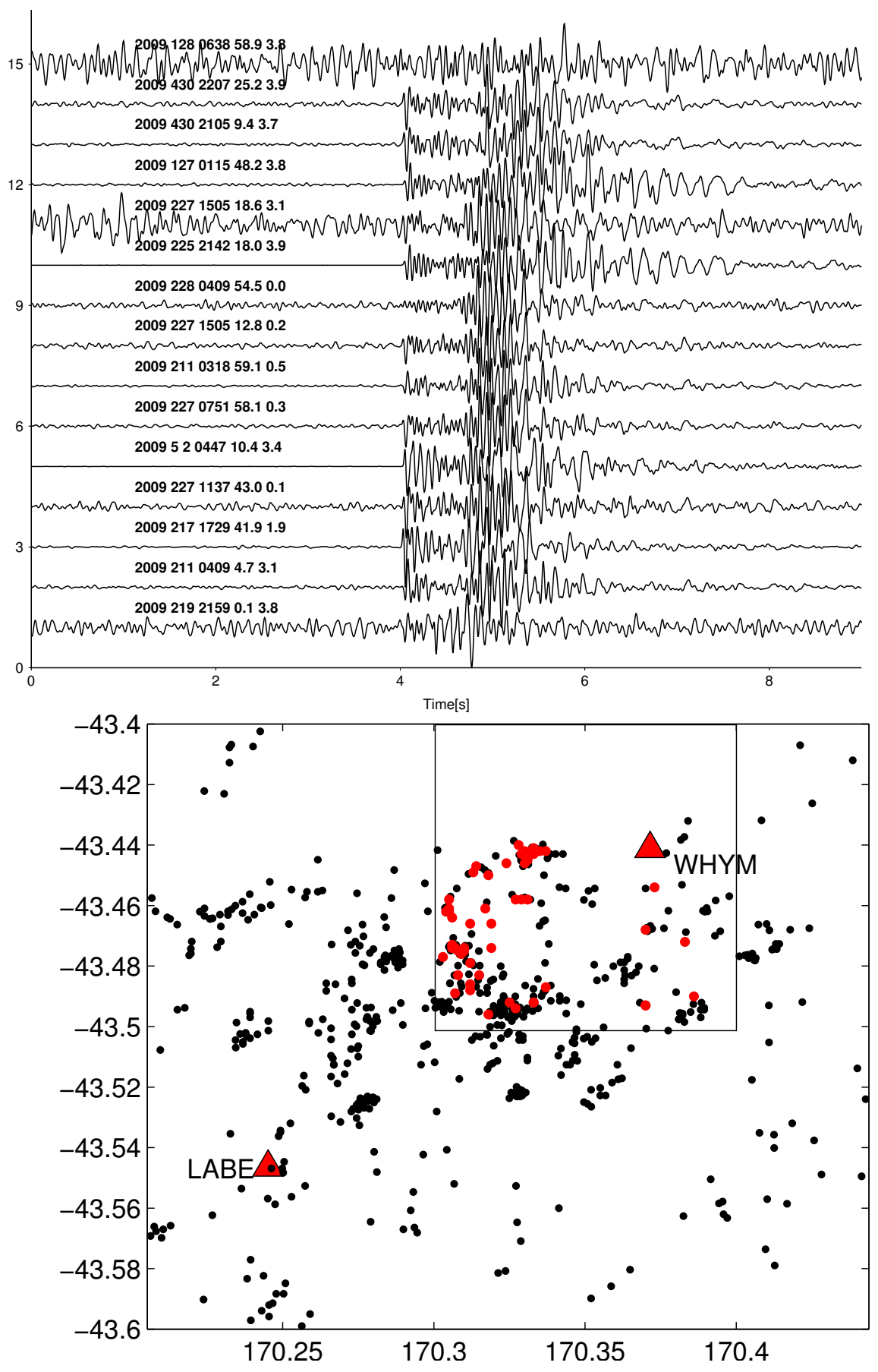

Figure 6.18. Shallow earthquakes $(\leq 4 \mathrm{~km})$ recorded on the vertical component of station WHYM between November 2008 and March 2009 (top) and all shallow events (red) investigated in the marked area plotted in map view (bottom). 


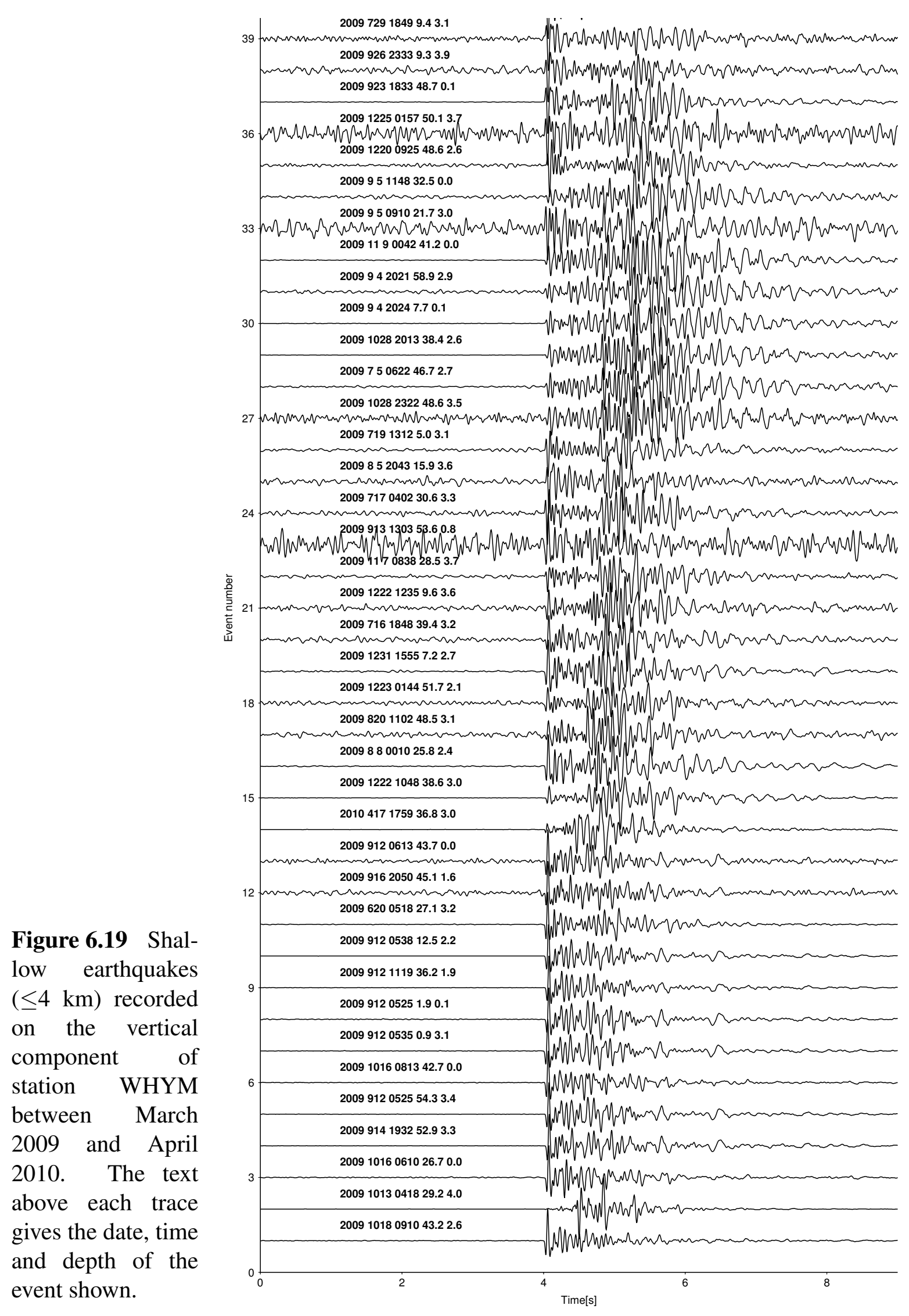




\section{Summary and conclusions}

The SAMBA network in combination with the DFDP10 and GeoNet networks formed the densest station array with the longest station deployment ever installed in the area of highest topography of the Southern Alps. The main focus of this study has been the microseismicity, which is revealed in much more detail than in any previous study, and the remotely triggered seismicity, which has not been observed before or reported on in New Zealand. Our results apply particularly to processes occurring in the upper crust but phenomena observed in the lower crust and upper mantle are briefly reported on, too.

\subsection{Main contributions}

Our study enables a number of key conclusions to be drawn regarding the seismicity distribution and seismogenesis as outlined below. These have been or are planned to be the subject of publications.

- The thickness of the seismogenic zone varies with distance from the Alpine Fault $(10 \pm 2(1 \sigma) \mathrm{km}$ beneath the surface trace, $8 \pm 2 \mathrm{~km}$ within $20 \mathrm{~km}$ distance and $15 \pm 2 \mathrm{~km}$ at larger distances from the fault), and follows the $390 \Omega \mathrm{m}$ resistivity contour (Fig. 4.12). Earthquake hypocentres are concentrated in areas of high-resistivity, whereas rocks with resistivities $<100 \Omega \mathrm{m}$ are too hot, too fluid-saturated, or too weak to produce detectable earthquakes. Consequently, the combined observations allow us to determine width and extent of zones prone to failure in earthquakes and directly reflect rheological processes at depth.

- Remotely triggered seismicity is the result of dynamic stresses of $\sim 0.9 \mathrm{MPa}$ imposed by the surface waves of large earthquakes that cause fluid diffusion from a shallow (overpressured) fluid reservoir into the surrounding fractured rock. This provides a mechanism for ubiquitous observations of elevated seismicity following large earthquakes that persists for as long as weeks after the passage of the surface waves. 
- The Alpine Fault is the second major transform plate boundary found to generate tectonic tremor of short durations below the seismogenic zone at depths of $15-50 \mathrm{~km}$, suggesting that tremor is the manifestation of slow, deep slip in various tectonic settings.

These and other key results are elaborated on and put into a broader context below.

\subsection{Main results}

\subsubsection{Earthquake distribution}

The earthquake density, depth and magnitude distribution is highly variable at distances up to $40 \mathrm{~km}$ southeast of the Alpine Fault. The zone that exhibits microseismicity adjacent to the Alpine Fault is narrow $(15-20 \mathrm{~km})$ at the southern end of the study area, wide $(35-45 \mathrm{~km})$ in the centre and narrow $(20-25 \mathrm{~km})$ in the north. This overall width reflects the distance between the Alpine Fault and the Main Divide Fault Zone (Fig. 1.4). The seismicity in plan view is distributed around a major low-seismicity zone extending between the Whataroa and Wanganui rivers at $15-30 \mathrm{~km}$ distance from the fault (Fig. 4.1). The low-seismicity region is not obviously related to lithology, topography and bedding in this area but correlates with high resistivities and low attenuation, suggesting a strong and unfractured block that is enclosed by a damage zone of high earthquake activity (high attenuation) (Fig. 4.13). A spatial pattern of quiescence and persistent earthquake activity is distinct in the long-term and short-term seismicity. In general, the seismicity distribution does not correspond to mapped faults at the surface (Fig. 4.1). The seismicity is confined to shallow depths (90\% above $12.2 \mathrm{~km}$ and centred at $5.3 \mathrm{~km}$ ), and correlates well with high resistivities and high attenuation in the area.

Little low-magnitude $\left(-0.14 \leq \mathrm{M}_{\mathrm{L}} \leq 2.8\right.$, with the lower value being the detection threshold) seismicity occurs within $10 \mathrm{~km}$ of the Alpine Fault, most likely reflecting different numbers and characteristics of fractures in the highly-compacted and metamorphosed schist relative to the greywacke further southeast. Four large seismicity clusters have been identified which may represent active backthrusts that act as fluid conduits (Fig. 4.1 (c) and 4.4). The energy released by earthquakes in the northeastern cluster is $\sim 100$ times larger than in the southwestern cluster (Fig. 6.17) due to the generally larger events (87 events of $1.8 \leq \mathrm{M}_{\mathrm{L}} \leq 4.3$ versus 28 events of $1.8 \leq \mathrm{M}_{\mathrm{L}} \leq 3.5$ ). Larger earthquakes occur at the edges of the seismicity clusters around the gap and in the vicinity of the $1984 \mathrm{M}_{\mathrm{W}} 6.1$ Godley Valley 
earthquake (compare also $M_{L} \geq 4$ events recorded by GeoNet in the last 35 years; Fig. 4.11).

The velocity structure is poorly-resolved in tomography with the current dataset but in general the modified 1-D velocity model of O' Keefe (2008) is adequate for the location of shallow earthquakes within the SAMBA station network.

Some deep earthquakes just west and southwest of the SAMBA array at depth $\geq 50 \mathrm{~km}$ were recorded. These events occur below the semi-brittle zone at $\sim 30 \mathrm{~km}$ in which the majority of the tremor locates. The brittle faulting at these upper mantle depths may be explained by high strain-rates caused by plate bending in this zone.

\subsubsection{Magnitude distribution}

The magnitudes of earthquakes in the central Southern Alps region reported by GeoNet for source-receiver distances of $\leq 70 \mathrm{~km}$ are underestimated due to the small attenuation coefficient of $\gamma=6.7 \times 10^{-3} \mathrm{~km}^{-1}$ employed. Frequency-dependent attenuation has to be considered in order to obtain normally distributed magnitude residuals. We derive a frequencydependent attenuation coefficient $\gamma=\gamma_{0}$ f with $\gamma_{0}=(1.89 \pm 0.02) \times 10^{-3} \mathrm{~s} / \mathrm{km}$. The magnitude uncertainties obtained span $0.2-0.5$ magnitude units in part due to the uncertainty of the GeoNet magnitudes used for calibration.

\subsubsection{Focal mechanisms and stress field}

Focal mechanism solutions have been obtained for 379 earthquakes $\left(M_{L}>0.44\right)$ and exhibit predominantly strike-slip mechanisms. Typical uncertainties in strike, dip and rake are $\sim 30^{\circ}$. The estimation of the stress field from focal mechanisms indicates a homogeneous stress field prevails throughout the study area, with the maximum horizontal compressive stress direction $\mathrm{S}_{\mathrm{Hmax}}$ oriented at $115 \pm 10^{\circ}$. The Alpine Fault is oriented at a $60^{\circ}$ angle to $\mathrm{S}_{\mathrm{Hmax}}$ and is thus misorientated in the sense of Andersonian theory of faulting (Anderson 1951), suggesting either low coefficients of friction or high fluid pressures are required for the fault to fail. 


\subsubsection{Swarms and triggered seismicity}

Earthquake swarms occur frequently in the central Southern Alps region and are well recorded by the SAMBA array. All 14 swarms described here comprise at least 10 similar, low-magnitude events $\left(\mathrm{M}_{\mathrm{L}} \leq 2.8\right)$. They have either short durations ( $\leq 12$ days) or consist of several bursts of activity ( $\geq 30$ days). The swarms occur on near-vertical faults that are favourably oriented in the stress field according to Anderson's theory of faulting. A characteristic inter-event time pattern was identified with accelerating inter-event times in the beginning of the swarm followed by deceleration, characteristic of a decay process. Remotely triggered earthquake swarms occur if the peak ground velocity exceeds a threshold of 0.7 $\mathrm{cm} / \mathrm{s}$ at station FRAN, corresponding to peak dynamic stresses of $\sim 0.9 \mathrm{MPa}$. The triggered seismicity is followed by a quiescence period of approximately the same length as the time period of the elevated seismicity. This suggests that the faults experience clock-advance. The locations and delays of the triggered swarms are consistent with a common fluid source from which fluids diffuse in response to the dynamic stresses imposed by the surface waves. In general, the seismicity in the centre of the SAMBA array has a lot of similarities with that in a geothermal area, due to the thermal structure and fluid contents, but the swarms appear to be of one type (as seen from their inter-event time pattern) and are not as complicated as in geothermal areas.

\subsubsection{Tremor}

Tremor observed in the vicinity of the Alpine Fault below the seismogenic zone suggests deep slip on the downdip extension of the Alpine Fault and in the region where the bending of the Pacific and Australian Plates is largest. Similarities with tremor detected on the San Andreas Fault near Cholame in terms of duration, depth, spatial extent and evidence for high fluid-pressure nearby may indicate seismic property variations in the lower crust and upper mantle along the strike of the Alpine Fault.

\subsection{Implications}

Our results demonstrate the value of dense, intermediate-term station networks that enable microseismicity patterns to be studied in detail. Long-term measurements with sparse station coverage can only reveal the main features of the seismicity (e.g. Robinson 1978), but good depth resolution of those networks is limited to deep earthquakes (with depths on 
the order of the station spacing). The distribution of earthquakes in the central Southern Alps region shows little correlation with the faults exposed at the surface, suggesting that these mapped faults represent older, exhumed structures resulting from previous deformation. Microseismicity interpreted in conjunction with resistivity, attenuation and velocity models is a good indicator of rheological processes at depth. It has been shown for many locations worldwide (Table M.1, modified from Table 1 and 2 of Gürer and Bayrak 2007), that earthquakes occur in resistive structures or at the boundaries of resistive to conductive zones. High conductivity is associated with high saline fluid content (Wannamaker et al. 2002; Bedrosian et al. 2004; Wannamaker et al. 2009) and conductive regions have been inferred as fluid sources for earthquake and tremor zones (Ichiki et al. 1999; Goto et al. 2005; Gürer and Bayrak 2007; Becken et al. 2011). The maximum depth of the seismogenic layer often correlates with the top of the conductive lower crust (Gürer and Bayrak 2007). The depth of the brittle-ductile transition zone depends on the geothermal gradient, the geometry and mode of faulting, the fluid pressure, the crustal composition, the water content and the strain rate in the quasi-plastic regime (Fig. 7.1; Sibson 1984). Within 30-40 km southeast of the Alpine Fault the seismogenic thickness exhibits short-wavelength "roughness" according to Sibson (1984) with pronounced depth variations of up to $5 \mathrm{~km}$. We briefly discuss below the importance of these factors in the central Southern Alps region.

The temperature distribution plays an important role in the direct vicinity of the Alpine Fault, but temperature models (Shi et al. 1996; Toy et al. 2010) exhibit long-wavelength variations, so they may not fully explain short-scale variations in the thickness of the seismogenic layer between 15 and $30 \mathrm{~km}$ southeast of the Alpine Fault. Sibson (1984) stated that changes in the geothermal gradient by $10^{\circ} / \mathrm{km}$ depth along the strike of the fault (which would cause equivalent depth changes of 4-6 km of the seismogenic thickness, depending on rock type) are not unreasonable for tectonically active regimes. Therefore, we cannot exclude the possibility that the temperature may be more inhomogeneous throughout study area than revealed by the temperature models. The second most significant factor affecting the depth of the brittle-ductile transition zone according to Sibson (1984) is crustal composition. There are no indicators for lithological changes along the strike of the Alpine Fault in the study area. However, in combination with the water content and chemical alteration of the rocks, the composition may vary significantly in depth and laterally. Variations in fluid pressure certainly exist throughout the area based on the resistivity and attenuation structures. High shear-strain rates in the quasi-plastic regime within a $35 \mathrm{~km}$ zone adjacent to the Alpine Fault (Fig. 6.15; Beavan and Haines 2001) have created a broad zone of intense shearing and low permeabilities, as shown by the high-conductivity zones, in which trapped fluids are transported towards the Alpine Fault. 
The fluid distribution appears to be tectonically controlled as suggested by the resistivity structure (Fig. 4.3). High conductivities occur beneath the strong and unfractured block between the Whataroa and Wanganui rivers and the Alpine Fault, which may form a seal. The conductivity decreases at $30 \mathrm{~km}$ distance from the fault, where the seismicity is high (Boese et al. 2012) and steeply-dipping faults have been mapped at the surface (Little et al. 2005). In this region, fluids can escape through backthrusts acting as fluid conduits. Wide-angle reflection data and teleseismic delays of P-wave arrivals provide evidence for high fluid pressure and reduced P-wave velocities extending from 6-35 km depth adjacent to the Alpine Fault on SIGHT transect T2. Tomographic 3-D inversion (Brikké 2010) and the 2-D velocity profile along SIGHT transect T1 (Van Avendonk et al. 2004) suggest that the low-velocity zone persists along the strike of the Alpine Fault but that the uppermost part of this zone shifts away from the fault, consistent with the seismicity.

The area of high swarm activity may be located above a fluid pocket. This area has a high fracture density and the remotely triggered swarms are consistent with diffusion from a fluid source that starts with the passage of the surface waves of the triggering events. This suggests the region is particularly susceptible to small stress changes. The background seismicity in this area consists of an abundance of small events and several earthquake swarms.

The focal mechanism solutions obtained in this study indicate that microearthquakes do not contribute to the uplift of the Southern Alps. The compressional component of the plate motion must either be accommodated aseismically (as it is the case at depth where a 1-2 km thick, high-strain mylonite zone accommodates the plate motion according to Norris and Cooper 2003) or released during the rupture of large earthquakes. Three observations support the latter: large reverse faults east of the Main Divide Fault Zone have been mapped (Cox et al. 2012), an increase of the ratio of reverse to strike-slip mechanisms with event magnitude has been seen (as shown in Fig. 4.7 in this study, see also Cox et al. 2012, their Fig. 8), and the dip-slip rates inferred geodetically and geologically differ by $3-5 \mathrm{~mm} / \mathrm{yr}$ (Beavan et al. 2004; Beavan et al. 2010a; Norris and Cooper 2001, and references therein). Similarly, Hardebeck and Hauksson (2001) interpreted the strike-slip, $1992 \mathrm{M}_{\mathrm{W}}$ 6.2 Big Bear earthquake and the primarily strike-slip faulting regime of the young San Bernardino Mountains, as an indication that the oblique convergence there is partitioned into strike-slip and thrust earthquakes. The orientation of the thrust faults perpendicular to the maximum horizontal compressive stress direction enables them to fail in the strike-slip regime. 


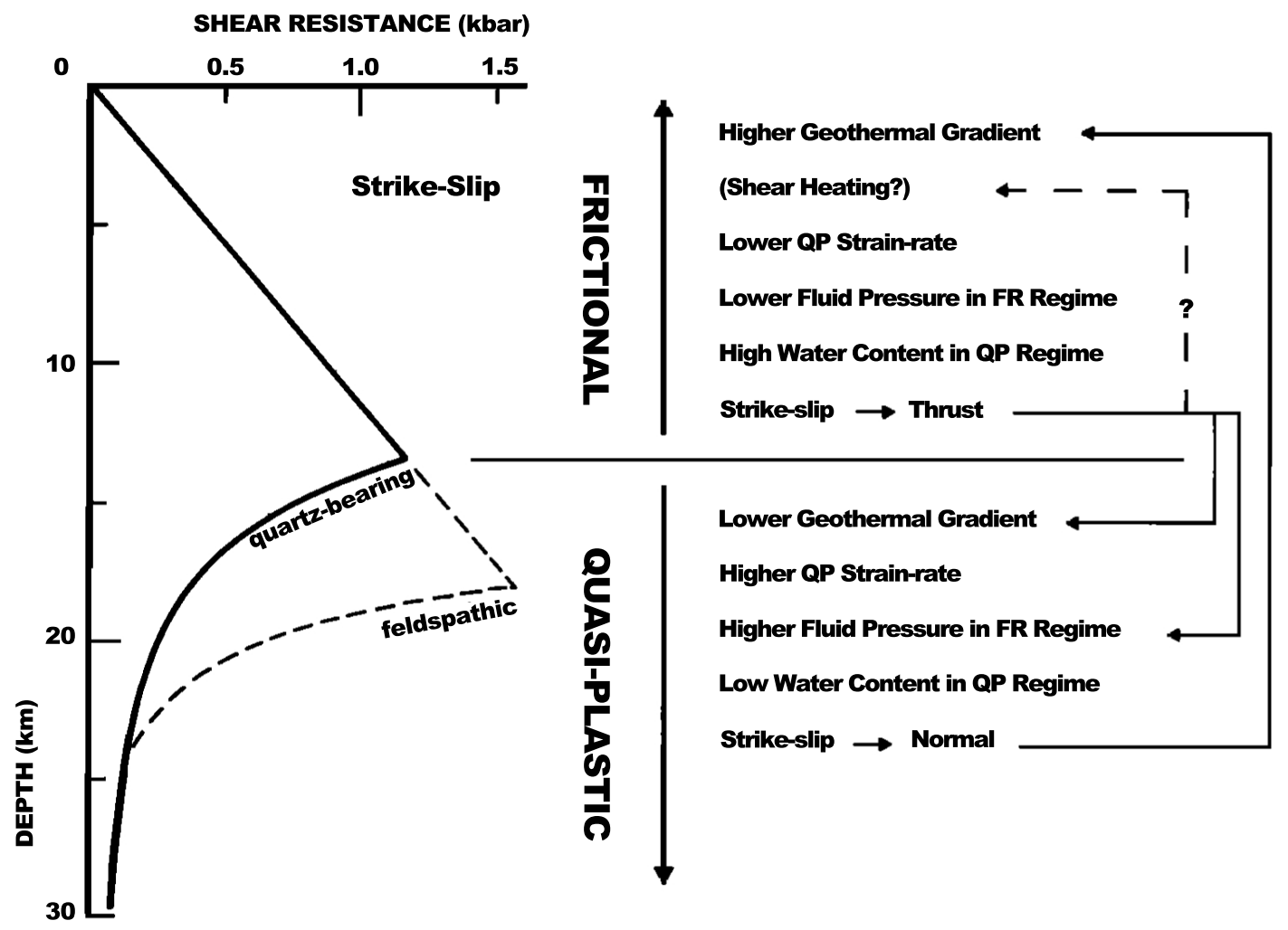

Figure 7.1. Factors influencing the depth of the brittle-ductile transition zone as shown by Sibson (1984) (his Fig. 7). High geothermal gradients, high water content in the quasiplastic (QP) regime, low fluid pressure in the frictional (FR) or low strain-rates in the QPregime lower the thickness of the frictional regime. In principle, thrust faulting decreases the frictional zone, however Sibson (1984) reports that in combination with other factors such as higher fluid pressure in the FR regime or lower geothermal gradients the QP-FR transition occurs at larger depth in thrust regimes in comparison to strike-slip regimes. For normal faulting regimes the QP-FR transition theoretically deepens compared to strike-slip regimes but effectively the transition zone becomes lower due to high geothermal gradients associated with extensional settings.

Due to pronounced variations in the thickness of the seismogenic zone, the depth extent and therefore the size of $\mathrm{M} \geq 5.5$ earthquakes adjacent to the Alpine Fault will vary with distance perpendicular to the fault (Boese et al. 2012). The largest events in the immediate vicinity of the Alpine Fault $(\leq 17.6 \mathrm{~km})$ exhibit magnitudes of $\mathrm{M}_{\mathrm{W}}$ 5.4-5.8. At distances $\geq 25 \mathrm{~km}$ from the fault, the magnitude of the major events lie in the range $M_{\mathrm{W}} 6.1-6.7$ (Fig. 1.6). The area between the Whataroa and Wanganui rivers poses a hazard of a $M \geq 6.5$ earthquake at $15-30 \mathrm{~km}$ from the Alpine Fault.

The cumulative strain-rate released by the microseismicity within $\sim 40 \mathrm{~km}$ of the Alpine Fault within one year is equivalent to an $\mathrm{M}_{\mathrm{L}} 4.5$ earthquake, which accounts for $\leq 1 \%$ of 
the accumulated strain-rate determined geodetically. The microseismicity distribution may correlate with high shear-strain rates (Fig. 6.16), suggesting fatigue of faults near failure in the tectonic stress field.

Inversion of the focal mechanism solutions for the tectonic stress has shown that the orientation of the Alpine Fault with respect to the maximum horizontal compressive stress direction requires the fault to be weak to fail in (large) earthquakes. Paleoseismic evidence for large earthquakes every 200-400 yr has been identified in several geomorphological features (Adams 1980; Wells and Goff 2007; Sutherland et al. 2007, and references therein), trenches across the active fault trace (Berryman et al. 1992; Langridge et al. 2010), forest (re-)establishments and tree-ring growth (Wells et al. 1999). The orientation of the Alpine Fault relative to the stress field suggests that the fault sustains a low ratio of shear to effective normal stress. Modelling of the stresses on the fault plane (Section 4.4) shows that the weakest scenario has been obtained for near-lithostatic fluid pressures and similar absolute values of the near-vertical intermediate stress $S_{2}$ and the near-horizontal least compressive stress $S_{3}$. If the Alpine Fault acts as a permeability boundary for fluids, as suggested for faults in general (e.g. Audin et al. 2002), near-lithostatic fluid pressures within the fault zone are quite realistic. With the stress inversion performed, we cannot obtain information about the stress amplitude. However, elevated stress ratios were obtained from focal mechanism inversion in the study area, indicating similar $S_{2}$ and $S_{3}$ values at shallow depths (Fig. 4.8 and Table 4.1).

The Alpine Fault appears to be the second major strike-slip fault that exhibits tremor. While tremor on the San Andreas Fault underlies the surface fault trace at $15-40 \mathrm{~km}$ depth, it is not clear whether tremor is confined to the downdip extension of the Alpine Fault or extends beyond it in the lower crust and lithospheric mantle. Becken et al. (2011) suggested that tremor results from brittle failure in a ductile deformation regime due to high fluid pressures causing embrittlement. The coincidence of the tremor depth with the high-attenuation and low-velocity zone (Scherwath et al. 2003; Eberhart-Phillips et al. 2008), the bright seismic reflections extending from 15 to $35 \mathrm{~km}$ depth (e.g. Kleffman et al. 1998; Stern et al. 2007, and references therein) and the inferred high fluid-pressure zone (Stern et al. 2001; Stern et al. 2007) support this interpretation. Trapping of fluids in the ductile shear zone and transport towards the Alpine Fault as observed in the resistivity structure (Wannamaker et al. 2002) $60 \mathrm{~km}$ north of the tremor region may account for the generation of high fluid pressure adjacent to the Alpine Fault. 


\subsection{Suggestions for future work}

Several of the subsidiary topics introduced in Chapter 6 have potential for further research. The mechanisms of deep earthquakes could be determined from inversion of P-wave polarities given a broader station distribution in the Southern Alps region (as obtained in 2012 with the installation of the WIZARD array and the ALFA array) and sufficient recording time (since approximately 1-2 deep events occur per year). The arrivals of the events studied here were impulsive and $\mathrm{P}_{\mathrm{n}}$ polarities could be obtained for stations at distances of $\leq 280 \mathrm{~km}$ from the earthquake. Alternatively, mechanisms could be obtained using waveform inversion, if the events are recorded by at least three broadband stations. A superficial search for deep events in the catalogue of O' Keefe (2008) revealed at least three recorded events deeper than $25 \mathrm{~km}$. These events were not studied due to uncertain polarities of the CAlF stations (O' Keefe 2008).

The tomography results could be greatly improved with more earthquake data recorded by stations to the north of the SAMBA array (as will be provided by the WIZARD array in the next few years). Of particular interest will be the velocities in the high-resistivity/lowattenuation structure to the north. With longer recording periods of station COVA, the area of resolution could also be extended to the south. As the attenuation model by Eberhart-Phillips et al. (2008) proved of importance in this study regarding the earthquake and tremor locations, a high-resolution local attenuation model for $\mathrm{Q}_{\mathrm{P}}$ and $\mathrm{Q}_{\mathrm{S}}$ obtained from spectral fitting of the earthquakes recorded in this study would improve the interpretation of elevated pore pressures and earthquake zones.

The swarms analysis could be extended by studying source parameters of the events. The smallest earthquake in the swarm could be used as a Green's function to remove the impulse response of the Earth. While the triggering threshold of earthquakes was exceeded only by the two large events, tremor could have been triggered by all events listed in Table 5.3 because the threshold for triggered tremor appears to be much lower $(1 \mathrm{kPa}$ as determined by Guilhem et al. 2010). It would also be interesting to analyse earthquakes of low-frequency recorded at station MTFO. If these events are low-frequency earthquakes they could be used to search for low-frequency events embedded in the tremor signal as identified by Shelly et al. $(2006,2007)$ in the subduction zone of Japan and on the San Andreas Fault near Cholame (Shelly et al. 2009; Shelly 2009).

A systematic analysis of the abundance of recorded signals related to ice movement would also be of interest. These events could be compared to the collapse of the glacier 
terminal at Fox Glacier (8 January 2009 4:20 pm NZ local time) and the collapse of the face of the Tasman glacier $\left(30 \times 10^{9} \mathrm{~kg}\right)$ that was triggered by the $\mathrm{M}_{\mathrm{W}} 6.3$ Christchurch earthquake (R. Dykes pers. comm., 2011). A check for seasonality in the occurrence of these events would help to identify and characterise them. In Iceland, an annual cycle has been observed for icequakes with most of the events occurring in autumn when the glaciers are thinnest and start to regrow, so that the ice load is increasing (Tryggvason 1973). Some of these signals may also result from rockfalls that occur predominantly along the Main Divide (S. Cox pers. comm., 2011). These events occur in "swarms" on cold days following a warm period when freeze-thawing occurs. A large rockfall ( $\geq 100000 \mathrm{~m}^{3}$ mass movement) occurs approximately every 100 years. The last major rockfall occurred on the southeastern side of Mt. Cook in December 1991 causing an equivalent seismic signal to a $\mathrm{M}_{\mathrm{L}} 3.9$ earthquake (McSaveney 2002).

Distinct secondary phases have been noticed on GOVA, EORO, FRAN, WHAT and POCR that could be studied to identify reflectors at depth. Preliminary modelling of the most prominent arrivals recorded by station WHYM suggests that these are not reflected from the Alpine Fault. Instead, they may indicate the presence of heterogeneous local structures that play a role in controlling the shallow maximum depth of the seismogenic zone in this region. 


\section{A. Response functions}

To understand the response of a seismometer to ground movement, one first has to understand the instrument itself and the recording system as a whole. A purely mechanical (short-period) seismometer is a velocity transducer consisting of a magnet and a coil (Fig. A.1). Ground movement either moves the magnet or the coil, inducing a current in either case. The instrument output is a voltage from the coil, which is proportional to the external acceleration (e.g. Havskov and Alguacil 2004).

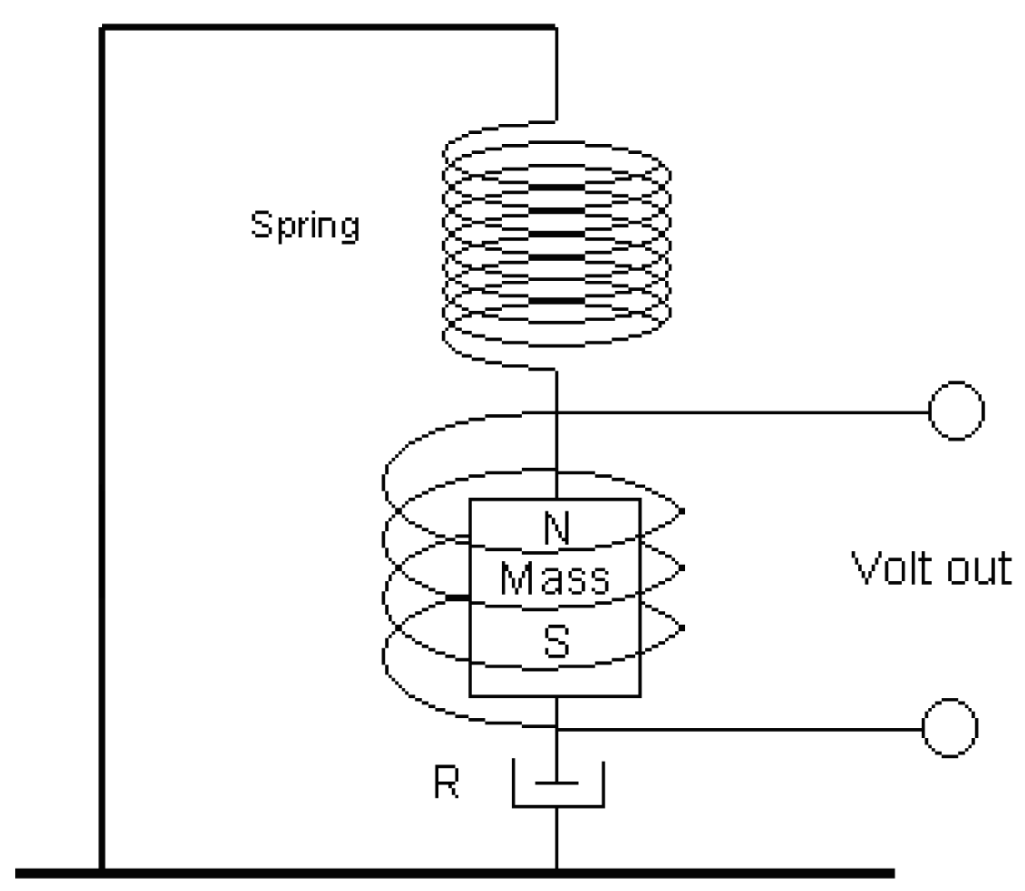

Figure A.1. Schematic representation of a passive seismometer, a so-called velocity transducer, from Havskov and Ottemöller (2010)

The system response of a seismometer describes mathematically how the recorded voltage 
relates to the ground motion. It contains information about the inertial response of the suspended mass/coil to external motion, damping of the movement (so that excessive motion near the resonance frequency is suppressed), coil resistance, manipulations applied to the voltage output (e.g. amplification or gain), the digitalisation of the voltage and it should also account for reversed polarity (in general, a positive velocity causes a positive voltage Havskov and Alguacil 2004). To understand the inertial response of the motion of the mass/coil, which is called the phase response, the equation of motion is needed:

$$
\mathrm{m}(\ddot{\mathrm{u}}+\ddot{\mathrm{z}})+\mathrm{d} \dot{\mathrm{z}}+\mathrm{kz}=0
$$

with the vertical ground motion $\mathrm{u}=\mathrm{u}(\mathrm{t})$, the displacement of the mass/coil $\mathrm{z}=\mathrm{z}(\mathrm{t})$, the damping $\mathrm{d}$ and the spring constant $\mathrm{k}$.

Using $\omega_{0}=\sqrt{\mathrm{k} / \mathrm{m}}$ and the damping constant $\mathrm{h}=\mathrm{d} / 2 \omega_{0} \mathrm{~m}$ equation A.2 becomes

$$
\ddot{\mathrm{z}}+2 \mathrm{~h} \omega_{0} \dot{\mathrm{z}}+\omega_{0}^{2} \mathrm{z}=-\ddot{\mathrm{u}}
$$

At high frequencies, the acceleration term dominates, so $\ddot{\mathrm{z}} \sim-\ddot{\mathrm{u}}$ and the motion of the mass/coil is of reversed polarity to the ground motion (Havskov and Alguacil 2004). This is because of the inertia of the mass/coil, which tends to remain stationary, so that the motion is phase-shifted by $\pi$. At low frequencies, the relative displacement of the mass/coil is proportional to the ground acceleration:

$$
\mathrm{z}=-\frac{1}{\omega_{0}^{2}} \ddot{\mathrm{u}}
$$

There is no phase shift at low frequencies because $\ddot{\mathrm{u}} \sim-\mathrm{u}$. The phase response at the resonance frequency is $\pi / 2$ (Havskov and Alguacil 2004).

The digitiser converts the measured analogue voltage into a discrete number for digital data storage. This sampling is done according to the pre-defined sampling rate. Usually, the data also acquires a GPS time stamp during this process. The measured voltage is amplified, which is expressed by the gain. For the Reftek Data Acquisition System, used in this study, the recorded signal is amplified by 32 (high gain setting). An input voltage of $1.589 \mu \mathrm{V}$ at unity gain and $49 \mathrm{nV}$ at high gain is converted to the same count value.

The displacement amplitude spectrum of a damped oscillator can be expressed as:

$$
\mathrm{A}_{\mathrm{d}}(\omega)=\mathrm{c} \frac{\left(i \omega-\mathrm{z}_{1}\right)\left(i \omega-\mathrm{z}_{2}\right)\left(i \omega-\mathrm{z}_{3}\right) \cdots}{\left(i \omega-\mathrm{p}_{1}\right)\left(i \omega-\mathrm{p}_{2}\right)\left(i \omega-\mathrm{p}_{3}\right) \ldots}
$$


where $\mathrm{c}$ is a gain factor, $\mathrm{z}$ are the zeros and $\mathrm{p}$ the poles (Havskov and Ottemöller 2010). The zeros, as the name suggests, describe the zero crossing of the displacement amplitude function. The poles describe the decay behaviour of exponential functions which are components of the displacement amplitude function and together define the complete displacement amplitude function. The phase shift increases with the number of poles (Havskov and Ottemöller 2010). The absolute value of the displacement spectrum is

$$
\mathrm{A}_{\mathrm{d}}(\omega)=\frac{\mathrm{G} \omega^{3}}{\sqrt{\left(\omega_{0}^{2}-\omega^{2}\right)^{2}+4 \mathrm{~h}^{2} \omega_{0}^{2} \omega^{2}}}
$$

where $\mathrm{G}$ is the generator constant, a measure of the sensitivity of the coil to ground velocity. However, the seismometer response function is usually given as the amplitude response to velocity:

$$
\mathrm{A}_{\mathrm{v}}(\omega)=\frac{\mathrm{G} \omega^{2}}{\sqrt{\left(\omega_{0}^{2}-\omega^{2}\right)^{2}+4 \mathrm{~h}^{2} \omega_{0}^{2} \omega^{2}}},
$$

The (velocity) response of a seismometer flattens at frequencies above the natural frequency $\mathrm{f}_{0}$. Below $\mathrm{f}_{0}$, the sensitivity of the instrument is reduced.

In summary, all the information about how the input displacement of the ground is manipulated (sensor, amplifier, filter and digitizer) to finally become the waveform of the seismogram, is stored in the response function.

\section{A. 1. Response functions of the SAMBA stations}

To create a response file using SEISAN (Havskov and Ottemöller 2000), the following input has to be provided:

- Natural period of the seismometer $\mathrm{T}_{0}=1 / \mathrm{f}_{0}$ (Table A.1 and A.2)

- The damping ratio of the seismometer $h$. This parameter was always set to 0.7 because it was assumed that the damping under load and not the open circuit damping $\mathrm{h}_{0}$ is required

- The generator constant of the sensor $\mathrm{G}$ in [V s/m] (Table A.1 and A.2)

- The recording media gain in $[$ counts/V], which was calculated to be $1 / 1.589 \times 10^{-6}=629327$ for unity gain and $1 / 49 \times 10^{-9}=20408164$ for high gain

- The digitiser sample rate, which is 200 samples/s (Section 1.4.2) 
- The amplifier gain in $[\mathrm{dB}]$. As no preamplifier was used we set this value to 0 .

The poles and zeros were calculated with SEISAN and are stored in GSE format. Response files for the GeoNet stations were extracted from the dataless SEED volume provided by GeoNet $^{1}$. SEISAN can directly read SEED response information of poles and zeros and calculate the corresponding response function.

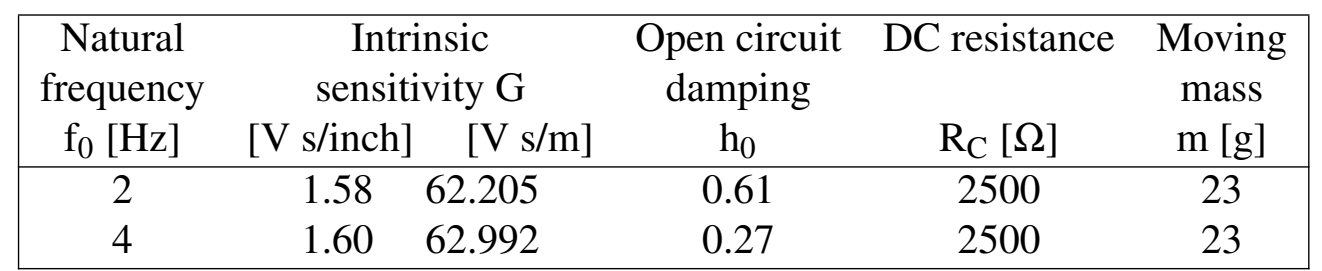

Table A.1. Specification for the GeoSpace Technologies HS-1-LT sensor (from specification sheets number S11230 and S11510).

\begin{tabular}{|c|c|c|c|c|c|c|}
\hline \multirow[t]{2}{*}{$\begin{array}{l}\text { Sensor } \\
\text { type }\end{array}$} & $\begin{array}{c}\text { Natural } \\
\text { frequency }\end{array}$ & \multicolumn{2}{|c|}{$\begin{array}{c}\text { Transduction } \\
\text { G }\end{array}$} & \multirow{2}{*}{$\begin{array}{c}\text { Open circuit } \\
\text { damping } \\
\mathrm{h}_{0}\end{array}$} & \multirow{2}{*}{$\begin{array}{c}\text { Coil } \\
\text { resistance } \\
\mathrm{R}_{\mathrm{C}}[\Omega]\end{array}$} & \multirow{2}{*}{$\begin{array}{c}\text { Suspended } \\
\text { mass } \\
\mathrm{m}[\mathrm{kg}]\end{array}$} \\
\hline & $\mathrm{f}_{0}[\mathrm{~Hz}]$ & [V s/inch] & [V s/m] & & & \\
\hline L-4C & 1 & 7.02 & 276.378 & 0.28 & $5500^{2}$ & 0.5 \\
\hline L-22D & 2 & & 88 & & 4300 & \\
\hline
\end{tabular}

Table A.2. Specification for the Mark Products sensors.

\begin{tabular}{|c|c|c|c|c|c|}
\hline Station & $\begin{array}{l}\text { Normalisation } \\
\text { factor } \\
\mathrm{A}_{0}\end{array}$ & $\begin{array}{l}\text { Norm. } \\
\text { freq. } \\
\mathrm{f}_{0}[\mathrm{~Hz}]\end{array}$ & Gain & $\begin{array}{l}\text { Complex } \\
\text { zeros } \\
\text { z }\end{array}$ & $\begin{array}{l}\text { Complex } \\
\text { poles } \\
\text { p }\end{array}$ \\
\hline FOZ & $2.30426 \times 10^{6}$ & 1 & 2042.4 & 0,0 & $\begin{array}{c}-160,-80,-0.01178-0.01178 i \\
-0.01178+0.01178 \mathrm{i},-180\end{array}$ \\
\hline WVZ & $2.30426 \times 10^{6}$ & 1 & 2050.6 & 0,0 & $\begin{array}{c}-160,-80,-0.01178-0.01178 i \\
-0.01178+0.01178 i,-180\end{array}$ \\
\hline RPZ & 46.2282 & 1 & 994.8 & $0,0,146.5$ & $\begin{array}{c}-73.2-37.6 i,-73.2+37.6 i \\
-0.00589-0.00589 i \\
-0.00589+0.00589 i\end{array}$ \\
\hline
\end{tabular}

Table A.3. Specification for the GeoNet sensors Guralp CMG-3ESP of FOZ and WVZ, and Guralp CMG-3TB of RPZ obtained from the Dataless SEED file provided by GeoNet.

\footnotetext{
${ }^{1}$ obtained from ftp://ftp.geonet.org.nz/seed/RESPONSE/

${ }^{2}$ This coil resistance has been measured by myself for the used Marks Products L4-3D sensors number 602 and 733 . Note that the sensitivity of $166.54 \mathrm{~V} \mathrm{~s} / \mathrm{m}$ listed by IRIS is for the sensor with coil resistance $2000 \Omega$
} 
Specifications provided for the different sensor are listed in Table A.1, A.2 and A.3. The amplitude and phase response are plotted in Figures A.2 and A.3. The latter figure clearly shows that the response function provided by GeoNet for RPZ is wrong, because it reverses the correct polarity of the instrument. We can confirm that the polarity of the RPZ sensor is correct by comparing polarities of all stations from recordings of two teleseismic events (Section B). This wrong response has been noted before (Behr 2011). It does not affect the focal mechanisms or the magnitude determinations, since polarities are picked on raw seismograms and magnitudes are determined as half the maximum peak to peak amplitude value on the deconvoluted seismograms, and a sign change does not change this value.
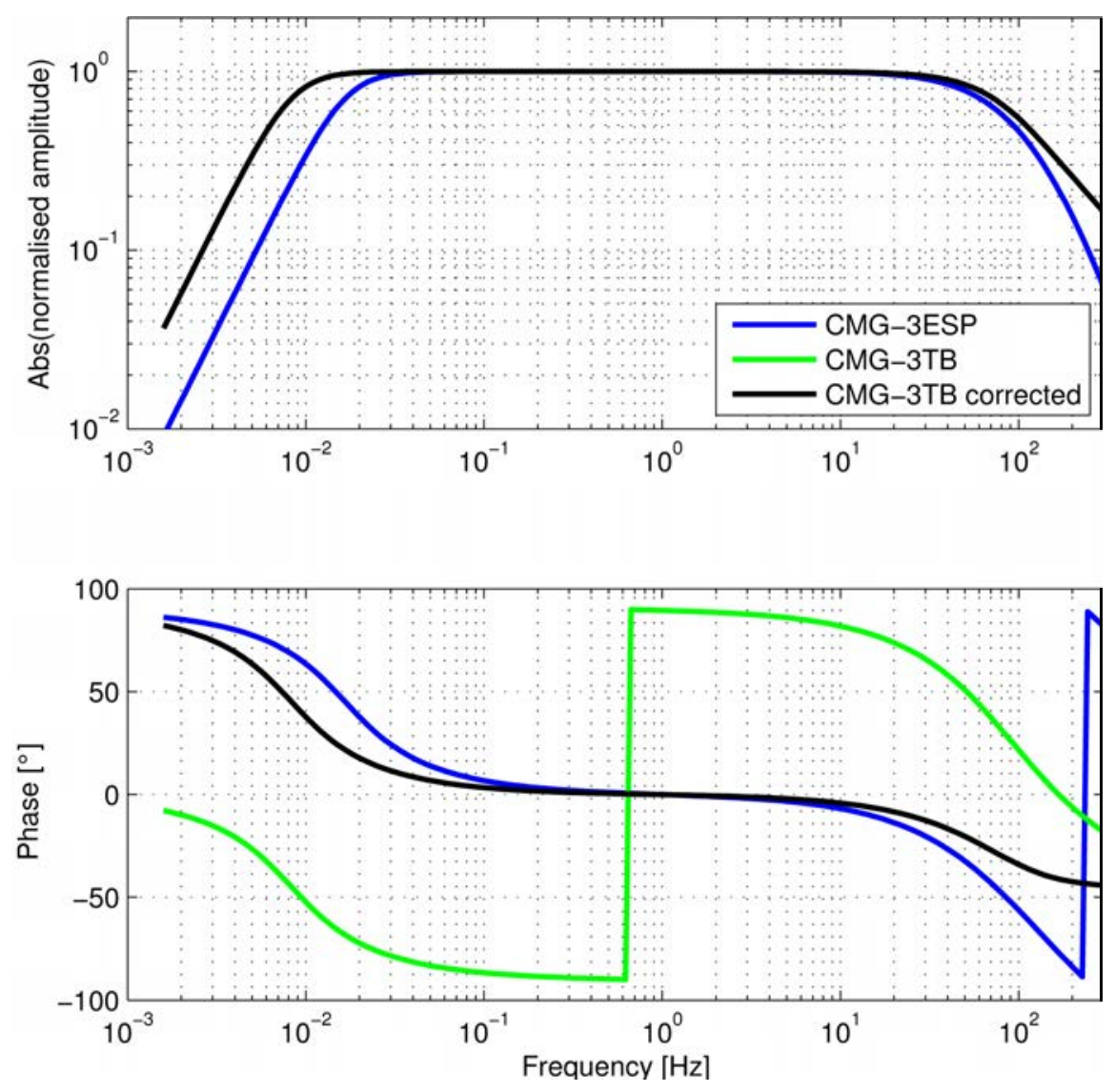

Figure A.2. Amplitude and phase response of the Guralp sensors at the GeoNet stations FOZ, WVZ (CMG-3ESP) and RPZ (CMG-3TB). Note that the response as provided by GeoNet is plotted in green (which shows a reversed polarity) and the corrected response function is shown in black. 

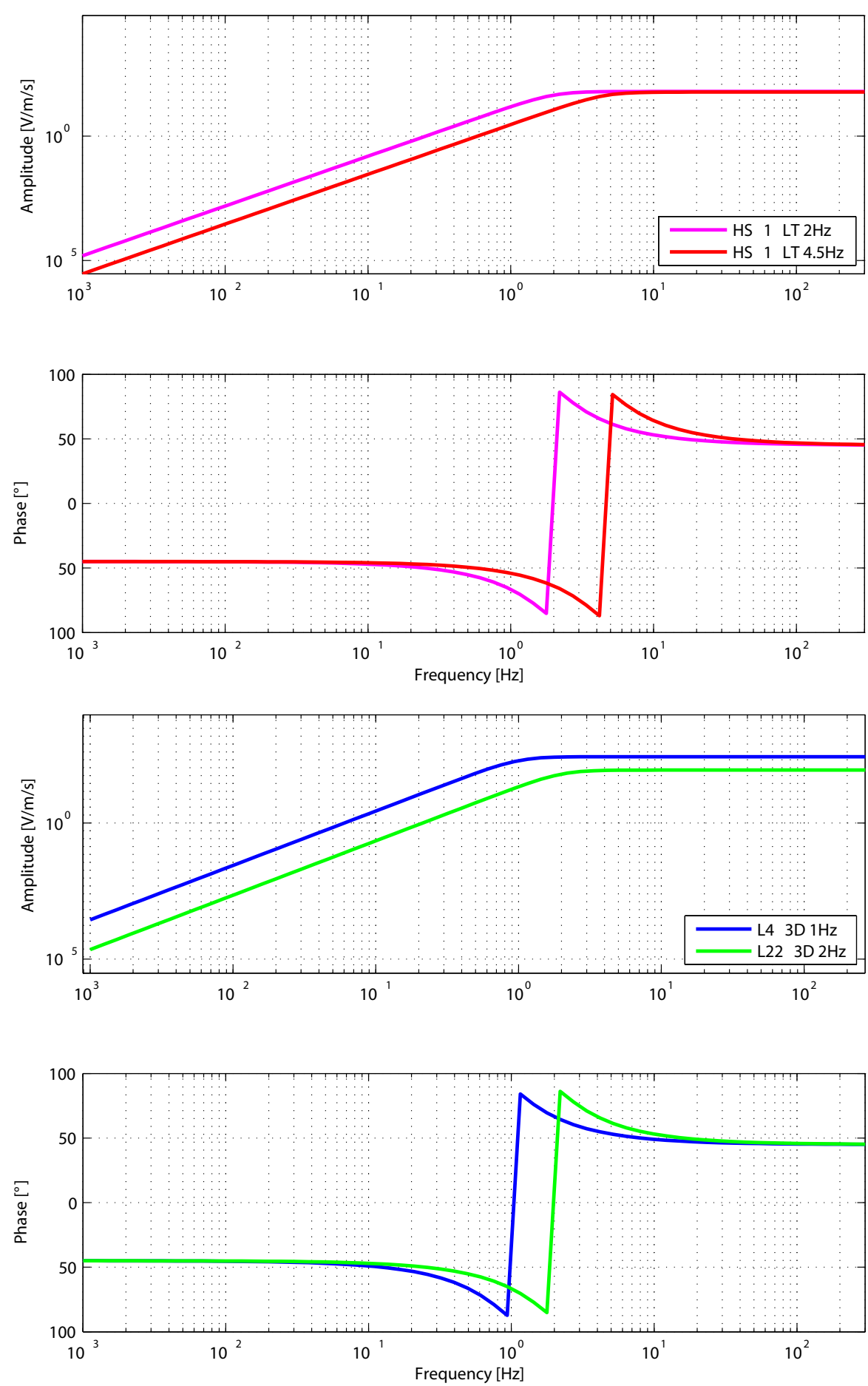

Figure A.3. Amplitude and phase response of the GeoSpace Technologies HS-1-LT sensors employed at the SAMBA stations, the Mark Products sensors used as addition surface sensor (L4-3D) to supplement the borehole sensor and the Mark Products sensors (L22-3D) used for the DFDP10 array. 


\section{B. Polarity tests}

The consistency of station polarities is a prerequisite for focal mechanism solutions. The polarity of all sensors is usually tested in the lab or with a "cluster" test in the field. Another possibility for testing of the polarity is to compare the first onset polarity at all stations for a teleseismic event. Serendipitously, we recorded two teleseismic earthquakes with exceptionally clear P-wave onsets, so we could use these earthquakes to check the polarity. Therefore, polarity-reversals are exactly known for our dataset. The only station which shows an emergent onset and does not reveal a clear polarity for the teleseismic earthquakes is station REYN. For this reason and due to inconsistent polarities found for this station, we excluded all polarity picks from that station from the focal mechanism analysis. Both events clearly show that the polarity is reversed for the short-period Mark Products L4-3D sensors, which were deployed at this time at station WHAT2 and POCR2.

One of the Mark Products L4-3D sensors was later installed as a surface sensor at station COVA, so this station has a reversed polarity in comparison with the other SAMBA stations. All stations of the DFDP10 array, deployed between January and May 2010, were equipped with short-period Mark Products L22-3D sensors. It was suspected that these sensors have reversed vertical-component polarities, too. One teleseismic event of intermediate depth (Fig. B.3) shows reversed polarities at stations ERE, WNQ, BON, NOL, and DRC, but is ambiguous for the remaining DFDP10 stations.

Several quarry blasts have been recorded by the SAMBA and the combined SAMBA/DFDP10 array. All polarities are upwards for the SAMBA stations and downwards for the DFDP10 stations, consistent with the inferred polarity reversal of the DFDP10 stations (Fig. B.4 and 3.13). 


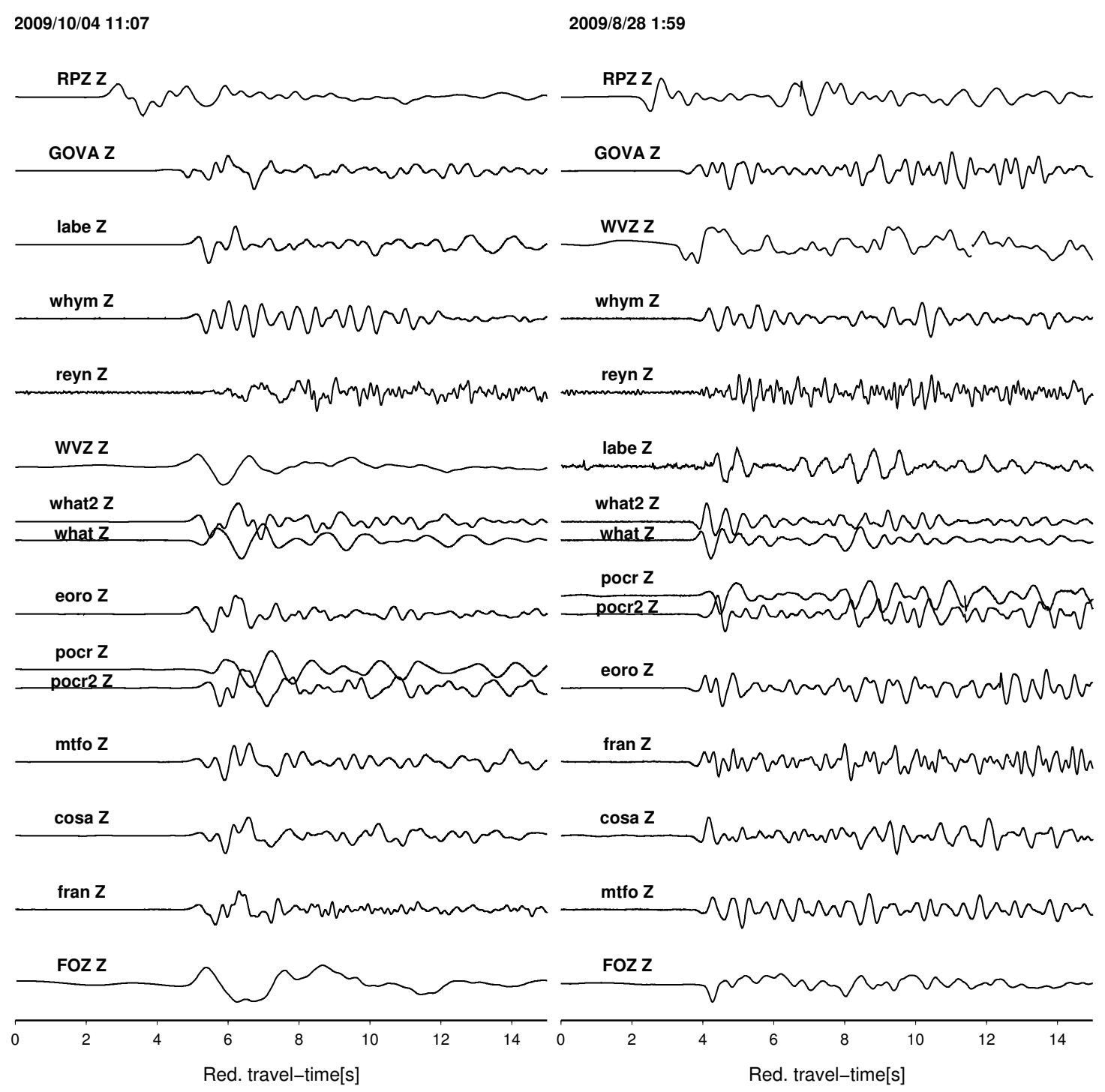

Figure B.1. Waveforms of the raw (unfiltered, no instrument response removed) Zcomponent seismograph traces of all SAMBA and GeoNet stations. The teleseismic earthquakes which produced these clear onsets are the $\mathrm{M}_{\mathrm{W}}=6.6$ of 4 October 2009 (10:58:03.6 GMT, lat $=6.77^{\circ}$, lon $=123.56^{\circ}$, depth $=626 \mathrm{~km}$ ) and the $\mathrm{M}_{\mathrm{W}}=6.9$ event of 28 August 2009 (1:51:25.9 GMT, lat $=-7.09^{\circ}$, lon $=123.46^{\circ}$, depth $=634 \mathrm{~km}$, see Fig. B.2). Note that the traveltime for station COSA for the latter event had to be corrected by $24.235 \mathrm{~s}$ due to GPS uncertainties. 


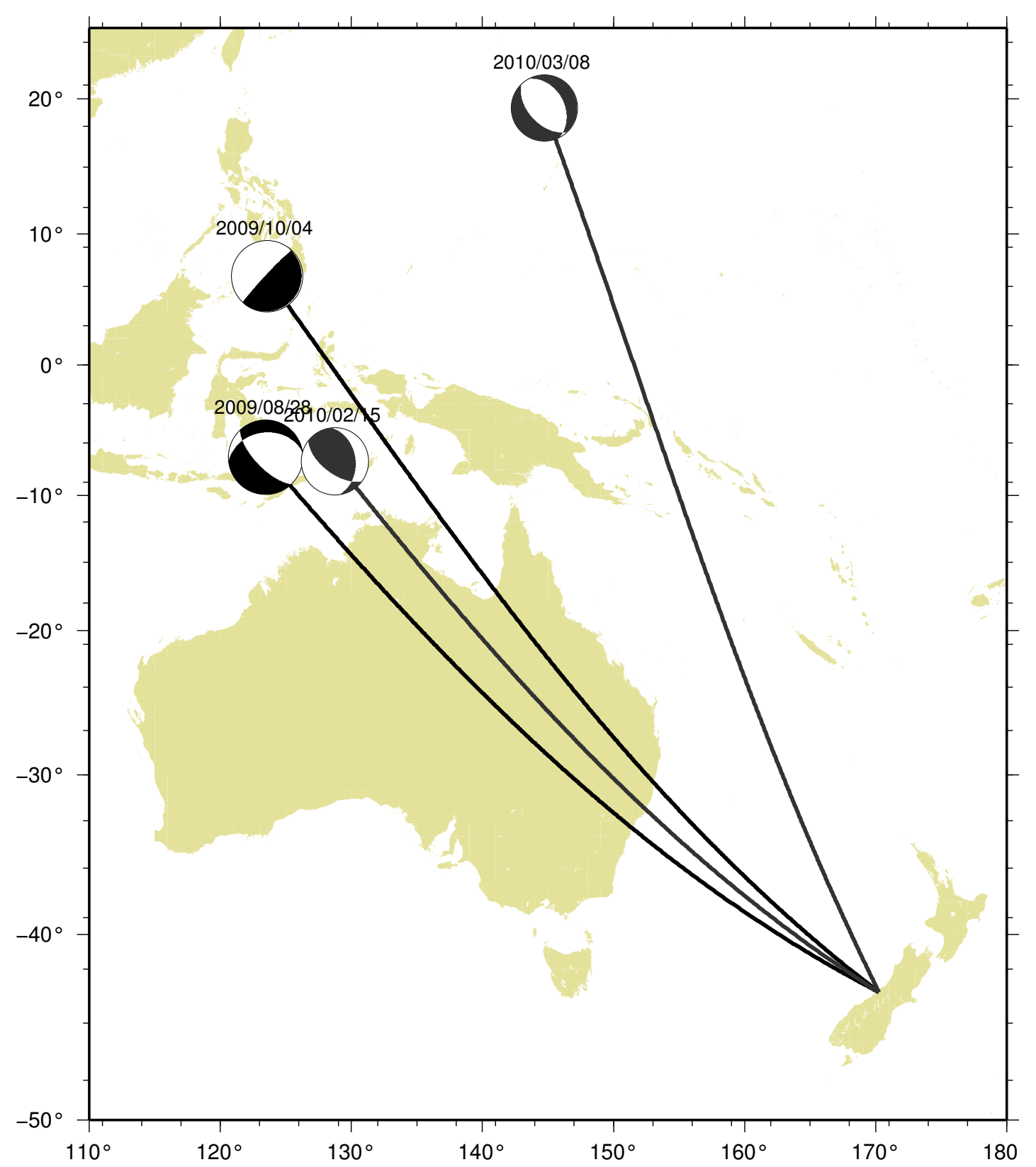

Figure B.2. Locations and focal mechanisms of the events shown in Fig. B.1 (black) and Fig B.3 (grey) 


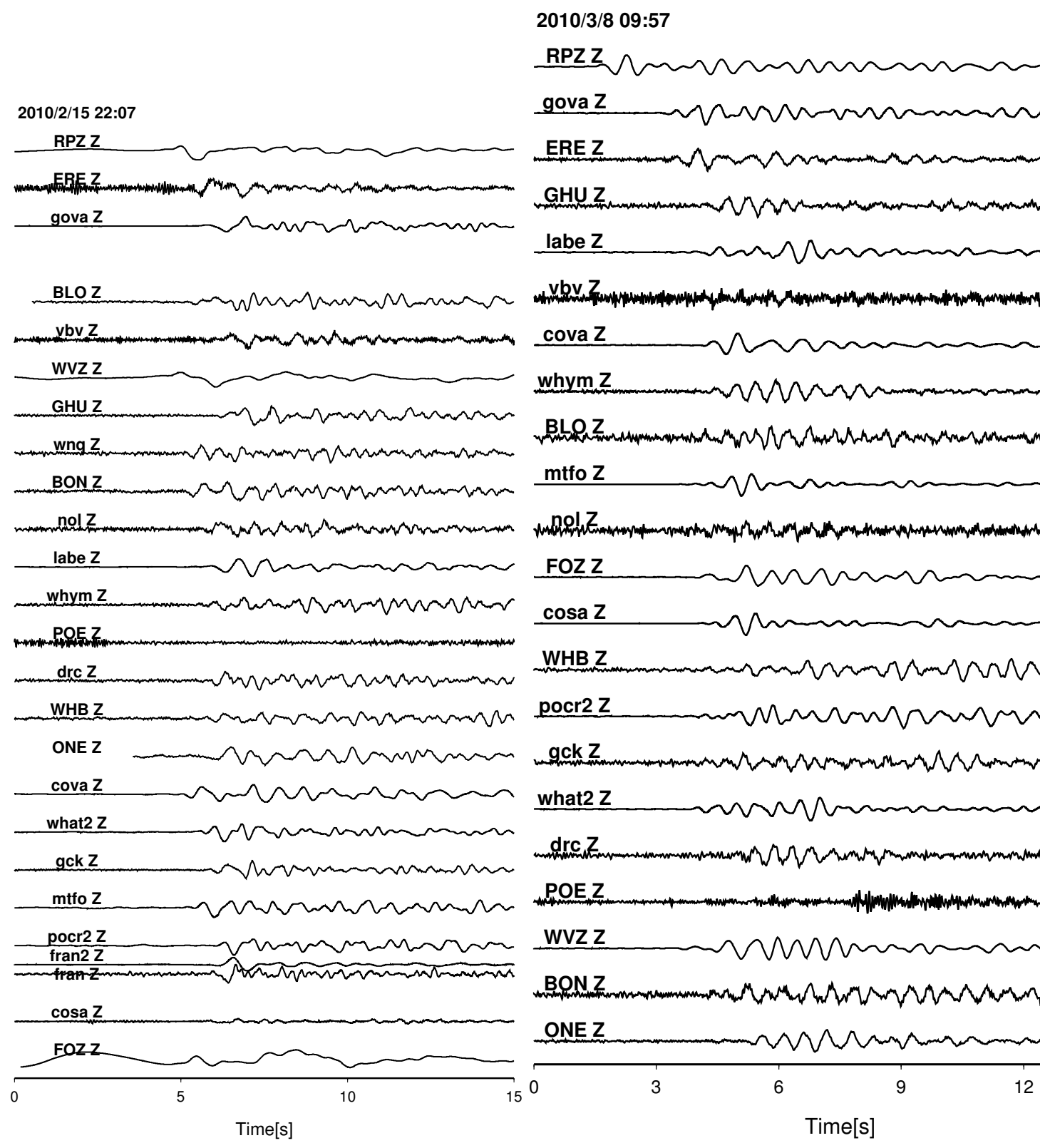

Figure B.3. Waveforms of the raw (unfiltered, no instrument response removed) Zcomponent seismograph traces for all SAMBA, DFDP10 and GeoNet stations. The teleseismic earthquakes which produced these onsets are the $\mathrm{M}_{\mathrm{W}}=6.2$ earthquake of 15 February

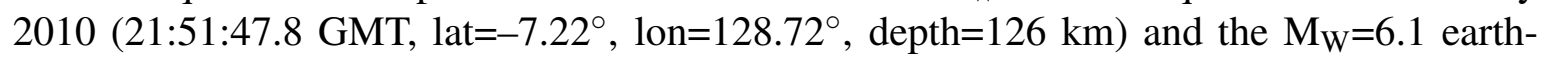

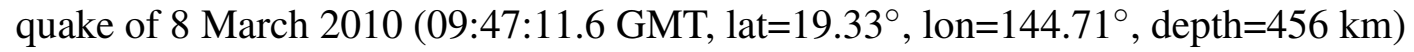




\section{Fozz54 54 m.

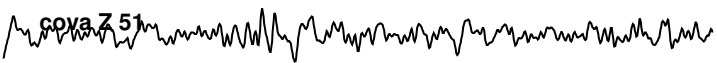

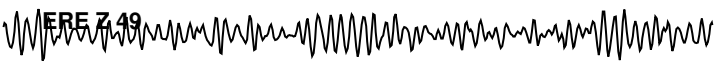

2009/6/22 4:01

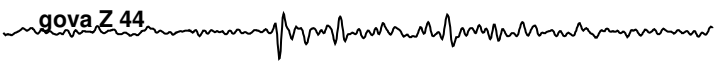
FOZZ52.

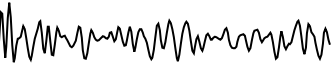

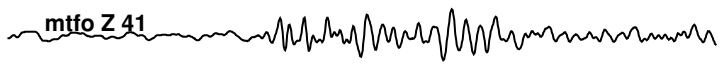
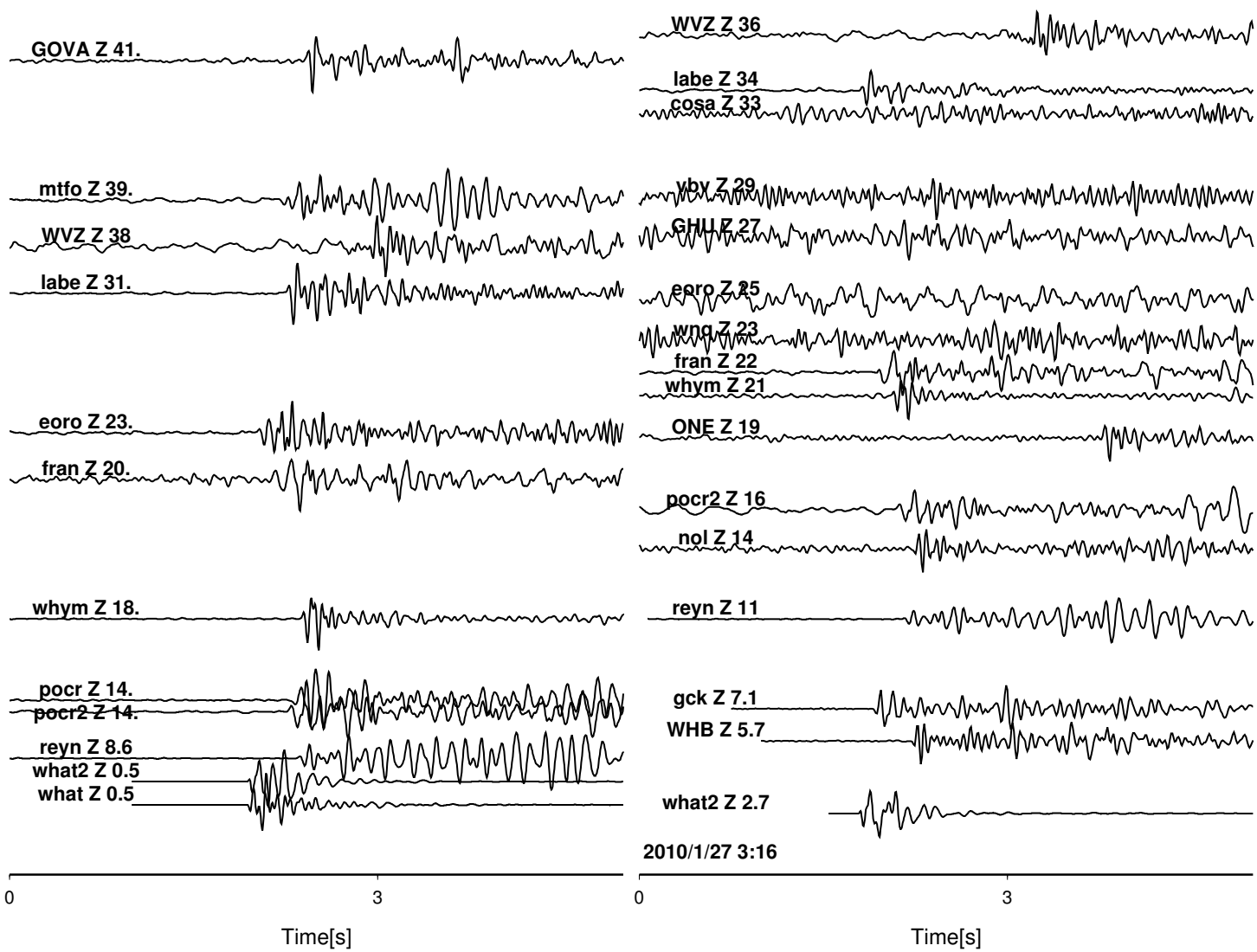

Figure B.4. Waveforms of the Z-component traces of all SAMBA and GeoNet stations which recorded a quarry blast near station WHAT. Clear onsets are upwards (compressional) for all stations. Waveforms of the vertical seismograph traces of all SAMBA, DFDP10 and GeoNet stations that recorded a quarry blast in a similar location to that in Fig. B.4. Clear onsets for the DFDP10 stations are downwards (reversed polarity). 


\begin{tabular}{|rrrrrr|}
\hline Date & Time (UTC) & Latitude & Longitude & Depth [km] & $\mathrm{M}_{\mathrm{W}}$ \\
\hline 4 October 2009 & $10: 58$ & $6.77^{\circ}$ & $123.56^{\circ}$ & 626 & 6.6 \\
28 August 2009 & $01: 51$ & $-7.09^{\circ}$ & $123.46^{\circ}$ & 634 & 6.9 \\
15 February 2010 & $21: 51$ & $-7.22^{\circ}$ & $128.72^{\circ}$ & 126 & 6.2 \\
\hline
\end{tabular}

Table B.1. Origin time and hypocentre locations from the USGS Preliminary Determination of Epicentres (PDE) of teleseismic earthquakes with impulsive P-arrivals recorded by the SAMBA/DFDP10 stations. 


\section{Station recording times}

Figure C.1 displays the recording time in days for the SAMBA and DFDP10 stations. Note that for GeoNet stations FOZ, WVZ and RPZ only those days from Julian day 125 of 2010 onwards are shown which were analysed. Horizontal lines indicate 1 January of each year for orientation. Small numbers above each trace indicate Julian days when recording began or stopped. See Section 1.4.1 for station names and locations.

Figure C.1. (facing page) Station recording time of the SAMBA, GeoNet and DFDP10 stations between November 2008 and December 2010. Small numbers above the traces indicate when the recording began or stopped. 


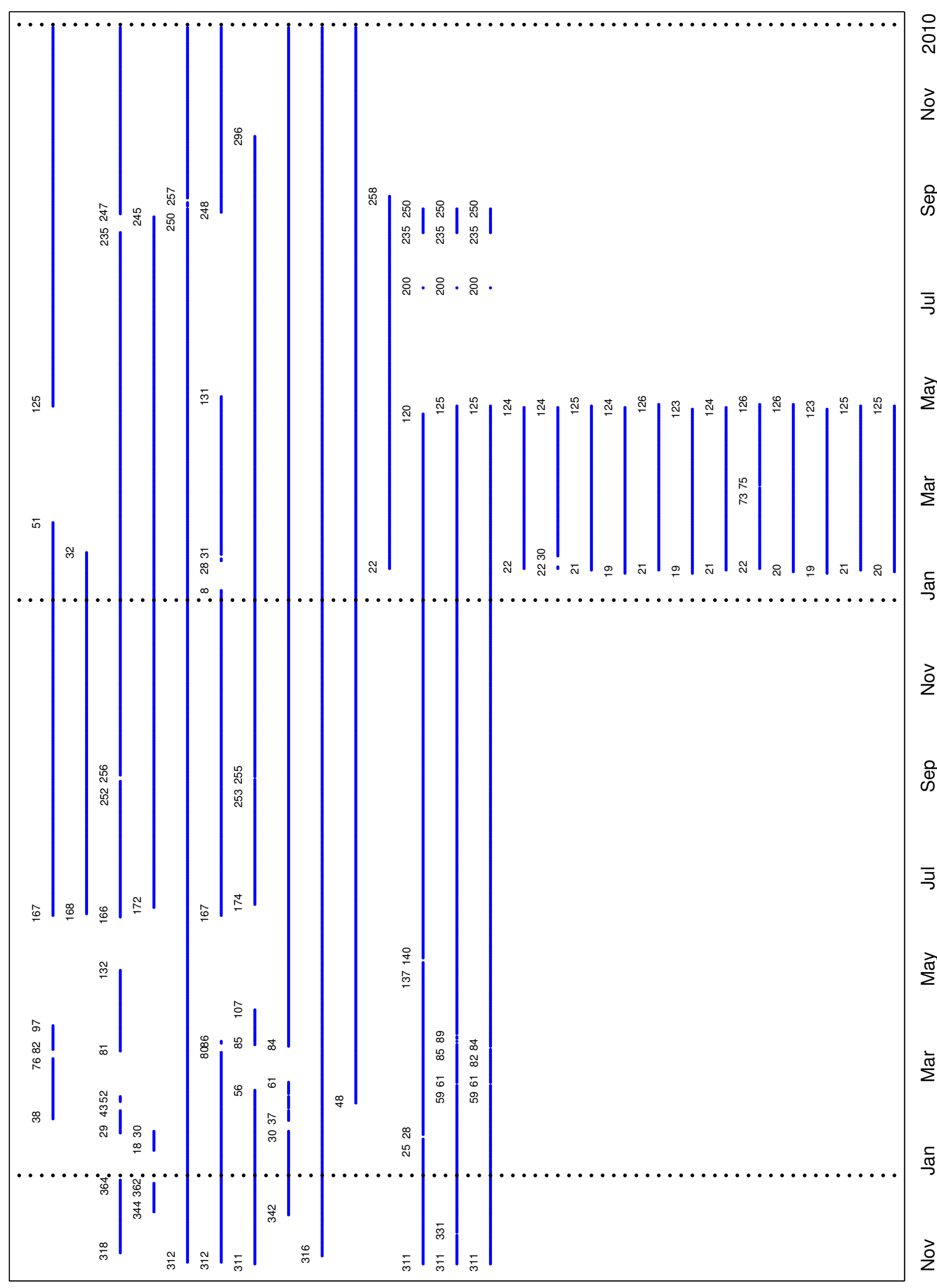

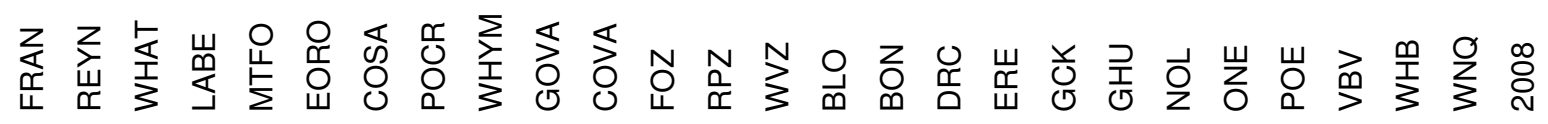




\section{Noise signals}

In this appendix some of the spurious signals caused by instrumentation or other identifiable noise sources are listed. This is by no means a complete catalogue of the recorded noise signals, but it may be useful as a reference in future seismicity studies. The reason why these signals are so prominent in the SAMBA data may be due the high gain setting.

\section{D.1. Solar controller}

The data recorded by the SAMBA stations exhibits prominent spikes, although the same equipment and station setup have been used before in other VUW seismicity studies. The regular occurrence of these spikes was found to be strongly related to sunshine hours and therefore the source of these spikes could be identified in the power system. Solar controllers apply pulse-modulation-width charging to recharge the battery. Different solar controllers were used at the SAMBA stations (Table D.1), which caused different spikes in the data (Fig. D.1).

\begin{tabular}{|llll|}
\hline $\begin{array}{l}\text { Solar } \\
\text { controller }\end{array}$ & $\begin{array}{l}\text { Spike } \\
\text { gener- } \\
\text { ation }\end{array}$ & $\begin{array}{l}\text { Recurrence } \\
\text { period of } \\
\text { spikes [s] }\end{array}$ & $\begin{array}{l}\text { Characteristics/ } \\
\text { comments }\end{array}$ \\
\hline SunSaver 6 & yes & $37 \mathrm{~s}$ & $\begin{array}{l}\text { amplitude variation de- } \\
\text { pending on sun intensity }\end{array}$ \\
SunSaver 10 & yes & $37 \mathrm{~s}$ & double spike up down with \\
ProStar-15 & yes & $6 \mathrm{~min}$ & $1.3 \mathrm{~s}$ spacing in between \\
ProStar-30 & yes & $6 \mathrm{~min}$ & low in amplitude \\
\hline Steca Solsum & yes & $1.5 \mathrm{~s}$ & devices failed after less than one year, \\
Powertech & no & & cannot be purchased in New Zealand \\
Flexcharge NC 12 & no & &
\end{tabular}

Table D.1. Solar controller used in this study and their recurrence period and characteristics of spikes generated. 


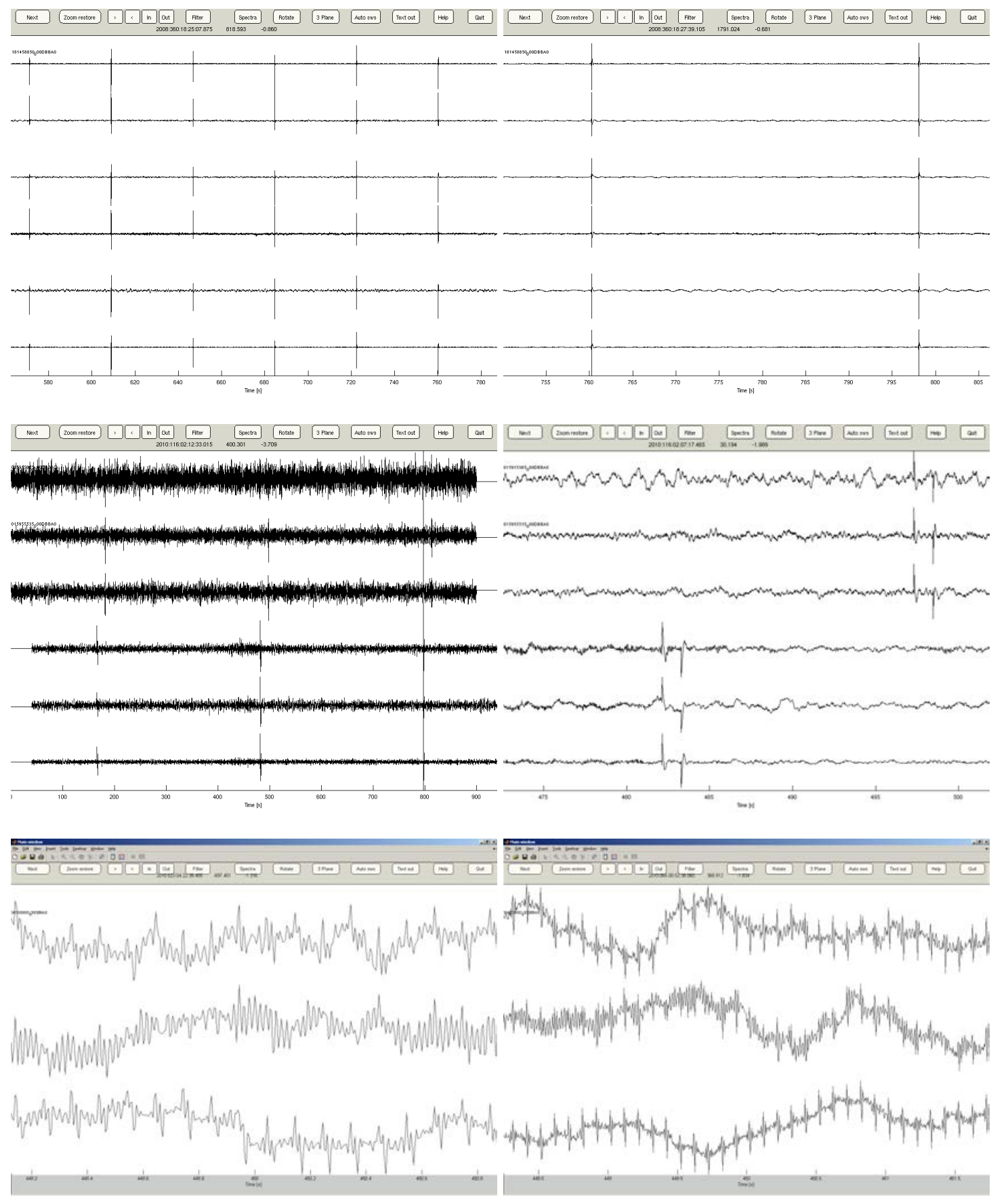

Figure D.1. Spikes generated by SunSaver 10 (first row), ProStar-30 (second row) solar controllers. The figures in the right column give an enlarged view of those in the left column. The third row shows spikes of unknown origin recorded at stations COSA and COVA 


\section{D.2. Other noise sources}

Other anomalous signals that have been observed are shown in Figures D.2, D.3 and D.4. When water leaked into the box containing the solar controller, sudden one-sided amplitude changes (either positive or negative) were observed (Fig. D.2). A frequency and amplitude change of the signal was observed on one channel at station WHAT, which was found to have a "dry" soldering joint. Similar signals were observed on the N-components of DFDP10 station BLO and GeoNet station WVZ. These channels recorded only the high frequencies of the signal and the amplitude of the signal amounts to only $10 \%$ of that of the other horizontal component. At station REYN, the E-component, which turned out not to be grounded at the sensor, also showed a reduced amplitude/amplification and is characterised by jumps in the signal.

Lightning and thunder, as shown in Fig. D.3, can be seen on all stations except those installed in boreholes. This signal is characterised by a spike followed by an emergent noisy signal with varying time delay according to the distance from the storm. These records usually show noisier traces associated with wind and rain.

Internal noise, identified at station COSA, resembles the spikes of unknown origin at stations COSA and COVA but persisted when the sensor and GPS cables were removed from the Reftek. On closer inspection, these spikes were found to occur every second with a duration of $0.1 \mathrm{~s}$ and always show the same form and amplitude. The recorded signal of a helicopter passing by the stations lasts for a few minutes and typically oscillates with a period of $0.05 \mathrm{~s}$. The signal resembles a beating wave. An electric fence recorded on a borehole sensor generates a "ringing" spike every $1.3 \mathrm{~s}$ with only a positive or negative amplitude. In this case, the steel casing of the borehole acted as an antenna transferring the signal to the sensor. Grounding of the casing prevented further recording of this signal. The amplitude of the spike shows a variability associated with the current. After a new fencing system was installed at the property on which the senor is located, the spikes were much larger in amplitude. 

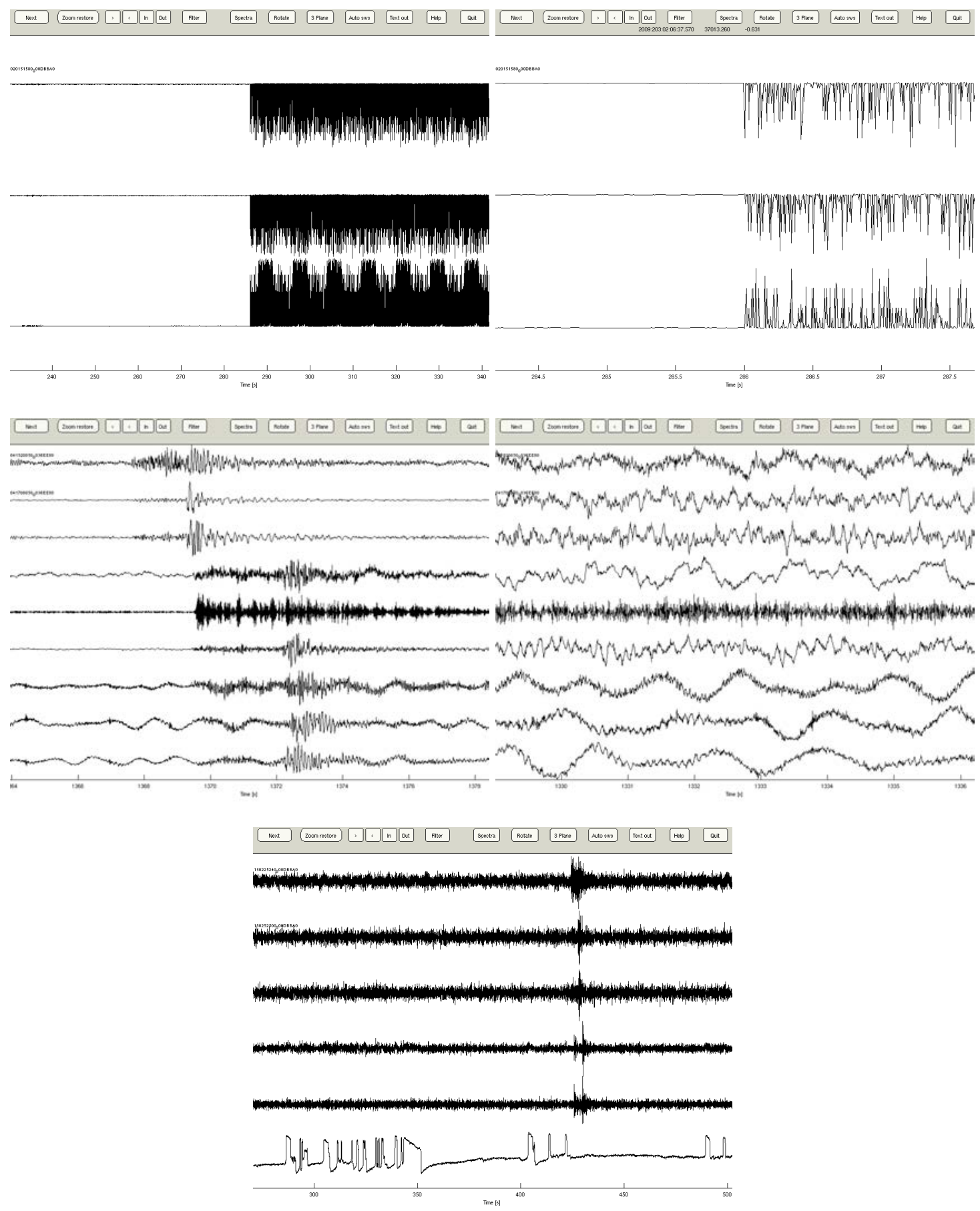

Figure D.2. Noise generated by water in solar controller (first row), one channel with a "dry" soldering joint (second row), and an ungrounded channel (third row). The figures in the right column give a closeup view of those in the left column 

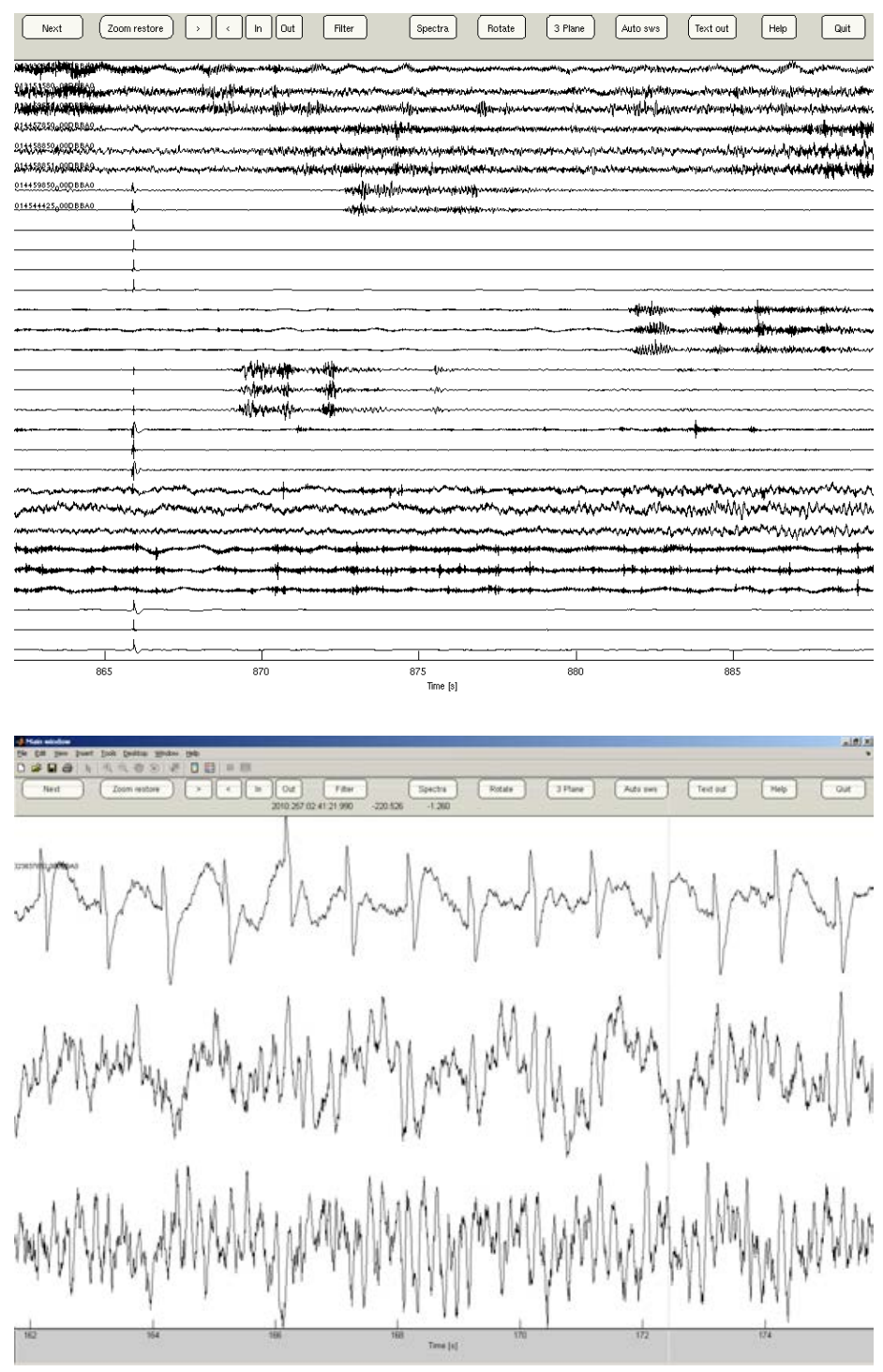

Figure D.3. Noise generated by lightning and thunder (top) and internal noise generated by the Reftek (bottom). 


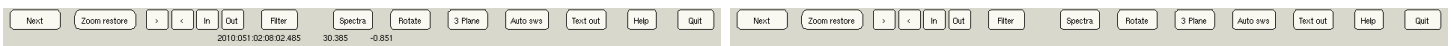

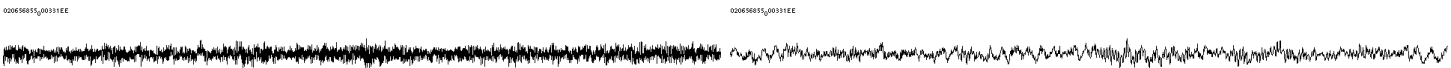
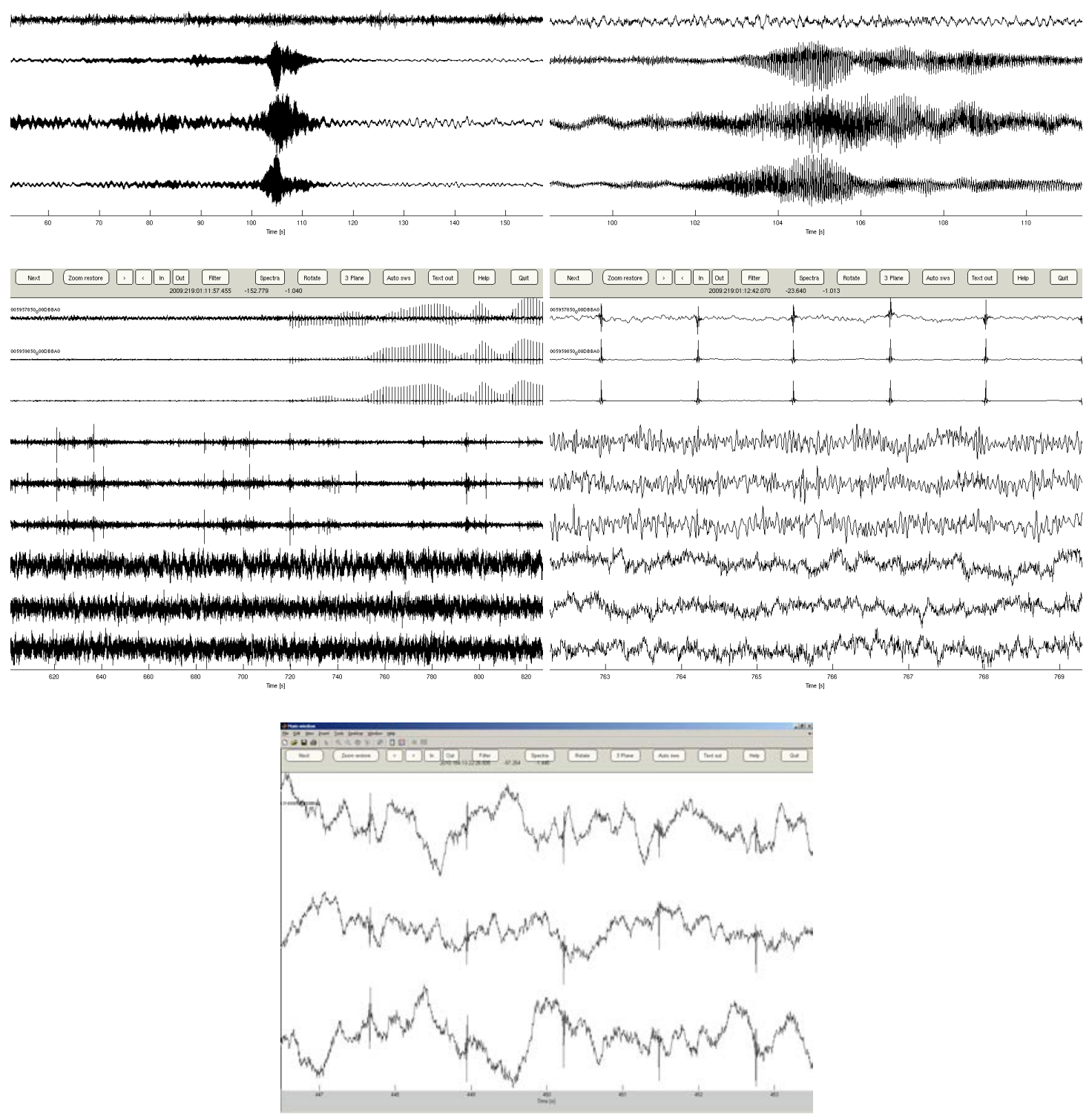

Figure D.4. Noise generated by helicopter (first row) and electric fence (second and third row). The figures in the right column give a closeup view of those in the left column 


\section{E. Assessment of individual station performance}

The following two tables (E.1 (a) and (b)) discuss the overall performance of the SAMBA and DFDP10 sites, noise sources near the sensors and other problems that occurred. For the mountain sites requiring helicopter access, brief comments regarding the possibility of telemetry are added. 


\begin{tabular}{|c|c|}
\hline $\begin{array}{l}\text { Station } \\
\text { name }\end{array}$ & Performance and problems \\
\hline COSA & $\begin{array}{l}\text { good recording during night times, but noisy during the day due } \\
\text { to road traffic, sensor not accessible any more, since site was covered } \\
\text { by at least } 5 \mathrm{~m} \text { of sediments, but no equipment damage, internal noise }\end{array}$ \\
\hline EORO & $\begin{array}{l}\text { site close to earthquake swarms and low noise levels for high frequencies, } \\
\text { sometimes noisier due to change in course of nearby stream, faulty N-channel, } \\
\text { site accessibility difficult ( } 15 \text { min walk), sunshine hours marginal in winter }\end{array}$ \\
\hline MTFO* & $\begin{array}{l}\text { continuously recording site, little snow, intensive kea damage, } \\
\text { telemetry possible (line of sight and cell phone reception) }\end{array}$ \\
\hline WHAT & $\begin{array}{l}\text { noisy during daytime due to machinery used in nearby quarry, } \\
\text { recorded several quarry blasts, damage to solar panel holder due to } \\
\text { strong wind, once cows in quarry }\end{array}$ \\
\hline WHYM* & $\begin{array}{l}\text { reliable, continuously recording site, close to earthquake cluster, } \\
\text { clear waveforms although in a boulder of a landslide, full sun and } \\
\text { little snow, telemetry problematic (in valley), visible from walking track }\end{array}$ \\
\hline POCR & $\begin{array}{l}\text { performance ok, due to low-period noise, but good in addition to station } \\
\text { FRAN, electric fence noise, cows }\end{array}$ \\
\hline LABE* & $\begin{array}{l}\text { site recorded many avalanches, lots of snow, but solar panel } \\
\text { free of snow due to strong winds, initial solar panel setup blown away, kea } \\
\text { damage, telemetry possible (line of sight and cell phone reception) }\end{array}$ \\
\hline GOVA & $\begin{array}{l}\text { reliable, continuously recording site, telemetered to lakeside, clear simple } \\
\text { waveforms, low noise levels, recorded all earthquakes even from large distances }\end{array}$ \\
\hline FRAN & $\begin{array}{l}\text { good site, sometimes noise from rock crusher in riverbed nearby when } \\
\text { worked on }\end{array}$ \\
\hline REYN* & $\begin{array}{l}\text { problematic/poor site, one broken channel, very emergent signal, site } \\
\text { covered by snow in winter, landslide hazards, removed in September } 2010 \\
\text { due to flat batteries, telemetry possible to upper Whataroa river }\end{array}$ \\
\hline COVA* & $\begin{array}{l}\text { site performance ok, site covered in snow during winter, area too } \\
\text { sheltered }\end{array}$ \\
\hline
\end{tabular}

Table E.1. (a) Observations of site conditions and assessment of the station performance. Sites marked with star require helicopter access. 


\begin{tabular}{|cl|}
\hline Station name & Performance and problems \\
\hline BLO* & $\begin{array}{l}\text { close to large cluster of earthquakes, site directly on solid rock, } \\
\text { however, no soil to bury sensor, strong wind and lots of snow, sensor } \\
\text { frozen to ground in autumn, faulty E-component, kea damage }\end{array}$ \\
\hline BON* & $\begin{array}{l}\text { good site, few places to put sensor because of steep topography and } \\
\text { cell phone towers, no outcrop because of vegetation, sensor buried } \\
\text { in soil, kea damage }\end{array}$ \\
\hline DRC & $\begin{array}{l}\text { sensor buried in moraine on farm, noisy, likely to have cows/deer on } \\
\text { field, swampy, little sun, GPS had problems getting satellite contact }\end{array}$ \\
\hline ERE & noisy due to nearby farm, sensor buried in soil, waveforms emergent \\
\hline GCK & $\begin{array}{l}\text { sensor buried in river gravels, performance alright, sometimes noisy } \\
\text { (woodworks), now several sensors installed at DFDP1 boreholes }\end{array}$ \\
\hline GHU* & $\begin{array}{l}\text { good site, sensor buried in moraine, important site because close to } \\
\text { earthquakes, kea damage }\end{array}$ \\
\hline NOL* & $\begin{array}{l}\text { site performed better than expected, despite in moraine, no bedrock } \\
\text { in area close by, kea damage }\end{array}$ \\
\hline ONE & noisy but signal not too bad for farmland, huge station term of $0.7 \mathrm{~s}$ \\
\hline POE & site next to farm track in river gravels, sometimes noisy \\
\hline VBV* & $\begin{array}{l}\text { buried in moraine close to bivouac, quiet site, sheltered valley, } \\
\text { little sun, maybe snow in winter, kea damage }\end{array}$ \\
\hline WHB & in river gravels on farm, cows, noisy, picks up quarry blasts \\
\hline WNQ & sensor buried in gravels, little quarry noise, little sun \\
\hline
\end{tabular}

Table E.1. (b) Assessment of the performance of DFDP10 seismometer sites. Sites marked with star require helicopter access. 
E. Assessment of individual station performance 


\section{F. Noise characteristics of the SAMBA stations}

The analysis of power spectral densities shows that the N-component of the station EORO, the E-component of the station REYN and the first horizontal component of WHAT are faulty. These channels do not properly record frequencies below their natural frequencies of $2 \mathrm{~Hz}$. This has been recognised and fixed at station WHAT which had a "dry" soldering joint. For station REYN this problem could not be fixed as this channel appears to be ungrounded at the sensor (see also section D.2). For EORO, the malfunction of the channel is not particularly obvious in seismograms and has not been addressed yet. 
2009627 what 2

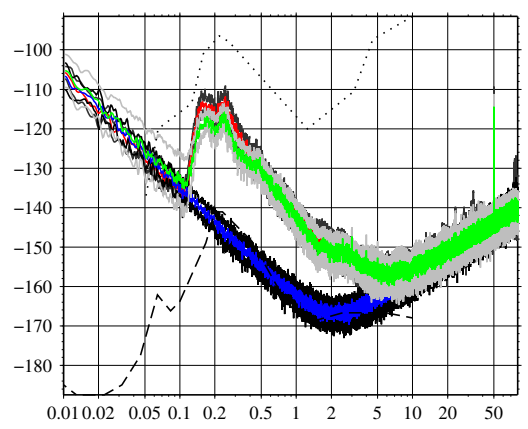

2009627 pocr2

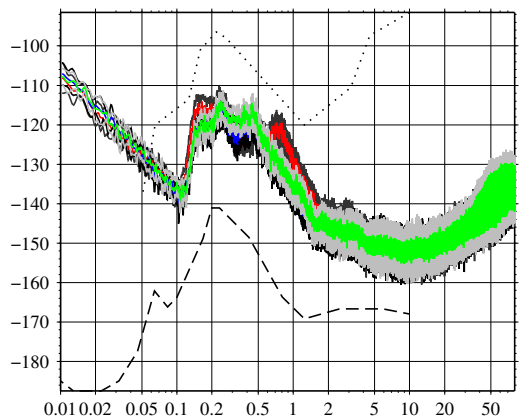

- SH Z av+sd - SH 1 av+sd

- SHZ av-sd - SH 1 av-sd

- $\mathrm{SH} \mathrm{Z}$ av
2009629 what 2

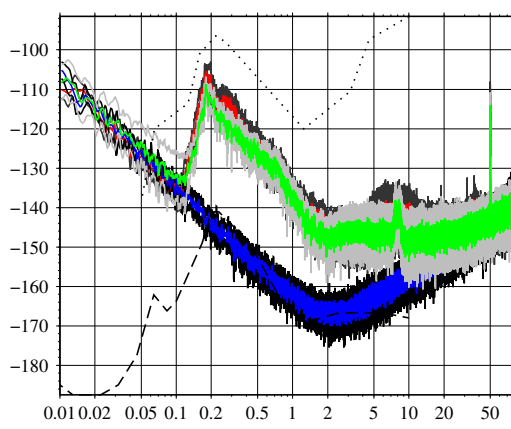

2009629 pocr2

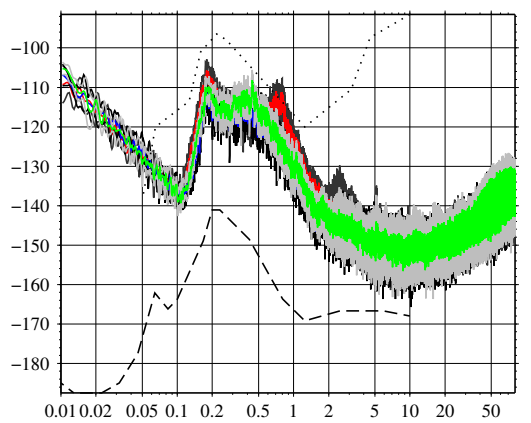

- SH 2 av+sd - - NHNM

- SH 2 av-sd $\quad \cdots \quad$ NLNM

- $\mathrm{SH} 2$ av

Figure F.1. Power spectral density for "low" (left) and "high" (right) noise conditions for the deep SAMBA stations, see Fig. 1.10 (c) for more detail 
$2009627 \mathrm{WVZ}$

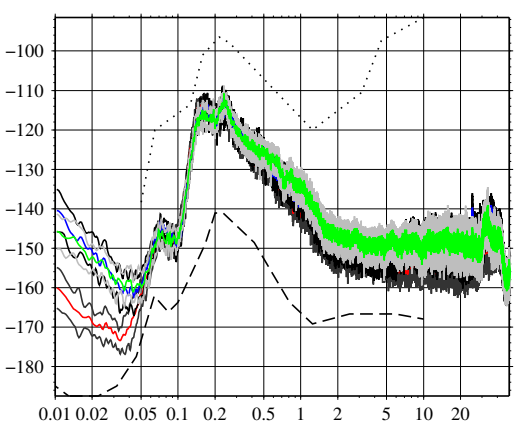

$-\mathrm{HH} \mathrm{Z}$ av+sd $-\mathrm{HH} \mathrm{N}$ av+sd

- $\mathrm{HH} \mathrm{Z}$ av-sd $-\mathrm{HH} \mathrm{N}$ av-sd

- $\mathrm{HHZ}$ av

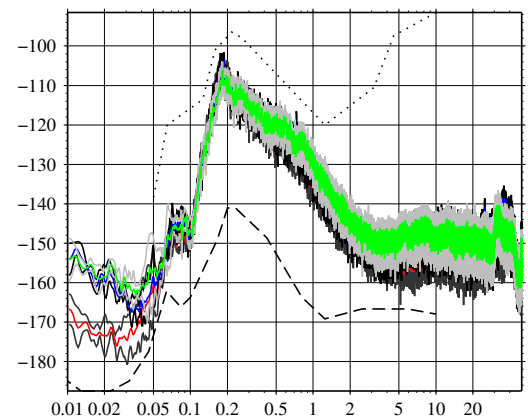

- HH E av+sd - - NHNM

- HH E av-sd … NLNM

- HH E av
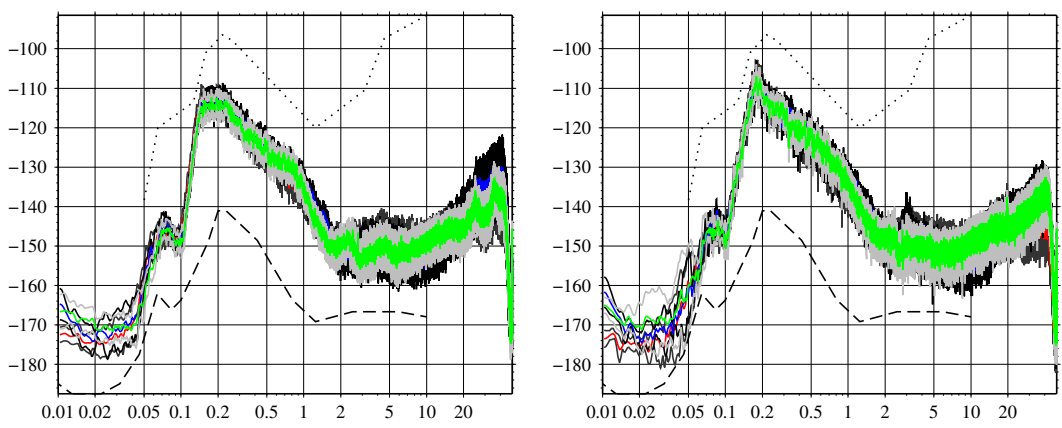

$$
\begin{aligned}
& \text { - HH Z av+sd - HH } 1 \text { av+sd - HH } 2 \text { av+sd - - NHNM }
\end{aligned}
$$

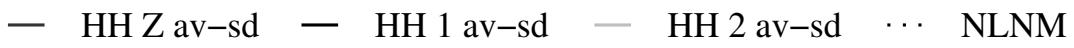

$$
\begin{aligned}
& -\mathrm{HHZav}-\mathrm{HH} 1 \mathrm{av}-\mathrm{HH} 2 \mathrm{av}
\end{aligned}
$$

Figure F.2. (a) Power spectral density for "low" (left) and "high" (right) noise conditions at the GeoNet stations, see Fig. 1.10 (c) for details. 
F. Noise characteristics of the SAMBA stations 


\section{G. Travel-time residuals of SAMBA and DFDP 10 stations}

Figure G.1. (a-d, following pages) Travel-time residuals for P (blue) and S-waves (red) versus event number for the combined SAMBA/GeoNet stations between 24 March and December 2009 when the SAMBA station network was complete and for the DFDP10 stations between January 2010 to April 2010. All values were reduced by the median of the distribution. Dashed red and blue lines show the range of one and two standard deviations. Travel-time residuals larger than two standard deviations were considered as outliers. 


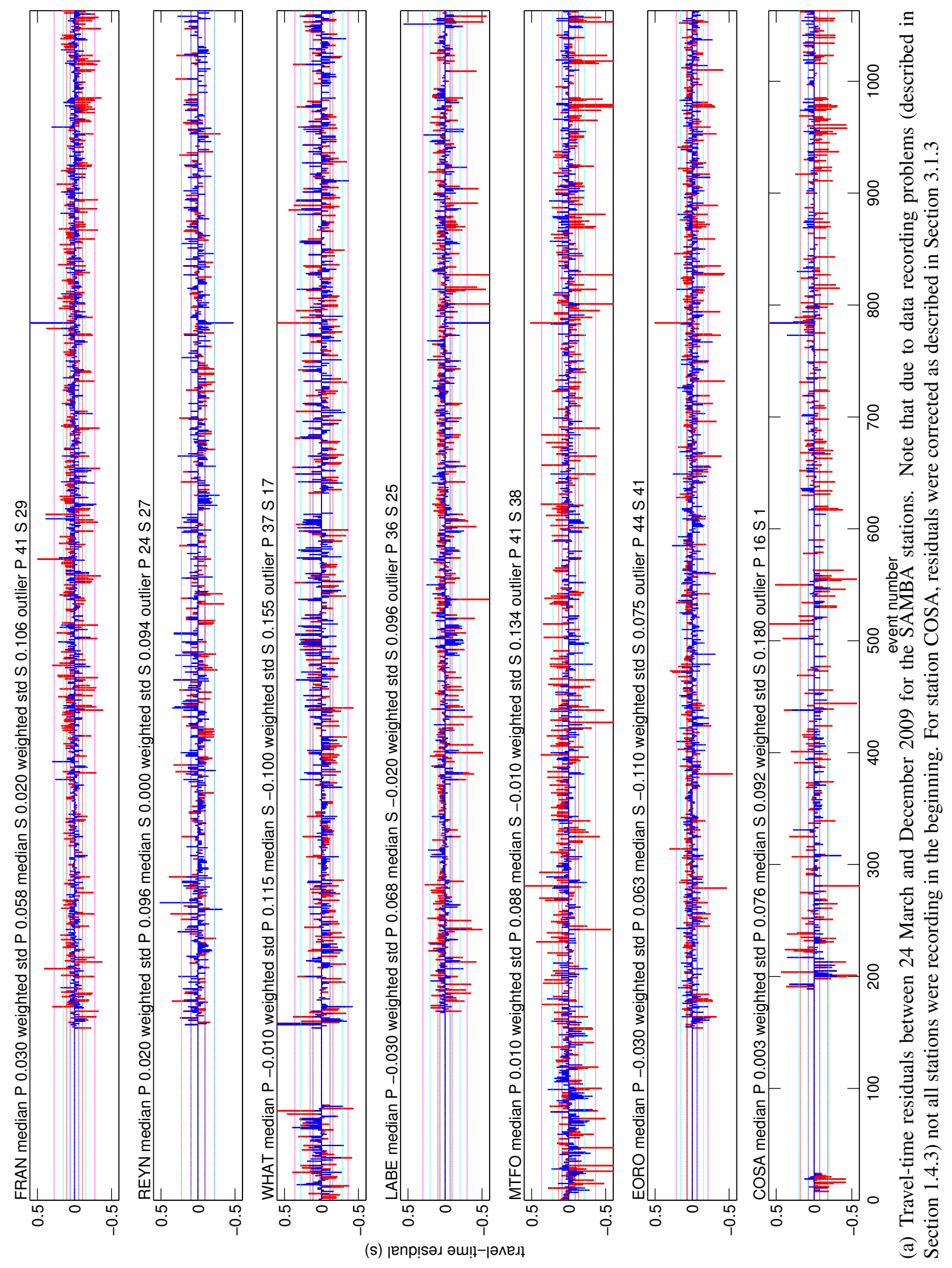



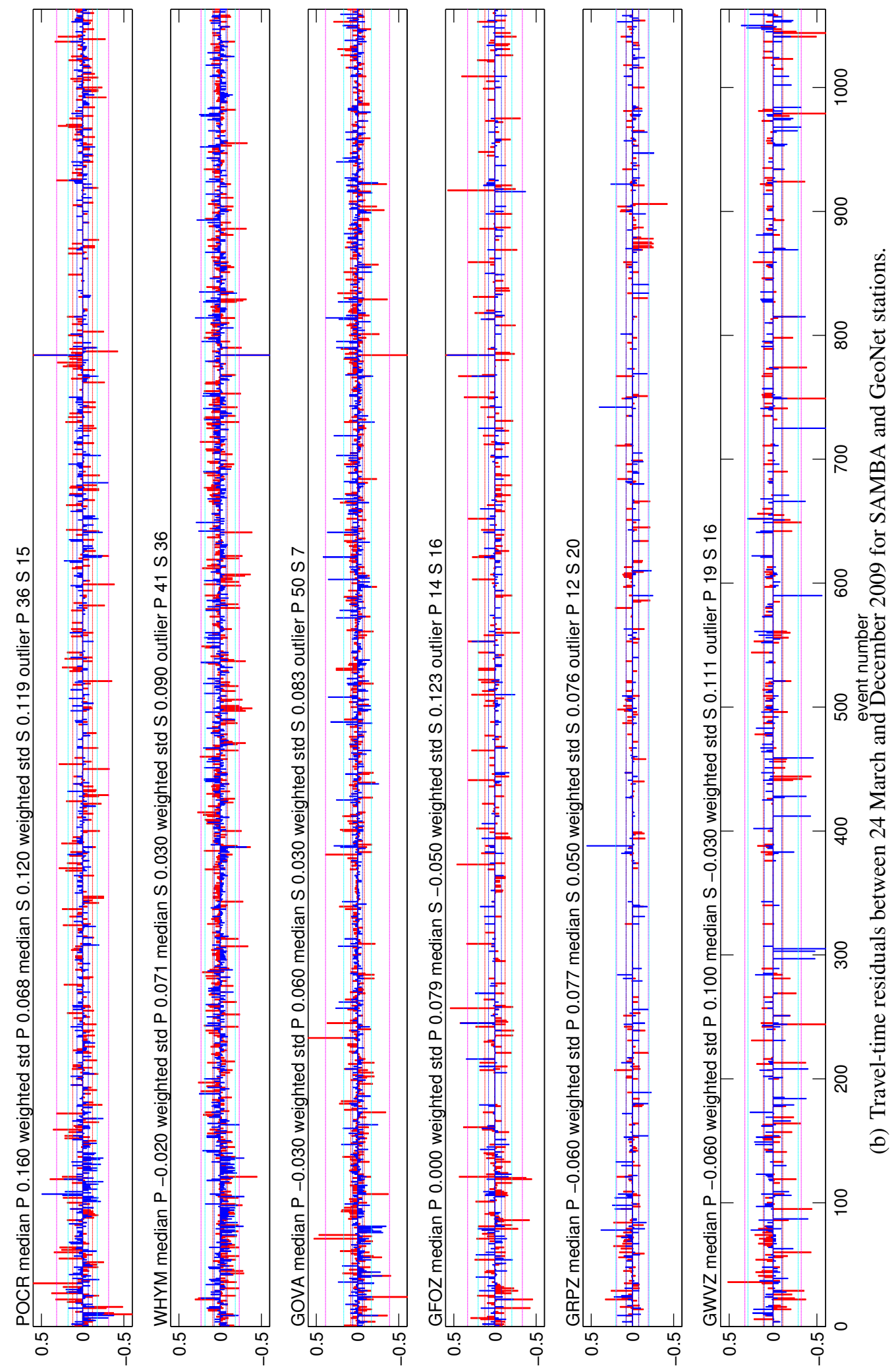

(s) ןenp!sәג әш!!-|әлеג 

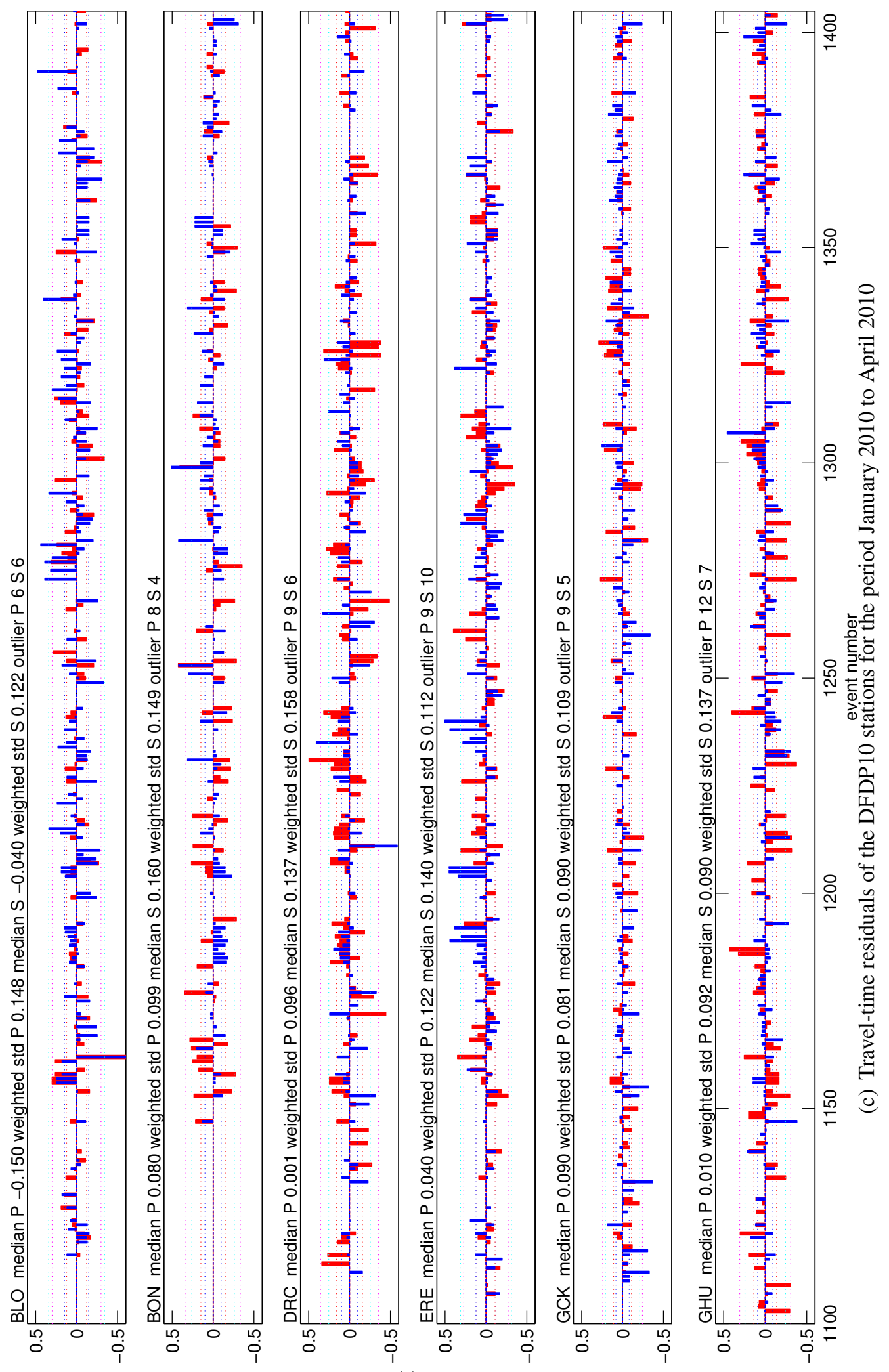

(s) ןenp!səג әш!!-|әлеגן 


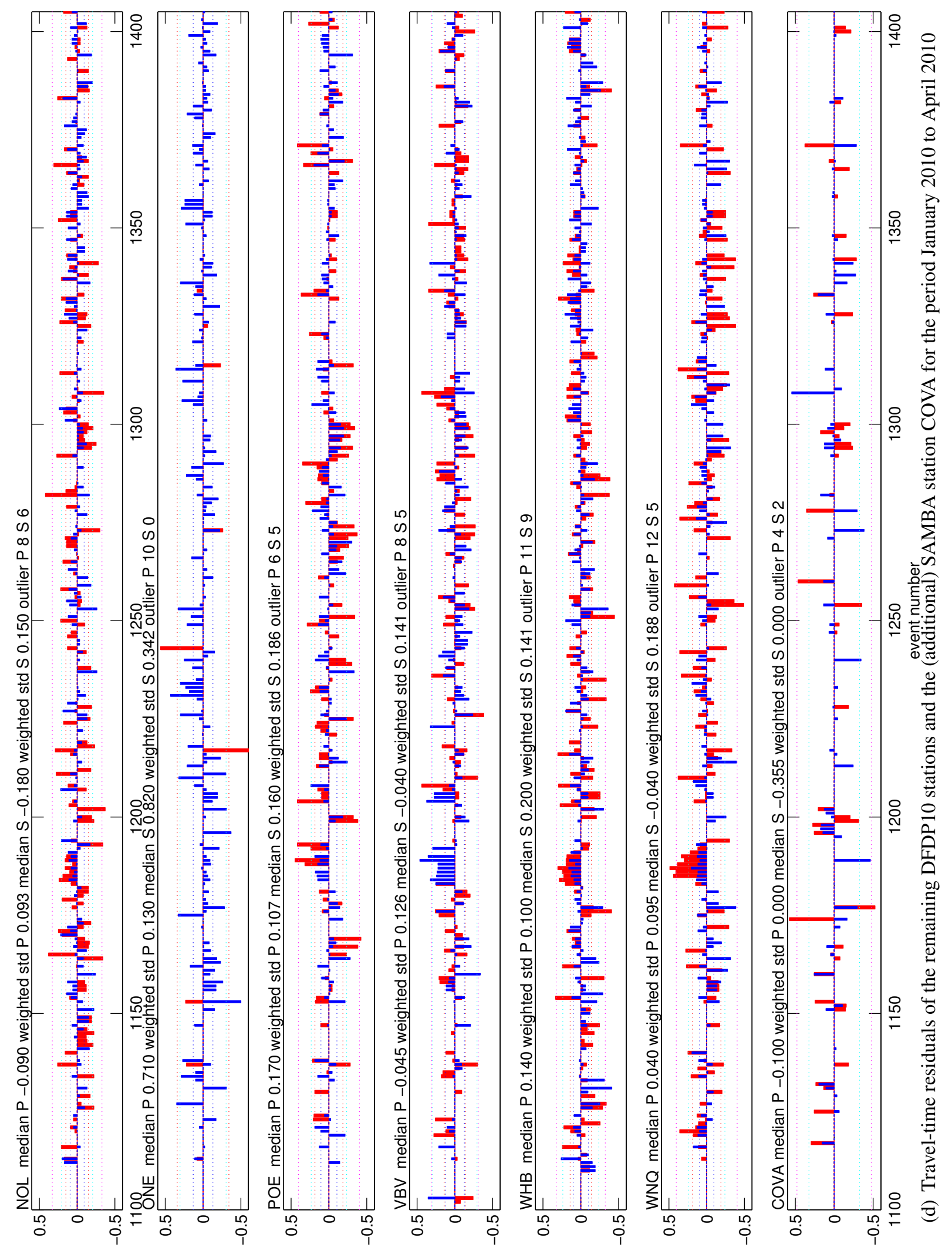


G. Travel-time residuals of SAMBA and DFDP10 stations 


\section{H. Comparisons of focal mechanism solutions}



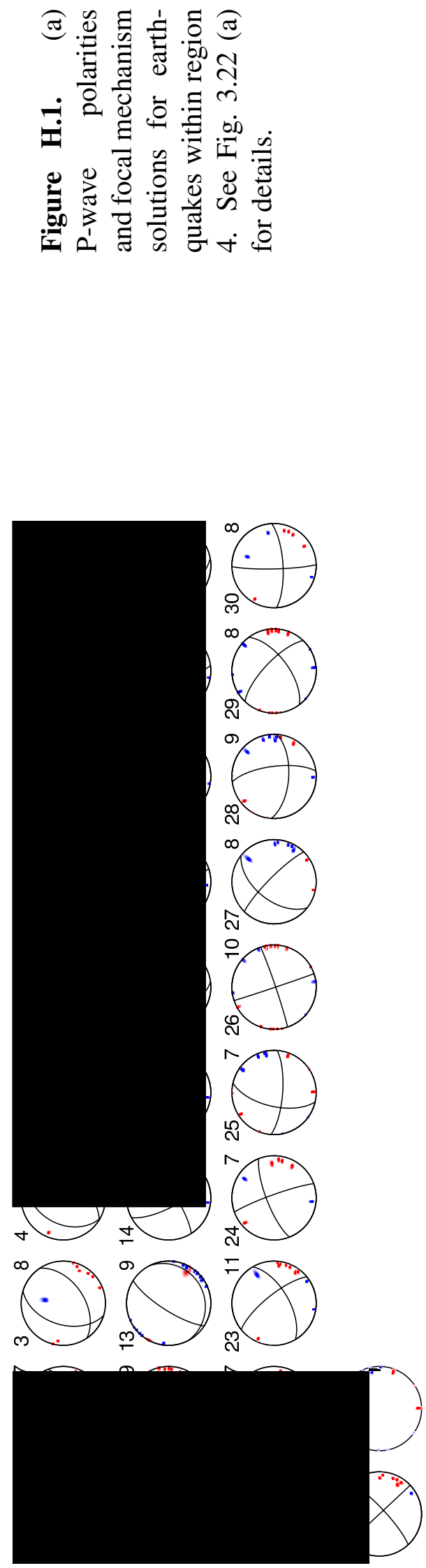

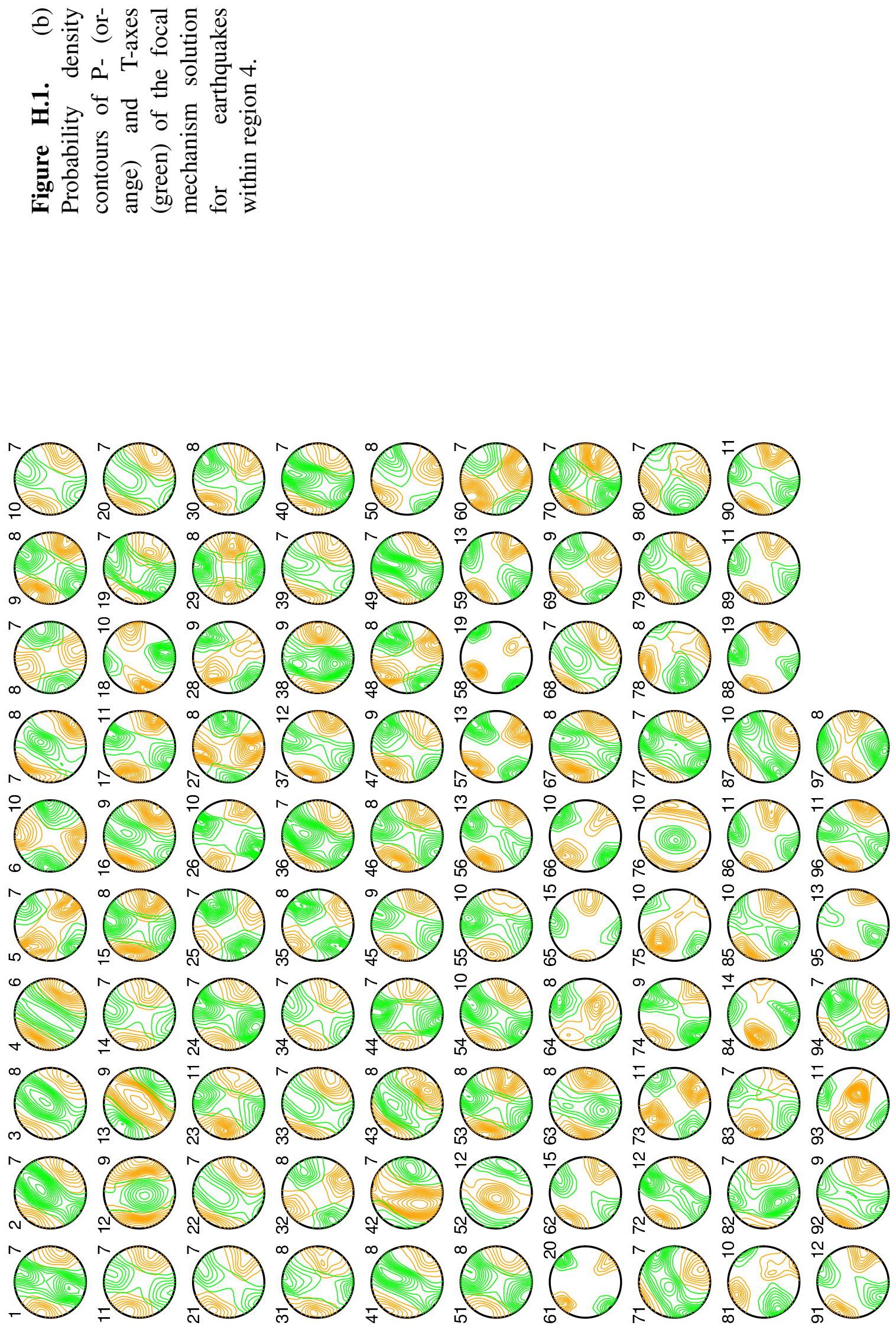

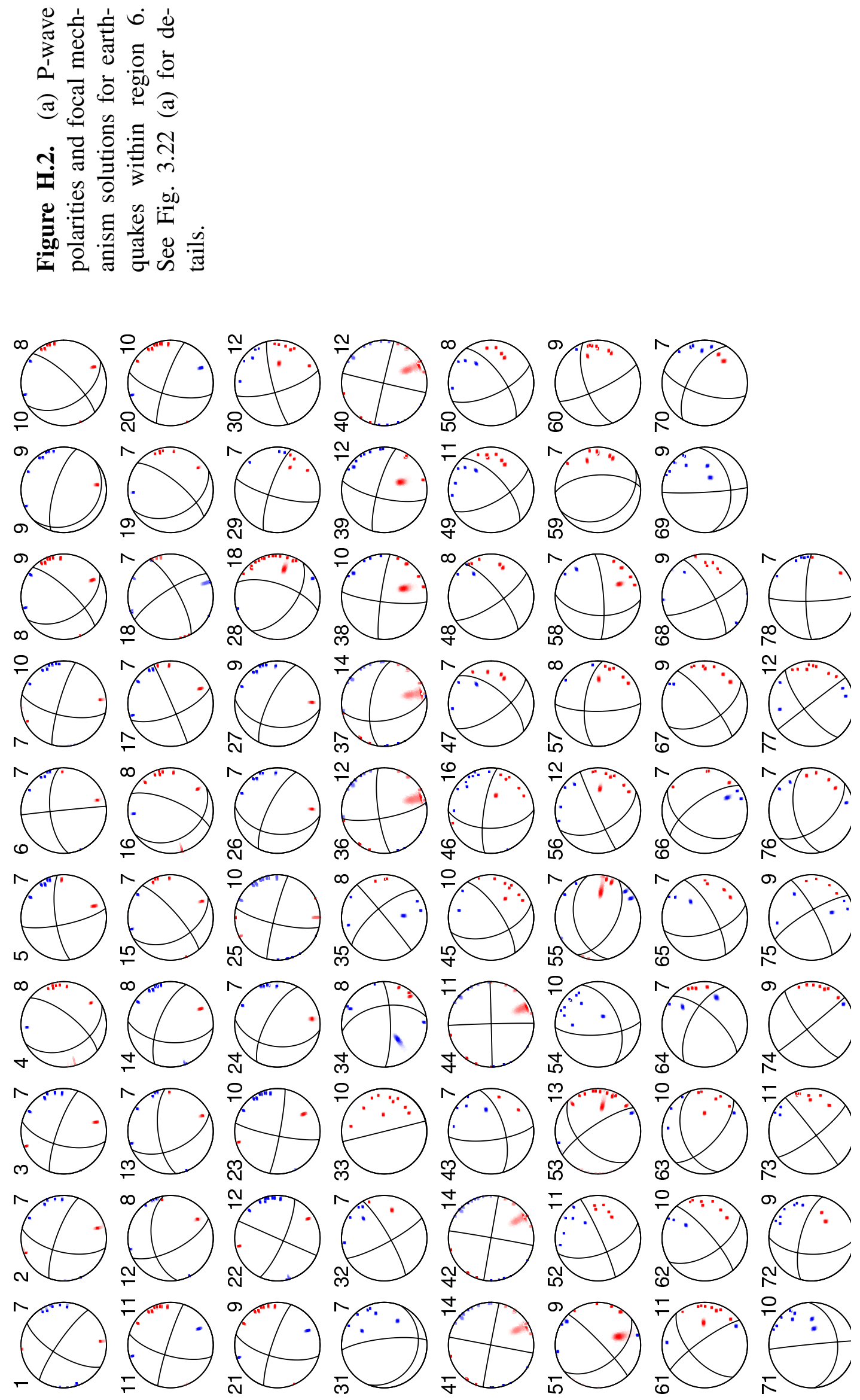
ڤ่

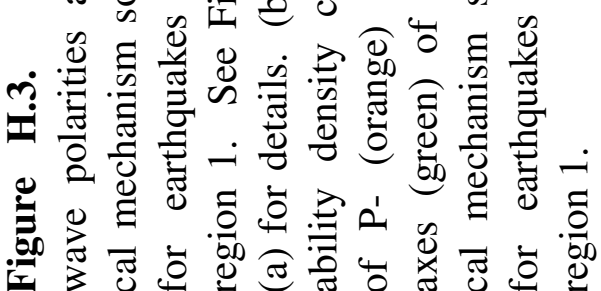
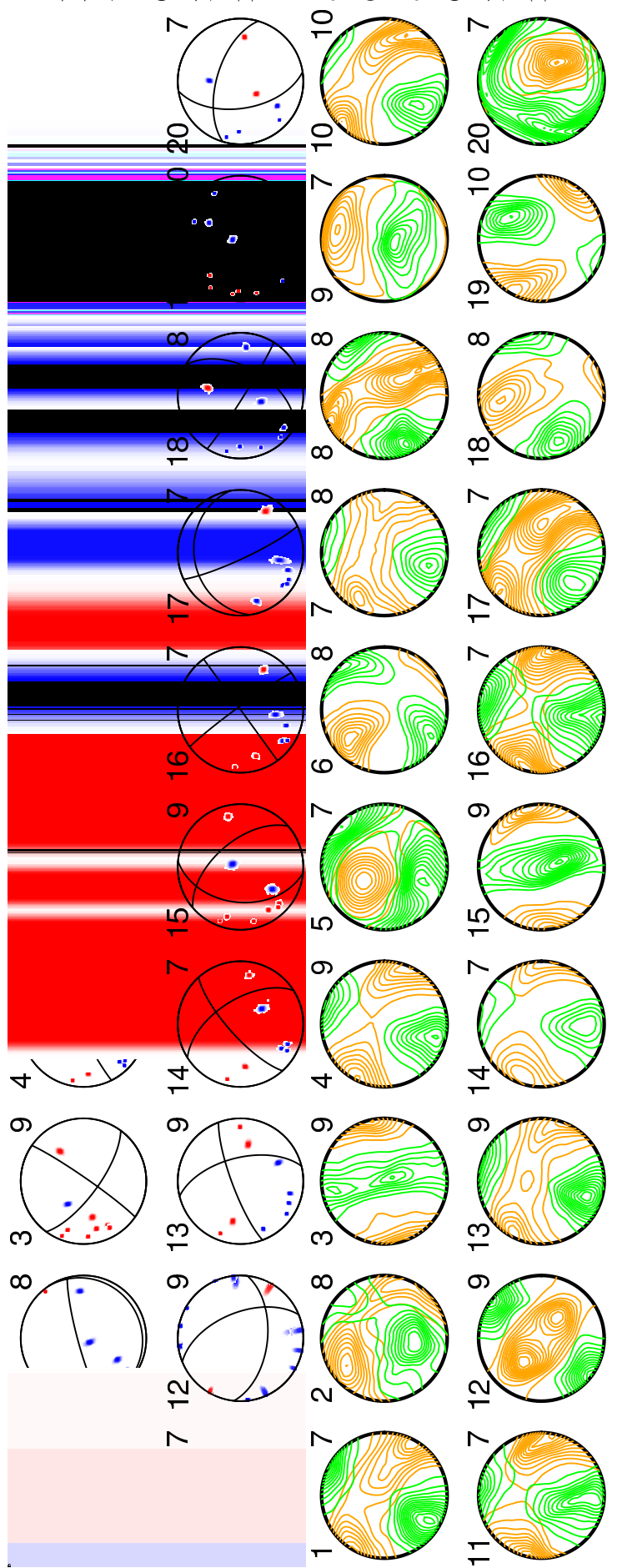
H. Comparisons of focal mechanism solutions 


\section{Slip, frequency, rupture and recording range of various-sized earthquakes}

\begin{tabular}{|c|c|c|c|c|c|}
\hline $\begin{array}{c}\text { Moment } \\
\text { Magnitude } \\
\mathrm{M}_{\mathrm{W}}\end{array}$ & $\begin{array}{c}\text { Average } \\
\text { slip }\end{array}$ & $\begin{array}{c}\text { Rupture length } \\
\text { or width } \\
\text { L or W }\end{array}$ & $\begin{array}{c}\text { Rupture } \\
\text { area } \\
\text { A } \sim \mathrm{L} \times \mathrm{W}\end{array}$ & $\begin{array}{c}\text { Relative } \\
\text { frequency }\end{array}$ & $\begin{array}{c}\text { Recording } \\
\text { range }\end{array}$ \\
\hline 8 & $4 \mathrm{~m}$ & $\begin{array}{c}100 \mathrm{~km} \\
(650 \mathrm{~km} / 15 \mathrm{~km})\end{array}$ & $10^{4} \mathrm{~km}^{2}$ & $\mathrm{Nyr}^{-1}$ & \\
7 & $1 \mathrm{~m}$ & $\begin{array}{c}30 \mathrm{~km} \\
(60 \mathrm{~km} / 15 \mathrm{~km})\end{array}$ & $10^{3} \mathrm{~km}^{2}$ & $10 \mathrm{~N} \mathrm{yr}{ }^{-1}$ & \\
6 & $40 \mathrm{~cm}$ & $10 \mathrm{~km}$ & $18 \mathrm{~km}^{2}$ & $10^{2} \mathrm{~N} \mathrm{yr}^{-1}$ & \\
5 & $10 \mathrm{~cm}$ & $3 \mathrm{~km}$ & $10 \mathrm{~km}^{2}$ & $10^{3} \mathrm{~N} \mathrm{yr}^{-1}$ & \\
4 & $4 \mathrm{~cm}$ & $1 \mathrm{~km}$ & $1 \mathrm{~km}^{2}$ & $10^{2} \mathrm{~N} \mathrm{yr}^{-1}$ & \\
3 & $1-4 \mathrm{~cm}$ & $300 \mathrm{~m}$ & $10^{5} \mathrm{~km}^{2}$ & $10^{5} \mathrm{~N} \mathrm{yr}^{-1}$ & $\sim 20 \mathrm{~km}$ \\
2 & $0.4-1 \mathrm{~cm}$ & $100 \mathrm{~m}$ & $10^{4} \mathrm{~m}^{2}$ & $10^{6} \mathrm{~N} \mathrm{yr}^{-1}$ & \\
1 & $1-4 \mathrm{~mm}$ & $30 \mathrm{~m}$ & $10^{3} \mathrm{~m}^{2}$ & $10^{7} \mathrm{~N} \mathrm{yr}^{-1}$ & \\
0 & $0.4-1 \mathrm{~mm}$ & & $30 \mathrm{~m}^{2}$ & $10^{8} \mathrm{~N} \mathrm{yr}^{-1}$ & $>3 \mathrm{~km}$ \\
-1 & $0.1-0.4 \mathrm{~mm}$ & & $3 \mathrm{~m}^{2}$ & $10^{9} \mathrm{~N} \mathrm{yr}^{2}-1$ & $1.5 \mathrm{~km}$ \\
-2 & $0.04-0.1 \mathrm{~mm}$ & & $0.3 \mathrm{~m}^{2}$ & $10^{10} \mathrm{~N} \mathrm{yr}^{-1}$ & $0.75 \mathrm{~km}$ \\
-3 & $10-40 \mu \mathrm{m}$ & & $0.03 \mathrm{~m}^{2}$ & $10^{11} \mathrm{~N} \mathrm{yr}^{-1}$ & $0.45 \mathrm{~km}$ \\
-4 & $\leq 10 \mu \mathrm{m}$ & & $0.003 \mathrm{~m}^{2}$ & $10^{11} \mathrm{~N} \mathrm{yr}^{-1}$ & $\leq 30 \mathrm{~m}$ \\
\hline
\end{tabular}

Table I.1. Source dimensions, frequency of occurrence and recording range for earthquakes of different magnitude. Table modified from Sibson (1989) and extended to earthquakes with $\mathrm{M}_{\mathrm{W}}<0$ 


\begin{tabular}{|c|c|c|c|c|}
\hline & & Stress $(\mathrm{MPa})$ & & Period \\
\hline Solid Earth tides & & $10^{-3}$ & & $12 \mathrm{~h}$ \\
Ocean tides & & $10^{-2}$ & & $12 \mathrm{~h}$ \\
Hydrological loading & & $10^{-3}-10^{-1}$ & & days-years \\
Glacier loading & & $10^{1}-10^{2}$ & & $10^{3}$ years \\
& $10^{2} \mathrm{~km}$ & $10^{3} \mathrm{~km}$ & $10^{4} \mathrm{~km}$ & \\
Static stress changes, M8 & $10^{-1}$ & $10^{-4}$ & $10^{-7}$ & $\mathrm{NA}$ \\
Dynamic stress changes, M8 & 3 & 0.06 & 0.001 & $20 \mathrm{~s}$ \\
\hline
\end{tabular}

Table I.2. Table 2 from Manga and Brodsky (2006) showing amplitudes and periods of stress changes from different sources compared with static and dynamic stresses imposed by earthquakes. 


\section{J. Hypocentre locations}

Hypocentre locations for the period November 2008 to December 2009 are available from the supplementary material Table 1 of Boese et al. (2012). The remaining events from January to April 2010 are listed below.

\begin{tabular}{|c|c|c|c|c|c|c|c|c|c|c|}
\hline $\begin{array}{r}\text { Date } \\
\text { yyyymmdd }\end{array}$ & $\begin{array}{l}\text { Time } \\
\text { hrmin }\end{array}$ & $\begin{array}{r}\mathrm{Sec} \\
{[\mathrm{s}]}\end{array}$ & $\begin{array}{r}\text { Latitude } \\
{\left[{ }^{\circ}\right]}\end{array}$ & $\begin{array}{r}\text { Longitude } \\
{\left[{ }^{\circ}\right]}\end{array}$ & $\begin{array}{r}\text { Depth } \\
{[\mathrm{km}]}\end{array}$ & $\begin{array}{r}\text { RMS } \\
{[\mathrm{s}]}\end{array}$ & STN & $\mathrm{NPH}$ & $\begin{array}{r}\text { GAP } \\
{\left[{ }^{\circ}\right]}\end{array}$ & Mag \\
\hline 20100101 & $2: 16$ & 48.89 & -43.414 & 170.236 & 4.52 & 0.03 & 3 & 6 & 264 & -0.04 \\
\hline 20100101 & $8: 58$ & 12.28 & -43.532 & 0.576 & -1.86 & 0.08 & & 11 & 238 & 0.95 \\
\hline 20100101 & $8: 58$ & 12.13 & -43.538 & 170.575 & 5.14 & 0.10 & & 12 & 238 & 0.95 \\
\hline 20100101 & $17: 06$ & 52.01 & -43.551 & 579 & 6.08 & 0.15 & 11 & 24 & 101 & 3.01 \\
\hline 20100101 & 17:07 & 4.61 & -43.556 & 583 & 7.60 & 0.14 & & 0 & 101 & 2.71 \\
\hline 20100101 & $21: 21$ & 21.24 & -43.956 & .752 & 23.03 & 0.09 & 4 & 12 & 306 & 2.31 \\
\hline 20100102 & $16: 34$ & 26.48 & -43.262 & 754 & 8.47 & 0.17 & ( & 19 & 158 & 2.48 \\
\hline 20100104 & 1:08 & 25.32 & -43.248 & 374 & 2.02 & 0.13 & & 16 & 297 & 1.85 \\
\hline 20100104 & 10:02 & 26.34 & -43.2 & & 8.57 & 0.20 & & 18 & 157 & 2.86 \\
\hline 20100105 & $1: 02$ & 6.23 & -43.1 & 21 & 11.42 & 0.17 & & 1 & 233 & 1.96 \\
\hline 20100105 & $3: 03$ & 41.65 & -43 & 302 & 9.27 & 0.11 & & 1 & 165 & 1.78 \\
\hline 20100105 & $5: 19$ & 55.09 & -43 & 80 & 9.27 & 0.18 & 7 & 17 & 218 & 2.16 \\
\hline 105 & 6:02 & 56.09 & -43 . & & 7.88 & 0 & & & 222 & 1.33 \\
\hline 05 & $6: 55$ & 8.35 & -43 & 63 & 10.03 & 0.12 & & 13 & 230 & 1.39 \\
\hline 20100105 & $8: 23$ & 44.65 & -43 & 372 & 0.08 & 0.09 & & 9 & 222 & NA \\
\hline 20100105 & $12: 01$ & 22.71 & -43.5 & & 9.41 & 0.20 & & 19 & 224 & 1.65 \\
\hline 20100105 & $12: 01$ & 33.85 & -43 . & & 7.9 & 0.09 & & 7 & 235 & 1.49 \\
\hline 105 & $12: 13$ & 34 & -4 & & 9. & 0 . & & 19 & 222 & 1.20 \\
\hline 105 & 13:08 & 12.39 & -43 . & 82 & 7.67 & 0.12 & 7 & 17 & 218 & 1.70 \\
\hline 20100105 & 13:09 & 43.42 & -43 & & 8.92 & 0.11 & & 14 & 229 & 1.24 \\
\hline 20100105 & $15: 19$ & 8.56 & -43.584 & & 8.99 & 0.16 & 7 & 17 & 219 & 1.64 \\
\hline 20100106 & $4: 35$ & 53.77 & -43.5 & 78 & 8.7 & 0. & & 13 & 220 & 1.60 \\
\hline 201 & $6: 16$ & 5 & -43 . & & 5.28 & 0.04 & & 1 & 212 & 0.76 \\
\hline 2010 & 13:04 & 4.24 & -43 . & & 7.95 & 0.14 & 10 & 22 & 129 & 2.36 \\
\hline 20100107 & $16: 29$ & 28.90 & -43.597 & 17 & 8.61 & 0.12 & 7 & 18 & 132 & 1.71 \\
\hline 2010 & $8: 18$ & 1.38 & -43.467 & 277 & 1.78 & 0.12 & 8 & 18 & 67 & 0.87 \\
\hline 20100108 & $9: 27$ & 19.38 & -43.5 & 17 & 2.9 & 0.13 & 9 & 19 & 141 & 1.37 \\
\hline 20100108 & $19: 31$ & 44.31 & -43.585 & & 0.00 & 0 . & & 5 & 172 & 1.10 \\
\hline 20100108 & $20: 34$ & 24.48 & -43.692 & & 12.63 & 0.02 & 2 & 8 & 232 & 1.60 \\
\hline 20100109 & $0: 25$ & 29.32 & -43.528 & 170.055 & 3.06 & 0.02 & 2 & 6 & 240 & NA \\
\hline & & & & & 2.61 & 0. & 5 & 14 & 140 & 0.93 \\
\hline 20100110 & $20: 42$ & 44.22 & -43.254 & 170.765 & 10.41 & 0.12 & 5 & 11 & 162 & 2.00 \\
\hline
\end{tabular}




\begin{tabular}{|c|c|c|c|c|c|c|c|c|c|c|}
\hline $\begin{array}{r}\text { Date } \\
\text { yyyymmdd }\end{array}$ & $\begin{array}{c}\text { Time } \\
\text { hrmin }\end{array}$ & $\begin{array}{r}\text { Sec } \\
{[\mathrm{s}]}\end{array}$ & $\begin{array}{r}\text { Latitude } \\
{\left[{ }^{\circ}\right]}\end{array}$ & $\begin{array}{r}\text { Longitude } \\
{\left[{ }^{\circ}\right]}\end{array}$ & $\begin{array}{r}\text { Depth } \\
{[\mathrm{km}]}\end{array}$ & $\begin{array}{r}\text { RMS } \\
{[\mathrm{s}]}\end{array}$ & STN & NPH & $\begin{array}{r}\text { GAP } \\
{\left[{ }^{\circ}\right]}\end{array}$ & Mag \\
\hline 20100110 & $20: 54$ & 1.53 & -43.456 & 170.400 & 6.42 & 0.18 & 7 & 17 & 125 & 1.85 \\
\hline 20100111 & $4: 38$ & 0.60 & -43.888 & 99.736 & 13.18 & 10 & & 14 & 303 & 1.96 \\
\hline 20100111 & $11: 44$ & 34.81 & -43.592 & 170.238 & 2.68 & 0.14 & 10 & 20 & 176 & 1.94 \\
\hline 20100117 & $22: 39$ & 1.77 & -43.377 & 169.772 & 57.56 & 0.12 & 4 & 8 & 318 & NA \\
\hline 20100112 & $11: 34$ & 47.38 & -43.454 & 171.061 & 13.84 & 0.16 & 10 & 21 & 213 & 2.35 \\
\hline 20100113 & $16: 51$ & 43.51 & -43.569 & 169.860 & 8.50 & 0.12 & 6 & 13 & 218 & 1.28 \\
\hline 20100114 & $5: 27$ & 40.36 & -43.538 & 70.590 & 6.56 & 0.11 & 10 & 21 & 104 & 1.42 \\
\hline 20100115 & $21: 34$ & 47.72 & -43.418 & 0.174 & 5.85 & 0.11 & 10 & 21 & 94 & 2.15 \\
\hline 20100116 & 11:02 & 31.26 & -43. & & 6.03 & 0.17 & 11 & $J$ & 86 & 1.95 \\
\hline 20100117 & $11: 41$ & 13.41 & -43.389 & 37 & 5.66 & 0.25 & 10 & 22 & 144 & 1.87 \\
\hline 20100117 & $22: 39$ & 1.77 & -43.377 & 772 & 57.56 & 0.12 & 4 & 8 & 318 & 1.45 \\
\hline 20100118 & $2: 40$ & 44.41 & -43.385 & 735 & 10.69 & 0.14 & 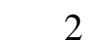 & 7 & 213 & 1.28 \\
\hline 20100118 & $9: 58$ & 15.59 & -43.818 & & 15.13 & 0.11 & 6 & 14 & 308 & 1.34 \\
\hline 20100118 & $17: 23$ & 27.02 & -43 . & 1 & 16.93 & 0.15 & 3 & 11 & 309 & 1.19 \\
\hline 20100119 & $3: 53$ & 1.02 & -43 . & & 11.24 & 08 & & 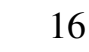 & 308 & 2.23 \\
\hline 20100119 & $8: 20$ & 47.06 & -43 . & & 10.58 & 0.16 & ) & 21 & 298 & 3.12 \\
\hline 20100119 & 10:41 & 14.58 & -43.546 & & -1.98 & 0.12 & 6 & 15 & 148 & 1.22 \\
\hline 20100120 & $12: 11$ & 20.52 & -43.455 & & 2.19 & 0.05 & 6 & 12 & 93 & 1.00 \\
\hline 20100120 & $12: 11$ & 23.98 & -43 . & & 3.34 & 0.09 & 3 & 10 & 104 & 1.00 \\
\hline 20100120 & $17: 30$ & 3.21 & -43 & & -1.93 & 0 & & 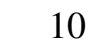 & 81 & 1.59 \\
\hline 20100121 & $14: 16$ & 56.85 & -43 & & 17.90 & 0.16 & & 15 & 299 & 1.50 \\
\hline 20100121 & $20: 12$ & 29.58 & -43 . & & 15.96 & 0.09 & & 14 & 298 & 1.80 \\
\hline 20100121 & $23: 44$ & 7.36 & -43.472 & 27 & 10.38 & 0.10 & $\varepsilon$ & 17 & 86 & 1.07 \\
\hline 20100121 & $23: 44$ & 7.38 & -43.470 & & 10.17 & 0 . & & 16 & 85 & 1.07 \\
\hline 2010 & $1: 29$ & 27.54 & -43 . & & 0.01 & 0.08 & & $\delta$ & 293 & 1.09 \\
\hline 20100122 & $7: 38$ & .49 & -43 . & & 3.75 & 0.22 & 4 & 12 & 145 & 1.36 \\
\hline 20100122 & $9: 12$ & 95 & -43 . & & 3.22 & & & 1 & 104 & 1.26 \\
\hline 20100123 & $9: 50$ & 39.59 & -43.879 & & 14.95 & 0. & 7 & $1 ?$ & 246 & 1.62 \\
\hline 20100123 & $9: 52$ & 25.60 & -43.256 & & 7.46 & 0 . & r & 19 & 190 & 1.82 \\
\hline 2010 & $16: 38$ & 8.19 & -43 . & & 5.18 & 0.09 & 5 & 13 & 94 & 0.68 \\
\hline 20100124 & $4: 43$ & 19.50 & -43 . & & 2.54 & 0.07 & 5 & 12 & 121 & 0.64 \\
\hline 20100124 & & & -43.291 & & & & & r & 250 & 1.35 \\
\hline 20100124 & $6: 31$ & 46.38 & -43.310 & & 10.45 & 0 . & 8 & 2 & 201 & 1.80 \\
\hline 20100124 & $8: 46$ & 29.88 & -43.2 & & -1.97 & 0. & 6 & 18 & 190 & 2.43 \\
\hline 2010 & $22: 03$ & 37.72 & -43 & & 5.94 & 0.27 & 6 & 17 & 199 & 1.65 \\
\hline 20100125 & $2: 45$ & 45.99 & -43 . & & -1.93 & 0.14 & 4 & 8 & 228 & 1.30 \\
\hline 20100125 & $3: 26$ & 19.54 & -43.646 & & 4. & 0 . & $J$ & 12 & 199 & 0.85 \\
\hline 20100125 & $17: 50$ & 27.97 & -43.479 & & 1.11 & 0.09 & 5 & 13 & 78 & 1.06 \\
\hline 20100125 & $18: 17$ & 20.77 & -43.247 & 17 & 10.00 & 0.22 & 2 & 7 & 272 & 2.01 \\
\hline 20100125 & $19: 35$ & 11.35 & -43.504 & & 5.14 & 0.04 & 4 & 9 & 131 & 0.82 \\
\hline 20100125 & $22: 48$ & 37.95 & -43.474 & 266 & -1.97 & 0.11 & 6 & 15 & 76 & 1.09 \\
\hline 20100126 & $9: 53$ & 33.24 & -43.547 & & 5.89 & 0.14 & 0 & 16 & 99 & 1.45 \\
\hline 20100126 & $20: 11$ & 12.14 & & & 1.01 & 0.08 & 4 & 9 & 198 & 0.92 \\
\hline 20100127 & & 2.34 & -43.278 & & -0.01 & 0.23 & 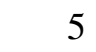 & 14 & 176 & NA \\
\hline 20100127 & $11: 57$ & 36.88 & -43.144 & & 7.60 & 0.16 & 4 & 16 & 225 & 1.82 \\
\hline 20100127 & $20: 30$ & 30.08 & -43.170 & 170.757 & 2.85 & 0.00 & 1 & 4 & 244 & 1.31 \\
\hline 20100128 & $9: 14$ & 28.53 & -43.572 & 171.136 & 14.81 & 0.09 & 6 & 15 & 232 & 1.71 \\
\hline
\end{tabular}




\begin{tabular}{|c|c|c|c|c|c|c|c|c|c|c|}
\hline $\begin{array}{r}\text { Date } \\
\text { yyyymmdd }\end{array}$ & $\begin{array}{l}\text { Time } \\
\text { hrmin }\end{array}$ & $\begin{array}{r}\mathrm{Sec} \\
{[\mathrm{s}]}\end{array}$ & $\begin{array}{r}\text { Latitude } \\
{\left[{ }^{\circ}\right]}\end{array}$ & $\begin{array}{r}\text { Longitude } \\
{\left[{ }^{\circ}\right]}\end{array}$ & $\begin{array}{r}\text { Depth } \\
{[\mathrm{km}]}\end{array}$ & $\begin{array}{r}\text { RMS } \\
{[\mathrm{s}]}\end{array}$ & STN & $\mathrm{NPH}$ & $\begin{array}{r}\text { GAP } \\
{\left[{ }^{\circ}\right]}\end{array}$ & Mag \\
\hline 20100128 & 16:07 & 42.46 & -43.594 & 170.623 & 9.11 & 0.28 & 13 & 26 & 131 & 2.37 \\
\hline 20100128 & $16: 35$ & 22.58 & -43.130 & 170.916 & 12.08 & 0.17 & 2 & 14 & 238 & 2.12 \\
\hline 20100128 & $17: 44$ & 24.87 & -43.549 & 170.240 & 6.15 & 0.11 & 6 & 15 & 157 & 1.19 \\
\hline 20100129 & $1: 53$ & 44.90 & -43.373 & 170.804 & -0.96 & 0.05 & 2 & 6 & 161 & 1.37 \\
\hline 20100129 & $17: 47$ & 55.27 & -43.493 & 170.324 & 4.43 & 0.09 & 8 & 18 & 104 & 1.14 \\
\hline 20100130 & $2: 29$ & 40.27 & -43.492 & 170.323 & 4.27 & 0.10 & 7 & 16 & 103 & 1.21 \\
\hline 20100130 & $2: 29$ & 46.93 & -43.491 & 170.322 & 4.34 & 0.10 & 3 & 11 & 102 & 0.69 \\
\hline 20100130 & $2: 40$ & 23.51 & -43.492 & 170.322 & 3.79 & 0.09 & 5 & 13 & 103 & 1.08 \\
\hline 20100130 & $2: 42$ & 14.05 & -43.494 & 170.323 & 4.36 & 0.11 & 7 & 17 & 104 & 1.25 \\
\hline 20100130 & 4:00 & 39.45 & -43.493 & 170.323 & 4.50 & 0.10 & 8 & 17 & 103 & 1.15 \\
\hline 20100130 & 7:51 & 25.04 & -43.038 & 171.213 & 21.09 & 0.21 & 7 & 19 & 286 & 2.44 \\
\hline 20100130 & $10: 58$ & 35.79 & -43.504 & 170.328 & 3.23 & 0.05 & 5 & 13 & 109 & 1.06 \\
\hline 20100130 & $10: 58$ & 39.57 & -43.503 & 170.328 & 3.58 & 0.06 & 5 & 15 & 109 & 1.06 \\
\hline 20100130 & $14: 49$ & 8.03 & -43.504 & 170.329 & 4.08 & 0.12 & 8 & 18 & 110 & 1.15 \\
\hline 20100130 & $14: 59$ & 15.57 & -43.457 & 170.395 & 7.05 & 0.21 & 9 & 19 & 123 & 1.77 \\
\hline 20100131 & $2: 29$ & 33.62 & -43.442 & 170.126 & 5.00 & 0.19 & 8 & 19 & 118 & 1.10 \\
\hline 20100131 & $11: 47$ & 36.61 & -43.425 & 170.053 & 8.45 & 0.11 & 10 & 23 & 177 & 2.44 \\
\hline 20100131 & 13:04 & 17.68 & -43.418 & 170.713 & 2.54 & 0.18 & 10 & 21 & 137 & 1.75 \\
\hline 20100201 & $4: 24$ & 50.68 & -43.266 & 170.361 & 0.95 & 0.19 & 3 & 12 & 292 & 0.74 \\
\hline 20100201 & 19:19 & 8.14 & -43.206 & 170.636 & -1.97 & 0.19 & 4 & 13 & 145 & 2.15 \\
\hline 20100201 & 19:19 & 8.19 & -43.200 & 170.625 & -1.97 & 0.20 & 7 & 17 & 146 & 2.15 \\
\hline 20100201 & $19: 27$ & 37.39 & -43.248 & 170.561 & 25.87 & 0.03 & 3 & 7 & 299 & 1.78 \\
\hline 20100201 & $22: 25$ & 58.35 & -43.220 & 170.846 & 12.84 & 0.02 & 2 & 5 & 239 & 1.69 \\
\hline 20100201 & $22: 39$ & 55.01 & -43.970 & 169.939 & 15.68 & 0.13 & 5 & 14 & 297 & 1.88 \\
\hline 20100201 & $23: 25$ & 58.33 & -43.202 & 170.628 & -1.93 & 0.08 & 3 & 8 & 159 & 1.78 \\
\hline 20100202 & $1: 28$ & 22.88 & -43.239 & 170.885 & 12.80 & 0.13 & 4 & 12 & 199 & 2.12 \\
\hline 20100202 & $2: 55$ & 58.73 & -43.460 & 170.233 & 7.33 & 0.06 & 6 & 12 & 83 & 0.99 \\
\hline 20100202 & $4: 26$ & 44.85 & -43.462 & 170.229 & 8.09 & 0.13 & 6 & 13 & 80 & 1.74 \\
\hline 20100202 & 9:01 & 17.39 & -43.582 & 170.623 & 8.00 & 0.21 & 12 & 24 & 123 & 3.54 \\
\hline 20100202 & 10:09 & 5.20 & -43.258 & 170.752 & 7.05 & 0.23 & 5 & 13 & 157 & 1.46 \\
\hline 20100202 & $20: 55$ & 18.70 & -43.474 & 170.541 & 9.61 & 0.20 & 9 & 20 & 103 & 2.11 \\
\hline 20100202 & $20: 59$ & 55.58 & -43.475 & 170.533 & 7.22 & 0.10 & 3 & 8 & 258 & 1.35 \\
\hline 20100202 & $21: 11$ & 33.23 & -43.470 & 170.551 & 8.99 & 0.16 & 6 & 14 & 172 & 1.64 \\
\hline 20100203 & $3: 38$ & 28.59 & -43.314 & 170.828 & 7.22 & 0.01 & 2 & 6 & 173 & 1.43 \\
\hline 20100203 & $11: 14$ & 39.37 & -43.577 & 170.614 & 9.27 & 0.13 & 8 & 20 & 119 & 1.73 \\
\hline 20100203 & $14: 35$ & 35.56 & -43.494 & 170.420 & 2.54 & 0.11 & 7 & 15 & 169 & 1.02 \\
\hline 20100203 & $16: 33$ & 19.10 & -43.431 & 170.385 & 3.15 & 0.16 & 7 & 17 & 164 & 1.13 \\
\hline 20100203 & $23: 21$ & 46.90 & -43.169 & 170.797 & 11.24 & 0.02 & 2 & 5 & 229 & 1.47 \\
\hline 20100204 & $3: 38$ & 35.18 & -43.234 & 170.763 & 0.01 & 0.03 & 2 & 5 & 211 & 1.60 \\
\hline 20100204 & $10: 48$ & 9.04 & -43.344 & 170.330 & -1.97 & 0.16 & 9 & 20 & 114 & 1.59 \\
\hline 20100204 & $13: 36$ & 24.52 & -43.469 & 170.549 & 7.19 & 0.18 & 6 & 16 & 104 & 1.39 \\
\hline 20100204 & $16: 30$ & 14.67 & -43.413 & 170.713 & -1.97 & 0.15 & 5 & 14 & 137 & 1.73 \\
\hline 20100204 & $19: 29$ & 56.51 & -43.473 & 170.541 & 7.22 & 0.07 & 2 & 8 & 223 & 1.18 \\
\hline 20100205 & $0: 37$ & 41.23 & -43.501 & 170.352 & 27.40 & 0.00 & 2 & 4 & 360 & 0.66 \\
\hline 20100205 & 7:01 & 39.10 & -43.464 & 170.552 & 6.08 & 0.16 & 6 & 16 & 105 & 1.46 \\
\hline 20100205 & $14: 27$ & 56.04 & -43.501 & 170.510 & -1.97 & 0.11 & 5 & 12 & 208 & 1.05 \\
\hline 20100205 & 23:07 & 30.08 & -43.296 & 170.782 & -1.97 & 0.23 & 5 & 12 & 163 & 1.57 \\
\hline
\end{tabular}




\begin{tabular}{|c|c|c|c|c|c|c|c|c|c|c|}
\hline $\begin{array}{r}\text { Date } \\
\text { yyyymmdd }\end{array}$ & $\begin{array}{r}\text { Time } \\
\text { hrmin }\end{array}$ & $\begin{array}{r}\mathrm{Sec} \\
{[\mathrm{s}]}\end{array}$ & $\begin{array}{r}\text { Latitude } \\
{\left[{ }^{\circ}\right]}\end{array}$ & $\begin{array}{r}\text { Longitude } \\
{\left[{ }^{\circ}\right]}\end{array}$ & $\begin{array}{r}\text { Depth } \\
{[\mathrm{km}]}\end{array}$ & $\begin{array}{r}\text { RMS } \\
{[\mathrm{s}]}\end{array}$ & STN & $\mathrm{NPH}$ & $\begin{array}{r}\text { GAP } \\
{\left[{ }^{\circ}\right]}\end{array}$ & Mag \\
\hline 20100206 & $8: 44$ & 55.21 & -43.268 & 170.807 & -1.97 & 0.22 & 7 & 16 & 225 & 2.26 \\
\hline 20100206 & $8: 54$ & 0.38 & -43.264 & 170.794 & -1.97 & 0.21 & 7 & 18 & 170 & 1.72 \\
\hline 20100206 & $8: 54$ & 55.67 & -43.265 & 170.792 & -1.97 & 0.22 & 5 & 13 & 169 & 1.61 \\
\hline 20100206 & $9: 48$ & 37.70 & -43.261 & 170.792 & 6.67 & 0.21 & 6 & 17 & 169 & 1.93 \\
\hline 20100206 & $11: 55$ & 3.56 & -43.262 & 170.803 & -1.97 & 0.25 & 5 & 16 & 172 & 1.71 \\
\hline 20100206 & $18: 56$ & 52.56 & -43.270 & 170.809 & -1.93 & 0.19 & 6 & 17 & 226 & 2.28 \\
\hline 20100206 & 19:04 & 18.05 & -43.270 & 170.815 & -1.97 & 0.19 & 7 & 17 & 227 & 2.05 \\
\hline 20100207 & $6: 58$ & 31.35 & -43.268 & 170.807 & -1.97 & 0.21 & 4 & 8 & 225 & 1.27 \\
\hline 20100207 & 19:48 & 22.56 & -43.257 & 170.763 & 8.19 & 0.06 & 3 & 6 & 212 & 1.46 \\
\hline 20100207 & $22: 26$ & 1.52 & -43.202 & 170.894 & 19.56 & 0.03 & 1 & 6 & 210 & 1.86 \\
\hline 20100208 & $7: 19$ & 52.89 & -43.536 & 170.668 & 6.11 & 0.08 & 4 & 12 & 270 & 1.57 \\
\hline 20100208 & 19:41 & 20.08 & -43.706 & 170.035 & 9.34 & 0.10 & 5 & 12 & 238 & 1.05 \\
\hline 20100209 & $4: 21$ & 17.63 & -43.543 & 169.971 & 7.41 & 0.13 & 9 & 19 & 119 & 1.66 \\
\hline 20100209 & $5: 33$ & 19.63 & -43.546 & 169.972 & 8.64 & 0.09 & 4 & 9 & 143 & 0.59 \\
\hline 20100209 & $5: 33$ & 35.99 & -43.543 & 169.974 & 7.33 & 0.11 & 5 & 11 & 118 & 0.83 \\
\hline 20100209 & $8: 26$ & 11.89 & -43.508 & 170.503 & 7.41 & 0.20 & 10 & 22 & 95 & 2.01 \\
\hline 20100209 & $8: 50$ & 46.78 & -43.498 & 170.286 & 3.79 & 0.22 & 11 & 23 & 79 & 2.43 \\
\hline 20100209 & $11: 23$ & 30.94 & -43.542 & 169.973 & 7.40 & 0.15 & 8 & 17 & 119 & 1.21 \\
\hline 20100209 & $11: 42$ & 9.76 & -43.542 & 169.974 & 7.64 & 0.16 & 10 & 20 & 119 & 1.77 \\
\hline 20100209 & $13: 48$ & 17.30 & -43.430 & 170.683 & 9.16 & 0.06 & 3 & 6 & 269 & 1.43 \\
\hline 20100209 & $14: 57$ & 1.48 & -43.270 & 170.806 & -1.97 & 0.19 & 5 & 12 & 225 & 1.37 \\
\hline 20100209 & $14: 57$ & 47.18 & -43.269 & 170.831 & -1.93 & 0.12 & 2 & 7 & 232 & 1.29 \\
\hline 20100209 & $19: 39$ & 27.97 & -43.310 & 170.905 & 10.55 & 0.09 & 6 & 16 & 192 & 2.00 \\
\hline 20100209 & $19: 57$ & 9.12 & -43.259 & 170.840 & 8.30 & 0.19 & 5 & 16 & 183 & 2.54 \\
\hline 20100210 & $6: 28$ & 1.46 & -43.171 & 170.341 & 18.80 & 0.02 & 2 & 4 & 265 & 1.57 \\
\hline 20100211 & $3: 39$ & 58.53 & -43.155 & 170.928 & 11.17 & 0.20 & 1 & 9 & 231 & 2.08 \\
\hline 20100211 & $18: 58$ & 7.38 & -43.311 & 170.362 & 9.79 & 0.06 & 2 & 4 & 195 & 1.29 \\
\hline 20100211 & $20: 05$ & 16.78 & -43.449 & 170.241 & 6.89 & 0.14 & 6 & 14 & 71 & 1.13 \\
\hline 20100211 & $21: 50$ & 10.58 & -43.138 & 170.948 & 11.97 & 0.26 & 4 & 15 & 241 & 2.36 \\
\hline 20100212 & $13: 32$ & 59.74 & -43.207 & 170.595 & 6.94 & 0.09 & 1 & 11 & 151 & 1.74 \\
\hline 20100213 & $2: 59$ & 14.24 & -43.203 & 170.640 & 4.17 & 0.11 & 4 & 10 & 163 & 1.56 \\
\hline 20100213 & $11: 36$ & 45.31 & -43.417 & 170.711 & -1.97 & 0.18 & 9 & 21 & 136 & 2.54 \\
\hline 20100213 & $19: 32$ & 13.17 & -43.584 & 170.620 & 5.73 & 0.21 & 10 & 22 & 124 & 1.97 \\
\hline 20100214 & 1:04 & 26.64 & -43.152 & 170.901 & 7.01 & 0.23 & 4 & 8 & 226 & 1.75 \\
\hline 20100214 & $7: 27$ & 43.41 & -43.535 & 170.425 & 3.69 & 0.09 & 6 & 14 & 161 & 1.24 \\
\hline 20100214 & $8: 41$ & 32.43 & -43.460 & 170.285 & 6.70 & 0.14 & 4 & 13 & 65 & 1.09 \\
\hline 20100214 & $13: 26$ & 0.92 & -43.209 & 170.866 & -0.34 & 0.01 & 1 & 4 & 246 & 1.13 \\
\hline 20100214 & $23: 42$ & 35.65 & -43.172 & 170.787 & 10.90 & 0.01 & 2 & 5 & 181 & 1.66 \\
\hline 20100215 & $9: 40$ & 30.90 & -43.257 & 170.821 & 6.60 & 0.15 & 3 & 7 & 229 & 1.24 \\
\hline 20100215 & $13: 30$ & 29.97 & -43.525 & 170.690 & -1.97 & 0.15 & 7 & 17 & 121 & 1.68 \\
\hline 20100215 & $15: 56$ & 56.70 & -43.528 & 170.302 & 4.83 & 0.12 & 8 & 18 & 118 & 1.25 \\
\hline 20100216 & $11: 22$ & 7.21 & -43.134 & 170.971 & 12.73 & 0.32 & 5 & 16 & 246 & 1.89 \\
\hline 20100216 & $20: 48$ & 17.56 & -43.777 & 170.510 & 3.96 & 0.03 & 2 & 4 & 322 & 1.01 \\
\hline 20100216 & 21:02 & 45.67 & -43.401 & 170.746 & -1.97 & 0.16 & 5 & 11 & 217 & 1.54 \\
\hline 20100217 & $0: 32$ & 32.60 & -43.425 & 170.218 & 8.30 & 0.15 & 7 & 14 & 133 & 0.99 \\
\hline 20100217 & 1:09 & 12.64 & -43.403 & 170.779 & -1.97 & 0.16 & 8 & 18 & 152 & 1.88 \\
\hline 20100217 & $2: 10$ & 51.29 & -43.155 & 170.935 & 10.00 & 0.22 & 3 & 9 & 233 & 1.82 \\
\hline
\end{tabular}




\begin{tabular}{|c|c|c|c|c|c|c|c|c|c|c|}
\hline $\begin{array}{r}\text { Date } \\
\text { yyyymmdd }\end{array}$ & $\begin{array}{r}\text { Time } \\
\text { hrmin }\end{array}$ & $\begin{array}{r}\mathrm{Sec} \\
{[\mathrm{s}]}\end{array}$ & $\begin{array}{r}\text { Latitude } \\
{\left[{ }^{\circ}\right]}\end{array}$ & $\begin{array}{r}\text { Longitude } \\
{\left[{ }^{\circ}\right]}\end{array}$ & $\begin{array}{r}\text { Depth } \\
{[\mathrm{km}]}\end{array}$ & $\begin{array}{r}\text { RMS } \\
{[\mathrm{s}]}\end{array}$ & STN & $\mathrm{NPH}$ & $\begin{array}{r}\text { GAP } \\
{\left[{ }^{\circ}\right]}\end{array}$ & Mag \\
\hline 20100217 & $5: 57$ & 26.01 & -43.128 & 170.964 & 15.26 & 0.23 & 3 & 10 & 246 & 1.83 \\
\hline 20100217 & $7: 21$ & 29.56 & -43.152 & 170.929 & 12.08 & 0.19 & 2 & 12 & 233 & 2.63 \\
\hline 20100217 & $7: 28$ & 57.28 & -43.155 & 170.923 & 11.94 & 0.17 & 2 & 13 & 230 & 3.15 \\
\hline 20100217 & 7:31 & 38.24 & -43.147 & 170.937 & 15.06 & 0.05 & 2 & 5 & 277 & 1.31 \\
\hline 20100217 & $7: 55$ & 29.53 & -43.159 & 171.003 & -0.96 & 0.08 & 3 & 6 & 284 & 1.57 \\
\hline 20100217 & $8: 10$ & 49.08 & -43.301 & 170.810 & -1.97 & 0.23 & 2 & 7 & 226 & 1.50 \\
\hline 20100217 & $8: 29$ & 55.82 & -43.437 & 170.384 & 5.02 & 0.10 & 7 & 15 & 163 & 1.27 \\
\hline 20100217 & $8: 33$ & 26.74 & -43.169 & 170.986 & -1.93 & 0.21 & 5 & 13 & 279 & 2.21 \\
\hline 20100217 & 9:02 & 54.61 & -43.720 & 170.649 & 9.13 & 0.11 & 2 & 9 & 204 & 1.62 \\
\hline 20100217 & $10: 03$ & 59.29 & -43.150 & 171.029 & 8.05 & 0.21 & 5 & 15 & 289 & 2.53 \\
\hline 20100217 & $14: 32$ & 53.06 & -43.266 & 170.790 & -1.97 & 0.22 & 5 & 10 & 168 & 1.84 \\
\hline 20100218 & $6: 26$ & 40.51 & -43.264 & 170.797 & -1.93 & 0.16 & 4 & 10 & 170 & 1.93 \\
\hline 20100218 & 11:02 & 48.48 & -43.417 & 170.714 & -1.97 & 0.19 & 7 & 15 & 211 & NA \\
\hline 20100218 & 2:02 & 53.01 & -43.552 & 170.578 & 6.39 & 0.08 & 3 & 8 & 264 & NA \\
\hline 20100219 & 2:02 & 52.99 & -43.552 & 170.580 & 6.39 & 0.08 & 3 & 8 & 265 & 1.46 \\
\hline 20100219 & $10: 03$ & 36.96 & -43.505 & 170.690 & 8.12 & 0.06 & 3 & 9 & 272 & 1.36 \\
\hline 20100219 & $17: 58$ & 20.80 & -43.565 & 170.532 & 6.70 & 0.10 & 9 & 19 & 135 & 1.73 \\
\hline 20100219 & 23:04 & 6.56 & -43.564 & 170.223 & 6.42 & 0.06 & 4 & 10 & 177 & 0.77 \\
\hline 20100220 & $2: 31$ & 30.94 & -43.171 & 170.888 & 8.19 & 0.21 & 3 & 13 & 217 & 3.27 \\
\hline 20100221 & $2: 27$ & 26.17 & -43.421 & 170.701 & 9.34 & 0.19 & 7 & 14 & 134 & 1.55 \\
\hline 20100221 & $15: 59$ & 12.22 & -43.034 & 171.215 & 12.25 & 0.28 & 6 & 16 & 287 & 2.29 \\
\hline 20100221 & 18:08 & 32.78 & -43.385 & 170.310 & 4.76 & 0.13 & 4 & 11 & 122 & 1.02 \\
\hline 20100221 & 18:08 & 38.92 & -42.912 & 171.447 & 6.84 & 0.37 & 5 & 15 & 307 & 3.27 \\
\hline 20100222 & $5: 59$ & 9.41 & -43.507 & 170.501 & 6.84 & 0.22 & 8 & 18 & 95 & 1.95 \\
\hline 20100222 & 6:00 & 41.76 & -43.506 & 170.509 & 4.83 & 0.12 & 6 & 13 & 207 & 1.47 \\
\hline 20100222 & $10: 47$ & 56.58 & -43.253 & 170.866 & -1.97 & 0.24 & 8 & 16 & 191 & 1.65 \\
\hline 20100222 & 11:41 & 12.70 & -43.503 & 170.513 & -1.97 & 0.12 & 5 & 12 & 209 & 1.16 \\
\hline 20100222 & $13: 25$ & 40.09 & -43.384 & 170.313 & 6.22 & 0.13 & 5 & 12 & 125 & 1.20 \\
\hline 20100222 & $20: 26$ & 57.67 & -43.171 & 170.868 & 8.75 & 0.23 & 3 & 9 & 211 & 1.90 \\
\hline 20100223 & $7: 30$ & 1.32 & -43.616 & 169.779 & 9.58 & 0.13 & 5 & 12 & 317 & 1.72 \\
\hline 20100223 & $11: 49$ & 7.11 & -43.252 & 170.789 & -1.93 & 0.14 & 3 & 8 & 169 & 1.58 \\
\hline 20100223 & $22: 22$ & 0.00 & -43.304 & 170.501 & 0.98 & 0.05 & 3 & 7 & 256 & NA \\
\hline 20100223 & $22: 25$ & 8.40 & -43.282 & 170.362 & -0.01 & 0.12 & 2 & 10 & 111 & NA \\
\hline 20100224 & $22: 17$ & 49.07 & -43.550 & 170.672 & 9.23 & 0.02 & 2 & 5 & 210 & 1.63 \\
\hline 20100225 & $3: 42$ & 21.61 & -43.358 & 170.615 & -1.93 & 0.14 & 3 & 7 & 178 & 1.60 \\
\hline 20100225 & $11: 53$ & 18.49 & -43.671 & 171.113 & 9.61 & 0.06 & 6 & 15 & 247 & 2.43 \\
\hline 20100225 & $14: 04$ & 34.43 & -43.363 & 170.799 & -1.97 & 0.20 & 5 & 12 & 161 & 1.51 \\
\hline 20100226 & $1: 30$ & 16.01 & -43.505 & 170.503 & 6.29 & 0.20 & 8 & 17 & 96 & 2.30 \\
\hline 20100226 & 20:08 & 46.85 & -43.537 & 170.609 & 5.56 & 0.08 & 5 & 10 & 252 & 1.33 \\
\hline 20100226 & $20: 52$ & 58.13 & -43.411 & 170.441 & 5.04 & 0.13 & 5 & 10 & 193 & 1.05 \\
\hline 20100227 & $6: 20$ & 23.82 & -43.576 & 170.640 & 11.42 & 0.09 & 3 & 11 & 149 & 1.69 \\
\hline 20100227 & $6: 41$ & 13.03 & -43.578 & 170.639 & 12.04 & 0.08 & 3 & 10 & 148 & 1.61 \\
\hline 20100227 & 8:06 & 15.64 & -43.092 & 170.789 & 12.04 & 0.26 & 7 & 18 & 230 & 2.81 \\
\hline 20100227 & $18: 55$ & 11.76 & -43.571 & 170.639 & 9.30 & 0.08 & 5 & 10 & 270 & 1.47 \\
\hline 20100228 & $3: 35$ & 39.34 & -43.256 & 170.875 & -1.93 & 0.11 & 3 & 7 & 244 & 1.31 \\
\hline 20100228 & $5: 51$ & 39.85 & -43.104 & 170.804 & 10.55 & 0.08 & 1 & 6 & 263 & 1.65 \\
\hline 20100228 & $10: 18$ & 35.28 & -43.095 & 170.770 & 11.62 & 0.18 & 7 & 18 & 214 & 2.69 \\
\hline
\end{tabular}




\begin{tabular}{|c|c|c|c|c|c|c|c|c|c|c|}
\hline $\begin{array}{r}\text { Date } \\
\text { yyyymmdd }\end{array}$ & $\begin{array}{c}\text { Time } \\
\text { hrmin }\end{array}$ & $\begin{array}{r}\text { Sec } \\
{[\mathrm{s}]}\end{array}$ & $\begin{array}{r}\text { Latitude } \\
{\left[{ }^{\circ}\right]}\end{array}$ & $\begin{array}{r}\text { Longitude } \\
{\left[{ }^{\circ}\right]}\end{array}$ & $\begin{array}{r}\text { Depth } \\
{[\mathrm{km}]}\end{array}$ & $\begin{array}{r}\text { RMS } \\
{[\mathrm{s}]}\end{array}$ & STN & $\mathrm{JPH}$ & $\begin{array}{r}\text { GAP } \\
{\left[{ }^{\circ}\right]}\end{array}$ & Mag \\
\hline 20100228 & $16: 35$ & 1.81 & -43.243 & 170.883 & -1.97 & 0.18 & 7 & 17 & 198 & 2.34 \\
\hline 20100228 & $16: 40$ & 32.99 & -43.249 & 70.897 & -1.93 & 09 & & 7 & 250 & 1.64 \\
\hline 20100228 & $17: 53$ & 2.84 & -43.085 & 0.822 & 12.08 & 0.12 & 3 & 9 & 285 & 1.77 \\
\hline 20100228 & $18: 20$ & 59.02 & -44.033 & 170.103 & 15.54 & 0.14 & 9 & 19 & 272 & 2.76 \\
\hline 20100228 & 20:24 & 8.48 & -43.537 & 170.712 & 8.47 & 0.01 & & 6 & 170 & 1.75 \\
\hline 20100228 & $23: 42$ & 59.59 & -43.544 & 171.118 & 11.83 & 0.14 & & 16 & 225 & 2.27 \\
\hline 20100301 & $2: 56$ & 22.63 & -43.296 & 170.827 & -1.93 & 0.14 & 3 & 8 & 175 & 1.76 \\
\hline 20100301 & $13: 41$ & 43.92 & -43.172 & 1.048 & 12.28 & 0.09 & 2 & 5 & 287 & 2.01 \\
\hline 20100301 & $13: 43$ & 23.59 & -43.168 & 7 & 17.34 & 0.12 & & 7 & 284 & 2.15 \\
\hline 20100301 & 18:12 & 31.84 & -43.246 & 75 & -1.93 & 0.12 & & 6 & 245 & 1.60 \\
\hline 20100302 & $7: 39$ & 32.52 & -43.169 & & 8.23 & 0.24 & & 16 & 208 & 2.43 \\
\hline 20100302 & $12: 43$ & 14.89 & -43.266 & 58 & -1.93 & 0.15 & 2 & 6 & 187 & 1.65 \\
\hline 20100302 & $12: 57$ & 28.79 & -43.236 & & -0.96 & 0.03 & 2 & 5 & 234 & 1.44 \\
\hline 20100302 & $13: 32$ & 37.22 & -43.592 & 20 & 8.61 & 0.17 & 11 & 22 & 129 & 2.89 \\
\hline 20100302 & 21:50 & 21.88 & -43. & & 6.94 & 14 & & 7 & 275 & 2.11 \\
\hline 20100302 & $22: 23$ & 53.45 & -43 . & & 5.80 & 0.19 & 0 & 16 & 116 & 2.01 \\
\hline 20100303 & $23: 24$ & 55.10 & -43.493 & & 5.75 & 0.18 & 6 & 15 & 117 & 1.38 \\
\hline 20100304 & $4: 45$ & 43.47 & -43.798 & & 8.02 & 0.16 & 10 & 21 & 216 & 2.30 \\
\hline 20100304 & $6: 50$ & 38.98 & -43 & 6 & 4.17 & 0 & 6 & 14 & 225 & 2.09 \\
\hline 20100305 & 19:57 & 56.51 & -43 . & & 4.21 & & & 18 & 147 & 1.74 \\
\hline 20100305 & $22: 28$ & 37.03 & -43 & & 2.89 & 0.21 & 0 & 16 & 81 & 2.27 \\
\hline 20100305 & $22: 49$ & 3.77 & -43.494 & & 3.34 & 0.21 & & 20 & 72 & 2.35 \\
\hline 20100307 & $1: 15$ & 6.18 & -43.400 & 3 & 10.41 & 0.13 & 5 & 11 & 275 & 1.97 \\
\hline 20100307 & $6: 30$ & 58.60 & -43.451 & & 11.10 & 0 . & & 6 & 257 & 0.85 \\
\hline 2010 & 7:06 & 38.02 & -43.444 & & 10.03 & 0.17 & 4 & 12 & 123 & 1.42 \\
\hline 20100307 & $20: 38$ & 0.06 & -43.401 & & -1.97 & 0.19 & 6 & 15 & 153 & NA \\
\hline 20100307 & $23: 41$ & 41.39 & -43. & & 8.75 & & & 10 & 192 & 1.60 \\
\hline 20100308 & $19: 43$ & 35.21 & -43.254 & & -1.93 & 0.18 & 5 & 12 & 248 & 1.91 \\
\hline 20100308 & $21: 23$ & 45.31 & -43.155 & & 13.01 & 0.29 & 5 & 16 & 262 & 2.59 \\
\hline 20100312 & 7:09 & 7.47 & -43 . & & 5.31 & 0.21 & $c$ & 19 & 111 & 2.04 \\
\hline 20100312 & 10:18 & 21.05 & -43 . & & 6.94 & 0.24 & & 8 & 218 & 1.64 \\
\hline 20100312 & $22: 03$ & 29.22 & -43.1 & & 11.73 & 0.20 & & 7 & 202 & 1.50 \\
\hline 20100312 & $23: 48$ & 30.63 & -43.550 & & 8.02 & 0.11 & 7 & 16 & 148 & 1.51 \\
\hline 20100313 & $6: 57$ & 38.66 & $-43 .($ & & 8.61 & 0 . & 2 & 10 & 275 & 2.35 \\
\hline 2010 & 8 & 2.42 & -43 & & -1.86 & 0.15 & 3 & 7 & 220 & 0.96 \\
\hline 20100313 & $13: 12$ & 13.10 & -43 . & & 14.05 & 0.19 & 6 & 15 & 225 & 1.96 \\
\hline 20100314 & & 20.25 & -43.161 & & 10.83 & 0.18 & 2 & 12 & 226 & 2.50 \\
\hline 20100314 & $11: 45$ & 43.66 & -43.254 & & -1.97 & 0.24 & 4 & 14 & 129 & 1.44 \\
\hline 20100314 & 19:15 & 17.57 & -43.268 & & -1.93 & 0. & 3 & 9 & 179 & 1.61 \\
\hline 20100314 & $19: 33$ & 38.67 & -43.198 & & 11.17 & 0.00 & 2 & 4 & 228 & 1.01 \\
\hline 20100314 & $22: 33$ & 12.14 & -43.138 & 170.884 & 15.92 & 0.20 & 2 & 9 & 228 & 1.84 \\
\hline 20100315 & & 4.80 & -43.436 & & 4.22 & 0.20 & 7 & 15 & 170 & 0.85 \\
\hline 20100315 & & 7.92 & -43.1 & & 13.29 & 0.24 & 3 & 11 & 229 & 1.26 \\
\hline 20100317 & $15: 10$ & 51.57 & -43.310 & & -1.97 & 0.17 & 3 & 8 & 173 & 1.09 \\
\hline 20100317 & $15: 48$ & 22.43 & -43.274 & & -1.97 & 0.22 & 4 & 11 & 208 & 1.24 \\
\hline 20100318 & 9:19 & 45.13 & -43.308 & 171.490 & 22.82 & 0.01 & 1 & 5 & 285 & 2.61 \\
\hline 20100318 & $10: 33$ & 31.11 & -43.186 & 170.883 & -1.93 & 0.06 & 3 & 10 & 255 & 1.93 \\
\hline
\end{tabular}




\begin{tabular}{|c|c|c|c|c|c|c|c|c|c|c|}
\hline $\begin{array}{r}\text { Date } \\
\text { yyyymmdd }\end{array}$ & $\begin{array}{l}\text { Time } \\
\text { hrmin }\end{array}$ & $\begin{array}{r}\text { Sec } \\
{[\mathrm{s}]}\end{array}$ & $\begin{array}{r}\text { Latitude } \\
{\left[{ }^{\circ}\right]}\end{array}$ & $\begin{array}{r}\text { Longitude } \\
{\left[{ }^{\circ}\right]}\end{array}$ & $\begin{array}{r}\text { Depth } \\
{[\mathrm{km}]}\end{array}$ & $\begin{array}{r}\text { RMS } \\
{[\mathrm{s}]}\end{array}$ & STN & $\mathrm{NPH}$ & $\begin{array}{r}\text { GAP } \\
{\left[{ }^{\circ}\right]}\end{array}$ & Mag \\
\hline 20100318 & $16: 03$ & 32.61 & -43.192 & 170.971 & 18.04 & 0.11 & 1 & 6 & 229 & 1.44 \\
\hline 20100319 & $6: 14$ & 5.99 & -43.149 & 170.792 & -1.45 & 0.09 & 2 & 8 & 232 & 1.32 \\
\hline 20100319 & $9: 55$ & 31.56 & -43.547 & 170.558 & 10.31 & 0.17 & 7 & 17 & 99 & 1.23 \\
\hline 20100319 & $10: 20$ & 27.01 & -43.507 & 170.650 & 5.14 & 0.17 & 10 & 21 & 117 & 1.46 \\
\hline 20100319 & $10: 50$ & 6.28 & -43.538 & 170.570 & 7.67 & 0.18 & 7 & 16 & 102 & 1.32 \\
\hline 20100319 & $12: 48$ & 26.82 & -43.542 & 170.566 & 10.19 & 0.25 & 9 & 20 & 101 & 1.55 \\
\hline 20100319 & $15: 05$ & 37.13 & -43.538 & 170.617 & 3.75 & 0.06 & 3 & 11 & 155 & 1.10 \\
\hline 20100319 & 19:08 & 6.33 & -43.261 & 170.599 & -1.10 & 0.10 & 2 & 8 & 162 & 1.04 \\
\hline 20100319 & $21: 13$ & 26.15 & -43.402 & 170.780 & -1.97 & 0.12 & 4 & 10 & 153 & 1.20 \\
\hline 20100319 & $21: 36$ & 49.10 & -43.438 & 170.711 & -1.97 & 0.17 & 8 & 17 & 135 & 1.92 \\
\hline 20100320 & $17: 28$ & 39.39 & -43.196 & 170.974 & 16.89 & 0.20 & 6 & 16 & 229 & 2.41 \\
\hline 20100320 & $18: 22$ & 38.73 & -43.196 & 170.994 & 17.07 & 0.00 & 2 & 5 & 276 & 1.69 \\
\hline 20100321 & $23: 42$ & 45.46 & -43.101 & 170.955 & 14.26 & 0.20 & 3 & 12 & 255 & 2.91 \\
\hline 20100322 & 13:05 & 49.48 & -43.049 & 171.033 & 13.01 & 0.28 & 5 & 16 & 276 & 2.88 \\
\hline 20100322 & $14: 40$ & 42.37 & -43.486 & 170.677 & -1.97 & 0.23 & 5 & 13 & 124 & 1.82 \\
\hline 20100325 & 4:49 & 48.15 & -43.112 & 170.827 & 6.77 & 0.18 & 6 & 16 & 265 & 2.67 \\
\hline 20100325 & $21: 25$ & 10.27 & -43.533 & 170.634 & 5.25 & 0.17 & 7 & 16 & 111 & 1.85 \\
\hline 20100326 & $6: 57$ & 14.42 & -43.533 & 170.684 & 4.86 & 0.10 & 5 & 12 & 119 & 1.70 \\
\hline 20100327 & $12: 09$ & 18.64 & -43.325 & 170.990 & -1.93 & 0.08 & 3 & 8 & 264 & 1.54 \\
\hline 20100327 & $12: 32$ & 26.52 & -43.161 & 170.879 & 11.28 & 0.32 & 3 & 12 & 218 & 1.71 \\
\hline 20100328 & $10: 46$ & 8.49 & -43.080 & 170.812 & 9.48 & 0.25 & 7 & 18 & 251 & 2.14 \\
\hline 20100329 & $10: 36$ & 52.90 & -43.539 & 170.627 & 8.28 & 0.22 & 10 & 21 & 109 & 2.27 \\
\hline 20100329 & $16: 58$ & 19.35 & -43.530 & 170.629 & 3.58 & 0.16 & 6 & 16 & 111 & 1.68 \\
\hline 20100329 & $18: 50$ & 54.35 & -43.469 & 170.416 & 6.15 & 0.01 & 1 & 5 & 171 & 1.48 \\
\hline 20100329 & $18: 50$ & 56.52 & -43.467 & 170.422 & 5.80 & 0.13 & 5 & 12 & 174 & 1.48 \\
\hline 20100329 & $18: 51$ & 9.39 & -43.455 & 170.457 & 2.92 & 0.06 & 3 & 6 & 191 & NA \\
\hline 20100329 & $19: 23$ & 26.91 & -43.537 & 170.629 & 8.00 & 0.19 & 9 & 19 & 110 & 2.15 \\
\hline 20100330 & $1: 54$ & 7.38 & -43.466 & 170.416 & 6.86 & 0.18 & 9 & 20 & 87 & 2.18 \\
\hline 20100331 & $8: 23$ & 18.38 & -43.541 & 170.634 & 8.02 & 0.19 & 7 & 15 & 214 & 1.52 \\
\hline 20100331 & $10: 34$ & 5.88 & -43.109 & 171.037 & 6.94 & 0.18 & 2 & 9 & 298 & 2.27 \\
\hline 20100401 & $2: 57$ & 57.86 & -43.380 & 170.710 & -1.97 & 0.18 & 4 & 10 & 139 & 1.49 \\
\hline 20100401 & $11: 18$ & 27.02 & -43.518 & 170.647 & 10.55 & 0.14 & 6 & 13 & 165 & 1.60 \\
\hline 20100401 & $11: 18$ & 27.10 & -43.513 & 170.650 & 8.16 & 0.14 & 5 & 12 & 166 & 1.60 \\
\hline 20100401 & $11: 49$ & 40.87 & -43.036 & 171.045 & 21.64 & 0.22 & 1 & 9 & 280 & 1.74 \\
\hline 20100401 & $22: 14$ & 41.26 & -43.183 & 170.901 & -1.86 & 0.09 & 1 & 6 & 260 & 1.69 \\
\hline 20100401 & $22: 14$ & 41.06 & -43.182 & 170.913 & -1.93 & 0.13 & 2 & 7 & 263 & 1.69 \\
\hline 20100402 & 16:04 & 21.74 & -43.133 & 170.827 & 12.04 & 0.30 & 3 & 13 & 214 & 2.55 \\
\hline 20100402 & $16: 36$ & 11.05 & -43.499 & 170.379 & 4.05 & 0.17 & 10 & 20 & 117 & 1.97 \\
\hline 20100402 & $19: 34$ & 8.91 & -43.572 & 171.131 & 14.71 & 0.03 & 3 & 8 & 231 & 1.74 \\
\hline 20100402 & 21:02 & 16.93 & -43.497 & 170.379 & 2.68 & 0.19 & 9 & 18 & 151 & 1.75 \\
\hline 20100402 & $23: 42$ & 54.19 & -43.402 & 170.797 & -0.99 & 0.10 & 4 & 11 & 157 & 1.71 \\
\hline 20100403 & $5: 57$ & 53.70 & -43.499 & 170.379 & 3.44 & 0.14 & 9 & 18 & 151 & 1.74 \\
\hline 20100403 & $7: 11$ & 9.54 & -43.496 & 170.382 & 3.58 & 0.12 & 6 & 15 & 152 & 1.29 \\
\hline 20100403 & $7: 17$ & 23.13 & -43.553 & 170.669 & 10.97 & 0.03 & 1 & 5 & 273 & 1.77 \\
\hline 20100403 & $7: 22$ & 49.67 & -43.493 & 170.387 & 4.71 & 0.16 & 8 & 18 & 92 & 2.92 \\
\hline 20100403 & $11: 12$ & 47.22 & -43.494 & 170.385 & 4.53 & 0.17 & 9 & 19 & 92 & 1.87 \\
\hline 20100403 & $12: 48$ & 26.13 & -43.494 & 170.389 & 3.58 & 0.10 & 6 & 14 & 155 & 1.36 \\
\hline
\end{tabular}




\begin{tabular}{|c|c|c|c|c|c|c|c|c|c|c|}
\hline $\begin{array}{r}\text { Date } \\
\text { yyyymmdd }\end{array}$ & $\begin{array}{c}\text { Time } \\
\text { hrmin }\end{array}$ & $\begin{array}{r}\text { Sec } \\
{[\mathrm{s}]}\end{array}$ & $\begin{array}{r}\text { Latitude } \\
{\left[{ }^{\circ}\right]}\end{array}$ & $\begin{array}{r}\text { Longitude } \\
{\left[{ }^{\circ}\right]}\end{array}$ & $\begin{array}{r}\text { Depth } \\
{[\mathrm{km}]}\end{array}$ & $\begin{array}{r}\text { RMS } \\
{[\mathrm{s}]}\end{array}$ & STN & NPH & $\begin{array}{r}\text { GAP } \\
{\left[{ }^{\circ}\right]}\end{array}$ & Mag \\
\hline 20100404 & $19: 13$ & 13.92 & -43.520 & 170.648 & 11.00 & 0.14 & 7 & 15 & 164 & 1.63 \\
\hline 20100405 & $11: 29$ & 20.46 & -43.498 & 70.383 & 4.14 & 15 & 10 & 20 & 118 & 1.92 \\
\hline 20100405 & 12:04 & 38.31 & -43.239 & 170.878 & 8.47 & 0.14 & 5 & 14 & 197 & 1.84 \\
\hline 20100405 & $17: 10$ & 22.98 & -43.493 & 170.289 & 1.15 & 0.15 & , & 19 & 77 & 1.98 \\
\hline 20100405 & $22: 15$ & 25.59 & -43.495 & 170.382 & 3.44 & 0.11 & 0 & 15 & 118 & 1.47 \\
\hline 20100406 & $13: 49$ & 42.46 & -43.177 & 170.830 & 8.05 & 0.16 & 1 & 9 & 197 & 1.82 \\
\hline 20100407 & $17: 55$ & 12.56 & -43.352 & 170.657 & -1.97 & 0.23 & 6 & 13 & 129 & 1.31 \\
\hline 20100408 & 10:06 & 32.34 & -43.160 & 170.820 & 11.76 & 0.16 & 3 & 14 & 199 & 2.64 \\
\hline 20100408 & $18: 43$ & 33.47 & -43.099 & 96 & 5.90 & 0.18 & I & 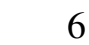 & 303 & 1.35 \\
\hline 20100408 & 20:40 & 20.87 & -43.496 & & 3.51 & 0.11 & & 15 & 153 & 1.38 \\
\hline 20100408 & $22: 40$ & 6.31 & -43.493 & & 3.44 & 0.14 & & 10 & 154 & 1.05 \\
\hline 20100409 & $16: 59$ & 49.29 & -43.352 & 30 & -1.97 & 0.18 & 5 & 11 & 208 & 1.00 \\
\hline 20100409 & 19:36 & 55.90 & -43.490 & 57 & 14.33 & 0.08 & $T$ & 13 & 210 & 1.51 \\
\hline 20100409 & 22:04 & 37.18 & -43.187 & 56 & -1.93 & 0.07 & 2 & 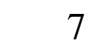 & 247 & 1.31 \\
\hline 20100410 & $5: 51$ & 7.92 & -43.143 & & 9.58 & 0.11 & & 7 & 275 & 1.62 \\
\hline 20100410 & $8: 31$ & 3.95 & -43.297 & & -1.97 & 0.17 & I & 0 & 225 & 1.11 \\
\hline 20100410 & $9: 17$ & 26.60 & -43.172 & & 21.37 & 0.17 & 2 & , & 271 & 2.14 \\
\hline 20100410 & $11: 24$ & 24.73 & -43.494 & & 4.55 & 0.18 & & 20 & 92 & 1.83 \\
\hline 20100410 & $16: 40$ & 20.33 & -43.3 & 7 & -1.97 & 0 . & 7 & 17 & 139 & 2.35 \\
\hline 20100410 & $23: 16$ & 10 & -43 . & & 0.01 & & & 6 & 18 & 1.82 \\
\hline 20100411 & $4: 42$ & 19.97 & -43.256 & & -1.03 & 0.05 & 2 & 5 & 249 & 1.63 \\
\hline 20100412 & $7: 35$ & 1.09 & -43.129 & & -1.10 & 0.07 & & 6 & 311 & 1.57 \\
\hline 20100413 & $18: 35$ & 11.35 & -43.223 & & 6.98 & 0.17 & 5 & 15 & 152 & 2.00 \\
\hline 20100415 & $22: 47$ & 36.15 & -43.242 & & 0.01 & 0 . & & 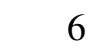 & 208 & 1.66 \\
\hline 2010 & $15: 40$ & 47.29 & -43 . & & -0.96 & 0.22 & & S & 302 & 2.05 \\
\hline 20100416 & 18:03 & 3.56 & -43 . & & 16.24 & 0.00 & 1 & 4 & 228 & 1.19 \\
\hline 20100417 & $12: 29$ & 56.53 & -43 . & & 10.62 & 0.03 & & 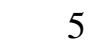 & 293 & 1.13 \\
\hline 20100417 & $17: 59$ & 36.82 & -43.471 & & 0.46 & 0.11 & 2 & 10 & 157 & 1.52 \\
\hline 20100418 & $13: 50$ & 44.22 & -43.314 & 97 & -1.97 & 0.14 & 5 & 13 & 168 & 1.42 \\
\hline 20100418 & $14: 19$ & 52.57 & -43 . & & 0.08 & 0.08 & 3 & 8 & 219 & 1.26 \\
\hline 20100418 & $14: 43$ & 34.82 & -43 . & & -1.97 & 0.15 & 3 & 9 & 167 & 1.33 \\
\hline 20100418 & $17: 37$ & 38.46 & -43.319 & & -1.97 & 0 . & & 12 & 229 & 2.84 \\
\hline 20100419 & & 57.44 & -43.101 & & 14.85 & 0 . & 2 & 12 & 253 & 2.04 \\
\hline 20100419 & $10: 42$ & 20.99 & -43. & & -1.97 & 0.21 & 6 & 14 & 133 & 1.38 \\
\hline 20100421 & 4:02 & 56.48 & -43 . & & 8.94 & 0.18 & 8 & 17 & 103 & 1.62 \\
\hline 20100421 & $15: 42$ & 1.96 & -43.661 & & 9.48 & & 8 & 18 & 173 & 1.65 \\
\hline 20100422 & $16: 54$ & 51.42 & -43.245 & & 5.07 & 0.00 & 1 & 4 & 308 & 1.53 \\
\hline 20100423 & $11: 17$ & 24.38 & -43.245 & & 21.16 & 0 . & 3 & 6 & 317 & 1.69 \\
\hline 20100424 & $8: 49$ & 9.92 & -43.548 & & 10.31 & 0. & 3 & 0 & 248 & 1.20 \\
\hline 20100424 & $17: 31$ & 3.33 & -43.501 & & 7.88 & 0.13 & 6 & 16 & 126 & 2.09 \\
\hline 20100430 & $16: 16$ & 21.00 & -43.077 & 170.803 & 6.98 & 0.29 & 3 & 9 & 253 & 1.91 \\
\hline 20100501 & $2: 53$ & 28.60 & -43.464 & .618 & 6.74 & 0.12 & 6 & 13 & 251 & 1.75 \\
\hline 20100828 & $15: 18$ & 54.49 & & & 4.07 & 0.09 & 8 & 16 & 110 & 0.97 \\
\hline 20100828 & $15: 19$ & 12.19 & -43.508 & & 4.53 & 0.12 & 3 & 18 & 112 & 2.57 \\
\hline 20100828 & $15: 20$ & 13.19 & -43.506 & & 4.07 & 0.09 & 7 & 16 & 110 & 1.13 \\
\hline 20100828 & $15: 20$ & 13.19 & -43.507 & 170.151 & 4.00 & 0.09 & 7 & 15 & 111 & 1.13 \\
\hline 20100828 & $15: 32$ & 21.05 & -43.510 & 170.153 & 5.18 & 0.08 & 7 & 15 & 113 & 0.87 \\
\hline
\end{tabular}




\begin{tabular}{|c|c|c|c|c|c|c|c|c|c|c|}
\hline $\begin{array}{r}\text { Date } \\
\text { yyyymmdd }\end{array}$ & $\begin{array}{r}\text { Time } \\
\text { hrmin }\end{array}$ & $\begin{array}{r}\mathrm{Sec} \\
{[\mathrm{s}]}\end{array}$ & $\begin{array}{r}\text { Latitude } \\
{\left[{ }^{\circ}\right]}\end{array}$ & $\begin{array}{r}\text { Longitude } \\
{\left[{ }^{\circ}\right]}\end{array}$ & $\begin{array}{r}\text { Depth } \\
{[\mathrm{km}]}\end{array}$ & $\begin{array}{r}\text { RMS } \\
{[\mathrm{s}]}\end{array}$ & STN & $\mathrm{NPH}$ & $\begin{array}{r}\text { GAP } \\
{\left[{ }^{\circ}\right]}\end{array}$ & Mag \\
\hline 20100828 & $17: 53$ & 5.73 & -43.508 & 170.150 & 4.90 & 0.10 & 7 & 16 & 112 & 0.97 \\
\hline 20100828 & $20: 22$ & 21.29 & -43.542 & 170.139 & 2.78 & 0.10 & 0 & 17 & 129 & 1.08 \\
\hline 20100828 & $20: 22$ & 33.74 & -43.541 & 170.136 & 4.97 & 0.07 & & 8 & 145 & 0.42 \\
\hline 20100828 & $23: 48$ & 36.45 & -43.163 & 0.931 & 11.38 & 0.11 & & 11 & 229 & 2.02 \\
\hline 20100829 & $8: 14$ & 26.85 & -43.540 & 0.139 & 4.00 & 0.08 & $\varepsilon$ & 17 & 128 & 1.06 \\
\hline 20100829 & $8: 23$ & 30.78 & -43.466 & 170.185 & 6.44 & 0.08 & $\varepsilon$ & 17 & 75 & 1.46 \\
\hline 20100829 & $17: 30$ & 22.90 & -43.442 & 170.679 & 12.46 & 0.12 & & 11 & 210 & 1.10 \\
\hline 20100829 & $21: 37$ & 8.95 & -43.577 & 170.521 & 8.57 & 0.02 & & 7 & 230 & 0.69 \\
\hline 20100829 & $22: 59$ & 19.94 & -43.579 & 523 & 8.57 & 0.09 & & 18 & 148 & 1.62 \\
\hline 20100829 & 23:07 & 21.88 & -43.575 & 521 & 8.12 & 0.01 & & 8 & 230 & 0.89 \\
\hline 20100830 & $7: 47$ & 5.46 & -43.509 & 53 & 5.59 & 0.08 & & 13 & 112 & 0.52 \\
\hline 20100830 & $17: 58$ & 51.66 & -43.523 & 83 & 4.64 & 0.13 & & 17 & 103 & 1.13 \\
\hline 20100830 & $21: 30$ & 43.22 & -43.507 & 47 & 2.75 & 0.11 & & 18 & 111 & 1.43 \\
\hline 20100831 & $5: 24$ & 0.88 & -43.509 & & 4.62 & 0.08 & & 10 & 148 & 0.53 \\
\hline 20100831 & $6: 33$ & 48.72 & -43.507 & 52 & 4.00 & 0.10 & & 17 & 111 & 1.11 \\
\hline 20100831 & $6: 48$ & 16.64 & -43.506 & & 3.30 & 0.10 & & 16 & 110 & 1.00 \\
\hline 20100831 & $7: 28$ & 10.33 & -43 & 55 & 3.48 & 0.08 & & 17 & 112 & 1.03 \\
\hline 20100831 & $8: 29$ & .14 & -43 & & 3 & 0.08 & & & 113 & 0.78 \\
\hline 20100831 & $8: 36$ & 1.40 & -43 & & 4 & 0.11 & 9 & & 113 & 1.64 \\
\hline 20100831 & $8: 49$ & 20.62 & -43.582 & & 13 & 0.10 & 10 & 20 & 147 & 1.83 \\
\hline 20100831 & $9: 29$ & 33.04 & -43.555 & 59 & 7.67 & 0.11 & & 17 & 256 & 1.48 \\
\hline 20100831 & $13: 26$ & 48.81 & -43.5 & & 7. & 0. & & & 232 & 1.09 \\
\hline 831 & $13: 27$ & 16.54 & -43 & & 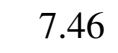 & 0.08 & & & 233 & 0.80 \\
\hline 20100831 & $13: 34$ & 4.34 & -43 . & & 5 & 0.08 & & 15 & 229 & 1.24 \\
\hline 20100831 & $13: 38$ & 7.25 & -43 & & & 0.07 & & & 234 & 1.37 \\
\hline 20100831 & $13: 41$ & 18.28 & -43.568 & & 7.6 & 0.06 & & & 244 & 0.73 \\
\hline 20100831 & $13: 42$ & 7.03 & -43.5 & 52 & 6.2 & 1.0 & & & 251 & 0.78 \\
\hline 31 & $13: 56$ & 29.19 & -43 & & 5. & 0.07 & & $1 J$ & 123 & 1.52 \\
\hline 31 & $14: 08$ & 4.51 & -43 . & & 0 & 0.03 & & 7 & 231 & 0.44 \\
\hline 20100831 & $14: 08$ & 32.38 & -43 & & & 0.06 & & 6 & 144 & 0.20 \\
\hline 20100831 & $20: 22$ & 9.81 & -43.501 & & -1 . & 0.10 & & 13 & 81 & 0.64 \\
\hline 20100831 & $20: 22$ & 22.62 & -43.502 & 80 & -1. & 0.10 & & 12 & 82 & 0.87 \\
\hline 831 & 22:09 & 57 & -43 & & 9.2. & 0.01 & & 5 & 233 & 0.31 \\
\hline 20100831 & $22: 12$ & .20 & -43 . & & & 0.09 & & 11 & 86 & 0.33 \\
\hline 20100901 & & 3.51 & -43.706 & & 5. & 0.06 & & 16 & 31 & 1.24 \\
\hline 20100901 & $23: 39$ & 59.91 & -43.568 & & 8.1 & 0.01 & 1 & 4 & 250 & 0.45 \\
\hline 20100902 & 4:01 & 5 & -43.5 & 1 & 5.4 & 0.11 & 7 & 15 & 132 & 0.96 \\
\hline 20100903 & 7:44 & 52.15 & -43.572 & & 7 & 0.05 & 5 & 11 & 236 & 1.20 \\
\hline 20100903 & $8: 20$ & & -43.406 & & -1.97 & 0.13 & 0 & 17 & 147 & 1.65 \\
\hline 20100903 & $14: 30$ & 27.99 & -43.227 & 170.835 & 15. & 0.19 & 4 & 12 & 187 & 1.83 \\
\hline 20100903 & $17: 13$ & 17.84 & -4 & 95 & 3.2 & 0.01 & 2 & 5 & 271 & 1.47 \\
\hline 20100903 & $17: 13$ & 22.22 & -43.475 & & 4.0 & 0.06 & 3 & 8 & 155 & 1.47 \\
\hline 20100903 & $17: 52$ & 23.18 & -43.346 & 170.347 & 10.55 & 0.04 & 2 & 5 & 263 & NA \\
\hline 20100903 & 19:09 & 29.43 & -43.706 & 169.847 & 8.40 & 0.01 & 1 & 4 & 309 & NA \\
\hline 03 & 19:12 & 44.66 & -6 & & 9. & 0.04 & 2 & 5 & 300 & NA \\
\hline & $19: 18$ & 42.31 & & & & 0.00 & & 4 & 172 & NA \\
\hline 20100903 & $19: 22$ & 22.30 & -43.491 & 170.192 & 8.78 & 0.13 & 5 & 11 & 163 & 1.95 \\
\hline
\end{tabular}




\begin{tabular}{|c|c|c|c|c|c|c|c|c|c|c|}
\hline $\begin{array}{r}\text { Date } \\
\text { yyyymmdd }\end{array}$ & $\begin{array}{c}\text { Time } \\
\text { hrmin }\end{array}$ & $\begin{array}{r}\text { Sec } \\
{[\mathrm{s}]}\end{array}$ & $\begin{array}{r}\text { Latitude } \\
{\left[{ }^{\circ}\right]}\end{array}$ & $\begin{array}{r}\text { Longitude } \\
{\left[{ }^{\circ}\right]}\end{array}$ & $\begin{array}{r}\text { Depth } \\
{[\mathrm{km}]}\end{array}$ & $\begin{array}{r}\text { RMS } \\
{[\mathrm{s}]}\end{array}$ & STN & NPH & $\begin{array}{r}\text { GAP } \\
{\left[{ }^{\circ}\right]}\end{array}$ & Mag \\
\hline 20100903 & $20: 22$ & 3.52 & -43.679 & 169.861 & 9.06 & 0.11 & 7 & 15 & 262 & 2.55 \\
\hline 20100903 & $20: 25$ & 16.28 & -43.552 & 70.584 & 8.05 & 0.06 & & 6 & 267 & 1.82 \\
\hline 20100903 & 20:27 & 40.60 & -43.449 & 170.363 & 7.78 & 0.00 & 2 & 5 & 256 & NA \\
\hline 20100903 & $20: 48$ & 38.69 & -43.444 & 170.369 & 7.85 & 0.00 & 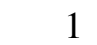 & 4 & 259 & NA \\
\hline 20100903 & $20: 51$ & 35.55 & -43.444 & 170.369 & 7.85 & 0.01 & & 4 & 259 & NA \\
\hline 20100903 & 21:01 & 10.33 & -43.479 & 170.285 & 5.56 & 0.00 & & 4 & 182 & NA \\
\hline 20100903 & 21:01 & 10.22 & -43.432 & 170.391 & 9.72 & 0.04 & & 5 & 215 & $\mathrm{NA}$ \\
\hline 20100903 & 21:01 & 37.13 & -43.515 & 170.283 & -1.10 & 0.03 & & 4 & 285 & NA \\
\hline 20100903 & $21: 20$ & 4.87 & -43.5 & 353 & 4.73 & 0.11 & & 13 & 128 & 1.32 \\
\hline 20100903 & 21:20 & 42.82 & -43.499 & 170.370 & 3.48 & 0.07 & & 8 & 162 & 1.01 \\
\hline 20100903 & $21: 26$ & 9.33 & -43.506 & 369 & 7.33 & 0.02 & & 7 & 141 & NA \\
\hline 20100903 & $21: 43$ & 57.57 & -43.578 & 524 & 8.68 & 0.01 & 1 & 4 & 233 & $\mathrm{NA}$ \\
\hline 20100903 & $21: 50$ & 10.81 & -43.578 & 518 & 19 & 0.05 & & 7 & 228 & 1.33 \\
\hline 20100903 & 22:00 & 23.02 & -43.500 & 363 & 7.01 & 0.00 & & 4 & 302 & 1.22 \\
\hline 20100903 & 22:01 & 53.20 & -43.524 & 27 & -1.93 & 0.08 & & 5 & 119 & 0.53 \\
\hline 20100903 & $22: 11$ & 1.99 & -43 & 93 & 9.23 & 0.01 & & 4 & 286 & NA \\
\hline 20100903 & $22: 22$ & 39.38 & -43.538 & 462 & -0.96 & 0.04 & & 5 & 198 & NA \\
\hline 20100903 & $22: 34$ & 48.73 & -43.464 & 206 & 7.22 & 0.07 & & 8 & 149 & 1.02 \\
\hline 20100903 & $22: 48$ & 59.38 & -43.339 & 354 & 10.55 & 0.10 & 4 & 9 & 270 & 1.64 \\
\hline 20100903 & $22: 49$ & 6 & -43 . & & -1.93 & 0 . & & 5 & 177 & NA \\
\hline 20100903 & $22: 50$ & 10.66 & -43 . & 67 & 1.61 & 0.08 & $T$ & 11 & 140 & 1.14 \\
\hline 20100903 & $23: 50$ & 52.79 & -43. & & 5.42 & 0.04 & & 8 & 166 & 0.79 \\
\hline 20100904 & $0: 43$ & 52.25 & -43.482 & .378 & 3.96 & 0.01 & 1 & 4 & 309 & NA \\
\hline 20100904 & $0: 56$ & 39.79 & -43.455 & 271 & 4.59 & 0. & 4 & 10 & 115 & 1.39 \\
\hline 20100904 & $0: 56$ & 49.97 & -43 . & 66 & 5.00 & 0.01 & & 5 & 246 & 0.78 \\
\hline 20100904 & $2: 59$ & 9.86 & -43 . & 67 & 3.30 & 0.10 & 6 & 12 & 143 & 1.54 \\
\hline 20100904 & 3:01 & 21.81 & -43. & & 4.14 & 0.08 & & 10 & 99 & 1.49 \\
\hline 20100904 & 4:08 & 31.13 & -43.6 & .793 & 7.12 & 0.08 & 6 & 13 & 278 & 2.22 \\
\hline 20100904 & $4: 14$ & 55.46 & -43.500 & 364 & 2.33 & 0.08 & 6 & 13 & 138 & 1.29 \\
\hline 20100904 & $4: 24$ & 6.91 & -43 . & 01 & .41 & 0.09 & 4 & 12 & 188 & 2.64 \\
\hline 20100904 & $4: 24$ & 26.77 & -43 . & & 0 & 0.07 & 5 & 10 & 109 & 2.14 \\
\hline 20100904 & $4: 40$ & & -43.498 & & 3.37 & 0.10 & . & 11 & 109 & 1.27 \\
\hline 20100904 & $4: 53$ & 11.79 & -43.503 & 329 & -1.97 & 0.13 & 4 & 10 & 110 & 0.98 \\
\hline 20100904 & $5: 11$ & 29.89 & -43.5 & 85 & 4.86 & 0.02 & 2 & 5 & 157 & 1.37 \\
\hline 20100904 & $5: 15$ & 12.01 & -43 . & 77 & 4 & 0.00 & 1 & 4 & 156 & NA \\
\hline 20100904 & $5: 55$ & 54.09 & -43.492 & & 4.34 & 0.11 & 4 & 10 & 127 & 0.89 \\
\hline 20100904 & $6: 02$ & 12.83 & -43.470 & 387 & 6. & 0.01 & 1 & 4 & 320 & NA \\
\hline 20100904 & $6: 42$ & 16.62 & -43.487 & & 4.45 & 0.07 & 1 & 5 & 307 & NA \\
\hline 20100904 & $6: 59$ & 29.24 & -43.460 & 17 & 5.14 & 0.03 & - & 7 & 228 & 1.03 \\
\hline 20100904 & $7: 23$ & 40.40 & -43.535 & 637 & 11.17 & 0.03 & 1 & 5 & 281 & NA \\
\hline 20100904 & $7: 32$ & 51.20 & -43.492 & 170.367 & 4.62 & 0.08 & 2 & 7 & 160 & 1.00 \\
\hline 20100904 & $8: 00$ & 17.75 & -43.494 & .368 & 3.89 & 0.08 & 5 & 9 & 143 & 0.96 \\
\hline 20100904 & 8:07 & 7.14 & -43.491 & & $4.5 J$ & 0.10 & 3 & 9 & 144 & 1.01 \\
\hline 20100904 & $8: 37$ & 32.12 & -43.494 & & 0.29 & 0.07 & 2 & 0 & 290 & NA \\
\hline 20100904 & $10: 53$ & 56.84 & -43.453 & 170.410 & 5.66 & 0.09 & 4 & 9 & 282 & 0.50 \\
\hline 20100904 & $10: 59$ & 54.19 & -43.456 & 170.252 & 7.60 & 0.08 & 2 & 7 & 152 & NA \\
\hline 20100904 & 11:00 & 29.43 & -43.475 & 170.239 & 4.31 & 0.04 & 2 & 5 & 258 & 0.65 \\
\hline
\end{tabular}




\begin{tabular}{|c|c|c|c|c|c|c|c|c|c|c|}
\hline $\begin{array}{r}\text { Date } \\
\text { yyyymmdd }\end{array}$ & $\begin{array}{c}\text { Time } \\
\text { hrmin }\end{array}$ & $\begin{array}{r}\mathrm{Sec} \\
{[\mathrm{s}]}\end{array}$ & $\begin{array}{r}\text { Latitude } \\
{\left[{ }^{\circ}\right]}\end{array}$ & $\begin{array}{r}\text { Longitude } \\
{\left[{ }^{\circ}\right]}\end{array}$ & $\begin{array}{r}\text { Depth } \\
{[\mathrm{km}]}\end{array}$ & $\begin{array}{r}\text { RMS } \\
{[\mathrm{s}]}\end{array}$ & STN & $\mathrm{NPH}$ & $\begin{array}{r}\text { GAP } \\
{\left[{ }^{\circ}\right]}\end{array}$ & Mag \\
\hline 20100904 & 11:09 & 40.67 & -43.469 & 170.594 & -0.96 & 0.01 & 1 & 5 & 243 & NA \\
\hline 20100904 & $11: 34$ & 50.86 & -43.460 & 170.247 & 6.35 & 0.15 & 7 & 15 & 98 & 2.29 \\
\hline 20100904 & $11: 38$ & 44.74 & -43.442 & 170.262 & 7.60 & 0.11 & 4 & 8 & 219 & 0.96 \\
\hline 20100904 & $11: 47$ & 31.49 & -43.437 & 170.388 & 6.01 & 0.14 & 6 & 13 & 164 & 1.03 \\
\hline 20100904 & $12: 18$ & 40.70 & -43.492 & 170.380 & 4.41 & 0.07 & 2 & 7 & 156 & 0.82 \\
\hline 20100904 & $12: 38$ & 40.11 & -43.492 & 170.382 & 4.45 & 0.07 & 1 & 6 & 155 & 0.76 \\
\hline 20100904 & 13:01 & 2.88 & -43.397 & 170.368 & -0.96 & 0.04 & 1 & 4 & 241 & -0.25 \\
\hline 20100904 & $13: 13$ & 12.31 & -43.427 & 170.391 & 5.00 & 0.01 & 1 & 4 & 233 & 0.03 \\
\hline 20100904 & $13: 21$ & 37.93 & -43.490 & 170.375 & 4.79 & 0.00 & 1 & 4 & 307 & 0.05 \\
\hline 20100904 & $13: 23$ & 7.68 & -43.450 & 170.353 & 4.45 & 0.01 & 1 & 4 & 239 & 0.19 \\
\hline 20100904 & $13: 55$ & 5.41 & -43.554 & 170.591 & 5.42 & 0.11 & 2 & 6 & 248 & 1.23 \\
\hline 20100904 & $14: 13$ & 4.66 & -43.490 & 170.389 & 5.11 & 0.08 & 4 & 9 & 156 & 0.80 \\
\hline 20100904 & $14: 18$ & 51.06 & -43.308 & 170.786 & -1.86 & 0.10 & 3 & 9 & 220 & 1.47 \\
\hline 20100904 & $14: 18$ & 50.96 & -43.310 & 170.796 & -1.93 & 0.12 & 4 & 10 & 223 & 1.47 \\
\hline 20100904 & $14: 39$ & 51.93 & -43.451 & 170.360 & 4.59 & 0.06 & 1 & 5 & 256 & 0.38 \\
\hline 20100904 & $14: 59$ & 10.67 & -43.422 & 170.359 & 8.12 & 0.00 & 1 & 4 & 210 & NA \\
\hline 20100904 & $15: 00$ & 11.46 & -43.343 & 170.387 & 4.45 & 0.05 & 3 & 7 & 203 & 0.86 \\
\hline 20100904 & $15: 07$ & 32.76 & -43.490 & 170.203 & 5.70 & 0.07 & 2 & 5 & 276 & 0.64 \\
\hline 20100904 & $18: 23$ & 47.03 & -43.435 & 170.394 & 5.94 & 0.12 & 7 & 15 & 168 & 1.47 \\
\hline 20100904 & $18: 29$ & 24.70 & -43.427 & 170.400 & 5.14 & 0.05 & 1 & 5 & 247 & 0.22 \\
\hline 20100904 & $18: 41$ & 12.16 & -43.487 & 170.359 & 5.45 & 0.10 & 3 & 8 & 160 & NA \\
\hline 20100904 & $18: 42$ & 34.36 & -43.489 & 170.357 & 5.28 & 0.09 & 3 & 9 & 135 & 0.84 \\
\hline 20100904 & $18: 50$ & 2.08 & -43.487 & 170.347 & 0.36 & 0.09 & 0 & 4 & 287 & NA \\
\hline 20100904 & $18: 53$ & 44.14 & -43.434 & 170.393 & 6.01 & 0.11 & 5 & 13 & 167 & 1.30 \\
\hline 20100904 & $19: 33$ & 48.60 & -43.492 & 170.357 & 4.59 & 0.06 & 3 & 6 & 296 & NA \\
\hline 20100904 & $19: 54$ & 3.23 & -43.462 & 170.381 & 7.29 & 0.00 & 1 & 4 & 315 & NA \\
\hline 20100904 & 20:04 & 1.30 & -43.495 & 170.364 & 5.42 & 0.00 & 1 & 4 & 301 & NA \\
\hline 20100904 & $20: 11$ & 25.38 & -43.502 & 170.344 & 3.10 & 0.14 & 8 & 17 & 121 & 1.24 \\
\hline 20100904 & $20: 11$ & 38.45 & -43.450 & 170.354 & 4.59 & 0.00 & 1 & 4 & 241 & 0.48 \\
\hline 20100904 & $20: 37$ & 38.79 & -43.494 & 170.356 & 4.73 & 0.05 & 3 & 7 & 253 & 0.49 \\
\hline 20100904 & $21: 27$ & 45.64 & -43.649 & 169.914 & 9.48 & 0.11 & 4 & 10 & 280 & 1.26 \\
\hline 20100904 & $23: 32$ & 11.02 & -43.484 & 170.370 & 3.93 & 0.10 & 3 & 7 & 262 & 0.86 \\
\hline 20100904 & $23: 51$ & 26.20 & -43.506 & 170.372 & 4.07 & 0.20 & 8 & 16 & 145 & 1.54 \\
\hline 20100905 & $0: 12$ & 21.04 & -43.489 & 170.385 & 5.28 & 0.05 & 3 & 7 & 308 & 0.79 \\
\hline 20100905 & $1: 17$ & 11.89 & -43.558 & 169.660 & 10.62 & 0.06 & 5 & 10 & 319 & 1.71 \\
\hline 20100905 & $1: 18$ & 57.08 & -43.547 & 169.669 & 12.32 & 0.07 & 6 & 13 & 317 & 1.97 \\
\hline 20100905 & 2:07 & 25.13 & -43.427 & 170.391 & 5.94 & 0.05 & 3 & 6 & 233 & 0.82 \\
\hline 20100905 & 2:07 & 43.40 & -43.437 & 170.389 & 6.16 & 0.14 & 8 & 17 & 165 & 1.74 \\
\hline 20100905 & 2:07 & 43.26 & -43.433 & 170.399 & 6.77 & 0.16 & 6 & 14 & 125 & 1.74 \\
\hline 20100905 & $11: 11$ & 30.84 & -43.491 & 170.389 & 5.25 & 0.06 & 4 & 9 & 156 & 1.54 \\
\hline 20100906 & 16:01 & 11.81 & -43.599 & 169.981 & 5.73 & 0.09 & 4 & 10 & 117 & 0.98 \\
\hline 20100906 & 16:01 & 27.07 & -43.607 & 169.994 & 6.49 & 0.05 & 2 & 6 & 216 & 0.62 \\
\hline 20100906 & $20: 17$ & 40.92 & -43.493 & 170.339 & 3.34 & 0.08 & 4 & 9 & 157 & 0.52 \\
\hline 20100906 & $20: 51$ & 25.39 & -43.492 & 170.374 & 4.97 & 0.09 & 5 & 11 & 149 & 0.77 \\
\hline 20100906 & $21: 15$ & 40.87 & -43.491 & 170.372 & 4.34 & 0.08 & 4 & 9 & 147 & 0.72 \\
\hline 20100906 & $21: 31$ & 29.51 & -43.502 & 170.360 & 1.81 & 0.00 & 1 & 4 & 155 & NA \\
\hline 20100907 & $1: 45$ & 39.86 & -43.512 & 170.274 & 3.75 & 0.02 & 2 & 6 & 142 & 0.38 \\
\hline
\end{tabular}




\begin{tabular}{|rrrrrrrrrrr|}
\hline $\begin{array}{r}\text { Date } \\
\text { yyyymmdd }\end{array}$ & $\begin{array}{r}\text { Time } \\
\text { hrmin }\end{array}$ & $\begin{array}{r}\text { Sec } \\
{[\mathrm{s}]}\end{array}$ & $\begin{array}{r}\text { Latitude } \\
\left.{ }^{\circ}\right]\end{array}$ & $\begin{array}{r}\text { Longitude } \\
{\left[{ }^{\circ}\right]}\end{array}$ & $\begin{array}{r}\text { Depth } \\
{[\mathrm{km}]}\end{array}$ & $\begin{array}{r}\text { RMS } \\
{[\mathrm{s}]}\end{array}$ & STN & NPH & $\begin{array}{r}\text { GAP } \\
{\left[{ }^{\circ}\right]}\end{array}$ & Mag \\
\hline 20100907 & $9: 12$ & 31.17 & -43.560 & 170.563 & 7.50 & 0.10 & 2 & 8 & 236 & 1.15 \\
20100907 & $12: 58$ & 11.46 & -43.562 & 170.545 & 7.05 & 0.15 & 5 & 12 & 227 & 1.24 \\
20100907 & $13: 16$ & 19.07 & -43.565 & 170.532 & 7.33 & 0.15 & 4 & 9 & 219 & 1.15 \\
20100907 & $20: 24$ & 8.48 & -43.577 & 170.515 & 8.61 & 0.02 & 2 & 5 & 226 & 0.80 \\
20100907 & $21: 31$ & 7.58 & -43.513 & 170.259 & 6.94 & 0.07 & 3 & 7 & 119 & 0.49 \\
20100908 & $0: 19$ & 41.93 & -43.508 & 170.362 & 3.06 & 0.01 & 2 & 6 & 157 & NA \\
20100908 & $3: 54$ & 58.58 & -43.298 & 170.803 & 10.13 & 0.14 & 3 & 9 & 224 & 1.52 \\
20100908 & $5: 12$ & 50.86 & -43.447 & 170.358 & 0.74 & 0.06 & 2 & 6 & 218 & -0.18 \\
20100908 & $7: 37$ & 30.28 & -43.501 & 170.327 & 5.21 & 0.05 & 3 & 8 & 165 & 0.28 \\
20100908 & $9: 25$ & 30.36 & -43.500 & 170.107 & -0.75 & 0.01 & 1 & 4 & 346 & NA \\
20100908 & $13: 07$ & 31.30 & -43.448 & 170.535 & 8.85 & 0.11 & 5 & 11 & 224 & 1.07 \\
20100908 & $14: 09$ & 42.04 & -43.565 & 170.543 & 8.47 & 0.14 & 4 & 9 & 226 & 0.81 \\
20100908 & $19: 01$ & 25.70 & -43.559 & 169.932 & 6.49 & 0.12 & 4 & 10 & 251 & NA \\
20100908 & $19: 06$ & 35.56 & -43.564 & 169.918 & 7.74 & 0.10 & 4 & 9 & 260 & 2.33 \\
20100908 & $23: 32$ & 27.24 & -43.542 & 170.322 & -0.02 & 0.15 & 3 & 7 & 189 & 0.19 \\
\hline
\end{tabular}

Table J.1. Hypocentre locations for all events recorded between January and April 2010. 


\section{K. Focal mechanism solutions}

Focal mechanism solutions for the period November 2008 to April 2010. Cluster- and event-numbers refer to those events shown in Fig. 3.22, H.1-H.3

\begin{tabular}{|c|c|c|c|c|c|c|}
\hline $\begin{array}{r}\text { Date } \\
\text { yyyymmdd }\end{array}$ & $\begin{array}{l}\text { Time } \\
\text { hrmin }\end{array}$ & $\begin{array}{r}\mathrm{Sec} \\
{[\mathrm{s}]}\end{array}$ & $\begin{array}{r}\text { Strike } \\
{\left[{ }^{\circ}\right]}\end{array}$ & $\begin{array}{l}\text { Dip } \\
{\left[{ }^{\circ}\right]}\end{array}$ & $\begin{array}{r}\text { Rake } \\
{\left[{ }^{\circ}\right]}\end{array}$ & Cluster/Event \\
\hline 20081113 & $12: 53$ & 28.94 & 158 & 79 & -41 & \\
\hline 20081130 & $11: 05$ & 32.05 & 237 & 69 & 151 & \\
\hline 20081208 & $17: 34$ & 22.48 & 341 & 77 & 45 & $2 / 1$ \\
\hline 20081213 & $11: 23$ & 2.96 & 338 & 87 & 7 & $2 / 2$ \\
\hline 20081214 & $5: 30$ & 43.85 & 68 & 60 & 135 & \\
\hline 20081214 & $9: 56$ & 5.13 & 57 & 49 & 119 & \\
\hline 20081217 & $5: 39$ & 6.45 & 160 & 79 & -2 & $2 / 3$ \\
\hline 20081219 & $14: 53$ & 39.20 & 339 & 83 & 24 & $2 / 4$ \\
\hline 20081220 & $15: 22$ & 41.33 & 256 & 69 & 167 & $1 / 1$ \\
\hline 20081221 & $4: 10$ & 11.60 & 310 & 73 & -146 & $5 / 1$ \\
\hline 20081223 & $1: 36$ & 50.07 & 201 & 38 & 76 & \\
\hline 20081225 & $7: 18$ & 40.81 & 267 & 49 & 161 & \\
\hline 20081225 & $7: 42$ & 55.09 & 0 & 78 & 29 & \\
\hline 20081227 & $22: 35$ & 41.09 & 254 & 82 & 92 & $1 / 2$ \\
\hline 20090110 & $8: 44$ & 0.43 & 202 & 69 & 30 & \\
\hline 20090111 & $14: 28$ & 52.48 & 252 & 78 & -162 & \\
\hline 20090127 & $12: 33$ & 17.44 & 271 & 69 & -158 & \\
\hline 20090205 & $8: 19$ & 36.70 & 248 & 55 & 157 & \\
\hline 20090211 & $5: 28$ & 7.08 & 224 & 78 & 0 & \\
\hline 20090224 & $19: 43$ & 21.29 & 201 & 38 & 57 & \\
\hline 20090225 & $8: 32$ & 31.99 & 259 & 81 & -179 & $2 / 5$ \\
\hline 20090225 & $21: 42$ & 18.05 & 335 & 87 & 16 & $2 / 6$ \\
\hline 20090315 & $9: 20$ & 6.27 & 202 & 70 & -13 & \\
\hline 20090316 & $17: 32$ & 25.74 & 12 & 72 & 11 & $2 / 7$ \\
\hline 20090413 & $1: 05$ & 12.02 & 74 & 81 & 169 & \\
\hline 20090419 & $15: 20$ & 57.83 & 159 & 68 & 7 & \\
\hline 20090503 & $13: 28$ & 31.16 & 89 & 86 & 176 & $3 / 1$ \\
\hline 20090507 & $7: 27$ & 46.39 & 288 & 78 & -153 & $5 / 2$ \\
\hline 20090507 & $17: 20$ & 5.30 & 287 & 80 & -153 & $5 / 3$ \\
\hline 20090508 & $0: 34$ & 38.36 & 151 & 48 & -44 & \\
\hline 20090513 & $4: 27$ & 42.30 & 233 & 57 & 165 & $2 / 8$ \\
\hline 20090524 & $5: 17$ & 59.58 & 15 & 56 & 7 & $2 / 9$ \\
\hline 20090526 & $9: 57$ & 9.30 & 236 & 74 & 169 & $3 / 2$ \\
\hline 20090601 & $2: 58$ & 0.14 & 153 & 81 & 6 & \\
\hline 20090618 & $5: 11$ & 18.57 & 197 & 43 & 107 & \\
\hline
\end{tabular}




\begin{tabular}{|c|c|c|c|c|c|c|}
\hline $\begin{array}{r}\text { Date } \\
\text { yyyymmdd }\end{array}$ & $\begin{array}{l}\text { Time } \\
\text { hrmin }\end{array}$ & $\begin{array}{r}\mathrm{Sec} \\
{[\mathrm{s}]}\end{array}$ & $\begin{array}{r}\text { Strike } \\
{\left[{ }^{\circ}\right]}\end{array}$ & $\begin{array}{l}\text { Dip } \\
{\left[{ }^{\circ}\right]}\end{array}$ & $\begin{array}{r}\text { Rake } \\
{\left[{ }^{\circ}\right]}\end{array}$ & Cluster/Event \\
\hline 20090618 & $7: 25$ & 9.29 & 106 & 63 & -61 & $2 / 10$ \\
\hline 20090622 & $1: 10$ & 48.47 & 63 & 16 & -60 & \\
\hline 20090622 & 4:06 & 6.23 & 286 & 48 & -96 & \\
\hline 20090622 & $14: 07$ & 1.80 & 181 & 67 & 93 & \\
\hline 20090623 & $1: 52$ & 0.04 & 56 & 77 & 161 & \\
\hline 20090623 & $1: 53$ & 22.24 & 57 & 77 & 160 & \\
\hline 20090623 & $2: 59$ & 21.22 & 158 & 70 & 13 & \\
\hline 20090627 & $0: 13$ & 5.76 & 259 & 83 & -167 & \\
\hline 20090628 & $18: 23$ & 21.95 & 35 & 86 & 160 & $1 / 3$ \\
\hline 20090630 & $17: 43$ & 37.06 & 240 & 71 & 178 & $2 / 11$ \\
\hline 20090701 & $8: 47$ & 20.91 & 55 & 65 & 128 & \\
\hline 20090701 & $19: 36$ & 29.80 & 162 & 79 & 12 & \\
\hline 20090703 & $18: 36$ & 16.53 & 13 & 66 & 15 & $2 / 12$ \\
\hline 20090705 & $1: 53$ & 54.10 & 158 & 89 & -25 & $2 / 13$ \\
\hline 20090705 & $18: 34$ & 18.13 & 306 & 81 & 7 & \\
\hline 20090707 & $7: 57$ & 44.36 & 14 & 57 & 47 & $2 / 14$ \\
\hline 20090707 & $16: 29$ & 25.00 & 180 & 64 & 22 & $2 / 15$ \\
\hline 20090708 & $6: 18$ & 8.91 & 303 & 70 & 12 & \\
\hline 20090708 & $9: 24$ & 6.44 & 75 & 74 & 153 & $2 / 16$ \\
\hline 20090708 & $14: 15$ & 7.31 & 284 & 40 & -152 & \\
\hline 20090709 & $4: 37$ & 10.26 & 112 & 41 & -65 & \\
\hline 20090709 & 13:02 & 47.97 & 248 & 38 & 124 & $2 / 17$ \\
\hline 20090709 & $13: 26$ & 7.77 & 258 & 37 & 121 & $2 / 18$ \\
\hline 20090711 & $23: 32$ & 18.62 & 51 & 68 & 122 & \\
\hline 20090712 & $6: 03$ & 45.62 & 74 & 81 & 165 & \\
\hline 20090714 & $1: 35$ & 15.19 & 46 & 66 & 113 & \\
\hline 20090714 & $6: 00$ & 46.95 & 55 & 72 & 162 & \\
\hline 20090714 & $9: 58$ & 52.30 & 321 & 73 & -30 & \\
\hline 20090715 & $7: 35$ & 16.46 & 33 & 84 & 86 & \\
\hline 20090715 & $10: 59$ & 19.90 & 330 & 82 & 0 & $2 / 19$ \\
\hline 20090715 & $17: 29$ & 22.09 & 64 & 67 & -166 & $2 / 20$ \\
\hline 20090715 & $17: 46$ & 47.11 & 160 & 84 & -2 & $2 / 21$ \\
\hline 20090715 & $19: 25$ & 11.34 & 331 & 80 & -2 & $2 / 22$ \\
\hline 20090715 & $20: 28$ & 55.51 & 158 & 69 & -34 & $3 / 3$ \\
\hline 20090716 & $6: 54$ & 12.34 & 73 & 66 & -174 & $2 / 23$ \\
\hline 20090716 & $9: 25$ & 1.31 & 38 & 67 & 127 & $5 / 4$ \\
\hline 20090716 & $14: 32$ & 4.42 & 173 & 72 & 1 & $3 / 4$ \\
\hline 20090716 & $14: 49$ & 55.19 & 325 & 74 & -21 & $2 / 24$ \\
\hline 20090717 & $10: 21$ & 53.03 & 76 & 81 & 164 & $3 / 5$ \\
\hline 20090717 & $15: 31$ & 15.39 & 334 & 72 & 5 & $1 / 4$ \\
\hline 20090718 & $8: 43$ & 57.80 & 338 & 32 & 43 & $2 / 25$ \\
\hline 20090718 & $9: 45$ & 1.75 & 63 & 64 & -168 & $2 / 26$ \\
\hline 20090718 & $16: 42$ & 33.42 & 96 & 50 & -135 & $1 / 5$ \\
\hline 20090719 & $18: 22$ & 59.04 & 231 & 82 & -168 & \\
\hline 20090720 & $11: 56$ & 26.79 & 167 & 76 & -17 & $5 / 5$ \\
\hline 20090720 & $13: 13$ & 7.86 & 355 & 87 & 29 & $5 / 6$ \\
\hline 20090724 & $15: 17$ & 16.17 & 94 & 79 & -137 & $2 / 27$ \\
\hline
\end{tabular}




\begin{tabular}{|c|c|c|c|c|c|c|}
\hline $\begin{array}{r}\text { Date } \\
\text { yyyymmdd }\end{array}$ & $\begin{array}{l}\text { Time } \\
\text { hrmin }\end{array}$ & $\begin{array}{r}\text { Sec } \\
{[\mathrm{s}]}\end{array}$ & $\begin{array}{r}\text { Strike } \\
{\left[{ }^{\circ}\right]}\end{array}$ & $\begin{array}{r}\text { Dip } \\
{\left[{ }^{\circ}\right]}\end{array}$ & $\begin{array}{r}\text { Rake } \\
{\left[{ }^{\circ}\right]}\end{array}$ & Cluster/Event \\
\hline 20090724 & $15: 24$ & 1.40 & 194 & 64 & 46 & $2 / 28$ \\
\hline 20090726 & $14: 55$ & 12.35 & 248 & 75 & -164 & $2 / 29$ \\
\hline 20090727 & 8:07 & 18.53 & 320 & 54 & -21 & $2 / 30$ \\
\hline 20090729 & $11: 13$ & 47.29 & 339 & 83 & 15 & \\
\hline 20090729 & $11: 41$ & 43.41 & 240 & 68 & 179 & $2 / 31$ \\
\hline 20090731 & $0: 29$ & 45.31 & 242 & 63 & -173 & $2 / 32$ \\
\hline 20090801 & $2: 27$ & 55.44 & 84 & 83 & -151 & $1 / 6$ \\
\hline 20090801 & $5: 17$ & 17.01 & 191 & 64 & 16 & \\
\hline 20090801 & $19: 57$ & 13.61 & 240 & 84 & -179 & \\
\hline 20090803 & $8: 43$ & 21.71 & 285 & 80 & -155 & $5 / 7$ \\
\hline 20090806 & $16: 45$ & 45.26 & 255 & 64 & -161 & $3 / 6$ \\
\hline 20090807 & $6: 44$ & 41.18 & 161 & 89 & 3 & \\
\hline 20090808 & $15: 41$ & 42.68 & 251 & 86 & 141 & $1 / 7$ \\
\hline 20090808 & $17: 36$ & 57.43 & 307 & 18 & -26 & \\
\hline 20090811 & $16: 28$ & 42.10 & 17 & 55 & 38 & $2 / 33$ \\
\hline 20090813 & 7:07 & 12.56 & 148 & 46 & 20 & $5 / 8$ \\
\hline 20090814 & $16: 24$ & 5.75 & 152 & 38 & -28 & $5 / 9$ \\
\hline 20090815 & $12: 42$ & 50.42 & 18 & 80 & 22 & $1 / 8$ \\
\hline 20090815 & $18: 30$ & 30.55 & 149 & 45 & 21 & $5 / 10$ \\
\hline 20090816 & $21: 56$ & 56.40 & 102 & 31 & 90 & $1 / 9$ \\
\hline 20090818 & $1: 51$ & 2.42 & 357 & 71 & 33 & $1 / 10$ \\
\hline 20090818 & $10: 34$ & 43.91 & 285 & 87 & 18 & $5 / 11$ \\
\hline 20090819 & $10: 50$ & 28.00 & 217 & 53 & -13 & \\
\hline 20090820 & $13: 49$ & 9.06 & 51 & 32 & 81 & \\
\hline 20090820 & $18: 39$ & 2.49 & 234 & 65 & 171 & \\
\hline 20090820 & $21: 25$ & 9.91 & 256 & 58 & 148 & $2 / 34$ \\
\hline 20090821 & $11: 33$ & 36.06 & 223 & 60 & -177 & \\
\hline 20090822 & $0: 38$ & 20.77 & 319 & 79 & 13 & $1 / 11$ \\
\hline 20090826 & $11: 51$ & 12.34 & 93 & 60 & -158 & \\
\hline 20090828 & $1: 47$ & 33.92 & 52 & 64 & -160 & \\
\hline 20090828 & $6: 55$ & 10.57 & 76 & 89 & 179 & $2 / 35$ \\
\hline 20090904 & $20: 24$ & 7.70 & 144 & 67 & -26 & $2 / 36$ \\
\hline 20090905 & $11: 48$ & 32.51 & 244 & 60 & -146 & $2 / 37$ \\
\hline 20090905 & $18: 47$ & 10.91 & 178 & 83 & 17 & \\
\hline 20090906 & 11:03 & 32.86 & 152 & 66 & -40 & $5 / 12$ \\
\hline 20090906 & $12: 30$ & 33.46 & 47 & 80 & 179 & \\
\hline 20090907 & $22: 17$ & 17.33 & 155 & 56 & -28 & $5 / 13$ \\
\hline 20090908 & $19: 20$ & 47.68 & 292 & 66 & -141 & $5 / 14$ \\
\hline 20090909 & $14: 21$ & 10.59 & 220 & 46 & 61 & \\
\hline 20090912 & $5: 38$ & 12.46 & 144 & 82 & 1 & $2 / 38$ \\
\hline 20090912 & $11: 19$ & 36.18 & 144 & 85 & 1 & $2 / 39$ \\
\hline 20090913 & $10: 54$ & 18.80 & 10 & 53 & 102 & \\
\hline 20090913 & $11: 45$ & 20.79 & 162 & 73 & 139 & \\
\hline 20090914 & $19: 32$ & 52.90 & 44 & 74 & -176 & $2 / 40$ \\
\hline 20090915 & 9:54 & 54.23 & 191 & 83 & -4 & \\
\hline 20090915 & $14: 25$ & 0.71 & 59 & 85 & -158 & $2 / 41$ \\
\hline 20090916 & 7:59 & 6.12 & 48 & 68 & 124 & \\
\hline
\end{tabular}




\begin{tabular}{|rrrrrrr|}
\hline Date & Time & Sec & Strike & Dip & Rake & Cluster/Event \\
yyyymmdd & hrmin & {$[\mathrm{s}]$} & {$\left[{ }^{\circ}\right]$} & $\left.{ }^{\circ}\right]$ & $\left.{ }^{\circ}\right]$ & \\
\hline 20090917 & $10: 07$ & 12.42 & 72 & 82 & 176 & \\
20090918 & $21: 00$ & 48.49 & 141 & 38 & 28 & $3 / 7$ \\
20090919 & $4: 07$ & 43.81 & 45 & 62 & 148 & \\
20090920 & $6: 02$ & 42.18 & 337 & 56 & -43 & $1 / 12$ \\
20090921 & $13: 30$ & 22.32 & 60 & 78 & -171 & $2 / 42$ \\
20090921 & $23: 56$ & 7.74 & 234 & 59 & -166 & $2 / 43$ \\
20090922 & $6: 48$ & 1.98 & 12 & 85 & 45 & \\
20090922 & $18: 39$ & 39.56 & 270 & 71 & -153 & \\
20090923 & $6: 38$ & 11.76 & 92 & 84 & -171 & \\
20090925 & $8: 35$ & 21.90 & 219 & 68 & 129 & $2 / 44$ \\
20090925 & $20: 12$ & 29.27 & 48 & 77 & 132 & $5 / 15$ \\
20090926 & $12: 47$ & 54.88 & 220 & 71 & 126 & $2 / 45$ \\
20090926 & $13: 02$ & 41.11 & 219 & 68 & 131 & $2 / 46$ \\
20090926 & $18: 27$ & 35.89 & 1 & 80 & 21 & \\
20090926 & $22: 23$ & 5.26 & 90 & 74 & 162 & \\
20090927 & $5: 17$ & 27.13 & 250 & 78 & 148 & $1 / 13$ \\
20090929 & $6: 41$ & 34.96 & 21 & 87 & 34 & \\
20090929 & $16: 07$ & 51.96 & 327 & 58 & 17 & $1 / 14$ \\
20090930 & $2: 25$ & 13.96 & 148 & 32 & 39 & $5 / 16$ \\
20091001 & $14: 37$ & 43.31 & 320 & 74 & 23 & $2 / 47$ \\
20091002 & $2: 52$ & 43.43 & 158 & 66 & 2 & $5 / 17$ \\
20091002 & $10: 57$ & 2.21 & 55 & 78 & 177 & $2 / 48$ \\
20091002 & $10: 57$ & 23.85 & 221 & 70 & 126 & $2 / 49$ \\
20091003 & $3: 34$ & 35.10 & 202 & 85 & -1 & $2 / 50$ \\
20091005 & $1: 53$ & 46.93 & 319 & 66 & -33 & $2 / 51$ \\
20091005 & $19: 47$ & 44.45 & 128 & 20 & -126 & \\
20091009 & $21: 29$ & 6.05 & 219 & 70 & 129 & $2 / 52$ \\
20091010 & $18: 06$ & 38.43 & 328 & 77 & -15 & $5 / 18$ \\
20091010 & $19: 02$ & 15.90 & 282 & 52 & -63 & \\
20091011 & $13: 54$ & 18.87 & 34 & 71 & 125 & $3 / 8$ \\
20091013 & $17: 06$ & 11.05 & 183 & 42 & 124 & $1 / 15$ \\
20091015 & $12: 22$ & 22.31 & 168 & 88 & -2 & $2 / 53$ \\
20091016 & $8: 13$ & 42.70 & 307 & 77 & -19 & $2 / 54$ \\
20091017 & $14: 47$ & 14.29 & 45 & 72 & -173 & $2 / 55$ \\
20091018 & $9: 10$ & 43.22 & 307 & 76 & -19 & $2 / 56$ \\
20091019 & $6: 01$ & 54.10 & 38 & 72 & 124 & $5 / 19$ \\
20091020 & $8: 19$ & 53.33 & 323 & 86 & 0 & $1 / 16$ \\
20091023 & $18: 54$ & 32.80 & 180 & 86 & -1 & $2 / 57$ \\
20091024 & $12: 53$ & 2.79 & 73 & 78 & -146 & $2 / 58$ \\
20091024 & $20: 22$ & 27.16 & 146 & 72 & 25 & $2 / 59$ \\
20091027 & $0: 01$ & 13.73 & 337 & 72 & 14 & $2 / 60$ \\
20091028 & $20: 13$ & 38.46 & 242 & 62 & -148 & \\
20091028 & $20: 32$ & 22.17 & 45 & 87 & 176 & \\
20091101 & $7: 07$ & 46.83 & 317 & 56 & 9 & \\
20091109 & $4: 37$ & 46.54 & 56 & 66 & 127 & \\
20091109 & $13: 59$ & 4.96 & 60 & 76 & 164 & \\
20091109 & $14: 02$ & 27.71 & 223 & 39 & 154 & \\
\hline & & & & & & \\
\end{tabular}




\begin{tabular}{|c|c|c|c|c|c|c|}
\hline $\begin{array}{r}\text { Date } \\
\text { yyyymmdd }\end{array}$ & $\begin{array}{l}\text { Time } \\
\text { hrmin }\end{array}$ & $\begin{array}{r}\text { Sec } \\
{[\mathrm{s}]}\end{array}$ & $\begin{array}{r}\text { Strike } \\
{\left[{ }^{\circ}\right]}\end{array}$ & $\begin{array}{r}\text { Dip } \\
{\left[{ }^{\circ}\right]}\end{array}$ & $\begin{array}{r}\text { Rake } \\
{\left[{ }^{\circ}\right]}\end{array}$ & Cluster/Event \\
\hline 20091109 & 14:09 & 59.45 & 156 & 68 & 17 & \\
\hline 20091109 & $14: 21$ & 42.20 & 157 & 68 & 17 & \\
\hline 20091110 & $8: 13$ & 15.44 & 106 & 84 & -128 & $2 / 63$ \\
\hline 20091112 & $1: 17$ & 3.31 & 287 & 82 & 21 & $5 / 20$ \\
\hline 20091117 & $15: 40$ & 19.76 & 173 & 57 & 34 & \\
\hline 20091117 & 23:07 & 37.85 & 235 & 27 & -22 & \\
\hline 20091118 & $7: 22$ & 4.34 & 54 & 50 & 94 & $2 / 64$ \\
\hline 20091118 & $14: 13$ & 23.78 & 286 & 82 & 21 & $5 / 21$ \\
\hline 20091118 & 19:37 & 12.29 & 69 & 81 & 90 & \\
\hline 20091120 & 13:04 & 3.47 & 23 & 89 & -14 & $5 / 22$ \\
\hline 20091124 & 2:00 & 18.06 & 53 & 84 & 169 & \\
\hline 20091129 & $23: 36$ & 46.69 & 323 & 82 & 16 & \\
\hline 20091202 & 4:37 & 19.89 & 154 & 81 & -64 & $1 / 17$ \\
\hline 20091205 & $11: 30$ & 52.85 & 156 & 85 & 12 & \\
\hline 20091205 & $11: 40$ & 6.97 & 69 & 77 & -178 & \\
\hline 20091205 & $17: 00$ & 5.56 & 100 & 84 & 171 & $5 / 23$ \\
\hline 20091205 & $19: 32$ & 49.22 & 81 & 89 & 174 & $2 / 65$ \\
\hline 20091209 & 19:39 & 39.16 & 1 & 83 & -22 & \\
\hline 20091215 & 13:01 & 18.46 & 189 & 79 & 8 & \\
\hline 20091216 & $17: 27$ & 4.05 & 59 & 72 & 157 & \\
\hline 20091217 & $3: 46$ & 58.24 & 329 & 75 & -11 & $2 / 66$ \\
\hline 20091217 & 4:00 & 15.62 & 329 & 74 & -10 & $2 / 67$ \\
\hline 20091217 & $10: 27$ & 20.12 & 327 & 69 & -13 & $2 / 68$ \\
\hline 20091217 & $16: 15$ & 32.53 & 178 & 51 & -23 & $3 / 9$ \\
\hline 20091221 & $16: 26$ & 6.85 & 126 & 72 & 6 & \\
\hline 20091221 & $21: 02$ & 43.15 & 162 & 67 & 38 & $2 / 69$ \\
\hline 20091222 & $2: 45$ & 34.18 & 162 & 64 & 40 & $2 / 70$ \\
\hline 20091222 & $10: 48$ & 38.57 & 162 & 64 & 41 & $2 / 71$ \\
\hline 20091223 & $23: 18$ & 33.18 & 194 & 82 & 5 & \\
\hline 20091225 & 4:22 & 39.67 & 64 & 85 & 166 & \\
\hline 20091225 & $13: 56$ & 21.95 & 26 & 68 & -99 & \\
\hline 20091228 & $12: 47$ & 47.52 & 297 & 68 & -132 & $5 / 24$ \\
\hline 20091229 & $10: 11$ & 53.37 & 60 & 76 & 162 & \\
\hline 20091230 & $15: 10$ & 14.88 & 283 & 85 & -167 & $5 / 25$ \\
\hline 20091231 & $15: 55$ & 7.26 & 145 & 48 & 14 & $2 / 72$ \\
\hline 20100101 & $17: 06$ & 52.01 & 70 & 82 & 150 & \\
\hline 20100102 & $16: 34$ & 26.48 & 295 & 71 & -131 & $5 / 26$ \\
\hline 20100104 & 10:02 & 26.33 & 294 & 72 & -131 & $5 / 27$ \\
\hline 20100107 & 13:04 & 44.24 & 53 & 59 & -174 & \\
\hline 20100108 & $9: 27$ & 19.38 & 44 & 83 & 87 & $2 / 73$ \\
\hline 20100110 & $20: 54$ & 1.53 & 84 & 55 & 158 & $2 / 74$ \\
\hline 20100112 & 11:34 & 47.38 & 70 & 76 & 165 & \\
\hline 20100115 & $21: 34$ & 47.72 & 338 & 67 & 13 & \\
\hline 20100116 & 11:02 & 31.26 & 93 & 76 & -152 & $2 / 75$ \\
\hline 20100119 & $3: 53$ & 1.02 & 328 & 33 & -64 & \\
\hline 20100119 & $8: 20$ & 47.05 & 117 & 49 & -126 & \\
\hline 20100121 & $23: 44$ & 7.36 & 230 & 76 & 143 & \\
\hline
\end{tabular}




\begin{tabular}{|c|c|c|c|c|c|c|}
\hline $\begin{array}{r}\text { Date } \\
\text { yyyymmdd }\end{array}$ & $\begin{array}{l}\text { Time } \\
\text { hrmin }\end{array}$ & $\begin{array}{r}\mathrm{Sec} \\
{[\mathrm{s}]}\end{array}$ & $\begin{array}{r}\text { Strike } \\
{\left[{ }^{\circ}\right]}\end{array}$ & $\begin{array}{r}\text { Dip } \\
{\left[{ }^{\circ}\right]}\end{array}$ & $\begin{array}{r}\text { Rake } \\
{\left[{ }^{\circ}\right]}\end{array}$ & Cluster/Event \\
\hline 20100122 & $9: 12$ & 20.95 & 339 & 75 & 16 & $2 / 76$ \\
\hline 20100123 & $9: 52$ & 25.60 & 203 & 60 & -147 & $5 / 28$ \\
\hline 20100124 & $6: 31$ & 46.37 & 103 & 80 & -168 & $5 / 29$ \\
\hline 20100124 & $8: 46$ & 29.88 & 161 & 74 & -17 & $5 / 30$ \\
\hline 20100126 & $9: 53$ & 33.24 & 122 & 84 & -141 & $1 / 18$ \\
\hline 20100127 & $3: 16$ & 2.34 & 159 & 69 & 18 & \\
\hline 20100127 & $11: 57$ & 36.89 & 83 & 29 & 156 & $5 / 31$ \\
\hline 20100128 & $9: 14$ & 28.53 & 250 & 65 & -142 & \\
\hline 20100128 & $16: 07$ & 42.46 & 58 & 60 & 148 & \\
\hline 20100128 & $16: 35$ & 22.57 & 157 & 73 & 12 & $5 / 32$ \\
\hline 20100129 & $17: 47$ & 55.27 & 1 & 67 & 20 & $2 / 77$ \\
\hline 20100130 & $2: 42$ & 14.05 & 43 & 51 & 23 & $2 / 78$ \\
\hline 20100131 & $11: 47$ & 36.61 & 255 & 85 & -149 & $1 / 19$ \\
\hline 20100131 & 13:04 & 17.68 & 175 & 59 & -30 & \\
\hline 20100201 & $19: 19$ & 8.19 & 4 & 59 & -35 & \\
\hline 20100201 & 19:19 & 8.14 & 126 & 49 & -90 & \\
\hline 20100202 & $1: 28$ & 22.88 & 302 & 51 & -128 & $5 / 33$ \\
\hline 20100202 & $4: 26$ & 44.85 & 88 & 44 & 165 & \\
\hline 20100202 & 9:01 & 17.38 & 101 & 62 & -170 & \\
\hline 20100202 & 10:09 & 5.20 & 89 & 87 & -142 & $5 / 34$ \\
\hline 20100202 & $20: 55$ & 18.70 & 182 & 85 & 76 & \\
\hline 20100202 & $21: 11$ & 33.23 & 13 & 60 & 156 & \\
\hline 20100203 & $11: 14$ & 39.36 & 55 & 62 & 145 & \\
\hline 20100203 & $14: 35$ & 35.56 & 290 & 74 & 15 & $2 / 79$ \\
\hline 20100203 & $16: 33$ & 19.10 & 147 & 67 & 33 & $2 / 80$ \\
\hline 20100204 & $16: 30$ & 14.68 & 102 & 74 & -166 & \\
\hline 20100205 & 7:01 & 39.11 & 51 & 27 & 178 & \\
\hline 20100205 & 23:07 & 30.08 & 54 & 79 & 169 & $5 / 35$ \\
\hline 20100206 & $8: 44$ & 55.20 & 187 & 89 & 0 & $5 / 36$ \\
\hline 20100206 & $8: 54$ & 0.38 & 103 & 82 & -172 & $5 / 37$ \\
\hline 20100206 & $8: 54$ & 55.66 & 280 & 81 & -168 & $5 / 38$ \\
\hline 20100206 & $9: 48$ & 37.70 & 101 & 82 & 169 & $5 / 39$ \\
\hline 20100206 & $11: 55$ & 3.56 & 7 & 82 & -7 & $5 / 40$ \\
\hline 20100206 & $18: 56$ & 52.56 & 285 & 84 & -165 & $5 / 41$ \\
\hline 20100206 & 19:04 & 18.04 & 285 & 80 & -170 & $5 / 42$ \\
\hline 20100207 & $22: 26$ & 1.53 & 183 & 57 & 13 & $5 / 43$ \\
\hline 20100208 & $19: 41$ & 20.09 & 316 & 38 & -21 & \\
\hline 20100209 & $4: 21$ & 17.63 & 286 & 58 & -137 & $1 / 20$ \\
\hline 20100209 & $8: 26$ & 11.89 & 13 & 67 & 13 & \\
\hline 20100209 & $8: 50$ & 46.77 & 86 & 62 & 159 & $2 / 81$ \\
\hline 20100209 & $14: 57$ & 1.48 & 171 & 87 & 7 & $5 / 44$ \\
\hline 20100209 & $19: 39$ & 27.97 & 139 & 35 & -17 & $5 / 45$ \\
\hline 20100209 & $19: 57$ & 9.11 & 286 & 85 & -159 & $5 / 46$ \\
\hline 20100211 & $3: 39$ & 58.53 & 144 & 66 & -19 & $5 / 47$ \\
\hline 20100211 & $20: 05$ & 16.78 & 244 & 68 & 147 & \\
\hline 20100212 & $13: 32$ & 59.74 & 181 & 71 & 20 & \\
\hline 20100213 & $2: 59$ & 14.24 & 123 & 64 & -30 & \\
\hline
\end{tabular}




\begin{tabular}{|c|c|c|c|c|c|c|}
\hline $\begin{array}{r}\text { Date } \\
\text { yyyymmdd }\end{array}$ & $\begin{array}{r}\text { Time } \\
\text { hrmin }\end{array}$ & $\begin{array}{r}\text { Sec } \\
{[\mathrm{s}]}\end{array}$ & $\begin{array}{r}\text { Strike } \\
{\left[{ }^{\circ}\right]}\end{array}$ & $\begin{array}{r}\text { Dip } \\
{\left[{ }^{\circ}\right]}\end{array}$ & $\begin{array}{r}\text { Rake } \\
{\left[{ }^{\circ}\right]}\end{array}$ & Cluster/Event \\
\hline 20100213 & $11: 36$ & 45.31 & 351 & 64 & -27 & \\
\hline 20100213 & $19: 32$ & 13.17 & 77 & 82 & -179 & \\
\hline 20100214 & $7: 27$ & 43.41 & 162 & 74 & 23 & $2 / 82$ \\
\hline 20100215 & $13: 30$ & 29.97 & 216 & 53 & 139 & \\
\hline 20100215 & $15: 56$ & 56.70 & 213 & 71 & 123 & $2 / 83$ \\
\hline 20100216 & 21:02 & 45.66 & 174 & 86 & 21 & \\
\hline 20100217 & 1:09 & 12.65 & 145 & 74 & -14 & \\
\hline 20100217 & $5: 57$ & 25.99 & 145 & 84 & -42 & $5 / 48$ \\
\hline 20100217 & $7: 21$ & 29.56 & 146 & 73 & -10 & $5 / 49$ \\
\hline 20100217 & $7: 28$ & 57.28 & 146 & 72 & -8 & $5 / 50$ \\
\hline 20100217 & $14: 32$ & 53.06 & 309 & 78 & -10 & $5 / 51$ \\
\hline 20100218 & $11: 02$ & 48.47 & 268 & 79 & -165 & \\
\hline 20100219 & 10:03 & 36.96 & 251 & 66 & -144 & \\
\hline 20100219 & $17: 58$ & 20.81 & 270 & 65 & -147 & \\
\hline 20100220 & $2: 31$ & 30.96 & 246 & 84 & -162 & $5 / 52$ \\
\hline 20100221 & $2: 27$ & 26.17 & 285 & 75 & -150 & \\
\hline 20100221 & $15: 59$ & 12.23 & 190 & 77 & 62 & \\
\hline 20100221 & $18: 08$ & 32.78 & 300 & 72 & 13 & \\
\hline 20100222 & $5: 59$ & 9.41 & 234 & 77 & 106 & $2 / 84$ \\
\hline 20100222 & $10: 47$ & 56.58 & 287 & 58 & -35 & $5 / 53$ \\
\hline 20100223 & $22: 22$ & 0.00 & 92 & 62 & 145 & \\
\hline 20100223 & $22: 25$ & 8.40 & 156 & 79 & 15 & \\
\hline 20100225 & $3: 42$ & 21.63 & 153 & 71 & -22 & \\
\hline 20100225 & $11: 53$ & 18.50 & 325 & 71 & -38 & \\
\hline 20100225 & 14:04 & 34.43 & 250 & 58 & -143 & \\
\hline 20100227 & $6: 41$ & 13.03 & 181 & 42 & -14 & \\
\hline 20100227 & 8:06 & 15.63 & 70 & 52 & 145 & $5 / 54$ \\
\hline 20100228 & $3: 35$ & 39.35 & 94 & 49 & -103 & $5 / 55$ \\
\hline 20100228 & $10: 18$ & 35.28 & 74 & 54 & 146 & \\
\hline 20100228 & $16: 35$ & 11.82 & 252 & 70 & -161 & $5 / 56$ \\
\hline 20100228 & $16: 40$ & 32.98 & 181 & 59 & -36 & $5 / 57$ \\
\hline 20100228 & $18: 20$ & 59.02 & 179 & 75 & -16 & \\
\hline 20100228 & $23: 42$ & 59.58 & 237 & 62 & -146 & \\
\hline 20100301 & $2: 56$ & 22.63 & 298 & 62 & -148 & $5 / 58$ \\
\hline 20100301 & $13: 41$ & 43.91 & 212 & 71 & -142 & $5 / 59$ \\
\hline 20100301 & $13: 43$ & 23.59 & 137 & 62 & -36 & $5 / 60$ \\
\hline 20100301 & $18: 12$ & 31.85 & 106 & 61 & -35 & $5 / 61$ \\
\hline 20100302 & $7: 39$ & 32.52 & 136 & 50 & -11 & $5 / 62$ \\
\hline 20100302 & $13: 32$ & 37.22 & 72 & 76 & 179 & \\
\hline 20100302 & $22: 23$ & 53.45 & 222 & 74 & 70 & $2 / 85$ \\
\hline 20100303 & $23: 24$ & 55.09 & 10 & 76 & 0 & $2 / 86$ \\
\hline 20100304 & $4: 45$ & 43.47 & 286 & 65 & -160 & \\
\hline 20100304 & $6: 50$ & 38.98 & 289 & 69 & -142 & \\
\hline 20100305 & $22: 28$ & 37.03 & 88 & 64 & 159 & $2 / 87$ \\
\hline 20100305 & $22: 49$ & 3.77 & 263 & 65 & 148 & $2 / 88$ \\
\hline 20100307 & $1: 15$ & 6.18 & 347 & 81 & -12 & \\
\hline 20100307 & $20: 38$ & 0.06 & 342 & 59 & -38 & \\
\hline
\end{tabular}




\begin{tabular}{|rrrrrrr|}
\hline Date & Time & Sec & Strike & Dip & Rake & Cluster/Event \\
yyyymmdd & hrmin & {$[\mathrm{s}]$} & {$\left[{ }^{\circ}\right]$} & $\left.{ }^{\circ}\right]$ & $\left.{ }^{\circ}\right]$ & \\
\hline 20100308 & $19: 43$ & 35.22 & 68 & 55 & -141 & $5 / 63$ \\
20100308 & $21: 23$ & 45.29 & 324 & 76 & -15 & \\
20100312 & $7: 09$ & 7.46 & 260 & 15 & -157 & \\
20100312 & $10: 18$ & 21.02 & 58 & 62 & -116 & $5 / 64$ \\
20100312 & $22: 03$ & 29.22 & 265 & 83 & -157 & $5 / 65$ \\
20100312 & $23: 48$ & 30.63 & 51 & 61 & 123 & \\
20100317 & $15: 10$ & 51.58 & 290 & 88 & 6 & $5 / 66$ \\
20100318 & $10: 33$ & 31.12 & 145 & 68 & -26 & $5 / 67$ \\
20100319 & $9: 55$ & 31.56 & 40 & 64 & 25 & \\
20100319 & $10: 20$ & 27.01 & 161 & 63 & -31 & \\
20100319 & $10: 50$ & 6.30 & 288 & 87 & 148 & \\
20100319 & $12: 48$ & 26.82 & 290 & 83 & 155 & \\
20100319 & $15: 05$ & 37.12 & 309 & 82 & 39 & \\
20100319 & $21: 13$ & 26.15 & 325 & 74 & -14 & \\
20100319 & $21: 36$ & 49.10 & 158 & 67 & 23 & \\
20100320 & $17: 28$ & 39.39 & 264 & 55 & -124 & $5 / 68$ \\
20100322 & $13: 05$ & 49.47 & 341 & 81 & 15 & \\
20100322 & $14: 40$ & 42.37 & 338 & 60 & -32 & \\
20100325 & $4: 49$ & 48.15 & 79 & 35 & 156 & $5 / 69$ \\
20100325 & $21: 25$ & 10.28 & 166 & 57 & 27 & \\
20100326 & $6: 57$ & 14.42 & 268 & 62 & -148 & \\
20100327 & $12: 32$ & 26.52 & 285 & 66 & 161 & $5 / 70$ \\
20100328 & $10: 46$ & 8.50 & 185 & 63 & 37 & $5 / 71$ \\
20100329 & $10: 36$ & 52.90 & 158 & 59 & 14 & \\
20100329 & $19: 23$ & 26.91 & 51 & 61 & 145 & \\
20100330 & $1: 54$ & 7.38 & 197 & 65 & 150 & $2 / 99$ \\
20100401 & $11: 18$ & 27.10 & 246 & 83 & 179 & \\
20100401 & $11: 18$ & 27.02 & 245 & 89 & -158 & \\
20100402 & $16: 04$ & 21.74 & 187 & 43 & 19 & \\
20100402 & $16: 36$ & 11.06 & 358 & 54 & 16 & \\
20100402 & $19: 34$ & 8.89 & 265 & 65 & -139 & \\
20100402 & $21: 02$ & 16.93 & 355 & 59 & 15 & \\
20100403 & $5: 57$ & 53.70 & 207 & 81 & 88 & \\
20100403 & $7: 22$ & 49.67 & 226 & 76 & 103 & \\
20100403 & $11: 12$ & 47.22 & 348 & 14 & 56 & \\
20100403 & $12: 48$ & 26.13 & 209 & 86 & 95 & \\
20100404 & $19: 13$ & 13.92 & 250 & 77 & -146 & \\
20100405 & $11: 29$ & 20.46 & 256 & 82 & 156 & \\
20100405 & $17: 10$ & 22.98 & 4 & 71 & 30 & \\
20100407 & $17: 55$ & 12.56 & 151 & 77 & 15 & \\
20100408 & $10: 06$ & 32.32 & 228 & 71 & -156 & \\
20100408 & $20: 40$ & 20.87 & 210 & 81 & 89 & \\
20100410 & $9: 17$ & 26.64 & 214 & 67 & -143 & \\
20100410 & $11: 24$ & 24.73 & 358 & 54 & 17 & \\
20100410 & $16: 40$ & 20.33 & 175 & 81 & 10 & \\
20100411 & $4: 42$ & 19.97 & 54 & 49 & -90 & \\
20100413 & $18: 35$ & 11.35 & 112 & 58 & -38 & \\
\hline & & & & & & \\
\end{tabular}




\begin{tabular}{|rrrrrrr|}
\hline $\begin{array}{r}\text { Date } \\
\text { yyyymmdd }\end{array}$ & $\begin{array}{r}\text { Time } \\
\text { hrmin }\end{array}$ & $\begin{array}{r}\text { Sec } \\
{[\mathrm{s}]}\end{array}$ & $\begin{array}{r}\text { Strike } \\
{\left[{ }^{\circ}\right]}\end{array}$ & $\begin{array}{r}\text { Dip } \\
{\left[{ }^{\circ}\right]}\end{array}$ & $\begin{array}{r}\text { Rake } \\
{\left[{ }^{\circ}\right]}\end{array}$ & Cluster/Event \\
\hline 20100417 & $17: 59$ & 36.82 & 258 & 88 & -159 & $2 / 100$ \\
20100418 & $13: 50$ & 44.23 & 309 & 84 & 18 & $5 / 75$ \\
20100418 & $14: 19$ & 52.57 & 197 & 68 & -21 & \\
20100418 & $14: 43$ & 34.82 & 321 & 70 & -20 & $5 / 76$ \\
20100418 & $17: 37$ & 38.46 & 228 & 75 & -164 & $5 / 77$ \\
20100419 & $10: 42$ & 20.99 & 244 & 78 & -172 & \\
20100421 & $4: 02$ & 56.48 & 96 & 69 & -141 & \\
20100422 & $16: 54$ & 51.44 & 192 & 89 & 13 & $5 / 78$ \\
20100424 & $17: 31$ & 3.34 & 255 & 59 & -152 & \\
20100501 & $2: 53$ & 28.60 & 159 & 57 & 32 & \\
\hline
\end{tabular}

Table K.1. Focal mechanism solutions for all events recorded between November 2008 and April 2010. 
K. Focal mechanism solutions 


\section{Waveform examples of earthquake sequences}




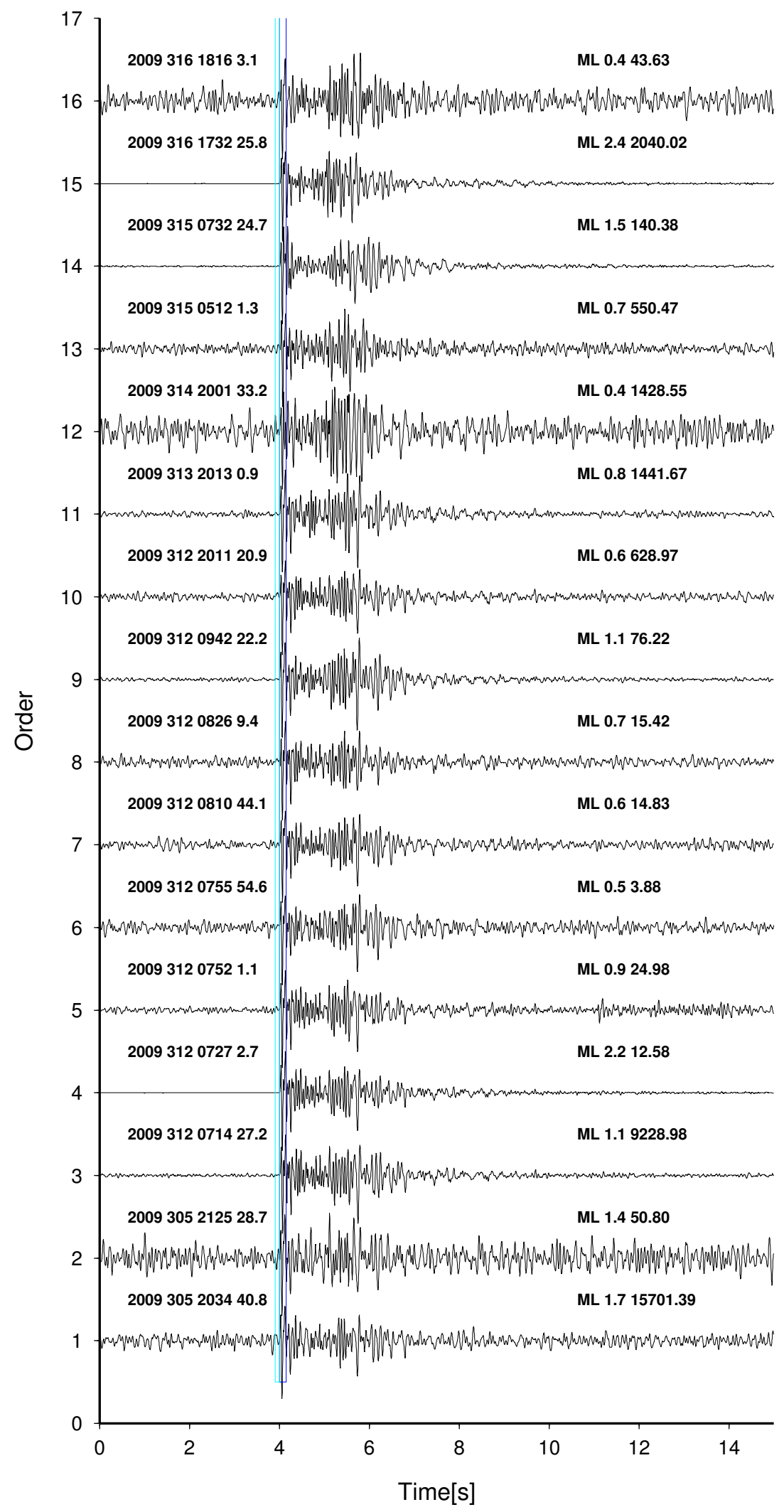

Figure L.1. Earthquake swarm on 12 March 2009 as recorded on the vertical component by station WHYM. 


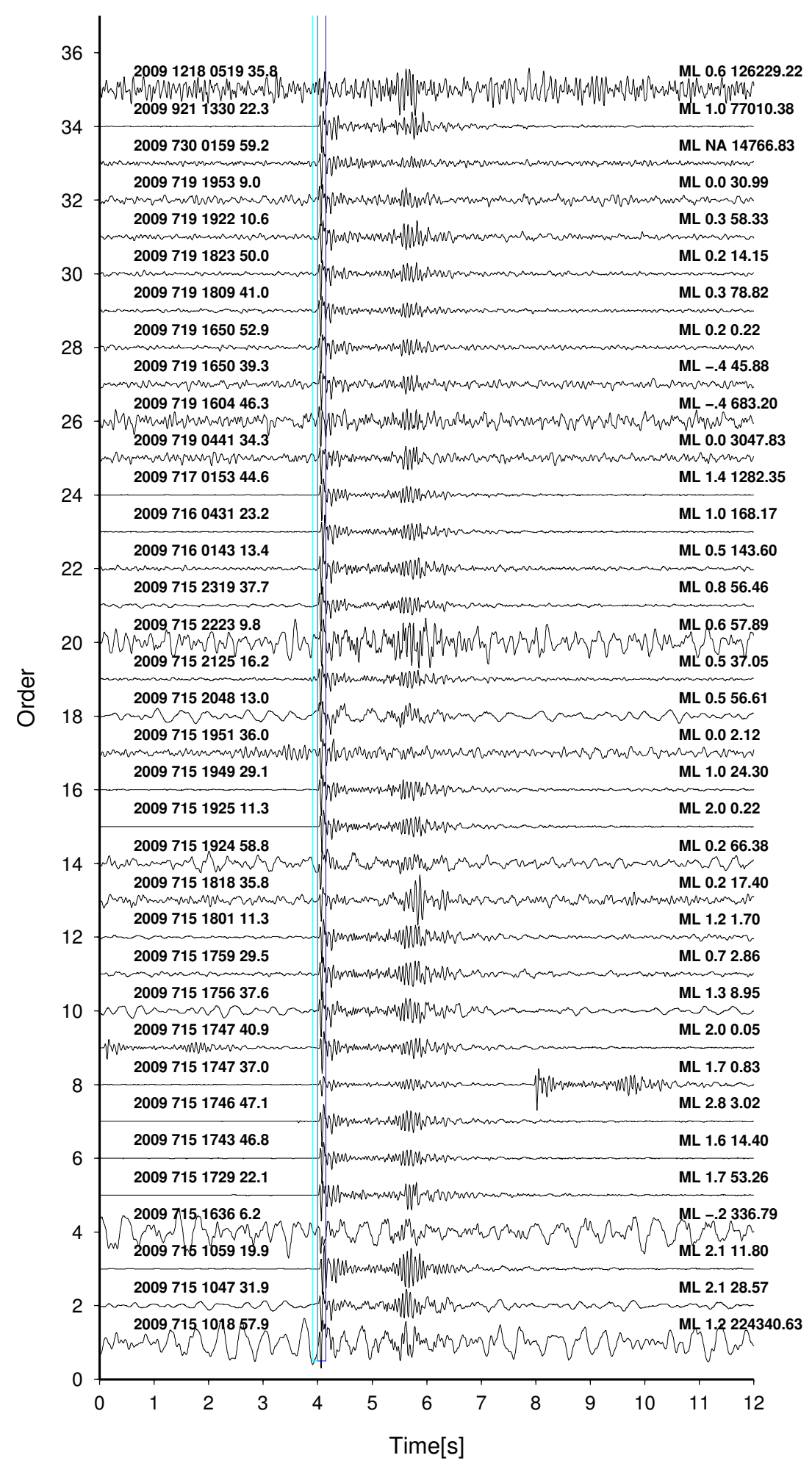

Figure L.2. Earthquake swarm on 15 July 2009 as recorded on the vertical component by station WHYM. Note that the event on the 19 July are slightly shallower $(5 \mathrm{~km})$. 


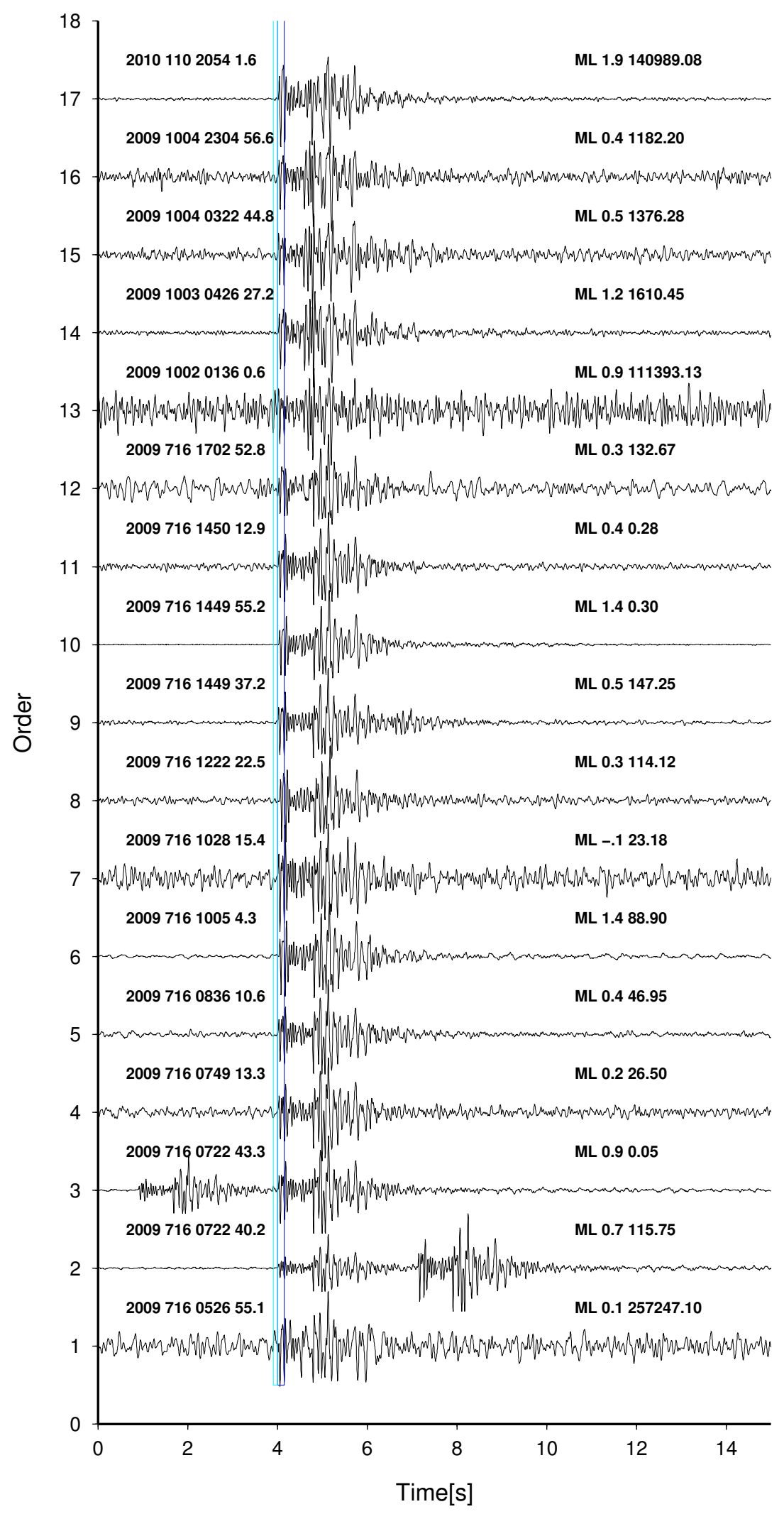

Figure L.3. Earthquake swarm on 16 July 2009 as recorded on the vertical component by station WHYM. Note that the later events in October are deeper $(7.5 \mathrm{~km})$ than the events at the beginning $(5.5 \mathrm{~km}$ versus $6.5 \mathrm{~km})$. 


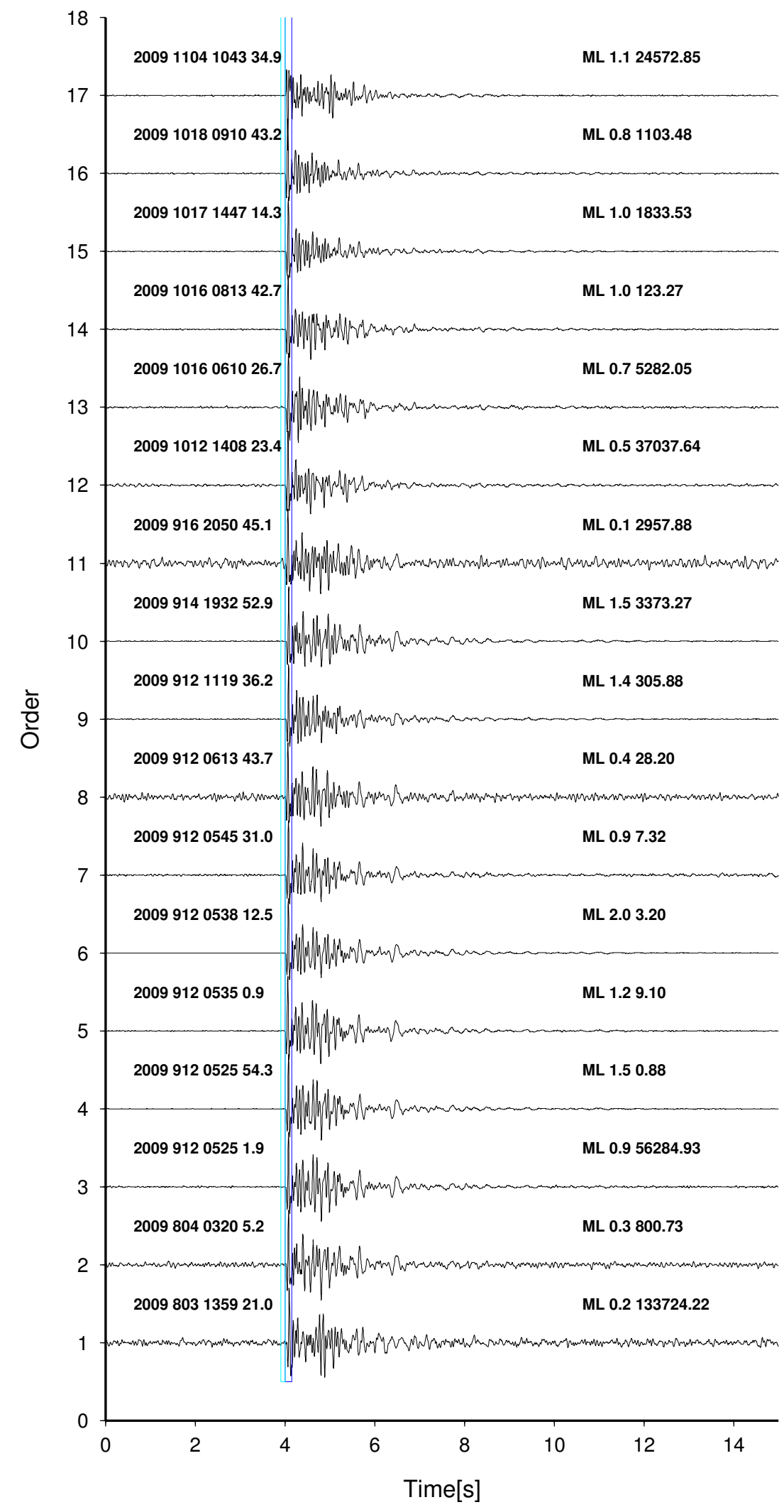

Figure L.4. Earthquake swarm on 12 September 2009 as recorded on the vertical component by station WHYM. 


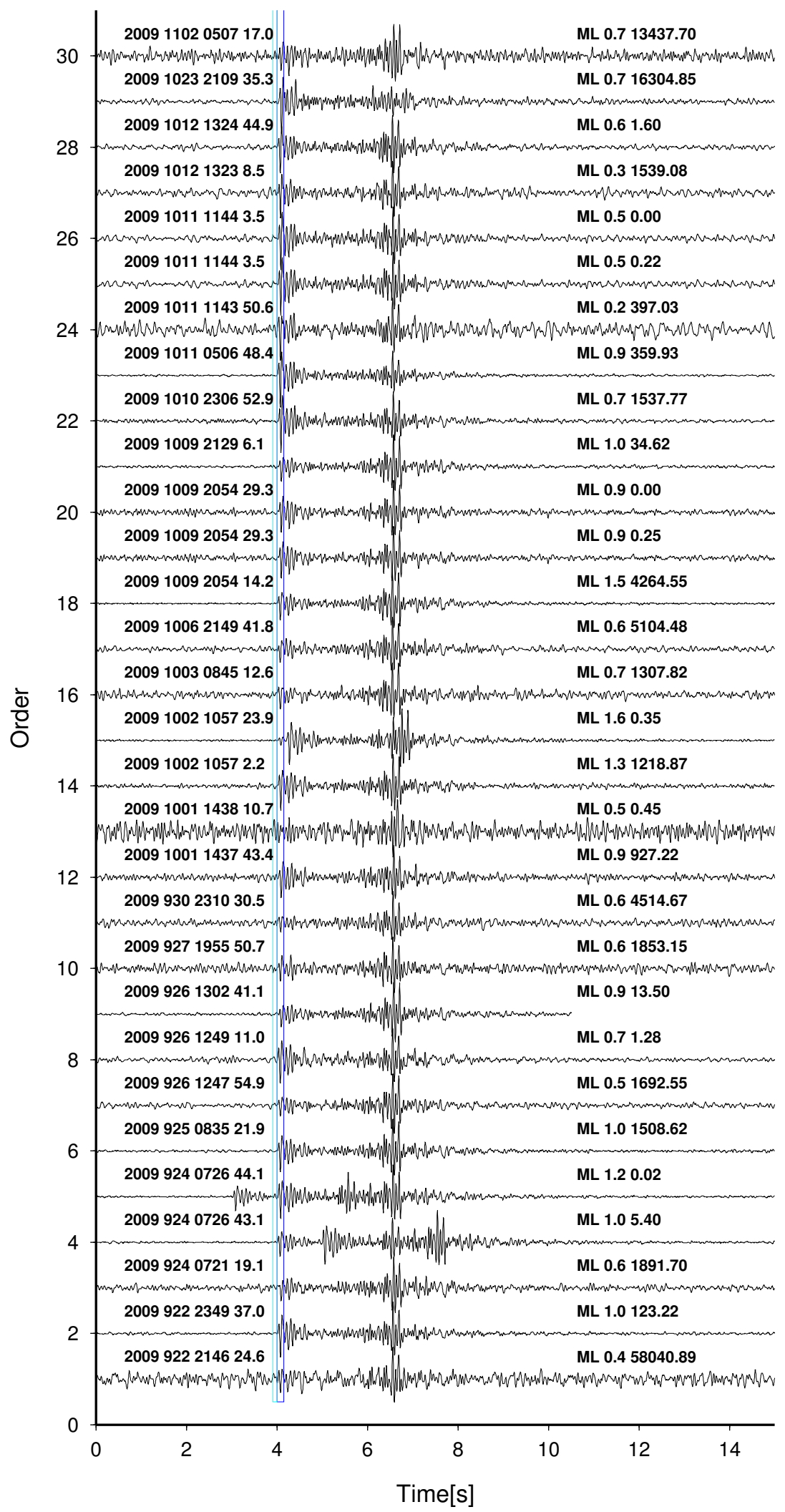

Figure L.5. Earthquake swarm on 22 September 2009 as recorded on the vertical component by station WHYM. 


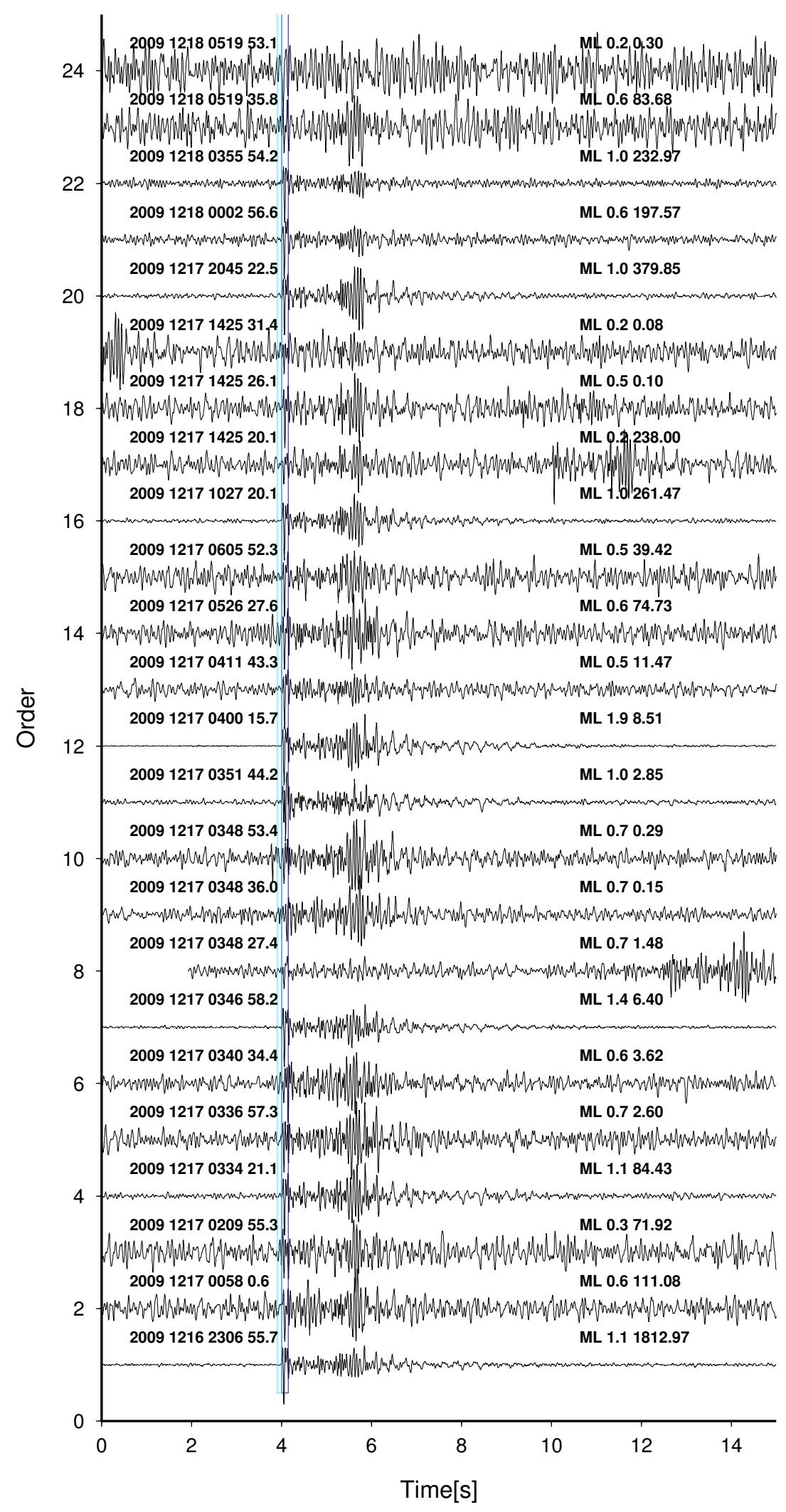

Figure L.6. Earthquake swarm on 17 December 2009 as recorded on the vertical component by station WHYM. 


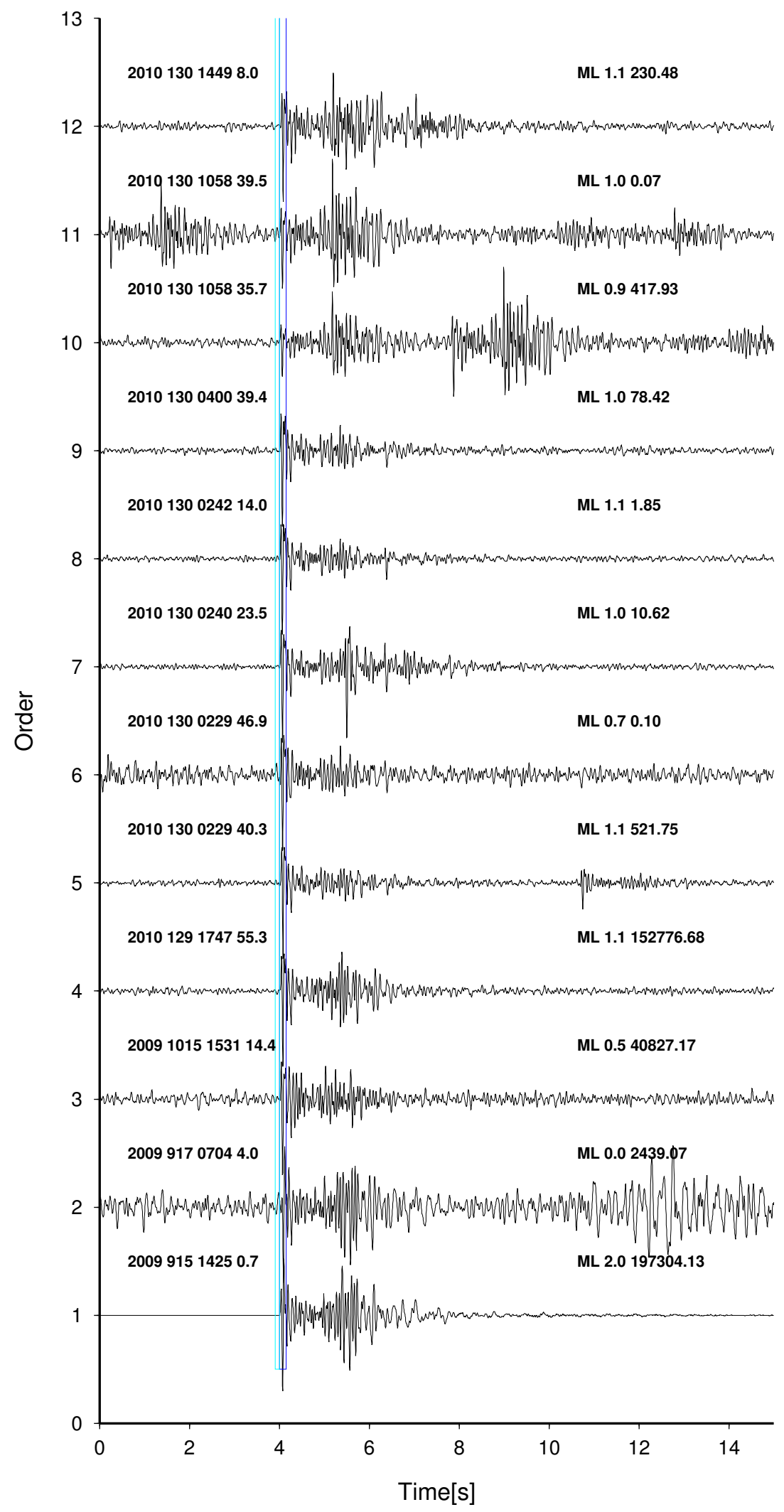

Figure L.7. Earthquake swarm on 30 January 2010 as recorded on the vertical component by station WHYM. 


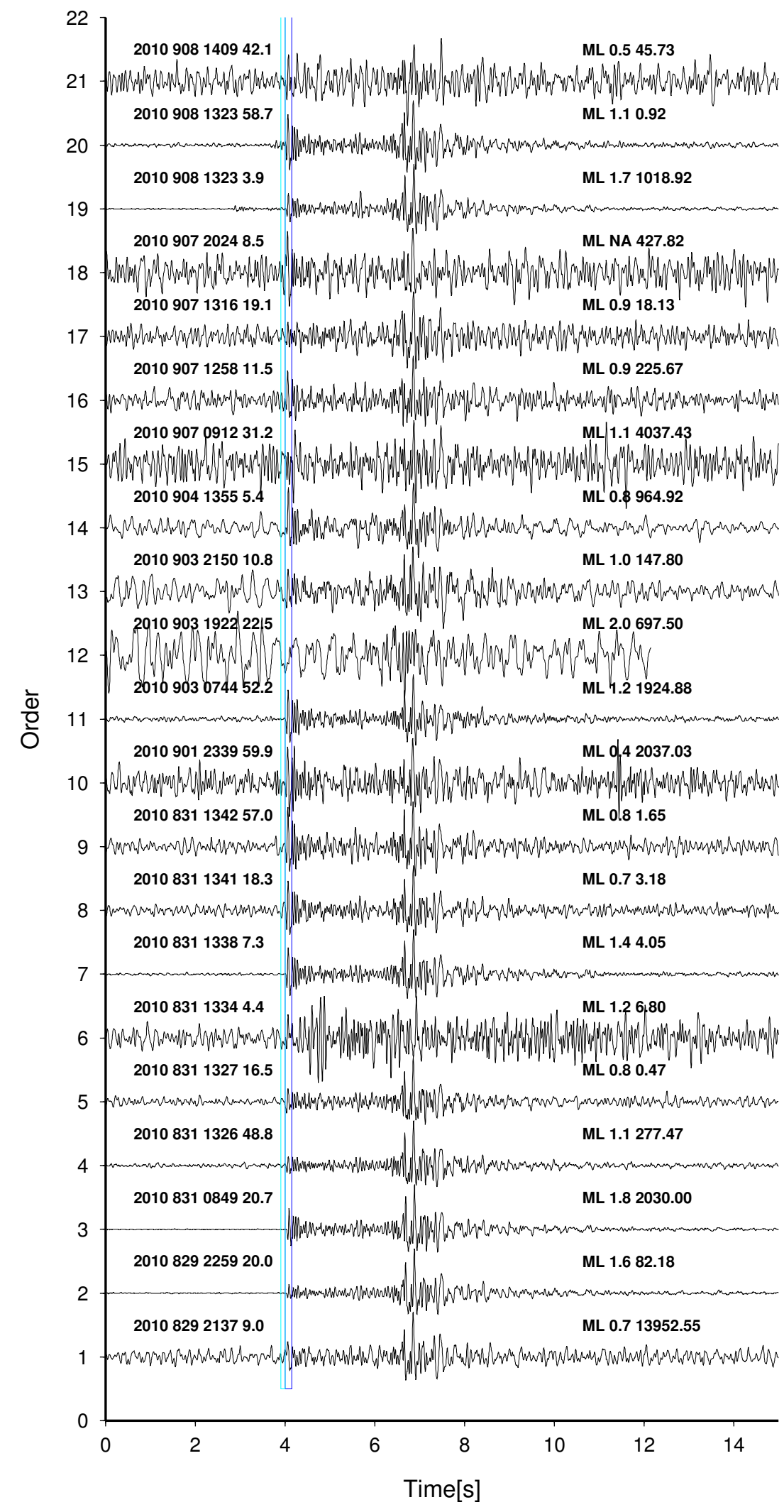

Figure L.8. Earthquake swarm on 28 August 2010 as recorded on the vertical component by station WHYM. 


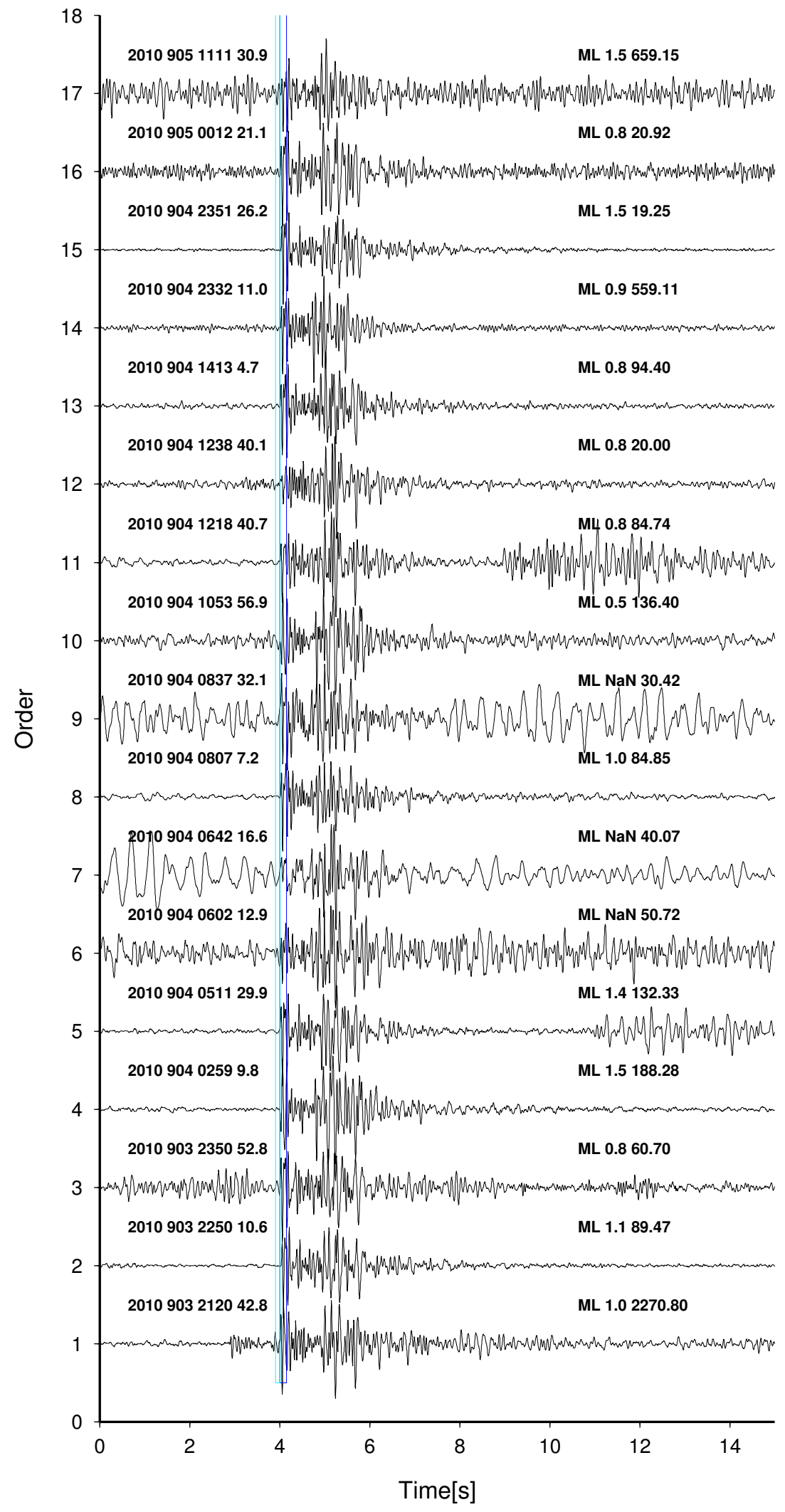

Figure L.9. Earthquake swarm on 03 September 2010 as recorded on the vertical component by station WHYM. 


\section{Overview of combined global studies of seismicity and resistivity}




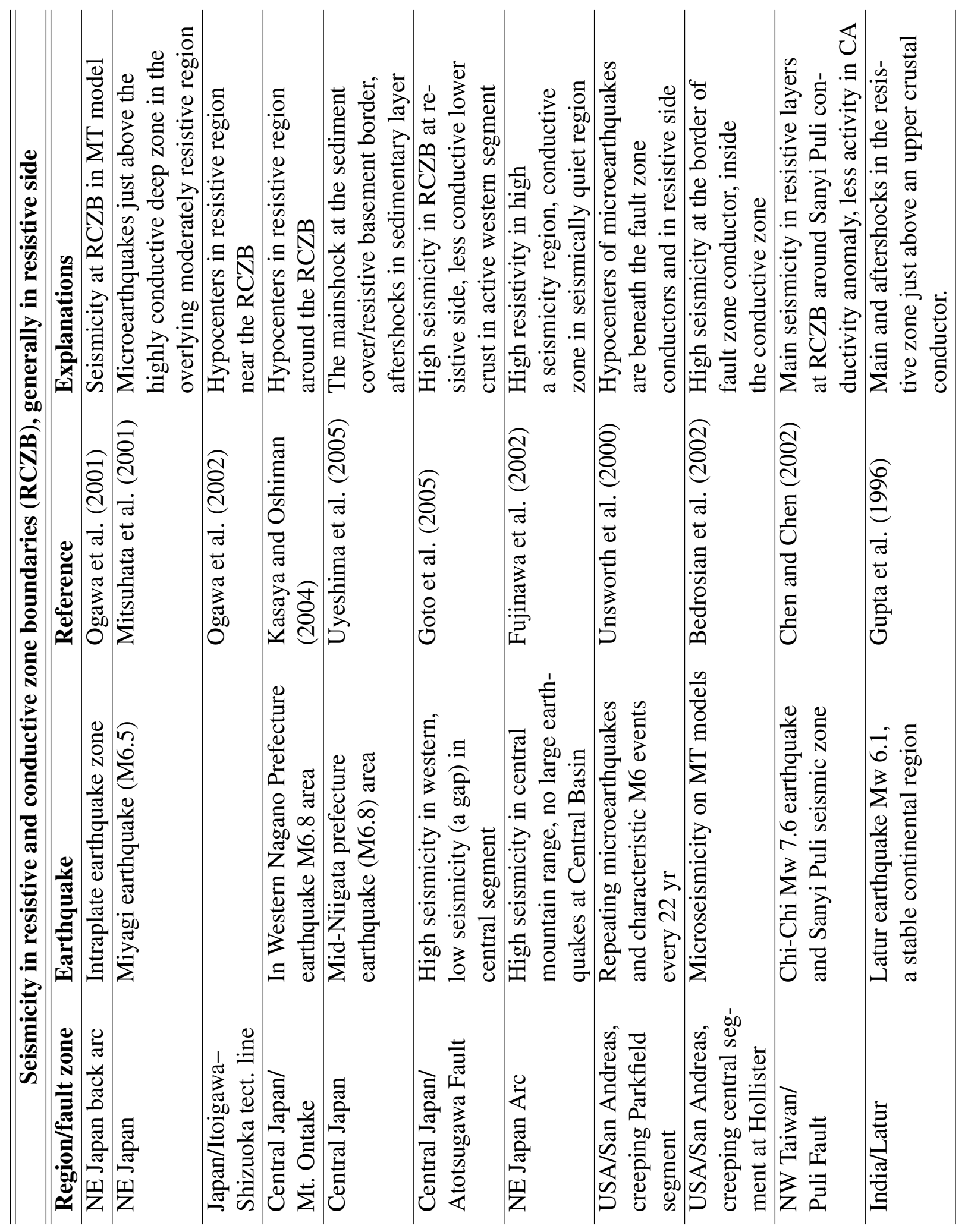




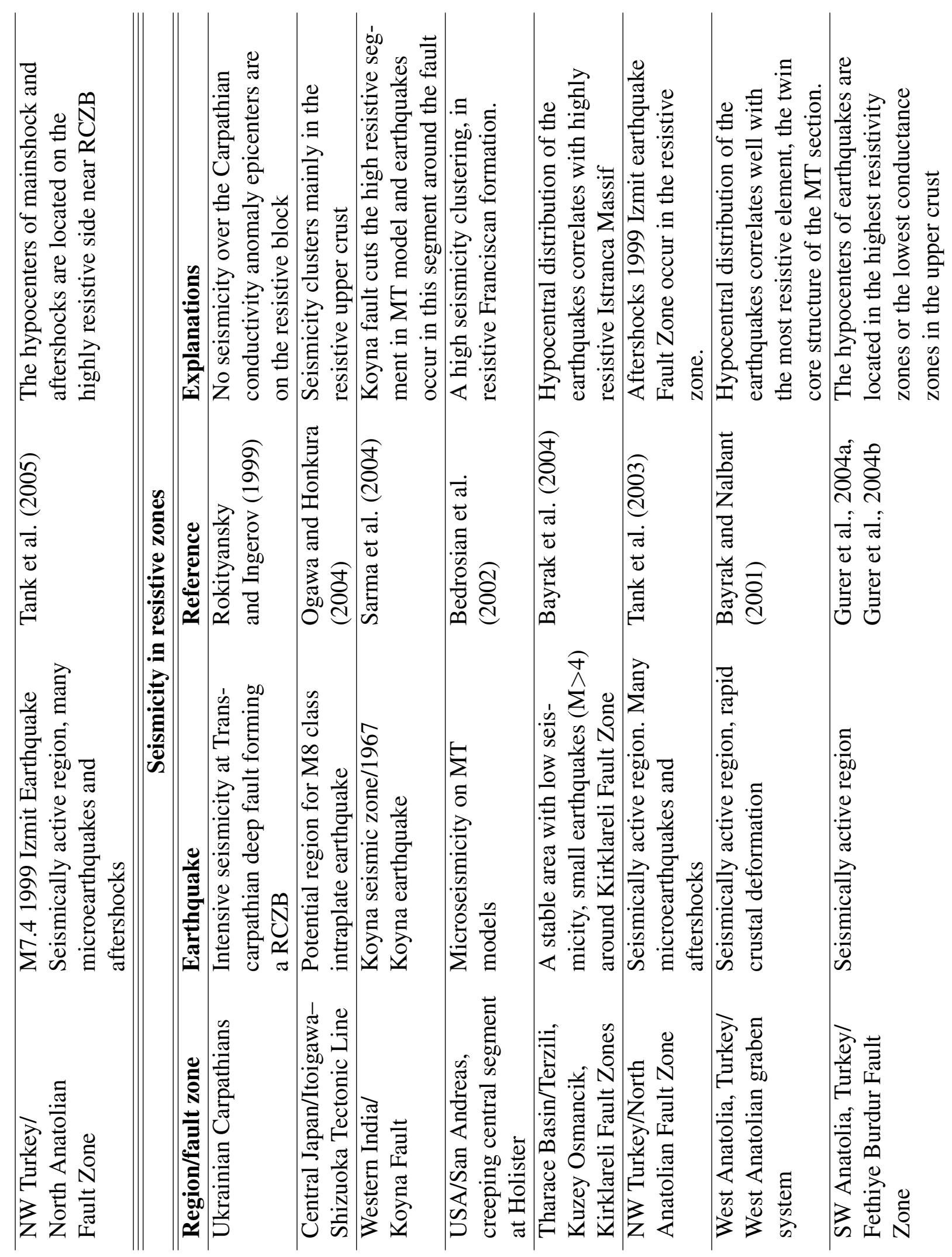




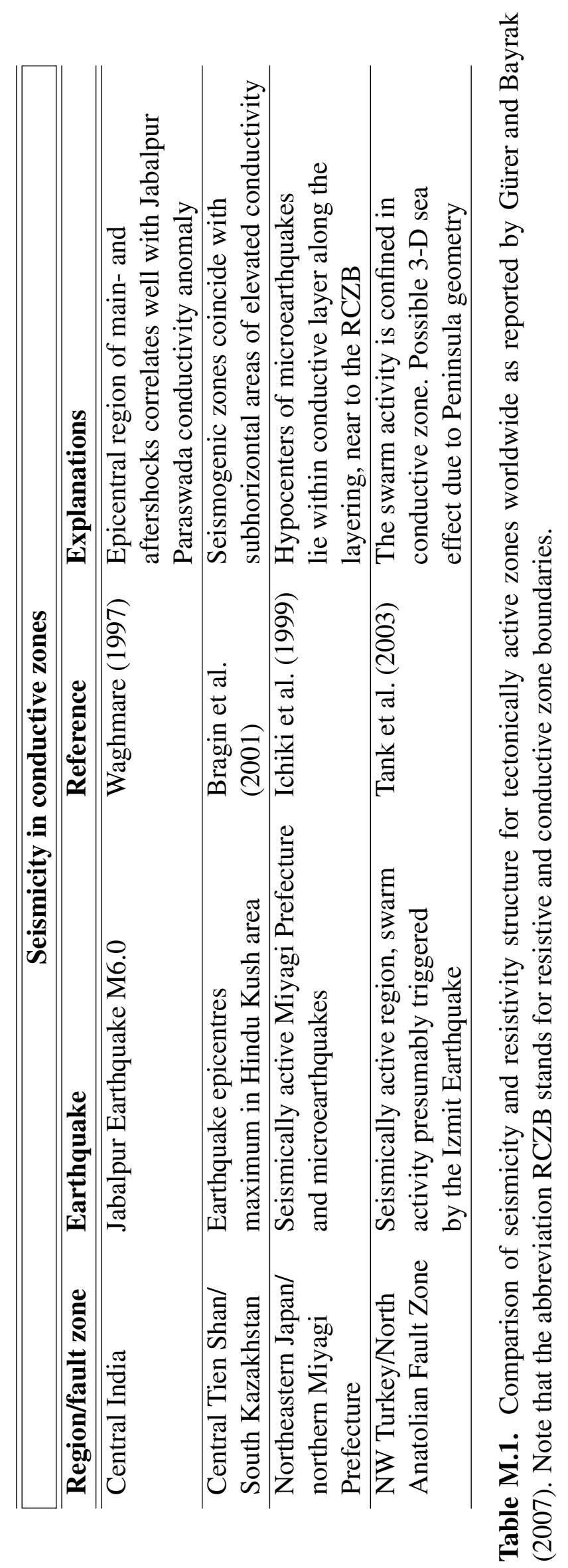




\section{Bibliography}

Abercrombie, R., A summary of attenuation measurements from borehole recordings of earthquakes: the $10 \mathrm{~Hz}$ transition problem, Pure and Applied Geophysics, 153, 475-487, 1998.

Abercrombie, R., T. Webb, R. Robinson, P. McGinty, R. Beavan, and J. Mori, The enigma of the Arthur's Pass, New Zealand, earthquake. 1. Reconciling a variety of data for an unusual earthquake sequence, Journal of Geophysical Research, 105, 16,119-16,137, 2000.

Abercrombie, R., S. Bannister, A. Pancha, T. Webb, and J. Mori, Determination of fault planes in a complex aftershock sequence using two-dimensional slip inversion, Geophysical Journal International, 146, 134-142, 2001.

Adams, D., and R. Abercrombie, Seismic attenuation above $10 \mathrm{~Hz}$ in southern California from coda waves recorded in the Cajon Pass borehole, Journal of Geophysical Research, 103, 24,257-24, 1998.

Adams, J., Paleoseismicity of the Alpine fault seismic gap, New Zealand, Geology, 8, 72-76, 1980.

Aki, K., Maximum likelihood estimate of $\mathrm{b}$ in the formula $\log \mathrm{N}=\mathrm{a}-\mathrm{bM}$ and its confidence limits, Bulletin of the Earthquake Research Institute Tokyo University, 43, 237-239, 1965.

Aki, K., and P. Richards, Quantitative seismology: Theory and methods, vol. 1, Freeman, 1980.

Allis, R. G., and Y. Shi, New insights to temperature and pressure beneath the central Southern Alps, New Zealand, New Zealand Journal of Geology and Geophysics, 38, 585-592, 1995.

Allmann, B., P. Shearer, and E. Hauksson, Spectral discrimination between quarry blasts and earthquakes in southern California, Bulletin of the Seismological Society of America, 98, 2073, 2008.

Anderson, E., The dynamics of faulting and dyke formation with applications to Britain: Edinburgh, Oliver and Boyd, 206, 1951.

Anderson, H., and W. Webb, New Zealand seismicity: patterns revealed by the upgraded National Seismograph Network, New Zealand Journal of Geology and Geophysics, 37, 477-493, 1994.

Anderson, H., W. Webb, and J. Jackson, Focal mechanisms of large earthquakes in the South Island of New Zealand: implications for the accommodation of Pacific-Australia plate motion, Geophysical Journal International, 115, 1032-1054, 1993.

Anderson, H., D. Eberhart-Phillips, T. V. McEvilly, F. T. Wu, and R. Uhrhammer, Southern Alps passive seismic experiment, Science Repository, 97, 1997.

Anderson, J., J. Brune, J. Louie, Y. Zeng, M. Savage, G. Yu, Q. Chen, and D. dePolo, Seismicity in the western Great Basin apparently triggered by the Landers, California, earthquake, 28 June 1992, Bulletin of the Seismological Society of America, 84, 863, 1994. 
Anderson, K., Robust earthquake location using M-estimates, Physics of the Earth and Planetary Interiors, 30, 119-130, 1982.

Ansell, J., and S. Bannister, Shallow morphology of the subducted Pacific plate along the Hikurangi margin, New Zealand, Physics of the Earth and Planetary Interiors, 93, 3-20, 1996.

Árnadóttir, T., J. Beavan, and C. Pearson, Deformation associated with the 18 June 1994 Arthur's Pass earthquake, New Zealand, New Zealand Journal of Geology and Geophysics, 38, 553-558, 1995.

Arnold, R., and J. Townend, A Bayesian approach to estimating tectonic stress from seismological data, Geophysical Journal International, 170, 1336-1356, 2007.

Audet, P., M. Bostock, N. Christensen, and S. Peacock, Seismic evidence for overpressured subducted oceanic crust and megathrust fault sealing, Nature, 457, 76-78, 2009.

Audin, L., J. Avouac, M. Flouzat, and J. Plantet, Fluid-driven seismicity in a stable tectonic context — The Remiremont fault zone, Vosges, France, Geophysical Research Letters, 29, 15-1, 2002.

Bakun, W., Seismic moments, local magnitudes, and coda-duration magnitudes for earthquakes in central California, Bulletin of the Seismological Society of America, 74, 439-458, 1984.

Balfour, N. J., M. K. Savage, and J. Townend, Stress and crustal anisotropy in Marlborough, New Zealand: evidence for low fault strength and structure-controlled anisotropy, Geophysical Journal International, 163, 1073-1086, 2005.

Barnes, I., C. Downes, and J. Hulston, Warm springs, South Island, New Zealand, and their potentials to yield laumontite, American Journal of Science, 278, 1412, 1978.

Barnes, P., Postglacial (after $20 \mathrm{ka}$ ) dextral slip rate of the offshore Alpine Fault, New Zealand: Geology, 37, 3-6, 2009.

Barnes, P., R. Sutherland, and J. Delteil, Strike-slip structure and sedimentary basins of the southern Alpine Fault, Fiordland, New Zealand, Bulletin of the Geological Society of America, 117, 411, 2005.

Barrell, D., and D. Strong, General distribution and characteristics of active faults and folds in the Mackenzie District, South Canterbury, 2010.

Båth, M., Lateral inhomogeneities of the upper mantle, Tectonophysics, 2, 483-514, 1965.

Batt, G., and J. Braun, On the thermomechanical evolution of compressional orogens, Geophysical Journal International, 128, 364-382, 1997.

Beaumont, C., P. Kamp, J. Hamilton, and P. Fullsack, The continental collision zone, South Island, New Zealand: Comparison of geodynamical models and observations, Journal of Geophysical Research, 101, 3333-3359, 1996.

Beavan, J., and J. Haines, Contemporary horizontal velocity and strain rate fields of the PacificAustralian plate boundary zone through New Zealand, Journal of Geophysical Research, 106, 741-770, 2001. 
Beavan, J., M. Moore, C. Pearson, M. Henderson, B. Parsons, S. Bourne, P. England, D. Walcott, G. Blick, D. Darby, and K. Hodgkinson, Crustal deformation during 1994-1998 due to oblique continental collision in the central Southern Alps, New Zealand, and implications for seismic potential of the Alpine fault, Journal of Geophysical Research, 104, 25,233, 1999.

Beavan, J., D. Matherson, P. Denys, M. Denham, T. Herring, B. Hager, P. Molnar, and D. Walcott, A vertical deformation profile across the Southern Alps, New Zealand, from 3.5 years of continuous GPS data, in Proceedings of the Cahiers du Centre Européen de Géodynamique et de Séismologie workshop: The State of GPS Vertical Positioning Precision: Separation of Earth Processes by Space Geodesy, Luxembourg, vol. 23, pp. 111-123, 2004.

Beavan, J., S. Ellis, L. Wallace, and P. Denys, Kinematic constraints from GPS on oblique convergence of the Pacific and Australian plates, central South Island, New Zealand, Geophysical monograph, 175, 75-94, 2007.

Beavan, J., P. Denys, M. Denham, B. Hager, T. Herring, and P. Molnar, Distribution of presentday vertical deformation across the Southern Alps, New Zealand, from 10 years of GPS data, Geophysical Research Letters, 37, L16,305, 2010a.

Beavan, J., S. Samsonov, P. Denys, R. Sutherland, N. Palmer, and M. Denham, Oblique slip on the Puysegur subduction interface in the 2009 July $\mathrm{M}_{\mathrm{W}} 7.8$ Dusky Sound earthquake from GPS and InSAR observations: implications for the tectonics of southwestern New Zealand, Geophysical Journal International, 183, 1265-1286, 2010b.

Beavan, J., E. Fielding, M. Motagh, S. Samsonov, and N. Donnelly, Fault location and slip distribution of the 22 February $2011 \mathrm{M}_{\mathrm{W}} 6.2$ Christchurch, New Zealand, earthquake from geodetic data, Seismological Research Letters, 82, 789, 2011.

Becken, M., O. Ritter, P. Bedrosian, and U. Weckmann, Correlation between deep fluids, tremor and creep along the central San Andreas fault, Nature, 480, 87-90, 2011.

Bedrosian, P., M. Unsworth, G. Egbert, and C. Thurber, Geophysical images of the creeping segment of the San Andreas fault: implications for the role of crustal fluids in the earthquake process, Tectonophysics, 385, 137-158, 2004.

Behr, Y., Imaging New Zealand's crustal structure using ambient seismic noise recordings from permanent and temporary instruments, Ph.D. thesis, Victoria University Wellington, 2011.

Benoit, J., S. McNutt, and Geological Survey (US), Global volcanic earthquake swarm database 1979-1989, US Department of the Interior, US Gological Survey, 1996.

Beroza, G., and S. Ide, Slow earthquakes and non-volcanic tremor, Annual Review of Earth and Planetary Sciences, 39, 271-296, 2011.

Berryman, K., and P. Villamor, Surface rupture of the Poulter Fault in the 1929 March 9 Arthur's Pass earthquake, and redefinition of the Kakapo Fault, New Zealand, New Zealand Journal of Geology and Geophysics, 47, 341-351, 2004.

Berryman, K., S. Beanland, A. Cooper, H. Cutten, R. Norris, and P. Wood, The Alpine Fault, New Zealand: variation in Quaternary structural style and geomorphic expression, in Annales Tectonicae VI, vol. 126, p. 163, 1992. 
Berryman, K., A. Cooper, R. Norris, P. Villamor, R. Sutherland, T. Wright, E. Schermer, R. Langridge, and G. Biasi, Late Holocene Rupture History of the Alpine Fault in South Westland, New Zealand, Bulletin of the Seismological Society of America, 102, 620-638, 2012.

Blick, G., S. Read, and P. Hall, Deformation monitoring of the Ostler fault zone, South Island, New Zealand, Tectonophysics, 167, 329-339, 1989.

Boatwright, J., K. Thywissen, and L. Seekins, Correlation of ground motion and intensity for the 17 January 1994 Northridge, California, earthquake, Bulletin of the Seismological Society of America, 91, 739-752, 2001.

Bodin, P., and J. Gomberg, Triggered seismicity and deformation between the Landers, California, and Little Skull Mountain, Nevada, earthquakes, Bulletin of the Seismological Society of America, 84, 835, 1994.

Boese, C. M., J. Townend, E. G. C. Smith, and T. A. Stern, Microseismicity and stress in the vicinity of the Alpine Fault, central Southern Alps, New Zealand, Journal of Geophysical Research, 117, 2012.

Bormann, P., Conversion and comparability of data presentations on seismic background noise, Journal of Seismology, 2, 37-45, 1998.

Bormann, P., Seismic signals and noise, IASPEI-New Manual of Seismological Observatory Practice, 2002.

Boulton, C., B. Carpenter, V. Toy, and C. Marone, Physical properties of surface outcrop cataclastic fault rocks, Alpine Fault, New Zealand, Geochemistry Geophysics Geosystems, 13, Q01,018, 2012.

Bourguignon, S., Lithospheric deformation at the South Island oblique collision, New Zealand, Ph.D. thesis, Victoria University of Wellington, 2009.

Brikké, N. E. A., 3-D Seismic travel-time tomography of the central South Island, New Zealand, Master's thesis, Victoria University of Wellington, New Zealand, 2010.

Brodsky, E., Long-range triggered earthquakes that continue after the wave train passes, Geophysical Research Letters, 33, 2006.

Brodsky, E., and S. Prejean, New constraints on mechanisms of remotely triggered seismicity at Long Valley Caldera, Journal of Geophysical Research, 110, B04,302, 2005.

Brodsky, E., V. Karakostas, and H. Kanamori, A new observation of dynamically triggered regional seismicity: earthquakes in Greece following the August, 1999 Izmit, Turkey earthquake, Geophysical Research Letters, 27, 2741-2744, 2000.

Brodsky, E., E. Roeloffs, D. Woodcock, I. Gall, and M. Manga, A mechanism for sustained groundwater pressure changes induced by distant earthquakes, Journal of Geophysical Research, 108, 2390, 2003.

Brown, J., G. Beroza, and D. Shelly, An auto-correlation method to detect low-frequency earthquakes within tremor, Geophysical Research Letters, 35, L16,305, 2008.

Buland, R., The mechanics of locating earthquakes, Bulletin of the Seismological Society of America, 66, 173, 1976. 
Caldwell, J. G., and C. Frohlich, Microearthquake study of the Alpine fault zone near Haast, South Island, New Zealand, Bulletin of the Seismological Society of America, 65, 1097-1104, 1975.

Calhaem, I., A. Haines, M. Lowry, and Seismological Observatory (NZ), An intermediate-depth earthquake in the central region of the South Island used to determine a local crustal thickness, Seismological Observatory, 1977.

Cande, S., and J. Stock, Cenozoic reconstructions of the Australia-New Zealand-South Pacific sector of Antarctica, The Cenozoic Southern Ocean: Tectonics, Sedimentation and Climate Change between Australia and Antarctica, pp. 5-18, 2005.

Cande, S. C., and J. M. Stock, Pacific-Antarctic-Australia motion and the formation of the Macquarie Plate, Geophysical Journal International, 157, 399-414, 2004.

Cappa, F., Modeling crustal deformation and rupture processes related to upwelling of deep $\mathrm{CO}_{2}$-rich fluids during the 1965-1967 Matsushiro Earthquake Swarm in Japan, 2010.

Chinn, T., New Zealand glacier responses to climate change of the past century, New Zealand Journal of Geology and Geophysics, 39, 415-428, 1996.

Cooper, A., Retrograde alteration of chromian kyanite in metachert and amphibolite whiteschist from the Southern Alps, New Zealand, with implications for uplift on the Alpine Fault, Contributions to Mineralogy and Petrology, 75, 153-164, 1980.

Cowan, H., Structure, seismicity and tectonics of the Porter's Pass-Amberley fault zone, North Canterbury, New Zealand, 1992.

Cowan, H., A. Nicol, and P. Tonkin, A comparison of historical and paleoseismicity in a newly formed fault zone and a mature fault zone, North Canterbury, New Zealand, New Zealand. Journal of Geophysical Research, 101, 6021-6036, 1996.

Cowan, H. A., The North Canterbury earthquake of September 1, 1888, Journal of the Royal Society of New Zealand, 21, 1-12, 1991.

Cox, S., and D. Barrell, Geology of the Aoraki area, New Zealand: 1:250 000 geological map, 15, $71,2007$.

Cox, S., and R. Findlay, The Main Divide Fault Zone and its role in formation of the Southern Alps, New Zealand, New Zealand Journal of Geology and Geophysics, 38, 489-499, 1995.

Cox, S., and R. Sutherland, Regional geological framework of South Island, New Zealand, and its significance for understanding the active plate boundary, Geophysical Monograph, 175, 235-251, 2007.

Cox, S., D. Craw, and C. Chamberlain, Structure and fluid migration in a late Cenozoic duplex system forming the Main Divide in the central Southern Alps, New Zealand, New Zealand Journal of Geology and Geophysics, 40, 359-373, 1997.

Cox, S., M. W. Stirling, M. Gerstenberger, and J. Ristau, Potentially active faults in the rapidly eroding landscape adjacent to the Alpine Fault, central Southern Alps, New Zealand, Tectonics, 2012.

Craw, D., Fluid inclusion evidence for geothermal structure beneath the Southern Alps, New Zealand, New Zealand Journal of Geology and Geophysics, 40, 43-52, 1997. 
Das, S., and C. Scholz, Theory of time-dependent rupture in the earth, Journal of Geophysical Research, 86, 6039-6051, 1981.

Davey, F., Crustal seismic reflection profile across the Alpine Fault and coastal plain at Whataroa, South Island, New Zealand Journal of Geology and Geophysics, 53, 359-368, 2010.

Davey, F., T. Henyey, W. Holbrook, D. Okaya, T. Stern, A. Melhuish, S. Henrys, H. Anderson, D. Eberhart-Phillips, T. McEvilly, et al., Preliminary results from a geophysical study across a modern, continent-continent collisional plate boundary-the Southern Alps, New Zealand, Tectonophysics, 288, 221-235, 1998.

Davey, F., D. Eberhart-Phillips, M. Kohler, S. Bannister, G. Caldwell, S. Henrys, M. Scherwath, T. Stern, and H. van Avendonk, Geophysical structure of the Southern Alps orogen, South Island, New Zealand, Geophysical Monograph, 175, 47-73, 2007.

De Mets, C., R. G. Gordon, D. F. Argus, and S. Stein, Effect of recent revisions to the geomagnetic reversal timescale on estimates of current plate motions, Geophysical Research Letters, 21, 21912194, 1994.

De Paor, D., The theory of shear stress and shear strain on planes inclined to the principal directions, Journal of Structural Geology, 12, 923-927, 1990.

Deichmann, N., Structural and rheological implications of lower-crustal earthquakes below northern Switzerland, Physics of the Earth and Planetary Interiors, 69, 270-280, 1992.

Deichmann, N., Local magnitude, a moment revisited, Bulletin of the Seismological Society of America, 96, 1267, 2006.

Dieterich, J., A constitutive law for rate of earthquake production and its application to earthquake clustering, Journal of Geophysical Research, 99, 2601-2601, 1994.

Dorn, C., S. Carpentier, A. Kaiser, A. Green, H. Horstmeyer, F. Campbell, J. Campbell, R. Jongens, M. Finnemore, and D. Nobes, First seismic imaging results of tectonically complex structures at shallow depths beneath the northwest Canterbury Plains, New Zealand, Journal of Applied Geophysics, 70, 317-331, 2010.

Doser, D. I., T. H. Webb, and D. E. Maunder, Source parameters of large historical (1918-1962) earthquakes, South Island, New Zealand, Geophysical Journal International, 139, 769-794, 1999.

Dowrick, D., Magnitude reassessment of New Zealand earthquakes, Earthquake Engineering \& Structural Dynamics, 20, 577-596, 1991.

Du, W., C. Thurber, and D. Eberhart-Phillips, Earthquake relocation using cross-correlation time delay estimates verified with the bispectrum method, Bulletin of the Seismological Society of America, 94, 856, 2004.

Dunn, M., Relocation of eastern Tennessee earthquakes using hypoDD, Ph.D. thesis, Virginia Polytechnic Institute and State University, 2004.

Dziewonski, A., G. Ekstrom, and N. Maternovskaya, Centroid-moment tensor solutions for OctoberDecember, 1998, Physics of the Earth and Planetary Interiors, 115, 1-16, 1999. 
Eberhart-Phillips, D., Three-dimensional velocity structure in northern California Coast Ranges from inversion of local earthquake arrival-times, Bulletin of the Seismological Society of America, 76, 1025-1052, 1986.

Eberhart-Phillips, D., Examination of seismicity in the central Alpine Fault region, South Island, New Zealand, New Zealand Journal of Geology and Geophysics, 38, 571-578, 1995.

Eberhart-Phillips, D., and S. Bannister, Three-dimensional crustal structure in the Southern Alps region of New Zealand from inversion of local earthquake and active source data, Journal of Geophysical Research, 107, 1-22, 2002.

Eberhart-Phillips, D., V. Labson, W. Stanley, A. Michael, and B. Rodriguez, Preliminary velocity and resistivity models of the Loma Prieta earthquake region, Geophysical Research Letters, 17, 1235-1238, 1990.

Eberhart-Phillips, D., M. Chadwick, and S. Bannister, Three-dimensional attenuation structure of central and southern South Island, New Zealand, from local earthquakes, Journal of Geophysical Research, 113, 1-22, 2008.

Eberhart-Phillips, D., M. Reyners, S. Bannister, M. Chadwick, and S. Ellis, Establishing a versatile 3-D seismic velocity model for New Zealand, Seismological Research Letters, 81, 992, 2010.

Eiby, G. A., Seismic regions of the South Island of New Zealand, Transactions of the Royal Society of New Zealand, Earth Sciences, 8, 29-39, 1971.

Ellis, S., J. Beavan, D. Eberhart-Phillips, and B. Stöckhert, Simplified models of the Alpine Fault seismic cycle: Stress transfer in the mid-crust, Geophysical Journal International, 166, 386-402, 2006.

Evison, F. F., Seismicity of the Alpine Fault, New Zealand, Recent crustal movements, Royal Society of New Zealand Bulletin, 9, 161-165, 1971.

Felzer, K., T. Becker, R. Abercrombie, G. Ekström, and J. Rice, Triggering of the $1999 \mathrm{M}_{\mathrm{W}} 7.1$ Hector Mine earthquake by aftershocks of the $1992 \mathrm{M}_{\mathrm{W}}$ 7.3 Landers earthquake, Journal of Geophysical Research, 107, 2002.

Felzer, K. R., Calculating the Gutenberg-Richter b-value, AGU Fall Meeting Abstracts, p. C8, 2006.

Fialko, Y., Evidence of fluid-filled upper crust from observations of postseismic deformation due to the $1992 \mathrm{M}_{\mathrm{W}}$ 7.3 Landers earthquake, Journal of Geophysical Research, 109, 2004.

Fialko, Y., L. Rivera, and H. Kanamori, Estimate of differential stress in the upper crust from variations in topography and strike along the San Andreas fault, Geophysical Journal International, 160, 527-532, 2005.

Forsyth, D., Determinations of focal depths of earthquakes associated with the bending of oceanic plates at trenches, Physics of The Earth and Planetary Interiors, 28, 141-160, 1982.

Frankel, A., Mechanisms of seismic attenuation in the crust: scattering and anelasticity in New York State, South Africa, and southern California, Journal of Geophysical Research, 96, 6269-6289, 1991. 
Frankel, A., W. McCann, and A. Murphy, Observations from a seismic network in the Virgin Islands region: tectonic structures and earthquake swarms, Journal of Geophysical Research, 85, 2669$2678,1980$.

Fremont, M.-J., and S. D. Malone, High-precision relative locations of earthquakes at Mount St. Helens, Washington, Journal of Geophysical Research, 92, 10,223-10,236, 1987.

Frohlich, C., Earthquakes with non-double-couple mechanisms, Science, 264, 804, 1994.

Fry, B., S. Bannister, J. Beavan, L. Bland, B. Bradley, S. Cox, J. Cousins, N. Gale, G. Hancox, C. Holden, et al., The $\mathrm{M}_{\mathrm{W}}$ 7.6 Dusky Sound Earthquake of 2009: Preliminary Report, 2010.

Gans, C., K. Furlong, and R. Malservisi, Fault creep and microseismicity on the Hayward fault, California: Implications for asperity size, Geophysical Research Letters, 30, 2000, 2003.

Geiger, L., Herdbestimmung bei Erdbeben aus den Ankunftzeiten, Gesellschaft der Wissenschaften zu Göttingen, 4, 331-349, 1910.

Geller, R., and C. Mueller, Four similar earthquakes in central California, Geophysical Research Letters, 7, 821-824, 1980.

Gephart, J., and D. Forsyth, An improved method for determining the regional stress tensor using earthquake focal mechanism data: application to the San Fernando earthquake sequence, Journal of Geophysical Research, 89, 9305-9320, 1984.

Gerbault, M., F. Davey, and S. Henrys, Three-dimensional lateral crustal thickening in continental oblique collision: an example from the Southern Alps, New Zealand, Geophysical Journal International, 150, 770-779, 2002.

Ghisetti, F., A. Gorman, and R. Sibson, Surface breakthrough of a basement fault by repeated seismic slip episodes: The Ostler Fault, South Island, New Zealand, Tectonics, 26, TC6004, 2007.

Gledhill, K., R. Robinson, T. Webb, R. Abercrombie, J. Beavan, J. Cousins, and D. Eberhart-Phillips, The $M_{\mathrm{W}} 6.2$ Cass, New Zealand, earthquake of 24 November 1995: reverse faulting in a strike-slip region, New Zealand Journal of Geology and Geophysics, 43, 255-270, 2000.

Gledhill, K., J. Ristau, M. Reyners, B. Fry, and C. Holden, The Darfield (Canterbury, New Zealand) $\mathrm{M}_{\mathrm{W}}$ 7.1 Earthquake of September 2010: A Preliminary Seismological Report, Seismological Research Letters, 82, 378, 2011.

Glowacka, E., F. Nava, G. de Cossio, V. Wong, and F. Farfan, Fault slip, seismicity, and deformation in Mexicali Valley, Baja California, Mexico, after the M 7.1 1999 Hector Mine earthquake, Bulletin of the Seismological Society of America, 92, 1290, 2002.

Godfrey, N., N. Christensen, and D. Okaya, Anisotropy of schists: contribution of crustal anisotropy to active source seismic experiments and shear-wave-splitting observations, Journal of Geophysical Research, 105, 27-991, 2000.

Gomberg, J., The failure of earthquake failure models, Journal of Geophysical Research, 106, 16,253-16, 2001.

Gomberg, J., and P. Bodin, Triggering of the $\mathrm{M}_{\mathrm{S}}=5.4$ Little Skull Mountain, Nevada, earthquake with dynamic strains, Bulletin of the Seismological Society of America, 84, 844, 1994. 
Gomberg, J., K. Shedlock, and S. Roecker, The effect of S-wave arrival times on the accuracy of hypocenter estimation, Bulletin of the Seismological Society of America, 80, 1605, 1990.

Gomberg, J., N. Beeler, M. Blanpied, and P. Bodin, Earthquake triggering by transient and static deformations, Journal of Geophysical Research, 103, 24, 1998.

Gomberg, J., P. Reasenberg, P. Bodin, and R. Harris, Earthquake triggering by seismic waves following the Landers and Hector Mine earthquakes, Nature, 411, 462-466, 2001.

Gomberg, J., P. Bodin, and P. Reasenberg, Observing earthquakes triggered in the near field by dynamic deformations, Bulletin of the Seismological Society of America, 93, 118, 2003.

Gomberg, J., P. Bodin, K. Larson, and H. Dragert, Earthquake nucleation by transient deformations caused by the M 7.9 Denali, Alaska, earthquake, Nature, 427, 621-624, 2004.

Goto, T., Y. Wada, N. Oshiman, and N. Sumitomo, Resistivity structure of a seismic gap along the Atotsugawa Fault, Japan, Physics of the Earth and Planetary Interiors, 148, 55-72, 2005.

Grapes, R., T. Little, and G. Downes, Rupturing of the Awatere Fault during the 1848 October 16 Marlborough earthquake, New Zealand: historical and present day evidence, New Zealand Journal of Geology and Geophysics, 41, 387-399, 1998.

Grünthal, G., V. Schenk, A. Zeman, and Z. Schenkova, Seismotectonic model for the earthquake swarm of 1985-1986 in the Vogtland/West Bohemia focal area, Tectonophysics, 174, 369-383, 1990.

Guilhem, A., Z. Peng, and R. Nadeau, High-frequency identification of non-volcanic tremor triggered by regional earthquakes, Geophysical Research Letters, 37, L16,309, 2010.

Gürer, A., and M. Bayrak, Relation between electrical resistivity and earthquake generation in the crust of West Anatolia, Turkey, Tectonophysics, 445, 49-65, 2007.

Gutenberg, B., and C. Richter, Frequency of earthquakes in California, Bulletin of the Seismological Society of America, 34, 185, 1944.

Hagiwara, T., and T. Iwata, 23. Summary of the seismographic observation of Matsushiro Swarm Earthquakes, 1968.

Haines, A., Seismic wave velocities in the uppermost mantle beneath New Zealand, New Zealand Journal of Geology and Geophysics, 22, 245-257, 1979.

Haines, A., A local magnitude scale for New Zealand earthquakes, Bulletin of the Seismological Society of America, 71, 275, 1981.

Haines, A., I. Calhaem, and D. Ware, Crustal seismicity near Lake Pukaki, South Island, The origin of the Southern Alps. The Royal Society of New Zealand Bulletin, 18, 87-94, 1979.

Hainzl, S., Z. Gert, and F. Scherbaum, Earthquake clusters resulting from delayed rupture propagation infinite fault segments, Journal of Geophysical Research, 2002.

Hanks, T., and H. Kanamori, A moment magnitude scale, Journal of Geophysical Research, 84, 2348-2350, 1979.

Hanley, E., D. Dewitt, and R. Roy, The thermal diffusivity of eight well-characterized rocks for the temperature range 300-1000 K, Engineering Geology, 12, 31-47, 1978. 
Hardebeck, J., Homogeneity of small-scale earthquake faulting, stress, and fault strength, Bulletin of the Seismological Society of America, 96, 1675, 2006.

Hardebeck, J., and E. Hauksson, Crustal stress field in southern California and its implications for fault mechanics, Journal of Geophysical Research, 106, 21,859-21,882, 2001.

Hardebeck, J., and P. Shearer, A new method for determining first-motion focal mechanisms, Bulletin of the Seismological Society of America, 92, 2264, 2002.

Hardebeck, J., and P. Shearer, Using S/P amplitude ratios to constrain the focal mechanisms of small earthquakes, Bulletin of the Seismological Society of America, 93, 2434, 2003.

Harrington, R., and E. Brodsky, The absence of remotely triggered seismicity in Japan, Bulletin of the Seismological Society of America, 96, 871, 2006.

Haslinger, F., and E. Kissling, Investigating effects of 3-D ray tracing methods in local earthquake tomography, Physics of the Earth and Planetary Interiors, 123, 103-114, 2001.

Hauksson, E., and P. Shearer, Attenuation models $\left(\mathrm{Q}_{\mathrm{P}}\right.$ and $\left.\mathrm{Q}_{\mathrm{S}}\right)$ in three dimensions of the southern California crust: Inferred fluid saturation at seismogenic depths, Journal of Geophysical Research, 111, 302, 2006.

Havskov, J., and G. Alguacil, Instrumentation in earthquake seismology, Springer Verlag, 2004.

Havskov, J., and L. Ottemöller, SEISAN: The earthquake analysis software, Institute of Solid Earth Physics. University of Bergen, Norway, p. 236, 2000.

Havskov, J., and L. Ottemöller, Routine data processing in earthquake seismology: with sample data, exercises and software, Springer Verlag, 2010.

Herman, F., and J. Braun, Fluvial response to horizontal shortening and glaciations: a study in the Southern Alps of New Zealand, Journal of Geophysical Research, 111, F01,008, 2006.

Herman, F., E. Rhodes, J. Braun, and L. Heiniger, Uniform erosion rates and relief amplitude during glacial cycles in the Southern Alps of New Zealand, as revealed from OSL-thermochronology, Earth and Planetary Science Letters, 297, 183-189, 2010.

Hetzel, R., and A. Hampel, Slip-rate variations on normal faults during glacial-interglacial changes in surface loads, Nature, 435, 81-84, 2005.

Hill, D., Dynamic stresses, Coulomb failure, and remote triggering, Bulletin of the Seismological Society of America, 98, 66, 2008.

Hill, D., P. Reasenberg, A. Michael, W. Arabaz, G. Beroza, D. Brumbaugh, J. Brune, R. Castro, S. Davis, D. dePolo, W. L. Ellsworth, J. Gomberg, S. Harmsen, L. House, S. M. Jackson, M. J. S. Johnston, L. Jones, R. Keller, S. Malone, L. Munguia, S. Nava, J. C. Pechmann, A. Sanford, R. W. Simpson, R. B. Smith, M. Stark, M. Stickney, A. Vidal, S. Walter, V. Wong, and J. Zollweg, Seismicity remotely triggered by the magnitude 7.3 Landers, California, earthquake, Science, 260, 1617, 1993.

Hill, D., F. Pollitz, and C. Newhall, Earthquake-volcano interactions, Physics Today, 55, 41-47, 2002. 
Hincapie, J., D. Doser, and R. Robinson, Stress changes induced by earthquakes and secular stress accumulation in the Buller region, South Island, New Zealand (1929-2002), Pure and Applied Geophysics, 162, 291-310, 2005.

Holcomb, G., L. Sandoval, and B. Hutt, Controlling tilt noise in boreholes with sand, Tech. rep., USGS, Albuquerque Seismological Laboratory, 1997.

Holden, C., Kinematic source model of the 22 February $2011 \mathrm{M}_{\mathrm{W}} 6.2$ Christchurch earthquake using strong motion data, Seismological Research Letters, 82, 783, 2011.

Holt, W., and A. Haines, The kinematics of northern South Island, New Zealand, determined from geologic strain rates, Journal of Geophysical Research, 100, 17,991-18, 1995.

Hubbert, M., and W. Rubey, Role of fluid pressure in mechanics of overthrust faulting, Parts I and II, Geological Society of America Bulletin, 70, 115-205, 1959.

Husen, S., and R. Smith, Probabilistic earthquake relocation in three-dimensional velocity models for the Yellowstone National Park region, Wyoming, Bulletin of the Seismological Society of America, 94, 880, 2004.

Husen, S., E. Kissling, E. Flueh, and G. Asch, Accurate hypocentre determination in the seismogenic zone of the subducting Nazca Plate in northern Chile using a combined on-/offshore network, Geophysical Journal International, 138, 687-701, 1999.

Husen, S., E. Kissling, N. Deichmann, S. Wiemer, D. Giardini, and M. Baer, Probabilistic earthquake location in complex three-dimensional velocity models: application to Switzerland, Journal of Geophysical Research, 108, 2077, 2003.

Husen, S., S. Wiemer, and R. Smith, Remotely triggered seismicity in the Yellowstone National Park region by the $2002 \mathrm{M}_{\mathrm{W}}$ 7.9 Denali fault earthquake, Alaska, Bulletin of the Seismological Society of America, 94, S317, 2004.

Husker, A., and E. Brodsky, Seismicity in Idaho and Montana triggered by the Denali Fault Earthquake: a window into the geologic context for seismic triggering, Bulletin of the Seismological Society of America, 94, S310, 2004.

Hutchings, L., and F. Wu, Empirical Green's functions from small earthquakes: a waveform study of locally recorded aftershocks of the 1971 San Fernando earthquake, Journal of Geophysical Research, 95, 1187-1214, 1990.

Hutton, L., and D. Boore, The $\mathrm{M}_{\mathrm{L}}$ scale in southern California, Bulletin of the Seismological Society of America, 77, 2074, 1987.

Hyndman, R., and D. Weichert, Seismicity and rates of relative motion on the plate boundaries of western North America, Geophysical Journal of the Royal Astronomical Society, 72, 59-82, 1983.

Ichiki, M., M. Mishina, T. Goto, N. Oshiman, N. Sumitomo, and H. Utada, Magnetotelluric investigations for the seismically active area in Northern Miyagi Prefecture, northeastern Japan, Earth Planets and Space, 51, 351-362, 1999.

Ide, S., D. Shelly, and G. Beroza, Mechanism of deep low-frequency earthquakes: Further evidence that deep non-volcanic tremor is generated by shear-slip on the plate interface, Geophysical Research Letters, 34, L03,308, 2007. 
Imanishi, K., Y. Kuwahara, T. Takeda, T. Mizuno, H. Ito, K. Ito, H. Wada, and Y. Haryu, Depthdependent stress field in and around the Atotsugawa fault, central Japan, deduced from microearthquake focal mechanisms: Evidence for localized aseismic deformation in the downward extension of the fault, Journal of Geophysical Research, 116, B01,305, 2011.

Jackson, J., and D. McKenzie, The relationship between plate motions and seismic moment tensors, and the rates of active deformation in the Mediterranean and Middle East, Geophysical Journal, 93, 45-73, 1988.

Jacobs, K., E. Smith, M. Savage, and J. Zhuang, Cumulative rate analysis: a clustering algorithm for swarm-dominated catalogs, Journal of Geophysical Research, submitted.

Jaeger, J., and N. Cook, Fundamentals of rock mechanics, Third Edition Chapman and Hall, 1979.

James, D., I. Sacks, E. Lazo, and P. Aparicio, On locating local earthquakes using small networks, Bulletin of the Seismological Society of America, 59, 1201, 1969.

Jeffreys, H., On travel-times in seismology, in Collected Papers of Sir Harold Jeffreys on Geophysics and Other Sciences, edited by H. Jeffreys, pp. 36-120, Gordon and Breach Sci. Publ., London, 1973.

Jenkin, G., D. Craw, and A. Fallick, Stable isotopic and fluid inclusion evidence for meteoric fluid penetration into an active mountain belt; Alpine Schist, New Zealand, Journal of Metamorphic Geology, 12, 429-444, 1994.

Jennings, C. W., Fault map of California with locations of volcanoes, thermal springs, and thermal wells, no. 1 in Geologic Data Map, California Division of Mines and Geology, Sacramento CA, 1975.

Jiracek, G. R., V. M. Gonzalez, T. G. Caldwell, P. E. Wannamaker, and D. Kilb, Seismogenic, electrically conductive, and fluid zones at continental plate boundaries in New Zealand, Himalaya, and California-USA, Geophysical Monograph, 175, 235-251, 2007.

Johnston, M., R. Borcherdt, A. Linde, and M. Gladwin, Continuous borehole strain and pore pressure in the near field of the 28 September 2004 M 6.0 Parkfield, California, earthquake: Implications for nucleation, fault response, earthquake prediction, and tremor, Bulletin of the Seismological Society of America, 96, S56-S72, 2006.

Jónsson, S., P. Segall, R. Pedersen, and G. Björnsson, Post-earthquake ground movements correlated to pore-pressure transients, Nature, 424, 179-183, 2003.

Kamp, P. J., P. F. Green, and S. H. White, Fission-track analysis reveals character of collisional tectonics in New Zealand, Tectonics, 8, 169-195, 1989.

Karow, T., Three-dimensional finite-element modeling of slip rate variations on faults caused by glacial-interglacial changes in ice and water volumes: Parameter study and application to nature, Ph.D. thesis, Ruhr-University Bochum, 2010.

Karow, T., and A. Hampel, Slip-rate variations on faults in the Basin-and-Range Province caused by regression of Late Pleistocene Lake Bonneville and Lake Lahontan, International Journal of Earth Sciences, 99, 1941-1953, 2010. 
Kasaya, T., N. Oshiman, N. Sumitomo, M. Uyeshima, Y. Iio, and D. Uehara, Resistivity structure around the hypocentral area of the 1984 Western Nagano Prefecture earthquake in central Japan, Earth Planets and Space, 54, 107-118, 2002.

Kato, A., S. Sakai, T. Iidaka, T. Iwasaki, and N. Hirata, Non-volcanic seismic swarms triggered by circulating fluids and pressure fluctuations above a solidified diorite intrusion, Geophysical Research Letters, 37, L15,302, 2010.

Kilb, D., J. Gomberg, and P. Bodin, Triggering of earthquake aftershocks by dynamic stresses, Nature, 408, 570-574, 2000.

Kim, W., The $\mathrm{M}_{\mathrm{L}}$ scale in eastern North America, Bulletin of the Seismological Society of America, $88,935,1998$.

King, G., R. Stein, and J. Lin, Static stress changes and the triggering of earthquakes, Bulletin of the Seismological Society of America, 84, 935-953, 1994.

Kissling, E., Geotomography with local earthquake data, Reviews of Geophysics, 26, 659-698, 1988.

Kleffman, S., F. Davey, A. Melhuish, D. Okaya, T. Stern, and SIGHT Team, Crustal structure in the central South Island, New Zealand, from the Lake Pukaki seismic experiment, New Zealand Journal of Geology and Geophysics, 41, 39-49, 1998.

Knopoff, L., Attenuation, in Mantle and Core in Planetary Physics, edited by J. Coulomb and M. Caputo, pp. 146-156, Elsevier, New York, 1971.

Knuepfer, P., Temporal variations in latest Quaternary slip across the Australian-Pacific plate boundary, northeastern South Island, New Zealand, Tectonics, 11, 449-464, 1992.

Kohler, M., and D. Eberhart-Phillips, Intermediate-depth earthquakes in a region of continental convergence: South Island, New Zealand, Bulletin of the Seismological Society of America, 93, 85, 2003.

Koons, P., Some thermal and mechanical consequences of rapid uplift: an example from the Southern Alps, New Zealand, Earth and Planetary Science Letters, 86, 307-319, 1987.

Koons, P., Two-sided orogen: collision and erosion from the sandbox to the Southern Alps, New Zealand, Geology, 18, 679, 1990.

Koulakov, I., T. Yudistira, B.-G. Luehr, and Wandono, P, S velocity and VP/VS ratio beneath the Toba caldera complex (Northern Sumatra) from local earthquake tomography, Geophysical Journal International, 177, 1121-1139, 2009.

Kradolfer, U., Seismische Tomographie der Schweiz, Ph.D. thesis, Eidgenössische Technische Hochschule Zürich, 2003.

Lamb, S., and H. Bibby, The last $25 \mathrm{Ma}$ of rotational deformation in part of the New Zealand plateboundary zone, Journal of Structural Geology, 11, 473-492, 1989.

Langridge, R., J. Campbell, N. Hill, V. Pere, J. Pope, J. Pettinga, B. Estrada, K. Berryman, et al., Paleoseismology and slip rate of the Conway Segment of the Hope Fault at Greenburn Stream, South Island, New Zealand, Annals of Geophysics, 2003. 
Langridge, R., P. Villamor, R. Basili, P. Almond, J. Martinez-Diaz, and C. Canora, Revised slip rates for the Alpine fault at Inchbonnie: Implications for plate boundary kinematics of South Island, New Zealand, Lithosphere, 2, 139, 2010.

Lei, X., C. Xie, and B. Fu, Remotely triggered seismicity in Yunnan, southwestern China, following the $2004 \mathrm{M}_{\mathrm{W}}$ 9.3 Sumatra earthquake, Journal of Geophysical Research, 116, B08,303, 2011.

Leitner, B., D. Eberhart-Phillips, H. Anderson, and J. L. Nabelek, A focused look at the Alpine fault, New Zealand: Seismicity, focal mechanisms, and stress observations, Journal of Geophysical Research, 106, 2193-2220, 2001.

Lévěque, J., L. Rivera, and G. Wittlinger, On the use of the checker-board test to assess the resolution of tomographic inversions, Geophysical Journal International, 115, 313-318, 1993.

Li, Y., and J. Vidale, Low-velocity fault-zone guided waves: numerical investigations of trapping efficiency, Bulletin of the Seismological Society of America, 86, 371-378, 1996.

Li, Y., P. Leary, K. Aki, and P. Malin, Seismic trapped modes in the Oroville and San Andreas fault zones, Science, 249, 763, 1990.

Li, Y., K. Aki, J. Vidale, W. Lee, and C. Marone, Fine structure of the Landers fault zone: segmentation and the rupture process, Science, 265, 367, 1994.

Li, Y., F. Vernon, and K. Aki, San Jacinto fault-zone guided waves: a discrimination for recently active fault strands near Anza, California, Journal of Geophysical Research, 102, 11,689-11,701, 1997.

Li, Y., K. Aki, J. Vidale, and M. Alvarez, A delineation of the Nojima fault ruptured in the M7.2 Kobe, Japan, earthquake of 1995 using fault-zone trapped waves, Journal of Geophysical Research, 103, 7247-7263, 1998.

Li, Y., J. Vidale, S. Day, D. Oglesby, and E. Cochran, Postseismic fault healing on the rupture zone of the 1999 M 7.1 Hector Mine, California, earthquake, Bulletin of the Seismological Society of America, 93, 854-869, 2003.

Lienert, B., E. Berg, and L. Frazer, HYPOCENTER: an earthquake location method using centered, scaled, and adaptively damped least squares, Bulletin of the Seismological Society of America, 76, $771,1986$.

Linde, A., I. Sacks, M. Johnston, D. Hillt, and R. Bilham, Increased pressure from rising bubbles as a mechanism for remotely triggered seismicity, Nature, 371, 408-410, 1994.

Little, T., R. Holcombe, and B. Ilg, Kinematics of oblique collision and ramping inferred from microstructures and strain in middle crustal rocks, central Southern Alps, New Zealand, Journal of structural geology, 24, 219-239, 2002.

Little, T. A., Transpressive ductile flow and oblique ramping of lower crust in a two-sided orogen: insight from quartz grain-shape fabrics near the Alpine Fault, New Zealand, Tectonics, 23, 1-24, 2004.

Little, T. A., and A. Jones, Seven million years of strike-slip and related off-fault deformation, northeastern Marlborough fault system, South Island, New Zealand, Tectonics, 17, 285-302, 1998. 
Little, T. A., S. C. Cox, J. K. Vry, and G. Batt, Variations in exhumation level and uplift rate along the oblique-slip Alpine fault, central Southern Alps, New Zealand, Geological Society of America Bulletin, 117, 707, 2005.

Liu, L., and M. Zoback, The effect of topography on the state of stress in the crust: Application to the site of the Cajon Pass Scientific Drilling Project, Journal of Geophysical Research, 97, 5095-5108, 1992.

Lockner, D., C. Morrow, D. Moore, and S. Hickman, Low strength of deep San Andreas fault gouge from SAFOD core, Nature, 2011.

Lomax, A., The NonLinLoc Software Guide, version 6.0, http://alomax.free.fr/nlloc/, 2011.

Lomax, A., J. Virieux, P. Volant, and C. Berge, Probabilistic earthquake location in 3-D and layered models: introduction of a Metropolis-Gibbs method and comparison with linear locations, in $A d$ vances in Seismic Event Location, edited by C. Thurber and N. Rabinowitz, pp. 101-134, Kluwer, Amsterdam, 2000.

Lomax, A., A. Michelini, and A. Curtis, Earthquake location, direct, global-search methods, in Encyclopaedia of Complexity and Systems Science, edited by R. Meyers, Springer, Berlin, DE, 2009.

Long, D., S. Cox, S. Bannister, M. Gerstenberger, and D. Okaya, Upper-crustal structure beneath the eastern Southern Alps and the Mackenzie Basin, New Zealand, derived from seismic reflection data, New Zealand Journal of Geology and Geophysics, 46, 21-40, 2003.

Lund, B., and J. Townend, Calculating horizontal stress orientations with full or partial knowledge of the tectonic stress tensor, Geophysical Journal International, 170, 1328-1335, 2007.

Mahesh, P., B. Kundu, J. Catherine, and V. Gahalaut, Anatomy of the 2009 Fiordland earthquake $\left(\mathrm{M}_{\mathrm{W}}\right.$ 7.8), South Island, New Zealand, Geoscience Frontiers, 2011.

Malservisi, R., K. Furlong, and C. Gans, Microseismicity and creeping faults: Hints from modeling the Hayward fault, California (USA), Earth and Planetary Science Letters, 234, 421-435, 2005.

Manga, M., and E. Brodsky, Seismic triggering of eruptions in the far field: volcanoes and geysers, Annual Review of Earth and Planetary Sciences, 34, 263-291, 2006.

Maurer, H., and N. Deichmann, Microearthquake cluster detection based on waveform similarities, with an application to the western Swiss Alps, Geophysical Journal International, 123, 588-600, 1995.

Mavko, G., Velocity and attenuation in partially molten rocks, Journal of Geophysical Research, 85, 5173-5189, 1980.

McGinty, P., M. Reyners, and R. Robinson, Stress directions in the shallow part of the Hikurangi subduction zone, New Zealand, from the inversion of earthquake first motions, Geophysical Journal International, 142, 339-350, 2000.

McGinty, P., R. Robinson, and T. Webb, The $2001 \mathrm{M}_{\mathrm{L}} 6.2$ Jackson Bay earthquake sequence, South Island, New Zealand, New Zealand Journal of Geology and Geophysics, 48, 315-324, 2005.

McGuire, J., Seismic cycles and earthquake predictability on East Pacific Rise transform faults, Bulletin of the Seismological Society of America, 98, 1067, 2008. 
McKenzie, D., The relation between fault plane solutions for earthquakes and the directions of the principal stresses, Bulletin of the Seismological Society of America, 59, 591, 1969.

McSaveney, M., Recent rockfalls and rock avalanches in Mount Cook National Park, New Zealand, Catastrophic Landslides: Effects, Occurrence and Mechanisms, 15, 35-70, 2002.

Melhuish, A., W. Holbrook, F. Davey, D. Okaya, and T. Stern, Crustal and upper mantle seismic structure of the Australian Plate, South Island, New Zealand, Tectonophysics, 395, 113-135, 2005.

Menke, W., and D. Schaff, Absolute earthquake locations with differential data, Bulletin of the Seismological Society of America, 94, 2254, 2004.

Michael, A., Determination of stress from slip data: faults and folds, Journal of Geophysical Research, 89, 11,517-11, 1984.

Miller, S., C. Collettini, L. Chiaraluce, M. Cocco, M. Barchi, and B. Kaus, Aftershocks driven by a high-pressure $\mathrm{CO}_{2}$ source at depth, Nature, 427, 724-727, 2004.

Miyazawa, M., Propagation of an earthquake triggering front from the 2011 Tohoku-Oki earthquake, Geophysical Research Letters, 38, L23,307, 2011.

Mogi, K., Some discussions on aftershocks, foreshocks and earthquake swarms: the fracture of a semi-infinite body caused by an inner stress origin and its relation to the earthquake phenomena (third paper), 1963.

Mogi, K., Two kinds of seismic gaps, Pure and Applied Geophysics, 117, 1172-1186, 1979.

Mogi, K., The mechanism of the occurrence of the Matsushiro earthquake swarm in central Japan and its relation to the 1964 Niigata earthquake, Tectonophysics, 159, 109-119, 1989.

Mohamad, R., A. Darkal, D. Seber, E. Sandvol, F. Gomez, and M. Barazangi, Remote earthquake triggering along the Dead Sea Fault in Syria following the 1995 Gulf of Aqaba earthquake $\left(\mathrm{M}_{\mathrm{S}}=\right.$ 7.3), Seismological Research Letters, 71, 47, 2000.

Molnar, P., H. J. Anderson, E. Audoine, D. Eberhart-Phillips, K. R. Gledhill, E. R. Klosko, T. V. McEvilly, D. Okaya, M. K. Savage, T. Stern, and F. T. Wu, Continuous deformation versus faulting through the continental lithosphere of New Zealand, Science, 286, 516-519, 1999.

Moore, M., P. England, and B. Parsons, Relation between surface velocity field and shear-wave splitting in the South Island of New Zealand, Journal of Geophysical Research, 107, 2198, 2002.

Moran, S., J. Power, S. Stihler, J. Sanchez, and J. Caplan-Auerbach, Earthquake triggering at Alaskan volcanoes following the 3 November 2002 Denali fault earthquake, Bulletin of the Seismological Society of America, 94, S300, 2004.

Mortimer, N., New Zealand's geological foundations, Gondwana Research, 7, 261-272, 2004.

Mortimer, N., A. Tulloch, R. Spark, N. Walker, E. Ladley, A. Allibone, and D. Kimbrough, Overview of the Median Batholith, New Zealand: a new interpretation of the geology of the Median Tectonic Zone and adjacent rocks, Journal of African Earth Sciences, 29, 257-268, 1999.

Moser, T., T. Van Eck, and G. Nolet, Hypocenter determination in strongly heterogeneous earth models using the shortest path method, Journal of Geophysical Research, 97, 6563-6572, 1992. 
Nadeau, R., and D. Dolenc, Non-volcanic tremors deep beneath the San Andreas fault, Science, 307, $389,2005$.

Nadeau, R., and A. Guilhem, Non-volcanic tremor evolution and the San Simeon and Parkfield, California, earthquakes, Science, 325, 191, 2009.

Nadeau, R., W. Foxall, and T. McEvilly, Clustering and periodic recurrence of microearthquakes on the San Andreas fault at Parkfield, California, Science, 267, 503, 1995.

Nakahara, H., Correlation distance of waveforms for closely located events-I. Implication of the heterogeneous structure around the source region of the 1995 Hyogo-Ken Nanbu, Japan, earthquake $\left(\mathrm{M}_{\mathrm{W}}=6.9\right)$, Geophysical Journal International, 157, 1255-1268, 2004.

Nakamura, K., Surface faulting during the Matsushiro earthquakes, EOS Transactions, 50, 389-390, 1969.

Nathan, S., Cretaceous and Cenozoic sedimentary basins of the West Coast region, South Island, New Zealand, Department of Scientific and Industrial Research (Wellington, NZ), 1986.

Nelson, G., and J. Vidale, Earthquake locations by 3-D finite-difference travel times, Bulletin of the Seismological Society of America, 80, 395, 1990.

Norris, R., and A. Cooper, Erosional control on the structural evolution of a transpressional thrust complex on the Alpine Fault, New Zealand, Journal of Structural Geology, 19, 1323-1342, 1997.

Norris, R., and A. Cooper, Very high strains recorded in mylonites along the Alpine Fault, New Zealand: implications for the deep structure of plate boundary faults, Journal of Structural Geology, 25, 2141-2157, 2003.

Norris, R., P. Koons, and A. Cooper, The obliquely-convergent plate boundary in the South Island of New Zealand: implications for ancient collision zones, Journal of structural geology, 12, 715-725, 1990.

Norris, R. J., and A. F. Cooper, Origin of small-scale segmentation and transpressional thrusting along the Alpine fault, New Zealand, Geological Society of America Bulletin, 107, 231, 1995.

Norris, R. J., and A. F. Cooper, Late Quaternary slip rates and slip partitioning on the Alpine Fault, New Zealand Journal of Structural Geology, 23, 507-520, 2001.

O' Keefe, B. C., Microseismicity of the central Alpine Fault region, New Zealand, Master's thesis, Victoria University of Wellington, New Zealand, 2008.

Obara, K., Non-volcanic deep tremor associated with subduction in southwest Japan, Science, 296, 1679-1681, 2002.

Obara, K., H. Hirose, F. Yamamizu, and K. Kasahara, Episodic slow-slip events accompanied by nonvolcanic tremors in southwest Japan subduction zone, Geophysical Research Letters, 31, 2004.

Okaya, D., N. Christensen, D. Stanley, T. Stern, S. Transect, and W. Group, Crustal anisotropy in the vicinity of the Alpine Fault zone, South Island, New Zealand, New Zealand Journal of Geology and Geophysics, 38, 579-583, 1995.

Okaya, D., S. Henrys, and T. Stern, Double-sided onshore-offshore seismic imaging of a plate boundary: "super-gathers" across South Island, New Zealand, Tectonophysics, 355, 247-263, 2002. 
Page, E., Continuous inspection schemes, Biometrika, 41, 100-115, 1954.

Pankow, K., W. Arabasz, J. Pechmann, and S. Nava, Triggered seismicity in Utah from the 3 November 2002 Denali fault earthquake, Bulletin of the Seismological Society of America, 94, S332, 2004.

Papadopoulos, G., M. Charalampakis, A. Fokaefs, and G. Minadakis, Strong foreshock signal preceding the L'Aquila (Italy) earthquake ( $\mathrm{M}_{\mathrm{W}}$ 6.3) of 6 April 2009, Natural Hazards Earth System Science, 10, 19-24, 2010.

Parolai, S., P. Bormann, and C. Milkereit, New relationships between $\mathrm{V}_{\mathrm{S}}$, thickness of sediments, and resonance frequency calculated by the $\mathrm{H} / \mathrm{V}$ ratio of seismic noise for the Cologne area (Germany), Bulletin of the Seismological Society of America, 92, 2521, 2002.

Parotidis, M., E. Rothert, and S. Shapiro, Pore-pressure diffusion: a possible triggering mechanism for the earthquake swarms 2000 in Vogtland/NW-Bohemia, central Europe, Geophysical Research Letters, 30, 2075, 2003.

Parsons, T., A hypothesis for delayed dynamic earthquake triggering, Geophysical Research Letters, 32, L04,302, 2005.

Pavlis, G., Appraising earthquake hypocenter location errors: A complete, practical approach for single-event locations, Bulletin of the Seismological Society of America, 76, 1699, 1986.

Pearson, C., J. Beavan, D. Darby, G. Blick, and R. Walcott, Strain distribution across the AustralianPacific plate boundary in the central South Island, New Zealand, from 1992 GPS and earlier terrestrial observations, Journal of Geophysical Research, 100, 22,071, 1995.

Pearson, C., P. Denys, and K. Hodgkinson, Geodetic constraints on the kinematics of the Alpine Fault in the southern South Island of New Zealand, using results from the Hawea-Haast GPS Transect, Geophysical Research Letters, 27, 1319-1322, 2000.

Peng, Z., and P. Zhao, Migration of early aftershocks following the 2004 Parkfield earthquake, Nature Geoscience, 2, 877-881, 2009.

Peng, Z., J. Vidale, A. Wech, R. Nadeau, and K. Creager, Remote triggering of tremor along the San Andreas Fault in central California, Journal of Geophysical Research, 114, B00A06, 2009.

Peng, Z., W. Wang, Q. Chen, and T. Jiang, Remotely triggered seismicity in north China following the $2008 \mathrm{M}_{\mathrm{W}} 7.9$ Wenchuan earthquake, Earth Planets Space, 62, 893-898, 2010.

Petersen, T., K. Gledhill, M. Chadwick, N. Gale, and J. Ristau, The New Zealand National Seismograph Network, Seismological Research Letters, 82, 9, 2011.

Peterson, J., Observations and modeling of seismic background noise, US Geological Survey. OpenFile Report, 322, 1-95, 1993.

Podvin, P., and I. Lecomte, Finite difference computations of traveltimes in very contrasted velocity models: a massively parallel approach and its associated tools, Geophysical Journal International, 105, 271-284, 1991.

Prejean, S., D. Hill, E. Brodsky, S. Hough, M. Johnston, S. Malone, D. Oppenheimer, A. Pitt, and K. Richards-Dinger, Remotely triggered seismicity on the United States west coast following the M 7.9 Denali Fault earthquake, Bulletin of the Seismological Society of America, 94, S348, 2004. 
Pujol, J., Joint event location-The JHD technique and applications to data from local seismic networks, Modern Approaches in Geophysics, 18, 163-204, 2000.

Pulford, A., Crustal structure and lithospheric doming: aspects of deformation along an obliquely convergent plate margin, New Zealand, Ph.D. thesis, Victoria University Wellington, 2002.

Quigley, M., R. Van Dissen, N. Litchfield, P. Villamor, B. Duffy, D. Barrell, K. Furlong, T. Stahl, E. Bilderback, and D. Noble, Surface rupture during the $2010 \mathrm{M}_{\mathrm{W}} 7.1$ Darfield (Canterbury) earthquake: Implications for fault rupture dynamics and seismic-hazard analysis, Geology, 40, 55-58, 2012.

Rattenbury, M., Late low-angle thrusting and the Alpine Fault, central Westland, New Zealand, New Zealand Journal of Geology and Geophysics, 29, 437-446, 1986.

Reilly, W., Geodetic analysis of motion at a convergent plate boundary, Developments in FourDimensional Geodesy, pp. 139-159, 1990.

Reyners, M., Subcrustal earthquakes in the central South Island, New Zealand, and the root of the Southern Alps, Geology, 15, 1168-1171, 1987.

Reyners, M., Reservoir-induced seismicity at Lake Pukaki, New Zealand, Geophysical Journal of the Royal Astronomical Society, 93, 127-135, 1988.

Reyners, M., The 1943 Lake Hawea earthquake-a large subcrustal event beneath the Southern Alps of New Zealand, New Zealand Journal of Geology and Geophysics, 48, 147-152, 2005.

Reyners, M., and P. McGinty, Shallow subduction tectonics in the Raukumara Peninsula, New Zealand, as illuminated by earthquake focal mechanisms, Journal of Geophysical Research, 104, 3025-3034, 1999.

Reyners, M., and E. Robertson, Intermediate depth earthquakes beneath Nelson, New Zealand, and the southwestern termination of the subducted Pacific plate, Geophysical Research Letters, 31, L04,607, 2004.

Reyners, M., D. Eberhart-Phillips, and S. Bannister, Tracking repeated subduction of the Hikurangi Plateau beneath New Zealand, Earth and Planetary Science Letters, 2011.

Richter, C., An instrumental earthquake magnitude scale, Bulletin of the Seismological Society of America, 25, 1, 1935.

Ristau, J., Implementation of routine regional moment tensor analysis in New Zealand, Seismological Research Letters, 79, 400-415, 2008.

Ristau, J., Comparison of magnitude estimates for New Zealand earthquakes; moment magnitude, local magnitude, and teleseismic body-wave magnitude, Bulletin of the Seismological Society of America, 99, 1841-1852, 2009.

Robinson, R., Seismicity within a zone of plate convergence - the Wellington region, New Zealand, Geophysical Journal of the Royal Astronomical Society, 55, 693-702, 1978.

Robinson, R., Temporal variations in coda duration of local earthquakes in the Wellington region, New Zealand, Pure and Applied Geophysics, 125, 579-596, 1987.

Robinson, R., Extent and geometry of subduction in the northern South Island and Wellington regions, Miscellaneous Publication, 56, 44-46, 1991. 
Robinson, R., Potential earthquake triggering in a complex fault network: the northern South Island, New Zealand, Geophysical Journal International, 159, 734-748, 2004.

Robinson, R., and P. McGinty, The enigma of the Arthur's Pass, New Zealand, earthquake 2. The aftershock distribution and its relation to regional and induced stress fields, Journal of Geophysical Research, 105, 16,139-16,150, 2000.

Rogers, G., and H. Dragert, Episodic tremor and slip on the Cascadia subduction zone: The chatter of silent slip, Science, 300, 1942, 2003.

Roland, E., and J. McGuire, Earthquake swarms on transform faults, Geophysical Journal International, 178, 1677-1690, 2009.

Rubinstein, J., M. La Rocca, J. Vidale, K. Creager, and A. Wech, Tidal modulation of non-volcanic tremor, Science, 319, 186-189, 2008.

Rynn, J., and C. Scholz, Seismotectonics of the Arthur's Pass region, South Island, New Zealand, Bulletin of the Geological Society of America, 89, 1373, 1978.

Schaff, D., and F. Waldhauser, Waveform cross-correlation-based differential travel-time measurements at the Northern California Seismic Network, Bulletin of the Seismological Society of America, 95, 2446-2461, 2005.

Schaff, D., G. Bokelmann, G. Beroza, F. Waldhauser, and W. Ellsworth, High-resolution image of Calaveras Fault seismicity, Journal of Geophysical Research, 107, 2002.

Schaff, D., G. Bokelmann, W. Ellsworth, E. Zanzerkia, F. Waldhauser, and G. Beroza, Optimizing correlation techniques for improved earthquake location, Bulletin of the Seismological Society of America, 94, 705-721, 2004.

Scherwath, M., T. Stern, A. Melhuish, and P. Molnar, $\mathrm{P}_{\mathrm{n}}$ anisotropy and distributed upper mantle deformation associated with a continental transform fault, Geophysical Research Letters, 29, 16$1,2002$.

Scherwath, M., T. Stern, F. Davey, D. Okaya, W. Holbrook, R. Davies, and S. Kleffmann, Lithospheric structure across oblique continental collision in New Zealand from wide-angle P-wave modeling, Journal of Geophysical Research, 108, 2566, 2003.

Scholz, C., J. Rynn, R. Weed, and C. Frohlich, Detailed seismicity of the Alpine Fault zone and Fiordland region, New Zealand, Geological Society of America Bulletin, 84, 3297-3316, 1973.

Shapiro, S., E. Huenges, and G. Borm, Estimating the crustal permeability from fluid-injectioninduced seismic emission at the KTB site, Geophysical Journal International, 131, F15-F18, 1997.

Shelly, D., Possible deep fault slip preceding the 2004 Parkfield earthquake, inferred from detailed observations of tectonic tremor, Geophysical Research Letters, 36, L17,318, 2009.

Shelly, D., and J. Hardebeck, Precise tremor source locations and amplitude variations along the lower-crustal central San Andreas Fault, Geophysical Research Letters, 37, L14,301, 2010.

Shelly, D., G. Beroza, S. Ide, and S. Nakamula, Low-frequency earthquakes in Shikoku, Japan, and their relationship to episodic tremor and slip, Nature, 442, 188-191, 2006. 
Shelly, D., W. Ellsworth, T. Ryberg, C. Haberland, G. Fuis, J. Murphy, R. Nadeau, and R. Bürgemann, Precise location of San Andreas Fault tremors near Cholame, California using seismometer clusters: Slip on the deep extension of the fault?, Geophysical Research Letters, 36, L01,303, 2009.

Shelly, D. R., G. C. Beroza, and S. Ide, Non-volcanic tremor and low-frequency earthquake swarms, Nature, 446, 305-307, 2007.

Sherburn, S., Characteristics of earthquake sequences in the Central Volcanic Region, New Zealand, New Zealand Journal of Geology and Geophysics, 35, 57-68, 1992.

Shi, Y., R. Allis, and F. Davey, Thermal modeling of the Southern Alps, New Zealand, Pure and Applied Geophysics, 146, 469-501, 1996.

Shulmeister, J., D. Fink, H. Rother, and G. Thackray, The chronology of the last deglaciation from two New Zealand valleys and some climatic implications, in 18th International Union for Quaternary Research Congress, 21th-27th July, 18th INQUA Congress, 2011.

Sibson, R., Roughness at the base of the seismogenic zone: contributing factors, Journal of Geophysical Research, 89, 5791-5799, 1984.

Sibson, R., A note on fault reactivation, Journal of Structural Geology, 7, 751-754, 1985.

Sibson, R., Earthquake rupturing as a mineralizing agent in hydrothermal systems, Geology, 15, 701, 1987.

Sibson, R., Earthquake faulting as a structural process, Journal of Structural Geology, 11, 1-14, 1989.

Sibson, R., Crustal stress, faulting and fluid flow, Geological Society London Special Publications, $78,69,1994$.

Sibson, R., and G. Xie, Dip range for intracontinental reverse fault ruptures: Truth not stranger than friction?, Bulletin of the Seismological Society of America, 88, 1014, 1998.

Sibson, R., F. Ghisetti, and J. Ristau, Stress Control of an evolving strike-slip fault system during the 2010-2011 Canterbury, New Zealand, earthquake sequence, Seismological Research Letters, 82, 824, 2011.

Sibson, R. H., S. H. White, and B. K. Atkinson, Structure and distribution of fault rocks in the Alpine Fault Zone, New Zealand, Thrust and Nappe Tectonics, The Geological Society of London, 9, 197-210, 1981.

Sircombe, K., and P. Kamp, The South Westland Basin: seismic stratigraphy, basin geometry and evolution of a foreland basin within the Southern Alps collision zone, New Zealand, Tectonophysics, 300, 359-387, 1998.

Slunga, R., S. T. Rögnvaldsson, and R. Bödvarsson, Absolute and relative locations of similar events with application to microearthquakes in southern Iceland, Geophysical Journal International, 123, 409-419, 1995.

Smith, E., T. Stern, and B. O' Brien, A seismic velocity profile across the central South Island, New Zealand, from explosion data, New Zealand Journal of Geology and Geophysics, 38, 565-570, 1995. 
Song, T., D. Helmberger, M. Brudzinski, R. Clayton, P. Davis, X. Pérez-Campos, and S. Singh, Subducting slab ultra-slow velocity layer coincident with silent earthquakes in southern Mexico, Science, 324, 502, 2009.

Stark, M., and S. Davis, Remotely triggered microearthquakes at The Geysers geothermal field, California, Geophysical Research Letters, 23, 945-948, 1996.

Steacy, S., J. Gomberg, and M. Cocco, Introduction to special section: Stress transfer, earthquake triggering, and time-dependent seismic hazard, Journal of Geophysical Research, 110, B05S01, 2005.

Stein, S., and M. Wysession, An introduction to seismology, earthquakes, and earth structure, WileyBlackwell, 2003.

Stern, T., P. Molnar, D. Okaya, and D. Eberhart-Phillips, Teleseismic P-wave delays and modes of shortening the mantle lithosphere beneath South Island, New Zealand, Journal of Geophysical Research, 105, 615-21, 2000.

Stern, T., S. Kleffmann, D. Okaya, M. Scherwath, and S. Bannister, Low seismic-wave speeds and enhanced fluid pressure beneath the Southern Alps of New Zealand, Geology, 29, 679, 2001.

Stern, T., D. Okaya, and M. Scherwath, Structure and strength of a continental transform from onshore-offshore seismic profiling of South Island, New Zealand, Earth Planets and Space, 54, 1011-1020, 2002.

Stern, T., S. Kleffmann, M. Scherwath, S. Henrys, and F. Davey, Geophysical exploration and dynamics of the Alpine fault zone, Geophysical Monograph, 175, 207-233, 2007.

Stewart, I., J. Sauber, and J. Rose, Glacio-seismotectonics: ice sheets, crustal deformation and seismicity, Quaternary Science Reviews, 19, 1367-1389, 2000.

Stirling, M., S. Wesnousky, and K. Shimazaki, Fault trace complexity, cumulative slip, and the shape of the magnitude-frequency distribution for strike-slip faults: a global survey, Geophysical Journal International, 124, 833-868, 1996.

Sturtevant, B., H. Kanamori, and E. Brodsky, Seismic triggering by rectified diffusion in geothermal systems, Journal of Geophysical Research, 101, 1996.

Suggate, R., Late Pliocene and Quaternary glaciations of New Zealand, Quaternary Science Reviews, 9, 175-197, 1990.

Sutherland, R., Displacement since the Pliocene along the southern section of the Alpine Fault, New Zealand, Geology, 22, 327, 1994.

Sutherland, R., Transpressional development of the Australia-Pacific boundary through southern South Island, New Zealand: constraints from Miocene-Pliocene sediments, Waiho-1 borehole, South Westland, New Zealand Journal of Geology and Geophysics, 39, 251-264, 1996.

Sutherland, R., Cenozoic bending of New Zealand basement terranes and Alpine Fault displacement: a brief review, New Zealand Journal of Geology and Geophysics, 42, 295-301, 1999.

Sutherland, R., and R. J. Norris, Late Quaternary displacement rate, paleoseismicity, and geomorphic evolution of the Alpine Fault: evidence from Hokuri Creek, South Westland, New Zealand, New Zealand Journal of Geology and Geophysics, 38, 419-430, 1995. 
Sutherland, R., F. Davey, and J. Beavan, Plate-boundary deformation in South Island, New Zealand, is related to inherited lithospheric structure, Earth and Planetary Science Letters, 177, 141-151, 2000.

Sutherland, R., K. Berryman, and R. Norris, Quaternary slip rate and geomorphology of the Alpine fault: Implications for kinematics and seismic hazard in southwest New Zealand, Geological Society of America Bulletin, 118, 464, 2006.

Sutherland, R., D. Eberhart-Phillips, R. A. Harris, T. Stern, J. Beaven, S. Ellis, S. Henrys, S. Cox, R. J. Norris, K. R. Berryman, J. Townend, S. Bannister, J. Pettinga, B. Leitner, L. Wallace, T. A. Little, A. K. Cooper, M. Yetton, and M. Stirling, Do great earthquakes occur on the Alpine fault in central South Island, New Zealand?, Geophysical Monograph, 175, 235-251, 2007.

Sykes, L., Earthquake swarms and sea-floor spreading, Journal of Geophysical Research, 75, 6598$6611,1970$.

Syracuse, E., C. Thurber, C. Wolfe, P. Okubo, J. Foster, and B. Brooks, High-resolution locations of triggered earthquakes and tomographic imaging of Kilauea Volcano's south flank, Journal of Geophysical Research, 115, 2010.

Takeda, J., Y. Iio, Y. Kobayashi, K. Yamamoto, H. Sato, S. Ohmi, H. Ito, R. Ikeda, and E. Yamamoto, The relationship between seismicity and fluid existing in the crust inferred from $\mathrm{V}_{\mathrm{P}} / \mathrm{V}_{\mathrm{S}}$ ratio, Journal of the Seismological Society of Japan, 51, 419-430, 1999.

Tank, S., Y. Honkura, Y. Ogawa, N. Oshiman, M. Tunçer, M. Matsushima, C. Çelik, E. Tolak, and A. Istkara, Resistivity structure in the western part of the fault rupture zone associated with the 1999 Izmit earthquake and its seismogenic implication, Earth Planets and Space, 55, 437-442, 2003.

Tarantola, A., and B. Valette, Generalized non-linear inverse problems solved using the least squares criterion, Reviews of Geophysics, 20, 219-232, 1982a.

Tarantola, A., and B. Valette, Inverse problems=quest for information, Journal of Geophysics, 50, 150-170, 1982b.

Templeton, A., C. Chamberlain, P. Koons, and D. Craw, Stable isotopic evidence for mixing between metamorphic fluids and surface-derived waters during recent uplift of the Southern Alps, New Zealand, Earth and Planetary Science Letters, 154, 73-92, 1998.

Thouvenot, F., L. Jenatton, and J. Gratier, A 200-m-deep earthquake swarm in Tricastin (lower Rhône Valley, France) accounts for noisy seismicity over past centuries, Terra Nova, 21, 203-210, 2009.

Thurber, C., Non-linear earthquake location: theory and examples, Bulletin of the Seismological Society of America, 75, 779, 1985.

Toda, S., R. Stein, and J. Lin, Widespread seismicity excitation throughout central Japan following the $2011 \mathrm{M}=9.0$ Tohoku earthquake and its interpretation by Coulomb stress transfer, Geophysical Research Letters, 38, 2011.

Townend, J., What do faults feel? Observational constraints on the stresses acting on seismogenic faults, Geophysical Monograph, 170, 313, 2006.

Townend, J., and M. Zoback, Implications of earthquake focal mechanisms for the frictional strength of the San Andreas fault system, Geological Society London Special Publications, 186, 13, 2001. 
Townend, J., and M. Zoback, Regional tectonic stress near the San Andreas fault in central and southern California, Geophysical Research Letters, 31, 2004.

Toy, V., D. Craw, A. Cooper, and R. Norris, Thermal regime in the central Alpine Fault zone, New Zealand: constraints from microstructures, biotite chemistry and fluid inclusion data, Tectonophysics, 485, 178-192, 2010.

Trehu, A., and W. Wheeler, Possible evidence for subducted sedimentary materials beneath central California, Geology, 15, 254, 1987.

Tryggvason, E., Seismicity, earthquake swarms, and plate boundaries in the Iceland region, Bulletin of the Seismological Society of America, 63, 1327-1348, 1973.

Tso, W., T. Zhu, and A. Heidebrecht, Engineering implication of ground motion A/V ratio, Soil Dynamics and Earthquake Engineering, 11, 133-144, 1992.

Turcotte, D., and G. Schubert, Geodynamics, Cambridge University Press, 2002.

Turpeinen, H., A. Hampel, T. Karow, and G. Maniatis, Effect of ice sheet growth and melting on the slip evolution of thrust faults, Earth and Planetary Science Letters, 269, 230-241, 2008.

Uhrhammer, R., and E. Collins, Synthesis of Wood-Anderson seismograms from broadband digital records, Bulletin of the Seismological Society of America, 80, 702, 1990.

Um, J., and C. Thurber, A fast algorithm for two-point seismic ray-tracing, Bulletin of the Seismological Society of America, 77, 972-986, 1987.

Unsworth, M., and Bedrosian, On the geoelectric structure of major strike-slip faults and shear zones, Earth Planets and Space, 56, 1177-1184, 2004.

Unsworth, M., G. Egbert, and J. Booker, High-resolution electromagnetic imaging of the San Andreas fault in Central California, Journal of Geophysical Research, 104, 1131-1150, 1999.

Unsworth, M., P. Bedrosian, M. Eisel, G. Egbert, and W. Siripunvaraporn, Along-strike variations in the electrical structure of the San Andreas Fault at Parkfield, California, Geophysical Research Letters, 27, 3021-3024, 2000.

Upton, P., P. Koons, and C. Chamberlain, Penetration of deformation-driven meteoric water into ductile rocks: isotopic and model observations from the Southern Alps, New Zealand, New Zealand Journal of Geology and Geophysics, 38, 535-543, 1995.

Uski, M., and A. Tuppurainen, A new local magnitude scale for the Finnish seismic network, Tectonophysics, 261, 23-37, 1996.

Utsu, T., Y. Ogata, and R. Matsu'ura, The centenary of the Omori formula for a decay law of aftershock activity, Journal of Physics of the Earth, 43, 1-33, 1995.

Van Avendonk, H., W. Holbrook, D. Okaya, J. Austin, F. Davey, and T. Stern, Continental crust under compression: a seismic refraction study of South Island Geophysical Transect I, South Island, New Zealand, Journal of Geophysical Research, 109, 2004.

Velasco, A., S. Hernandez, T. Parsons, and K. Pankow, Global ubiquity of dynamic earthquake triggering, Nature Geoscience, 1, 375-379, 2008. 
Vidale, J., and P. Shearer, A survey of 71 earthquake bursts across southern California: Exploring the role of pore fluid pressure fluctuations and aseismic slip as drivers, Journal of Geophysical Research, 111, 1999-2000, 2006.

Vidale, J., K. Boyle, and P. Shearer, Crustal earthquake bursts in California and Japan: Their patterns and relation to volcanoes, Geophysical Research Letters, 33, 2006.

Vry, J., R. Powell, K. Golden, and K. Petersen, The role of exhumation in metamorphic dehydration and fluid production, Nature Geoscience, 2009.

Walcott, R., Present tectonics and late Cenozoic evolution of New Zealand, Geophysical Journal of the Royal Astronomical Society, 52, 137-164, 1978.

Walcott, R. I., Modes of oblique compression: late Cenozoic tectonics of the South Island of New Zealand, Reviews of Geophysics, 36, 1-26, 1998.

Waldhauser, F., and W. L. Ellsworth, A Double-Difference Earthquake Location Algorithm: Method and Application to the Northern Hayward Fault, California, Bulletin of the Seismological Society of America, 90, 1353-1368, 2000.

Wallace, L., J. Beavan, R. McCaffrey, K. Berryman, and P. Denys, Balancing the plate motion budget in the South Island, New Zealand using GPS, geological and seismological data, Geophysical Journal International, 168, 332-352, 2007.

Walsh, D., R. Arnold, and J. Townend, A Bayesian approach to determining and parametrizing earthquake focal mechanisms, Geophysical Journal International, 176, 235-255, 2009.

Wannamaker, P., T. Caldwell, G. Jiracek, V. Maris, G. Hill, Y. Ogawa, H. Bibby, S. Bennie, and W. Heise, Fluid and deformation regime of an advancing subduction system at Marlborough, New Zealand, Nature, 460, 733-736, 2009.

Wannamaker, P. E., G. R. Jiracek, J. A. Stodt, T. G. Caldwell, V. M. Gonzalez, J. D. McKnight, and A. D. Porter, Fluid generation and pathways beneath an active compressional orogen, the New Zealand Southern Alps, inferred from magnetotelluric data, Journal of Geophysical Research, 107, $1-20,2002$.

Wech, A., and K. Creager, Cascadia tremor polarization evidence for plate interface slip, Geophysical Research Letters, 34, L22,306, 2007.

Wech, A., and K. Creager, Automated detection and location of Cascadia tremor, Geophysical Research Letters, 35, L20,302, 2008.

Wech, A., C. Boese, T. Stern, and J. Townend, Tectonic tremor and deep slow slip on the Alpine Fault, Geophysical Research Letters, 39, L10,303, 2012.

Wells, A., and J. Goff, Coastal dunes in Westland, New Zealand, provide a record of paleoseismic activity on the Alpine fault, Geology, 35, 731, 2007.

Wells, A., M. D. Yetton, R. P. Duncan, and G. H. Stewart, Prehistoric dates of the most recent Alpine Fault earthquakes, New Zealand, Geology, 27, 995-998, 1999.

West, M., J. Sánchez, and S. McNutt, Periodically triggered seismicity at Mount Wrangell, Alaska, after the Sumatra earthquake, Science, 308, 1144, 2005. 
White, S., The Siberia Fault Zone, northwest Otago, and kinematics of mid-Cenozoic plate boundary deformation in southern New Zealand, New Zealand Journal of Geology and Geophysics, 45, 271$287,2002$.

Whittington, A., A. Hofmeister, and P. Nabelek, Temperature-dependent thermal diffusivity of the Earth's crust and implications for magmatism, Nature, 458, 319-321, 2009.

Wiemer, S., and M. Wyss, Mapping the frequency-magnitude distribution in asperities: an improved technique to calculate recurrence times?, Journal of Geophysical Research, 102, 15,115-15,128, 1997.

Wightman, R., and T. Little, Deformation of the Pacific Plate above the Alpine Fault ramp and its relationship to expulsion of metamorphic fluids: an array of backshears, Geophysical Monograph, 175, 177-205, 2007.

Wittlinger, G., G. Herquel, and T. Nakache, Earthquake location in strongly heterogeneous media, Geophysical Journal International, 115, 759-777, 1993.

Woessner, J., and S. Wiemer, Assessing the quality of earthquake catalogues: Estimating the magnitude of completeness and its uncertainty, Bulletin of the Seismological Society of America, 95, 684, 2005.

Woodward, D., The crustal structure of the Southern Alps, New Zealand, as determined by gravity, The origin of the Southern Alps, 18, 95-98, 1979.

Yamashita, T., Pore creation due to fault slip in a fluid-permeated fault zone and its effect on seismicity: generation mechanism of earthquake swarm, Pure and Applied Geophysics, 155, 625-648, 1999.

Yeats, R., and K. Berryman, South Island, New Zealand, and transverse ranges, California: a seismotectonic comparison, Tectonics, 6, 363-376, 1987.

Yoshida, K., A. Hasegawa, T. Okada, T. Iinuma, Y. Ito, and Y. Asano, Stress before and after the 2011 great Tohoku-oki earthquake and induced earthquakes in inland areas of eastern Japan, Geophysical Research Letters, 39, L03,302, 2012.

Zhang, H., Double-difference seismic tomography method and its application, Ph.D. thesis, University of Wisconsin-Madison, 2003.

Zhang, H., and C. Thurber, Double-difference tomography: The method and its application to the Hayward fault, California, Bulletin of the Seismological Society of America, 93, 1875, 2003.

Zhang, H., and C. Thurber, Development and applications of double-difference seismic tomography, Pure and Applied Geophysics, 163, 373-403, 2006.

Zoback, M., and J. Townend, Implications of hydrostatic pore pressures and high crustal strength for the deformation of intraplate lithosphere, Tectonophysics, 336, 19-30, 2001.

Zollo, A., and P. Bernard, S-wave polarization inversion of the 15 October 1979, 23:19 Imperial Valley Aftershock: Evidence for anisotropy and a simple source mechanism, Geophysical Research Letters, 16, 1047-1050, 1989. 